UNIVERSIDADE DE SÃO PAULO

INSTITUTO DE QUÍMICA DE SÃO CARLOS

MAYUMI SILVA KAWAMOTO

Produção de Materiais de Referência Para Nutrientes e Contaminantes Inorgânicos em Amostras de Ração e Tecido de Peixe 
Tese apresentada ao Instituto de Química de São Carlos, da Universidade de São Paulo, como parte dos requisitos para obtenção do título de Doutora em Ciências.

Área de Concentração: Química Analítica e Inorgânica

Orientadora: Dr. ${ }^{a}$ Ana Rita de Araújo Nogueira

*bolsista: CAPES

São Carlos 
Autorizo a reprodução e divulgação total ou parcial deste trabalho, por qualquer meio convencional ou eletrônico para fins de estudo e pesquisa, desde que citada a fonte.

\section{Assinatura: \\ Data:}

Ficha Catalográfica elaborada pela Seção de Referência e Atendimento ao Usuário do SBI/IQSC

Kawamoto, Mayumi Silva

Referências Bibliográficas

conferidas pelo SBIIIQSC.

Produção de materiais de referência para nutrientes e contaminantes inorgânicos em amostras de ração e tecido de peixe / Mayumi Silva Kawamoto.

- São Carlos, 2018. $216 \mathrm{f}$.

Tese (Doutorado em Química Analítica e Inorgânica) - Instituto de Química de São Carlos / Universidade de São Paulo, 2018.

Orientadora: Profa. Dra. Ana Rita de Araujo Nogueira

1. Controle da qualidade. 2. Qualidade dos alimentos. 3. Metrologia química. 4. Composição química. 5. Peixes. I. Título. 


\section{AGRADECIMENTOS}

A Deus por cada dia, pelas oportunidades, pelas bênçãos infindáveis, pelas pessoas maravilhosas que me permitiu encontrar nessa jornada.

À Dra. Ana Rita de Araujo Nogueira pela orientação, por todas as oportunidades, pela paciência e compreensão, pelos incentivos, pelos conselhos, pela confiança, pela generosidade. Por todos esses anos, minha sincera gratidão.

Ao Dr. Gilberto Batista de Souza, pela co-orientação não formal, pela amizade, pelas sugestões, por toda ajuda.

À Dra. Patrícia Grinberg e ao Dr. Zoltan Mester pela supervisão durante o tempo de estágio de doutoramento sanduíche no NRC, por todas as oportunidades, pela confiança, pelos ensinamentos, pela amizade. Exemplos de bondade e gentileza que levarei para o resto da vida.

À Dra. Kelly L. LeBlanc e ao Ovidiu Mihai, do NRC, pelo tempo de trabalho juntos, pelo conhecimento transmitido, pela parceria, pela amizade, pelos bons momentos compartilhados.

À Ruth Marie Hutchinson (in memoriam), por me receber em sua casa, pelas longas conversas, pela amizade e apoio durante o período no Canadá.

Aos membros e ex-membros do Grupo de Análise Instrumental Aplicada (GAIA). Principalmente aos amigos: Ana Beatriz, Carlos, Ivero. E à Julymar, que foi mais que essencial para a realização de parte deste trabalho.

Ao Instituto de Química de São Carlos da USP e ao Programa de Pós-Graduação em Química pela oportunidade.

À Embrapa Pecuária Sudeste por todo o suporte técnico para o desenvolvimento do trabalho.

Aos funcionários da Embrapa Pecuária Sudeste: Cidinha, Natal, Cristina, Gilbertinho, Márcio, Avelardo, Cadu, que direta ou indiretamente colaboraram para a realização deste trabalho.

Ao National Research Council Canada (NRCC) pela oportunidade e a todos os funcionários do Grupo de Metrologia Química pela acolhida durante os seis meses de estágio no Canadá.

Aos laboratórios envolvidos no ensaio colaborativo para a caracterização do material de referência de ração. 
Ao Comércio e Indústria Matsuda Importação e Exportação Ltda, aos Grupos Ambar Amaral e Netuno pelo fornecimento das amostras para preparo dos materiais de referência deste trabalho.

À Coordenação de Aperfeiçoamento de Pessoal de Nível Superior (CAPES) pela concessão da bolsa de doutorado no país (PROEX -0487) e da bolsa de estágio de Doutorado Sanduíche no Exterior (Processo $\left.n^{\circ} 88881.131772 / 2016-01\right)$. E ao Banco Nacional de Desenvolvimento Econômico e Social (BNDES) pelo financiamento do projeto do qual esta tese faz parte.

Ao Instituto Federal de Educação, Ciência e Tecnologia de São Paulo (IFSP), pela concessão do afastamento para a conclusão do doutoramento.

À minha amada família, meus pais Maurino e Fátima e meus irmãos Midory e Masharu.

Aos amigos de perto e de longe, que oram continuamente por mim e que permanecem no meu coração e no pensamento.

Ao Rodrigo Imaizumi pela dedicação, amor, paciência, companheirismo, cuidado e apoio.

A cada um que colaborou direta ou indiretamente para a realização deste trabalho. 
"Se as coisas são inatingíveis... ora!

Não é motivo para não querê-las...

Que tristes os caminhos, se não fora

A presença distante das estrelas!"

Mario Quintana

We live on an island surrounded by a sea of ignorance.

As our island of knowledge grows, so does the shore of our ignorance.

John Archibald Wheeler 


\section{RESUMO}

Para que o crescimento da produção pesqueira no Brasil aconteça de maneira sustentável é necessário o desenvolvimento de bases científicas e tecnológicas sólidas, que solucionem as demandas existentes nos diversos elos da cadeia produtiva. Uma das principais evidências da qualidade dos produtos é fornecida pelos resultados analíticos, cuja confiabilidade e exatidão podem ser asseguradas pelo emprego de materiais de referência (RM). Neste contexto, foi desenvolvido material de referência de ração para peixe para emprego em análises de macro e micronutrientes e alguns parâmetros bromatológicos, além de estar em fase final o desenvolvimento de um RM de tecido de peixe para nutrientes e contaminantes inorgânicos. A produção dos materiais seguiu as diretrizes dos ISO Guias 30-35, considerando a preparação, envase, irradiação, massa mínima, homogeneidade, estabilidade a curto e a longo prazo e caracterização do material. Para produzir os RMs de ração e tecido de peixe, as amostras foram obtidas a partir de fornecedores comerciais. Os materiais foram secos/liofilizados, moídos, homogeneizados e envasados em frascos de vidro âmbar que, posteriormente, foram submetidos à irradiação com raios gama, para esterilização do material, visando o aumento do seu tempo de prateleira. A caracterização química do RM de ração foi efetuada através de um ensaio colaborativo, com a participação de laboratórios de diferentes instituições, públicas e privadas. As avaliações da estimativa da massa mínima, da homogeneidade e da estabilidade do material foram realizadas, utilizando-se como técnicas de determinação a espectrometria de emissão óptica com plasma acoplado indutivamente (ICP OES) e a espectrometria de massa por plasma acoplado indutivamente (ICP-MS). Foi possível observar que o lote de ração para peixe pode ser considerado homogêneo para $\mathrm{Ca}, \mathrm{Cu}, \mathrm{Fe}, \mathrm{Mg}, \mathrm{Mn}, \mathrm{Na}$ e $\mathrm{S}$, uma vez que não foi verificada diferença significativa no intervalo de confiança de $95 \%$. A avaliação da estabilidade a longo prazo do RM de ração foi feita pela análise de resíduos da regressão em conjunto com a ANOVA e a avaliação da estabilidade a curto prazo foi obtida por meio de regressão linear simples. O RM de ração foi considerado suficientemente estável para ser armazenado à temperatura ambiente. Os resultados obtidos durante a produção do RM de ração e através do ensaio colaborativo possibilitaram a caracterização química e o cálculo das componentes de incerteza, sendo elaborado o documento com os valores de referência RM e as incertezas expandidas para cada um dos analitos avaliados. O RM de tecido de peixe foi avaliado em sua homogeneidade e estabilidade a curto prazo, sendo considerado homogêneo e estável para transporte a temperaturas inferiores a $37^{\circ} \mathrm{C}$.

Palavras-chave: material de referência, ensaio colaborativo, ração para peixe, tecido de peixe, nutrientes, ICP OES, ICP-MS. 


\begin{abstract}
In order the facilitate the growth of the Brazilian fishery production, in a sustainable way, it is necessary to develop sound scientific and technological base to address the existing demands in the various links of the production chain. One of the main evidences of the products' quality is provided by the analytical results, whose reliability and accuracy can be assured by the use of reference materials (RM). In this context, it was produced a RM of fish feed for macro-and micronutrients and proximates analysis. Also, a RM of fish tissue, which is in its final stage of development, for nutrients and inorganic contaminants. The production of reference materials followed the ISO Guides 30-35 standards: preparation and packaging, irradiation, minimum sample, homogeneity, short- and long-term stability, and material characterization. The materials were acquired from commercial suppliers. The materials were dried/freeze-dried, pulverized, homogenized and aliquoted into amber glass bottles. The bottles were gamma irradiated to a minimum dose to inhibit bacterial action. Characterization of the candidate fish feed RM was performed through a round robin exercise. The study of minimum sample mass, homogeneity and stability of the material were performed using inductively coupled plasma optical emission spectrometry (ICP-OES). Results from sub-samples (250 mg) were evaluated and it was verified that the fish feed proposed RM could be considered homogeneous for Ca, $\mathrm{Cu}, \mathrm{Fe}, \mathrm{Mg}, \mathrm{Mn}$ and $\mathrm{Na}$, as no significant difference in significance level of 0.05 was observed. Long-term stability study of this proposed RM was performed by the residual analysis in regression and ANOVA and the short-term stability study was performed by simple linear regression. This proposed RM could be considered sufficiently stable to be stored at room temperature. The data obtained along the production and through the round robin exercise allowed the characterization of the fish feed RM as well the determination of uncertainties components. For the proposed RM of fish tissue, Inductively coupled plasma mass spectrometry (ICP-MS) was also used for the assessment of homogeneity and short-term stability. Results from sub-samples $(250 \mathrm{mg})$ were evaluated and considered homogeneous and stable to be transported under temperature below $37^{\circ} \mathrm{C}$.
\end{abstract}

Keywords: reference material, round robin exercise, fish feed, fish tissue, nutrients, proximates, ICP-OES, ICP-MS. 


\section{LISTA DE FIGURAS}

Figura 1 - Etapas de produção de um material de referência..................................................35

Figura 2 - Países produtores e quantidade de CRMs produzidos............................................36

Figura 3 - Produção de rações para peixes no Brasil, entre 2000 e 2018 (dados do SINDIRAÇÕES)

Figura 4 - (a) Moagem das amostras de ração em moinho ultracentrífugo e (b) amostras envasadas em frascos âmbar com porções de aproximadamente $85 \mathrm{~g}$ cada......

Figura 5 - Forno de micro-ondas com cavidade modelo Ethos 1, Milestone com Rotor de 10

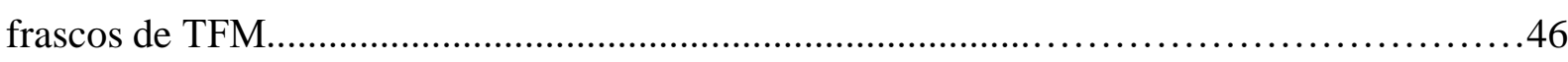

Figura 6 - ICP OES Thermo Scientific 6000 series dual view...........................47

Figura 7 - Equipamento de análise de fibras ANKOM 200 - Fiber Analyzer...........................50

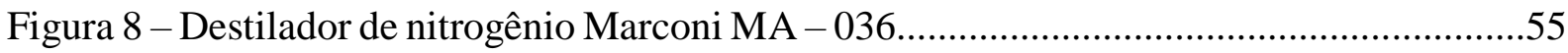

Figura 9 - Sistema de Extração de Óleos e Gorduras ANKOM XT-15..................................56

Figura 10 - Experimento de estabilidade em curto prazo, $37 \pm 3^{\circ} \mathrm{C}$ e $100 \pm 4 \%$ de umidade relativa.

Figura 11 - Curva da distribuição granulométrica do material de ração para peixe candidato a material de referência.

Figura 12 - (a) Gráfico de scores com as duas componentes principais da avaliação de homogeneidade entre frascos; (b) Gráfico para detecção de outliers .66

Figura 13 - Gráfico de scores com as duas componentes principais da avaliação de homogeneidade intra-frasco.

Figura 14 - Homogeneidade entre os frascos para os parâmetros bromatológicos: (a) MS; (b)

Cinzas; (c) PB; (d) FDN; (e) FDA; (f) Lignina; (g) FB; (h) EE; (i) NNP . .71

Figura 15 - Homogeneidade entre os frascos para os macro e micronutrientes: (a) $\mathrm{Ca}$; (b) $\mathrm{Cu}$;

(c) $\mathrm{Fe}$; (d) $\mathrm{K}$; (e) Mg; (f) Mn; (g) Na; (h) P e (i) Zn............................................................73

Figura 16 - Estabilidade a curto prazo para Matéria Seca - MS.............................................79

Figura 17 - Estabilidade a curto prazo para Cinzas............................................................. 80

Figura 18 - Estabilidade a curto prazo para Proteína Bruta - PB..........................................80

Figura 19 - Estabilidade a curto prazo para Fibra em Detergente Neutro - FDN.....................80

Figura 20 - Estabilidade a curto prazo para Fibra em Detergente Ácido - FDA.......................81

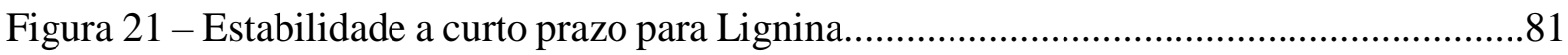

Figura 22 - Estabilidade a curto prazo para Fibra Bruta - FB..............................................81 
Figura 23 - Estabilidade a curto prazo para Extrato Etéreo - EE..........................................82

Figura 24 - Estabilidade a curto prazo para Nitrogênio Não Proteico - NNP..........................82

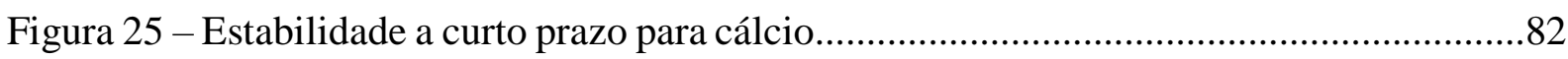

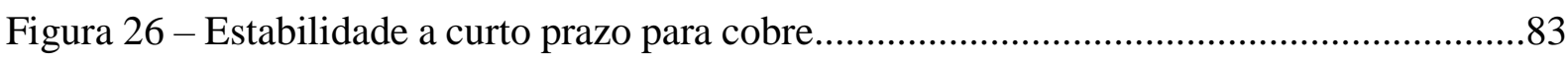

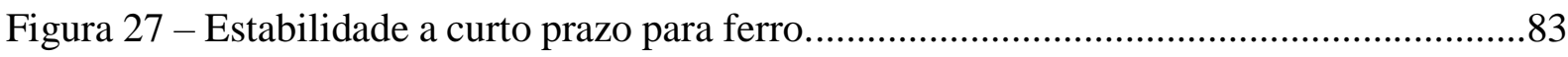

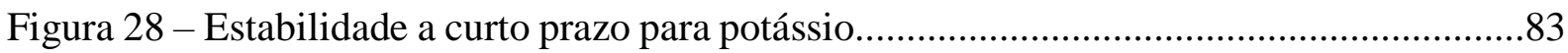

Figura 29 - Estabilidade a curto prazo para magnésio.............................................................84

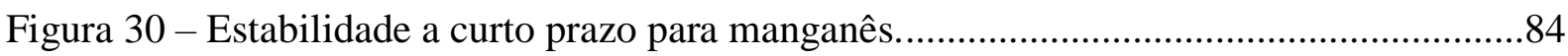

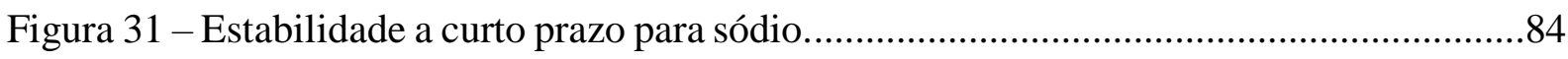

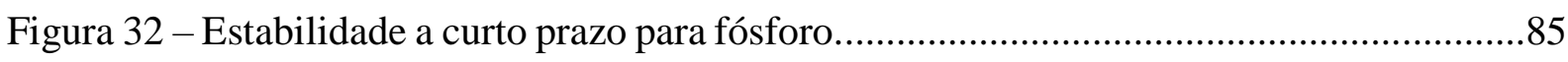

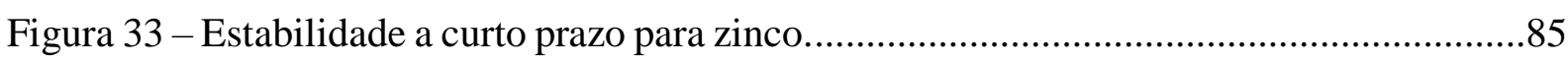

Figura 34 - Gráfico da análise de regressão dos resultados de estabilidade a longo prazo para cálcio.

Figura 35 - Gráfico da análise de regressão dos resultados de estabilidade a longo prazo para cobre.

Figura 36 - Gráfico da análise de regressão dos resultados de estabilidade a longo prazo para ferro.

Figura 37 - Gráfico da análise de regressão dos resultados de estabilidade a longo prazo para potássio.

Figura 38 - Gráfico da análise de regressão dos resultados de estabilidade a longo prazo para magnésio.

Figura 39 - Gráfico da análise de regressão dos resultados de estabilidade a longo prazo para manganês

Figura 40 - Gráfico da análise de regressão dos resultados de estabilidade a longo prazo para sódio.

Figura 41 - Gráfico da análise de regressão dos resultados de estabilidade a longo prazo para fósforo

Figura 42 - Gráfico da análise de regressão dos resultados de estabilidade a longo prazo para zinco.

Figura 43 - Média e intervalo de confiança, em base seca, para os resultados de parâmetros bromatológicos, reportados pelos participantes do ensaio colaborativo para a caracterização da ração para peixe candidata a RM. Valor de referência (- Incerteza expandida, $k=2$ (——). (a) MS; (b) Cinzas; (c) PB; (d) FDN; (e) FDA; (f) Lignina; (g) FB; (h) EE; (i) NNP..97 
Figura 44 - Média e intervalo de confiança, em base seca, para os resultados de macro e micronutrientes, reportados pelos participantes do ensaio colaborativo para a caracterização da ração para peixe candidata a RM. Valor de referência (- $(-)$, Incerteza expandida, $k=2$ (——). (a) $\mathrm{Ca}$; (b) $\mathrm{Cu}$; (c) $\mathrm{Fe}$; (d) $\mathrm{K}$; (e) $\mathrm{Mg}$; (f) $\mathrm{Mn}$; (g) $\mathrm{Na}$; (h) P; (i) $\mathrm{Zn}$. 101 Figura 45 - Valores de índice z obtidos para o RM candidato de ração para peixe para os parâmetros bromatológicos: (a) MS; (b) Cinzas; (c) PB; (d) FDN; (e) FDA; (f) Lignina; (g) FB; (h) EE; (i) NNP. 107

Figura 46 - Valores de índice z obtidos para o RM candidato de ração para peixe para os macro e micronutrientes: (a) $\mathrm{Ca}$; (b) $\mathrm{Cu}$; (c) Fe; (d) K ; (e) $\mathrm{Mg}$; (f) $\mathrm{Mn}$; (g) Na; (h) P; (i) Zn...... 109 Figura 47 - Contribuição individual das componentes de incerteza para os valores de propriedade dos parâmetros avaliados no material candidato a RM de ração para peixe. São apresentadas as componentes individuais e a incerteza combinada. (a) macronutrientes; (b) micronutrientes e (c) bromatológicos.

Figura 48 - Amostras envasadas em frasco de vidro âmbar com porções de aproximadamente $20 \mathrm{~g}$ cada.

Figura 49 - ICP OES Agilent 5110

Figura 50 - ICP-MS Agilent 7800 empregado na determinação multielementar no RM candidato de tecido de peixe. 131

Figura 51 - Estudo isócrono de estabilidade a curto prazo, $37^{\circ} \mathrm{C}$ e $100 \%$ U.R. 136 Figura 52 - Curva da distribuição granulométrica do material de tecido de peixe candidato a material de referência. 139

Figura 53 - Gráfico de scores com as duas componentes principais da avaliação de homogeneidade entre frascos.

Figura 54 - Investigação de tendência no estudo de homogeneidade dentro do frasco. Resultados apresentados por ordem de massa, com ajuste de curva linear. (a) As, (b) Ba, (c) Ca, (d) $\mathrm{Co}$, (e) $\mathrm{Cr}$, (f) $\mathrm{Cu}$, (g) Fe, (h) K, (i) $\mathrm{Mg}$, (j) Mn, (k) Mo, (l) Na, (m) Ni, (n) P, (o) Se, (p) Sr, (q) $\mathrm{Ti},(\mathrm{r}) \mathrm{V}$ e (s) Zn..... 147

Figura 55 - Homogeneidade entre os frascos para os macro e micronutrientes e contaminantes. (a) As, (b) $\mathrm{Ba}$, (c) $\mathrm{Ca}$, (d) Co, (e) Cr, (f) Cu, (g) Fe, (h) K, (i) $\mathrm{Mg}$, (j) Mn, (k) Mo, (l) Na, (m) $\mathrm{Ni}$, (n) P, (o) Se, (p) Sr, (q) Ti, (r)V e (s) Zn. 157

Figura 56 - Investigação de tendência no estudo de estabilidade a curto prazo para elementos obtidos por ICP OES, com resultados apresentados por ordem de tempo e ajuste de curva linear. (a) $\mathrm{Ca}$, (b) Fe, (c) K, (d) $\mathrm{Mg}$, (e) $\mathrm{Na}$, (f) P e (g) Zn. 165 
Figura 57 - Investigação de tendência no estudo de estabilidade a curto prazo para elementos obtidos por ICP-MS, com resultados apresentados por ordem de tempo e ajuste de curva linear. (a) As, (b) Ba, (c) Co, (d) Cr, (e) Cu, (f) Mn, (g) Mo, (h) Ni, (i) Se, (j) Sr, (k) Ti e (l)V .......168 Figura 58 - Razões $\mathrm{R}_{\mathrm{T}}$ para o estudo de estabilidade a curto prazo por ICP OES. (a) Ca, (b) Fe,

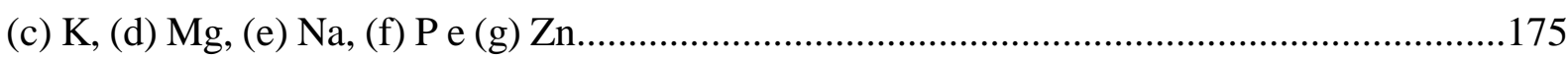
Figura 59 - Razões $\mathrm{R}_{\mathrm{T}}$ para o estudo de estabilidade a curto prazo por ICP-MS. (a) As, (b) Ba, (c) Co, (d) Cr, (e) Cu, (f) Mn, (g) Mo, (h) Ni, (i) Se, (j) Sr, (k) Ti e (l) V.............................177 


\section{LISTA DE TABELAS}

Tabela 1 - Produtores de Materiais de Referência Acreditados pela CGCRE na ABNT ISO

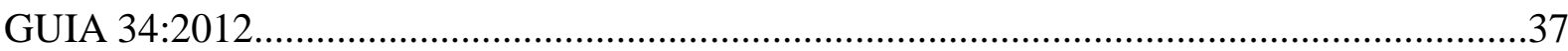

Tabela 2 - Programa de Aquecimento do Forno de Micro-ondas Ethos 1, Milestone.............46

Tabela 3 - Condições operacionais do ICP-OES iCap 6000 series........................................47

Tabela 4 - Programa de aquecimento do forno mufla........................................................49

Tabela 5 - Umidade residual do candidato RM de ração para peixe determinada em estufa a $105^{\circ} \mathrm{C}$ por $24 \mathrm{~h}$

Tabela 6 - Limites de detecção, faixa linear, comprimento de onda e orientação da tocha na determinação dos elementos $\mathrm{Ca}, \mathrm{Cu}, \mathrm{Fe}, \mathrm{K}, \mathrm{Mg}, \mathrm{Mn}, \mathrm{Na}, \mathrm{P}$ e $\mathrm{Zn}$, por ICP OES, na ração candidata a RM.

Tabela 7- Média dos teores obtidos para os materiais de referência certificados NIST 1566b e 1573a $(\mathrm{n}=3)$, determinados por ICP OES

Tabela 8 - Resultados das réplicas do teste de homogeneidade intra-amostral

Tabela 9 - Frações de massa de $\mathrm{Ca}, \mathrm{Fe}, \mathrm{K}, \mathrm{Mg}, \mathrm{Na}, \mathrm{P}$ e Zn, obtidas nas porções amostradas em digestão em micro-ondas com cavidade $(n=3)$.

Tabela 10 - Dados ANOVA fator único para a estimativa da massa mínima da ração candidata a RM

Tabela 11 - Dados da ANOVA fator único para a estimativa da massa mínima da amostra candidata a material de referência, após exclusão de dados.

Tabela 12 - Dados ANOVA fator único para a avaliação da homogeneidade entre frascos da ração candidata a RM para os parâmetros bromatológicos

Tabela 13 - Dados ANOVA fator único para a avaliação da homogeneidade entre frascos da ração candidata a RM para os macro e micronutrientes...........................................................77

Tabela 14 - Resumo da avaliação estatística para o estudo de homogeneidade. .78

Tabela 15 - Dados da ANOVA fator único dos frascos armazenados a $37^{\circ} \mathrm{C}$ e UR de $100 \%$ por um mês, para o estudo de estabilidade a curto prazo da amostra candidata a RM.

Tabela 16 - Concentrações médias $(\mathrm{n}=30)$ obtidas no teste de estabilidade a longo prazo........85

Tabela 17 - Análise da regressão do estudo de estabilidade a longo prazo.

Tabela 18 - Teste T com os dados obtidos por ICP OES para o estudo de estabilidade a longo prazo.

Tabela 19 - Alguns dos laboratórios que participaram do ensaio colaborativo 
Tabela 20 - Quantidade de laboratórios por parâmetro avaliado.

Tabela 21 - Técnicas analíticas utilizadas pelos laboratórios participantes do ensaio colaborativo para determinação de valores de propriedade de macro e micronutrientes.

Tabela 22 - Estimativas das incertezas padrão da caracterização ( $\left.\mathrm{u}_{\mathrm{char}}\right)$, homogeneidade $\left(\mathrm{u}_{\mathrm{bb}}\right)$, estabilidade a curto prazo $\left(\mathrm{u}_{\mathrm{sts}}\right)$, estabilidade a longo prazo $\left(\mathrm{u}_{\mathrm{lts}}\right)$ e a incerteza expandida $\left(\mathrm{U}_{\mathrm{RM}}\right)$ para cada parâmetro no material de referência de ração para peixe. 114

Tabela 23 - Valores de referência para a fração massa (na base seca) atribuídos aos parâmetros bromatológicos determinados no RM de ração para peixe e incerteza expandida em porcentagem $\left(U_{R M}\right)$

Tabela 24 - Valores de referência para a fração massa (na base seca) atribuídos aos macro e micronutrientes determinados no $\mathrm{RM}$ de ração para peixe e incerteza expandida em porcentagem $\left(U_{R M}\right)$

Tabela 25 - Materiais de referência de peixe identificados no banco de dados internacional de RMs - COMAR e na base de CRMs disponíveis do NIST...... .122

Tabela 26 - Panorama geral de materiais de referência de peixe produzidos no Brasil. 123 Tabela 27 - Parâmetros Operacionais para a determinação multielementar no ICP OES Agilent 5110. 128

Tabela 28 - Parâmetros Operacionais para a determinação multielementar no ICP-MS Agilent 7800

Tabela 29 - Planejamento isócrono para estudo de estabilidade a curto prazo 136

Tabela 30 - Planejamento isócrono para estudo de estabilidade a longo prazo...... 137

Tabela 31 - Umidade residual do RM candidato de tecido de peixe.

Tabela 32 - Limites de detecção, quantificação, faixa linear, comprimento de onda e orientação da tocha na determinação dos elementos $\mathrm{Ca}, \mathrm{Fe}, \mathrm{K}, \mathrm{Mg}, \mathrm{Na}, \mathrm{P}$ e Zn, por ICP OES.

Tabela 33 - Limites de detecção e quantificação, uso de padrões internos e de célula de colisão na determinação dos isótopos por ICP-MS

Tabela 34 - Média dos teores obtidos para os CRMs DOLT-5, NIST 1566b e RM FT-IPEN $(\mathrm{n}=6)$, determinados por ICP OES.

Tabela 35 - Recuperações (\%) obtidas para as diferentes condições de operação do ICP-MS (n $=6)$.

Tabela 36 - Média dos teores obtidos para os CRMs DOLT-5, NIST 1566b e RM FT-IPEN $(\mathrm{n}=6)$, determinados por ICP-MS 
Tabela 37 - Frações de massa de As, Ba, Ca, Co, Cr, Cu, Fe, K, Mg, Mn, Mo, Na, Ni, P, Se, $\mathrm{Sr}, \mathrm{Ti}, \mathrm{V}$ e $\mathrm{Zn}$, obtidas nas porções amostradas em digestão em micro-ondas com cavidade $(\mathrm{n}=6)$

Tabela 38 - Resultados dos testes estatísticos realizados para avaliar os requisitos de ANOVA na avaliação da homogeneidade intra-frasco.

Tabela 39 - Resultados dos testes estatísticos realizados para avaliar os requisitos de ANOVA na avaliação da homogeneidade intra-frasco, desconsiderando os dados da massa de 100mg para Ca e Co e sem a massa de $300 \mathrm{mg}$ para $\mathrm{Zn}$.

Tabela 40 - Dados ANOVA fator único para a estimativa da massa mínima da amostra de tecido de peixe candidata a RM.

Tabela 41 - Dados da ANOVA fator único para a estimativa da massa mínima da amostra candidata a material de referência, após exclusão de dados. 154

Tabela 42 - Estatísticas de ANOVA e teste de Kruskal-Wallis para os resultados obtidos.....155 Tabela 43 - Dados ANOVA fator único para a avaliação da homogeneidade entre frascos da ração candidata a RM para os dados obtidos por ICP OES

Tabela 44 - Dados ANOVA fator único para a avaliação da homogeneidade entre frascos da ração candidata a RM para os dados obtidos por ICP-MS.

Tabela 45 - Resumo da avaliação estatística para o estudo de homogeneidade para os elementos determinados por ICP OES.

Tabela 46 - Resumo da avaliação estatística para o estudo de homogeneidade para os elementos determinados por ICP-MS

Tabela 47 - Concentração dos elementos em mg kg-1 obtidas por ICP OES para o estudo de estabilidade a curto prazo (base úmida).

Tabela 48 - Concentração dos elementos em $\mu \mathrm{g} \mathrm{kg}^{-1}$ obtidas por ICP-MS para o estudo de estabilidade a curto prazo (base úmida).

Tabela 49 - Resultados normalizados do estudo de estabilidade a curto prazo obtidos por ICP OES.

Tabela 50 - Resultados normalizados do estudo de estabilidade a curto prazo obtidos por ICPMS. 


\section{LISTA DE ABREVIATURAS E SIGLAS}

ABNT Associação Brasileira de Normas Técnicas

ANOVA Análise de variância

BEC Background equivalent concentration (Concentração equivalente ao sinal de fundo)

BNDES Banco Nacional de Desenvolvimento Econômico e Social

CENA Centro de Energia Nuclear na Agricultura

CETEM Centro de Tecnologia Mineral

COMAR International Data Bank of Certified Reference Materials (Banco Internacional de Dados de Materiais de Referência Certificados)

CRM Certified Reference Material (Material de Referência Certificado)

EMBRAPA Empresa Brasileira de Pesquisa Agropecuária

EE Extrato Etéreo

EP Ensaios de Proficiência

EPLNA Ensaio de Proficiência para Laboratórios de Nutrição Animal

FAAS Flame atomic absorbtion spectroscopy (Espectrometria de Absorção Atômica de Chama)

FAO Food and Agriculture Organization of the United Nations (Organização das Nações Unidas para Agricultura e Alimentação)

FB Fibra Bruta

FDA Fibra em Detergente Ácido

FDN Fibra em Detergente Neutro

IAEA International Atomic Energy Agency (Agência Internacional de Energia Atômica)

ICP-MS Inductively Coupled Plasma Mass Spectrometry (Espectrometria de Massa por Plasma Acoplado Indutivamente)

ICP OES Inductively Coupled Plasma Optical Emission Spectrometry (Espectrometria de Emissão Óptica com Plasma Acoplado Indutivamente)

IEC International Electrotechnical Commission (Comissão Internacional de Eletrotécnica)

INAA Instrumental Neutron Activation Analysis (Análise por Ativação Neutrônica Instrumental)

INCQS Instituto Nacional de Controle de Qualidade na Saúde 
INMETRO Instituto Nacional de Metrologia, Qualidade e Tecnologia

IPEN Instituto de Pesquisas Energéticas e Nucleares

IPT Instituto de Pesquisas Tecnológicas do Estado de São Paulo

ISO International Organization for Standardization (Organização Internacional para a Padronização)

k Fator de abrangência

LOD Limit of detection (Limite de detecção)

LOQ Limit of quantification (Limite de quantificação)

MAPA Ministério da Agricultura, Pecuária e Abastecimento

MDIC Ministério da Indústria, Comércio Exterior e Serviços

MPA Ministério da Pesca e Aquicultura

NBS National Bureau of Standards (Departamento Nacional de Padrões)

NIRS Near-Infrared Spectroscopy (Espectroscopia de Infravermelho Próximo)

NIST National Institute of Standards and Technology (Instituto Nacional de Padrões e Tecnologia)

NNP Nitrogênio Não Proteico

NRC National Research Council Canada (Conselho Nacional de Pesquisa do Canadá)

PB Proteína Bruta

PCA Principal Component Analysis (Análise de Componentes Principais)

RM Reference material (Material de Referência)

RSD Relative Standard Deviation (Desvio Padrão Relativo)

SBR Signal to background ratio (Razão sinal analítico/sinal de fundo)

SINDIRAÇÕES Sindicato Nacional da Indústria de Alimentação Animal

$\mathbf{U}$

ubb

uchar

ults

URM

UCRM

usts

USDA

USP

VIM
Incerteza Expandida

Incerteza Padrão da Homogeneidade

Incerteza Padrão da Caracterização

Incerteza Padrão da Estabilidade a Longo Prazo

Incerteza Expandida do Material de Referência

Incerteza Expandida do Material de Referência Certificado

Incerteza Padrão da Estabilidade a Curto Prazo

United States Department of Agriculture (Departamento de Agricultura dos Estados Unidos)

Universidade de São Paulo

Vocabulário Internacional de Termos Fundamentais e Gerais de Metrologia 


\section{SUMÁRIO}

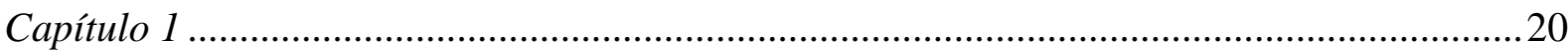

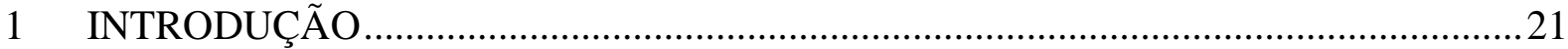

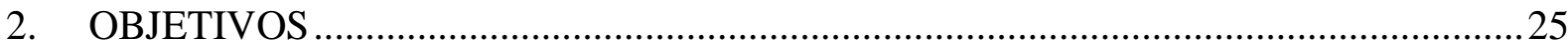

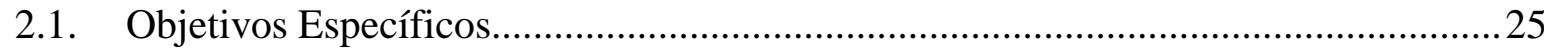

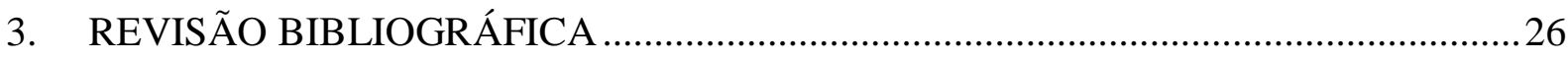

3.1. Material de Referência e Material de Referência Certificado....................................26

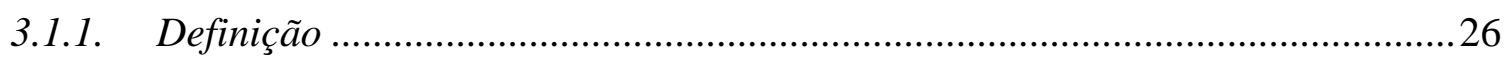

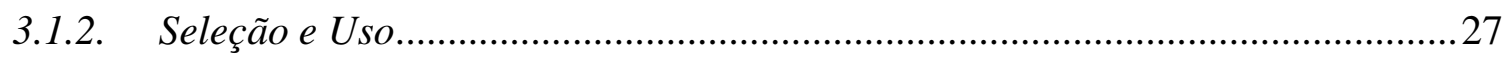

3.2. Produção de Material de Referência ..........................................................................29

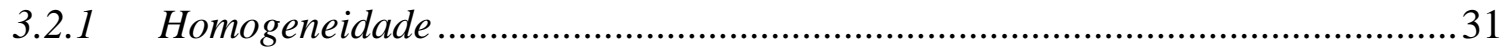

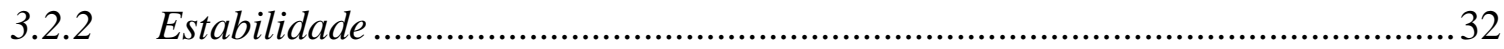

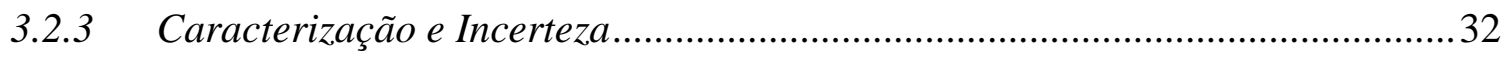

3.3. Histórico de Materiais de Referência.......................................................................... 35

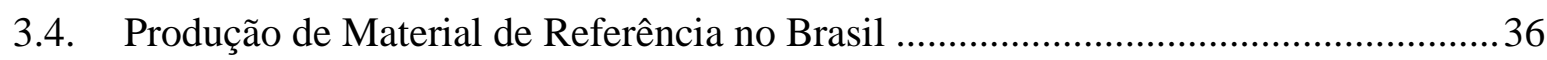

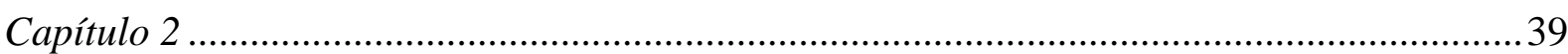

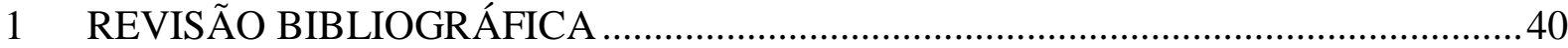

1.1 Material de Referência de Ração para Peixe .............................................................41

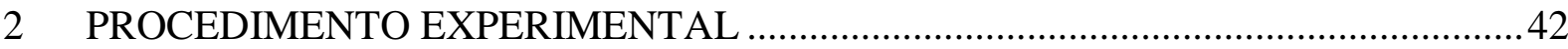

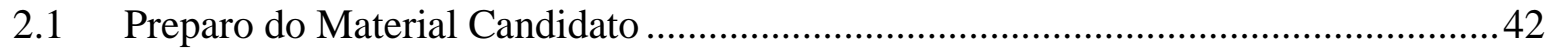

2.1.1 Obtenção e Preparação do Material.................................................................42

2.2 Caracterização Física do Material Candidato .............................................................43

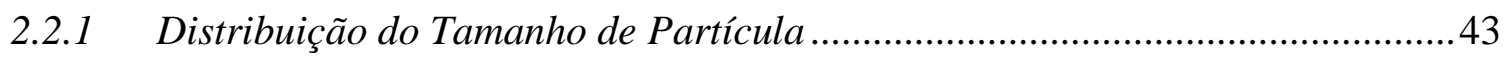

2.2.2 Determinação da Umidade Residual .................................................................43

2.3 Determinação dos Elementos por ICP OES …....................................................... 44

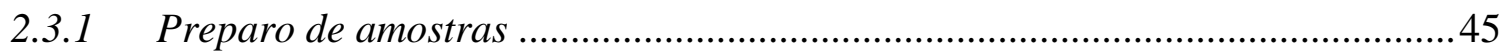

2.3.2 Quantificação dos macro e micronutrientes .......................................................46

2.4 Determinação dos Parâmetros Bromatológicos .......................................................48

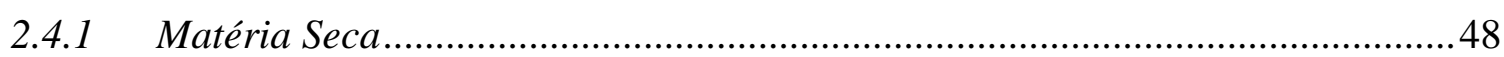

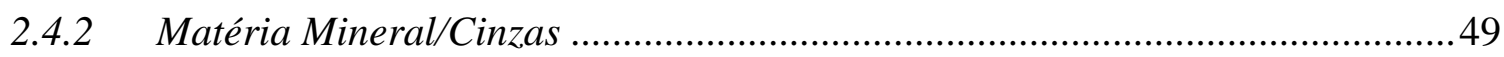

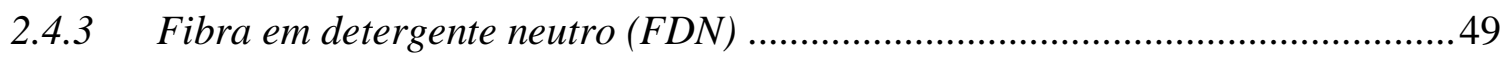

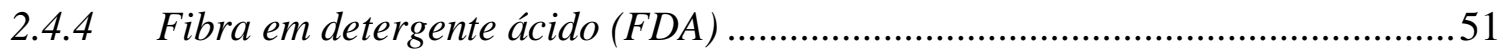

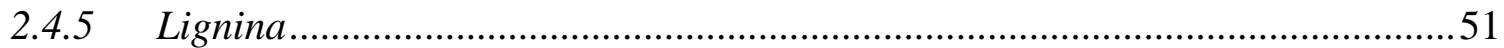

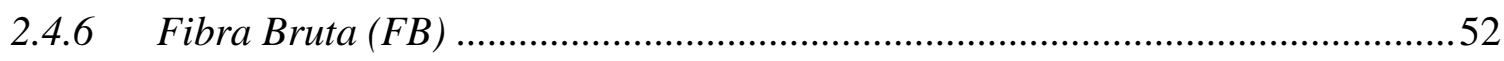

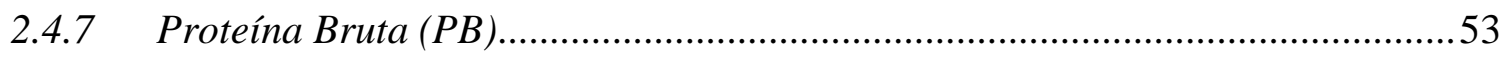

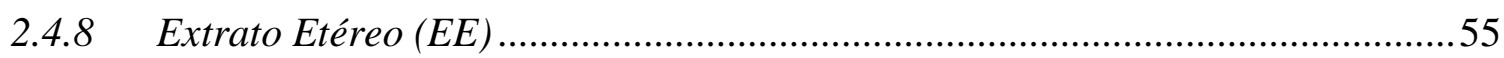

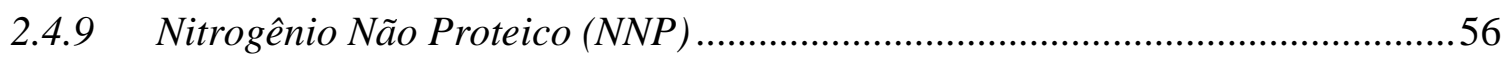


2.5 Estudo de Homogeneidade da Amostra de Ração Para Peixe Candidata a RM ........57

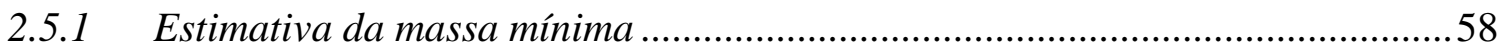

2.6 Estudo de Estabilidade da Amostra de Ração Para Peixe Candidata a RM ..............58

2.6.1 Estabilidade a Curto Prazo ....................................................................................59

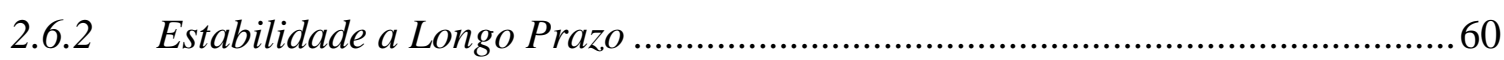

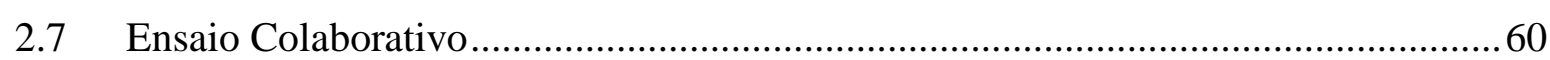

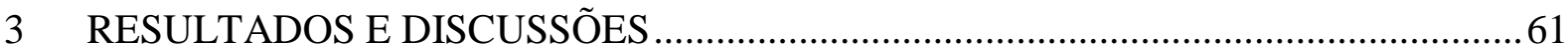

3.1 Distribuição do Tamanho de Partícula.........................................................................61

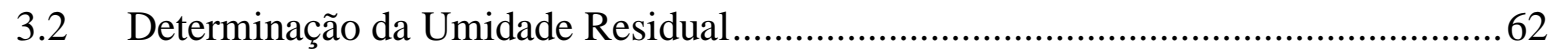

3.3 Limites de Detecção e Quantificação e Análises de CRMs.......................................63

3.4 Estudo de homogeneidade da amostra de ração para peixe .....................................65

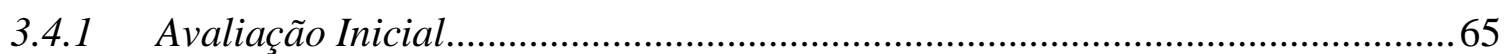

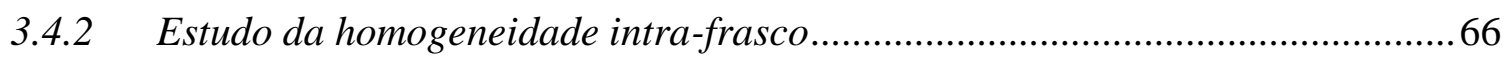

3.4.3 Estimativa da massa mínima de amostra ..........................................................68

3.4.4 Estudo da homogeneidade entre frascos .......................................................... 70

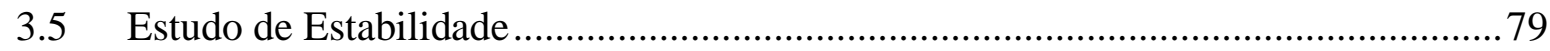

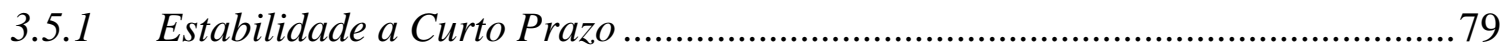

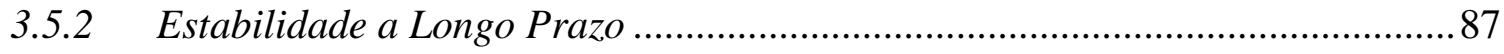

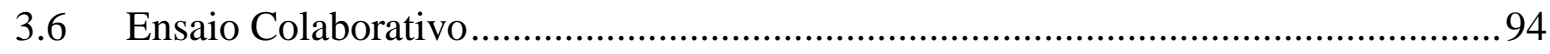

3.6.1 Avaliação dos resultados do ensaio colaborativo ............................................... 106

3.7 Caracterização final do material e determinação de incerteza.................................111

3.8 Atribuição dos valores de propriedades e incertezas obtidas................................... 113

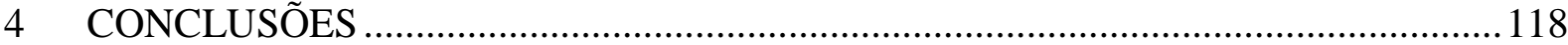

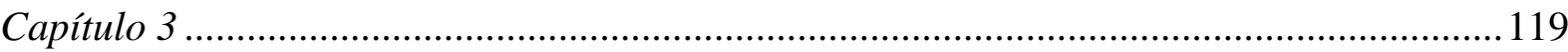

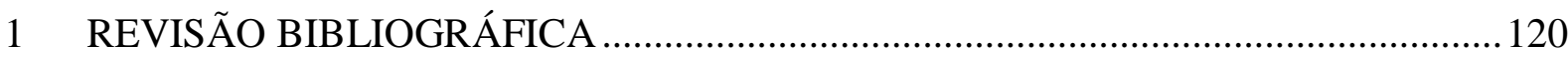

1.1 Material de Referência de Tecido de Peixe ....................................................... 121

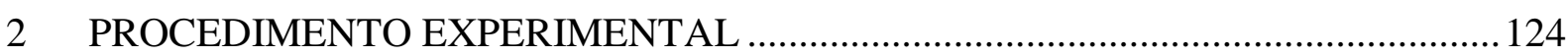

2.1 Preparo do Material Candidato .......................................................................... 124

2.1.1 Obtenção e Preparação das Amostras de Tecido de Peixe ................................ 124

2.2 Caracterização Física do Material Candidato ........................................................ 125

2.2.1 Distribuição de Tamanho de Partícula ......................................................... 125

2.2.2 Determinação da Umidade Residual ............................................................... 126

2.3 Determinação dos Elementos por ICP OES ....................................................... 126

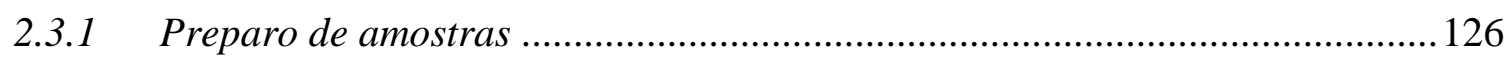

2.3.2 Quantificação de macro e micronutrientes ..................................................... 127

2.4 Determinação dos Elementos por ICP-MS …............................................................. 129

2.4.1 Quantificação de microelementos e contaminantes inorgânicos ...................... 130 
2.5 Estudo da Homogeneidade da Amostra de Tecido de Peixe Candidata a RM 132

2.5.1 Homogeneidade intra-frasco e Estimativa da Massa Mínima 132

2.5.2 Homogeneidade entre frascos 133

2.6 Estudo de Estabilidade da Amostra de Tecido de Peixe Candidata a RM...... 134

2.6.1 Estabilidade a Curto Prazo ............................................................................... 135

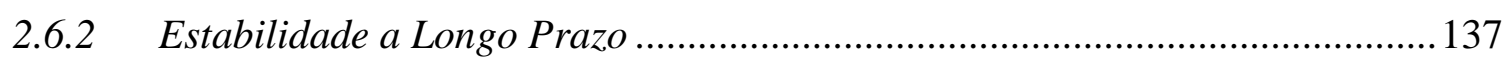

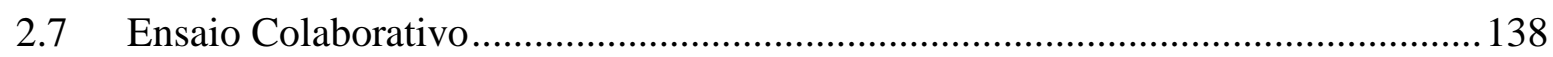

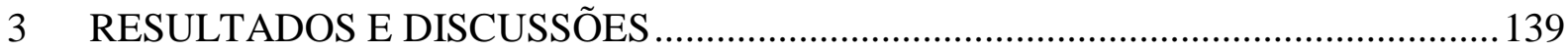

3.1 Distribuição de Tamanho de Partícula ................................................................... 139

3.2 Determinação da Umidade Residual.................................................................. 139

3.3 Caracterização de alguns parâmetros de validação das metodologias empregadas. 141

3.3.1 Limite de Detecção e Quantificação ................................................................ 141

3.3.2 Análise de Materiais de Referência Certificados ............................................. 142

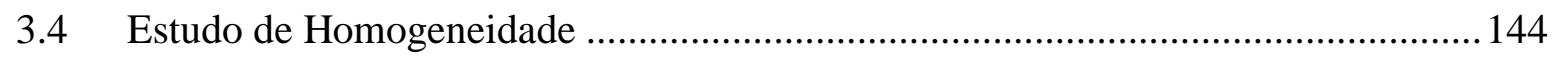

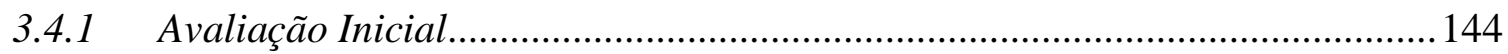

3.4.2 Estudo de Homogeneidade Intra-frasco e Estimativa da massa mínima .......... 145

3.4.3 Estudo de Homogeneidade Entre Frascos ...................................................... 156

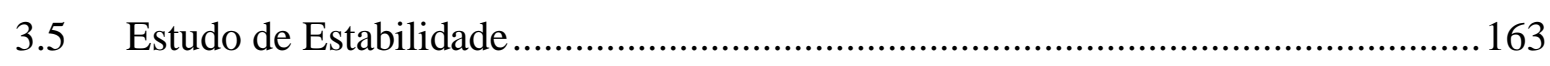

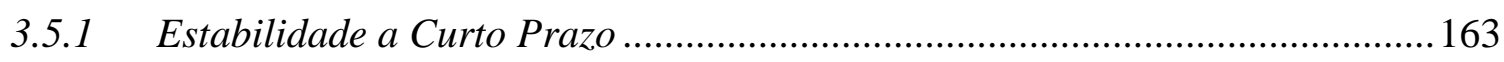

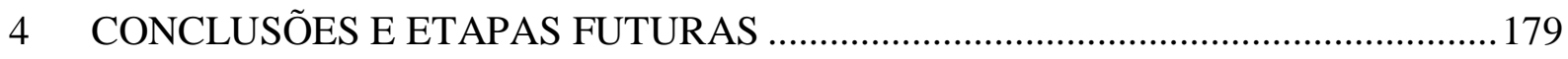

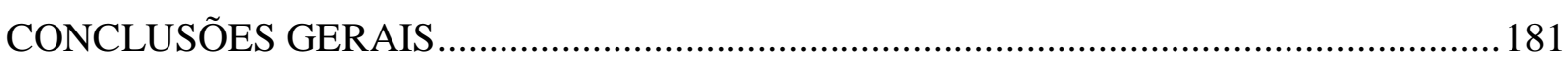

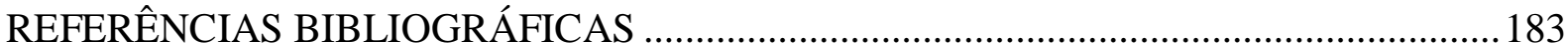

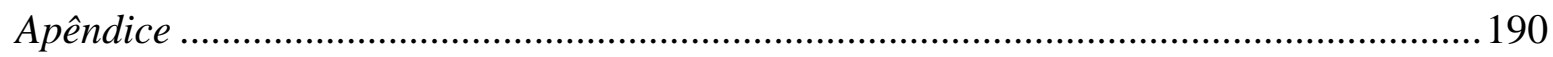


Capítulo 1 


\section{INTRODUÇÃO}

É inquestionável o potencial do Brasil para a produção pesqueira, considerando a extensão costeira e dimensão territorial, que dispõe de cerca de $13 \%$ da água doce do planeta. Com a quinta maior extensão territorial do mundo e uma população de milhões de habitantes, o Brasil é um dos maiores mercados do mundo. O potencial agropecuário é proporcional às dimensões do país. Entretanto, atualmente, prevalece uma desproporção na relação "produção nacional x importação" de pescado que faz com que Brasil tenha uma considerável dependência de países como China, Noruega, Argentina e Chile na importação de pescado e coprodutos. A dependência da importação traz como consequência um alto risco à balança comercial. Estrategicamente, o Governo brasileiro criou, em junho de 2009, o Ministério da Pesca e Aquicultura (MPA), incorporado ao Ministério da Agricultura, Pecuária e Abastecimento (MAPA) em 2015, e atualmente vinculado ao Ministério da Indústria, Comércio Exterior e Serviços (MDIC); demonstrando que este setor produtivo despertou a atenção governamental.

De acordo com a Organização das Nações Unidas para a Alimentação e a Agricultura (FAO), em 2015, haviam cerca de quatro milhões de pessoas envolvidas no setor pesqueiro. Atualmente, o Brasil é o $13^{\circ}$ maior produtor de peixes cultivados no mundo e o segundo no continente americano após o Chile (FAO, 2018) e é o quarto maior produtor de tilápia do mundo (PEIXEBR, 2018). As perspectivas para aquicultura são boas, com um crescimento esperado na produção de 52\% acima do nível médio, para o período entre 2012-14 e 2024, impulsionado pelo aumento da demanda interna e pelas políticas nacionais que apoiam o crescimento sustentável do setor (OECD/FAO, 2015).

A produção de pescado mundial atingiu 171 milhões de toneladas em 2016, sendo 88\% para consumo humano direto, decorrente do aumento de consumo per capita para $20,3 \mathrm{~kg}$. Desde 1961, o crescimento anual de consumo de pescado corresponde a duas vezes o crescimento da população global (FAO, 2018). Durante a última década, o consumo interno de peixe e produtos de pescado aumentou de forma estável, e a demanda foi atendida graças ao crescimento da produção de pesca e às importações. A piscicultura nacional produziu 697 mil toneladas de peixes de cultivo em 2017. Esse resultado é 8\% superior ao de 2016 (640.510 ton.) (PEIXEBR, 2018).

Desse modo, o aumento do consumo per capita de pescado será cada vez mais dependente da disponibilidade dos produtos oriundos da produção pesqueira e sua capacidade de adequação às exigências do mercado consumidor. 
O Brasil enfrenta desafios, como o atendimento à crescente demanda por alimentos e produtos agropecuários, em quantidade e qualidade. Para que o crescimento da produção do agronegócio no Brasil aconteça de maneira sustentável é necessário o desenvolvimento de bases científicas e tecnológicas sólidas, que solucionem as demandas existentes nos diversos elos da cadeia produtiva. É de extrema importância atender às exigências do comércio de exportação, garantindo a qualidade dos produtos.

O desenvolvimento econômico exige o estabelecimento de normas que controlem os comércios internacionais, nacionais, regionais e locais. A ciência analítica cumpre papel importante nesse contexto, desenvolvendo os métodos e os instrumentos para a execução de medições e estabelecendo parâmetros químicos que possibilitem a caracterização de produtos, possibilitando assim, que a demonstração de resultados analíticos seja obtida com qualidade para que possa ser aplicado tanto na indústria quanto no comércio e em pesquisa aplicada para que haja uma credibilidade e confiabilidade nas análises químicas principalmente no que diz respeito à tomada de decisões econômicas e políticas de proteção ao meio ambiente e à saúde.

Algumas espécies de pescado, como a tilápia, com alta importância econômica no mercado internacional (segunda espécie de peixe de água doce mais criada no mundo (FAO, 2018) e representatividade na cadeia produtiva da aquicultura nacional (mais de $50 \%$ de participação) (PEIXEBR, 2018), apresentam no Brasil fortes limitações sanitárias. Para contribuir na superação dos gargalos regulatórios e econômicos há a necessidade de se realizar estudos de qualidade de água e de gestão ambiental para apoio às políticas governamentais. Nesse sentido, deverão ser fornecidos pelos laboratórios envolvidos resultados analíticos confiáveis, com métodos validados. Para tanto, a utilização de materiais de referência certificados torna-se imprescindível.

A presença de elementos tóxicos em alimentos depende de alguns fatores, tais como as condições do ambiente, os métodos de produção e processamento, além da exposição aos resíduos de medicamentos, defensivos e fertilizantes. Normalmente a determinação dos teores desses elementos faz parte dos critérios para aprovação de um alimento, dentre os quais os pescados. No entanto, deve ser observado que os limites entre a essencialidade e a toxicidade de um elemento químico podem ser muito estreitos, tornando difícil sua discriminação (ELPO; FREITAS, 1995; SENESI et al., 1999). Devido a isso, há grande pressão por parte do mercado no sentido de obter resultados confiáveis e garantir a rastreabilidade (PAUWELS; LAMBERTY, 2001). 
A rastreabilidade metrológica é a propriedade do resultado de uma medição ou do valor de um padrão estar relacionado a referências estabelecidas, geralmente a padrões nacionais ou internacionais, através de uma cadeia contínua de comparações, todas contendo incertezas estabelecidas. Essa propriedade pode ser obtida a partir de uma combinação de práticas, por exemplo, a calibração de equipamentos de medição com padrões que possuam rastreabilidade garantida ao sistema internacional (SI); quando não for possível o uso de métodos primários, é desejável que o método adotado para a medida analítica seja comparado a um método previamente validado; quando os métodos utilizados tenham sua validade demonstrada e seja feito o uso de materiais de referência certificado de uma matriz que guarde o maior grau de similaridade possível com a amostra em questão (ELLISON, WILLIAMS, 2012; INMETRO, 2012).

Atualmente há técnicas analíticas instrumentais que possibilitam essa abordagem, porém é necessária uma evolução em estratégias de preparo de amostras para que uma maior confiabilidade seja alcançada, logo são necessários procedimentos de qualidade e certificação, que incluem o uso de métodos de análise validados, o uso de procedimentos internos de controle de qualidade com o emprego de material de referência $(\mathrm{RM})$ e de material de referência certificado (CRM), e procedimentos externos de controle de qualidade, como a participação em ensaios de proficiência.

A certificação pode ser realizada por um ou vários laboratórios, ou seja, é realizada por meio de Ensaios de Proficiência (EPs) que possibilitam, entre outros objetivos, analisar um material candidato a material de referência com o uso de metodologias reconhecidas, preferencialmente métodos previamente validados. Os laboratórios participantes devem seguir as recomendações estabelecidas pelo produtor do material de referência, ou seja, a metodologia e o procedimento analítico pré-estabelecidos no programa de certificação (HERZIG et al., 2002).

A importância dos CRMs é incontestável, porém, o grande problema é que não há materiais suficientes disponíveis para atender as demandas em todos os setores, principalmente, de produtos agropecuários e de alimentos que estão entre os mais carentes de materiais de referência certificado. No Brasil, essa demanda é atendida somente pela importação de países produtores a custos elevados, apesar de se iniciarem projetos voltados à produção de materiais de referência em algumas instituições de pesquisa. Além disso, para muitos setores não há disponibilidade de materiais adequados às necessidades brasileiras, uma vez que cada país produtor normalmente visa atender sua própria demanda. A seleção dos materiais de referência 
certificados desenvolvidos pelos grandes produtores mundiais tem sido pautada nas necessidades do usuário final, que precisa demonstrar a qualidade e a segurança dos produtos ofertados ao mercado consumidor nacional e internacional. Com isso, o domínio da tecnologia para a produção de materiais de referência no Brasil representa um avanço estratégico por colocar o país em condições de fornecer materiais específicos às próprias necessidades.

Dentro deste aspecto, a Embrapa Pecuária Sudeste apresenta experiência como provedor de ensaios de proficiência visando o controle de resultados analíticos, tanto de matérias de origem animal como de origem vegetal ou mineral. Esses ensaios contam com a participação de outros laboratórios representantes da Embrapa, de outros centros de pesquisa, de Universidades e de laboratórios do setor privado. A experiência adquirida nesta atividade e o acesso a diferentes laboratórios facilitam no que se refere ao recebimento dos resultados em rede, para a produção dos materiais de referência.

Considerando a necessidade da disponibilidade de materiais de referência no Brasil e a crescente importância de estudos voltados à piscicultura no País, é evidente a necessidade da produção de RMs de organismos aquáticos e suas fontes de alimentação, principalmente para auxiliar a obtenção de resultados analíticos confiáveis para o controle tanto de nutrientes quanto de contaminantes inorgânicos nesse tipo de amostra. 


\section{OBJETIVOS}

Produzir material de referência nacional de amostras de ração e tecido de peixe para avaliação de nutrientes e contaminantes inorgânicos, considerando as diretrizes das normas pertinentes.

\subsection{Objetivos Específicos}

- Produzir material de referência de ração para peixe para análise de macro e micronutrientes, além de parâmetros bromatológicos, baseado em requisitos estabelecidos internacionalmente pelos ISO GUIAS 30 a 35;

- Produzir material de referência de tecido de tilápia, contendo teores conhecidos de nutrientes e contaminantes inorgânicos, com base em requisitos estabelecidos internacionalmente pelos ISO GUIAS 30 a 35. 


\section{REVISÃO BIBLIOGRÁFICA}

\subsection{Material de Referência e Material de Referência Certificado}

\subsubsection{Definição}

A credibilidade dos resultados das análises quantitativas torna-se fundamental para cada propósito pretendido, garantindo a comparação dos resultados em programas de controle de qualidade. Para assegurar junto a seus clientes que é capaz de fornecer dados com a qualidade requisitada, o laboratório deve possuir procedimentos de gestão da qualidade e certificação. Tais procedimentos incluem uso de métodos de análise validados; uso de procedimentos internos de controle de qualidade com o emprego de materiais de referência (RMs) e/ou materiais de referência certificados (CRMs) e procedimentos externos de controle de qualidade, como a participação em ensaios de proficiência.

De acordo com o ABNT NBR ISO 17034 (2017), material de referência é: "material suficientemente homogêneo e estável com respeito a uma ou mais propriedades especificadas, que foi estabelecido como adequado para o seu uso pretendido em um processo de medição." Enquanto que material de referência certificado é um material de referência caracterizado por um procedimento metrologicamente válido para uma ou mais propriedades específicas, acompanhado por um certificado que fornece o valor da propriedade especificada, sua incerteza associada e uma declaração de rastreabilidade metrológica. O VIM - Vocabulário Internacional de Metrologia e o ABNT ISO Guia 30:2016 trazem definições semelhantes para esses termos.

A diferença entre ambos é que, enquanto um material de referência específico pode ser adequado para controle de qualidade, mas não para validação de metodologia, a definição de CRM leva em conta o importante termo rastreabilidade, utilizado para relacionar o resultado de medição a uma referência, permitindo a esse tipo de materiais usos variados e simultâneos.

O ABNT ISO Guia 30:2016 define rastreabilidade como "propriedade do resultado de uma medição ou do valor de um padrão, com uma incerteza indicada, estar relacionado a referências estabelecidas, usualmente padrões nacionais ou internacionais, através de uma cadeia de comparações ininterruptas”.

Assim, a rastreabilidade é requisito importante para a garantia da qualidade dos dados analíticos nos mercados nacionais e internacionais. A rastreabilidade permite também que a obtenção de uma medida, independentemente dos laboratórios participantes tenham uma escala 
de medição muito similar, assegurando, portanto, um controle maior do resultado (VERHALEN, 2014).

Conforme o ABNT NBR ISO 17034:2017, produtor de material de referência é um organismo (organização ou empresa, pública ou privada) que é completamente responsável pelo planejamento e gestão do projeto, atribuição e decisão sobre os valores de propriedade e incertezas relevantes, autorização de valores de propriedade e emissão de certificado ou outras declarações para os materiais de referência que produz. Pode acontecer de um produtor produzir tanto RMs quanto CRMs, uma vez que para ser considerado como CRM, o mesmo deve estar dentro do escopo de acreditação do produtor.

\subsubsection{Seleção e Uso}

Entre os diversos documentos e diretrizes referentes aos RMs, alguns são fundamentais, o ABNT ISO Guia 33, a DOQ-CGCRE-016, que trata de uma orientação para a seleção e uso de Materiais de Referência e a DOQ-CGCRE-033, que trata de uma orientação para a análise crítica da documentação associada aos materiais de referência adquiridos. São diversas as aplicações para os RMs, podendo ser citados, dentre os principais, o uso como uma ferramenta para a análise crítica da validade dos resultados dos ensaios; para a calibração de instrumentos de medição; para o controle interno da qualidade e validação de métodos; para a identificação de problemas nos laboratórios e na realização das ações corretivas necessárias para a melhoria do desempenho analítico; para estabelecimento da comparabilidade entre métodos de ensaios; para o fornecimento de confiança adicional aos clientes dos laboratórios; e, ainda, para atribuição de valores a outros materiais de referência.

Apenas RMs com valores atribuídos e incerteza associada podem ser utilizados para a calibração ou para o controle da veracidade e, portanto, podem prover rastreabilidade metrológica. Materiais de referência com ou sem valores atribuídos podem ser utilizados para controlar a precisão de medição, atividade para a qual não é requerido que o material seja fornecido por produtores acreditados.

Com relação à seleção de RMs ou CRMs, o ABNT ISO Guia 33 afirma que convém considerar não apenas o nível de incerteza requerido, mas também sua disponibilidade, seu custo e adequação química e física para o objetivo pretendido. É muito importante que o usuário se certifique de que o CRM que está sendo adquirido apresente matriz e características físicas e mecânicas semelhantes ao das amostras a serem analisadas para que as operações unitárias 
como dissolução e diluição envolvidas nas análises sejam sujeitas às mesmas condições analíticas. São os seguintes os principais itens a serem considerados quando da seleção de um CRM: selecionar o material mais adequado ao uso; matriz mais próxima possível da amostra da rotina; concentração e incerteza adequada; fornecedores.

Os RMs são usados para dar suporte a medições relacionadas à composição química, biológica, clínica, física e propriedades de engenharia. Eles podem ser caracterizados para "identidade" (ex: estrutura química, tipo de fibra, espécies microbiológicas, etc.) ou para "valores de propriedades" (ex: quantidade de substância química específica, dureza, sabor, odor, etc).

De acordo com INMETRO (2010), alguns tipos de materiais de referência comumente encontrados são:

1. Substâncias puras caracterizadas para pureza química e/ou traços de impureza;

2. Soluções padrão e misturas gasosas, frequentemente preparadas gravimetricamente a partir de substâncias puras e usadas para fins de calibração;

3. Materiais de referência em matrizes, caracterizados para a composição de componentes químicos principais, secundários ou elementos-traço. Tais materiais podem ser preparados a partir de matrizes contendo os componentes de interesse, ou através da preparação de misturas sintéticas;

4. Materiais de referência físico-químicos caracterizados para propriedades tais como ponto de fusão, viscosidade, e densidade óptica.

Os dois primeiros tipos de materiais são utilizados principalmente nas etapas de medição de um processo analítico (calibração de equipamentos, por exemplo) ou na determinação de alguma propriedade específica. Os materiais de referência de matriz são usualmente materiais genuínos contendo o analito ou analitos de interesse na sua forma natural. Este tipo de padrão deve observar o maior grau possível de semelhança com a natureza da amostra a ser analisada, conter analitos com valores de referência bem caracterizados e, na medida do possível, similares aos existentes na amostra em estudo. O uso mais importante de materiais de referência de matriz consiste em testar e validar metodologias analíticas. Juntos, são parte integrante e importante no desenvolvimento de todo processo analítico, assegurando dessa forma a qualidade em todas as etapas que envolvem a caracterização química de uma amostra. 


\subsection{Produção de Material de Referência}

A produção de amostras candidatas a materiais de referência é baseada em requisitos estabelecidos nos guias da série de ABNT ISO Guias 30 a 35 e na norma ABNT NBR ISO 17034:2017. Dentre estas normas, esta última - "Requisitos gerais para competência de produtores de material de referência" fornece todas as diretrizes e requisitos que devem ser cumpridos pelos produtores, desde o planejamento da produção do material de referência até a organização de toda a documentação necessária, sendo uma das normas mais importantes no processo de produção de um material de referência. Os produtores que aplicam a ABNT NBR ISO 17034 também devem estar alinhados o ABNT NBR ISO/IEC 17025, pois além de apresentarem alguns requisitos similares, esta última é citada como referência em vários requisitos da ABNT NBR ISO 17034.

As diretrizes estabelecidas pela ABNT NBR ISO 17034 incluem: análise qualitativa para a verificação do tipo do material; usinagem, moagem, homogeneização, peneiramento e quarteamento; determinação da distribuição dos tamanhos de partículas; limpeza de recipiente de amostra; secagem e esterilização; embalagem de amostras representativas do lote; testes de homogeneidade e estabilidade; e por fim, a caracterização das propriedades do RM.

Segundo o ISO Guia 35, as etapas envolvidas na produção de um material de referência são:

$\checkmark$ Definição do projeto e escolha do material de referência: basicamente, definem-se a matriz, as propriedades de certificação, e os níveis desejados e, também, o nível de incerteza pretendido;

$\checkmark$ Definição do procedimento de preparo das amostras;

$\checkmark$ Escolha dos métodos de medição apropriados para os testes de homogeneidade e estabilidade, e também de caracterização do material;

$\checkmark$ Amostragem e preparo (secagem, moagem para redução do tamanho de partículas, envase, homogeneização);

$\checkmark$ Teste de homogeneidade;

$\checkmark$ Teste de estabilidade;

$\checkmark$ Caracterização do material;

$\checkmark$ Combinação de todos os resultados e cálculo de todas as incertezas de medição;

$\checkmark$ Emissão do certificado. 
Todas as etapas são devidamente detalhadas e particularizadas em tópicos no guia, para elucidação dos procedimentos e cuidados que se devem considerar. A ABNT NBR ISO 17034:2017 ainda traz os requisitos básicos de organização e de implementação de sistemas da qualidade de um produtor de materiais de referência.

Para o processamento e interpretação corretos dos dados experimentais em um projeto de certificação típico são necessários: conhecimento do material e suas propriedades, dos métodos de medição empregados durante os ensaios de homogeneidade, de estabilidade e caracterização do material, juntamente com um amplo conhecimento dos métodos estatísticos.

A etapa de planejamento do material de referência e a escolha da matriz são cruciais para o sucesso do CRM final. Nessas etapas, devem ser avaliadas também a viabilidade e a adequação à finalidade do projeto, o que é necessário para se certificar que o material escolhido é adequado para o objetivo de uso do material, incluindo as propriedades de interesse para os laboratórios de análise.

Basicamente, são quatro etapas de trabalho para a produção de um CRM: preparo do material; envase das amostras, com verificação da homogeneidade do material nos frascos; estabelecimento da estabilidade, que garantirá ao material embalado ser mantido íntegro durante estocagem por tempo pré-estabelecido e a certificação dos valores atribuídos às propriedades de interesse do material preparado. A preparação é uma etapa crucial para garantir a representatividade do material e deve considerar os procedimentos de limpeza, secagem e moagem, os quais podem afetar diretamente a homogeneidade e a estabilidade do material. Após o preparo a verificação da distribuição do tamanho de partícula é necessária, pois a granulometria pode afetar diretamente a composição química, a homogeneidade e a representatividade de um RM, além da possibilidade de inviabilizar a execução de alguns ensaios. A granulometria deve ser apropriada para a obtenção de uma massa mínima aceitável para que a heterogeneidade do material não comprometa o método de medição.

A quantidade de material necessária para a produção de um RM é estabelecida pelo número de amostras do RM/CRM requeridas; necessidade de estudo de viabilidade; número de amostras requeridas para o estudo de homogeneidade; número de amostras requeridas para o estudo de estabilidade; número de amostras requeridas para a caracterização do candidato a CRM e quantidade de material requerida para uma medição.

A embalagem desse material também tem relevância, pois irá contribuir para manter sua integridade durante todo o período despendido no transporte e armazenamento. $\mathrm{O}$ valor de propriedade certificada dos materiais de referência deve ser mensurado a partir de cálculos 
estatísticos adequados e informado com suas incertezas devidamente estimadas, provenientes da caracterização da amostra, da homogeneidade, da estabilidade e dos métodos empregados nas determinações analíticas.

\subsubsection{Homogeneidade}

Segundo Moreira (2010), materiais de referência sólidos são, em uma primeira instância, heterogêneos. Efetivamente, o estudo de homogeneidade é empregado para averiguar se a heterogeneidade residual é significativa quando comparada com a incerteza de caracterização do material.

O teste de homogeneidade da amostra é um dos fatores essenciais para a garantia da manutenção das propriedades físico-químicas do material estudado e, portanto, o número de recipientes, retirados do lote preparado, selecionados para esta avaliação deve ser representativo em relação ao quantitativo final. Para o teste, segundo o ABNT ISO Guia 35:2012, o número de frascos selecionados aleatoriamente deve incluir entre 10 e 30 unidades do lote preparado, sendo que ocorrem variações em função do tamanho do lote preparado (OLIVARES et al, 2018). O ISO Guide 35:2017 indica que, atualmente, a melhor prática é aumentar o número de unidades, conforme aumenta o lote. As recomendações típicas estariam entre $\sqrt[3]{N_{\text {prod }}} \mathrm{e}$ $3 \times \sqrt[3]{N_{\text {prod }}}$, onde $N_{\text {prod }}$ representa a quantidade de unidades do lote produzido. Considerando os requisitos de graus de liberdade, tem-se um mínimo recomendado dado por: $N_{\min }=$ $\max \left(10, \sqrt[3]{N_{\text {prod }}}\right)$, onde $\max$ representa o máximo dos valores dentro dos parênteses.

O planejamento para verificar a homogeneidade de um lote de material preparado para fins de certificação deve indicar as variabilidades da amostra dentro do recipiente, assim como entre os recipientes que contêm os materiais que compõem o lote, devidamente envasados. Os dados para o teste de homogeneidade devem ser executados em condições de estrita repetibilidade (mesmo laboratório, mesmo analista e todas as amostras testadas no mesmo dia, se possível). Além disso, na variabilidade entre os frascos, deve ser incluída a incerteza relativa a tal condição. A avaliação do estudo de homogeneidade é baseada na ABNT ISO Guia 35 (análise de variância (ANOVA) de fator único). 


\subsubsection{Estabilidade}

Assim como a avaliação da homogeneidade, a avaliação da estabilidade é também prérequisito no processo de certificação do RM (VAN DER VEEN, 2001b) e tem como objetivo avaliar a estabilidade do mesmo após a sua preparação durante períodos específicos de tempo e temperatura, pois o material preparado pode ser suscetível à degradação com o tempo devido a fenômenos produzidos por: temperatura, luz, oxigênio, umidade, atividade microbiológica etc. Dois testes distintos de estabilidade serão realizados, estabilidade a curto e a longo prazos.

O estudo de estabilidade a curto prazo simula as condições de transporte, garantindo que o material não sofrerá degradação por alteração de temperatura durante o transporte, por exemplo. A variação de temperatura é um fator chave na degradação do material biológico e, portanto, frascos com o material são mantidos a diferentes temperaturas e analisadas em função do tempo para verificar possíveis alterações de suas propriedades. Por outro lado, a estabilidade a longo prazo (simula o tempo de prateleira) verifica se o material de referência pode ser armazenado em condições definidas, tais como temperatura ambiente, verificando assim seu comportamento na prateleira do produtor (ABNT, 2012).

Segundo a ABNT ISO Guia 35, o estudo de estabilidade requer um número considerável de frascos (unidades). Os estudos de longo prazo devem considerar pelo menos 10 a 12 frascos. Recomenda-se um número de frascos entre 6 e 10 para um estudo de estabilidade a curto prazo, para cada temperatura avaliada.

Ainda de acordo com a ABNT ISO Guia 35, o método escolhido para a realização do estudo de estabilidade deve considerar condições de repetitividade. Existem dois leiautes experimentos para o estudo de estabilidade: o planejamento clássico e o isócrono. No estudo clássico, as avaliações das amostras de um mesmo grupo são distribuídas durante o tempo de estudo, sob condições de reprodutibilidade, tendo, por consequência, maiores valores de incerteza e menores tempos de prateleira. $\mathrm{O}$ estudo isócrono permite a execução de todas as determinações sob condições de repetitividade, uma vez que todas as medições são feitas ao mesmo tempo, ao final da exposição das amostras às variadas temperaturas do estudo.

\subsubsection{Caracterização e Incerteza}

Conforme a ABNT NBR ISO 17034:2017, para materiais de referência certificados, o produtor deve utilizar e documentar procedimentos tecnicamente válidos para caracterizar seus 
materiais de referência. A caracterização deve estar em conformidade com os requisitos dos ABNT ISO Guia 35:2012 e ABNT NBR ISO/IEC 17025:2017 para ensaio, calibração e atividades relacionadas. Há várias abordagens tecnicamente válidas para a caracterização de um material de referência. Isto inclui realizar medições utilizando:

a) um único método (primário) em um único laboratório;

b) dois ou mais métodos de referência independentes em um ou mais laboratórios;

c) um ou mais métodos com exatidão demonstrável, realizado por uma rede de laboratórios competentes;

d) uma abordagem que forneça valores de propriedade métodos-específicos, operacionalmente definidos, utilizando uma rede de laboratórios competentes.

Dependendo do tipo de material de referência, do seu uso pretendido, da competência dos laboratórios envolvidos e da qualidade de métodos empregados, uma das abordagens pode ser escolhida como apropriada.

Os materiais de referência geralmente são caracterizados baseados na exatidão de todo o processo experimental e, desse modo, o valor certificado da propriedade representa a melhor estimativa do valor verdadeiro (VAN DER VEEN, 2001c). A incerteza declarada desse valor da propriedade deve levar em consideração todos os efeitos casuais e sistemáticos inerentes ao processo de medição, assim como a variabilidade entre as amostras (homogeneidade) e o tempo de validade do material (estabilidade).

Segundo INMETRO (2012), incerteza de medição é "parâmetro não negativo que caracteriza a dispersão dos valores atribuídos a um mensurado, com base nas informações utilizadas". Deste modo, a confiabilidade é maior quando é declarada a informação de incerteza associada a uma medição analítica.

A incerteza expandida, $U$, dá um intervalo dentro do qual se crê encontrar-se o valor do mensurando, com um maior grau de confiança. $\mathrm{O}$ valor de $\mathrm{U}$ é obtido pela multiplicação da incerteza padrão combinada, $\mathrm{u}$, por um fator de expansão $\mathrm{k}$. A escolha do fator k é baseada no grau de confiança desejado. Para um grau de confiança de aproximadamente $95 \%$, k geralmente é igual a 2, contudo onde a incerteza combinada for baseada em observações estatísticas com poucos graus de liberdade, sendo dominada por uma contribuição com menos que seis graus de liberdade, é recomendado que o valor de k seja igual ao t-student (95\% bicaudal) para o número de graus de liberdade associado a esta contribuição (ELLISON, WILLIAMS, 2012).

A abordagem das incertezas menciona os procedimentos para a certificação de materiais de referência e mostra a importância de se obter as incertezas de todas as etapas de 
sua preparação e assim contribuir para o valor da incerteza final que acompanha o valor de propriedade de um determinado material. A incerteza final do CRM ou RM leva em consideração as incertezas associadas aos testes de homogeneidade e estabilidade, a caracterização do material e inconsistências entre os resultados obtidos usando diversos métodos.

O estudo de homogeneidade entre os frascos fornecerá a incerteza da homogeneidade existente entre os mesmos e é avaliada de acordo com a Equação 1 (ABNT ISO GUIA 35: 2012; VAN DER VEEN et al, 2001a):

$$
s_{b b}^{2}=s_{A}^{2}=\frac{M Q_{\text {entre }}-M Q_{\text {dentro }}}{n_{0}}
$$

Onde $\mathrm{s}^{2}{ }_{\mathrm{bb}}$ : variância da homogeneidade entre os recipientes; $\mathrm{s}_{\mathrm{A}}^{2}$ : variância da homogeneidade dentro do recipiente; $\mathrm{MQ}_{\mathrm{entre}}=$ média quadrática entre os frascos; $\mathrm{MQ}_{\mathrm{dentro}}=$ média quadrática dentro dos frascos; $\mathrm{n}_{0}=$ número de replicatas. $\mathrm{E}$ assim, para a avaliação da incerteza assume-se que $\mathrm{s}^{2} \mathrm{bb}$ é idêntica $\mathrm{a} \mathrm{u}^{2} \mathrm{bb}$.

Em casos em que o método de medição escolhido, apresentar repetibilidade insuficiente ou o material não permitir uma sub amostragem $\left(\mathrm{MQ}_{\text {entre }}<\mathrm{MQ} \mathrm{Q}_{\text {dentro }}\right)$ é recomendado utilizar a Equação 2:

$$
u_{b b}=\sqrt{\frac{M Q_{\text {dentro }}}{n}} \sqrt[4]{\frac{2}{v_{M Q_{\text {dentro }}}}}
$$

Onde: $\mathrm{u}_{\mathrm{bb}}$ : incerteza da homogeneidade; $\mathrm{MQ}_{\mathrm{dentro}}=$ média quadrática dentro dos frascos; $\mathrm{n}=$ número de repetições; $\mathrm{n}_{\mathrm{MQdentro}}=$ graus de liberdade de $\mathrm{MQ}_{\text {dentro }}$.

A utilização destas fórmulas é dependente dos valores do desvio padrão da homogeneidade $\left(\mathrm{s}_{\mathrm{bb}}\right)$ e do desvio padrão de repetibilidade $\left(\mathrm{s}_{\mathrm{r}}\right)$. Quando $\mathrm{s}_{b}$ for menor que $\mathrm{s}_{\mathrm{r}}$, é adequado aplicar a segunda equação, pois esta expressão se baseia na amplitude de um intervalo de confiança de 95\%, levando em consideração a variância de repetibilidade das medições utilizadas no estudo de homogeneidade entre os recipientes (ABNT ISO GUIA 35: 2012).

A incerteza final do CRM ou RM leva em consideração as incertezas associadas aos testes de homogeneidade e estabilidade e a caracterização do material. Assim, a incerteza expandida associada ao valor de propriedade de um CRM pode ser expressa pela Equação 3: 


$$
U_{C R M}=k \sqrt{u_{c h a r}^{2}+u_{b b}^{2}+u_{s t s}^{2}+u_{l t s}^{2}}
$$

Onde k é o fator de abrangência, que neste trabalho usaremos $\mathrm{k}=2$, com intervalo de confiança de $95 \%$ e através das contribuições referentes à incerteza padrão da caracterização $\left(u_{c h a r}\right)$, da homogeneidade $\left(u_{b b}\right)$, da estabilidade a curto prazo $\left(u_{s t s}\right)$, da estabilidade a longo prazo $\left(u_{I t s}\right)$.

A Figura 1 apresenta as etapas da produção do material e as incertezas associadas a cada etapa, as quais devem ser computadas para a certificação de um CRM.

Figura 1 - Etapas de produção de um material de referência.

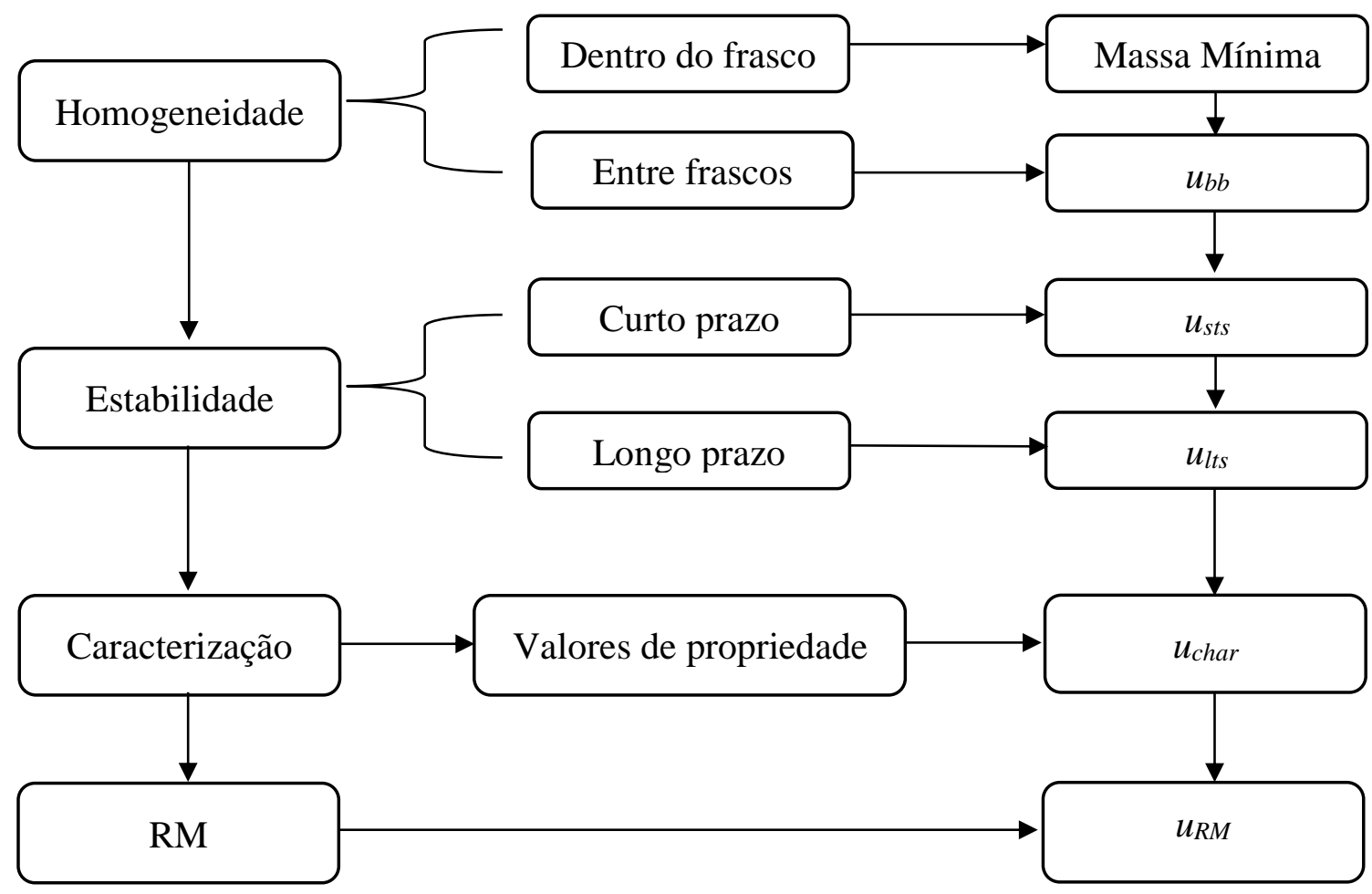

Fonte: ABNT, 2012.

\subsection{Histórico de Materiais de Referência}

A produção de materiais de referência acompanha o desenvolvimento da Química Analítica. Os primeiros registros de produção e uso de materiais de referência remonta ao século XIX.

Em 1905, foi criado o National Bureau of Standards (NBS), atualmente denominado NIST - National Institute of Standards and Technology, a partir da necessidade de efetuar comparações interlaboratoriais de resultados analíticos. E, em 1906, em atendimento a uma 
demanda industrial, o Instituto deu início ao primeiro programa de produção de RMs (ZSCHUNKE, 2000).

Houve uma grande produção de CRMs nos anos 1970 a partir de matrizes ambientais e, nos anos 1980, iniciou-se a produção de CRMs de alimentos: farinha de trigo, fígado bovino, tecido de ostra, entre outros (VERHALEN, 2014).

Nos dias atuais, diversos materiais de referência têm sido produzidos para atender às mais diversas áreas do conhecimento, sendo que existem sistemas de busca que podem ajudar a encontrar materiais de referência certificados. O COMAR (Banco Internacional de Dados de Materiais de Referência Certificados), por exemplo, é uma rede de organizações que dissemina informações sobre produtores e materiais de referência disponíveis em vários países. Em 2016 haviam 10654 RMs cadastrados neste banco de dados, contando com cerca de 240 produtores em 28 países, em 2018 são 8049 RMs, de 195 produtores em 26 países. Os maiores produtores de RMs são Japão, Alemanha, Reino Unido, IRMM (União Europeia) e China (Figura 2).

Figura 2 - Países produtores e quantidade de CRMs produzidos.

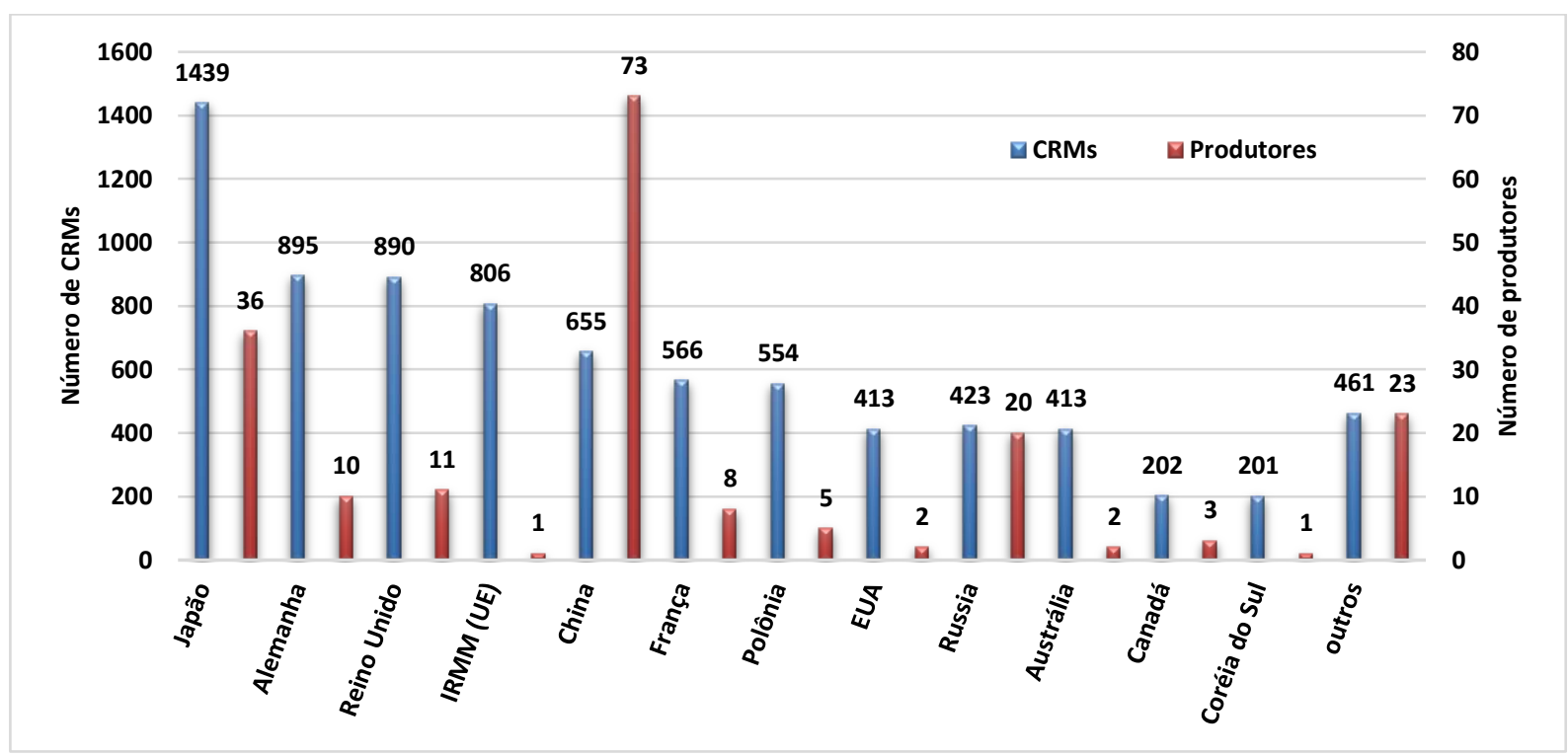

Fonte: Adaptado de COMAR, 2018.

\subsection{Produção de Material de Referência no Brasil}

Dentro de um panorama de produção nacional de RMs e CRMs, um pequeno número de instituições produz e os comercializa no País. O Instituto de Pesquisas Tecnológicas - IPT, localizado nas dependências da Universidade de São Paulo (USP), foi o pioneiro no Brasil na produção de materiais de referência. Atuando desde 1975 desenvolveu mais de 130 tipos de 
materiais de referência certificados, sendo que produz e comercializa padrões de minerais, metais, materiais inorgânicos diversos, entre outros.

Desde então outros produtores foram acreditados no País como produtores, de acordo com a avaliação de competência técnica, através de critérios harmonizados baseados na combinação da ABNT NBR ISO 17034 e da norma ABNT NBR ISO/IEC 17025. Atualmente existe uma pequena quantidade de laboratórios acreditados pela Coordenação Geral de Acreditação do Inmetro (CGCRE) no Brasil. Conforme pode ser visto na Tabela 1 existem 8 laboratórios acreditados em âmbito nacional.

Tabela 1 - Produtores de Materiais de Referência Acreditados pela CGCRE na ABNT NBR ISO 17034.

\begin{tabular}{|c|c|}
\hline Instituição & Categoria/Matriz \\
\hline $\begin{array}{l}\text { DIGICROM ANALÍTICA LTDA- EPP - } \\
\text { São Paulo/SP }\end{array}$ & Padrões de $\mathrm{pH}$ e de condutividade \\
\hline $\begin{array}{l}\text { Visomes Comercial Metrológica Ltda } \\
\text { São Paulo/SP }\end{array}$ & Padrões de $\mathrm{pH}$ e de condutividade \\
\hline $\begin{array}{l}\text { WHITE MARTINS GASES INDUSTRIAIS } \\
\text { LTDA. - Osasco/SP }\end{array}$ & Mistura de Gases \\
\hline $\begin{array}{l}\text { AIR LIQUIDE BRASIL LTDA - GASES } \\
\text { ESPECIAIS - ALPHAGAZ - São Paulo/SP }\end{array}$ & Mistura de Gases \\
\hline $\begin{array}{c}\text { LABORATÓRIOS BRUCH LTDA - São } \\
\text { Paulo/SP }\end{array}$ & $\begin{array}{c}\text { Soro Padrão Positivo - Anemia Infecciosa Equina } \\
\text { Antígeno - Anemia Infecciosa Equina }\end{array}$ \\
\hline $\begin{array}{c}\text { CONTROLLAB CONTROLE DE QUALIDADE } \\
\text { PARA LABORATÓRIOS LTDA - Rio de } \\
\text { Janeiro/RJ }\end{array}$ & Padrões de $\mathrm{pH}$ e de condutividade \\
\hline $\begin{array}{c}\text { Linde Gases Ltda. - Linde Gases Ltda. - Gases } \\
\text { Especiais - Jundiaí/SP }\end{array}$ & Mistura de Gases \\
\hline QMC Saneamento Ltda. - EPP - Florianópolis/SC & Águas \\
\hline
\end{tabular}

Fonte: http://inmetro.gov.br/credenciamento/acre_prod_RM.asp. Acesso em: 03 de outubro de 2018.

O Centro de Tecnologia Mineral - CETEM produz padrões de bauxita, minério de sulfetos de cobre e concentrado de sulfetos de cobre. O Instituto Nacional de Controle da Qualidade na Saúde (INCQS), unidade da Fundação Oswaldo Cruz, no Rio de Janeiro, iniciou em 1982 um programa para estabelecimento de materiais de referência.

O INMETRO produz e comercializa uma variedade considerável de CRM, tendo produzido recentemente materiais para a área de perícia criminal.

No setor agropecuário, o CENA colaborou com a Agência Internacional de Energia Atômica (IAEA), em 1992, na produção do RM Trace Elements in Soya Flour (IAEA RM361). Em 2006 foi finalizada, durante um pós-doutoramento, a preparação de RM de café, 
denominado Café Arábica. Adicionalmente, o IQ-USP e o IPEN produziram diversos materiais de referência a partir de amostras de pescados.

Em 2008, o CENA, a Faculdade de Ciências Farmacêuticas da USP de Ribeirão Preto (FCFRP-USP) e a Embrapa Pecuária Sudeste se tornaram parceiras de um Centro Colaborador de Defesa Agropecuária para Produção de Materiais de Referência Certificados e Organização de Ensaios de Proficiência de Resíduos e Contaminantes Inorgânicos, desenvolvendo o projeto CRM - Agro - Materiais de Referência para Agricultura, Pecuária e Toxicologia rendendo produção de diversos RM. No contexto deste projeto, a Embrapa Pecuária Sudeste produziu cinco RMs:

- CRM - Agro E2001a: RM de mistura mineral, contendo teores conhecidos de Ca, K, $\mathrm{Na}, \mathrm{P}, \mathrm{Cu}, \mathrm{Fe}, \mathrm{Mn}, \mathrm{Mg}$, Zn e os contaminantes As, $\mathrm{Cd}$ e $\mathrm{Pb}$;

- CRM - Agro E1001a: forrageira, contendo teores conhecidos de Ca, P, Mg, K, Cu, $\mathrm{Fe}, \mathrm{Mn}, \mathrm{Zn}$ e $\mathrm{Na}$ e os contaminantes $\mathrm{As}, \mathrm{Cd}, \mathrm{Cr}$ e $\mathrm{Pb}$;

- CRM -Agro E2002a: solo para análise de As, Ca, Cd, Cr, Cu, Fe, K, Mg, Mn, Na, P $\mathrm{e} \mathrm{Pb}$;

- CRM - Agro E3001a: fígado bovino para As, Pb, Cd, Ca, Mg, Na, Fe, Cu, Zn, K, Mn, P,Co, V, Se, Sr e Mo e

- CRM - Agro E2003a: fosfato de rocha, com valores de referência para Al, As, Ca, $\mathrm{Cd}, \mathrm{Cr}, \mathrm{Cu}, \mathrm{Fe}, \mathrm{K}, \mathrm{Mg}, \mathrm{Mn}, \mathrm{Na}, \mathrm{Ni}, \mathrm{P}, \mathrm{V}$ e Zn.

Todos os RM foram produzidos conforme os ISO Guias 30 a 35. Os materiais e seus certificados de análise estão disponíveis para distribuição no site da Embrapa (http://www2.cppse.embrapa.br/materiaisdereferencia/) (SILVA, 2011; BOSSU; 2013; VERHALEN, 2014; BIANCHI et al, 2016; NOGUEIRA et al, 2016; SILVA, 2016).

Todavia, muitos dos materiais produzidos em âmbito nacional, para o setor agropecuário, foram preparados como parte de teses de doutorado ou dissertação de mestrado, de modo que não estão disponíveis. Também não se tem conhecimento a respeito da quantidade produzida.

Considerando então, a importância da disponibilidade de materiais de referência no Brasil e a representatividade e abrangência da Embrapa, pretendeu-se preparar amostras de ração para piscicultura e de tecido de peixe (tilápia), devido à importância dessas matrizes para o setor pesqueiro. Ressalta-se a necessidade da produção deste tipo de material no país, principalmente para que haja um controle tanto de nutrientes quanto de contaminantes inorgânicos nesses tipos de amostras. 


\section{Capítulo 2}

Preparo e Caracterização de Material de Referência para Nutrientes e Parâmetros Bromatológicos de Ração para Peixe 


\section{REVISÃO BIBLIOGRÁFICA}

Um dos principais entraves tecnológicos para o desenvolvimento e expansão da aquicultura no Brasil é a alimentação dos organismos cultivados, uma vez que há a influência direta na cadeia produtiva, no crescimento e desenvolvimento saudável das espécies. Somado a isso, existe a questão referente à disponibilidade de rações adequadas que atendam às exigências nutricionais específicas, de cada espécie, nas várias fases de produção (RODRIGUES et al. 2017; FREITAS et al, 2016). Constitui-se, ainda, como o item de maior custo no cultivo, podendo representar até 70 a $80 \%$ dos custos totais.

A nutrição e alimentação dos organismos aquáticos possibilitam o melhor aproveitamento do potencial e a aceleração de crescimento dos peixes, o que pode aumentar a safra anual. A garantia da qualidade das rações utilizadas pode viabilizar melhorias na eficiência alimentar, otimizando custos de produção e reduzindo impactos dos efluentes do cultivo intensivo.

De acordo com o SINDIRAÇÕES (Sindicato Nacional da Indústria de Alimentação Animal), 1,10 milhões de toneladas de rações para peixes foram produzidas em 2017 e há a previsão de produção de 1,16 milhões de toneladas para 2018 (Figura 3), sendo que, somente no primeiro semestre, a produção de ração para aquicultura alcançou mais de 646 mil toneladas (SINDIRAÇÕES, 2018). Essa previsão para 2018 representa mais que o dobro da produção do ano de 2014, que foi de 723 mil toneladas de rações para peixes (KUBITZA, 2015). Esses dados reforçam o reconhecimento da aquicultura como setor de expressão no agronegócio brasileiro.

Figura 3 - Produção de rações para peixes no Brasil, entre 2000 e 2018.

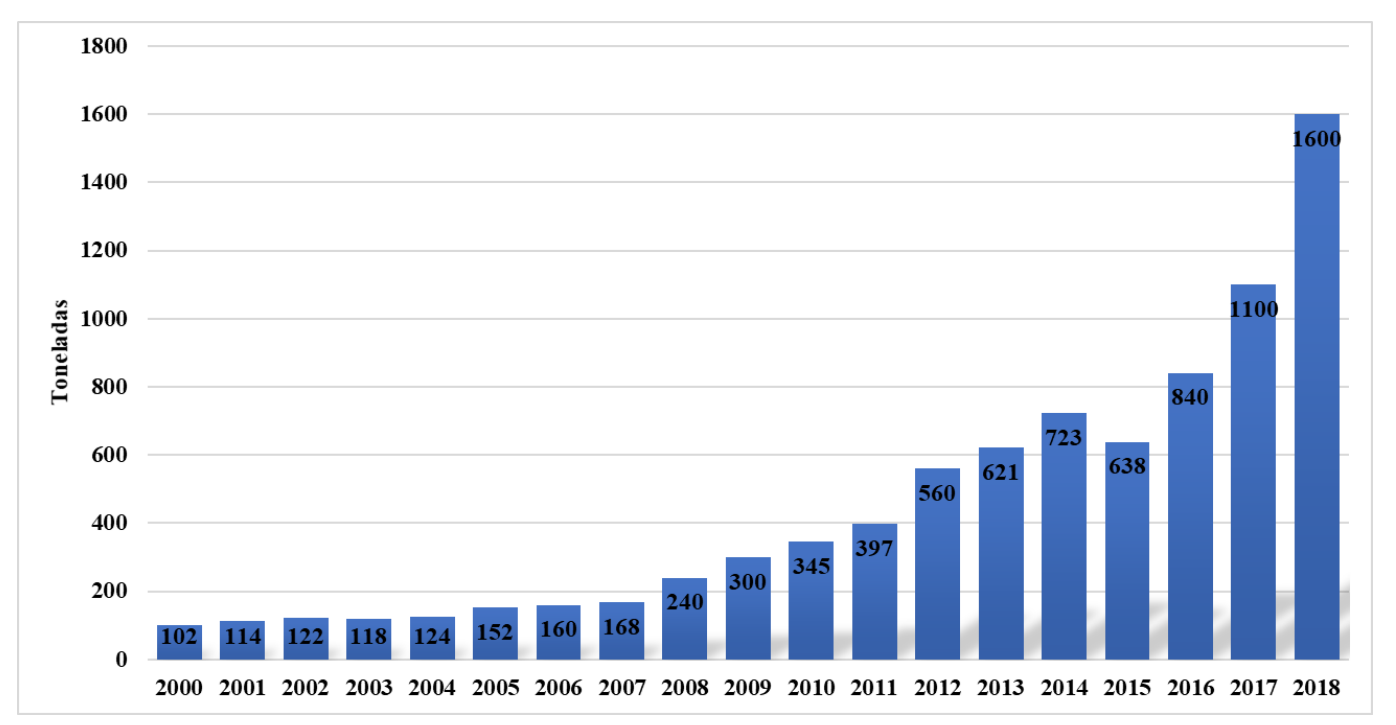

Fonte: SINDIRAÇÕES,2018. 
A escolha da ração para piscicultura deve ser guiada pelo critério da qualidade, a qual deve considerar basicamente a composição nutricional, avaliações físicas e químicas dos péletes de ração. A composição nutricional das rações pode ser avaliada por meio de análises químicas e bromatológicas, conduzidas em laboratórios de nutrição animal. Os dados obtidos permitem a comparação com níveis de garantia para rações comerciais. E a garantia da qualidade dessas análises exige o emprego de técnicas e equipamentos específicos por parte dos laboratórios especializados, bem como a obtenção de resultados analíticos confiáveis. Para este fim, faz-se necessária a validação dos métodos, que pode ser feita pela utilização de materiais de referência certificados, os quais são escassos e geralmente de alto custo.

\subsection{Material de Referência de Ração para Peixe}

De acordo com a base de dados de materiais de referência, COMAR, existem, em dezembro de 2018, 8049 RM cadastrados, sendo 54 voltados para agricultura e 375 para alimentos. Deste total, não foi verificado nenhum material específico de ração para aquicultura, contemplando nutrientes ou parâmetros bromatológicos. Há um RM, cadastrado no COMAR, de ração para aves, LGC7173, com valores de referência para umidade, cinzas, óleos, fibra bruta, nitrogênio, $\mathrm{Ca}, \mathrm{Cl}, \mathrm{Mg}, \mathrm{P}, \mathrm{K}, \mathrm{Na}, \mathrm{Fe}, \mathrm{Mn}$ e $\mathrm{Zn}$ e outro de ração sintética para vacas leiteiras, $\mathrm{BCR} \circledast$ - 708, certificado para proteína bruta, óleos e gorduras, fibra bruta, cinzas, $\mathrm{Ca}$, $\mathrm{Cu}, \mathrm{Mg}$ e $\mathrm{P}$.

$\mathrm{Na}$ literatura usualmente são utilizados CRM preparados a partir dos ingredientes convencionais de rações, para validação e controle de qualidade dos métodos de análise inorgânica e bromatológicas. Os macroingredientes comumente empregados, na formulação básica de rações para piscicultura, são: milho, farelo de soja ou de milho, trigo e coprodutos, farinhas/gorduras de origem animal (farinha de peixe, por exemplo), metionina, coprodutos de arroz e soja, sal, fosfato de cálcio, calcário, sorgo, etc. Os microingredientes correspondem às vitaminas, microminerais, aminoácidos, aditivos zootécnicos, aditivos tecnológicos, entre outros.

Um dos CRM que era largamente empregado nas análises de ração para peixe era o NIST SRM 8433 - Corn Bran, cuja validade era até 2011 (NEVES et al, 2009; SALEH et al, 2009), que passou a ser produzido pelo NRC em 2014 e comercializado sob o nome NRC BRAN-1, com validade atual até 2025. Outros CRMs comumente empregados no controle de qualidade de análises de rações são: NIST SRM 1567a - Wheat Flour, NIST SRM 1568b - 
Rice Flour, NIST SRM1566b - Oyster Tissue, NRC DOLT-5 - Dogfish Liver, NRC DORM-4 - Fish Protein, que são comercializados em frascos de 20 a 50g, com variação de preço entre US $\$ 400$ e US $\$ 750$, quando adquiridos diretamente dos produtores. Esse valor pode chegar até $\mathrm{R} \$ 10$ mil quando adquirido no Brasil.

Desta forma, é de elevada relevância a produção e disponibilização de um RM que venha a atender a demanda dos laboratórios que realizam análises de rações para piscicultura e que tenha composição similar àquela dos produtos disponíveis no mercado brasileiro.

\section{PROCEDIMENTO EXPERIMENTAL}

\subsection{Preparo do Material Candidato}

\subsubsection{Obtenção e Preparação do Material}

A amostra de ração para peixe, candidata a material de referência, foi fornecida pelo Grupo Matsuda e corresponde ao material de nome comercial Acqua Pesca 32 e é indicada para peixes onívoros em estágio de crescimento e engorda, cultivados em tanques-rede ou escavados. Foi utilizada ração com constituição típica às utilizadas pelos produtores, que possui $32 \%$ de proteína bruta. Para secagem da amostra foi utilizada estufa com circulação forçada de ar (Fanem, Brasil) a $60^{\circ} \mathrm{C}$ por $48 \mathrm{~h}$. A amostra foi moída em moinho ultracentrífugo, modelo ZM $200 ®$ (Retsch, Alemanha), com peneira de $0,75 \mathrm{~mm}$ e empregando-se velocidade de $6000 \mathrm{rpm}$, visando diminuição do tamanho de partícula (Figura 4a), sendo, em seguida, homogeneizada. Foram preparados aproximadamente $30 \mathrm{~kg}$ do material seco.

Após a moagem as amostras foram homogeneizadas e envasadas em 300 frascos de vidro âmbar, com capacidade de $100 \mathrm{~mL}$, previamente descontaminados em banho de ácido nítrico $10 \%$. A esses frascos foram adicionadas porções típicas de aproximadamente $85 \mathrm{~g}$ (Figura $4 b$ ). O envase foi sequencial e todos os frascos foram numerados. O lote preparado foi irradiado com radiação gama para aumento da estabilidade, na faixa compreendida entre 5-10 kGy, no Centro de Tecnologia das Radiações - CTR/IPEN/CNEN - SP. Por conseguinte, os frascos foram armazenados à temperatura ambiente, após acondicionamento individual em embalagens plásticas metálicas identificadas. 
Figura 4 - (a) Moagem das amostras de ração em moinho ultracentrífugo e (b) amostras envasadas em frascos âmbar com porções de aproximadamente $85 \mathrm{~g}$ cada.

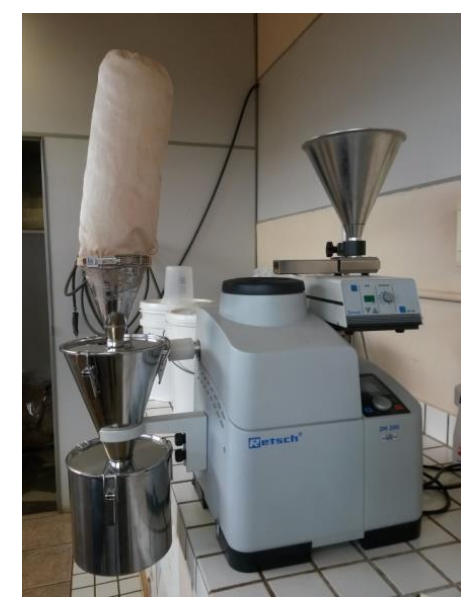

(a)

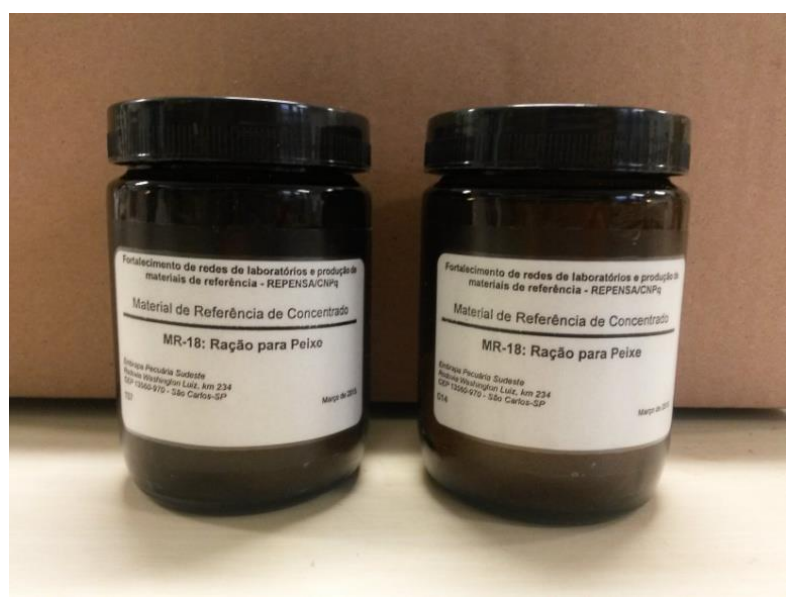

(b)

\subsection{Caracterização Física do Material Candidato}

\subsubsection{Distribuição do Tamanho de Partícula}

A ração moída foi avaliada em classificador de tamanho de partículas para verificar a distribuição atingida, uma vez que esta é uma característica importante para a homogeneidade. Um dos frascos do RM de ração foi submetido a ensaio de distribuição de tamanho de partículas (Analysette 22 MicroTec Plus, da Fritsch, Alemanha) no Centro de Energia Nuclear na Agricultura, na Universidade de São Paulo (CENA, USP), Piracicaba-SP.

\subsubsection{Determinação da Umidade Residual}

Os resultados de análise normalmente são expressos na forma de matéria seca. Dessa forma, o método de determinação de umidade deve ser claramente definido e facilmente realizável em cada laboratório. O teor de água na amostra depende da umidade ambiental, que por sua vez varia de acordo com diversos fatores. Se o método escolhido para a determinação da umidade não garantir a obtenção de resultados reproduzíveis, o erro no valor final pode chegar a algarismos percentuais. 
Para determinação de umidade residual do RM de ração para peixe, por secagem em estufa, foram selecionados aleatoriamente 3 frascos $\left(n^{\circ} 33,120\right.$ e 247). O ensaio consistiu na secagem do recipiente vazio durante $2 \mathrm{~h}$ (em estufa a $105^{\circ} \mathrm{C}$ ). Em seguida os recipientes foram retirados da estufa, colocados em dessecador por $1 \mathrm{~h}$ e pesados em balança analítica até peso constante. Após os recipientes serem secos e pesados, adicionou-se 1 g de amostra de cada um dos 3 frascos nos diferentes recipientes e pesou-se novamente. Foram efetuadas seis repetições para cada um dos três frascos. Transferiram-se os recipientes com as amostras para estufa a 105 ${ }^{\circ} \mathrm{C}$, permanecendo nesta temperatura por $24 \mathrm{~h}$. Após este período as amostras foram retiradas da estufa e colocadas em dessecador por $1 \mathrm{~h}$, sendo a seguir pesadas.

O cálculo da umidade residual foi realizado através da equação 4:

$$
\text { Umidade }(\%)=100-\frac{(A-B)}{C} \times 100
$$

Onde:
A: massa do recipiente + amostra seca após 24 h de estufa
B: massa do recipiente seco após $2 \mathrm{~h}$ de estufa
C: massa de amostra

\subsection{Determinação dos Elementos por ICP OES}

Neste trabalho, foi utilizada a técnica analítica de espectrometria de emissão óptica com plasma indutivamente acoplado, ICP OES, para a determinação da concentração dos macro e micronutrientes $(\mathrm{Ca}, \mathrm{Cu}, \mathrm{Fe}, \mathrm{K}, \mathrm{Mg}, \mathrm{Mn}, \mathrm{Na}, \mathrm{P}$ e $\mathrm{Zn})$ no candidato a material de referência de ração para peixe.

A ICP OES é uma técnica reconhecidamente eficaz para a determinação elementar em uma ampla variedade de matrizes, devido à sua alta sensibilidade e a possibilidade de análise multielementar. As amostras líquidas são introduzidas em um plasma de argônio em um campo magnético induzido por radiofrequência usando uma variedade de nebulizadores ou sistemas de introdução de amostras. No plasma, a altas temperaturas, as amostras transportadas em forma de aerossol sofrem dessolvatação, vaporização, dissociação e ionização, com emissão de luz, que é filtrada no espectrômetro de emissão e as intensidades luminosas são medidas, por serem proporcionais às concentrações dos elementos a serem analisados (HOU; JONES, 2000). 


\subsubsection{Preparo de amostras}

Todos os reagentes empregados foram de grau analítico. Para o preparo das soluções, utilizou-se água deionizada em um sistema de purificação Milli-Q® (Millipore, São Paulo, Brasil), com resistividade de $18,2 \mathrm{M} \Omega \mathrm{cm}$.

Toda vidraria e material de laboratório utilizados neste trabalho foram previamente lavados com detergente neutro e água corrente, enxaguados com água deionizada e descontaminados por imersão em $\mathrm{HNO}_{3} 10 \%$ (v/v) por, no mínimo, 24h, sendo posteriormente enxaguados com água deionizada e submetido a secagem em capela de fluxo laminar.

Para a pesagem das amostras foi utilizada balança analítica modelo AUX220 (Shimadzu, Japão).

Após avaliação e otimização de diversos procedimentos de digestão, foi selecionado o procedimento empregando $6 \mathrm{~mL}$ de $\mathrm{HNO}_{3} 50 \%$ e $2 \mathrm{~mL}$ de $\mathrm{H}_{2} \mathrm{O}_{2} 30 \%(\mathrm{~m} / \mathrm{v})$, para a digestão das amostras, utilizando o programa de aquecimento descrito na Tabela $2 . \mathrm{O} \mathrm{HNO}_{3}$ foi previamente destilado abaixo do ponto de ebulição em destilador de quartzo (Marconi, Piracicaba, SP, Brasil).

Para a digestão das amostras de ração foi utilizado um forno com radiação micro-ondas com cavidade (Ethos 1, Milestone, Itália) que contém rotor com 10 frascos de teflon TFM (Figura 5), com pressão máxima de trabalho de 100 bar, e o volume final foi ajustado para 50 $\mathrm{mL}$ com água deionizada. $\mathrm{O}$ mesmo procedimento de preparo foi utilizado para a digestão dos CRMs utilizados para avaliar a exatidão do método: NIST 1566b - Oyster Tissue e NIST 1573a - Tomato Leaves e para preparo dos brancos. 
Figura 5 - Forno de micro-ondas com cavidade modelo Ethos 1, Milestone com Rotor de 10 frascos de TFM.

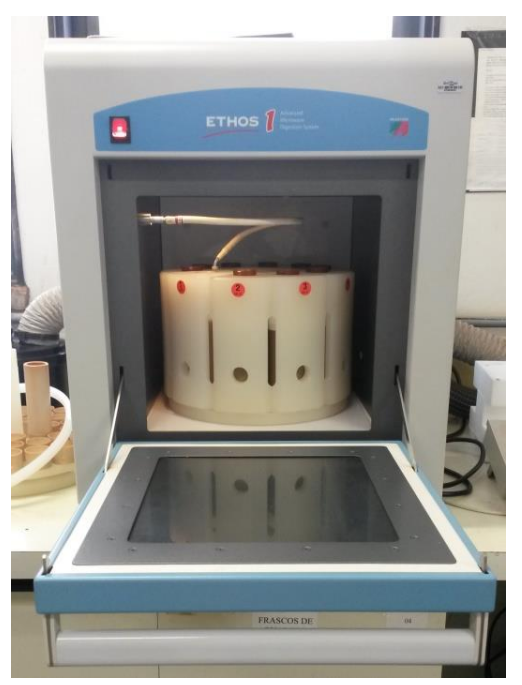

Tabela 2 - Programa de Aquecimento do Forno de Micro-ondas Ethos 1, Milestone.

\begin{tabular}{cccc}
\hline Etapa & Potência $(\mathbf{W})$ & Temperatura $\left({ }^{\circ} \mathbf{C}\right)$ & Tempo (min) \\
\hline 1 & 1300 & 120 & 15 \\
\hline 2 & 1300 & 200 & 20 \\
\hline 3 & 1300 & 200 & 20 \\
\hline 4 & 0 & 0 & 10 \\
\hline
\end{tabular}

As digestões das amostras foram realizadas nas dependências da Embrapa Pecuária Sudeste e as determinações foram realizadas nos laboratórios do Grupo de Análise Instrumental Aplicada (GAIA) instalados na Embrapa Pecuária Sudeste e no Departamento de Química da Universidade Federal de São Carlos (UFSCar).

\subsubsection{Quantificação dos macro e micronutrientes}

Os elementos $\mathrm{Ca}, \mathrm{Cu}, \mathrm{Fe}, \mathrm{K}, \mathrm{Mg}, \mathrm{Mn}, \mathrm{Na}, \mathrm{P}$ e $\mathrm{Zn}$ foram quantificados por espectrometria de emissão óptica com plasma indutivamente acoplado (ICP OES) utilizando um equipamento da marca Thermo Scientific, modelo iCap 6000 series (Figura 6), visão radial e axial, cujos parâmetros empregados estão descritos na Tabela 3. 
Figura 6 - ICP OES Thermo Scientific 6000 series dual view.

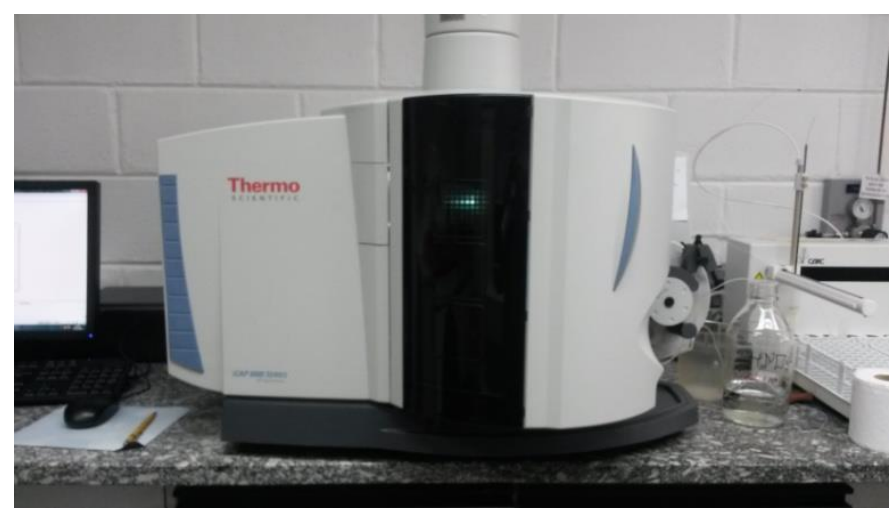

Tabela 3 - Condições operacionais do ICP OES iCap 6000 series.

\begin{tabular}{cc}
\hline Parâmetro & Características \\
\hline Potência de Radiofrequência $(\mathrm{W})$ & 1150 \\
Vazão de gás do plasma $\left(\mathrm{L} \mathrm{min}^{-1}\right)$ & 12 \\
Vazão do gás auxiliar $\left(\mathrm{L} \mathrm{min}^{-1}\right)$ & 0,5 \\
Vazão do nebulizador $\left(\mathrm{L} \mathrm{min}^{-1}\right)$ & Concêntrico \\
Nebulizador & Ciclônica \\
Câmara de nebulização & Duo (Axial e Radial) \\
Orientação da tocha & Ca I 422,673 (Radial) \\
& Cu 324,754 (Radial) \\
& Fe II 238,264 (Radial) \\
K I 766,490 (Axial) \\
Comprimento de onda (nm) & Mg II 280,270 (Radial) \\
& Mn 257,610 (Radial) \\
& Na I 589,592 (Axial) \\
& P I 263,168 (Axial) \\
Zn II 213,856 (Radial)
\end{tabular}

I - Linha atômica; II - Linha iônica

As soluções estoque de todos os elementos foram preparadas, por pesagem, a partir de diluição de solução padrão comercial $1000 \mathrm{mg} \mathrm{L}^{-1}$ (PlasmaCAL, SCP Science, USA), 
proveniente de produtor acreditado nas ISO 17025 e ISO 17034. As soluções para as curvas de calibração foram construídas utilizando o mesmo meio de preparo das amostras, com pelo menos sete concentrações diferentes, preparadas, por massa, com diluições adequadas a partir das soluções estoque.

\subsection{Determinação dos Parâmetros Bromatológicos}

Além da determinação de macro e micronutrientes, a amostra de ração para peixe candidata a material de referência foi submetida a determinação de parâmetros bromatológicos. Foram avaliados os valores de propriedade de Matéria seca; Matéria Mineral/ Cinzas; Fibra em detergente neutro (FDN); Fibra em detergente ácido (FDA); Lignina; Fibra Bruta (FB); Proteína Bruta (PB) e Extrato Etéreo. Os procedimentos utilizados seguiram as diretrizes dos métodos de referência do Laboratório de Nutrição Animal (LNA) da Embrapa Pecuária Sudeste e os métodos apresentados por Nogueira e Souza (2005).

\subsubsection{Matéria Seca}

Baseia-se na evaporação do conteúdo de água da amostra pela ação do calor. Esta análise é de alta relevância para outras determinações, uma vez que os resultados são corrigidos e fornecidos com base na matéria seca. O teor percentual de matéria seca é obtido por avaliação gravimétrica.

Os cadinhos vazios foram secos em estufa por $2 \mathrm{~h}$ a $105^{\circ} \mathrm{C}$. Em seguida, os recipientes foram retirados da estufa, colocados em dessecador por $1 \mathrm{~h}$ e pesados em balança analítica. Após os recipientes secos e pesados, adicionou-se cerca de $1 \mathrm{~g}$ de amostra nos diferentes recipientes e pesou-se novamente. Transferiram-se os recipientes com as amostras para estufa a $105^{\circ} \mathrm{C}$ durante $24 \mathrm{~h}$, até massa constante. As amostras foram retiradas da estufa e colocadas em dessecador por $1 \mathrm{~h}$, sendo a seguir pesadas.

O teor de matéria seca foi calculado conforme equação 5 abaixo:

$$
\text { MatériaSeca }(\%)=\frac{\left(m_{c+a s}-m_{c}\right)}{m_{a}} \times 100
$$

Onde:

$m_{c+a s}=$ massa do cadinho mais amostra seca;

$m_{c}=$ massa do cadinho seco em estufa;

$m_{a}=$ massa de amostra 


\subsubsection{Matéria Mineral/Cinzas}

O teor de cinzas, em amostras de alimentos concentrados, fornece uma estimativa da composição inorgânica total presente na amostra. Nesta análise a amostra é submetida à calcinação em forno tipo mufla, para a eliminação de matéria orgânica. O teor percentual de cinzas é obtido por avaliação gravimétrica.

A análise de matéria mineral foi realizada com as mesmas amostras da matéria seca. Após a pesagem dos cadinhos para a determinação da matéria seca, estes foram levados para um forno mufla, onde foi executada a programação constante da Tabela 4.

Tabela 4 - Programa de aquecimento do forno mufla.

\begin{tabular}{cccc}
\hline & Temperatura $\left({ }^{\circ} \mathbf{C}\right)$ & Velocidade $\left({ }^{\circ} \mathbf{C} \mathbf{~ m i n}^{-\mathbf{1}}\right)$ & Permanência (min) \\
\hline $\mathbf{1}$ & 350 & 10 & 60 \\
\hline $\mathbf{2}$ & 550 & 10 & 180 \\
\hline $\mathbf{3}$ & 0 & 0 & 0 \\
\hline
\end{tabular}

O teor de cinzas foi calculado conforme equação 6 abaixo:

$$
\operatorname{Cinzas}(m / m)(\%)=\frac{\left(m_{c+c i}-m_{c}\right)}{m_{a}} \times 100
$$

Onde:

$m_{c+c i}=$ massa do cadinho mais cinzas;

$m_{c}=$ massa do cadinho seco;

$m_{a}=$ massa de amostra

\subsubsection{Fibra em detergente neutro (FDN)}

O método de FDN se baseia na determinação de componentes da parede celular insolúvel em detergente neutro, basicamente constituída de celulose, hemicelulose, lignina e proteína lignificada e sílica (SOUZA, 2007).

Para esta análise foram utilizados recipientes/saquinhos de Nylon, denominados filtros 
(filter bags), Ankom, estes foram pesados e sua massa anotada sob o código SAQ. A cada filtro foi adicionado $0,5 \mathrm{~g}$ de amostra. Em seguida, foram seladas suas extremidades e as amostras foram previamente incubadas com amilase e ureia para a hidrólise do amido, uma vez que a ração contém milho em sua composição. Após a incubação, os filtros foram acondicionados nas bandejas do equipamento ANKOM 200 - Fiber Analyzer (Figura 7). No equipamento ANKOM foram introduzidos 24 filtros por batelada. Após a montagem e disposição das bandejas dentro do equipamento, foi adicionado aproximadamente $2 \mathrm{~L}$ de solução de detergente neutro (EDTA$\mathrm{Na}_{2}, \mathrm{Na}_{2} \mathrm{~B}_{4} \mathrm{O}_{7} \cdot 10 \mathrm{H}_{2} \mathrm{O}$, lauril sulfato de sódio, $\mathrm{Na}_{2} \mathrm{HPO}_{4}, 2$-metoxietanol) sobre os filtros. A programação de agitação foi executada por 75 minutos com temperatura de $90^{\circ} \mathrm{C}$. Após esse tempo foram realizadas 3 lavagens com água destilada sob agitação e aquecimento por 10 min cada. Em seguida, os filtros foram removidos do equipamento e emergidos em acetona por um minuto e dispostos em bandeja para evaporação da acetona. Depois de secos, os filtros foram transferidos para estufa a $105^{\circ} \mathrm{C}$ por $4 \mathrm{~h}$. Após esse período, foram transferidos para dessecador por $2 \mathrm{~h}$ e pesados (SAQ + FDN).

O teor de fibra em detergente neutro é calculado conforme a equação 7 abaixo:

$$
F D N(\%)=\frac{(S A Q+F D N)-S A Q}{m_{a}} \times 100
$$

Onde:

$S A Q+F D N=$ massa do filtro mais amostra após extração;

$S A Q=$ massa do filtro;

$m_{a}=$ massa de amostra.

Figura 7 - Equipamento de análise de fibras ANKOM 200 - Fiber Analyzer.

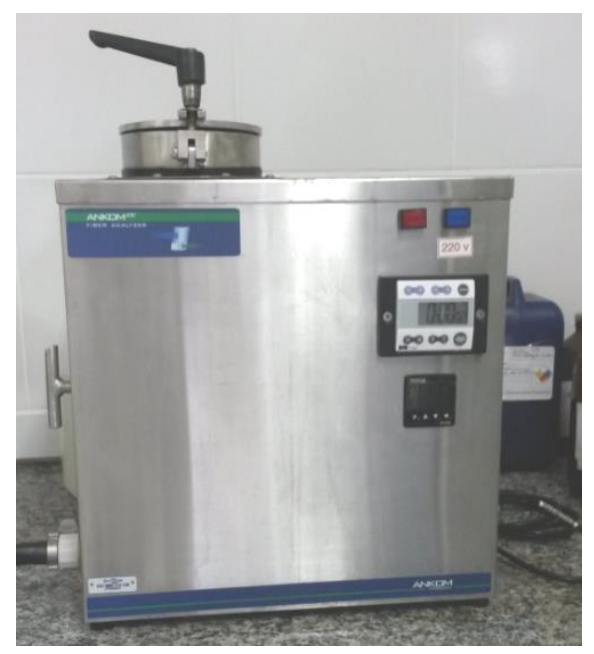




\subsubsection{Fibra em detergente ácido (FDA)}

O procedimento utilizado neste trabalho empregou a metodologia "nylon bag". Conforme descrito por Souza (2007), o teor de FDA é obtido com o auxílio de um analisador de fibra comercial (Ankom Technology, USA), apresentado na Figura 7, onde ocorrem os processos de digestão e filtração das amostras em filtros e em ambiente fechado. Resumidamente, por meio de reagentes específicos, a amostra é tratada com uma solução de detergente ácido, a qual solubiliza o conteúdo celular, a hemicelulose e a maior parte da proteína insolúvel. A lignina insolúvel, o nitrogênio insolúvel, a celulose e a sílica fazem parte do resíduo denominado FDA.

Procedimento similar à determinação de FDN, sendo realizado no mesmo equipamento, com a adição de $2 \mathrm{~L}$ de solução de detergente ácido (brometo de cetil trimetilamônio e $\mathrm{H}_{2} \mathrm{SO}_{4}$ 0,5 M). A programação de agitação foi executada por 60 minutos com temperatura de $90^{\circ} \mathrm{C}$. O procedimento de retirada e lavagem é idêntico e o registro da massa após a extração é feito com o código SAQ+FDA.

O teor de fibra em detergente ácido é calculado conforme a equação 8 abaixo:

$$
F D A(\%)=\frac{(S A Q+F D A)-S A Q}{m_{a}} \times 100
$$

Onde:

$S A Q+F D A=$ massa do filtro mais amostra após extração;

$S A Q=$ massa do filtro;

$m_{a}=$ massa de amostra.

\subsubsection{Lignina}

O teor de lignina em amostras de alimentos concentrados, caso da amostra de ração para peixe, é quantificado a partir da FDA, com a oxidação da lignina sob ação de ácido sulfúrico ou permanganato de potássio. $\mathrm{O}_{2} \mathrm{SO}_{4}$ oxida a celulose, presente no resíduo da FDA, remanescendo cinzas insolúveis em ácido (SOUZA, 2007).

Deste modo, para a análise de lignina foram aproveitados os filtros da análise de FDA. 
A análise de FDA foi realizada normalmente e após a pesagem dos filtros para finalizar a análise de FDA, estes foram colocados em um béquer de vidro e despejou-se $\mathrm{H}_{2} \mathrm{SO}_{4} 72 \%$ sobre eles. Os filtros permaneceram em banho ácido por $3 \mathrm{~h}$ sob agitação constante. Após a retirada, os filtros foram lavados em água quente diversas vezes, imersos em acetona e transferidos para estufa a $105^{\circ} \mathrm{C}$ por $24 \mathrm{~h}$. Após esse período, os filtros foram pesados e a massa anotada como SAQ+LIG+CIN. Os filtros foram transferidos para cadinhos, previamente pesados (CAD), e levados ao forno mufla sob aquecimento a $580^{\circ} \mathrm{C}$ por $3 \mathrm{~h}$. Depois de retirados da mufla, esfriados em dessecador, os cadinhos foram novamente pesados e massa registrada como $\mathrm{CAD}+\mathrm{CIN}$.

O teor de lignina é calculado pela equação 9:

$$
\operatorname{Lignina}(\%)=\frac{((C A D+C I N)-S A Q)-C A D}{m_{a}} \times 100
$$

Onde:

$C A D+C I N=$ massa do filtro mais amostra após extração;

$S A Q=$ massa do filtro;

$C A D=$ massa do cadinho;

$m_{a}=$ massa de amostra utilizada na FDA.

\subsubsection{Fibra Bruta $(F B)$}

A fibra bruta $(\mathrm{FB})$ corresponde à porção dos carboidratos totais que resiste à hidrólise ácida e alcalina, constituindo-se, basicamente, de celulose e lignina insolúvel.

Para análise de Fibra Bruta, o procedimento é feito de acordo com a recomendação da ANKOM (2018). Para esta análise foram utilizados recipientes de nylon, filtros Ankom, estes foram pesados e sua massa anotada (SAQ). A cada filtro foi adicionada cerca de $1 \mathrm{~g}$ de amostra seca e moída, sendo, em seguida, seladas suas extremidades. A gordura das amostras foi extraída deixando os filtros imersos em éter de petróleo por 10 minutos. O solvente foi descartado e os filtros foram secos ao ar. Para evitar a aglomeração inadequada das amostras, os filtros foram agitados para promover uma distribuição uniforme. Os filtros foram acondicionados nas bandejas do equipamento ANKOM 200 - Fiber Analyzer (Figura 7). No equipamento ANKOM foram introduzidos 24 filtros por batelada. Após a montagem e 
disposição das bandejas dentro do equipamento, adicionou-se $2 \mathrm{~L}$ de ácido sulfúrico 0,255 $\mathrm{N}$ sobre os filtros e o equipamento foi vedado e ligado. O tempo foi ajustado para 40 minutos e, após o período de extração, a agitação e o aquecimento foram desligados e a solução ácida, descartada. Foram realizadas duas programações de lavagem com $2 \mathrm{~L}$ de água destilada a $90^{\circ} \mathrm{C}$ por 5 minutos cada. Após a lavagem e descarte da água utilizada, adicionou-se $2 \mathrm{~L}$ de hidróxido de sódio $0,313 \mathrm{~N}$ e o equipamento foi vedado e ligado. $\mathrm{O}$ tempo foi ajustado para 40 minutos e após o período de extração, a solução básica foi descartada, em bombona adequadamente identificada, e o aquecimento e a agitação foram desligados. Após a extração, foram realizadas mais três programações de lavagem com $2 \mathrm{~L}$ de água destilada a $90^{\circ} \mathrm{C}$ por 5 minutos cada. Após a finalização do processo de extração de fibra bruta, os filtros foram retirados do equipamento e cada filtro foi pressionado suavemente para eliminar o restante de água. Em seguida, os filtros foram removidos do equipamento e emergidos em acetona por três a cinco minutos e dispostos em bandeja para evaporação da acetona. Depois de secos, os filtros foram transferidos para estufa a $105^{\circ} \mathrm{C}$ por $4 \mathrm{~h}$. Após esse período, foram transferidos para dessecador por $2 \mathrm{~h}$ e pesados. Após a pesagem os filtros foram transferidos para cadinhos, previamente pesados, e levados ao forno mufla sob aquecimento a $600^{\circ} \mathrm{C}$ por $2 \mathrm{~h}$. Depois de retirados da mufla, esfriados em dessecador, os cadinhos foram novamente pesados e massa registrada. Os brancos foram preparados seguindo mesmo procedimento empregado para as amostras.

O teor de fibra bruta é calculado conforme a equação 10 abaixo:

$$
F B(\%)=\frac{100 \times\left(W_{3}-\left(W_{1} \times C_{1}\right)\right)}{W_{2}}
$$

Onde:

$\mathrm{W}_{1}=$ massa do filtro

$\mathrm{W}_{2}=$ massa da amostra

$\mathrm{W}_{3}$ = massa da matéria orgânica (após ignição do saquinho e da fibra)

$\mathrm{C}_{1}=$ correção do branco

\subsubsection{Proteína Bruta $(P B)$}

Para a determinação de proteína bruta (PB), foi empregado o método de Kjeldahl para nitrogênio total. $\mathrm{O}$ valor de nitrogênio total é multiplicado por um fator que converte o 
nitrogênio em proteína. Esse fator é específico, pois depende da percentagem de nitrogênio encontrada na composição de cada proteína. No caso de rações concentradas, a proteína bruta (PB) é expressa pelo fator 6,25 (NOGUEIRA, SOUZA, 2005).

Foi pesada a massa de $0,1 \mathrm{~g}$ de amostra em um tubo de digestão. Adicionou-se $2 \mathrm{~g}$ de mistura catalisadora (sulfato de sódio, sulfato de cobre e selênio em pó), $3 \mathrm{~mL}$ de $\mathrm{H}_{2} \mathrm{SO}_{4}$ concentrado. Os tubos foram levados ao bloco digestor, dentro da capela de exaustão de gases, iniciando a uma temperatura de $250^{\circ} \mathrm{C}$, elevando a temperatura até $400^{\circ} \mathrm{C}$. A digestão finalizou quando o extrato adquiriu uma coloração verde brilhante e sem a presença de corpo de fundo. Os tubos foram retirados do bloco e esfriados à temperatura ambiente.

Para a realização da destilação, foi adicionado um pequeno volume de água aos tubos que foram posicionados no destilador de nitrogênio (Marconi MA-036) (Figura 8). O destilador possui um recipiente para $\mathrm{NaOH} 10 \mathrm{~mol} / \mathrm{L}$. Para cada tubo foi adicionado, através do sistema do destilador, um volume de $15 \mathrm{~mL}$ de $\mathrm{NaOH}$. Foi colocado um Erlenmeyer com $10 \mathrm{~mL}$ de solução receptora-indicadora (ácido bórico 2\%, vermelho de metila $0,1 \%$, verde de bromocresol a $0,1 \%$ ) na saída do destilador, que devia ficar mergulhada na solução. O equipamento foi ligado e iniciado o aquecimento. A destilação se encerrou quando o Erlenmeyer com a solução receptora-indicadora atingiu o volume de $50 \mathrm{~mL}$. Então foi desligado o aquecimento e retirados o tubo de destilação e o Erlenmeyer. O resíduo do tubo de destilação foi descartado em recipiente preparado para armazenamento desse resíduo. O conteúdo do Erlenmeyer foi titulado com $\mathrm{H}_{2} \mathrm{SO}_{4}$ 0,05 $\mathrm{N}$ até a mudança de coloração de verde para rósea clara. Foram anotados os volumes de solução ácida gastos na titulação.

Cálculo:

$$
N(\%)=\frac{\left(V_{A}-V_{B}\right) \times 0,046 \times 0,014 \times 100}{P_{1}}
$$

Onde:

$\mathrm{V}_{\mathrm{A}}=$ volume de solução ácida gasta na titulação da amostra;

$\mathrm{V}_{\mathrm{B}}=$ volume de solução ácida gasta na titulação do branco;

$\mathrm{P}_{1}=$ massa de amostra.

Proteína Bruta $=P B(\%)=\mathrm{N}(\%) \times 6,25$ 
Figura 8 - Destilador de nitrogênio Marconi MA - 036.

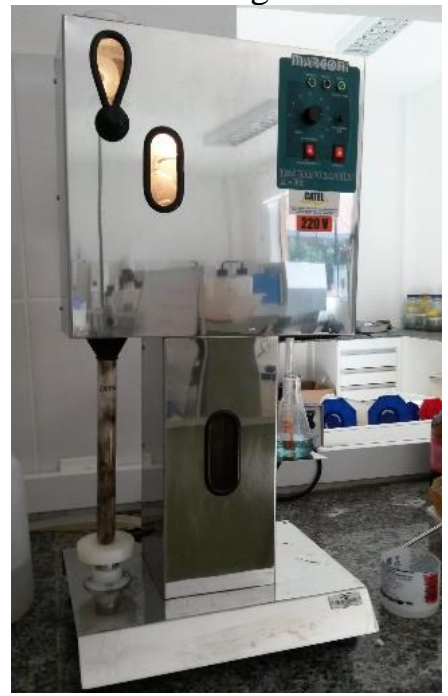

\subsubsection{Extrato Etéreo (EE)}

De acordo com Nogueira \& Souza (2005) e Souza (2007), o extrato etéreo (EE) corresponde à soma de gorduras e outras substâncias, tais como fosfatídeos, esteróis e clorofila que podem ser solubilizadas e extraídas pelo éter etílico ou éter de petróleo, a fração lipídica neutra.

A determinação do extrato etéreo é feita através da "lavagem" da amostra com éter etílico ou éter de petróleo, nos quais os lipídeos se solubilizam. Foi empregado um saco de filtro de Teflon®, modelo ANKOM XT4, cuja porosidade é de $3 \mu \mathrm{m}$ e utilizou-se o equipamento semiautomático ANKOM XT15 (ANKOM Technology Corporation, Fairport, NY, EUA) (Figura 9).

O filtro identificado foi mergulhado em éter para remover quaisquer resquícios de gordura que poderiam interferir no resultado da extração. Os filtros foram levados a estufa por 3 horas. Após esse tempo, foram retirados, colocados no dessecador para esfriamento e pesados. Um grama de amostra foi pesado e acondicionado nos saquinhos. Os sacos de filtro foram lacrados e pesados. Os sacos de filtro cheios foram, então, levados à estufa a $105{ }^{\circ} \mathrm{C}$ por 3 horas e novamente pesados. Até 5 amostras, em triplicata, foram inseridas simultaneamente na cápsula de extração do equipamento. Utilizou-se éter de petróleo como solvente. A temperatura e o tempo de extração foram ajustados para $90{ }^{\circ} \mathrm{C}$ e 60 minutos, respectivamente. Ao final do processo de extração, os sacos de filtro foram levados novamente à estufa a $105{ }^{\circ} \mathrm{C}$ por 30 minutos e pesados. O teor de extrato etéreo da amostra foi calculado como: 


$$
E E(\%)=\frac{100 \times\left(W_{2}-W_{3}\right)}{W_{1}}
$$

Onde:

$\mathrm{W}_{1}=$ massa da amostra

$\mathrm{W}_{2}=$ massa de filtro mais amostra pós estufa

$\mathrm{W}_{3}=$ massa de amostra seca com o saco de filtro após extração

Figura 9 - Sistema de Extração de Óleos e Gorduras ANKOM XT-15

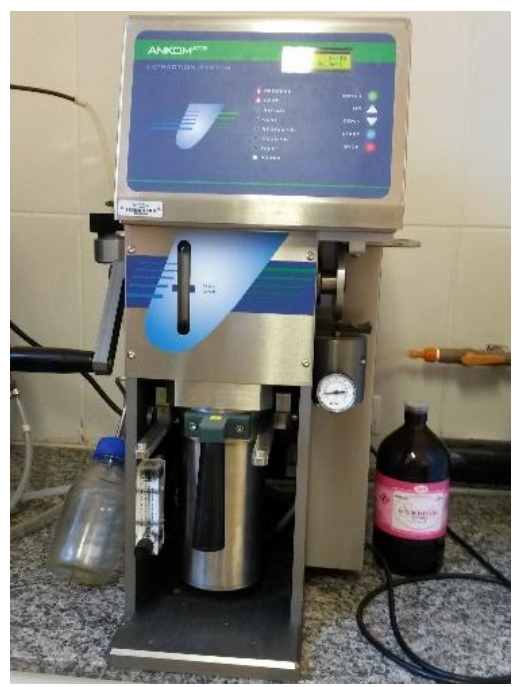

\subsubsection{Nitrogênio Não Proteico (NNP)}

A fração NNP, composta principalmente de amônio, peptídeos, aminoácidos e nitrato, é determinada pela diferença entre o nitrogênio total e o nitrogênio insolúvel em ácido tricloroacético (TCA) a 10\% (m/v) (SOUZA; NOGUEIRA; BATISTA, 2006).

Para a determinação de NNP, utilizou-se uma massa de aproximadamente $200 \mathrm{mg}$ de amostra de ração para peixe que após ser pesada foi transferida para um tubo de polipropileno, ao qual adicionou-se $20 \mathrm{~mL}$ de água destilada. Procedeu-se homogeneização e o sistema foi deixado em repouso por 30 minutos. Após esse período, adicionou-se $4 \mathrm{~mL}$ de solução de TCA, agitou-se e o sistema foi novamente deixado em repouso por 30 minutos. Por conseguinte, foi realizada filtração, com auxílio de vácuo moderado, em papel de filtro Whatman 54® (quantitativo - faixa preta) e o resíduo foi lavado duas vezes com a solução de TCA. O papel 
de filtro, com o resíduo, foi transferido para um tubo de digestão e procedeu-se a determinação de nitrogênio residual utilizando o procedimento de nitrogênio pelo método de Kjeldahl, descrito anteriormente. Para a digestão da amostra foi adicionado $5 \mathrm{~mL}$ de $\mathrm{H}_{2} \mathrm{SO}_{4}$.

O teor de nitrogênio solúvel em TCA $\left(\mathrm{N}_{\mathrm{S}-\mathrm{TCA}}\right)$, que corresponde ao nitrogênio nãoproteico, é calculado por diferença: $\mathrm{N}_{\mathrm{S}-\mathrm{TCA}}=\mathrm{N}_{\mathrm{T}}-\mathrm{N}_{\mathrm{I}-\mathrm{TCA}}$.

\subsection{Estudo de Homogeneidade da Amostra de Ração Para Peixe Candidata a RM}

Dentre as etapas de preparo de um material de referência, a homogeneização é uma das mais críticas e pode-se dizer que a boa homogeneidade é pré-requisito para um material de referência. De acordo com o ABNT ISO GUIA 30:2016, um material de referência homogêneo é definido como "material ou substância na qual uma ou mais de suas propriedades apresentam valores suficientemente homogêneos e bem estabelecidos, de modo que podem ser utilizados na calibração de instrumentos e na avaliação da exatidão do método proposto". A homogeneidade da amostra candidata a material de referência foi avaliada de acordo com os procedimentos estatísticos recomendados pelo guia ABNT ISO GUIA 35:2012. O que interessa é a homogeneidade aparente, ou seja, a mesma composição elementar média para a amostra e que pode ser representada com baixos desvios padrão em uma certa massa. Assim, foi determinada a massa mínima da alíquota a ser analisada, na qual a homogeneidade estaria assegurada.

Para uma avaliação inicial da homogeneidade entre frascos foi realizada uma coleta de espectros com o emprego de um espectrofotômetro de infravermelho próximo (NIRS) da marca BÜCHI modelo NIR-Flex N-500. As análises foram realizadas em duplicata, sendo que os espectros NIR foram obtidos no modo de reflectância difusa, por meio do software Operator 1.2 (Buchi, Flawil, Suiça), na faixa que abrange a região espectral de 10.000 a $4.000 \mathrm{~cm}^{-1}$, com resolução de $4 \mathrm{~cm}^{-1}$ e 32 varreduras por amostra. Para a avaliação qualitativa da homogeneidade e interpretação dos dados, realizou-se a análise de componentes principais (PCA) executada no software Pirouette ${ }^{\circledR}$ 4.0. A normalização dos espectros NIR foi utilizada como pré-tratamento dos dados.

Para a realização do estudo de homogeneidade entre frascos foram selecionados aleatoriamente 10 frascos $(13,46,64,118,135,155,206,233,269$ e 287). A avaliação estatística dos resultados de homogeneidade foi realizada por meio da análise de variância com fator único (ANOVA) em um nível de significância de 5\% $(\alpha=0,05)$. Dentre os 10 frascos 
selecionados, um (233) foi aleatoriamente escolhido para a retirada de 10 sub-amostras para avaliação da homogeneidade intra-amostral.

\subsubsection{Estimativa da massa mínima}

De acordo com o ABNT ISO Guia 35:2012, a quantidade mínima de amostra é determinada realizando-se um estudo de homogeneidade dentro do frasco para diferentes porções de ensaio e a ABNT NBR ISO 17034:2017 recomenda estabelecer a massa mínima para a utilização do candidato a material de referência. Esta é a porção mínima de ensaio que, quando tirada corretamente, pode ser considerada representativa do RM dentro da incerteza certificada. Analisando um intervalo de diferentes massas da amostra, pode-se estimar a massa mínima do material.

Portanto para o estudo da massa mínima para a ração de peixe, selecionou-se aleatoriamente 1 frasco (frasco $\mathrm{n}^{\circ}$ 163) para determinar $\mathrm{Ca}, \mathrm{Cu}, \mathrm{Fe}, \mathrm{K}, \mathrm{Mg}, \mathrm{Mn}, \mathrm{Na}, \mathrm{P}$ e $\mathrm{Zn}$. Foram avaliadas as massas de 100, 200, 250 e 300 mg. Após decomposição assistida por radiação micro-ondas, as amostras foram avolumadas para $50 \mathrm{~mL}$ com água deionizada e os elementos foram quantificados por espectrometria de emissão óptica com plasma acoplado indutivamente (ICP OES), com calibração externa, empregando as condições operacionais da Tabela 3.

A repetibilidade do método foi avaliada através do desvio padrão relativo, RSD e para avaliar se existem diferenças significativas entre os resultados obtidos nas diferentes massas utilizou-se a análise de variância com fator único (ANOVA) em um nível de significância de $5 \%(\alpha=0,05)$.

\subsection{Estudo de Estabilidade da Amostra de Ração Para Peixe Candidata a RM}

A estabilidade dos materiais de referência é um requisito essencial. Espera-se que os materiais de referência tenham uma longa vida de prateleira, resistindo à degradação devido a fatores como luz, oxidação, ação de micro-organismos, etc. Para isso existem dois tipos estabilidade a serem considerados na certificação de materiais de referência: a estabilidade ao longo prazo (que simula o tempo de prateleira) e a estabilidade ao curto prazo (que simula a estabilidade do material durante as condições de transporte). 


\subsubsection{Estabilidade a Curto Prazo}

O primeiro teste foi realizado em curta duração e a temperaturas elevadas, verificando a estabilidade durante condições temporárias e extremas, como o transporte. Para este teste 3 (três) frascos do candidato a RM foram selecionados aleatoriamente (7, 107 e 285) e acondicionados dentro de um aparato em que a temperatura e a umidade foram controladas.

O aparato correspondeu a um recipiente de vidro com tampa, dentro do qual foram adicionados cerca de 2 L de água e 4 frascos de vidro. Sobre os frascos abertos foi fixada uma peneira para servir de superfície uniforme de suporte para os frascos a serem avaliados. A água, inserida no sistema, foi a responsável pela garantia de umidade relativa $100 \pm 4 \%$. O aparato com os frascos foi colocado dentro de uma estufa com temperatura controlada, fixada em $37 \pm$ $3^{\circ} \mathrm{C}$ (Figura 10).

O sistema foi mantido por 4 semanas, com avaliação diária de temperatura e umidade, com auxílio de um termohigrômetro. Após este período, foram retiradas amostras de cada frasco para análise de $\mathrm{Ca}, \mathrm{Cu}, \mathrm{Fe}, \mathrm{K}, \mathrm{Mg}, \mathrm{Mn}, \mathrm{Na}, \mathrm{P}$ e $\mathrm{Zn}$ por ICP OES e dos parâmetros bromatológicos, em triplicata para cada frasco. A avaliação estatística dos resultados foi obtida por meio de regressão linear simples e os cálculos das incertezas foram realizados conforme o ABNT ISO Guia 35.

Figura 10 - Experimento de estabilidade em curto prazo, $37 \pm 3^{\circ} \mathrm{C}$ e $100 \pm 4 \%$ de umidade relativa.
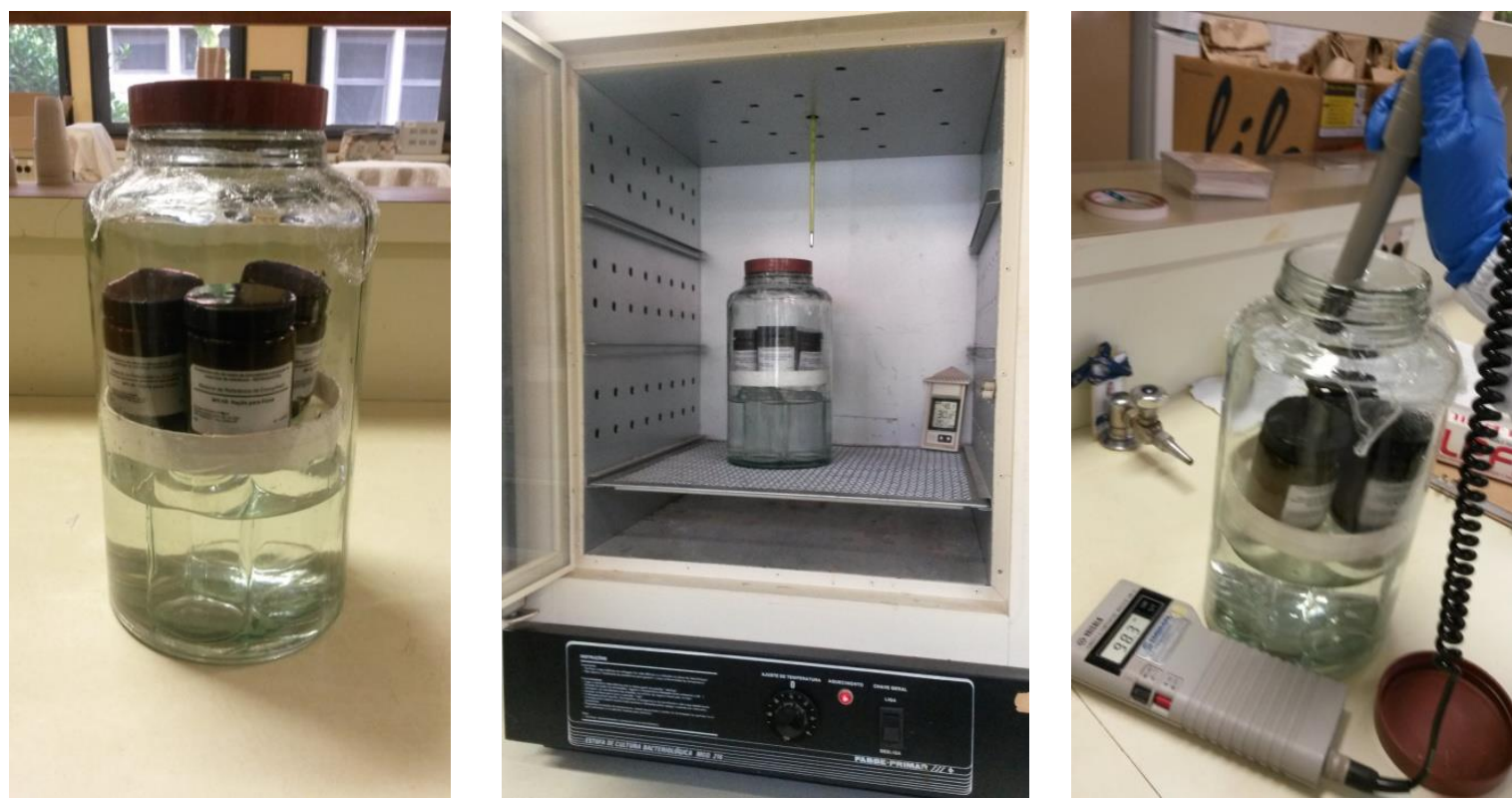


\subsubsection{Estabilidade a Longo Prazo}

O segundo teste foi o de longa duração e com temperatura ambiente (cerca de $25^{\circ} \mathrm{C}$ ), sendo realizado a fim de acompanhar a estabilidade do material sob condições adequadas de armazenamento. A estabilidade a longo prazo, assim como o teste de homogeneidade, é crucial no processo de produção de uma amostra candidata a material de referência. O teste irá garantir qual período para o qual os valores certificados estão garantidos, ou seja, o seu tempo de prateleira.

Para a realização deste teste foram escolhidos, aleatoriamente, 10 frascos do total armazenado (8, 40, 76, 99, 115, 162, 190, 220, 251 e 279), sendo amostrados em intervalos de 3 meses após o envase até que se completasse um ano. Dentro do período indicado foi realizada a quantificação dos analitos em estudo, em triplicata. Após esse período, o teste começou a ser repetido a cada 6 meses, até completar três anos do preparo do material e anualmente, após os primeiros três anos.

A avaliação da estabilidade a longo prazo do material foi feita pela análise de resíduos da regressão em conjunto com a análise de variância com fator único (ANOVA) em um nível de significância de 5\% $(\alpha=0,05)$. Os cálculos das incertezas foram realizados conforme o ABNT ISO Guia 35.

\subsection{Ensaio Colaborativo}

O ABNT ISO GUIA 35 estabelece quatro abordagens tecnicamente válidas para caracterizar o material de referência. Tais abordagens incluem a realização de medições empregando-se: um método único, primário, definitivo em um único laboratório; por dois ou mais métodos de referência independentes em um laboratório; por uma rede de laboratórios qualificados que utilizam um ou mais métodos de exatidão demonstrável; uma abordagem de método específico (estudo interlaboratorial) que forneça apenas valores de propriedades avaliados para este método. Neste trabalho foi empregado o método específico, através do ensaio colaborativo, que forneceu valores de propriedades avaliados através de uma rede de laboratórios. 
Os frascos contendo o material de ração para peixe candidato a material de referência foram distribuídos durante o Workshop Anual "Ensaio de Proficiência para Laboratórios de Nutrição Animal - EPLNA”, realizado nas dependências da Embrapa Pecuária Sudeste. Optouse por este procedimento em razão de os laboratórios fazerem este tipo de análise em materiais semelhantes de maneira rotineira e, como participantes de ensaio de proficiência, terem seu desempenho avaliado continuamente e, em caso de surgirem problemas analíticos, esses podem ser corrigidos de maneira imediata. Laboratórios com melhor desempenho, avaliado pelo EPLNA, foram convidados a participar do ensaio colaborativo. Desses, cerca de 49 laboratórios concordaram em participar e receberam um número interno e um frasco do material candidato previamente preparado, contendo cerca de $85 \mathrm{~g}$ e a descrição das ações a serem feitas. Destes laboratórios de 10 a 49 mandaram os resultados (dependendo do parâmetro), entre eles, empresas da iniciativa privada, instituições de pesquisa estatais e de ensino superior. Foi solicitada a realização de análise em 6 (seis) replicatas para as determinações de matéria seca (MS), cinzas, proteína bruta (PB), fibra em detergente ácido (FDA), fibra em detergente neutro $(\mathrm{FDN})$, fibra bruta $(\mathrm{FB})$, extrato etéreo (EE), lignina, nitrogênio não proteico (NNP), e os macro e micronutrientes $(\mathrm{Ca}, \mathrm{Cu}, \mathrm{Fe}, \mathrm{K}, \mathrm{Mg}, \mathrm{Mn}, \mathrm{Na}, \mathrm{P}$ e $\mathrm{Zn}$ ), de acordo com os procedimentos de rotina de cada laboratório, devendo os resultados serem informados individualmente (resultados para todas as réplicas, não somente as médias), bem como todos os procedimentos utilizados.

O tratamento dos resultados do ensaio colaborativo foi realizado através de diversas ferramentas estatísticas como o teste de Grubbs, teste de Cochran e a análise de variância ANOVA.

As técnicas analíticas que foram utilizadas para a determinação dos elementos de interesse nos laboratórios que efetivamente participaram do ensaio colaborativo enviando os resultados foram FAAS, ICP OES e INAA.

\section{RESULTADOS E DISCUSSÕES}

\subsection{Distribuição do Tamanho de Partícula}

Na Figura 11 apresenta-se o perfil de distribuição granulométrica típica do material de ração para peixe candidato a material de referência. Observa-se apenas um pico na curva, isto significa que a distribuição do tamanho de partícula do material tem uma distribuição homogênea. Este resultado é muito importante, pois distribuições granulométricas multimodais podem inviabilizar a homogeneidade do material candidato a RM. O estudo mostrou que $10 \%$ 
das partículas apresentavam diâmetro inferior a $38 \mu \mathrm{m}, 50 \%$ inferior a $281 \mu \mathrm{m}$ e $90 \%$ das partículas apresentavam diâmetro inferior a $625 \mu \mathrm{m}$.

Figura 11 - Curva da distribuição granulométrica do material de ração para peixe candidato a material de referência.

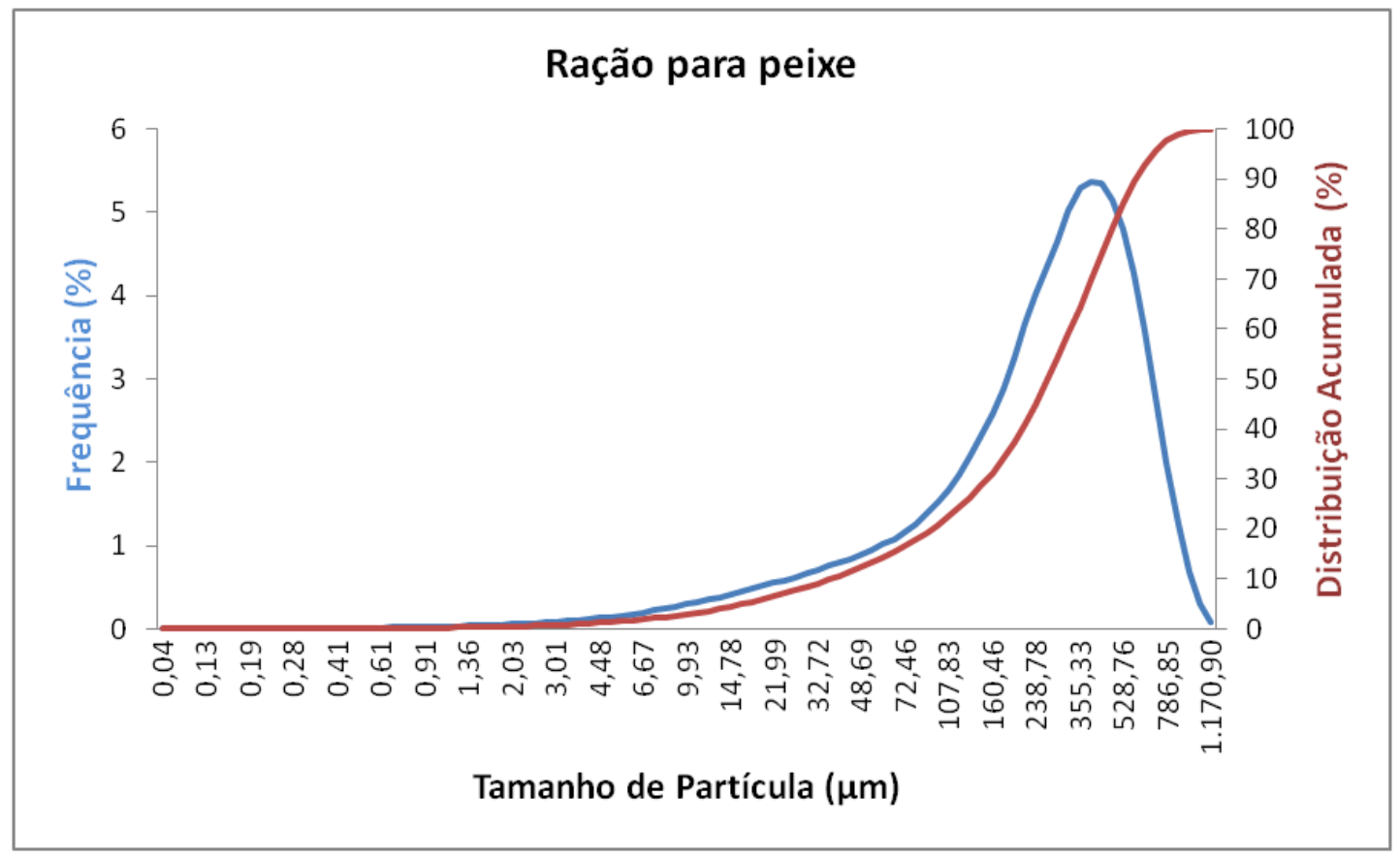

\subsection{Determinação da Umidade Residual}

Foram sorteados aleatoriamente 3 frascos $(33,120$ e 247) e o teor de umidade residual foi determinado em amostra de massa de $1 \mathrm{~g}$, aproximadamente, seco em estufa a $105^{\circ} \mathrm{C}$ por 24 h. Foi observado o resultado médio de $5,43 \pm 0,20 \%(n=18)$. Na Tabela 5 é apresentada a umidade residual realizado em três frascos do material de ração para peixe candidato RM.

Tabela 5 - Umidade residual do candidato $\mathrm{RM}$ de ração para peixe determinada em estufa a $105^{\circ} \mathrm{C}$ por $24 \mathrm{~h}$.

\begin{tabular}{ccc}
\hline Frascos & Umidade Residual (\%)* & Número de Determinações \\
\hline Frasco 33 & $5,32 \pm 0,26$ & 6 \\
\hline Frasco 120 & $5,60 \pm 0,11$ & 6 \\
\hline Frasco 247 & $5,37 \pm 0,06$ & 6 \\
\hline Média & $5,43 \pm 0,20$ & 18 \\
\hline
\end{tabular}

*média e desvio padrão 


\subsection{Limites de Detecção e Quantificação e Análises de CRMs}

O Limite de Detecção (LOD) equivale à menor concentração do analito de interesse que pode ser detectado, mas não necessariamente quantificado. O Limite de Quantificação (LOQ) é definido como a menor concentração do analito, que pode ser quantificada na amostra, com exatidão e precisão aceitáveis, sob as condições experimentais adotadas. O LOD e o LOQ podem ser estimados por meio do sinal/ruído, do desvio-padrão e por processos estatísticos. Estes limites foram calculados considerando-se as medidas da razão do sinal analítico/sinal de fundo (SBR) e a concentração do analito que produz um sinal líquido equivalente à intensidade do sinal de fundo (BEC). Foram utilizadas as equações 13 e 14 para os cálculos dos limites de LOD e LOQ (THOMSEN et al., 2000; BOSSU, 2013):

$$
\begin{aligned}
& L O D=\frac{3 \times R S D \times B E C}{100} \\
& L O Q=\frac{10 \times R S D \times B E C}{100}
\end{aligned}
$$

Onde RSD é o desvio padrão relativo do branco analítico, para 10 leituras de réplicas verdadeiras, e BEC, background equivalent concentration, é a concentração equivalente ao sinal de fundo, sendo calculada conforme a equação 15:

$$
B E C=\frac{C_{S}}{S B R}
$$

A razão do sinal analítico/sinal de fundo, signal to background ratio (SBR), foi calculada de acordo com a equação 16:

$$
S B R=\frac{I_{s r}-I_{b}}{I_{b}}
$$

Onde:

RSD é o desvio padrão relativo do branco analítico;

$\mathrm{C}_{\mathrm{s}}$ é a concentração da solução de referência mais concentrada;

$I_{s r}$ é a intensidade de emissão da solução de referência mais concentrada;

$\mathrm{I}_{\mathrm{b}}$ é a intensidade de emissão do branco; 
Os limites de detecção e quantificação calculados com base nas equações acima, assim como a faixa linear estão apresentados na Tabela 6 . A faixa linear corresponde ao intervalo de massas ou concentrações no qual se pode construir uma curva analítica linear.

Para avaliar e selecionar a linha de emissão e a configuração do equipamento, para cada elemento, foram verificadas as intensidades relativas, todavia este parâmetro não é suficiente para determinar a condição mais adequada para as determinações analíticas. Deste modo, foram calculados os valores de SBR, BEC, LOQ e LOD, conforme equações 13 a 16, para as configurações axial e radial. Para cada elemento foi escolhida a condição em que se obteve o menor limite de detecção e o maior valor de SBR, uma vez que quanto maior o valor deste parâmetro, menor será a contribuição do sinal de fundo para a análise.

Tabela 6 - Limites de detecção, faixa linear, comprimento de onda e orientação da tocha na determinação da fração de massa dos elementos $\mathrm{Ca}, \mathrm{Cu}, \mathrm{Fe}, \mathrm{K}, \mathrm{Mg}, \mathrm{Mn}, \mathrm{Na}, \mathrm{P}$ e Zn, por ICP OES, na ração para peixe candidata a RM.

\begin{tabular}{|c|c|c|c|c|c|}
\hline Elemento & $\begin{array}{c}\text { Comprimento de } \\
\text { onda (nm) }\end{array}$ & $\begin{array}{c}\text { Orientação } \\
\text { da tocha }\end{array}$ & $\begin{array}{c}\text { Faixa linear } \\
\left(\mathrm{mg} \mathrm{kg}^{-1}\right)\end{array}$ & $\begin{array}{c}\mathbf{L O D} \\
\left(\mathbf{m g ~ L}^{-1}\right)\end{array}$ & $\mathbf{R}^{2}$ \\
\hline $\mathbf{C a}$ & 422,673 & radial & $1-100$ & 0,024 & 0,9999 \\
\hline $\mathbf{C u}$ & 324,754 & radial & $0,01-1$ & 0,003 & 0,9999 \\
\hline $\mathbf{F e}$ & 238,204 & radial & $0,01-10$ & 0,003 & 0,9998 \\
\hline $\mathbf{K}$ & 766,49 & axial & $5-100$ & 0,003 & 0,9989 \\
\hline Mg & 280,270 & radial & $1-50$ & 0,003 & 0,9978 \\
\hline Mn & 257,610 & radial & $0,01-1$ & 0,007 & 0,9999 \\
\hline $\mathbf{N a}$ & 589,592 & axial & $1-50$ & 0,015 & 0,9994 \\
\hline $\mathbf{P}$ & 213,618 & axial & $1-50$ & 0,023 & 0,9995 \\
\hline Zn & 213,856 & radial & $0,01-5$ & 0,001 & 0,9999 \\
\hline
\end{tabular}

Para validação do método, foram utilizados dois materiais de referência certificados: NIST SRM 1566b - Oyster Tissue e NIST SRM 1573a - Tomato Leaves. Foram escolhidas três linhas de emissão em ICP OES para cada elemento, sendo definidas para os estudos subsequentes as linhas que apresentaram os menores valores de coeficiente de variação e os melhores valores de recuperação em relação aos materiais de referência certificados avaliados.

$\mathrm{Na}$ Tabela 7 são apresentados os resultados obtidos, em base seca, para $\mathrm{Ca}, \mathrm{Cu}, \mathrm{Fe}, \mathrm{K}$, Mg, Mn, Na, P e Zn, com recuperações entre 91 e 108\%, garantindo assim uma boa exatidão nos resultados. 
Tabela 7 - Média dos teores obtidos para os materiais de referência certificados NIST 1566b e 1573a $(n=3)$, determinados por ICP OES (base seca).

\begin{tabular}{|c|c|c|c|c|c|c|}
\hline \multirow[b]{2}{*}{ Elemento } & \multicolumn{3}{|c|}{ NIST 1566b - Oyster Tissue (OT) } & \multicolumn{3}{|c|}{ NIST 1573a- Tomato Leaves (TL) } \\
\hline & $\begin{array}{c}\text { Determinado } \pm \\
\text { SD }\end{array}$ & $\begin{array}{c}\text { Recuperação } \\
(\%)\end{array}$ & $\begin{array}{c}\text { Valor } \\
\text { certificado }\end{array}$ & $\begin{array}{l}\text { Determinado } \\
\pm \mathrm{SD}\end{array}$ & $\begin{array}{c}\text { Recuperação } \\
(\%)\end{array}$ & $\begin{array}{c}\text { Valor } \\
\text { certificado }\end{array}$ \\
\hline $\begin{array}{c}\mathrm{Ca} \\
\left(\mathrm{g} \mathrm{kg}^{-1}\right)\end{array}$ & $0,83 \pm 0,04$ & 99 & $\begin{array}{c}0,838 \pm \\
0,020\end{array}$ & $0,54 \pm 0,04$ & 107 & $\begin{array}{c}0,505 \pm \\
0,09\end{array}$ \\
\hline $\begin{array}{c}\mathrm{Cu} \\
\left(\mathrm{mg} \mathrm{kg}^{-1}\right)\end{array}$ & $76,6 \pm 1,1$ & 107 & $71,6 \pm 1,6$ & $4,81 \pm 0,23$ & 102 & $4,70 \pm 0,14$ \\
\hline $\begin{array}{c}\mathrm{Fe} \\
\left(\mathrm{mg} \mathrm{kg}^{-1}\right)\end{array}$ & $201,1 \pm 1,1$ & 98 & $205,8 \pm 6,8$ & $368,1 \pm 1,1$ & 100 & $368 \pm 7$ \\
\hline $\begin{array}{c}\mathrm{K} \\
\left(\mathrm{g} \mathrm{kg}^{-1}\right)\end{array}$ & $6,22 \pm 0,01$ & 95 & $6,52 \pm 0,09$ & $28,9 \pm 0,1$ & 107 & $27 \pm 0,5$ \\
\hline $\begin{array}{c}\mathrm{Mg} \\
\left(\mathrm{g} \mathrm{kg}^{-1}\right)\end{array}$ & $1,07 \pm 0,01$ & 99 & $\begin{array}{c}1,085 \pm \\
0,023\end{array}$ & $11,44 \pm 0,01$ & 95 & $12 *$ \\
\hline $\begin{array}{c}\text { Mn } \\
\left(\mathrm{mg} \mathrm{kg}^{-1}\right)\end{array}$ & $20,05 \pm 0,22$ & 108 & $18,5 \pm 0,2$ & $250,47 \pm 1,15$ & 102 & $246 \pm 8$ \\
\hline $\begin{array}{c}\text { Na }\left(\mathrm{g} \mathrm{kg}^{-1}\right. \\
\text { para OT e } \\
\text { mg kg-1 para }^{-1} \text { TL) }\end{array}$ & $3,15 \pm 0,01$ & 96 & $\begin{array}{c}3,297 \pm \\
0,053\end{array}$ & $150 \pm 1$ & 110 & $136 \pm 4$ \\
\hline $\begin{array}{c}\mathbf{P} \\
\left(\mathrm{g} \mathrm{kg}^{-1}\right) \\
\end{array}$ & - & - & - & $1,96 \pm 0,01$ & 91 & $2,16 \pm 0,04$ \\
\hline $\begin{array}{c}\mathrm{Zn} \\
\left(\mathrm{mg} \mathrm{kg}^{-1}\right)\end{array}$ & $1474 \pm 1$ & 104 & $1424 \pm 46$ & $30,82 \pm 0,24$ & 100 & $30,9 \pm 0,7$ \\
\hline
\end{tabular}

* Valores informativos.

\subsection{Estudo de homogeneidade da amostra de ração para peixe}

\subsubsection{Avaliação Inicial}

Para a avaliação e interpretação dos dados, foi utilizada análise multivariada de componentes principais (PCA) executada no Software Pirouette ${ }^{\circledR} 4.0$. Antes de efetuar estas análises, os espectros de NIR foram normalizados, a primeira derivada foi aplicada e, então, os espectros foram centrados na média.

Baseado na avaliação da homogeneidade pela PCA, pode se afirmar que com cinco componentes principais que é possível descrever 59,5\% da variabilidade dos dados, sendo que as duas primeiras componentes principais representam $34,7 \%$ da variância explicada para a avaliação entre frascos. Tendo em vista que a PCA possibilita o agrupamento de amostras com composição química similar, avaliada pelos espectros NIR, o gráfico de scores para a avaliação entre frascos (Figura 12a), sugere uma boa correlação entre os frascos e suas repetições, num intervalo de $95 \%$ de confiança (intervalo delineado pela elipse no gráfico de scores). Para a verificação de outliers foi empregado o método da verificação da distância de Mahanalobis e, de acordo com a Figura 12b, nenhum outlier foi identificado e nenhuma das amostras 
apresentou alto resíduo. Para a avaliação intra-frasco (Figura 13) foi possível observar uma distribuição aleatória das 10 replicatas em termos de scores, indicando que nenhum agrupamento foi formado. Este resultado sugere a homogeneidade da amostra de ração para peixe candidata a material de referência.

Figura 12 - (a) Gráfico de scores com as duas componentes principais da avaliação de homogeneidade entre frascos; (b) Gráfico para detecção de outliers.

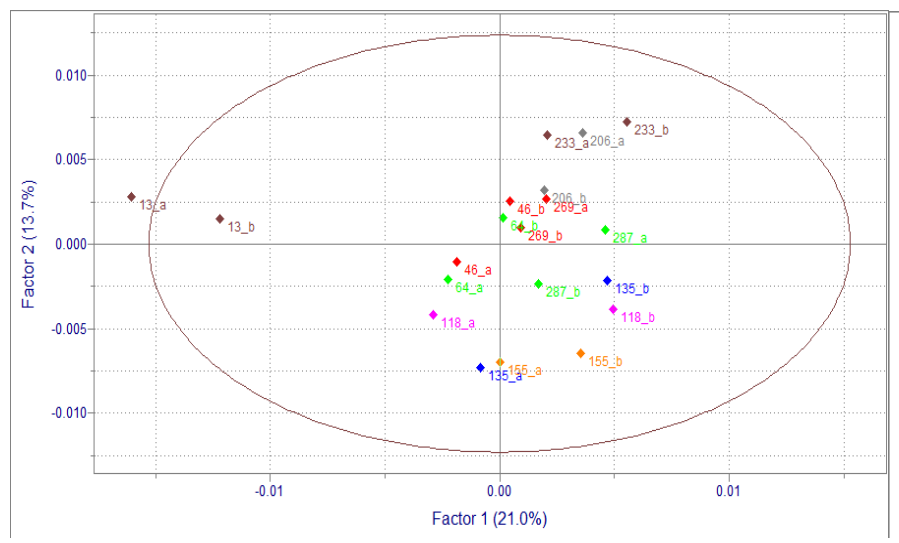

(a)

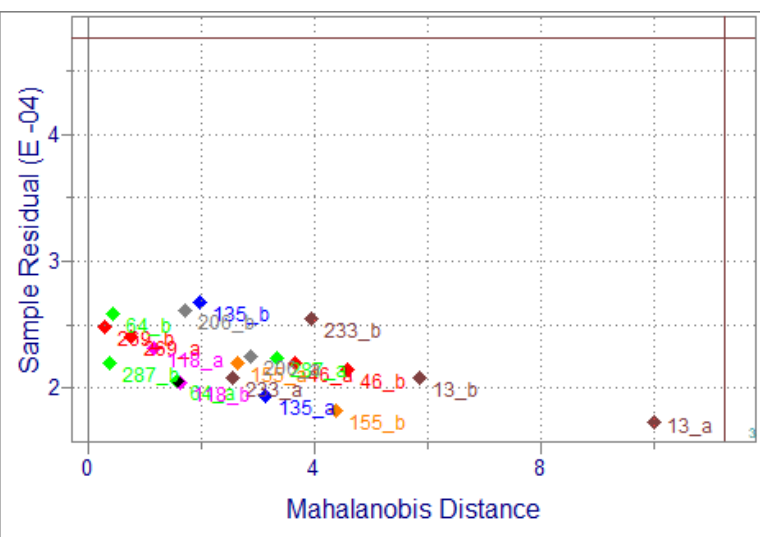

(b)

Figura 13 - Gráfico de scores com as duas componentes principais da avaliação de homogeneidade intra-frasco.

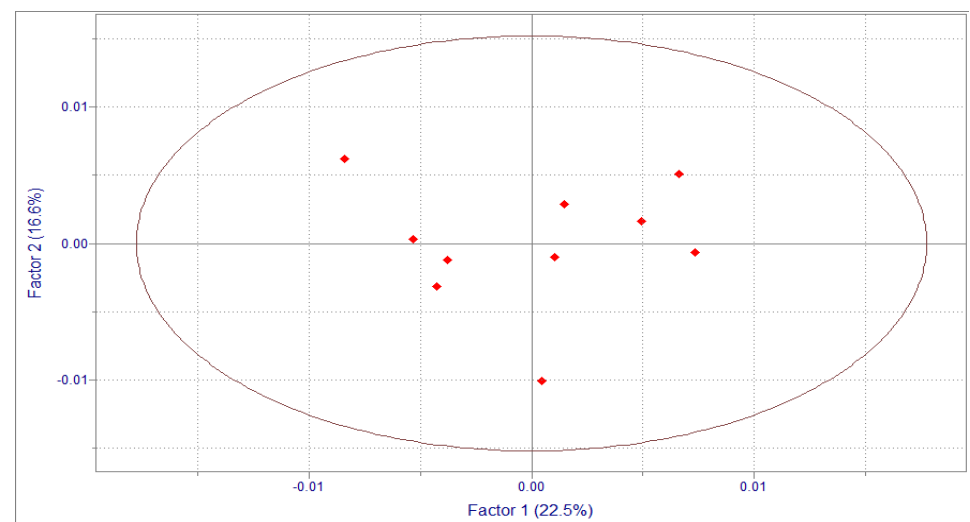

\subsubsection{Estudo da homogeneidade intra-frasco}

Este teste verifica se há diferença entre as porções amostradas dentro de um mesmo frasco. Foram realizadas 10 determinações aleatórias de réplicas verdadeiras, conforme procedimento descrito no item 2.3, com o frasco selecionado, empregando massa de $250 \mathrm{mg}$. Os resultados das determinações estão na Tabela 8. 
Para cada analito foi realizado teste de Grubbs para identificação de dados anômalos e exclusão de outliers significativos.

No teste de Grubbs (G) compara-se o valor da razão entre a diferença de cada resultado $\left(\mathrm{x}_{\mathrm{i}}\right)$ com a média de todos os resultados $(\mathrm{x})$ em relação ao desvio padrão (s). Se o valor de " $\mathrm{G}$ " é maior que o valor crítico correspondente a valores tabelados o valor suspeito é considerado como outlier a um nível de significância de 95\% (SILVA, 2016; VERHALEN, 2014).

$$
G=\frac{\left|\left(x_{i}-\bar{x}\right)\right|}{s}
$$

Nenhum outlier foi encontrado, a um nível de $95 \%$ de confiança sugerindo que os dados são homogêneos.

Tabela 8 - Resultados das réplicas do teste de homogeneidade intra-amostral.

\begin{tabular}{|c|c|c|c|c|c|c|c|c|c|c|c|c|c|c|c|}
\hline & \multicolumn{3}{|c|}{$\mathrm{Ca}\left(\mathrm{g} \mathrm{kg}^{-1}\right)$} & \multicolumn{3}{|c|}{$\mathrm{Cu}\left(\mathrm{mg} \mathrm{kg}^{-1}\right)$} & \multicolumn{3}{|c|}{$\mathrm{Fe}\left(\mathrm{mg} \mathrm{kg}^{-1}\right)$} & \multicolumn{3}{|c|}{$\mathrm{K}\left(\mathrm{g} \mathrm{kg}^{-1}\right)$} & \multicolumn{3}{|c|}{$\operatorname{Mg}\left(\mathrm{g} \mathrm{kg}^{-1}\right)$} \\
\hline & Média & $\mathbf{Z}$ & $\mathbf{Z}_{\text {crit }}$ & Média & $\mathbf{Z}$ & $\mathbf{Z}_{\text {crit }}$ & Média & $\mathbf{Z}$ & $\mathbf{Z}_{\text {crit }}$ & Média & $\mathbf{Z}$ & $\mathbf{Z}_{\text {crit }}$ & Média & $\mathbf{Z}$ & $\mathbf{Z}$ \\
\hline 1 & 28,18 & 0,06 & 2,29 & 11,46 & 0,90 & 2,29 & 247,18 & 0,39 & 2,29 & 5,79 & 0,47 & 2,29 & 1,43 & 1,24 & \\
\hline 2 & 28,13 & 0,02 & 2,29 & 12,10 & 1,50 & 2,29 & 235,58 & 0,68 & 2,29 & 5,88 & 1,35 & 2,29 & 1,47 & 0,53 & 2 , \\
\hline 3 & 30,15 & 1,57 & 2,29 & 11,59 & 0,41 & 2,29 & 250,33 & 0,69 & 2,29 & 5,84 & 0,55 & 2,29 & 1,48 & 0,98 & \\
\hline 4 & 27,96 & 0,11 & 2,29 & 12,14 & 1,65 & 2,29 & 254,71 & 1,09 & 2,29 & 5,77 & 0,87 & 2,29 & 1,46 & 0,09 & 2 , \\
\hline 5 & 30,13 & 1,56 & 2,29 & 11,37 & 1,24 & 2,29 & 242,24 & 0,06 & 2,29 & 5,87 & 1,15 & 2,29 & 1,48 & 0,98 & 2 , \\
\hline 6 & 28,82 & 0,55 & 2,29 & 11,61 & 0,34 & 2,29 & 237,98 & 0,46 & 2,29 & 5,75 & 1,27 & 2,29 & 1,43 & 1,24 & 2 , \\
\hline 7 & 27,27 & 0,64 & 2,29 & 11,64 & 0,23 & 2,29 & 235,76 & 0,67 & 2,29 & 5,79 & 0,47 & 2,29 & 1,46 & 0,09 & 2 , \\
\hline 8 & 27,29 & 0,63 & 2,29 & 11,74 & 0,15 & 2,29 & 262,71 & 1,83 & 2,29 & 5,78 & 0,67 & 2,29 & 1,45 & 0,36 & \\
\hline 9 & 26,17 & 1,49 & 2,29 & 11,89 & 0,71 & 2,29 & 226,46 & 1,53 & 2,29 & 5,78 & 0,67 & 2,29 & 1,43 & 1,24 & \\
\hline \multirow[t]{3}{*}{10} & 26,96 & 0,88 & 2,29 & 11,46 & 0,90 & 2,29 & 236,43 & 0,60 & 2,29 & 5,88 & 1,35 & 2,29 & 1,49 & 1,42 & \\
\hline & \multicolumn{4}{|c|}{$\operatorname{Mn}\left(\mathrm{mg} \mathrm{kg}^{-1}\right)$} & \multicolumn{3}{|c|}{$\mathrm{Na}\left(\mathrm{g} \mathrm{kg}^{-1}\right)$} & \multicolumn{4}{|c|}{$P\left(\mathrm{~g} \mathrm{~kg}^{-1}\right)$} & \multicolumn{3}{|c|}{$\mathrm{Zn}\left(\mathrm{mg} \mathrm{kg}^{-1}\right)$} & \\
\hline & Média & $\mathbf{Z}$ & & $Z_{\text {crit }}$ & édia & $\mathbf{Z}$ & $\mathbf{Z}_{\text {crit }}$ & Média & & $\mathbf{Z}$ & & Média & $\mathbf{Z}$ & $\mathbf{Z}_{\text {crit }}$ & \\
\hline 1 & 16,00 & 1,20 & & 29 & 07 & 1,64 & 2,29 & 13,89 & & 1,08 & & 123,55 & 0,99 & 2,29 & \\
\hline 2 & 17,49 & 1,02 & & 29 & 10 & 1,23 & 2,29 & 13,85 & & 1,12 & & 123,98 & 0,53 & 2,29 & \\
\hline 3 & 16,13 & 1,01 & & 29 & 19 & 0,03 & 2,29 & 14,58 & & 0,36 & & 123,89 & 0,63 & 2,29 & \\
\hline 4 & 17,08 & 0,41 & & 29 & 13 & 0,81 & 2,29 & 13,44 & & 1,54 & & 124,85 & 0,40 & 2,29 & \\
\hline 5 & 16,42 & 0,57 & & 29 & 18 & 0,11 & 2,29 & 16,40 & & 1,52 & & 125,11 & 0,68 & 2,29 & \\
\hline 6 & 16,39 & 0,62 & & 29 & 23 & 0,59 & 2,29 & 15,32 & & 0,40 & & 123,63 & 0,91 & 2,29 & \\
\hline 7 & 17,69 & 1,32 & & 29 & 20 & 0,17 & 2,29 & 15,59 & &, 68 & & 125,74 & 1,35 & 2,29 & \\
\hline 8 & 17,85 & 1,56 & & 29 & 28 & 1,28 & 2,29 & 15,38 & & 0,47 & & 123,89 & 0,63 & 2,29 & \\
\hline 9 & 16,42 & 0,57 & & 29 & 29 & 1,42 & 2,29 & 15,01 & & 0,08 & & 123,94 & 0,57 & 2,29 & \\
\hline 10 & 16,58 & 0,34 & & 29 & 21 & 0,31 & 2,29 & 15,84 & & 0,94 & & 126,18 & 1,83 & 2,29 & \\
\hline
\end{tabular}




\subsubsection{Estimativa da massa mínima de amostra}

Este estudo foi realizado utilizando um frasco, selecionado aleatoriamente, para verificar a existência de diferença entre as porções amostradas dentro de um mesmo frasco.

Na Tabela 9 são apresentados os resultados da média das concentrações obtidos por ICP OES a partir de diferentes massas de amostra (100 mg, 200 mg, $250 \mathrm{mg}$ e $300 \mathrm{mg}$ ), em três sub-amostras.

Tabela 9 - Frações de massa de $\mathrm{Ca}, \mathrm{Fe}, \mathrm{K}, \mathrm{Mg}, \mathrm{Na}, \mathrm{P}$ e Zn, obtidas nas porções amostradas em digestão em micro-ondas com cavidade $(\mathrm{n}=3)$.

\begin{tabular}{ccccccccc}
\hline Elementos & $\mathbf{1 0 0} \mathbf{~ m g}(\mathbf{m} \pm \mathbf{S D})$ & $\begin{array}{c}\mathbf{R S D} \\
(\boldsymbol{\%})\end{array}$ & $\begin{array}{c}\mathbf{2 0 0} \mathbf{~ m g} \\
(\mathbf{m} \pm \mathbf{S D})\end{array}$ & $\begin{array}{c}\mathbf{R S D} \\
(\boldsymbol{\%})\end{array}$ & $\begin{array}{c}\mathbf{2 5 0} \mathbf{~ m g} \\
(\mathbf{m} \pm \mathbf{S D})\end{array}$ & $\begin{array}{c}\mathbf{R S D} \\
(\boldsymbol{\%})\end{array}$ & $\begin{array}{c}\mathbf{3 0 0} \mathbf{~ m g} \\
(\mathbf{m} \pm \mathbf{S D})\end{array}$ & $\begin{array}{c}\text { RSD } \\
(\boldsymbol{\%})\end{array}$ \\
\hline $\mathbf{C a}\left(\mathbf{g ~ k g}^{-\mathbf{1}}\right)$ & $29,93 \pm 1,52$ & 5,07 & $30,00 \pm 0,68$ & 2,25 & $29,57 \pm 0,51$ & $\mathbf{1 , 7 3}$ & $31,09 \pm 2,18$ & 6,99 \\
$\mathbf{C u}\left(\mathbf{m g ~ k g}^{-1}\right)$ & $11,51 \pm 0,38$ & 3,34 & $10,44 \pm 0,43$ & 4,15 & $10,37 \pm 0,17$ & $\mathbf{1 , 6 6}$ & $10,55 \pm 0,26$ & 2,42 \\
$\mathbf{F e}\left(\mathbf{m g ~ k g}^{-1}\right)$ & $267,75 \pm 57,93$ & 21,64 & $247,65 \pm 3,78$ & 1,53 & $247,57 \pm 1,60$ & $\mathbf{0 , 6 5}$ & $241,05 \pm 15,27$ & 6,34 \\
$\mathbf{K}\left(\mathbf{g ~ k g}^{-1}\right)$ & $5,70 \pm 0,05$ & 0,85 & $6,15 \pm 0,06$ & 0,97 & $6,23 \pm 0,01$ & $\mathbf{0 , 1 8}$ & $6,28 \pm 0,05$ & 0,83 \\
$\mathbf{M g}\left(\mathbf{g ~ k g}^{-1}\right)$ & $1,36 \pm 0,02$ & 1,37 & $1,47 \pm 0,01$ & 0,52 & $1,502 \pm 0,001$ & $\mathbf{0 , 0 6}$ & $1,55 \pm 0,01$ & 0,57 \\
$\mathbf{M n}\left(\mathbf{m g ~ k g}^{-1}\right)$ & $17,11 \pm 0,58$ & 3,37 & $16,95 \pm 0,65$ & 3,82 & $19,92 \pm 0,14$ & $\mathbf{0 , 7 0}$ & $18,32 \pm 0,13$ & 0,72 \\
$\mathbf{N a}\left(\mathbf{g ~ k g}^{-1}\right)$ & $2,15 \pm 0,01$ & 0,51 & $2,20 \pm 0,02$ & 1,01 & $2,254 \pm 0,004$ & $\mathbf{0 , 1 6}$ & $2,30 \pm 0,04$ & 1,68 \\
$\mathbf{P}\left(\mathbf{g ~ k g}^{-1}\right)$ & $15,68 \pm 0,36$ & 2,32 & $15,65 \pm 0,30$ & 1,94 & $15,59 \pm 0,14$ & $\mathbf{0 , 8 8}$ & $16,07 \pm 1,05$ & 6,52 \\
$\mathbf{Z n}\left(\mathbf{m g ~ k g}^{-1}\right)$ & $128,34 \pm 1,01$ & 0,79 & $126,76 \pm 0,41$ & 1,15 & $126,09 \pm 0,41$ & $\mathbf{0 , 3 3}$ & $126,98 \pm 0,53$ & 0,42 \\
\hline & & & & & & & &
\end{tabular}

Foi realizada a análise de variância (ANOVA) de fator único dentro de um intervalo de confiança de $95 \%(\alpha=0,05)$ para avaliar se existem diferenças entre as quatro massas amostradas. Para avaliação comparou-se o valor de $\mathrm{F}_{\text {crítico }}$ em relação ao valor do $\mathrm{F}_{\text {calculado }}$ para cada elemento. Como foi verificada variação na concentração obtida em função da massa da sub-amostra utilizada para os elementos, o teste ANOVA foi repetido, após avaliação com teste Grubbs e remoção dos outliers significativos (para $\mathrm{Mg}$ ), até que o conjunto de dados fosse aprovado no teste de igualdade de massas. A Tabela 10 apresenta os dados estatísticos da ANOVA e a Tabela 11 apresenta a avaliação para Mg, após a exclusão de outliers. Mesmo com a exclusão de dados o valor de $\mathrm{F}_{\text {crítico, }}$ para $\mathrm{Mg}$, se manteve menor em relação ao valor do $F_{\text {calculado. }}$

Uma vez que não se pode definir a massa mínima pela avaliação de diferenças, foi definida a quantidade que resultou no menor desvio padrão relativo (RSD). Dessa forma, foi estabelecida a massa de $250 \mathrm{mg}$ para os estudos subsequentes, sendo obtidos os menores desvios para os elementos avaliados. 
Ademais, cabe enfatizar que, conforme disposto no ABNT ISO GUIA 33, para certos CRM, o nível de homogeneidade tem sua validade associada a uma massa definida, apresentada no Certificado de Análises do CRM, de modo que o usuário deve estar ciente de que a utilização de uma porção de ensaio que não atenda ou que exceda aquela especificação pode aumentar significativamente a contribuição da não homogeneidade do CRM para a incerteza da propriedade especificada, até o ponto em que os parâmetros estatísticos da certificação não são mais válidos.

Tabela 10 - Dados ANOVA fator único para a estimativa da massa mínima da ração candidata a RM.

\begin{tabular}{|c|c|c|c|c|c|c|c|}
\hline Elemento & Fonte da variação & $S Q$ & $g l$ & $M Q$ & $F_{\text {calculado }}$ & Valor-p & $F_{\text {crítico }}$ \\
\hline \multirow{3}{*}{$\mathrm{Ca}$} & Entre frascos & 3,878 & 3 & 1,293 & 0,667 & 0,596 & 4,066 \\
\hline & Dentre frascos & 15,513 & 8 & 1,939 & & & \\
\hline & Total & 19,391 & 11 & & & & \\
\hline \multirow{3}{*}{$\mathrm{Cu}$} & Entre frascos & 2,567 & 3 & 0,856 & 7,955 & 0,009 & 4,066 \\
\hline & Dentre frascos & 0,861 & 8 & 0,108 & & & \\
\hline & Total & 3,428 & 11 & & & & \\
\hline \multirow{3}{*}{$\mathrm{Fe}$} & Entre frascos & 1208,149 & 3 & 402,716 & 0,447 & 0,726 & 4,066 \\
\hline & Dentre frascos & 7211,784 & 8 & 901,473 & & & \\
\hline & Total & 8419,933 & 11 & & & & \\
\hline \multirow{3}{*}{ K } & Entre frascos & 0,646 & 3 & 0,215 & 98,393 & 0,000 & 4,066 \\
\hline & Dentre frascos & 0,018 & 8 & 0,002 & & & \\
\hline & Total & 0,664 & 11 & & & & \\
\hline \multirow{3}{*}{$\mathrm{Mg}$} & Entre frascos & 0,048 & 3 & 0,016 & 132,776 & 0,000 & 4,066 \\
\hline & Dentre frascos & 0,001 & 8 & 0,000 & & & \\
\hline & Total & 0,049 & 11 & & & & \\
\hline \multirow{3}{*}{$\mathrm{Mn}$} & Entre frascos & 17,01 & 3 & 5,67 & 28,78 & 0,000 & 4,066 \\
\hline & Dentre frascos & 1,58 & 8 & 0,20 & & & \\
\hline & Total & 18,59 & 11 & & & & \\
\hline \multirow{3}{*}{$\mathrm{Na}$} & Entre frascos & 0,039 & 3 & 0,013 & 24,831 & 0,000 & 4,066 \\
\hline & Dentre frascos & 0,004 & 8 & 0,001 & & & \\
\hline & Total & 0,044 & 11 & & & & \\
\hline \multirow{3}{*}{$\mathrm{P}$} & Entre frascos & 0,430 & 3 & 0,143 & 0,428 & 0,738 & 4,066 \\
\hline & Dentre frascos & 2,679 & 8 & 0,335 & & & \\
\hline & Total & 3,109 & 11 & & & & \\
\hline \multirow{3}{*}{$\mathrm{Zn}$} & Entre frascos & 8,036 & 3 & 2,679 & 2,980 & 0,096 & 4,066 \\
\hline & Dentre frascos & 7,191 & 8 & 0,899 & & & \\
\hline & Total & 15,227 & 11 & & & & \\
\hline
\end{tabular}

SQ: Soma Quadrática; g.l.: Grau de Liberdade; MQ: Média Quadrática; F crítico para $\alpha=0,05$ 
Tabela 11 - Dados da ANOVA fator único para a estimativa da massa mínima da amostra candidata a material de referência, após exclusão de dados.

\begin{tabular}{cccccccc}
\hline Elemento & Fonte da variação & $\boldsymbol{S Q}$ & $\boldsymbol{g} \boldsymbol{M}$ & $\boldsymbol{M Q}$ & $\boldsymbol{F}_{\text {calculado }}$ & Valor-p & $\boldsymbol{F}_{\text {crítico }}$ \\
\hline \multirow{3}{*}{$\mathrm{Mg}$} & Entre frascos & 0,044 & 3 & 0,015 & 107,875 & 0,000 & 4,757 \\
\cline { 2 - 8 } & Dentre frascos & 0,001 & 6 & 0,000 & & & \\
\cline { 2 - 8 } & Total & 0,045 & 9 & & & & \\
\hline
\end{tabular}

SQ: Soma Quadrática; g.l.: Grau de Liberdade; MQ: Média Quadrática; F crítico para $\alpha=0,05$

\subsubsection{Estudo da homogeneidade entre frascos}

Para este estudo, foram pesadas massas de $250 \mathrm{mg}$ de amostra, em triplicata, de cada um dos 10 frascos selecionados, em frascos de digestão, sendo adicionados $6 \mathrm{~mL}$ de $\mathrm{HNO}_{3} 50 \%$ e $2 \mathrm{~mL}$ de $\mathrm{H}_{2} \mathrm{O}_{2} 30 \%(\mathrm{~m} / \mathrm{v})$ e realizado o preparo conforme citado anteriormente e a análise dos parâmetros bromatológicos e a quantificação dos macro e micronutrientes por ICP OES.

Para avaliar se há ou não homogeneidade no lote de frascos preparados do material de ração candidato a material referência, foi utilizado ANOVA fator único no nível de significância de 5\% $(\alpha=0,05)$, como ferramenta estatística. A ANOVA verifica se há diferenças significativas nas concentrações dos elementos ao longo dos frascos, por meio do teste F. Portanto quando o $\mathrm{F}_{\text {calculado }}$ for menor que o $\mathrm{F}_{\text {crítico, }}$, se aceita que há homogeneidade entre as amostras em um nível de confiança de $95 \%$.

As Figuras 14 e 15 representam a homogeneidade entre frascos para cada parâmetro avaliado. Nelas são apresentadas as réplicas e os limites superiores e inferiores (linha vermelha) e central (linha preta). 


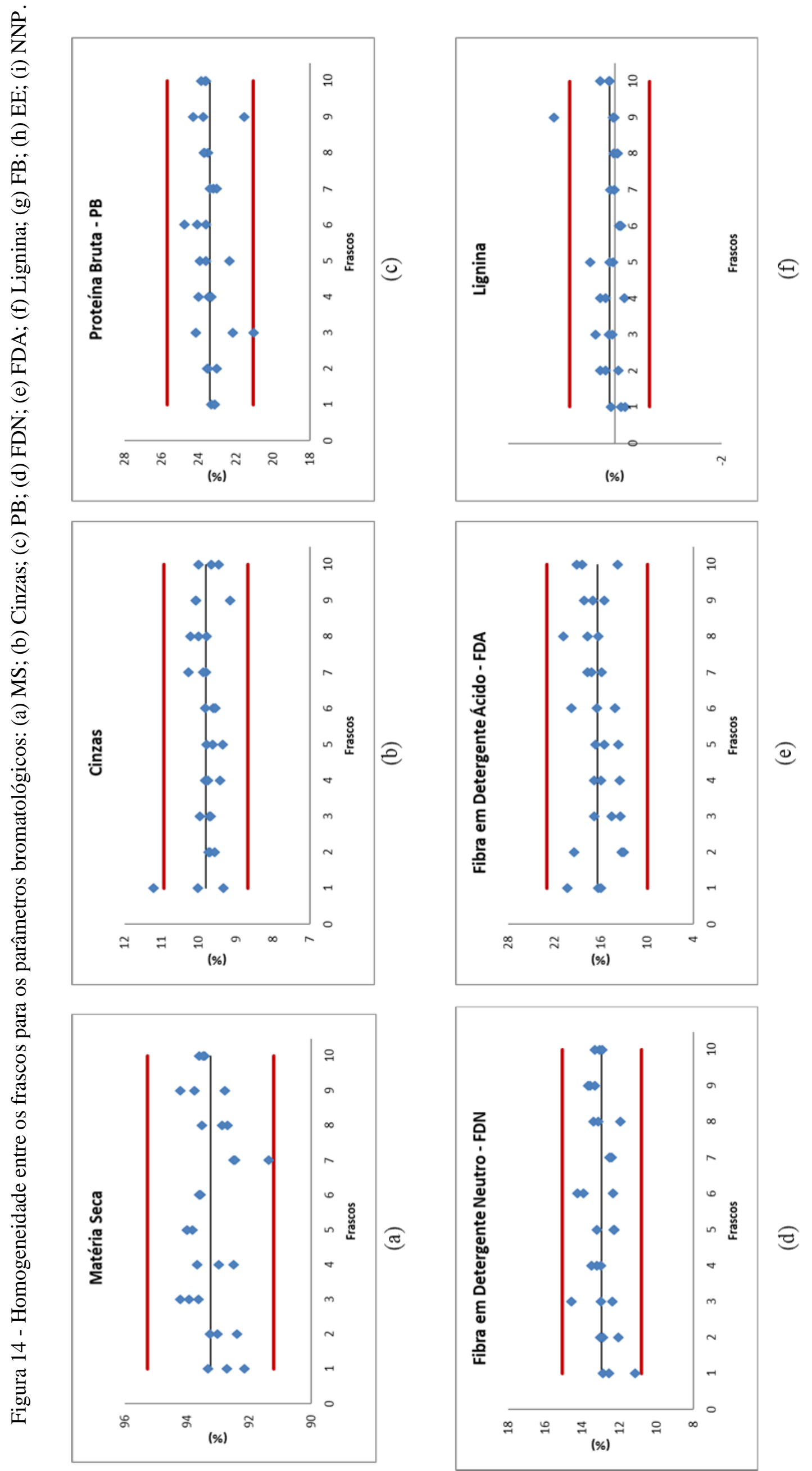


Figura 14 - Homogeneidade entre os frascos para os parâmetros bromatológicos: (a) MS; (b) Cinzas; (c) PB; (d) FDN; (e) FDA; (f) Lignina; (g) FB; (h) EE; (i) NNP. Continuação

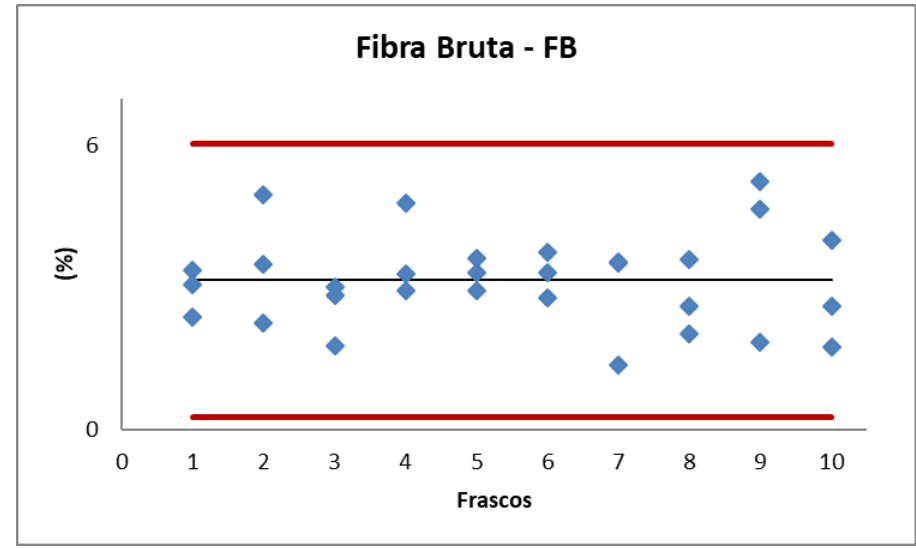

$(\mathrm{g})$

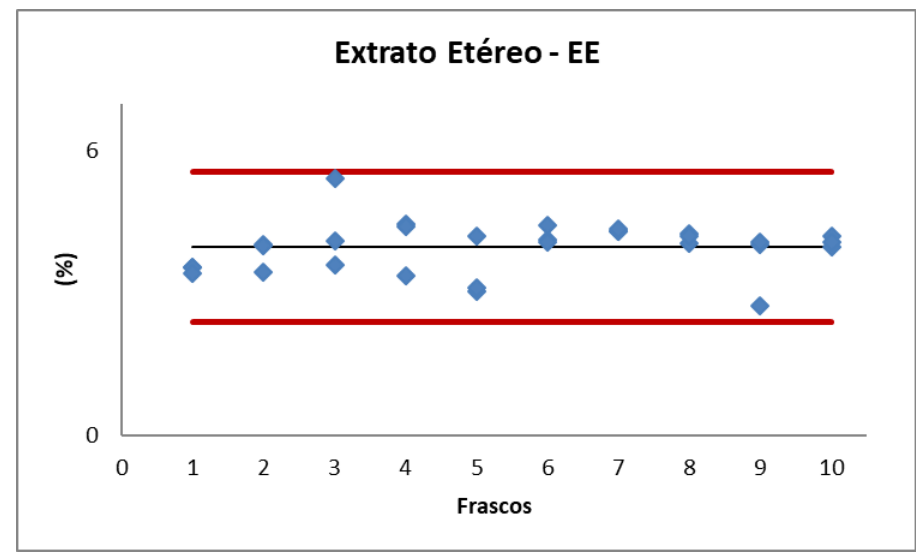

(h)

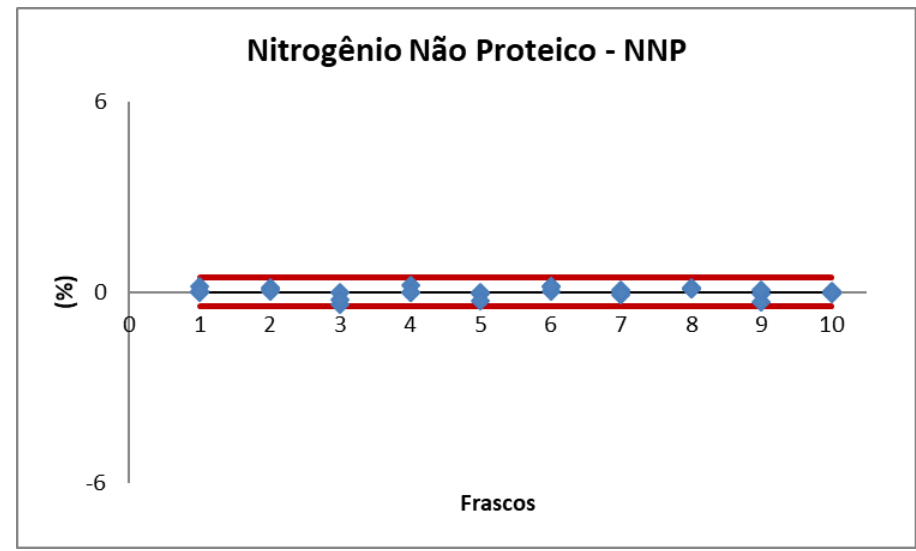

(i) 
Figura 15 - Homogeneidade entre os frascos para os macro e micronutrientes: (a) $\mathrm{Ca}$; (b) $\mathrm{Cu}$; (c) $\mathrm{Fe}$; (d) $\mathrm{K}$; (e) Mg; (f) Mn; (g) Na; (h) P e (i) Zn.

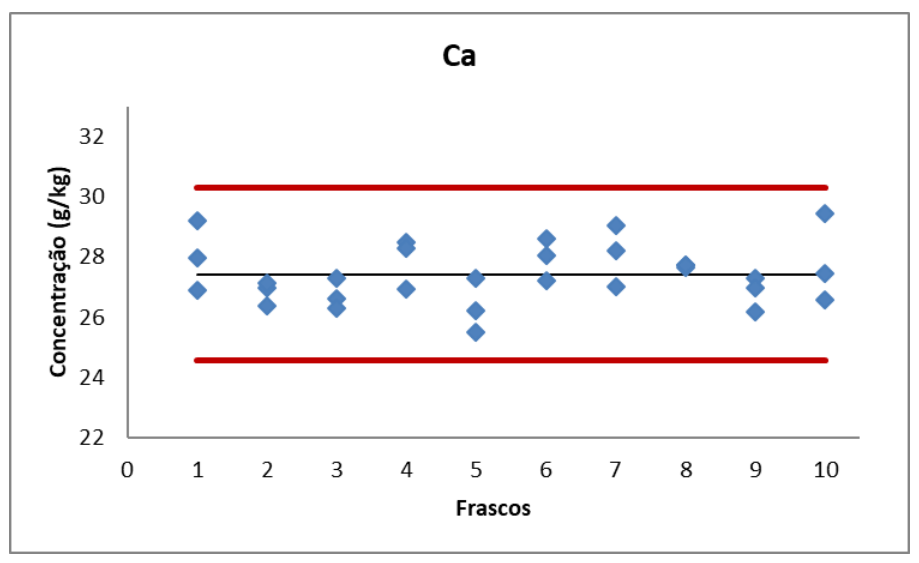

(a)

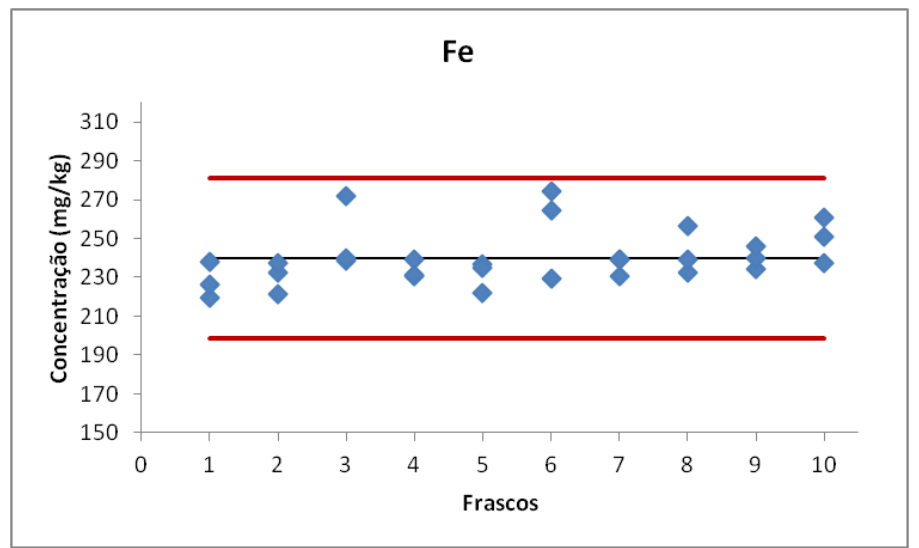

(c)

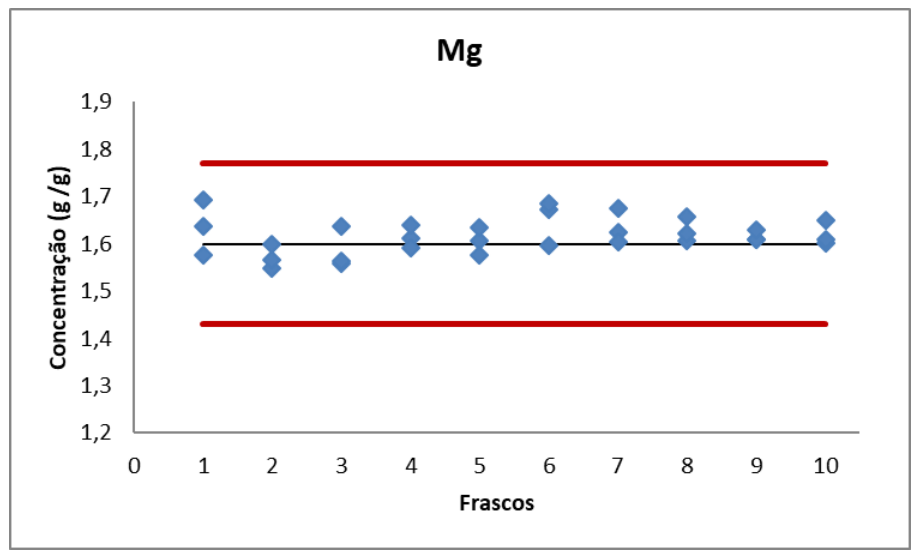

(e)

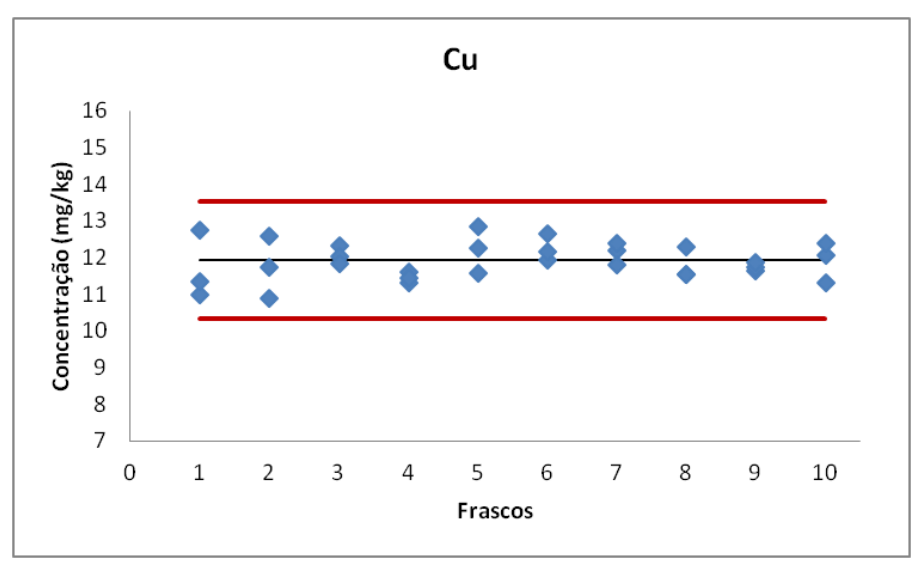

(b)

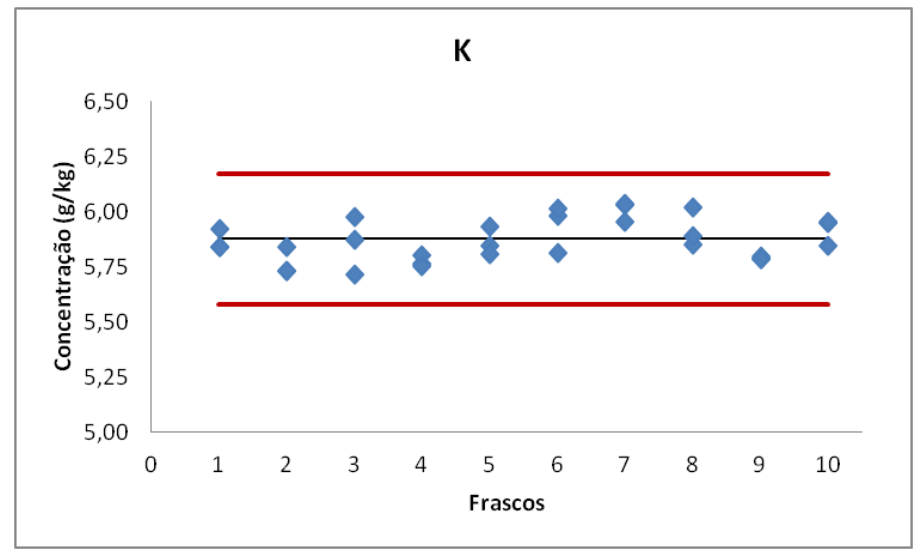

(d)

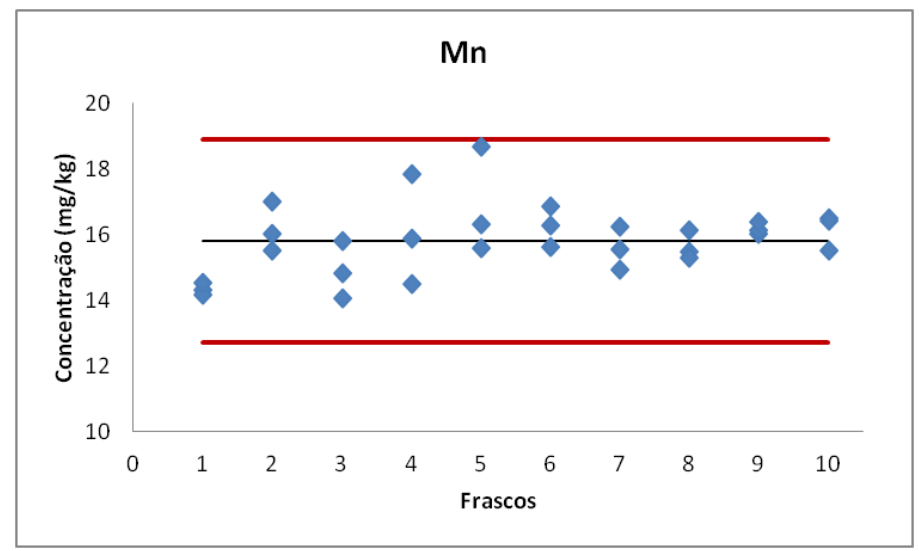

(f) 
Figura 15 - Homogeneidade entre os frascos para os macro e micronutrientes: (a) $\mathrm{Ca}$; (b) $\mathrm{Cu}$; (c) $\mathrm{Fe}$; (d) K; (e) Mg; (f) Mn; (g) Na; (h) P e (i) Zn. Continuação

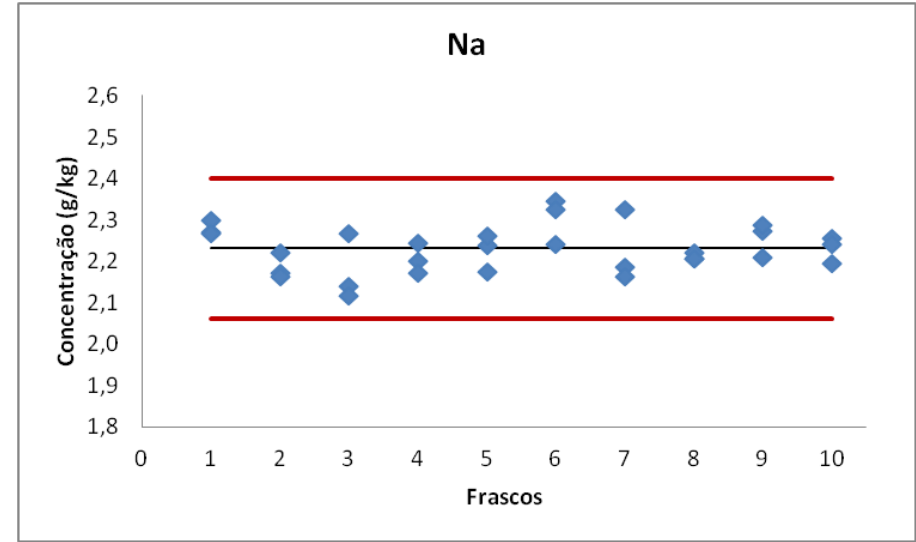

$(\mathrm{g})$

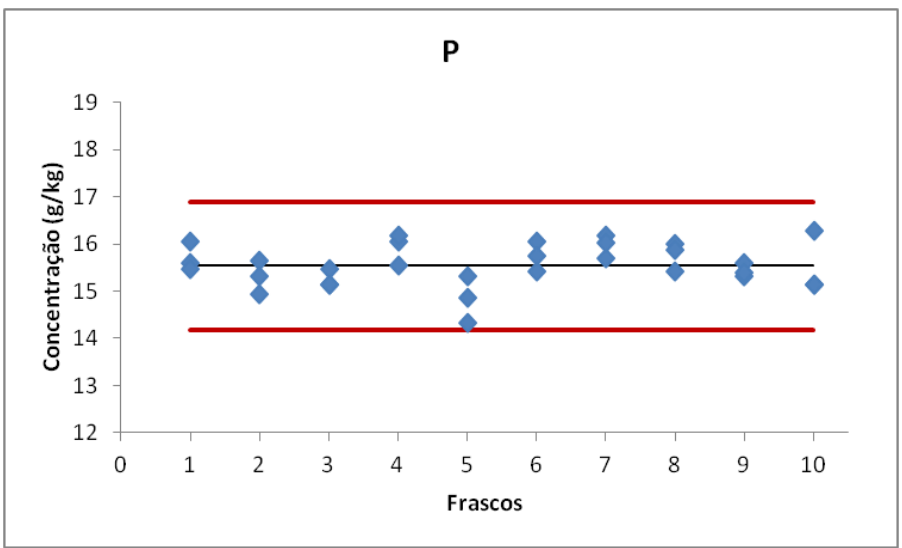

(h)

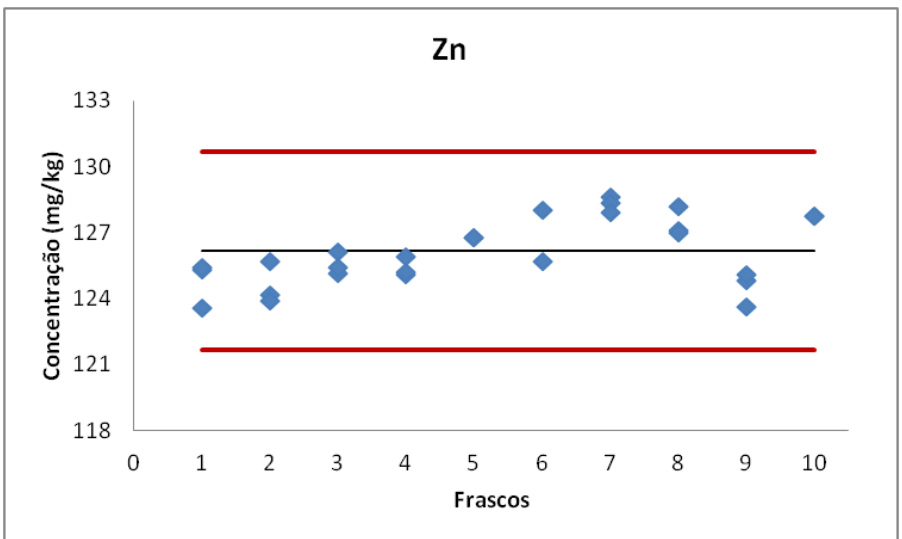

(i) 
Os gráficos de controle servem para sinalizar alguma anormalidade decorrente do comportamento do processo que está sendo executado, onde a partir da sua média podemos atribuir uma variação de +- 3 desvios padrão para determinar os seus limites superiores e inferiores de controle. A área interna de flutuação dos pontos (entre +3 e - 3 desvios, incluindo a média) é chamada de região de variação de causa comum do processo, enquanto que a área externa (acima do limite superior ou abaixo do limite inferior de controle) é chamada de região de variação de causas especiais. A existência de pontos na região de variação de causas especiais significa dizer que o processo está descontrolado e que existem variáveis que necessitam de investigação tais como, mão de obra sem treinamento, máquinas com problemas, instrumentos de medição descalibrados, métodos ineficientes, influências negativas do meio ambiente ou material inadequado utilizado no processo. Pode se observar que os dados variam dentro da região de interesse de causa comum. $\mathrm{Na}$ maioria dos gráficos, nenhum ponto ultrapassa as linhas vermelhas denominadas de limites superior e inferior de controle, de forma que pode se concluir que o processo está controlado e o material candidato a RM pode ser considerado homogêneo. As exceções são cinzas e lignina, que apresentam um ponto fora do limite superior, para um dos frascos avaliados.

Primeiramente, realizou-se a avaliação da existência de valores extremos no conjunto de resultados, aplicando-se o teste de Grubbs para identificação de dados anômalos e a exclusão de outliers significativos. Foram observados alguns dados extremos para $\mathrm{Fe}$ e $\mathrm{Zn}$, que foram eliminados para a obtenção dos valores médios para cada frasco. A avaliação estatística dos resultados foi obtida utilizando-se a análise de variância com fator único (ANOVA) no nível de significância de $5 \%(\alpha=0,05)$, considerando-se valor crítico de $F_{9,20}(\alpha=0,05)=2,39$ e o $F_{\text {crítico foi }}$ comparado ao $\mathrm{F}_{\text {calculado. }}$ A hipótese nula $\mathrm{H}_{0}$ é utilizada quando não há diferença significativa entre os valores das determinações, em um intervalo de confiança de $95 \%$. Enquanto que $\mathrm{H}_{1}$, a hipótese alternativa, é utilizada quando há diferença significativa, para o mesmo intervalo de confiança. Tendo isto em vista, se $\mathrm{F}_{\text {crítico }}$ for maior que o $\mathrm{F}_{\text {calculado, a hipótese nula é aceita e o }}$

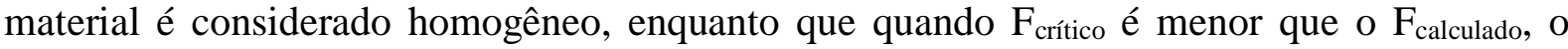
material não é considerado homogêneo. As Tabelas 12 e 13 apresentam os dados da ANOVA fator único no nível de significância de $5 \%(\alpha=0,05)$ para os parâmetros avaliados.

Ademais, foram calculados os valores das incertezas da homogeneidade $\left(u_{b b}\right)$ e o valorp, conforme o ABNT ISO GUIA 35:2012, usando as equações 1 e 2 citadas inicialmente. 
Tabela 12 - Dados ANOVA fator único para a avaliação da homogeneidade entre frascos da ração candidata a RM para os parâmetros bromatológicos.

\begin{tabular}{|c|c|c|c|c|c|c|c|}
\hline Parâmetro & Fonte da variação & $S Q$ & $g l$ & $M Q$ & $F_{\text {calculado }}$ & Valor-p & $\boldsymbol{F}_{\text {crítico }}$ \\
\hline \multirow{3}{*}{ MS } & Entre frascos & 9,033 & 9 & 1,004 & 4,714 & 0,002 & 2,393 \\
\hline & Dentre frascos & 4,258 & 20 & 0,213 & & & \\
\hline & Total & 13,291 & 29 & & & & \\
\hline \multirow{3}{*}{ Cinzas } & Entre frascos & 1,022 & 9 & 0,114 & 0,736 & 0,672 & 2,393 \\
\hline & Dentre frascos & 3,084 & 20 & 0,154 & & & \\
\hline & Total & 4,106 & 29 & & & & \\
\hline \multirow{3}{*}{$\mathrm{PB}$} & Entre frascos & 5,353 & 9 & 0,595 & 0,998 & 0,472 & 2,393 \\
\hline & Dentre frascos & 11,917 & 20 & 0,596 & & & \\
\hline & Total & 17,270 & 29 & & & & \\
\hline \multirow{3}{*}{ FDN } & Entre frascos & 5,741 & 9 & 0,638 & 1,422 & 0,244 & 2,393 \\
\hline & Dentre frascos & 8,975 & 20 & 0,449 & & & \\
\hline & Total & 14,716 & 29 & & & & \\
\hline \multirow{3}{*}{ FDA } & Entre frascos & 34,644 & 9 & 3,849 & 0,743 & 0,667 & 2,393 \\
\hline & Dentre frascos & 103,594 & 20 & 5,180 & & & \\
\hline & Total & 138,238 & 29 & & & & \\
\hline \multirow{3}{*}{ Lignina } & Entre frascos & 0,593 & 9 & 0,066 & 1,069 & 0,426 & 2,393 \\
\hline & Dentre frascos & 1,233 & 20 & 0,062 & & & \\
\hline & Total & 1,826 & 29 & & & & \\
\hline \multirow{3}{*}{ FB } & Entre frascos & 5,729 & 9 & 0,637 & 0,597 & 0,784 & 2,393 \\
\hline & Dentre frascos & 21,316 & 20 & 1,066 & & & \\
\hline & Total & 27,044 & 29 & & & & \\
\hline \multirow{3}{*}{$\mathrm{EE}$} & Entre frascos & 3,142 & 9 & 0,349 & 1,417 & 0,246 & 2,393 \\
\hline & Dentre frascos & 4,926 & 20 & 0,246 & & & \\
\hline & Total & 8,068 & 29 & & & & \\
\hline \multirow{3}{*}{ NNP } & Entre frascos & 0,345 & 9 & 0,038 & 2,670 & 0,032 & 2,393 \\
\hline & Dentre frascos & 0,287 & 20 & 0,014 & & & \\
\hline & Total & 0,631 & 29 & & & & \\
\hline
\end{tabular}


Tabela 13 - Dados ANOVA fator único para a avaliação da homogeneidade entre frascos da ração candidata a RM para os macro e micronutrientes.

\begin{tabular}{|c|c|c|c|c|c|c|c|}
\hline Elemento & Fonte da variação & $S Q$ & $g l$ & $M Q$ & $F_{\text {calculado }}$ & Valor-p & $F_{\text {crítico }}$ \\
\hline \multirow{3}{*}{$\mathrm{Ca}$} & Entre frascos & 11,734 & 9 & 1,304 & 1,771 & 0,137 & 2,393 \\
\hline & Dentre frascos & 14,720 & 20 & 0,736 & & & \\
\hline & Total & 26,455 & 29 & & & & \\
\hline \multirow{3}{*}{$\mathrm{Cu}$} & Entre frascos & 1,844 & 9 & 0,205 & 0,724 & 0,682 & 2,393 \\
\hline & Dentre frascos & 5,661 & 20 & 0,283 & & & \\
\hline & Total & 7,505 & 29 & & & & \\
\hline \multirow{3}{*}{$\mathrm{Fe}$} & Entre frascos & 2434,077 & 9 & 270,453 & 1,739 & 0,148 & 2,4227 \\
\hline & Dentre frascos & 2954,466 & 19 & 155,498 & & & \\
\hline & Total & 5388,544 & 28 & & & & \\
\hline \multirow{3}{*}{$\mathrm{K}$} & Entre frascos & 0,164 & 9 & 0,018 & 3,441 & 0,010 & 2,393 \\
\hline & Dentre frascos & 0,106 & 20 & 0,005 & & & \\
\hline & Total & 0,271 & 29 & & & & \\
\hline \multirow{3}{*}{$\mathrm{Mg}$} & Entre frascos & 0,016 & 9 & 0,002 & 1,374 & 0,264 & 2,393 \\
\hline & Dentre frascos & 0,025 & 20 & 0,001 & & & \\
\hline & Total & 0,041 & 29 & & & & \\
\hline \multirow{3}{*}{$\mathrm{Mn}$} & Entre frascos & 14,545 & 9 & 1,616 & 1,974 & 0,099 & 2,393 \\
\hline & Dentre frascos & 16,373 & 20 & 0,819 & & & \\
\hline & Total & 30,918 & 29 & & & & \\
\hline \multirow{3}{*}{$\mathrm{Na}$} & Entre frascos & 0,044 & 9 & 0,005 & 1,959 & 0,101 & 2,393 \\
\hline & Dentre frascos & 0,049 & 20 & 0,002 & & & \\
\hline & Total & 0,093 & 29 & & & & \\
\hline \multirow{3}{*}{$\mathrm{P}$} & Entre frascos & 3,320 & 9 & 0,369 & 2,814 & 0,026 & 2,393 \\
\hline & Dentre frascos & 2,622 & 20 & 0,131 & & & \\
\hline & Total & 5,941 & 29 & & & & \\
\hline \multirow{3}{*}{$\mathrm{Zn}$} & Entre frascos & 49,278 & 9 & 5,475 & 9,395 & $4,94 \mathrm{E}-05$ & 2,494 \\
\hline & Dentre frascos & 9,907 & 17 & 0,583 & & & \\
\hline & Total & 59,185 & 26 & & & & \\
\hline
\end{tabular}

SQ: Soma Quadrática; g.I.: Grau de Liberdade; MQ: Média Quadrática; F crítico para $\alpha=0,05$

Foi possível observar que o lote de ração para peixe pode ser considerado homogêneo para as análises de cinzas, PB, FDN, FDA, Lignina, FB, EE e $\mathrm{Ca}, \mathrm{Cu}, \mathrm{Fe}, \mathrm{Mg}, \mathrm{Mn}$ e $\mathrm{Na}$, uma vez que não foi verificada diferença estatística significativa no nível de confiança de 5\% (Tabela 
14). Para MS, NNP, K, P e Zn houve diferença significativa e, nesse enfoque, deve ser considerado o grau de heterogeneidade para esses parâmetros $\left(F_{\text {calculadoK }}>F_{\text {crítico }}=3,44>2,39\right.$; $\mathrm{F}_{\text {calculadoP }}>\mathrm{F}_{\text {crítico }}=2,81>2,39$ e $\mathrm{F}_{\text {calculadoZn }}>\mathrm{F}_{\text {crítico }}=4,02>2,39$ ).

Tabela 14 - Resumo da avaliação estatística para o estudo de homogeneidade.

\begin{tabular}{|c|c|c|c|c|}
\hline Parâmetro & $F_{\text {crítico }}$ & $F_{\text {calculado }}$ & $u_{b b}$ & Valor-p \\
\hline MS & 2,39 & 4,71 & 0,51 & 0,002 \\
\hline Cinzas & 2,39 & 0,74 & 0,13 & 0,67 \\
\hline PB & 2,39 & 1,00 & 0,25 & 0,47 \\
\hline FDN & 2,39 & 1,42 & 0,25 & 0,24 \\
\hline FDA & 2,39 & 0,74 & 0,74 & 0,67 \\
\hline Lignina & 2,39 & 1,07 & 1,07 & 0,43 \\
\hline FB & 2,39 & 0,60 & 0,34 & 0,78 \\
\hline $\mathrm{EE}$ & 2,39 & 1,42 & 0,19 & 0,25 \\
\hline NNP & 2,39 & 2,67 & 0,09 & 0,03 \\
\hline $\mathrm{Ca}$ & 2,39 & 1,77 & $0,44^{\mathrm{a}}$ & 0,14 \\
\hline $\mathrm{Cu}$ & 2,39 & 0,72 & $0,17^{\mathrm{b}}$ & 0,68 \\
\hline $\mathrm{Fe}$ & 2,39 & 1,83 & $6,40^{\mathrm{b}}$ & 0,12 \\
\hline $\mathrm{K}$ & 2,39 & 3,44 & $0,07^{\mathrm{a}}$ & 0,01 \\
\hline $\mathrm{Mg}$ & 2,39 & 1,37 & $0,01^{\mathrm{a}}$ & 0,26 \\
\hline $\mathrm{Mn}$ & 2,39 & 1,97 & $0,52^{\mathrm{b}}$ & 0,10 \\
\hline $\mathrm{Na}$ & 2,39 & 1,96 & $0,03^{\mathrm{a}}$ & 0,10 \\
\hline $\mathrm{P}$ & 2,39 & 2,81 & $0,28^{\mathrm{a}}$ & 0,03 \\
\hline $\mathrm{Zn}$ & 2,39 & 4,02 & $1,44^{\mathrm{b}}$ & 0,01 \\
\hline
\end{tabular}

a: $\mathrm{g} \mathrm{kg}^{-1} ; \mathrm{b}: \mathrm{mg} \mathrm{kg}^{-1}$

Com base na Tabela 14, podemos, ainda, afirma que os valores obtidos para o valor-p que resultaram maiores que 0,05 reiteram a aceitação da hipótese nula, $\mathrm{H}_{0}$, dos testes aplicados no intervalo de $95 \%$ de confiança, confirmando que o material candidato a $\mathrm{RM}$ de ração para peixe pode ser considerado homogêneo para os parâmetros que atenderam esse quesito. 


\subsection{Estudo de Estabilidade}

\subsubsection{Estabilidade a Curto Prazo}

Cada um dos 3 (três) frascos selecionados para este teste $(007,107$ e 285$)$ foi dividido em duas porções. A primeira porção de cada frasco foi acondicionado em um aparato com temperatura e umidade controladas, enquanto que o a segunda porção, denominada "controle", permaneceu, durante todo o tempo do estudo, armazenado à temperatura ambiente. O sistema montado foi mantido por 30 dias sob $37 \pm 2^{\circ} \mathrm{C}$ e $100 \pm 4 \%$ de UR, com monitoramento diário. Após a desmontagem do sistema as amostras foram preparadas em triplicata para a leitura em ICP OES dos macro e micronutrientes e para a realização das análises bromatológicas.

A seguir são apresentadas as Figuras de 16 a 33, que representam os estudos, para os parâmetros bromatológicos e para $\mathrm{Ca}, \mathrm{Cu}, \mathrm{Fe}, \mathrm{K}, \mathrm{Mg}, \mathrm{Mn}, \mathrm{Na}, \mathrm{P}$ e $\mathrm{Zn}$, com as réplicas (n=3) para cada frasco, juntamente com o controle

Foi realizada análise de variância $A N O V A$ de fator único e o $\mathrm{F}_{\text {calculado }}$ foi comparado com o F crítico.

Figura 16 - Estabilidade a curto prazo para Matéria Seca - MS.

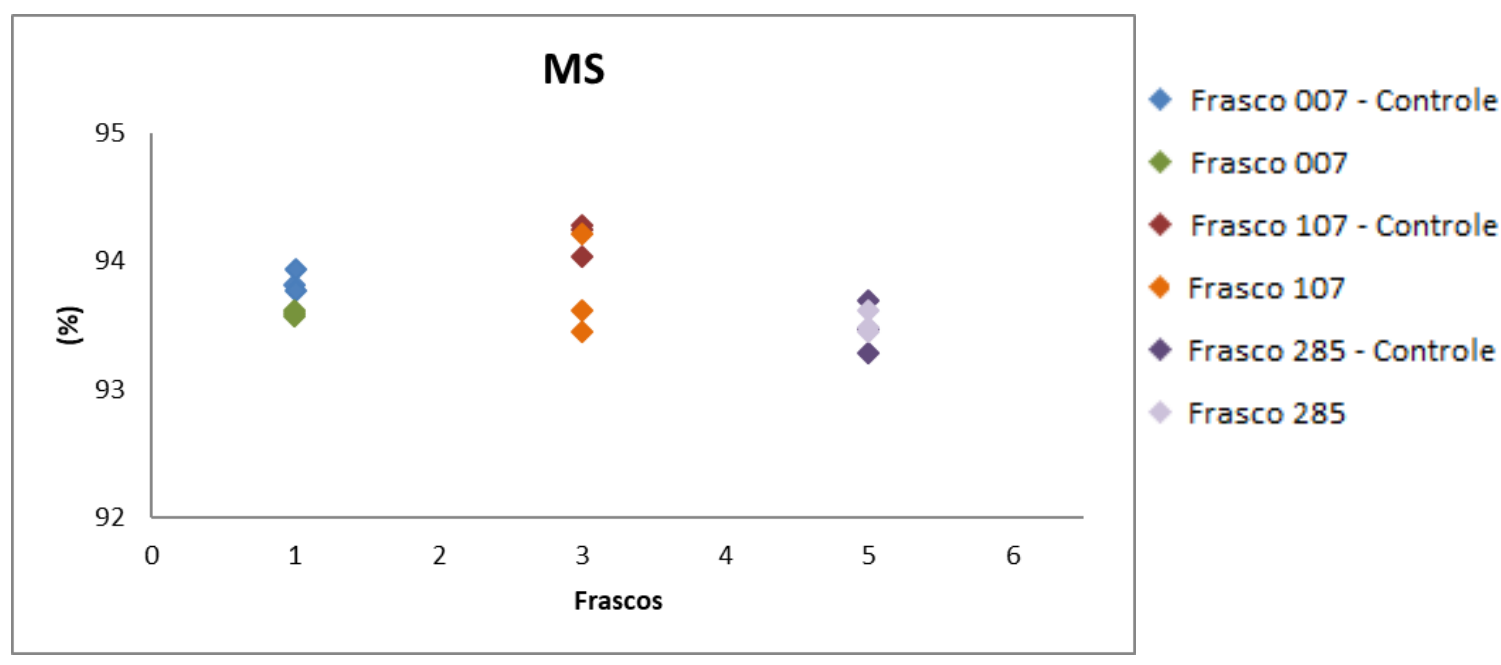


Figura 17 - Estabilidade a curto prazo para Cinzas.

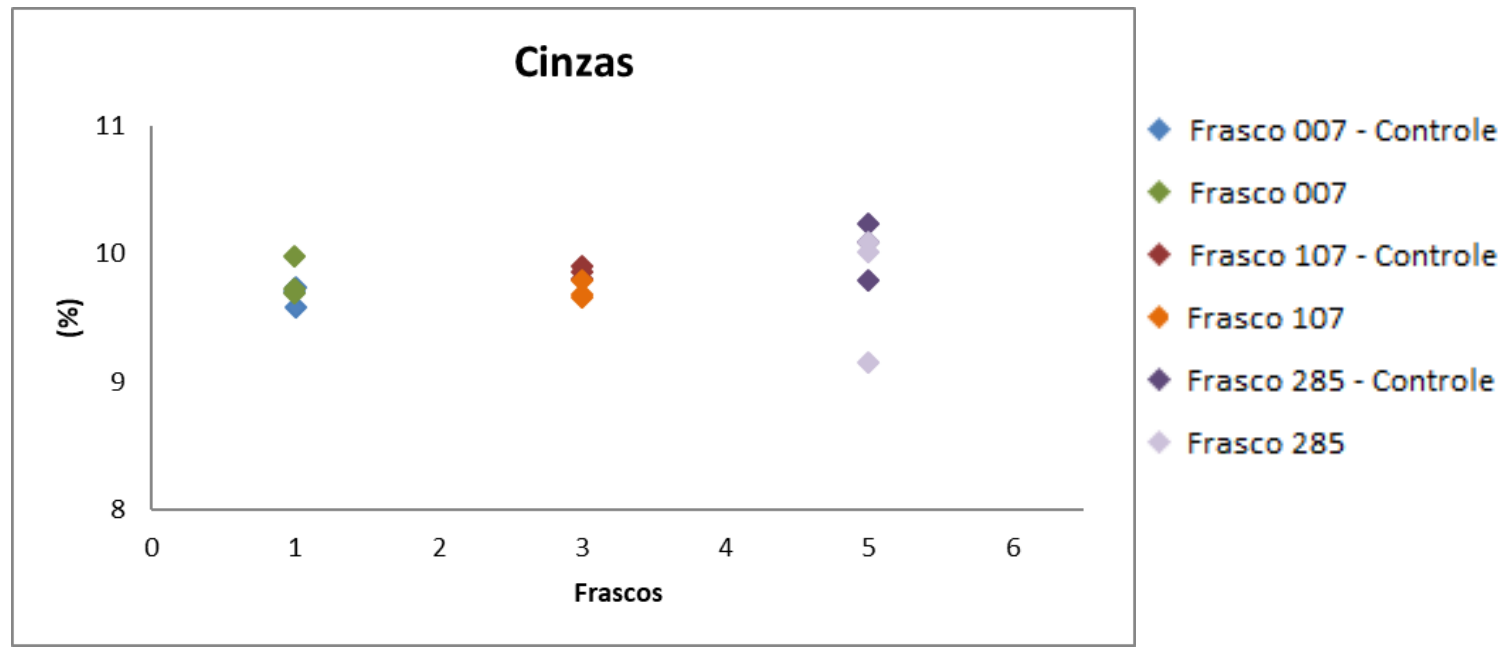

Figura 18 - Estabilidade a curto prazo para Proteína Bruta - PB.

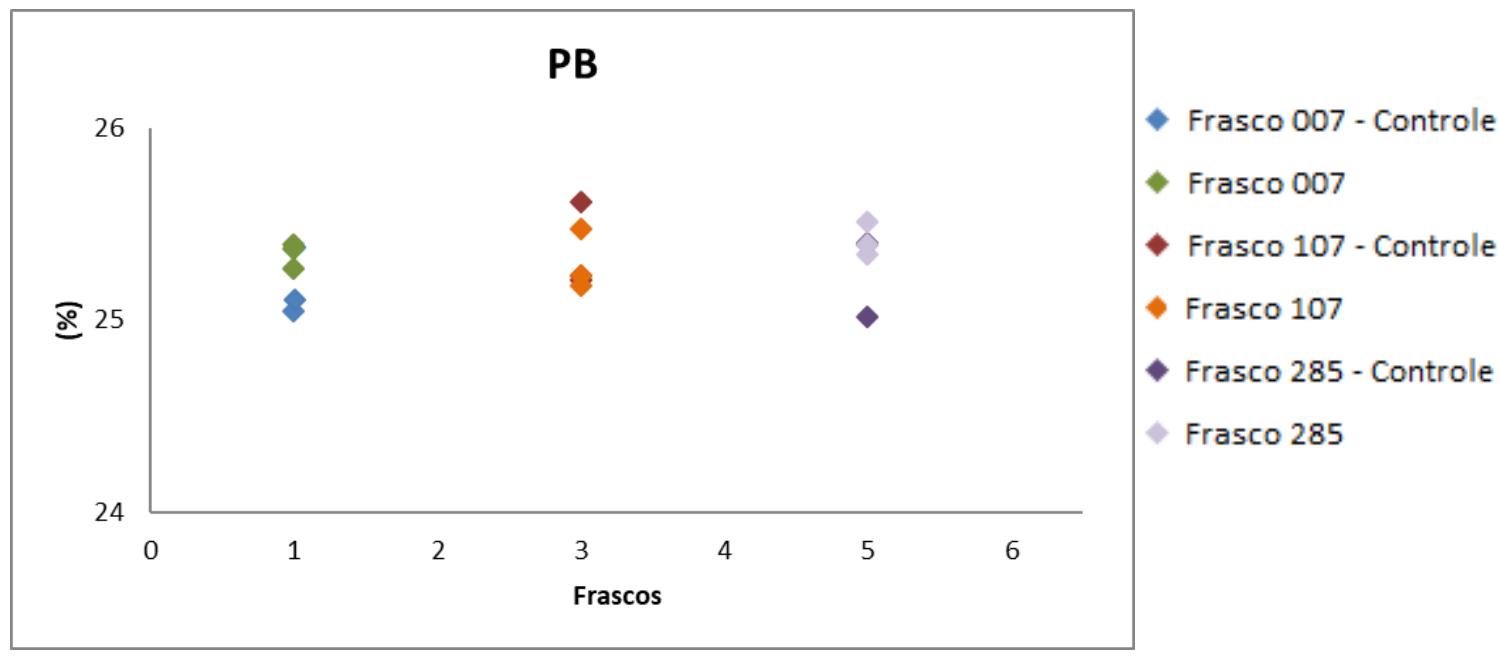

Figura 19 - Estabilidade a curto prazo para Fibra em Detergente Neutro - FDN.

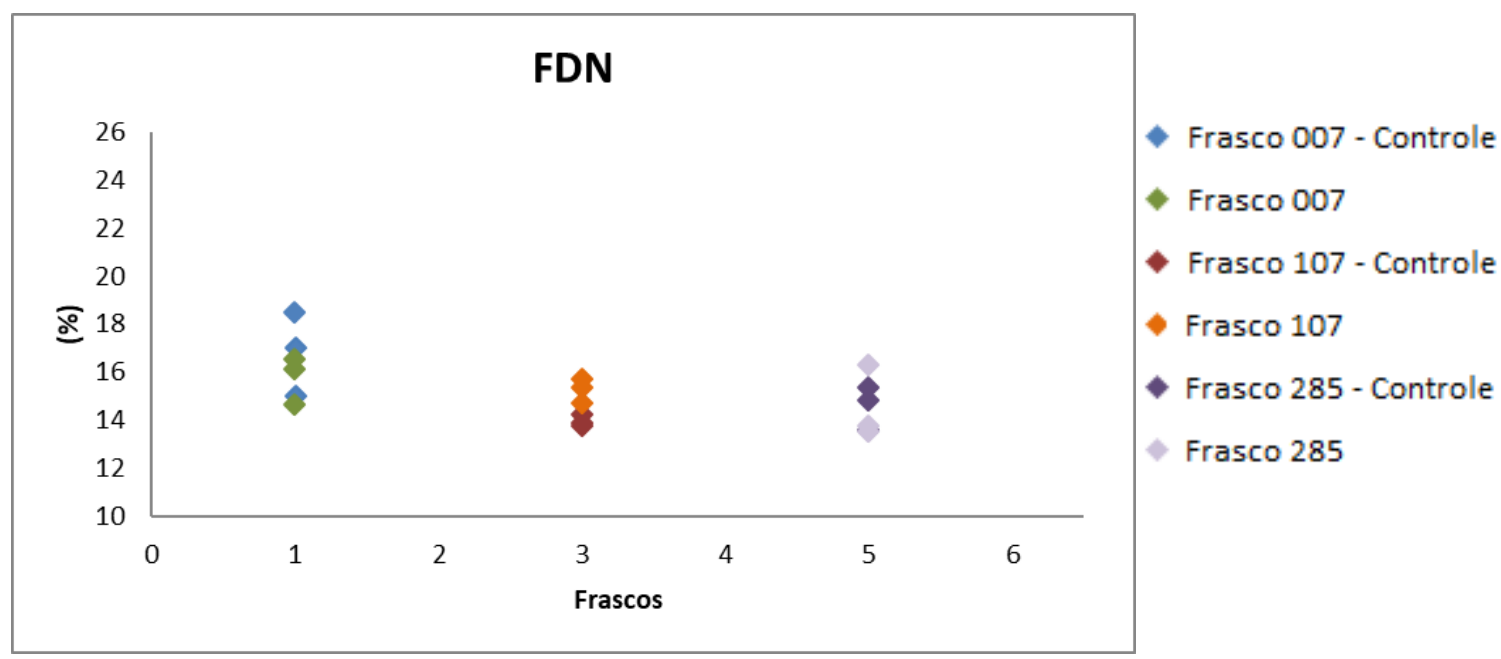


Figura 20 - Estabilidade a curto prazo para Fibra em Detergente Ácido - FDA.

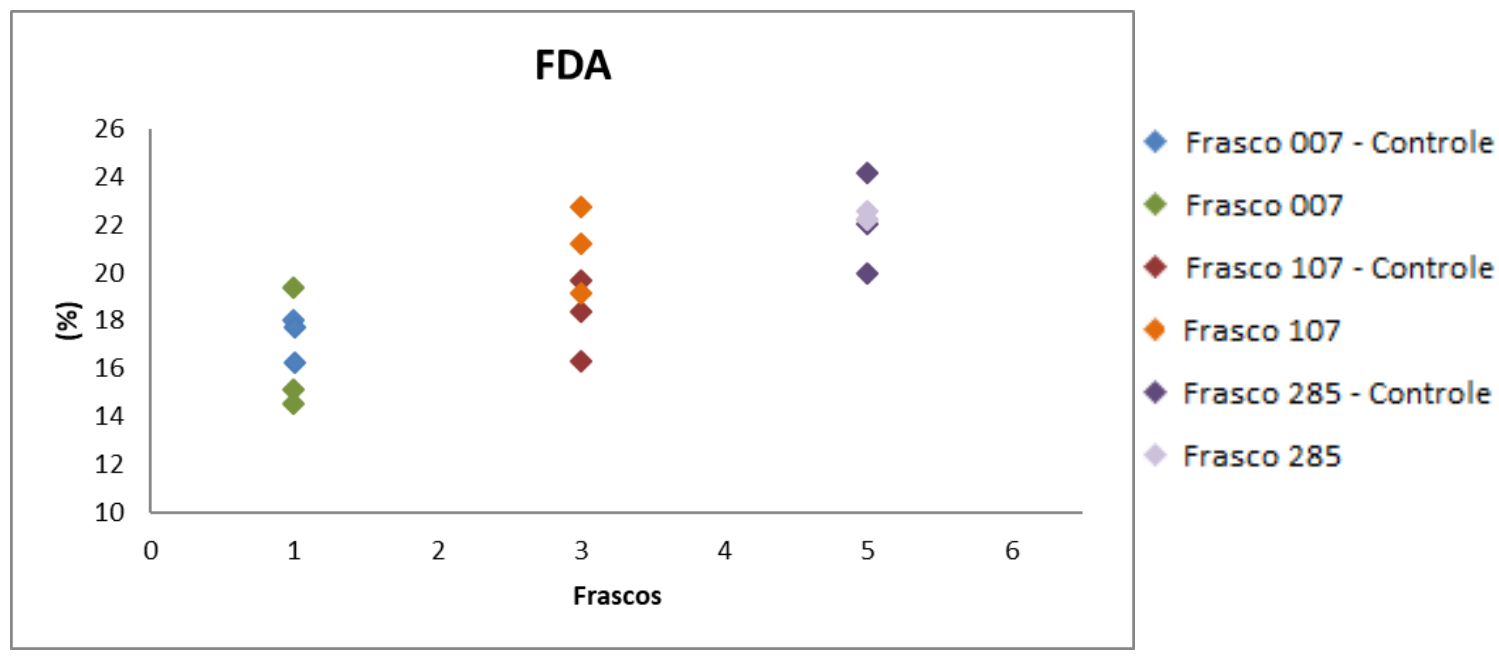

Figura 21 - Estabilidade a curto prazo para Lignina.

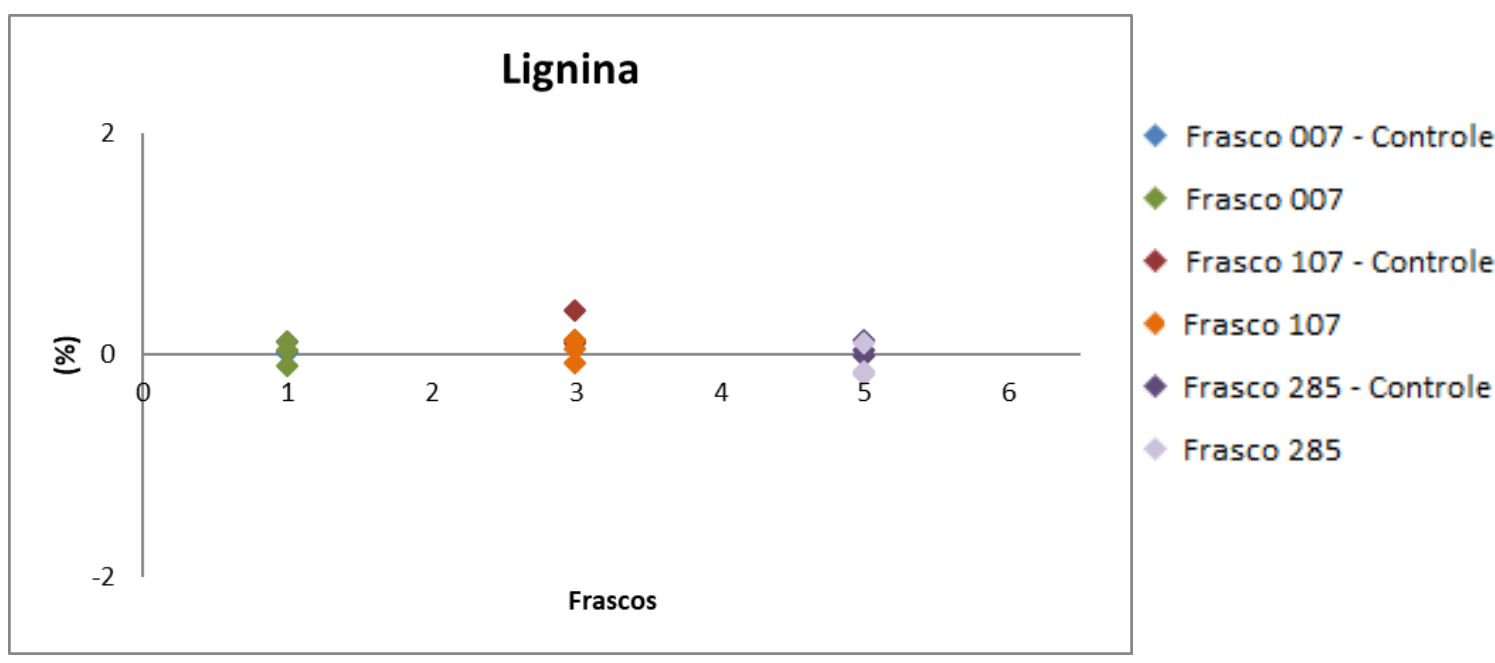

Figura 22 - Estabilidade a curto prazo para Fibra Bruta - FB.

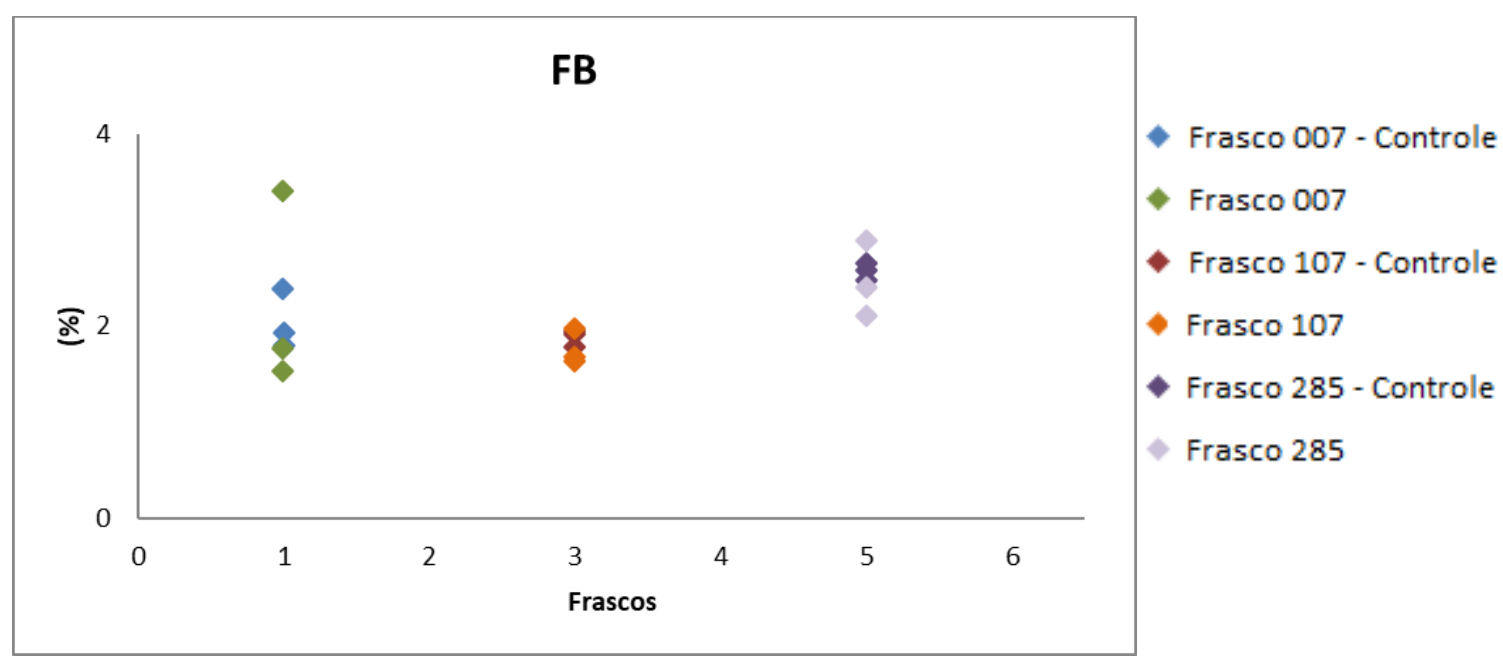


Figura 23 - Estabilidade a curto prazo para Extrato Etéreo - EE.

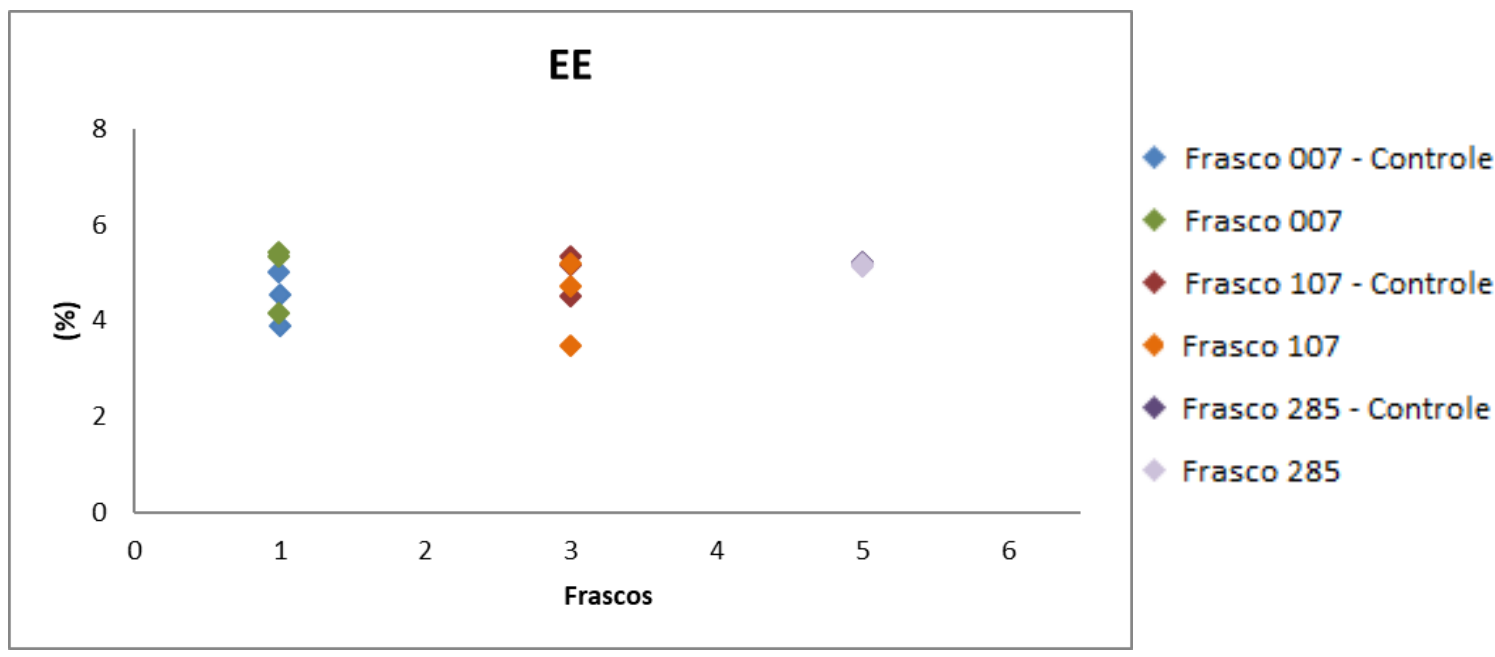

Figura 24 - Estabilidade a curto prazo para Nitrogênio Não Proteico - NNP.

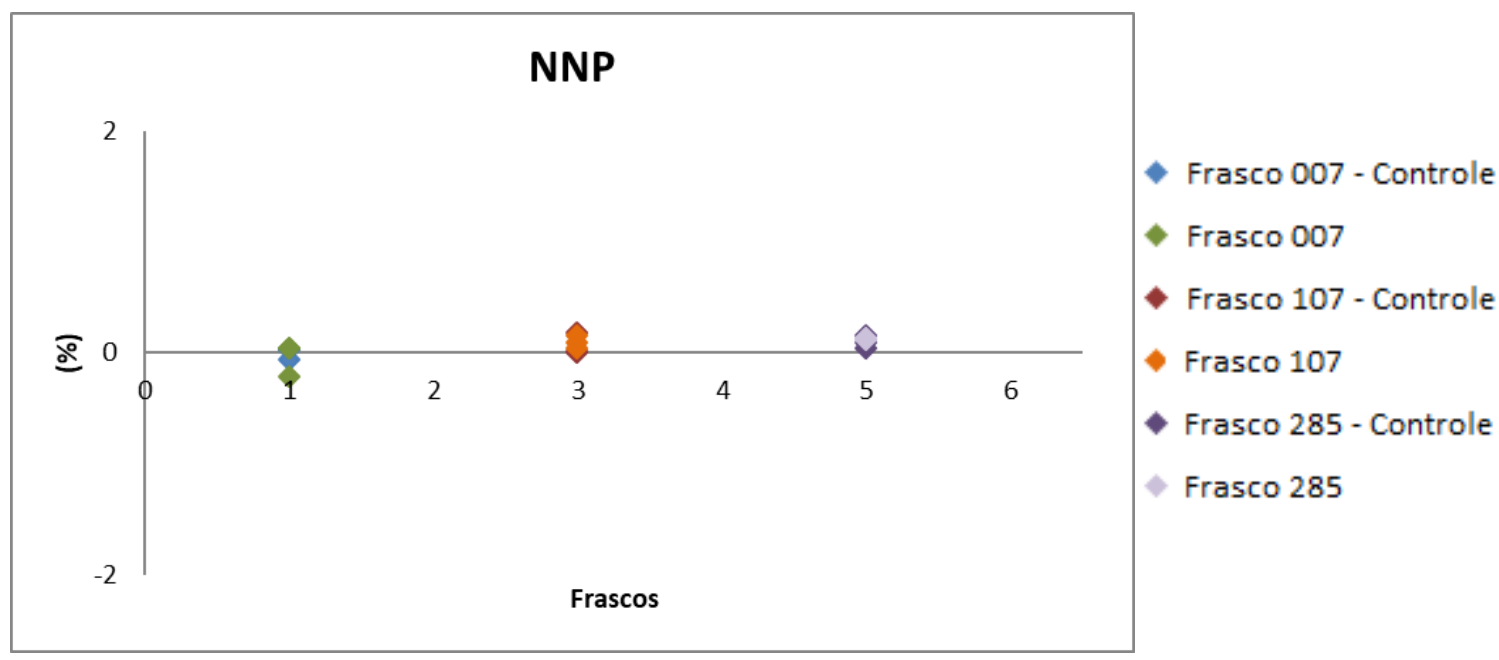

Figura 25 - Estabilidade a curto prazo para cálcio.

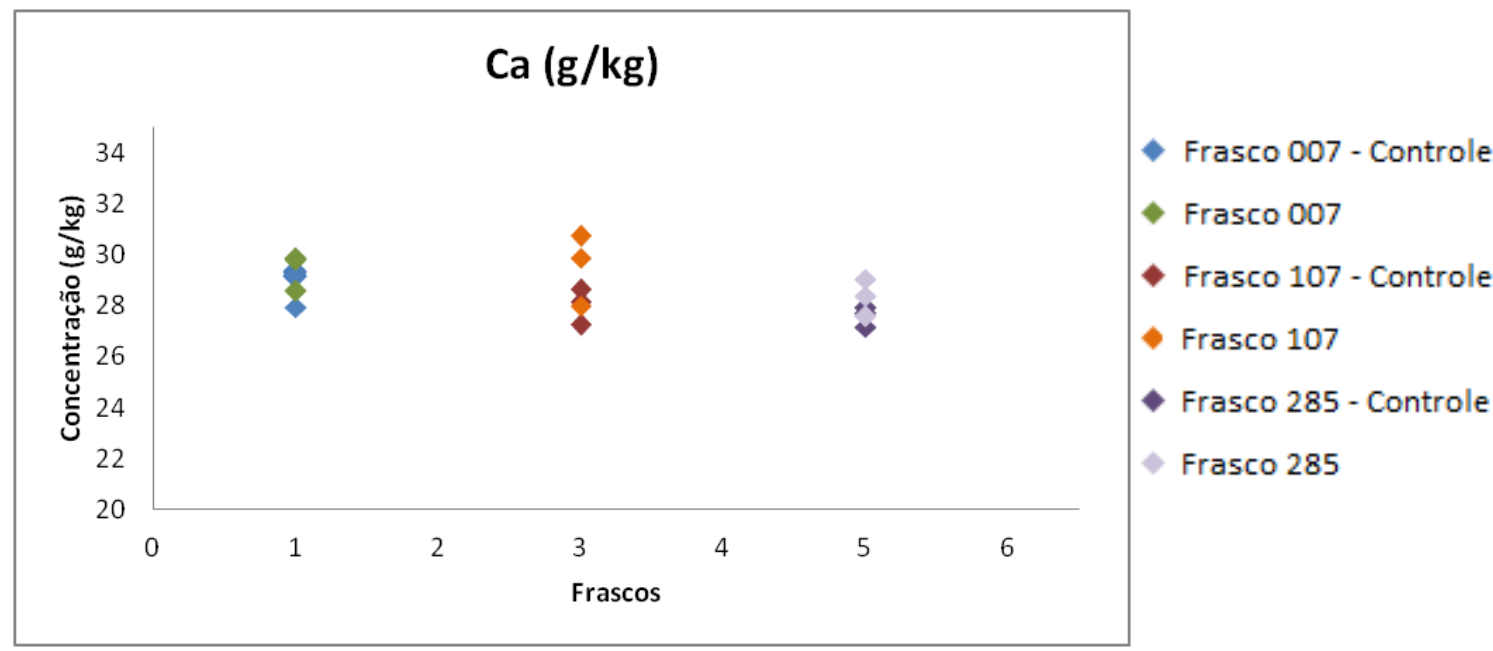


Figura 26 - Estabilidade a curto prazo para cobre.

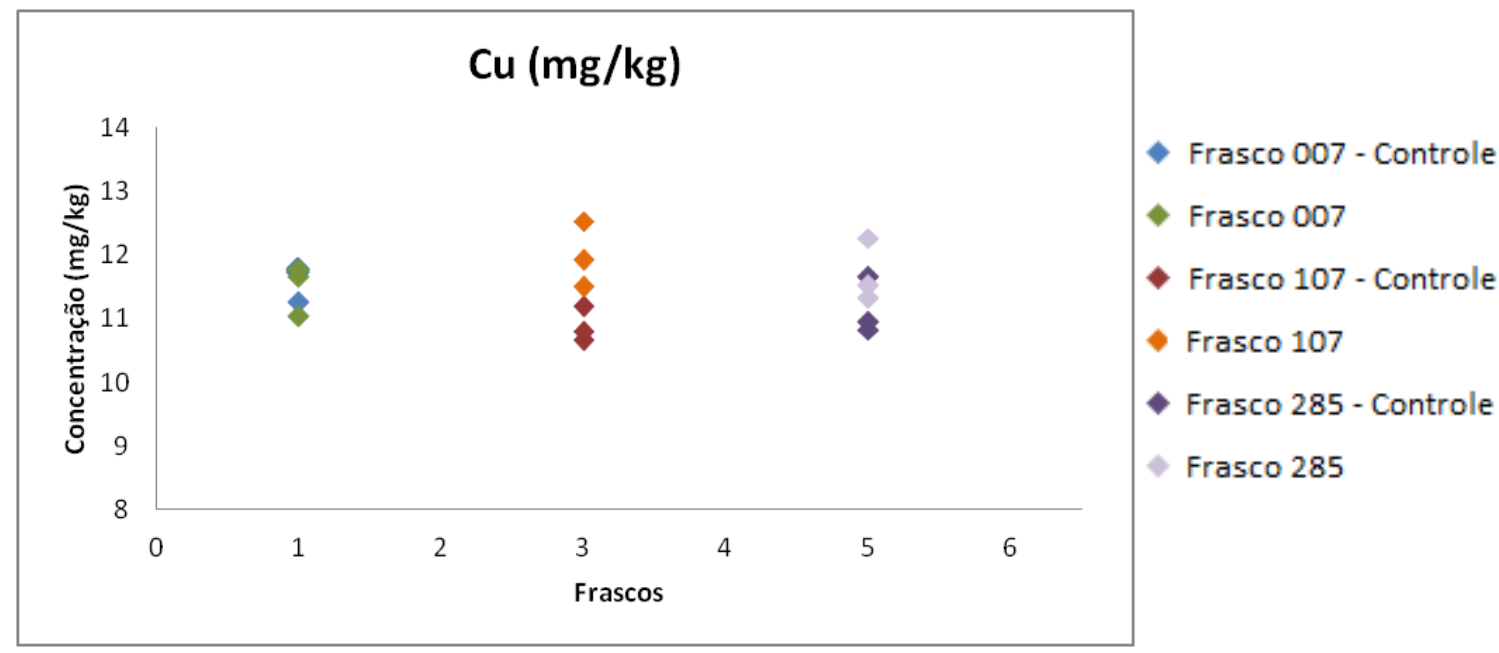

Figura 27 - Estabilidade a curto prazo para ferro.

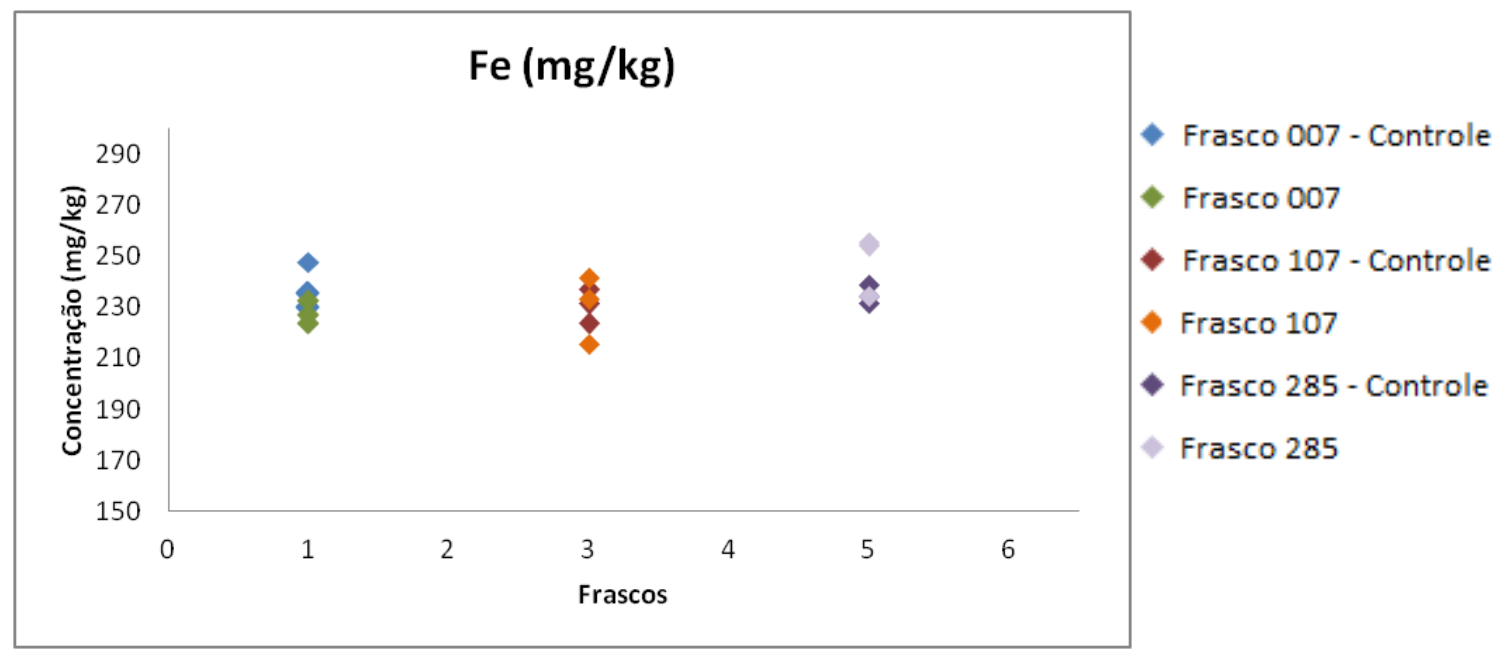

Figura 28 - Estabilidade a curto prazo para potássio.

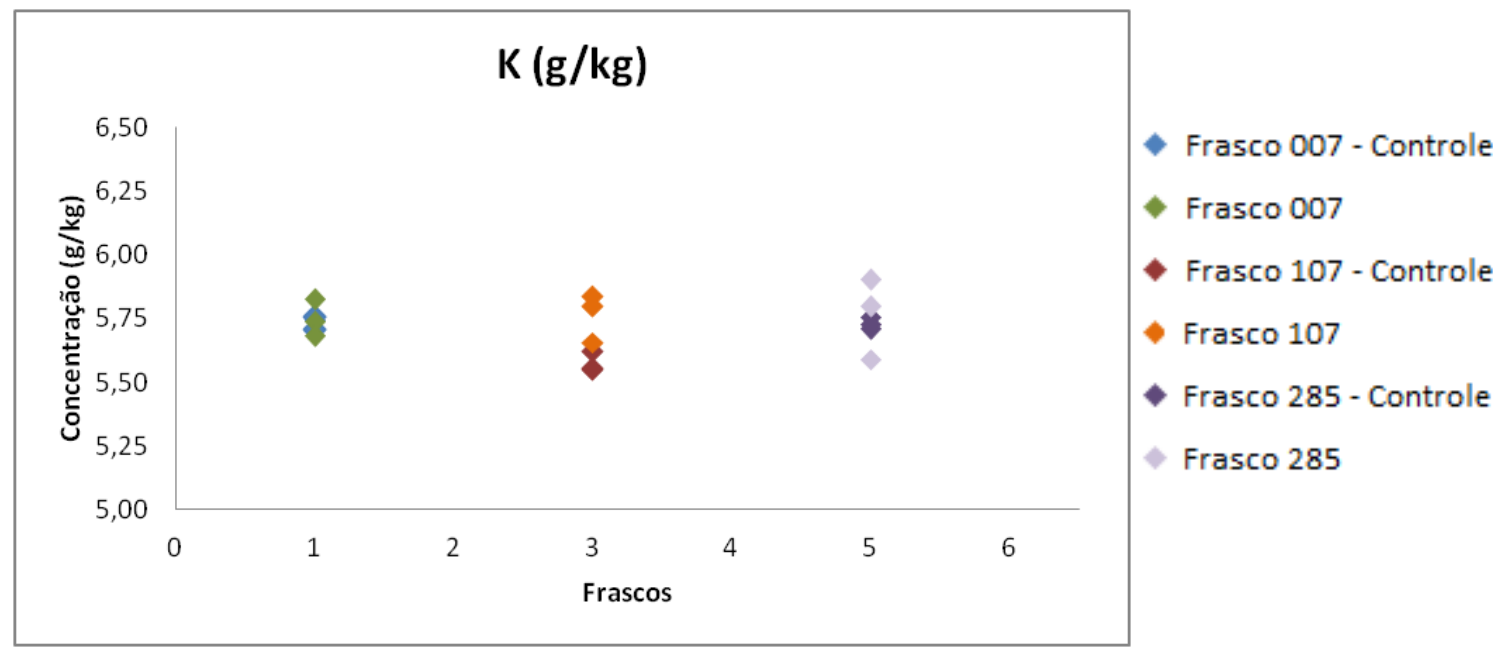


Figura 29 - Estabilidade a curto prazo para magnésio.

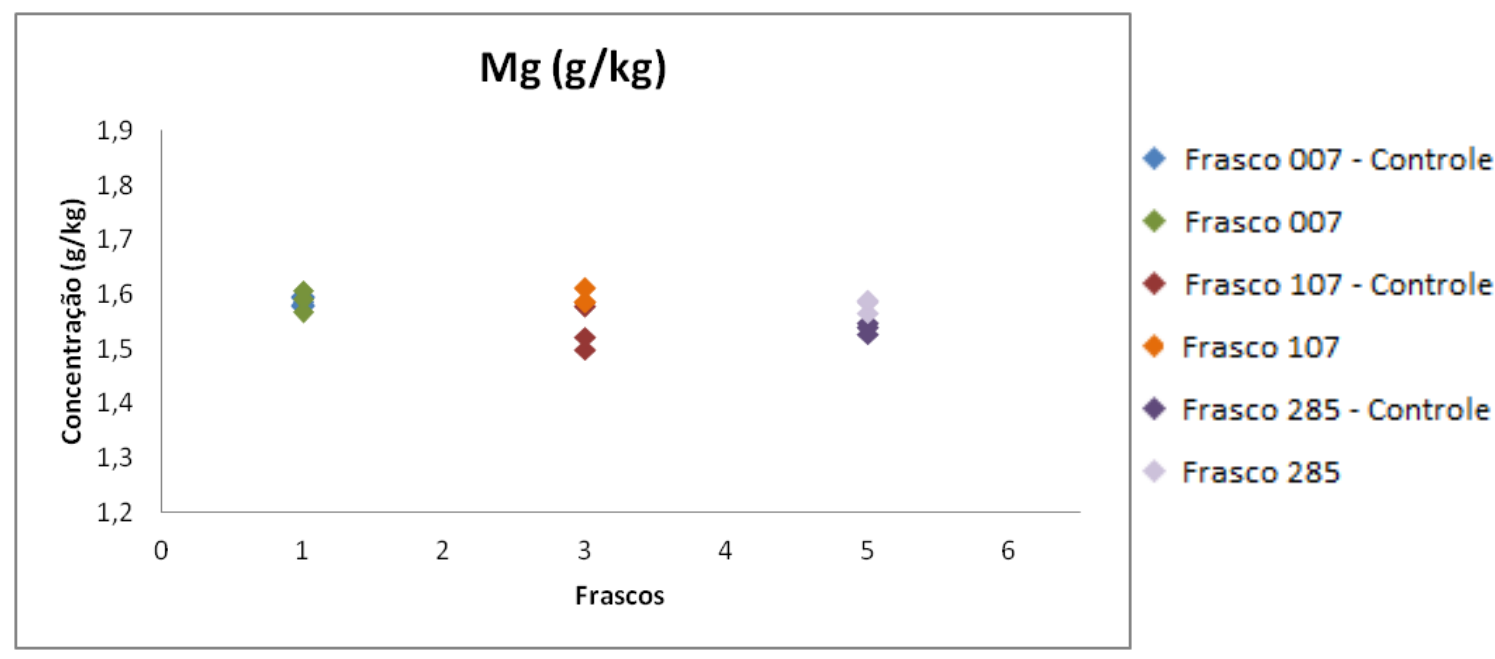

Figura 30 - Estabilidade a curto prazo para manganês.

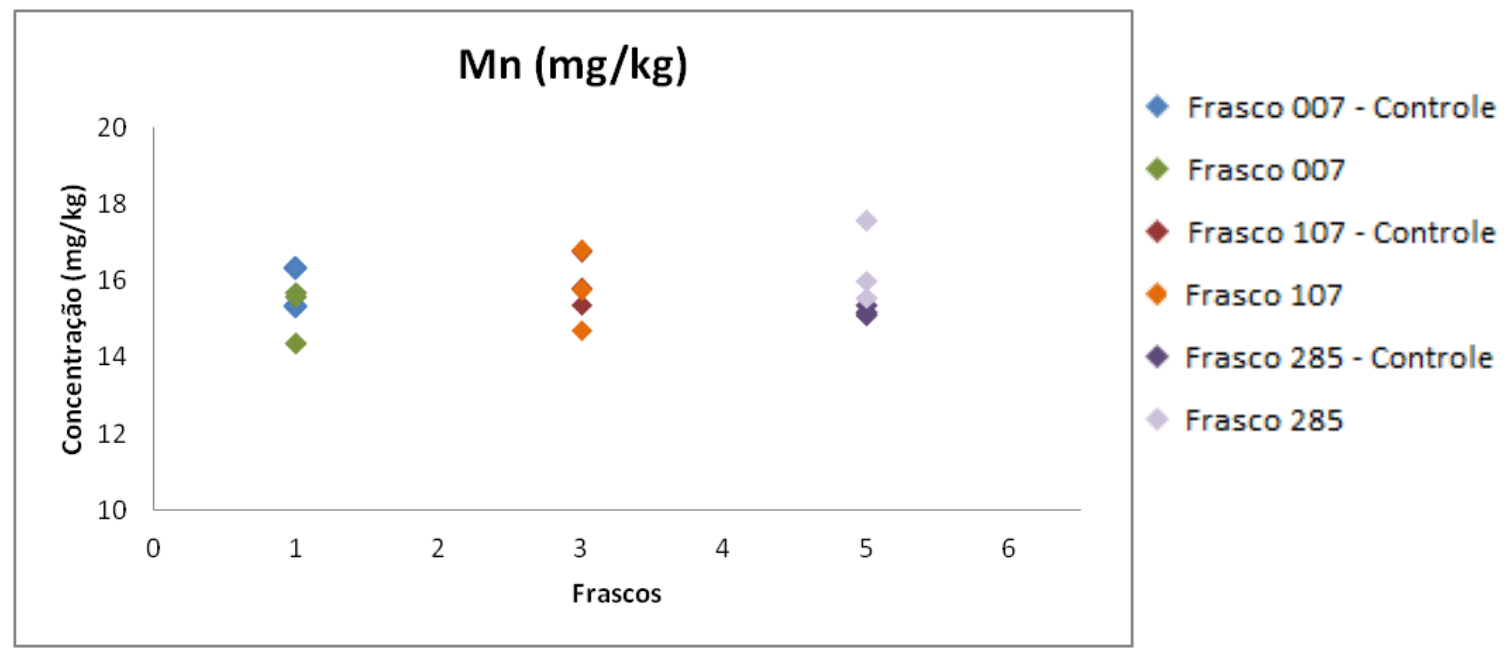

Figura 31 - Estabilidade a curto prazo para sódio.

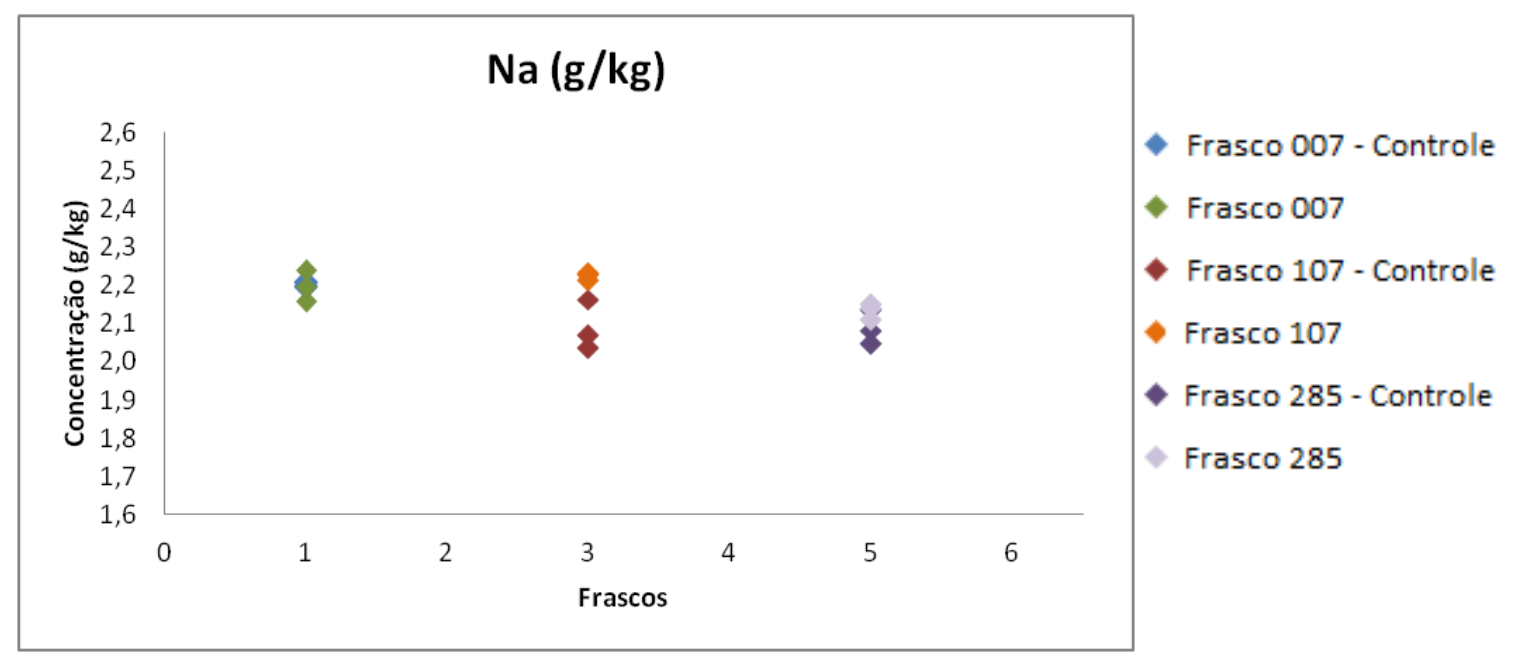


Figura 32 - Estabilidade a curto prazo para fósforo.

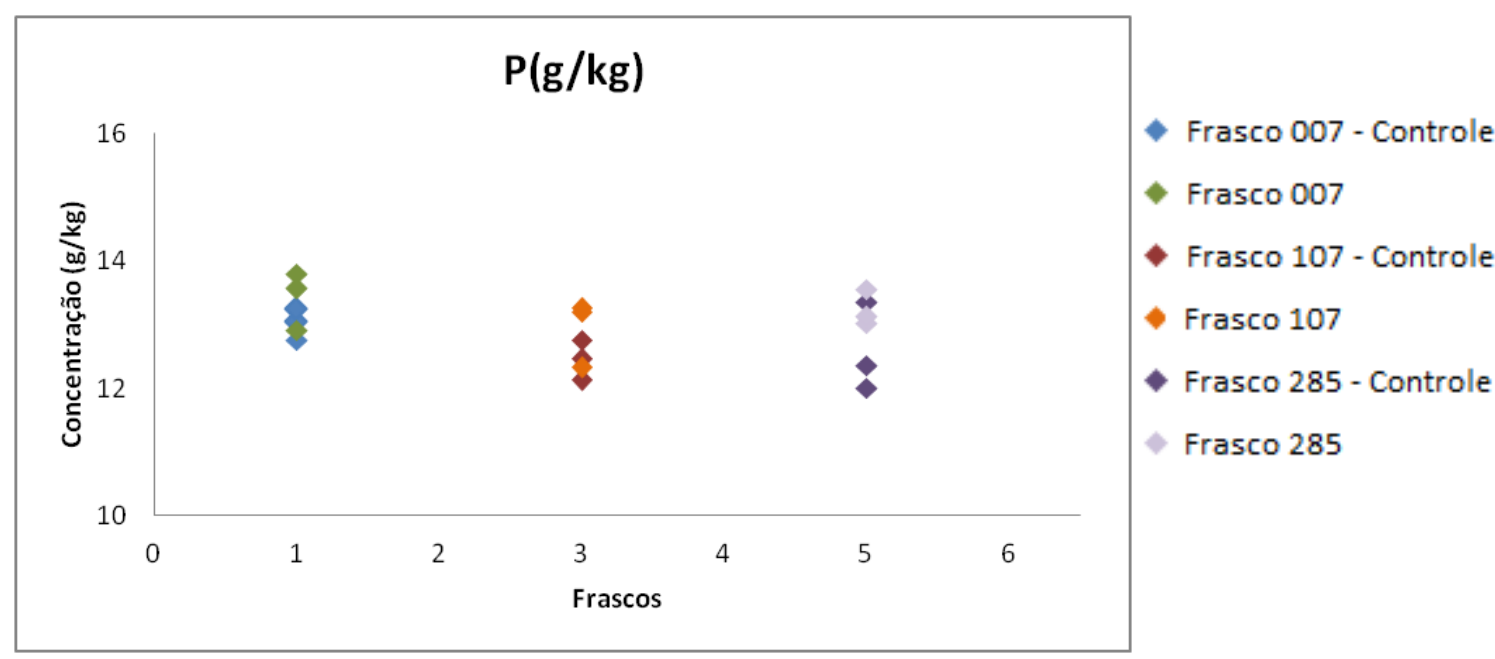

Figura 33 - Estabilidade a curto prazo para zinco.

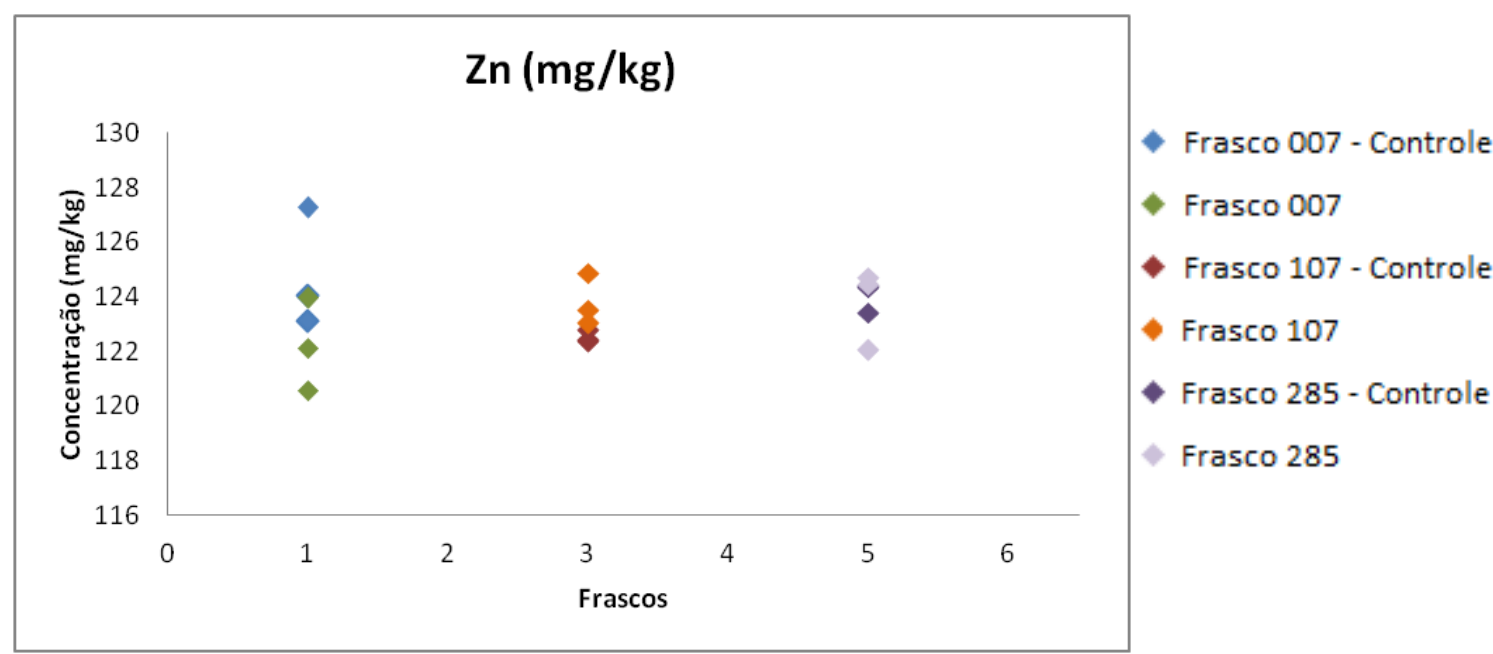

Graficamente, não são observadas diferenças consideráveis entre as concentrações dos elementos estudados dos frascos que foram submetidos a $37^{\circ} \mathrm{C}$ e $100 \%$ umidade relativa em relação aos seus respectivos frascos controle (temperatura ambiente). Para avaliar a estabilidade a curto prazo dos elementos do material de ração candidato a material referência foi utilizado ANOVA fator único no nível de significância de $5 \%(\alpha=0,05)$ como ferramenta estatística, como indicado na Tabelas 15 .

A avaliação da estabilidade a curto prazo foi realizada pela análise de variância de fator único (ANOVA) e por análise de regressão simples, sendo possível observar que $\mathrm{F}_{\text {crítico }}>\mathrm{F}_{\text {calculado }}$ para a maioria dos parâmetros bromatológicos e para $\mathrm{Ca}, \mathrm{Cu}, \mathrm{Fe}, \mathrm{K}, \mathrm{Mn}, \mathrm{P}$ e $\mathrm{Zn}$, enquanto que para MS, FDA, Mg e $\mathrm{Na} \mathrm{F}_{\text {crítico }}<\mathrm{F}_{\text {calculado }}$ o que não deve ser encarado como um limitante no uso do RM, tornando necessária a realização deste controle durante todo o período de uso do material. 
Tabela 15 - Dados da ANOVA fator único dos frascos armazenados a $37^{\circ} \mathrm{C}$ e UR de $100 \%$ por um mês, para o estudo de estabilidade a curto prazo da amostra candidata a RM.

\begin{tabular}{|c|c|c|c|c|c|c|c|}
\hline Parâmetro & Fonte da variação & $S Q$ & $g l$ & $M Q$ & F calculado & Valor-P & F crítico \\
\hline \multirow{3}{*}{ MS } & Entre frascos & 1,05 & 5 & 0,21 & 5,27 & 0,01 & 3,11 \\
\hline & Dentro dos frascos & 0,48 & 12 & 0,04 & & & \\
\hline & Total & 1,53 & 17 & & & & \\
\hline \multirow{3}{*}{ Cinzas } & Entre frascos & 0,26 & 5 & 0,05 & 0,85 & 0,54 & 3,11 \\
\hline & Dentro dos frascos & 0,72 & 12 & 0,06 & & & \\
\hline & Total & 0,98 & 17 & & & & \\
\hline \multirow{3}{*}{ PB } & Entre frascos & 0,10 & 5 & 0,02 & 0,71 & 0,63 & 3,11 \\
\hline & Dentro dos frascos & 0,34 & 12 & 0,03 & & & \\
\hline & Total & 0,44 & 17 & & & & \\
\hline \multirow{3}{*}{ FDN } & Entre frascos & 16,19 & 5 & 3,24 & 2,56 & 0,08 & 3,11 \\
\hline & Dentro dos frascos & 15,15 & 12 & 1,26 & & & \\
\hline & Total & 31,35 & 17 & & & & \\
\hline \multirow{3}{*}{ FDA } & Entre frascos & 100,17 & 5 & 20,03 & 6,54 & 0,00 & 3,11 \\
\hline & Dentro dos frascos & 36,77 & 12 & 3,06 & & & \\
\hline & Total & 136,94 & 17 & & & & \\
\hline \multirow{3}{*}{ Lignina } & Entre frascos & 0,13 & 5 & 0,03 & 1,97 & 0,16 & 3,11 \\
\hline & Dentro dos frascos & 0,16 & 12 & 0,01 & & & \\
\hline & Total & 0,30 & 17 & & & & \\
\hline \multirow{3}{*}{ FB } & Entre frascos & 1,54 & 5 & 0,31 & 1,38 & 0,30 & 3,11 \\
\hline & Dentro dos frascos & 2,69 & 12 & 0,22 & & & \\
\hline & Total & 4,23 & 17 & & & & \\
\hline \multirow{3}{*}{ EE } & Entre frascos & 1,60 & 5 & 0,32 & 1,09 & 0,41 & 3,11 \\
\hline & Dentro dos frascos & 3,52 & 12 & 0,29 & & & \\
\hline & Total & 5,12 & 17 & & & & \\
\hline \multirow{3}{*}{ NNP } & Entre frascos & 0,06 & 5 & 0,01 & 1,85 & 0,18 & 3,11 \\
\hline & Dentro dos frascos & 0,08 & 12 & 0,01 & & & \\
\hline & Total & 0,14 & 17 & & & & \\
\hline
\end{tabular}


Tabela 15 - Dados da ANOVA fator único dos frascos armazenados a $37^{\circ} \mathrm{C}$ e UR de $100 \%$ por um mês, para o estudo de estabilidade a curto prazo da amostra candidata a RM. Continuação.

\begin{tabular}{|c|c|c|c|c|c|c|c|}
\hline Parâmetro & Fonte da variação & $S Q$ & $g l$ & $M Q$ & F calculado & Valor-P & F crítico \\
\hline \multirow{3}{*}{$\mathbf{C a}$} & Entre frascos & 9,06 & 5 & 1,81 & 2,57 & 0,08 & 3,11 \\
\hline & Dentro dos frascos & 8,47 & 12 & 0,71 & & & \\
\hline & Total & 17,53 & 17 & & & & \\
\hline \multirow{3}{*}{$\mathrm{Cu}$} & Entre frascos & 2,37 & 5 & 0,48 & 2,76 & 0,07 & 3,11 \\
\hline & Dentro dos frascos & 2,07 & 12 & 0,17 & & & \\
\hline & Total & 4,44 & 17 & & & & \\
\hline \multirow{3}{*}{$\mathbf{F e}$} & Entre frascos & 812,45 & 5 & 162,49 & 2,06 & 0,14 & 3,11 \\
\hline & Dentro dos frascos & 948,20 & 12 & 79,02 & & & \\
\hline & Total & 1760,65 & 17 & & & & \\
\hline \multirow{3}{*}{$\mathbf{K}$} & Entre frascos & 0,08 & 5 & 0,02 & 2,20 & 0,12 & 3,11 \\
\hline & Dentro dos frascos & 0,09 & 12 & 0,01 & & & \\
\hline & Total & 0,17 & 17 & & & & \\
\hline \multirow{3}{*}{ Mg } & Entre frascos & 0,01 & 5 & 0,002 & 5,16 & 0,01 & 3,11 \\
\hline & Dentro dos frascos & 0,01 & 12 & $4,27 \mathrm{E}-04$ & & & \\
\hline & Total & 0,02 & 17 & & & & \\
\hline \multirow{3}{*}{ Mn } & Entre frascos & 3,028 & 5 & 0,606 & 1,01 & 0,45 & 3,11 \\
\hline & Dentro dos frascos & 7,214 & 12 & 0,601 & & & \\
\hline & Total & 10,212 & 17 & & & & \\
\hline \multirow{3}{*}{$\mathbf{N a}$} & Entre frascos & 0,05 & 5 & 0,01 & 5,60 & 0,01 & 3,33 \\
\hline & Dentro dos frascos & 0,02 & 10 & 0,002 & & & \\
\hline & Total & 0,06 & 15 & & & & \\
\hline \multirow{3}{*}{$\mathbf{P}$} & Entre frascos & 2,10 & 5 & 0,42 & 2,07 & 0,14 & 3,11 \\
\hline & Dentro dos frascos & 2,44 & 12 & 0,20 & & & \\
\hline & Total & 4,54 & 17 & & & & \\
\hline \multirow{3}{*}{$\mathbf{Z n}$} & Entre frascos & 14,30 & 5 & 2,86 & 1,56 & 0,25 & 3,11 \\
\hline & Dentro dos frascos & 22,05 & 12 & 1,84 & & & \\
\hline & Total & 36,35 & 17 & & & & \\
\hline
\end{tabular}

\subsubsection{Estabilidade a Longo Prazo}

Os resultados da análise de variância utilizados para estimar a variância dos valores avaliados na regressão linear para o estudo de estabilidade a longo prazo para $\mathrm{Ca}, \mathrm{Cu}, \mathrm{Fe}, \mathrm{K}$, Mg, Mn, Na, P e Zn estão mostrados nas Figuras 34 a 42, onde estão representadas graficamente as tendências destes resultados. A Tabela 16 apresenta as concentrações encontradas neste 
estudo, enquanto a Tabela 17 apresenta um resumo da análise de regressão do estudo de estabilidade. A análise foi realizada no intervalo de 3 em 3 meses, até completar um ano. Não foi possível realizar o estudo de estabilidade de longo prazo para os parâmetros bromatológicos por limitação de agenda e reagentes do laboratório utilizado.

Tabela 16 - Concentrações médias $(\mathrm{n}=30)$ obtidas no teste de estabilidade a longo prazo.

\begin{tabular}{cccccc}
\hline Elementos & Início & $\mathbf{3}$ meses & $\mathbf{6}$ meses & $\mathbf{9}$ meses & $\mathbf{1 2}$ meses \\
\hline $\mathbf{C a}\left(\mathbf{g ~ k g}^{-1}\right)$ & $31,78 \pm 1,32$ & $35,15 \pm 1,66$ & $33,51 \pm 1,29$ & $31,34 \pm 1,67$ & $28,44 \pm 0,89$ \\
\hline $\mathbf{C u}\left(\mathbf{m g ~ k g}^{-1}\right)$ & $11,40 \pm 0,39$ & $10,76 \pm 0,39$ & $10,49 \pm 0,16$ & $10,70 \pm 0,18$ & $11,97 \pm 0,48$ \\
\hline $\mathbf{F e}\left(\mathbf{m g ~ k g}^{-1}\right)$ & $246,03 \pm 15,91$ & $268,73 \pm 15,97$ & $236,49 \pm 10,51$ & $253,66 \pm 11,62$ & $245,42 \pm 20,04$ \\
\hline $\mathbf{K}\left(\mathbf{g ~ k g}^{-1}\right)$ & $6,08 \pm 0,10$ & $6,92 \pm 0,17$ & $6,93 \pm 0,12$ & $6,76 \pm 0,03$ & $6,26 \pm 0,05$ \\
\hline $\mathbf{M g}\left(\mathbf{g ~ k g}^{-1}\right)$ & $1,58 \pm 0,04$ & $1,76 \pm 0,05$ & $1,68 \pm 0,03$ & $1,72 \pm 0,02$ & $1,72 \pm 0,02$ \\
\hline $\mathbf{M n}\left(\mathbf{m g ~ k g}^{-1}\right)$ & $17,11 \pm 1,03$ & $22,42 \pm 1,77$ & $16,65 \pm 1,14$ & $19,38 \pm 2,60$ & $17,90 \pm 4,29$ \\
\hline $\mathbf{N a}\left(\mathbf{g ~ k g}^{-1}\right)$ & $2,18 \pm 0,05$ & $3,16 \pm 0,36$ & $2,89 \pm 0,07$ & $2,70 \pm 0,05$ & $2,45 \pm 0,03$ \\
\hline $\mathbf{P}\left(\mathbf{g ~ k g}^{-1}\right)$ & $14,16 \pm 0,48$ & $14,93 \pm 0,33$ & $14,91 \pm 0,41$ & $14,66 \pm 0,50$ & $15,40 \pm 0,35$ \\
\hline $\mathbf{Z n}\left(\mathbf{m g ~ k g}^{-1}\right)$ & $124,02 \pm 2,09$ & $119,04 \pm 4,30$ & $120,20 \pm 1,84$ & $123,51 \pm 1,57$ & $130,91 \pm 3,93$ \\
\hline
\end{tabular}

Figura 34 - Gráfico da análise de regressão dos resultados de estabilidade a longo prazo para cálcio.

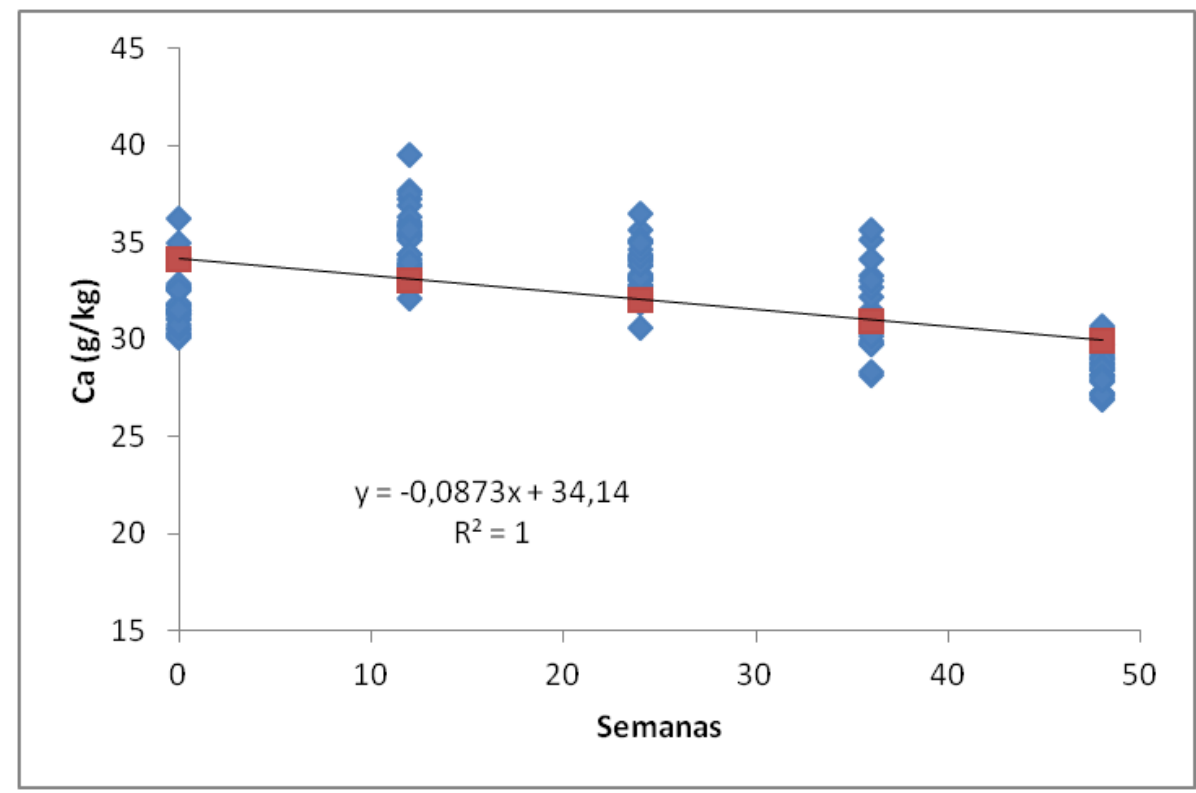


Figura 35 - Gráfico da análise de regressão dos resultados de estabilidade a longo prazo para cobre.

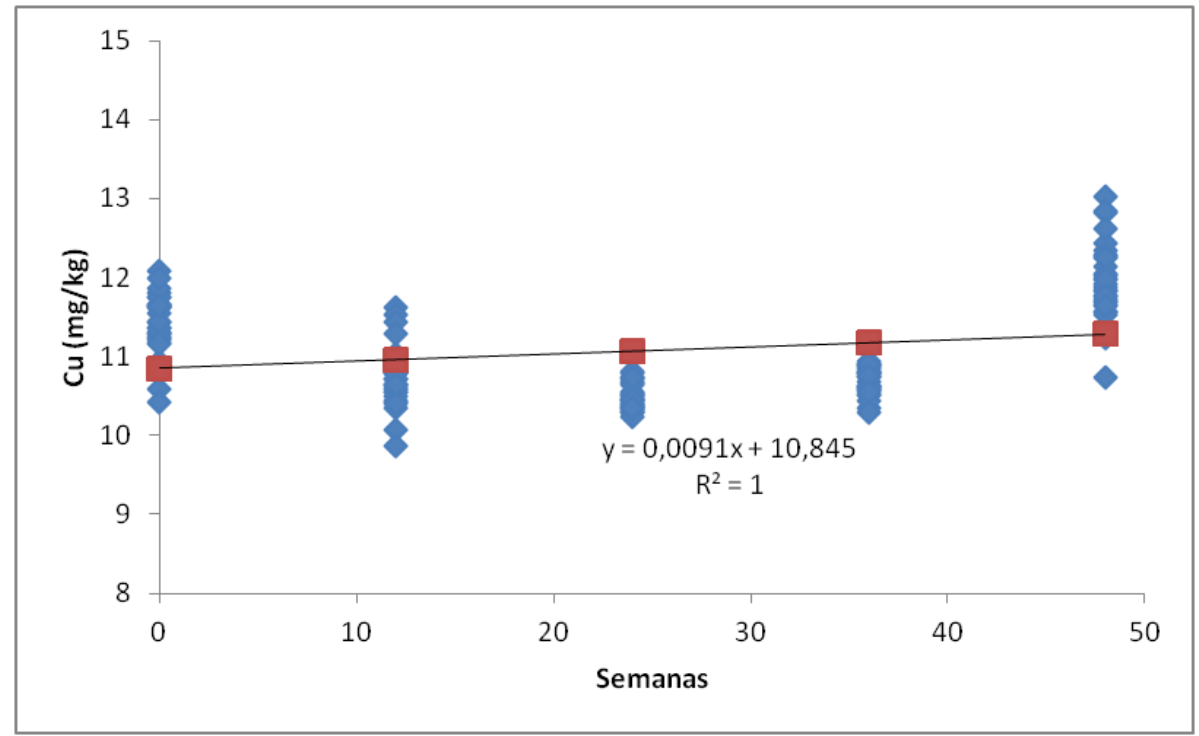

Figura 36 - Gráfico da análise de regressão dos resultados de estabilidade a longo prazo para ferro.

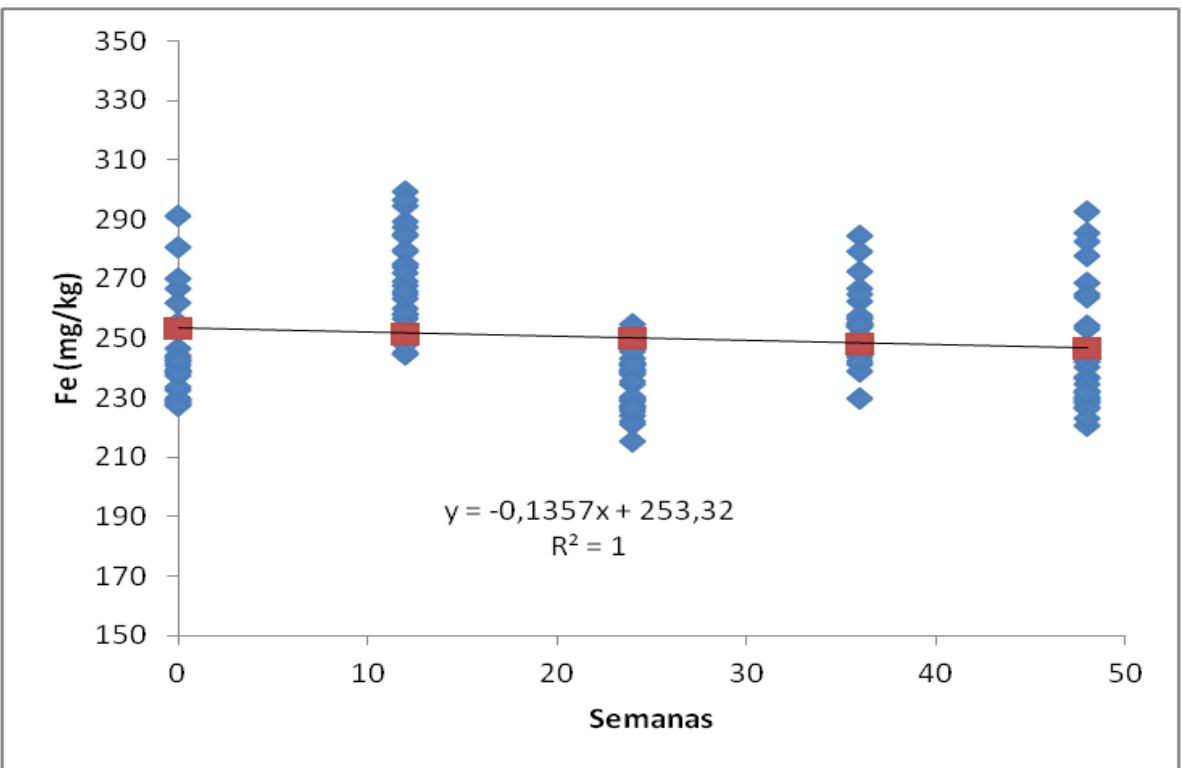


Figura 37 - Gráfico da análise de regressão dos resultados de estabilidade a longo prazo para potássio.

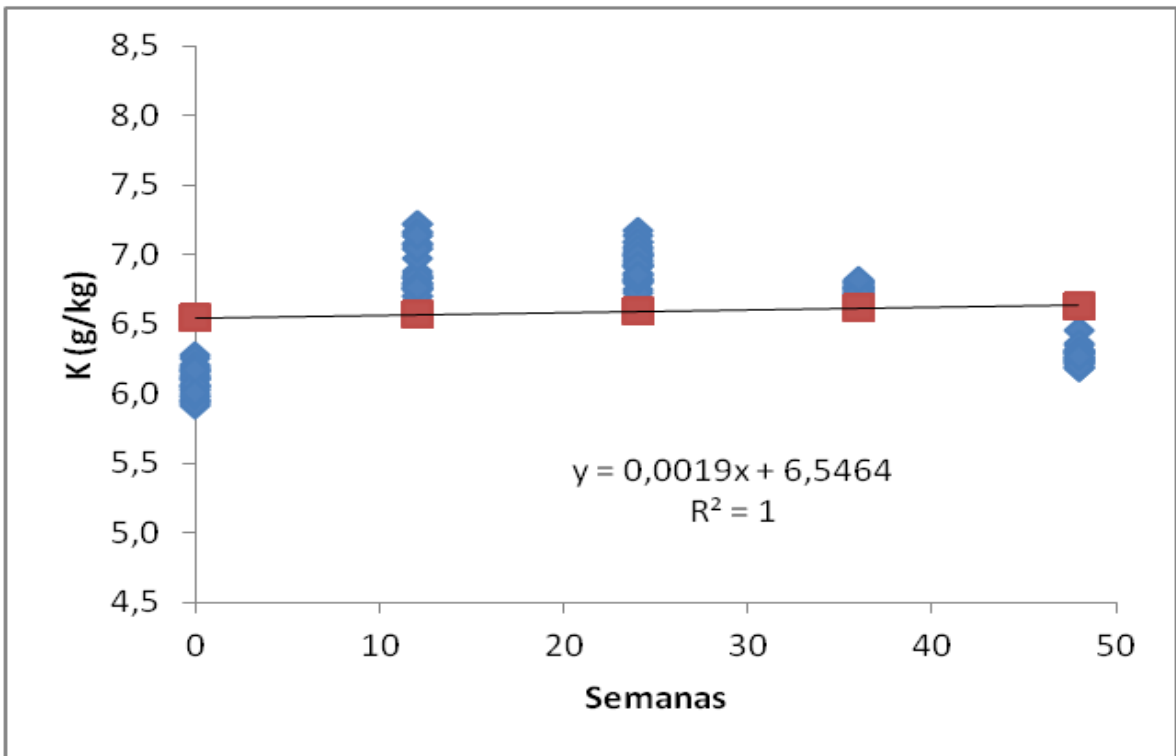

Figura 38 - Gráfico da análise de regressão dos resultados de estabilidade a longo prazo para magnésio.

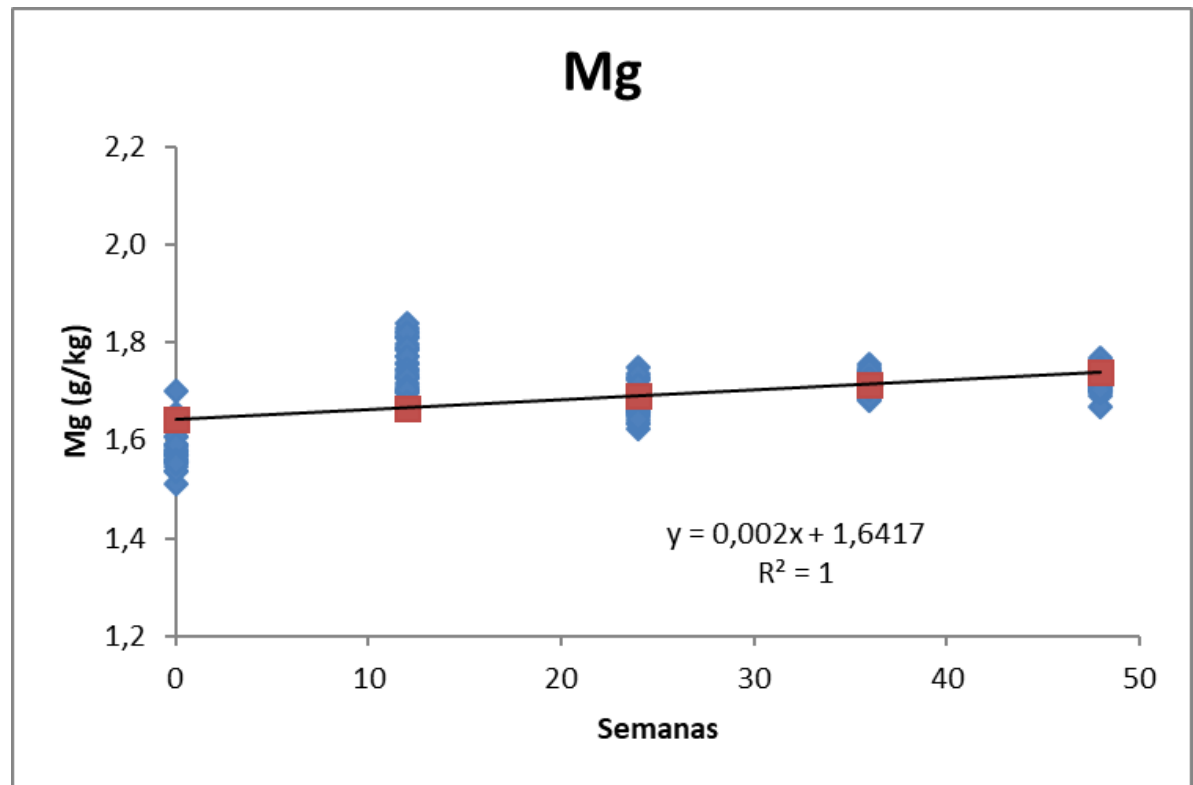


Figura 39 - Gráfico da análise de regressão dos resultados de estabilidade a longo prazo para manganês.

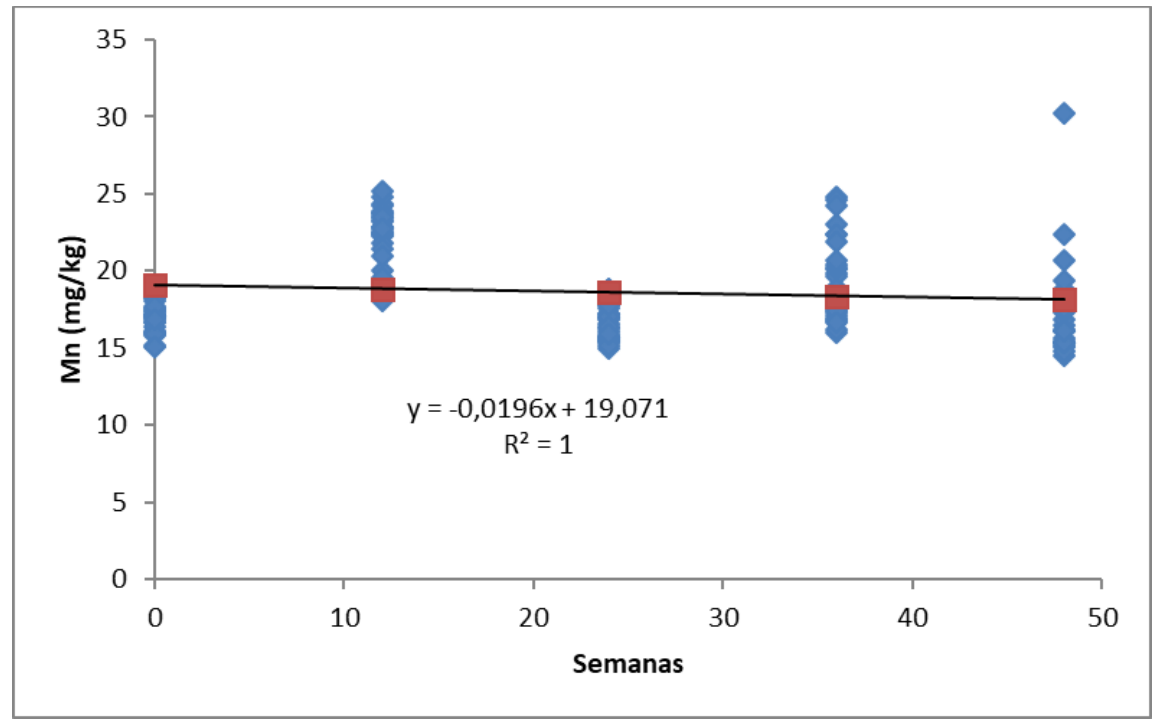

Figura 40 - Gráfico da análise de regressão dos resultados de estabilidade a longo prazo para sódio.

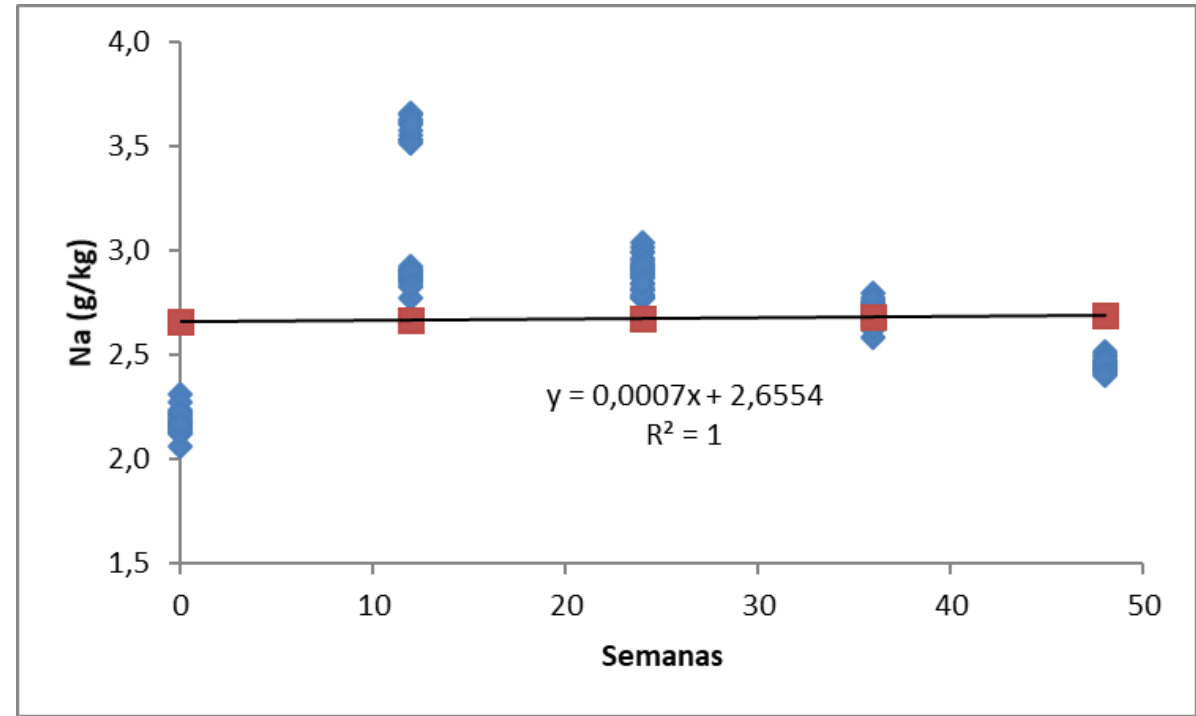


Figura 41 - Gráfico da análise de regressão dos resultados de estabilidade a longo prazo para fósforo.

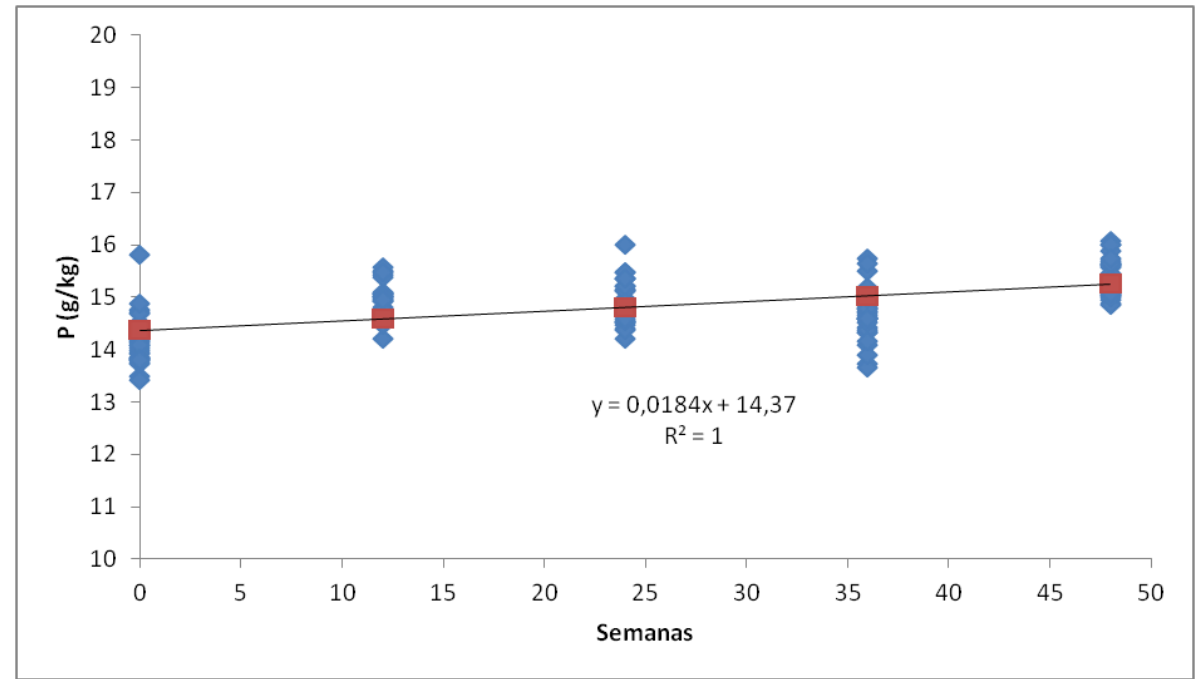

Figura 42 - Gráfico da análise de regressão dos resultados de estabilidade a longo prazo para zinco.

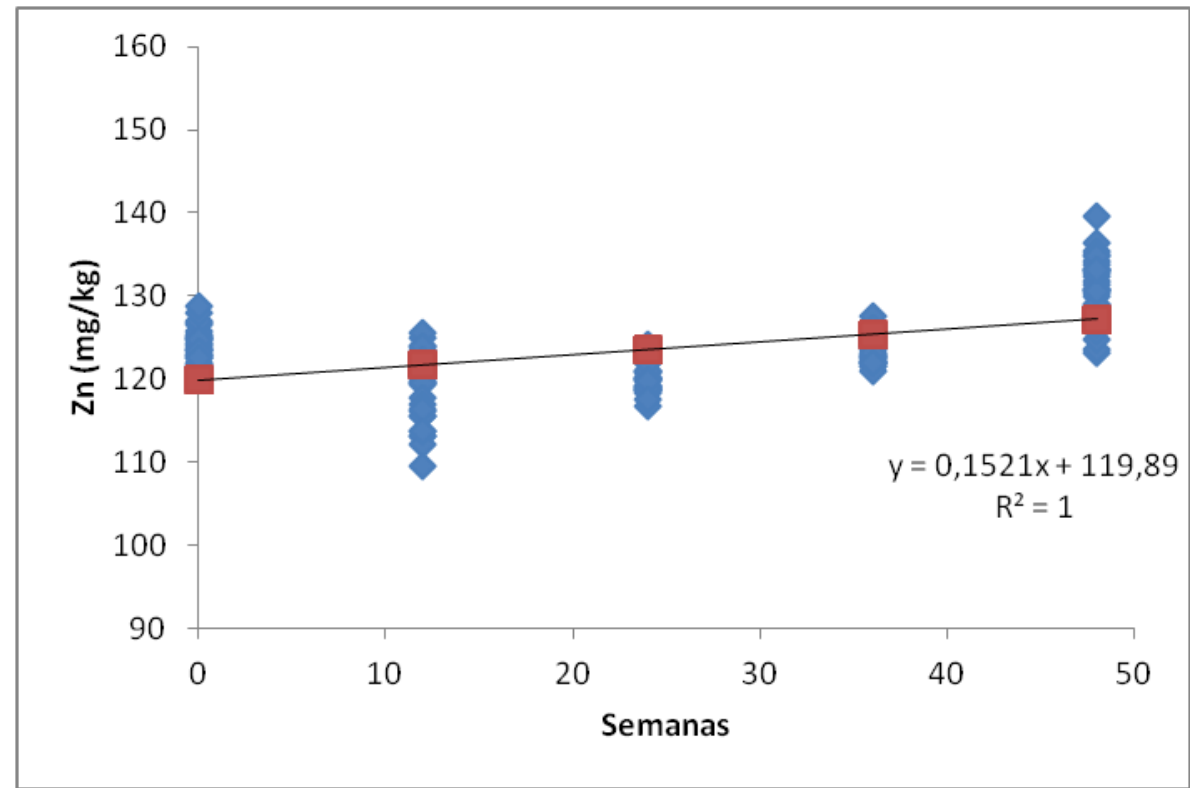


Tabela 17 - Análise da regressão do estudo de estabilidade a longo prazo.

\begin{tabular}{ccccc}
\hline Elementos & Coeficiente Angular & Limite Inferior (95\%) & Limite Superior (95\%) & Valor-p \\
\hline $\mathbf{C a}$ & $-0,087$ & $-0,108$ & $-0,066$ & $7,15 \mathrm{E}-14$ \\
\hline $\mathbf{C u}$ & 0,009 & 0,003 & 0,015 & 0,003 \\
\hline $\mathbf{F e}$ & $-0,136$ & $-0,311$ & 0,039 & 0,128 \\
\hline $\mathbf{K}$ & 0,002 & $-0,002$ & 0,005 & 0,295 \\
\hline $\mathbf{M g}$ & 0,002 & 0,001 & 0,003 & $1,22 \mathrm{E}-10$ \\
\hline $\mathbf{M n}$ & $-0,020$ & $-0,049$ & 0,010 & 0,195 \\
\hline $\mathbf{N a}$ & 0,001 & $-0,003$ & 0,004 & 0,687 \\
\hline $\mathbf{P}$ & 0,018 & 0,014 & 0,023 & $8,49 \mathrm{E}-13$ \\
\hline $\mathbf{Z n}$ & 0,152 & 0,110 & 0,194 & $2,92 \mathrm{E}-11$ \\
\hline
\end{tabular}

O ABNT ISO GUIA 35: 2012 estabelece que o elemento é estável se o produto da inclinação da reta for menor que o produto entre o t de Student e o desvio padrão da inclinação da reta. Na Tabela 18, estão os valores da inclinação da reta $\left(b_{1}\right)$ e o produto do desvio padrão com o t de Student $\left(\mathrm{t}_{(0,95, \mathrm{n}-2)}\right.$. $\left.\mathrm{s}_{(\mathrm{b} 1)}\right)$, calculados por meio das Equações 18 a 21. Se a condição $\left|b_{1}\right|<\left(t_{(0,95, n-2)}\right.$. $\left.s_{(b 1)}\right)$ for confirmada, nenhuma instabilidade será observada.

$$
\begin{gathered}
b_{0}=\bar{Y}-b_{1} \bar{X} \\
b_{1}=\frac{\sum_{i=1}^{n}\left(X_{i}-\bar{X}\right)\left(Y_{i}-\bar{Y}\right)}{\sum_{i=1}^{n}\left(X_{i}-\bar{X}\right)^{2}} \\
s^{2}=\frac{\sum_{i=1}^{n}\left(Y_{i}-b_{0}-b_{1} X_{1}\right)^{2}}{n-2} \\
s\left(b_{1}\right)=\frac{s}{\sqrt{\sum_{i=1}^{n}\left(X_{i}-\bar{X}\right)^{2}}}
\end{gathered}
$$

Onde:

$\mathrm{X}$ - Refere-se aos meses de duração do teste

Y - Refere-se à concentração do analito 
A partir desta avaliação, a componente da incerteza da estabilidade a longo prazo, $u_{l t s}$, é obtida multiplicando-se o valor do erro padrão da variável X obtido na análise de regressão linear dos dados de estabilidade para o analito testado por um tempo de $\mathrm{t}$ (semanas).

Tabela 18 - Teste T com os dados obtidos por ICP OES para o estudo de estabilidade a longo prazo.

\begin{tabular}{|c|c|c|c|}
\hline Elementos & $b_{1}$ & $\mathbf{t}_{(0,95, n-2)}{ }^{*} \mathbf{S}_{(\mathbf{b} 1)}$ & $\boldsymbol{u}_{t t s}$ \\
\hline $\mathrm{Ca}\left(\mathrm{g} \mathrm{kg}^{-1}\right)$ & 0,349 & 0,275 & 0,51 \\
\hline $\mathrm{Cu}\left(\mathrm{mg} \mathrm{kg}^{-1}\right)$ & 0,052 & 0,036 & 0,15 \\
\hline $\mathrm{Fe}\left(\mathrm{mg} \mathrm{kg}{ }^{-1}\right)$ & 0,543 & 1,714 & 4,25 \\
\hline K $\left(\mathrm{g} \mathrm{kg}^{-1}\right)$ & 0,007 & 0,057 & 0,09 \\
\hline $\operatorname{Mg}\left(\mathrm{g} \mathrm{kg}^{-1}\right)$ & 0,0080 & 0,0081 & 0,01 \\
\hline $\operatorname{Mn}\left(\mathrm{mg} \mathrm{kg}^{-1}\right)$ & 0,049 & 0,336 & 0,72 \\
\hline $\mathrm{Na}\left(\mathrm{g} \mathrm{kg}^{-1}\right)$ & 0,003 & 0,055 & 0,09 \\
\hline$P\left(\mathrm{~g} \mathrm{~kg}^{-1}\right)$ & 0,073 & 0,042 & 0,11 \\
\hline $\mathrm{Zn}\left(\mathrm{mg} \mathrm{kg}^{-1}\right)$ & 0,608 & 0,527 & 1,02 \\
\hline
\end{tabular}

Analisando os resultados da Tabela 18 é possível concluir que $\mathrm{Fe}, \mathrm{K}, \mathrm{Mg}, \mathrm{Mn}$ e $\mathrm{Na}$ atenderam a essa condição, portanto são considerados estáveis em um nível de confiança de 95\% e então o material de ração para peixe candidato a material de referência é suficientemente estável para ser armazenado à temperatura ambiente, sem alterações significativas na composição para estes elementos. Enquanto que para $\mathrm{Ca}, \mathrm{Cu}, \mathrm{P}$ e $\mathrm{Zn}$, a estabilidade deve ser continuamente avaliada durante o período de estocagem.

\subsection{Ensaio Colaborativo}

A caracterização química do material foi efetuada através de um ensaio colaborativo conduzido dentro do Ensaio de Proficiência para Laboratórios de Nutrição Animal "EPLNA", organizado anualmente pela Embrapa Pecuária Sudeste, em São Carlos. Este ensaio contou com a participação de diversos laboratórios de diferentes instituições (Tabela 19).

Após avaliação da homogeneidade e estabilidade do material, os frascos, identificados e devidamente embalados, foram encaminhados aos laboratórios convidados e que aceitaram participar do ensaio colaborativo, juntamente com um cronograma para envio dos resultados e documento orientativo referentes às análises bromatológicas e de nutrientes $\mathrm{Ca}, \mathrm{Cu}, \mathrm{Fe}, \mathrm{K}, \mathrm{Mg}$, $\mathrm{Mn}, \mathrm{Na}, \mathrm{P}$ e Zn. Cada laboratório recebeu um frasco e foram solicitados os resultados de seis replicatas para cada parâmetro.

A Tabela 20 apresenta a quantidade de laboratórios que enviaram resultados para cada parâmetro avaliado no candidato a $\mathrm{RM}$ de ração de peixe e que tiveram seus resultados 
qualificados nos testes estatísticos para a determinação dos valores de consenso. Foram recebidos resultados de diversos laboratórios, sendo que, para a determinação de macro e micronutrientes, foram utilizadas as técnicas analíticas apresentadas na Tabela 21.

Tabela 19 - Alguns dos laboratórios que participaram do ensaio colaborativo.

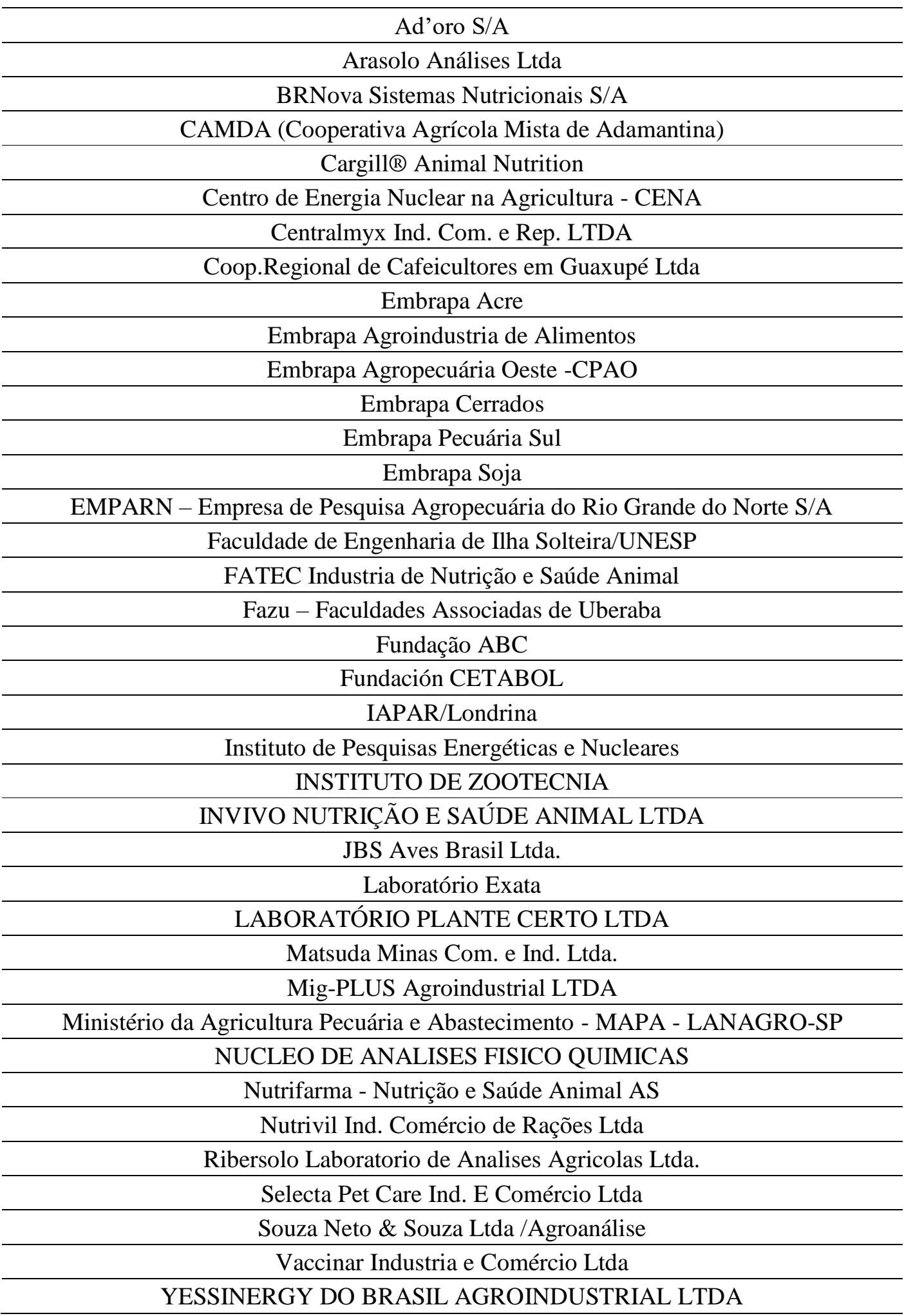


Tabela 20 - Quantidade de laboratórios por parâmetro avaliado.

\begin{tabular}{cccc}
\hline Parâmetro & $\begin{array}{c}\text { Quantidade de } \\
\text { laboratórios }\end{array}$ & Parâmetro & $\begin{array}{c}\text { Quantidade de } \\
\text { laboratórios }\end{array}$ \\
\hline MS & 49 & Ca & 35 \\
\hline Cinzas & 50 & Cu & 22 \\
\hline PB & 46 & Fe & 31 \\
\hline FDN & 26 & K & 27 \\
\hline FDA & 32 & Mg & 27 \\
\hline Lignina & 10 & Mn & 26 \\
\hline FB & 36 & $\mathbf{N a}$ & 30 \\
\hline EE & 31 & $\mathbf{P}$ & 26 \\
\hline NNP & 5 & $\mathbf{Z n}$ &
\end{tabular}

Tabela 21 - Técnicas analíticas utilizadas pelos laboratórios participantes do ensaio colaborativo para determinação de valores de propriedade de macro e micronutrientes.

\begin{tabular}{cccc}
\hline Elemento & Código da técnica & Elemento & Código da técnica \\
\hline \multirow{2}{*}{ Cálcio $(\mathrm{Ca})$} & FAAS & Manganês $(\mathrm{Mn})$ & FAAS \\
& ICP OES & & ICP OES \\
& INAA & Sódio $(\mathrm{Na})$ & FP \\
Cobre $(\mathrm{Cu})$ & FAAS & & ICP OES \\
& ICP OES & Fósforo $(\mathrm{P})$ & INAA \\
Ferro $(\mathrm{Fe})$ & FAAS & & COLOR \\
& ICP OES & ICP OES \\
& INAA & FAASco $(\mathrm{Zn})$ & ICP OES \\
Potássio $(\mathrm{K})$ & FP & & INAA \\
& ICP OES & & \\
Magnésio $(\mathrm{Mg})$ & INAA & & \\
& FAAS & & \\
\hline
\end{tabular}

\section{Técnicas:}

FAAS

FP

COLOR

ICP OES

INAA
Espectrometria de Absorção Atômica com Chama

Fotometria de Chama

Espectrofotometria de Absorção Molecular UV-VIS

Espectrometria de Emissão Óptica com Plasma Acoplado Indutivamente

Analise por Ativação Neutrônica Instrumental 
Nas Figuras 43 e 44 são apresentados todos os resultados fornecidos pelos participantes do ensaio colaborativo em forma de gráfico de controle

Figura 43 - Média e intervalo de confiança, em base seca, para os resultados de parâmetros bromatológicos, reportados pelos participantes do ensaio colaborativo para a caracterização da ração para peixe candidata a RM. Valor de referência (- $(-)$, Incerteza expandida, $k=2$ ( - ). (a) MS; (b) Cinzas; (c) PB; (d) FDN; (e) FDA; (f) Lignina; (g) FB; (h) EE; (i) NNP.

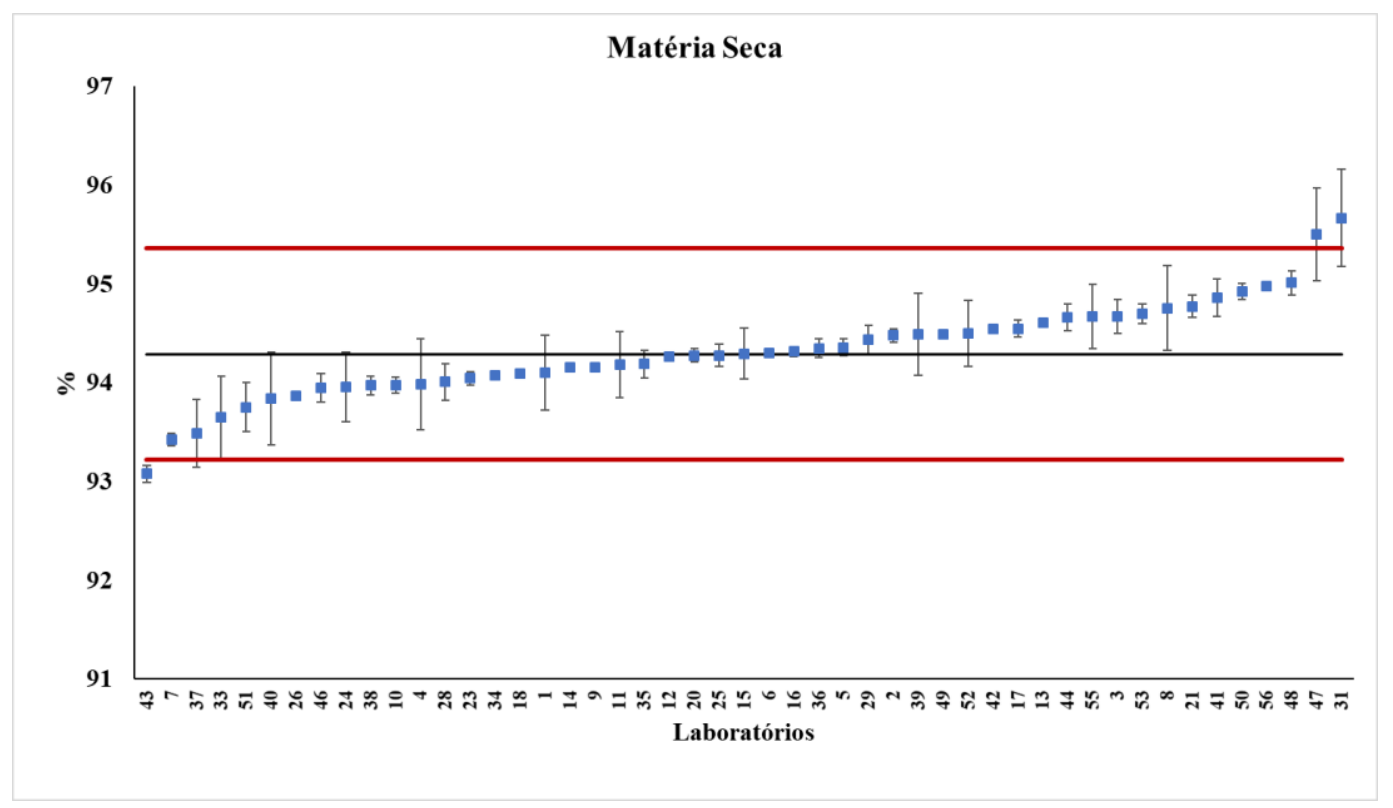

(a)

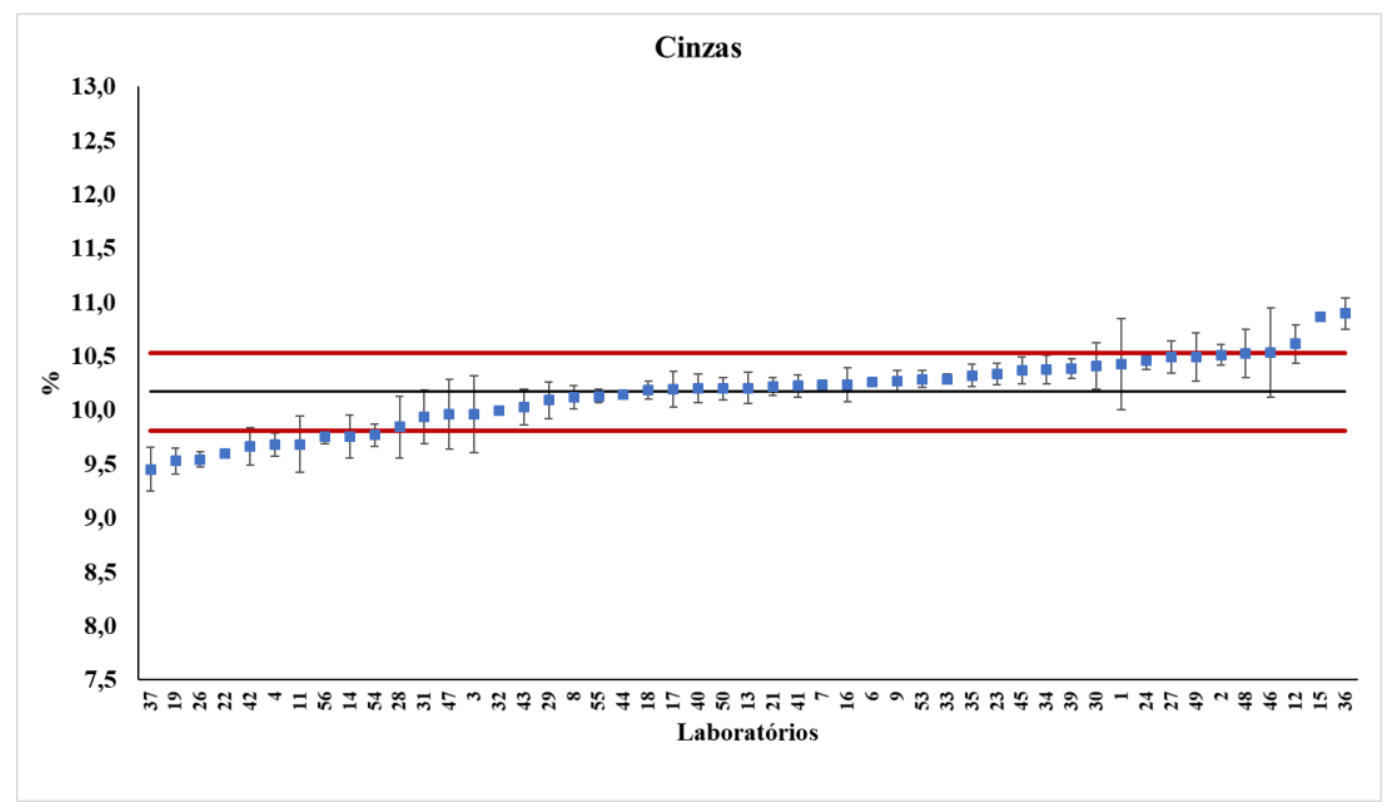

(b) 


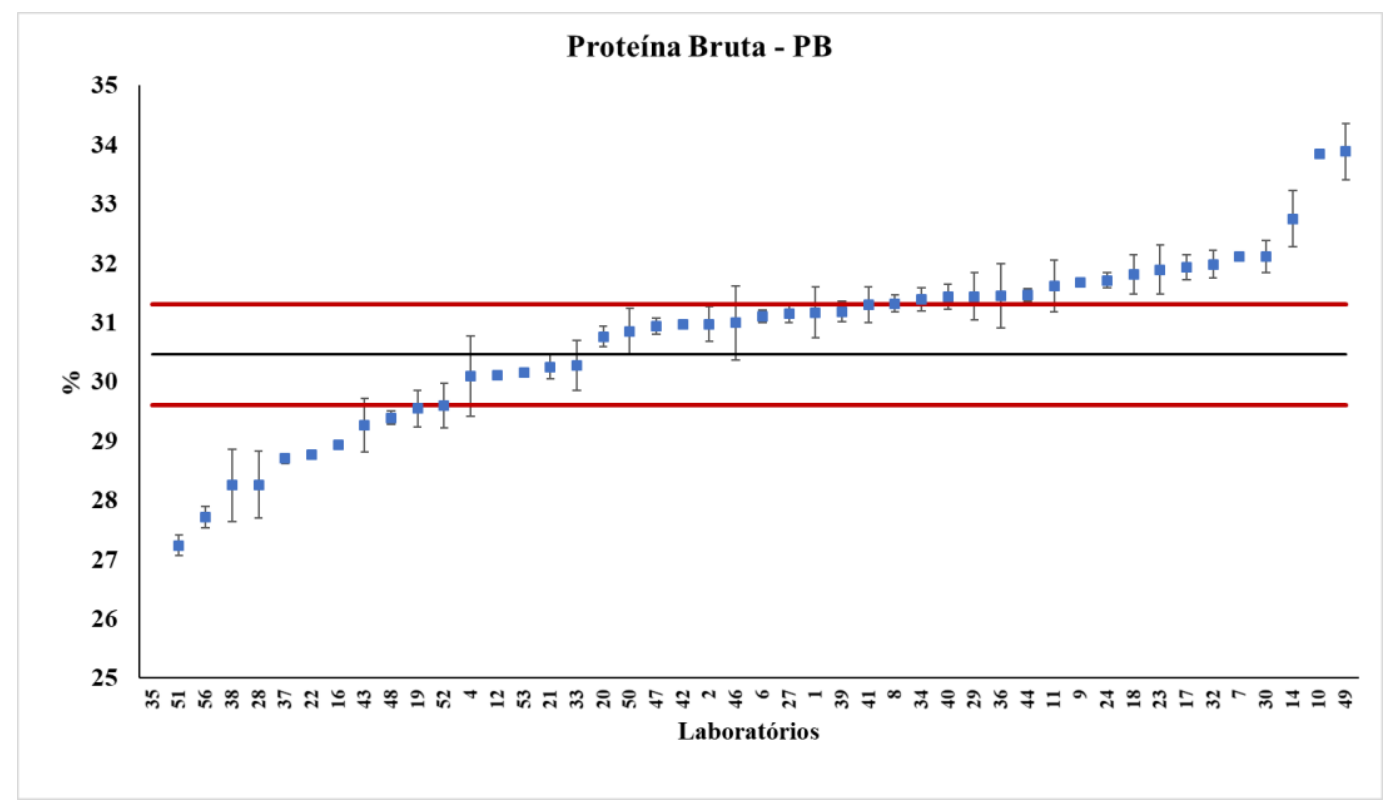

(c)

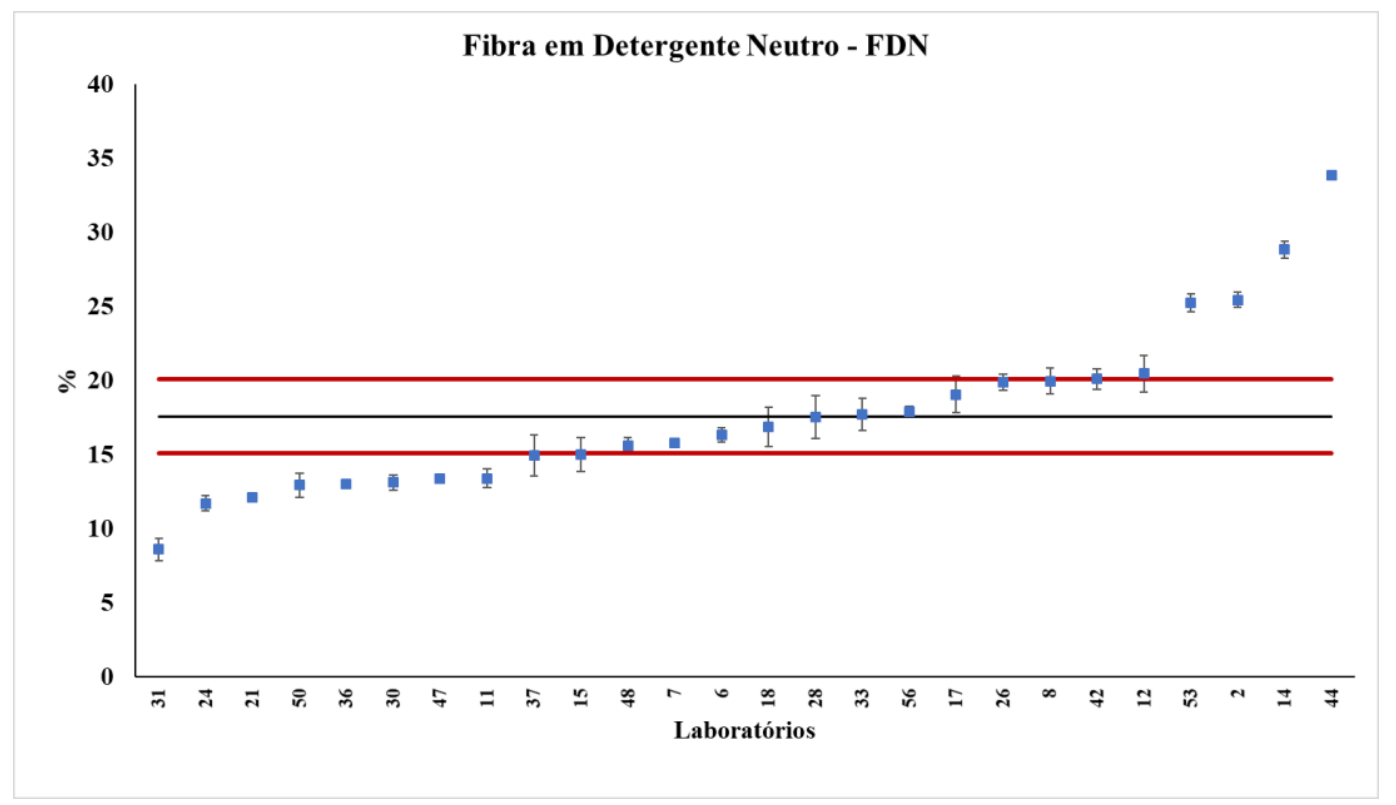

(d) 


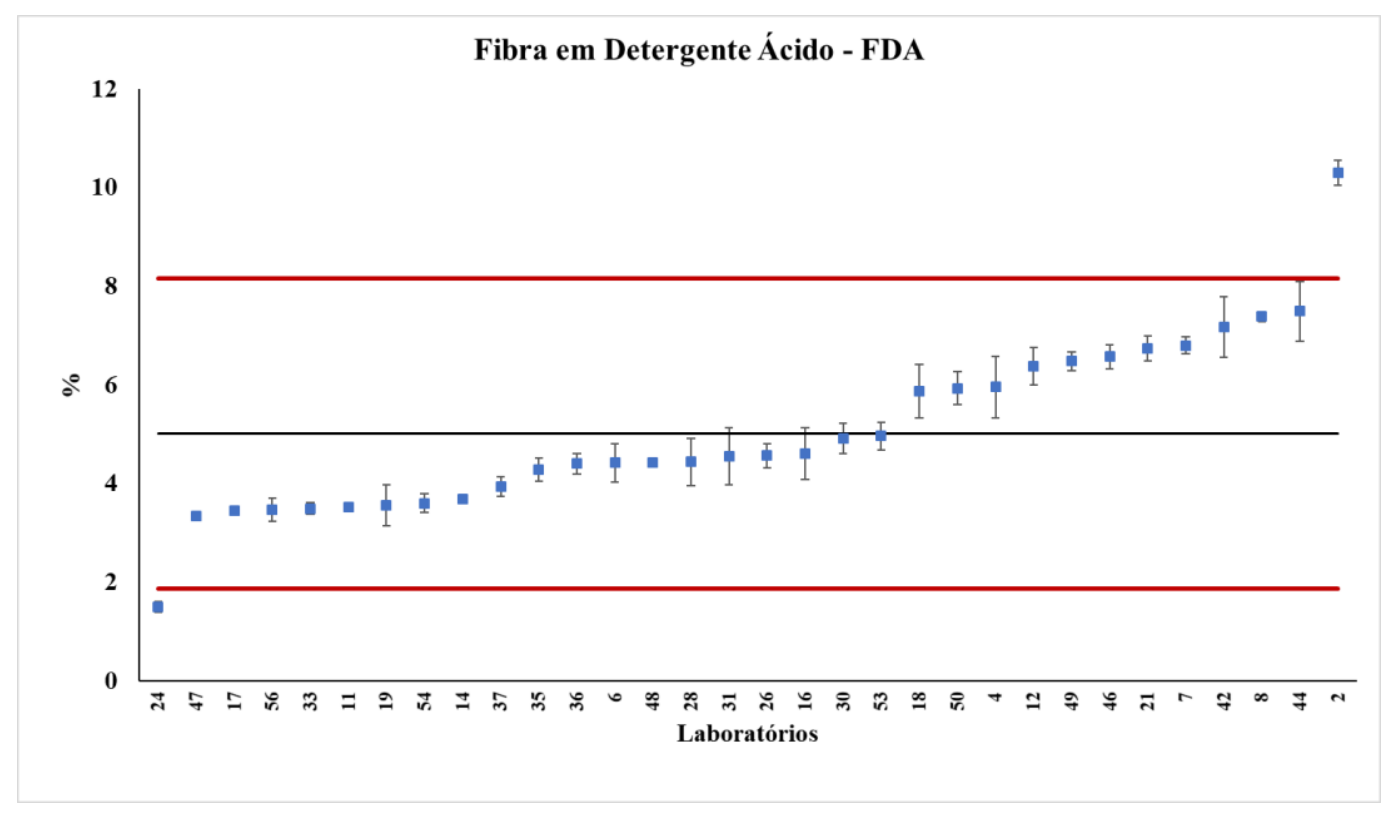

(e)

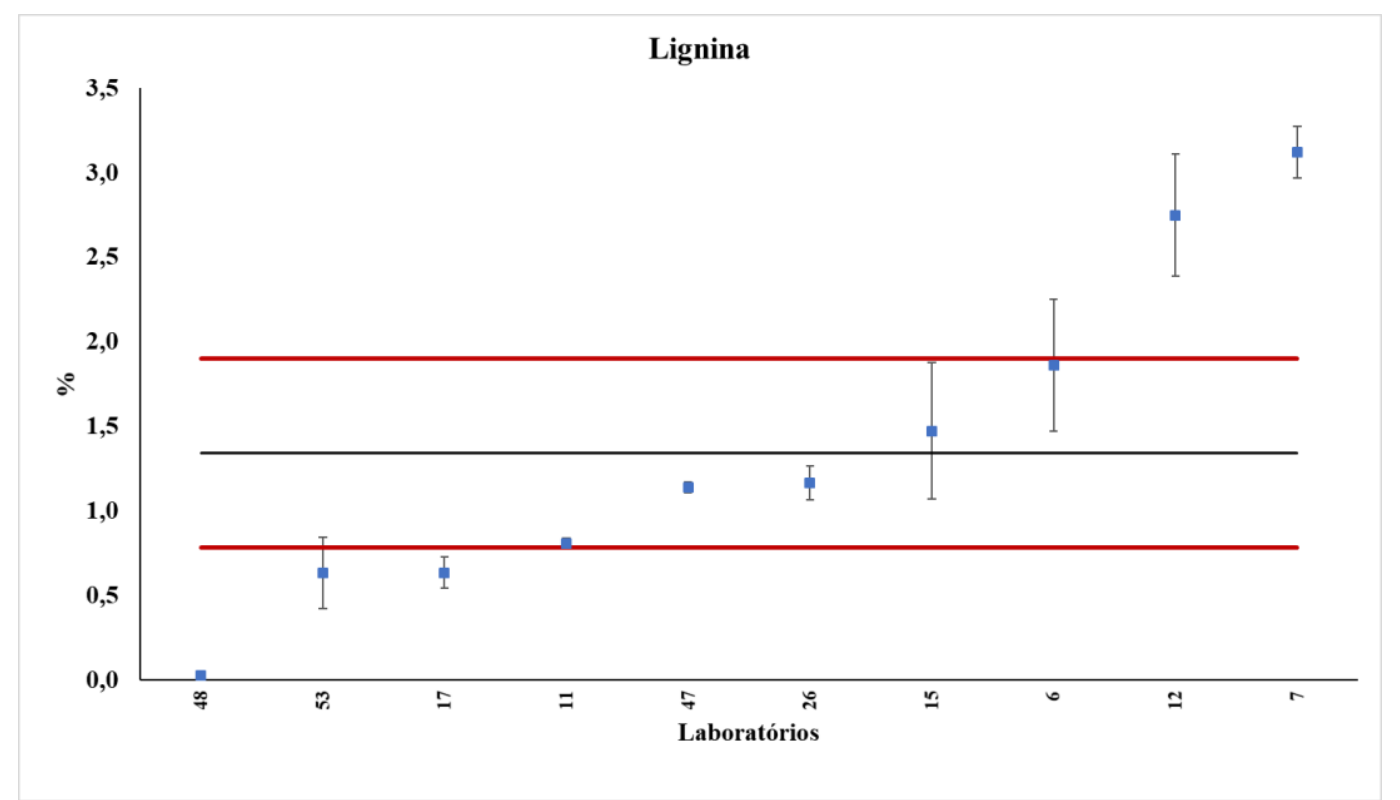

(f) 
Fibra Bruta - FB

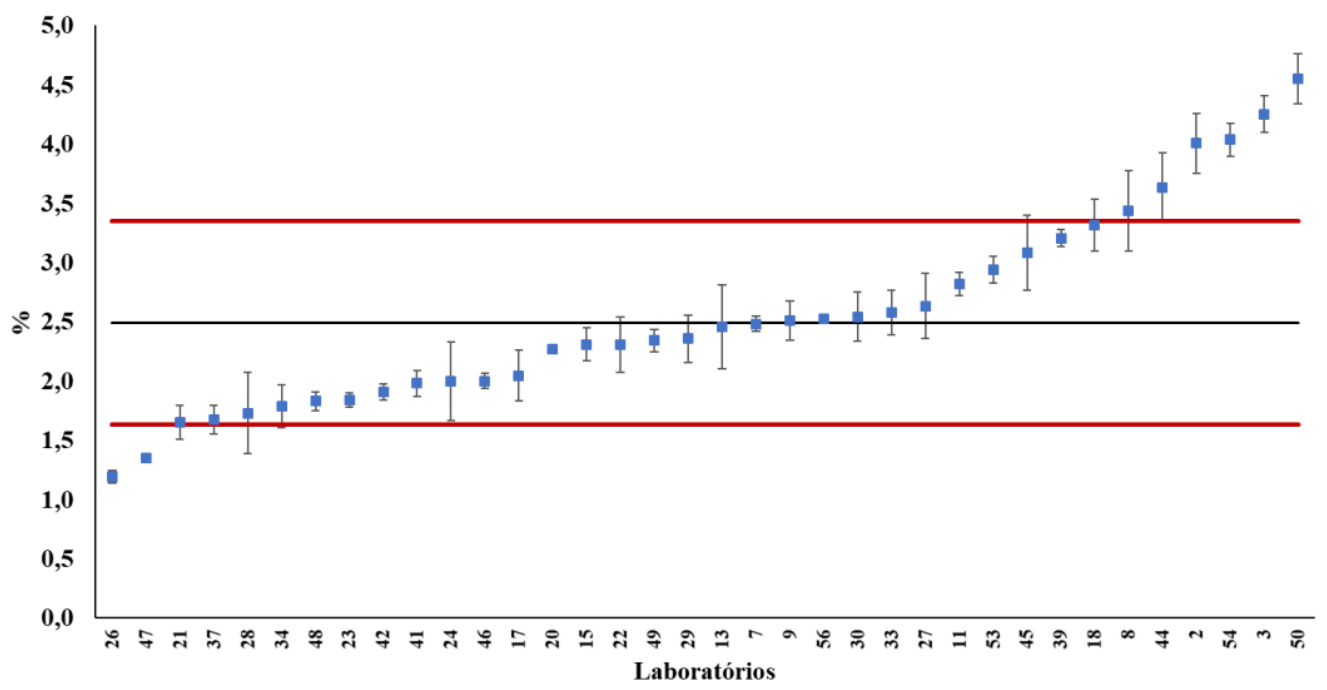

(g)

Extrato Etéreo - EE

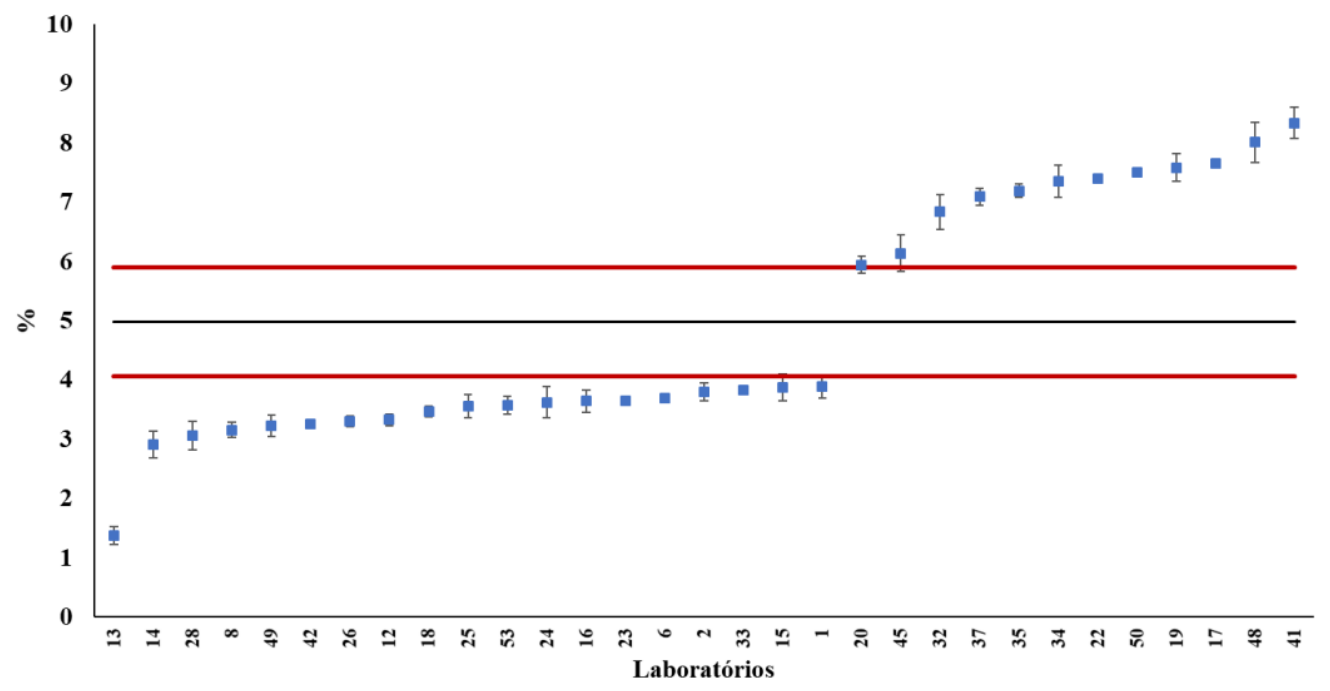

(h) 


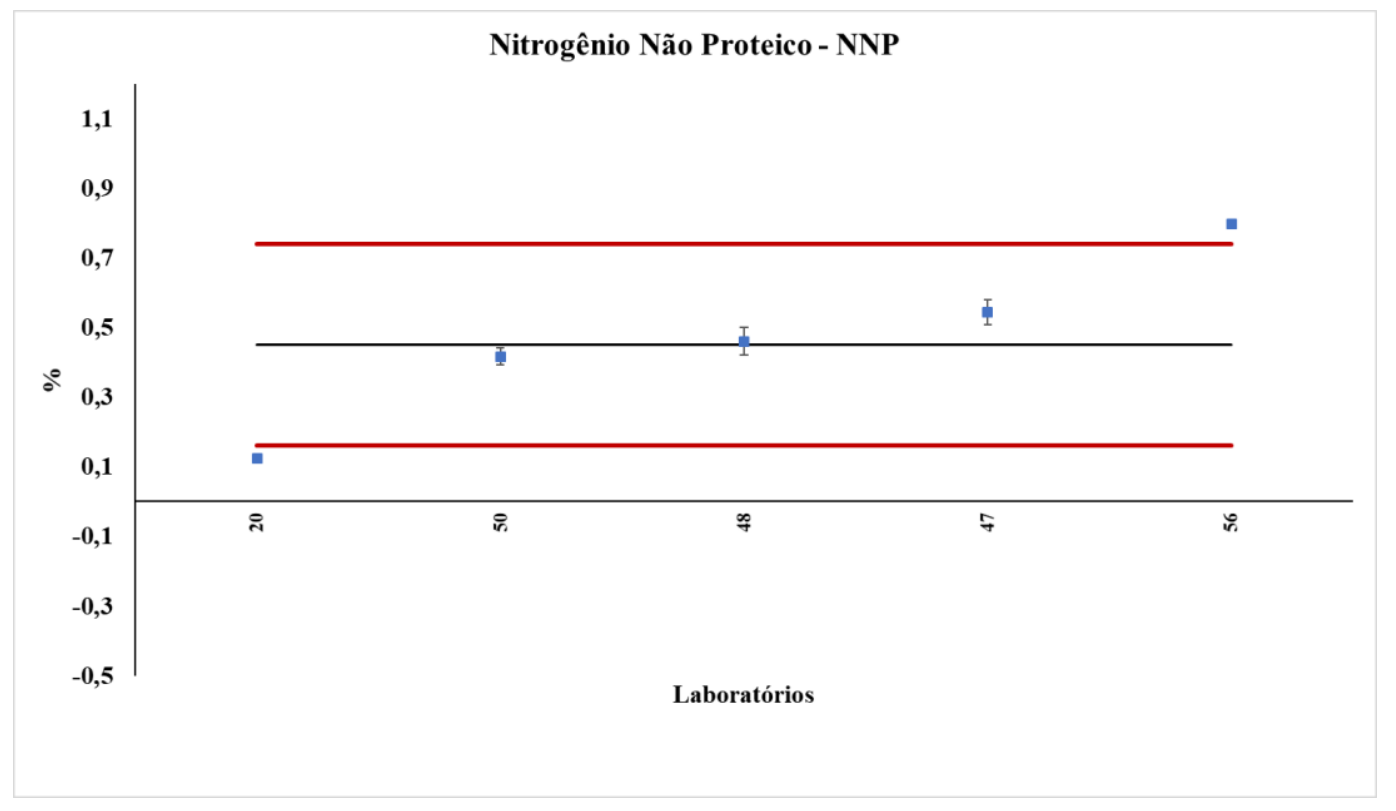

(i)

Figura 44 - Média e intervalo de confiança, em base seca, para os resultados de macro e micronutrientes, reportados pelos participantes do ensaio colaborativo para a caracterização da ração para peixe candidata a RM. Valor de referência (—), Incerteza expandida, $k=2$ (—). (a) $\mathrm{Ca}$; (b) $\mathrm{Cu}$; (c) Fe; (d) K ; (e) $\mathrm{Mg}$; (f) Mn; (g) Na; (h) P; (i) Zn.

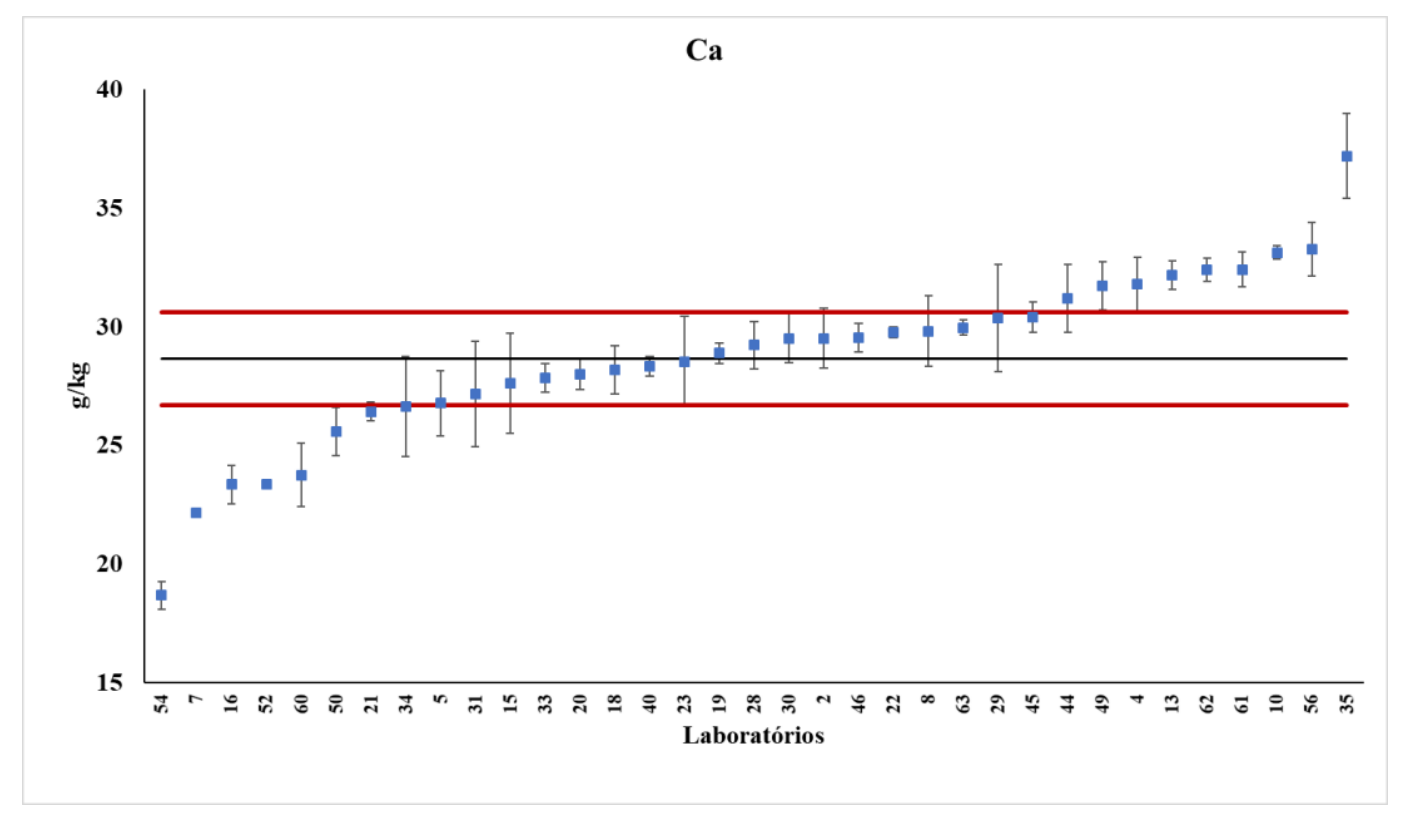

(a) 


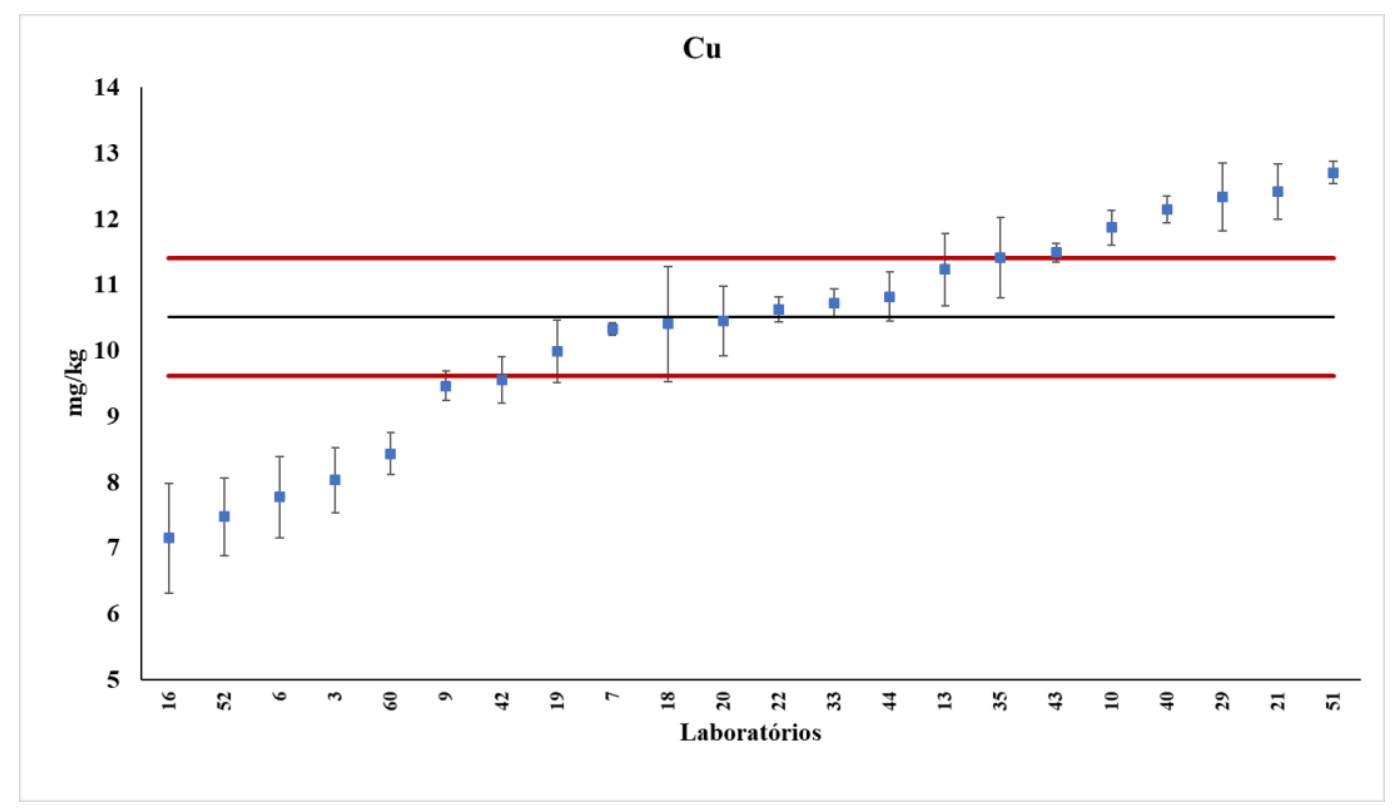

(b)

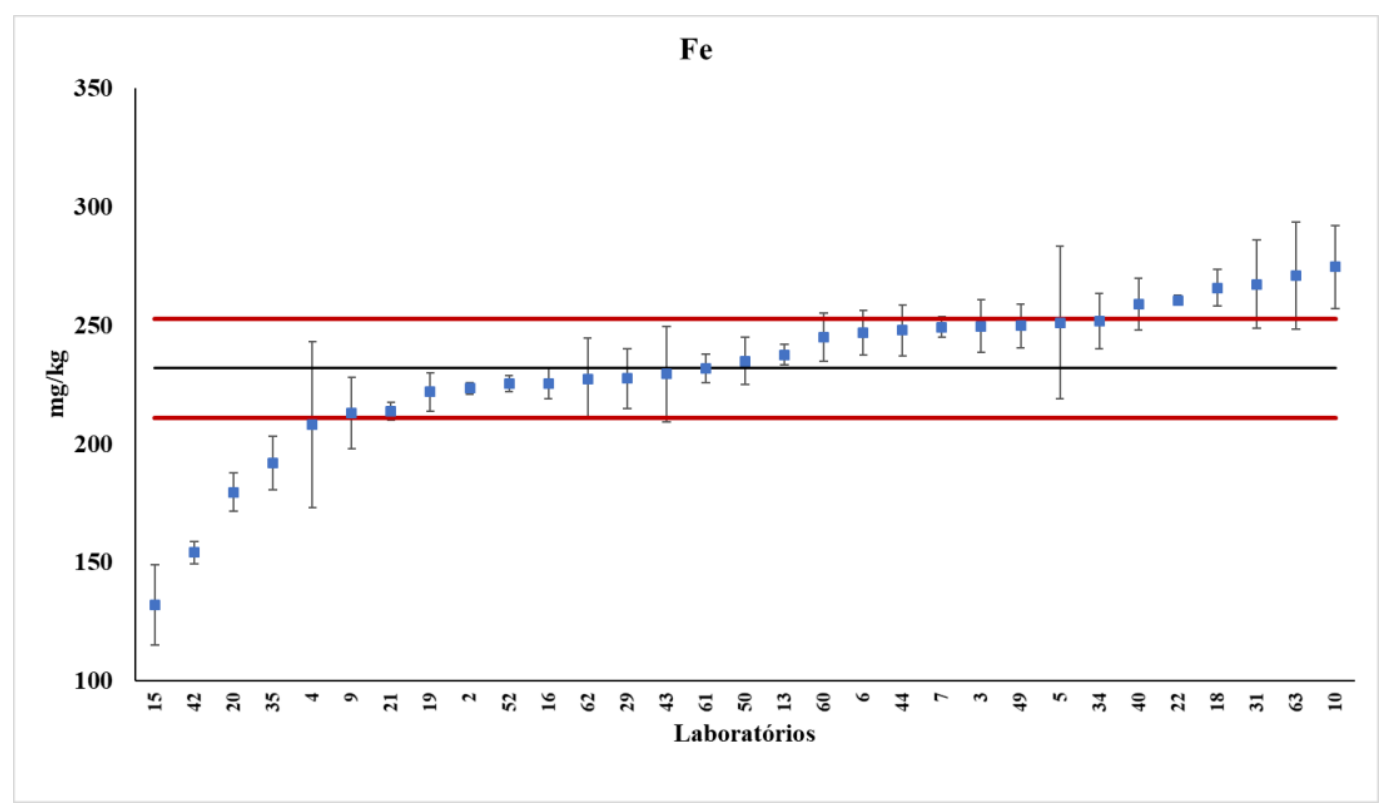

(c) 


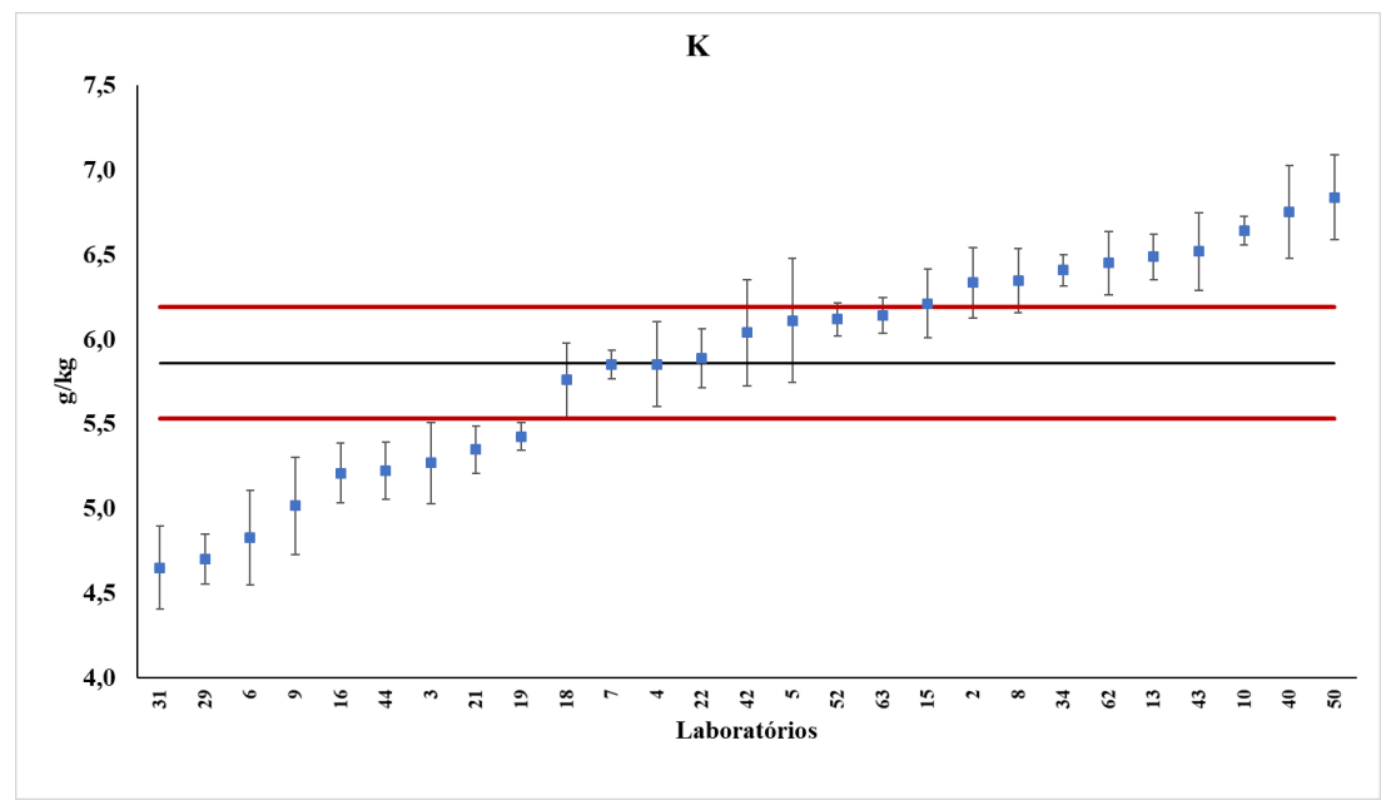

(d)

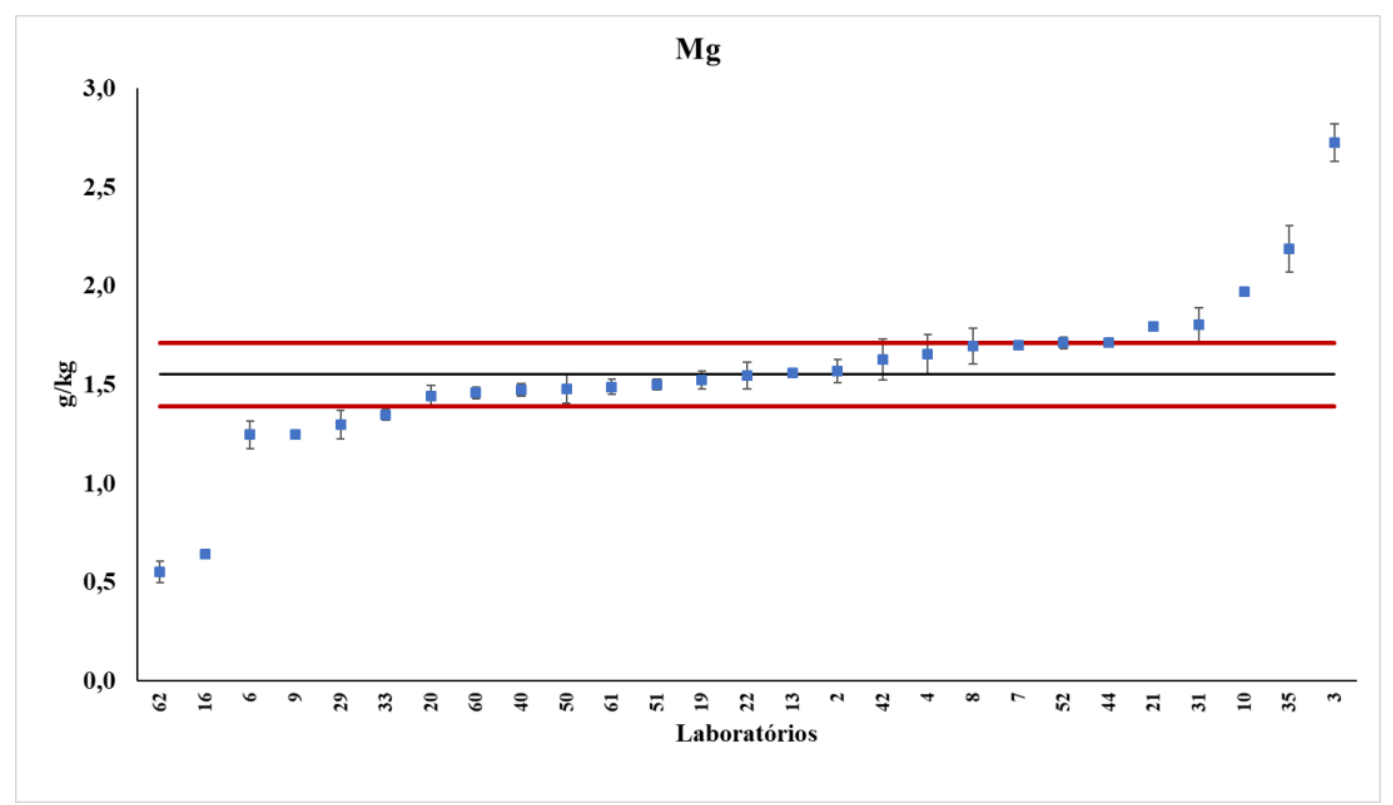

(e) 


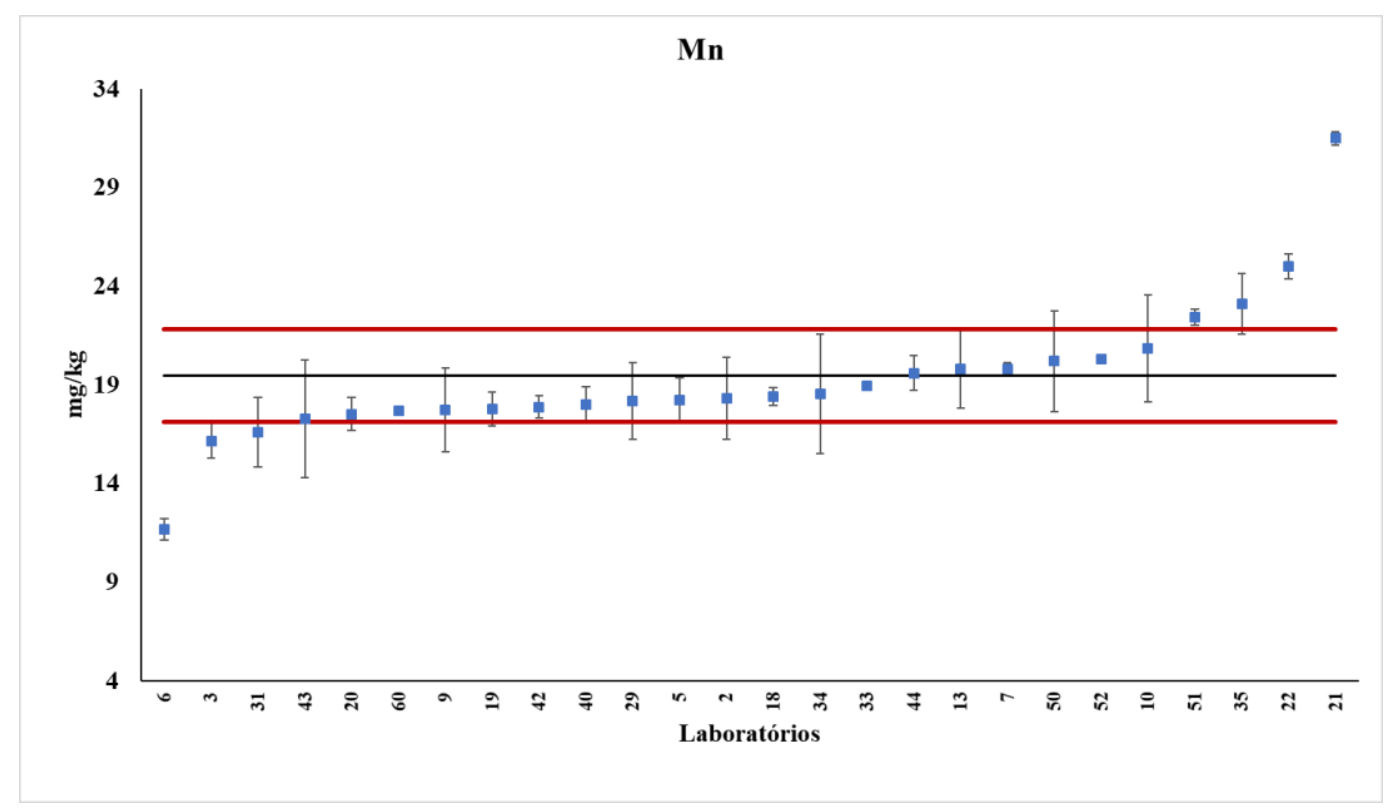

(f)

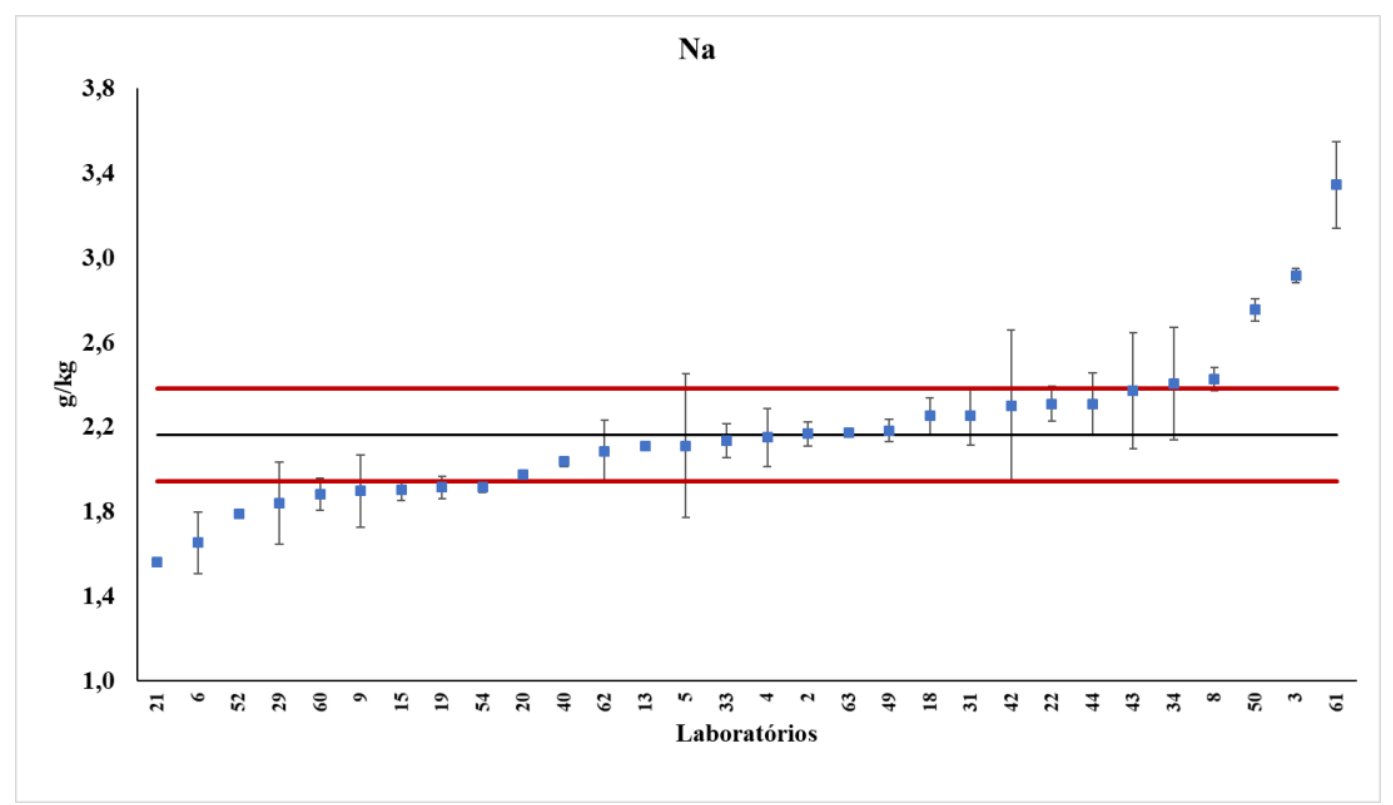

(g) 


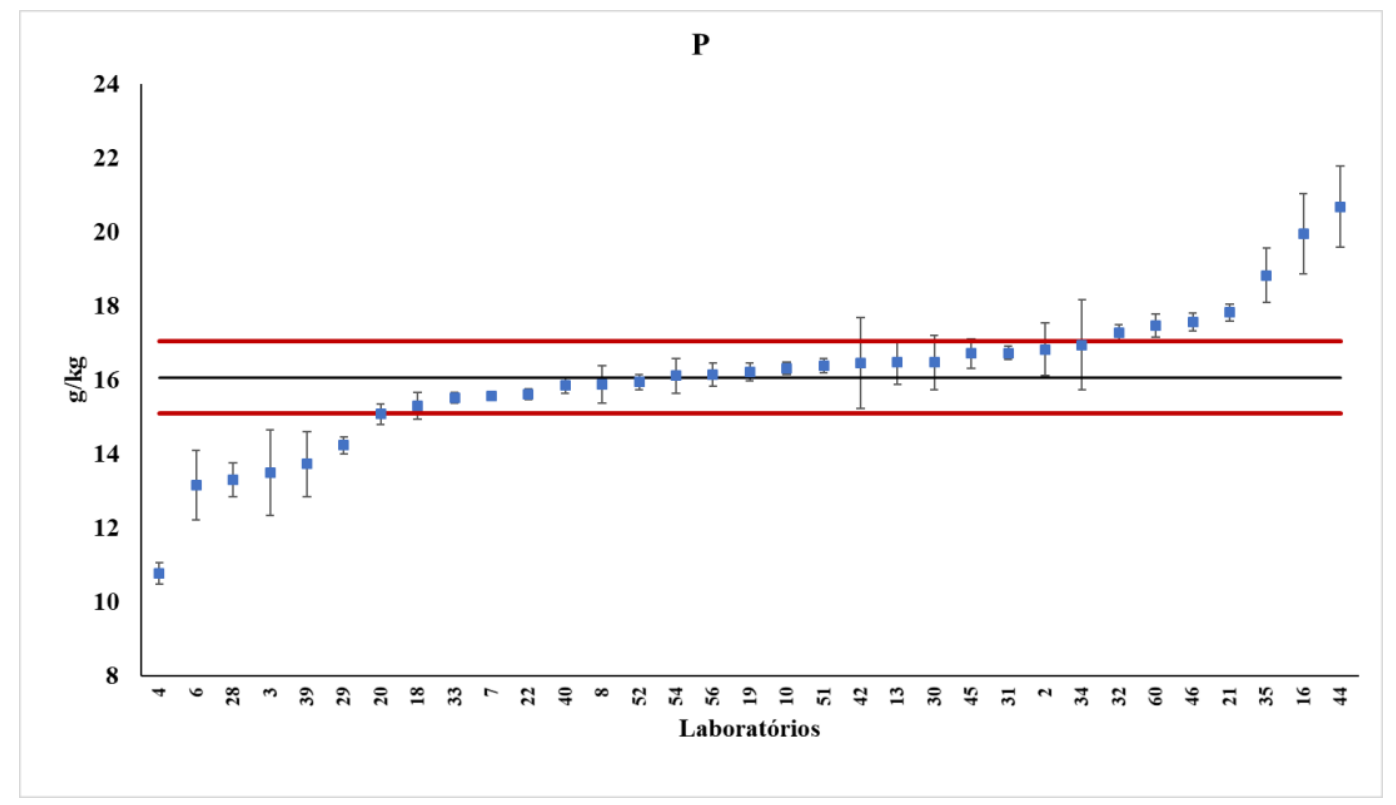

(h)

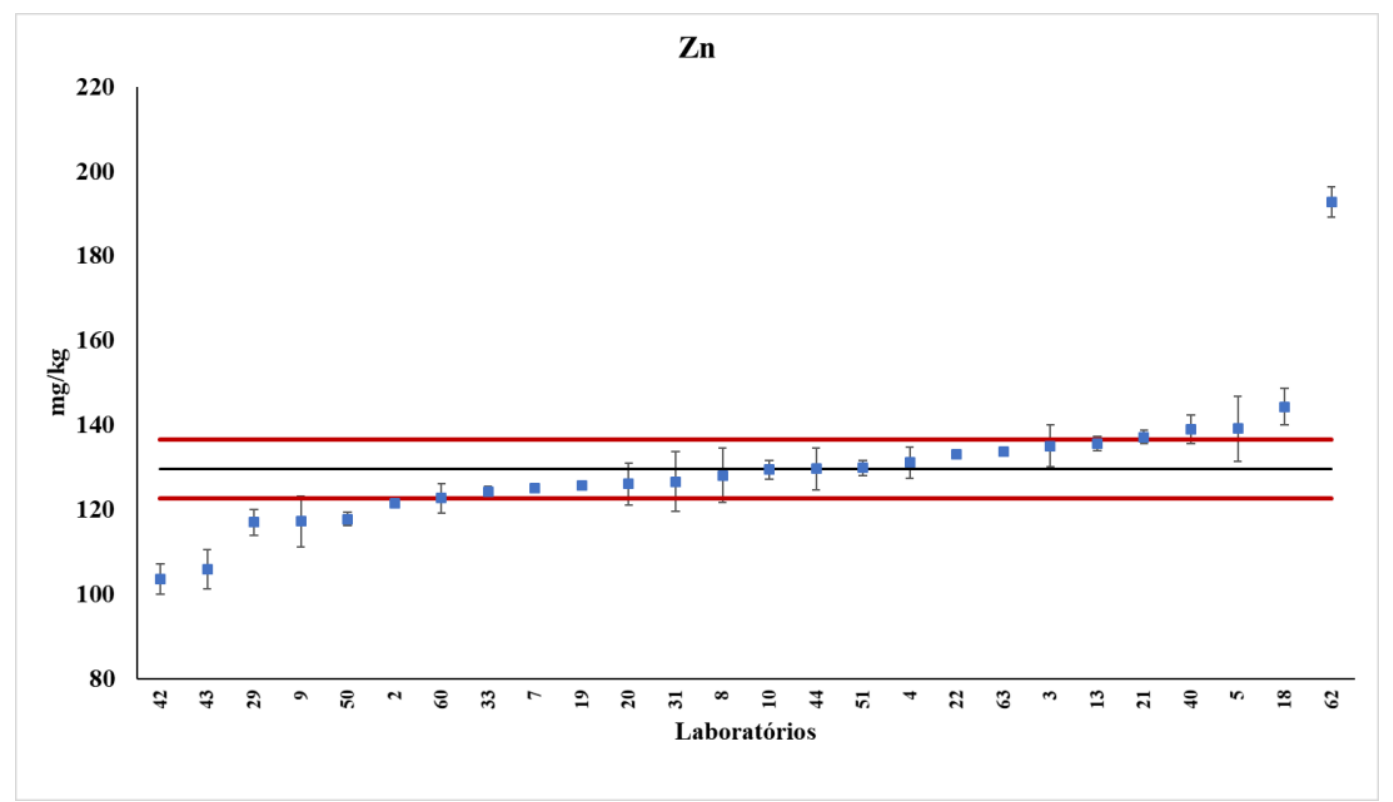

(i) 


\subsubsection{Avaliação dos resultados do ensaio colaborativo}

O consenso dos laboratórios participantes de ensaios colaborativos é o método mais usual para o estabelecimento de valores de propriedade, uma vez que se considera que os resultados disponibilizados não apresentam tendências, na maior parte dos casos, e a possibilidade de avaliação rápida da dispersão dos dados.

Para cada parâmetro, avaliado pelos laboratórios participantes, foi aplicado primeiramente o teste de Grubbs, conforme descrito no item 3.4.2, para a verificação de resultados discrepantes e exclusão de outliers. Em seguida, foi aplicado o teste Cochran para verificar a homogeneidade das variâncias, requisitos que devem ser cumpridos para a possibilidade de aplicação da análise de variância (ANOVA).

O teste de Cochran compara a maior variância com as demais. Para a aplicação do teste de Cochran, assume-se que o experimento é balanceado $n_{1}=n_{2}=\cdots=n_{k}=n$ e a variável C é calculada conforme a equação abaixo:

$$
C=\frac{s_{\max }^{2}}{\sum_{i=1}^{k} s_{i}^{2}}=\frac{\text { maior variância }}{\text { soma de todas as variâncias }}
$$

Onde:

$k$ : representa o número de níveis do fator;

$s_{i}^{2}$ : representa a variância amostral;

$n$ : representa o número de medidas em cada nível do fator.

A partir dos resultados foi possível estimar os valores de consenso e as incertezas padrão para a definição dos valores designados dos macro e micronutrientes.

No Apêndice A são apresentados os resultados apresentados por todos os laboratórios. Para a qualificação desses resultados foi calculado o índice z, comumente usado em programas interlaboratoriais para avaliar o desempenho dos participantes. Este índice representa uma medida da distância relativa do resultado da medição do laboratório em relação ao valor designado do ensaio de proficiência. O cálculo foi realizado conforme a Equação 23 abaixo:

$$
Z=\frac{\left(x_{i}-\bar{x}\right)}{\sigma_{p}}
$$


O termo $\left(x_{i}-\bar{x}\right)$ reflete o erro cometido na quantificação reportada pelo laboratório participante com relação ao valor designado, onde: $\mathrm{x}_{\mathrm{i}}$ é o resultado indicado pelo laboratório; $\bar{x}$ o valor designado ou a melhor estimativa dele e $\sigma_{p}$ é o desvio padrão alvo (SOUZA et al, 2009; SILVA, 2016).

A interpretação dos valores do índice $\mathrm{z}$ sugerem que para $|\mathrm{z}| \leq 2$, os resultados são considerados satisfatórios e quanto mais próximo o valor de $\mathrm{z}$ estiver de zero, melhor o resultado reportado pelo laboratório. Se $|z|$ estiver situado entre 2 e 3, o resultado é considerado questionável e se $|z| \geq 3$, os resultados são considerados insatisfatórios e inaceitáveis. Com a aplicação deste índice foi possível identificar problemas de reprodutibilidade para alguns parâmetros e em conjunto com o teste de Grubbs foi possível confirmar a existência e exclusão de outliers para a obtenção dos valores de consenso e o cálculo da incerteza associada à caracterização do material de ração para peixe candidato a RM.

As Figuras 45 e 46 apresentam gráficos de barras com os valores obtidos do índice z para todos os dados reportados pelos laboratórios participantes do ensaio colaborativo, ordenados conforme seu desempenho.

Figura 45 - Valores de índice z obtidos para o RM candidato de ração para peixe para os parâmetros bromatológicos: (a) MS; (b) Cinzas; (c) PB; (d) FDN; (e) FDA; (f) Lignina; (g) FB; (h) EE; (i) NNP.

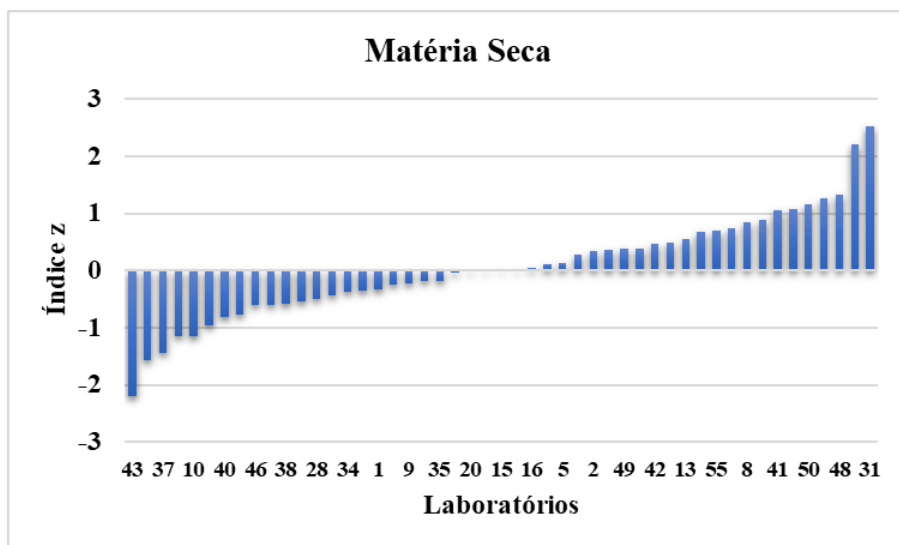

(a)

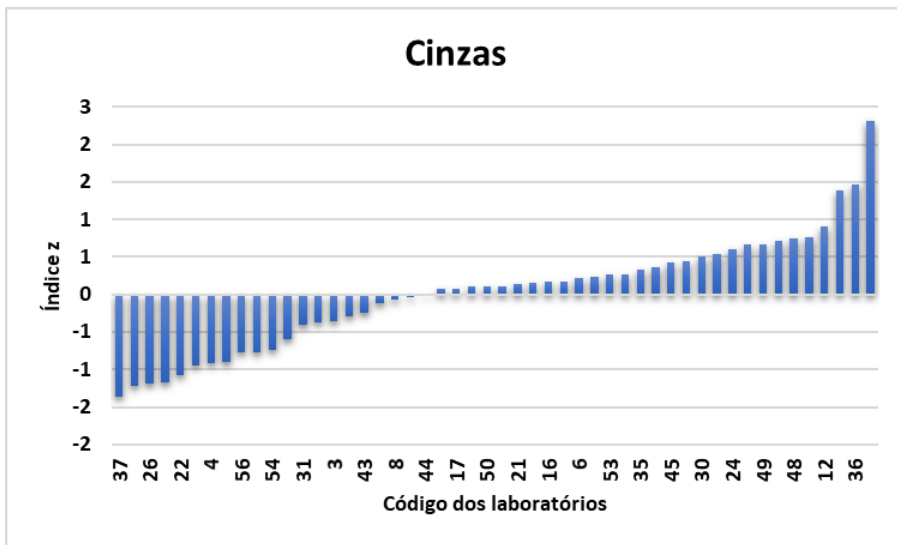

(b) 


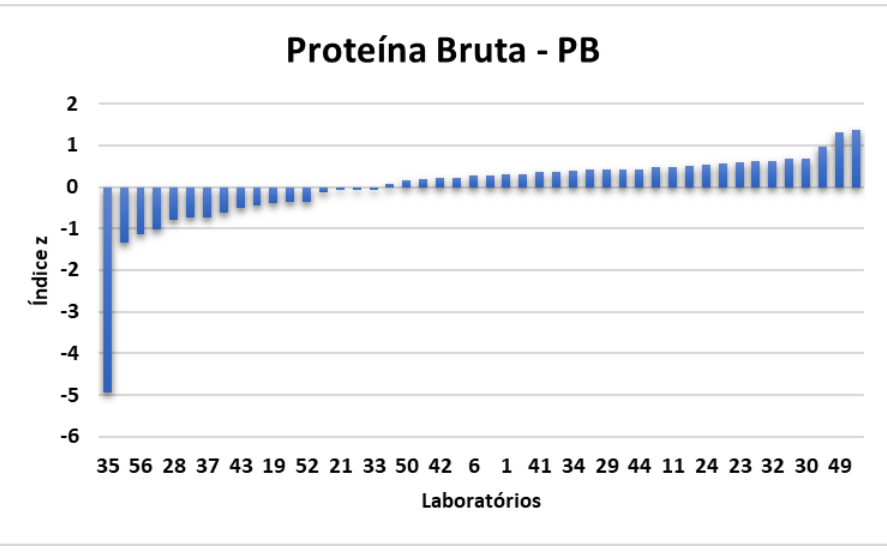

(c)

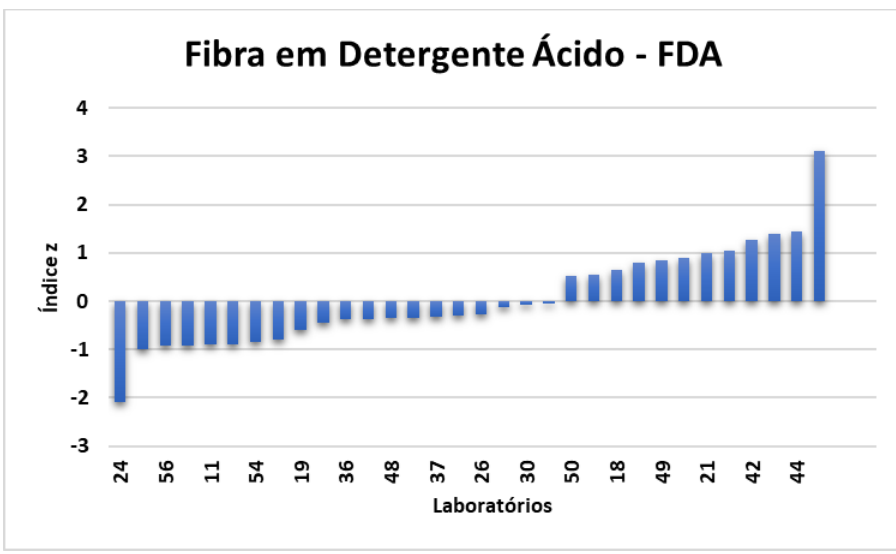

(e)

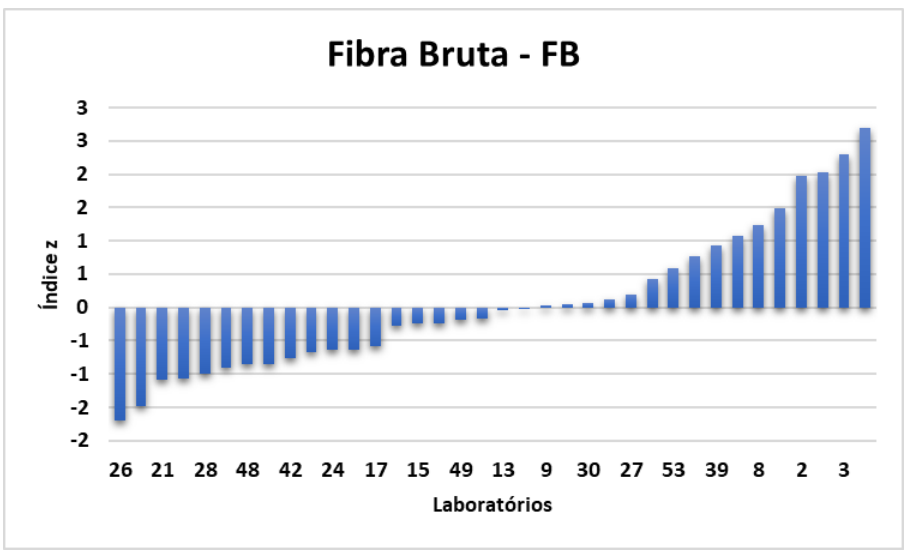

(g)

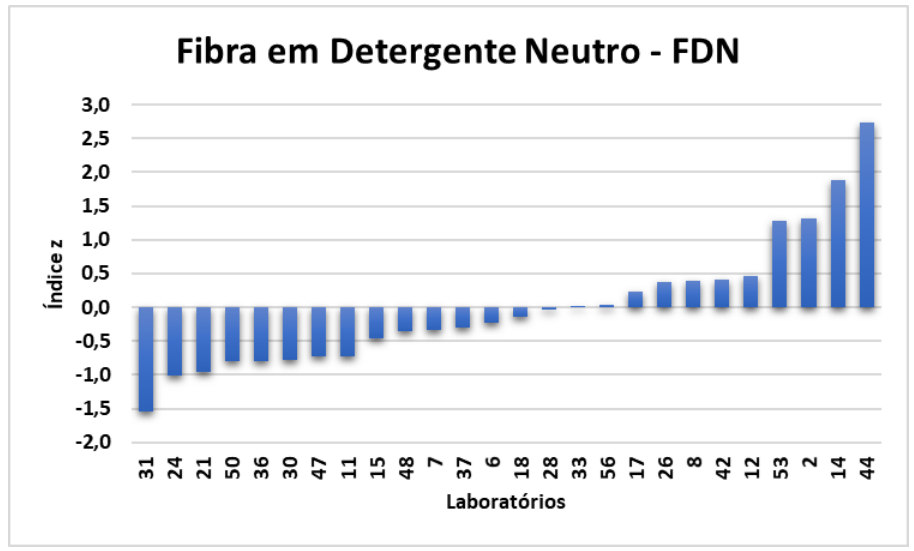

(d)

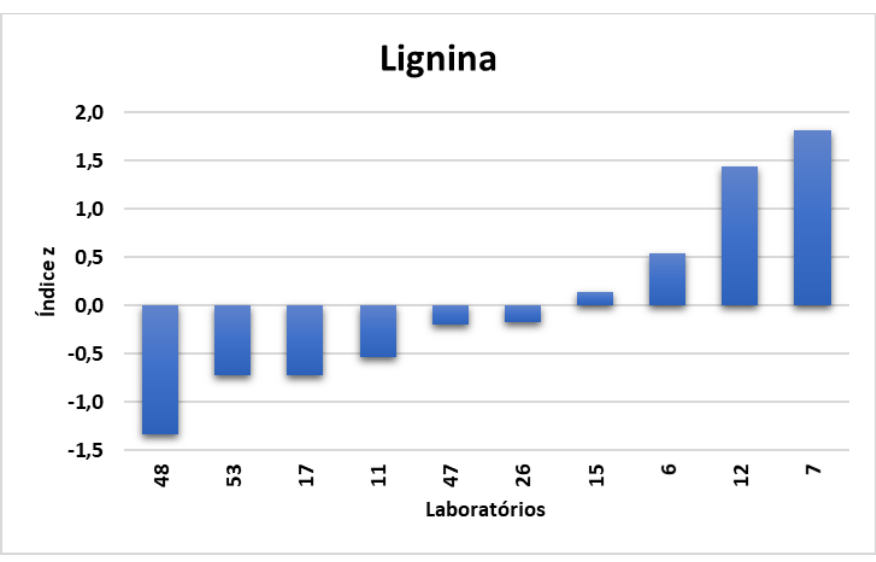

(f)

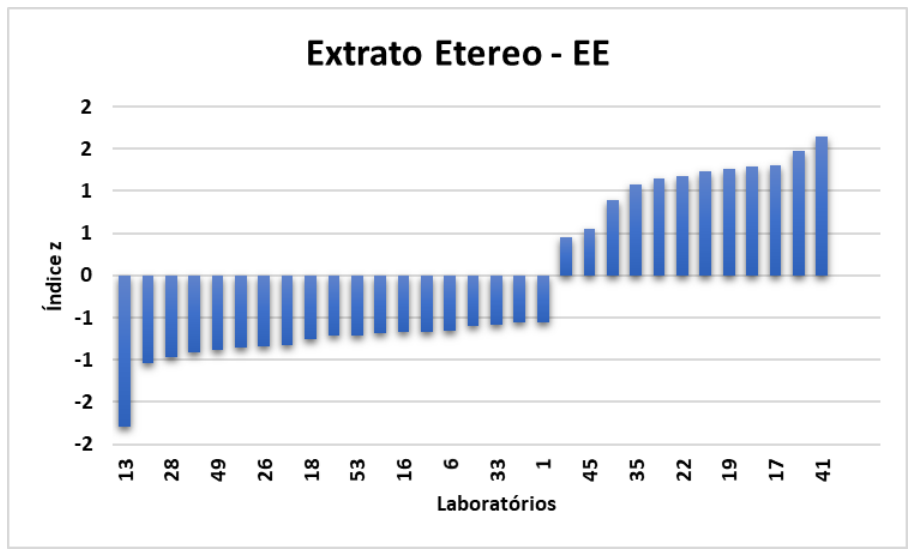

(h) 


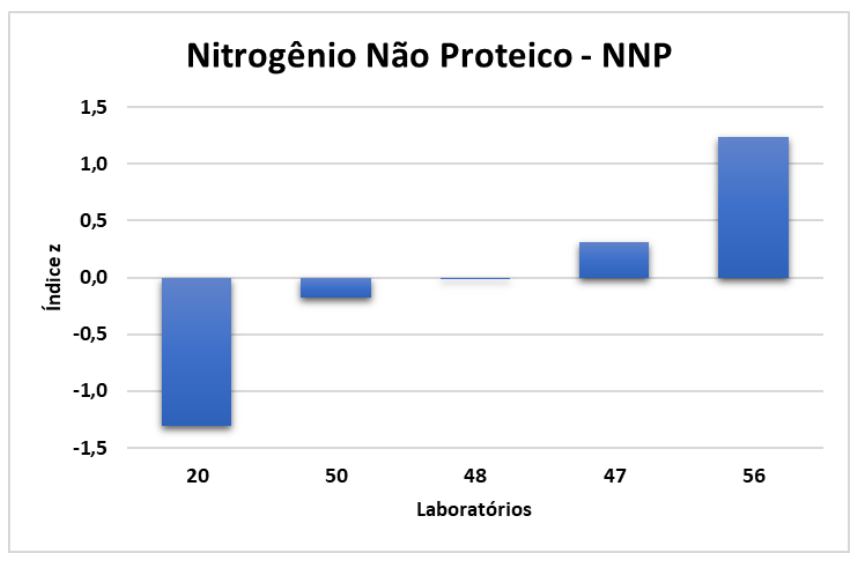

(i)

Figura 46 - Valores de índice z obtidos para o RM candidato de ração para peixe para os macro e micronutrientes: (a) $\mathrm{Ca}$; (b) $\mathrm{Cu}$; (c) Fe; (d) K ; (e) Mg; (f) Mn; (g) Na; (h) P; (i) Zn.

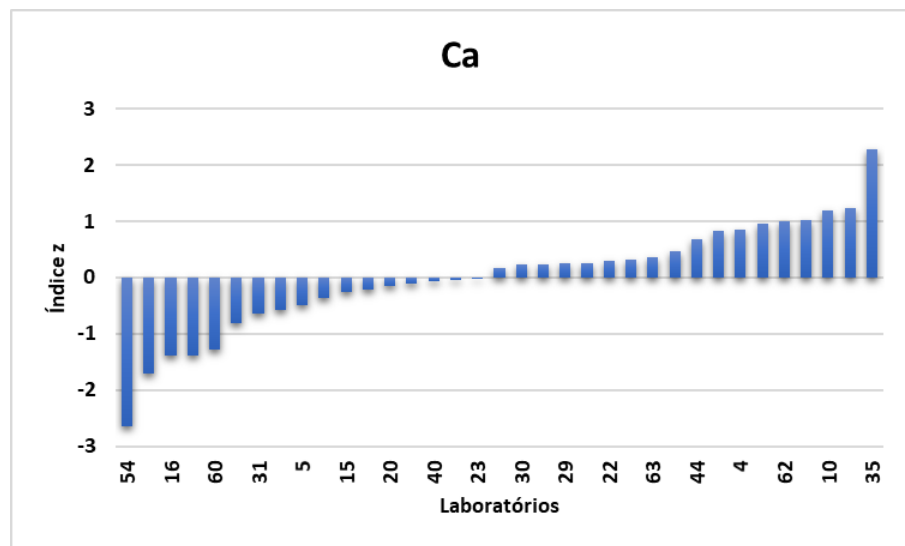

(a)

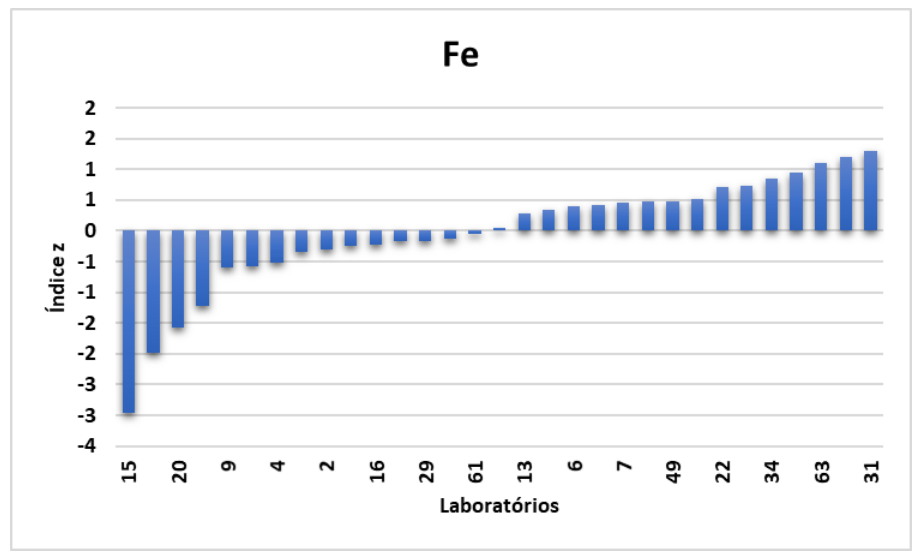

(c)

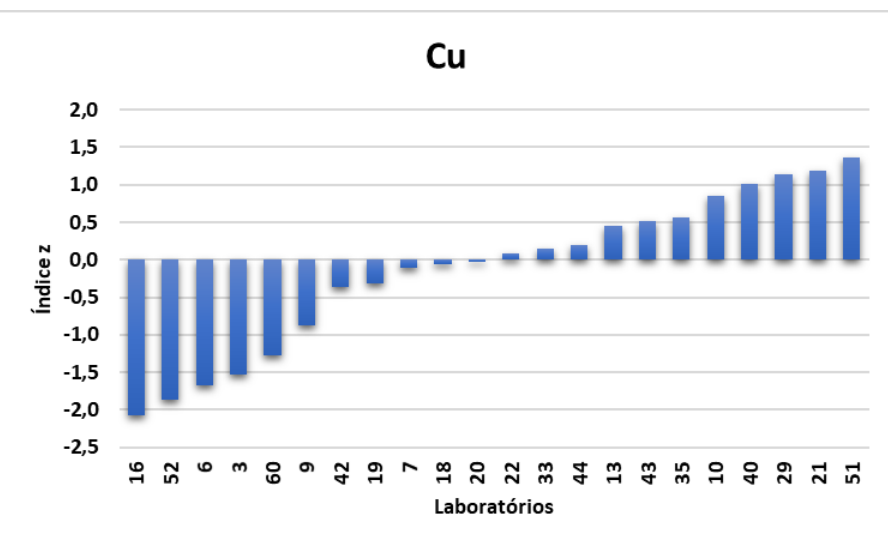

(b)

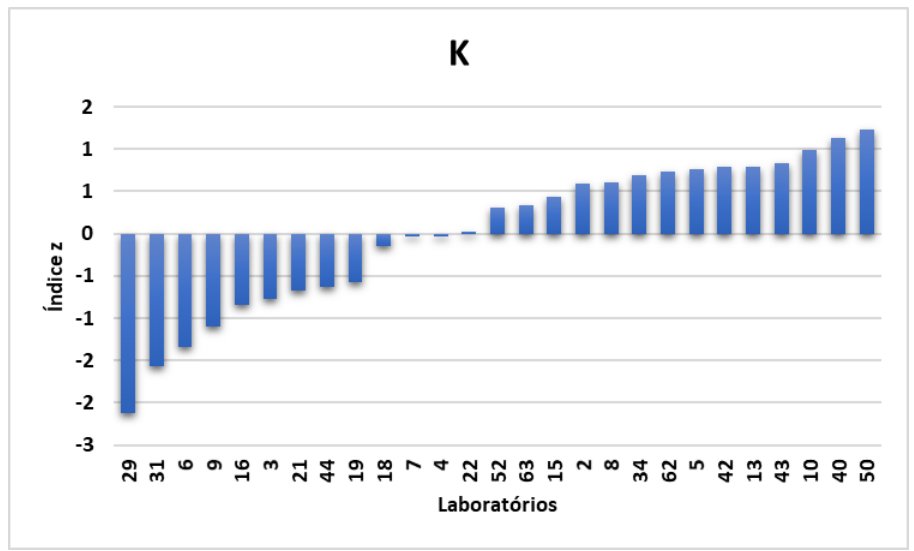

(d) 


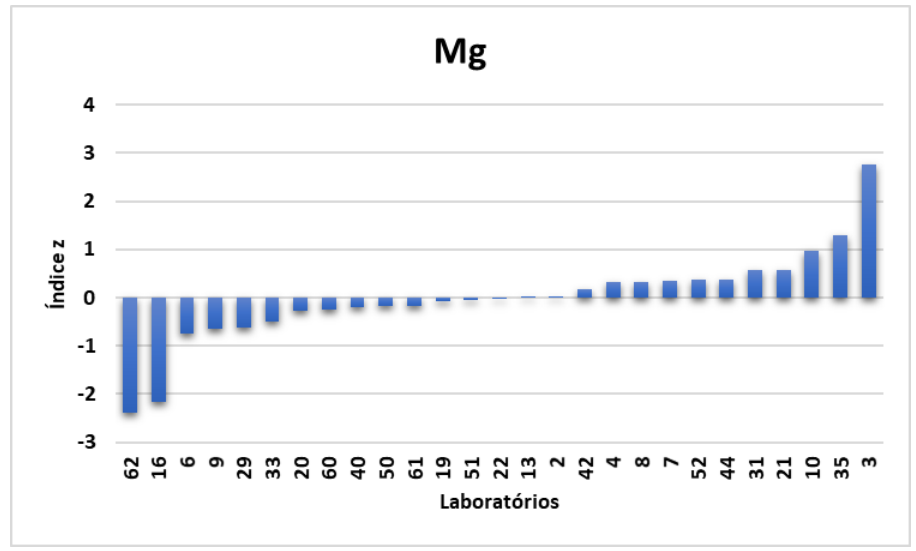

(e)

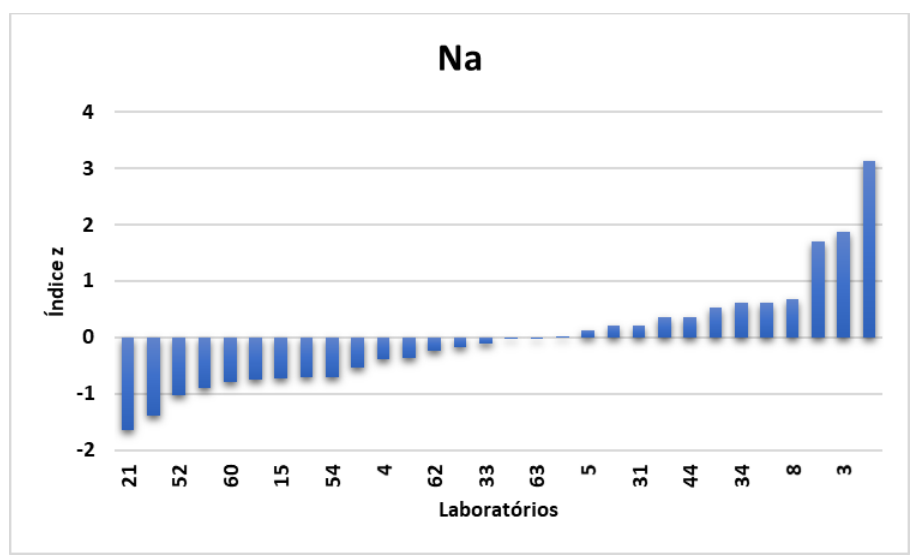

(g)

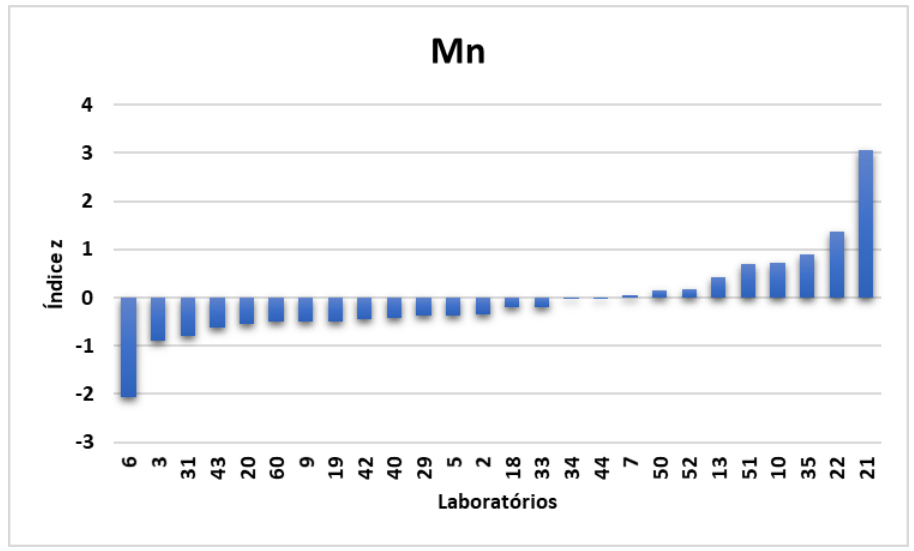

(f)

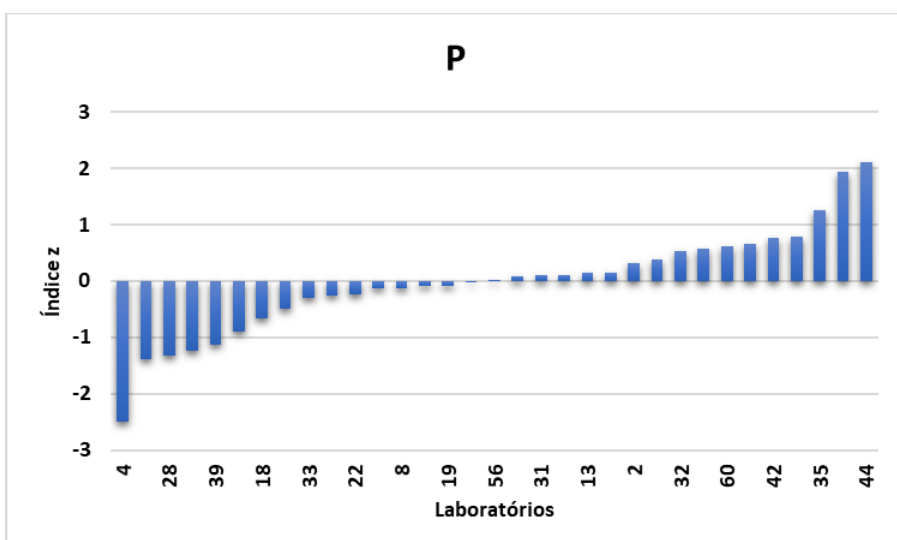

(h)

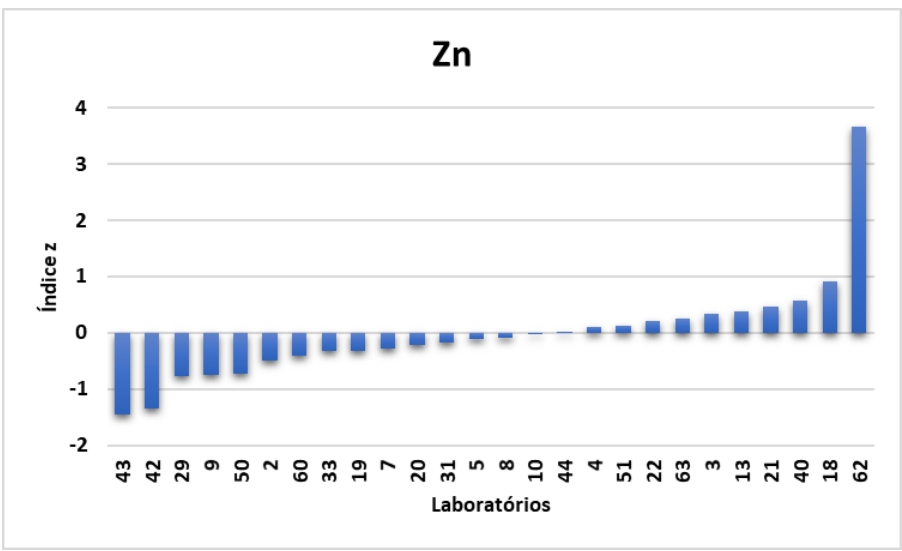

(i)

Para os cálculos dos valores de consenso do candidato a RM foram utilizados os valores que se encontram dentro do intervalo considerado satisfatório, isto é, entre $-2 \leq \mathrm{z} \leq 2$. Para a maioria dos parâmetros 1 laboratório apresentou resultados fora do intervalo considerado satisfatório, sendo que para $\mathrm{PB}$ e $\mathrm{Zn}, 1$ laboratório apresentou resultados considerados inaceitáveis e para MS, 3 laboratórios apresentaram resultados na faixa questionável. Resultados considerados questionáveis ou insatisfatórios foram excluídos do cálculo dos valores de referência. 


\subsection{Caracterização final do material e determinação de incerteza}

A incerteza expandida, $U_{\mathrm{CRM}}$, foi calculada de acordo com as recomendações estabelecidas pelo ABNT ISO GUIA 35 (2012), que considera as contribuições referentes à incerteza padrão da caracterização $\left(u_{c h a r}\right)$, da homogeneidade $\left(u_{b b}\right)$, da estabilidade a curto prazo $\left(u_{s t s}\right)$ e da estabilidade a longo prazo $\left(u_{l t s}\right)$. O fator $\mathrm{k}$ refere-se ao fator de abrangência, que neste trabalho foi considerado $\mathrm{k}=2$ (para intervalo de confiança de 95\%). Na equação 23 é apresentado o cálculo da incerteza expandida:

$$
U_{C R M}=k \sqrt{u_{c h a r}^{2}+u_{b b}^{2}+u_{s t s}^{2}+u_{l t s}^{2}}
$$

O valor designado para cada analito foi obtido através da média dos valores de consenso reportados pelos laboratórios participantes do ensaio colaborativo.

A parcela da incerteza padrão inerente à não homogeneidade $\left(\mathrm{u}_{\mathrm{bb}}\right)$ do material que compõe o lote de ração para peixe preparado foi obtida a partir dos mesmos dados gerados pela ANOVA com fator único, conforme o ABNT ISO GUIA 35. O cálculo da incerteza padrão a homogeneidade é função dos valores da média quadrática (MQ), considerando que as médias quadráticas entre grupos $\left(\mathrm{MQ}_{\mathrm{entre}}\right)$ e dentre grupos $\left(\mathrm{MQ}_{\mathrm{dentre}}\right)$ representam as variâncias extrínseca e intrínseca entre frascos.

O $\mathrm{S}_{\mathrm{bb}}$ pode ser tomado como estimativa para a incerteza padrão devida à homogeneidade entre frascos, $\mathrm{u}_{\mathrm{bb}}$, que é utilizada como componente de incerteza padrão combinada para certificação. Deste modo, quando o valor de $\mathrm{MQ}$ entre os grupos (MQ entre) for maior que dentre dos mesmos $\left(\mathrm{MQ}_{\text {dentre }}\right)$, a incerteza padrão devido à não homogeneidade $\left(\mathrm{u}_{\mathrm{bb}}\right)$ é equivalente ao desvio padrão $\left(S_{b b}\right)$, podendo ser calculada por meio da Equação 24 , com $n=$ número de replicatas efetuadas em cada frasco. Neste caso o número de réplicas é igual a 3 $(n=3)$.

$$
u_{b b}=s_{b b}=\sqrt{\frac{M Q_{\text {entre }}-M Q_{\text {dentre }}}{n}}
$$

Se o valor de $\mathrm{MQ}$ entre os grupos $\left(\mathrm{MQ}_{\mathrm{entre}}\right)$ for menor que dentre dos mesmos $\left(\mathrm{MQ}_{\mathrm{den}}\right.$ (re) a heterogeneidade pode estar mascarada pela repetitividade do método, sendo então recomendado considerar a contribuição da variância dentre grupos. Portanto, a incerteza padrão 
devido à não homogeneidade do lote preparado será representada pela Equação 25, que está sob influência da variância de repetitividade.

$$
u_{\text {homogeneidade }}=\sqrt{\frac{M Q_{\text {dentre }}}{n}} \sqrt[4]{\frac{2}{v_{M Q_{\text {dentre }}}}}
$$

Onde VMQdentre é igual ao grau de liberdade dentre grupos.

Os analitos $\mathrm{Ca}, \mathrm{Fe}, \mathrm{K}, \mathrm{Mg}, \mathrm{Mn}, \mathrm{Na}, \mathrm{P}$ e $\mathrm{Zn}$ tiveram $\mathrm{MQ}_{\text {entre }}>\mathrm{MQ}$ dentre (Tabela 13), portanto a incerteza a homogeneidade foi calculada usando a Equação 24. E para o $\mathrm{Cu} \mathrm{MQ}_{\text {entre }}<$

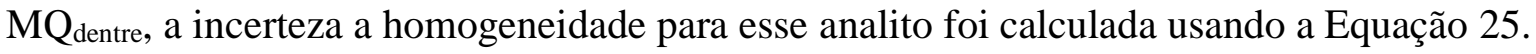

A estimativa da incerteza devida à estabilidade em curto prazo $\left(\mathrm{u}_{\mathrm{sts}}\right)$ e longo prazo $\left(\mathrm{u}_{\mathrm{lts}}\right)$ são obtidas multiplicando-se o valor do erro padrão da variável X obtido na análise de regressão linear dos dados de estabilidade para o analito testado por um tempo de t (semanas) (ABNT ISO GUIA 35, 2012). A estimativa de incertezas relacionada à estabilidade a curto prazo não é considerada no cálculo da $U_{C R M}$, pois só existe confiabilidade no uso de um RM ou CRM para qual as condições de transporte foram adequadas e não causem alteração no material durante o processo. Por meio da equação 26 calcula-se a estimativa da incerteza associada à estabilidade a curto prazo ( $\left.\mathrm{u}_{\mathrm{sts}}\right)$ e a longo prazo $\left(\mathrm{u}_{\mathrm{lts}}\right)$.

$$
u_{s t s, l t s}=S_{b 1} \times t
$$

Onde:

$S_{\mathrm{b} 1-}$ é o desvio padrão da inclinação da reta

$\mathrm{t}$ - Tempo total em semanas que o estudo foi realizado

A estimativa da incerteza associada à caracterização (uchar) foi calculada a partir dos parâmetros obtidos da ANOVA, conforme as Equações 27 a 29.

$$
u=u_{\text {char }}=\sqrt{\frac{S_{L}^{2}}{p}+\frac{S_{r}^{2}}{n \times p}}
$$

$$
S_{r}^{2}=M Q_{\text {entre }}
$$




$$
S_{L}^{2}=\frac{M Q_{\text {entre }}+M Q_{\text {dentre }}}{n_{0}}
$$

Onde:

$M Q_{\text {entre }}$ e $M Q_{\text {dentre }}$ - média quadrática entre e dentre dos grupos, dados obtidos pela ANOVA.

$n_{0}$ e $n$ - significa número de determinações, sendo que neste trabalho foram 6 repetições p - número de laboratórios que forneceram resultados considerados satisfatórios.

\subsection{Atribuição dos valores de propriedades e incertezas obtidas}

A incerteza implica em uma maior confiança na validade do resultado de medição, sendo que o valor designado apresentado com sua incerteza possibilita o emprego do material de referência na avaliação da precisão e/ou da exatidão de um método analítico.

$\mathrm{Na}$ Tabela 22 estão indicados os valores das incertezas padrão associadas a caracterização $\left(\mathrm{u}_{\mathrm{char}}\right)$, homogeneidade $\left(\mathrm{u}_{\mathrm{bb}}\right)$, estabilidade a longo prazo $\left(\mathrm{u}_{\mathrm{sts}}\right)$, estabilidade a longo prazo $\left(\mathrm{u}_{\mathrm{lts}}\right)$ e a incerteza expandida final do material de referência de ração para peixe $\left(U_{R M}\right)$.

As quatro componentes da caracterização apresentam igual importância e enfatizar menos uma delas pode comprometer a qualidade do material. Durante a avaliação da incerteza de um RM, as incertezas de estabilidade e homogeneidade devem ser incluídas e as contribuições de suas componentes são frequentemente mais importantes que a incerteza de caracterização do lote de amostras. Entretanto, cabe ressaltar que a incerteza de caracterização está também mais sujeita a erros pela variação dos laboratórios participantes do ensaio colaborativo. Na Figura 47 são apresentadas as contribuições de cada uma das componentes da incerteza calculadas na incerteza padrão combinada $u_{R M}$.

Uma vez que não foi possível realizar o estudo de estabilidade de longo prazo para os parâmetros bromatológicos, para o cálculo da incerteza padrão combinada e incerteza expandida foi considerado o maior valor obtido para a componente no estudo dos macronutrientes, no caso o valor obtido para $\mathrm{Ca}\left(u_{l t s}=0,51 \mathrm{~g} \mathrm{~kg}^{-1}\right)$. 
Tabela 22 - Estimativas das incertezas padrão da caracterização $\left(\mathrm{u}_{c h a r}\right)$, homogeneidade $\left(\mathrm{u}_{\mathrm{bb}}\right)$, estabilidade de curto prazo $\left(\mathrm{u}_{\mathrm{sts}}\right)$, estabilidade a longo prazo $\left(\mathrm{u}_{\mathrm{tss}}\right)$ e a incerteza expandida $\left(\mathrm{U}_{\mathrm{RM}}\right)$ para cada parâmetro no material de referência de ração para peixe.

\begin{tabular}{|c|c|c|c|c|c|c|c|}
\hline & $\mathbf{X}_{\text {caract }}$ & $\mathbf{u}_{\text {char }}$ & $\mathbf{u}_{\mathbf{b b}}$ & $\mathbf{u}_{\text {est.curto }}$ & $\mathbf{u}_{\text {lts }}$ & $\mathbf{u}_{\mathrm{RM}}$ & $\mathbf{U}_{\mathbf{R M}}$ \\
\hline & \multicolumn{7}{|c|}{ g $100 \mathrm{~g}^{-1}(\mathrm{~m} / \mathrm{m})$} \\
\hline MS & 94,29 & 0,06 & 0,51 & 0,14 & 0,05 & 0,54 & 1,07 \\
\hline PB & 30,46 & 0,33 & 0,25 & 0,07 & 0,05 & 0,43 & 0,85 \\
\hline FDA & 5,01 & 0,27 & 0,74 & 1,37 & 0,05 & 1,58 & 3,16 \\
\hline FDN & 17,61 & 1,03 & 0,25 & 0,66 & 0,05 & 1,25 & 2,51 \\
\hline FB & 2,49 & 0,12 & 0,34 & 0,24 & 0,05 & 0,43 & 0,87 \\
\hline Cinzas & 10,17 & 0,05 & 0,13 & 0,11 & 0,05 & 0,18 & 0,37 \\
\hline $\mathbf{E E}$ & 4,97 & 0,33 & 0,19 & 0,27 & 0,05 & 0,46 & 0,93 \\
\hline Lignina & 1,34 & 0,27 & 0,04 & 0,06 & 0,05 & 0,28 & 0,56 \\
\hline \multirow[t]{3}{*}{ NNP } & 0,45 & 0,10 & 0,09 & 0,04 & 0,05 & 0,15 & 0,30 \\
\hline & $\mathbf{X}_{\text {caract }}$ & $\mathbf{u}_{\text {char }}$ & $\mathbf{u}_{\mathbf{b b}}$ & $\mathbf{U}_{\text {est.curto }}$ & $\mathbf{u}_{\mathrm{lts}}$ & $\mathbf{u}_{\mathrm{RM}}$ & $\mathbf{U}_{\mathbf{R M}}$ \\
\hline & \multicolumn{7}{|c|}{$\mathrm{g} \mathrm{kg}^{-1}(\mathrm{~m} / \mathrm{m})$} \\
\hline $\mathbf{C a}$ & 28,65 & 0,57 & 0,44 & 0,43 & 0,51 & 0,98 & 1,96 \\
\hline $\mathbf{K}$ & 5,86 & 0,12 & 0,07 & 0,04 & 0,09 & 0,17 & 0,33 \\
\hline Mg & 1,55 & 0,08 & 0,01 & 0,01 & 0,01 & 0,08 & 0,16 \\
\hline $\mathbf{N a}$ & 2,16 & 0,06 & 0,03 & 0,03 & 0,09 & 0,11 & 0,22 \\
\hline \multirow[t]{3}{*}{$\mathbf{P}$} & 16,06 & 0,32 & 0,28 & 0,22 & 0,11 & 0,49 & 0,98 \\
\hline & $\mathbf{X}_{\text {caract }}$ & $\mathbf{u}_{\text {char }}$ & $\mathbf{u}_{\mathbf{b b}}$ & $\mathbf{U}_{\text {est.curto }}$ & $\mathbf{u}_{\text {lts }}$ & $\mathbf{u}_{\mathrm{RM}}$ & $\mathbf{U}_{\mathbf{R M}}$ \\
\hline & \multicolumn{7}{|c|}{$\mathrm{mg} \mathrm{kg}^{-1}(\mathrm{~m} / \mathrm{m})$} \\
\hline $\mathbf{C u}$ & 10,51 & 0,32 & 0,17 & 0,21 & 0,15 & 0,45 & 0,89 \\
\hline $\mathbf{F e}$ & 231,97 & 5,12 & 6,40 & 4,94 & 4,25 & 10,47 & 20,94 \\
\hline Mn & 19,46 & 0,65 & 0,52 & 0,38 & 0,72 & 1,16 & 2,33 \\
\hline $\mathbf{Z n}$ & 129,56 & 2,93 & 1,44 & 0,56 & 1,02 & 3,46 & 6,93 \\
\hline
\end{tabular}


Figura 47 - Contribuição individual das componentes de incerteza para os valores de propriedade dos parâmetros avaliados no material candidato a RM de ração para peixe. São apresentadas as componentes individuais e a incerteza combinada. (a) macronutrientes; (b) micronutrientes e (c) bromatológicos.

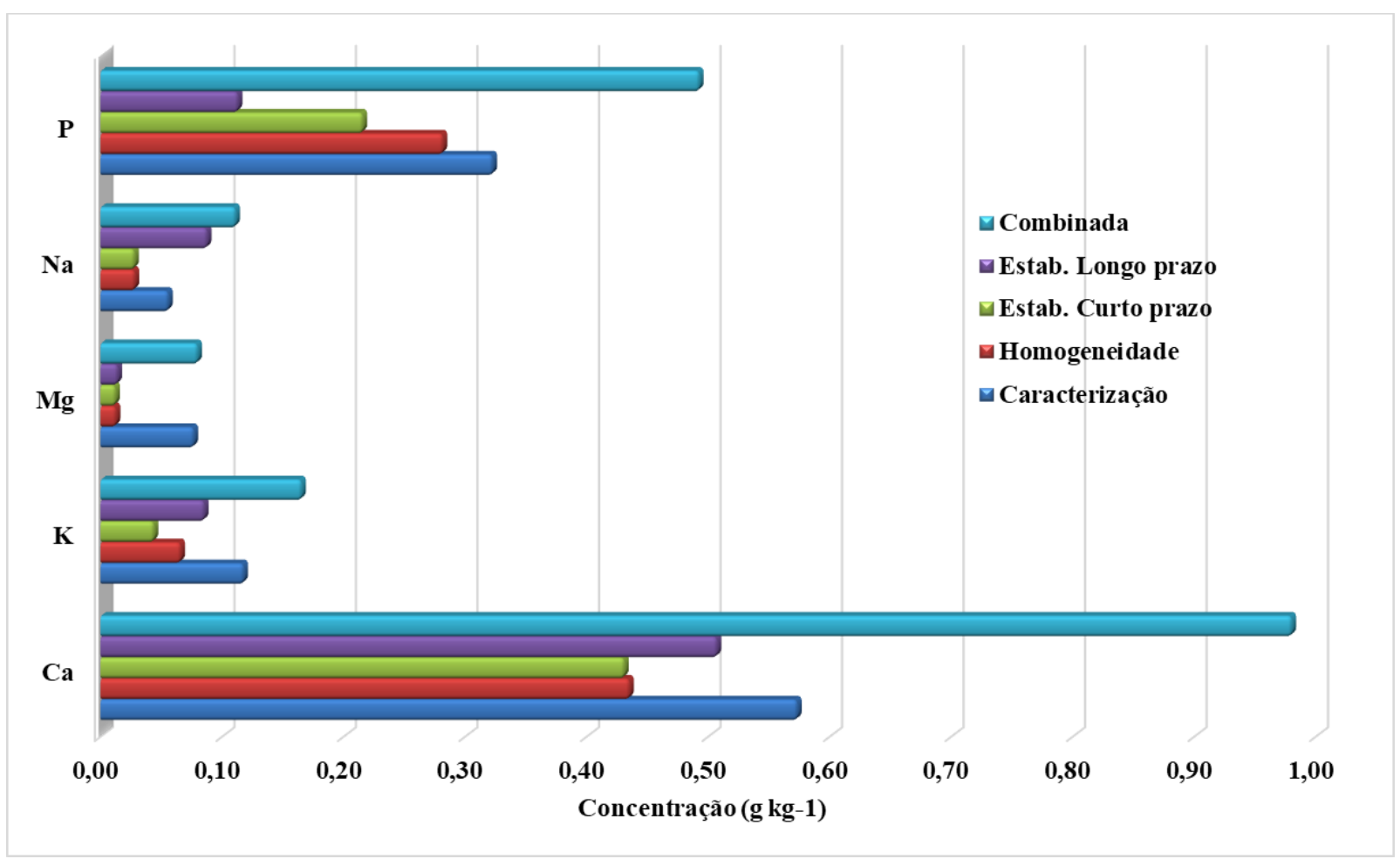

(a)

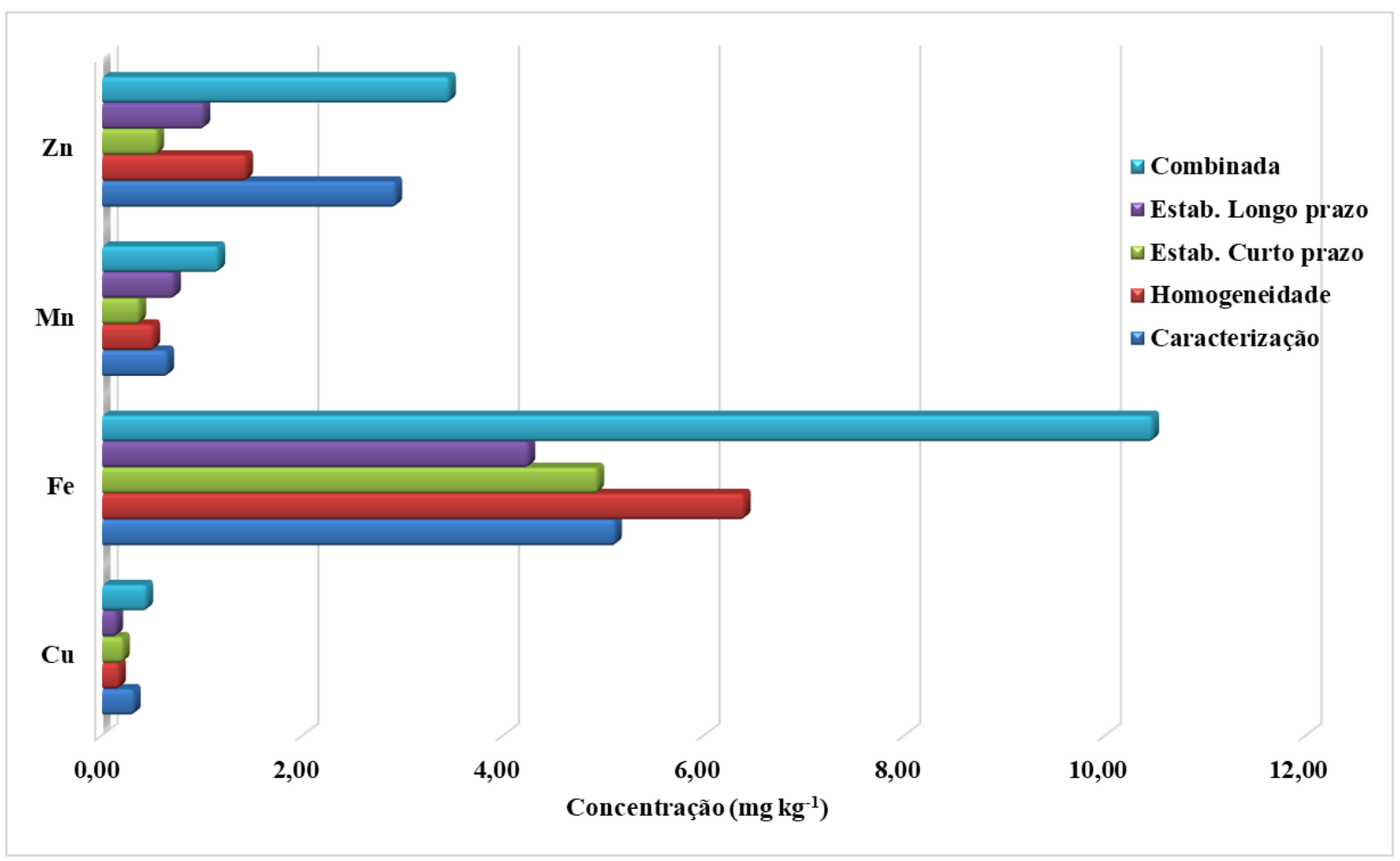

(b) 


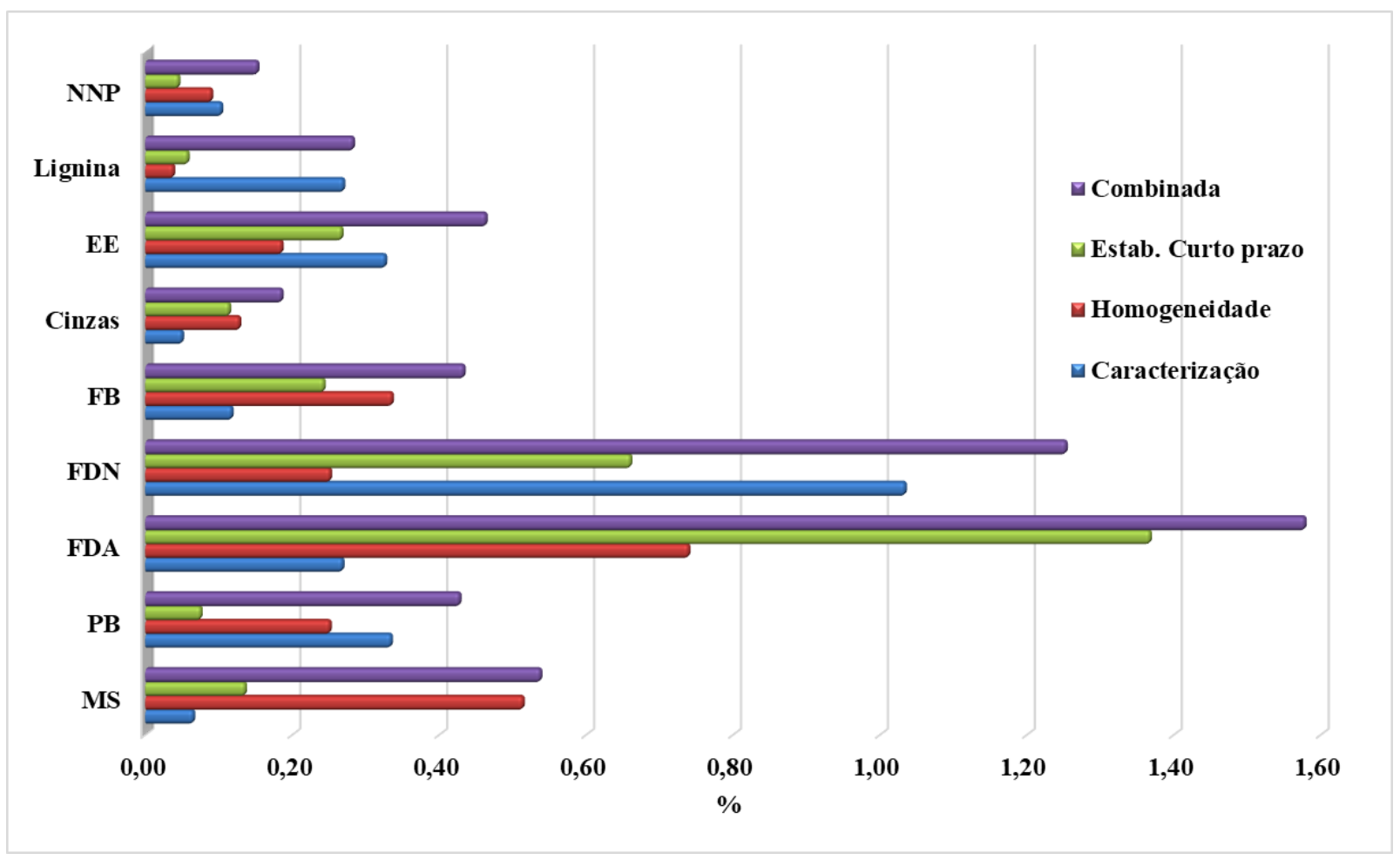

(c)

Conforme Tabela 22 e Figura 47, foi possível avaliar que a menor contribuição foi fornecida pela componente de homogeneidade, na maioria dos casos, para os macro e micronutrientes, sendo que para $\mathrm{Ca}, \mathrm{Cu}, \mathrm{K}, \mathrm{Mg}, \mathrm{Mn}, \mathrm{P}$ e $\mathrm{Zn}$ a influência da incerteza referente à caracterização foi a que mais contribuiu para a incerteza expandida final do material, o que pode ser justificado pela variação entre laboratórios, conforme mencionado anteriormente. Todavia, a maior contribuição de incerteza para $\mathrm{Na}$ foi a estabilidade a longo prazo e para $\mathrm{Fe}$, a homogeneidade. Por outro lado, para os demais parâmetros bromatológicos a menor contribuição é referente à incerteza de caracterização.

O valor designado para cada analito foi obtido pelos dados do ensaio colaborativo. Para cada analito foi obtida a incerteza expandida final e a porcentagem.

As Tabelas 23 e 24 mostram os valores de referência para os parâmetros bromatológicos e macro e micronutrientes determinadas por ICP OES e a incerteza expandida em porcentagem $\left(\mathrm{U}_{\mathrm{RM}}\right)$. 
Tabela 23 - Valores de referência para a fração massa (na base seca) atribuídos aos parâmetros bromatológicos determinados no RM de ração para peixe e incerteza expandida em porcentagem $\left(U_{R M}\right)$

\begin{tabular}{ccc}
\hline Elementos & Valor determinado & $\boldsymbol{U}_{\boldsymbol{R M}}(\boldsymbol{\%})$ \\
\hline Matéria Seca (\%) & $94,29 \pm 1,07$ & 1,14 \\
\hline Proteína Bruta (\%) & $30,46 \pm 0,85$ & 2,81 \\
\hline Fibra em Detergente Ácido (\%) & $5,01 \pm 3,16$ & 63,02 \\
\hline Fibra em Detergente Neutro (\%) & $17,61 \pm 2,51$ & 14,23 \\
\hline Fibra Bruta (\%) & $2,49 \pm 0,87$ & 34,79 \\
\hline Cinzas (\%) & $10,17 \pm 0,37$ & 3,64 \\
\hline Extrato Etéreo (\%) & $4,97 \pm 0,93$ & 18,63 \\
\hline Lignina (\%) & $1,34 \pm 0,56$ & 42,24 \\
\hline Nitrogênio Não Proteico (\%) & $0,45 \pm 0,30$ & 67,78 \\
\hline
\end{tabular}

Tabela 24 - Valores de referência para a fração massa (na base seca) atribuídos aos macro e micronutrientes determinados no RM de ração para peixe e incerteza expandida em porcentagem $\left(U_{R M}\right)$

\begin{tabular}{ccc}
\hline Elementos & Valor determinado & $\boldsymbol{U}_{\boldsymbol{R} M}(\boldsymbol{\%})$ \\
\hline $\mathbf{C a}\left(\mathbf{g ~ k g}^{-1}\right)$ & $28,65 \pm 1,84$ & 6,43 \\
\hline $\mathbf{C u}\left(\mathbf{m g ~ k g}^{-1}\right)$ & $10,51 \pm 0,87$ & 8,28 \\
\hline $\mathbf{F e}\left(\mathbf{m g ~ k g}^{-1}\right)$ & $231,97 \pm 20,17$ & 8,70 \\
\hline $\mathbf{K}\left(\mathbf{g ~ k g}^{-1}\right)$ & $5,86 \pm 0,31$ & 5,30 \\
\hline $\mathbf{M g}\left(\mathbf{g ~ k g}^{-1}\right)$ & $1,55 \pm 0,16$ & 10,23 \\
\hline $\mathbf{M n}\left(\mathbf{m g ~ k g}^{-1}\right)$ & $19,46 \pm 2,12$ & 10,91 \\
\hline $\mathbf{N a}\left(\mathbf{g ~ k g ~}^{-1}\right)$ & $2,16 \pm 0,19$ & 8,76 \\
\hline $\mathbf{P}\left(\mathbf{g ~ k g}^{-1}\right)$ & $16,06 \pm 0,97$ & 6,06 \\
\hline $\mathbf{Z n}\left(\mathbf{m g ~ k g}^{-1}\right)$ & $129,56 \pm 6,79$ & 5,24 \\
\hline
\end{tabular}




\section{CONCLUSÕES}

O objetivo de produção de um material de referência de ração para peixe foi atingido, tendo em vista que foi produzido um material com valores de propriedade atribuídos em conjunto com a incerteza associada. Os estudos de homogeneidade, estabilidade a curto prazo, estabilidade a longo prazo e caracterização, juntamente com as incertezas do material de referência de ração para peixe foram concluídos e obedeceram aos princípios das normas internacionais e nacionais. Todas as componentes da incerteza foram calculadas e suas contribuições na estimativa das incertezas combinadas foram devidamente avaliadas.

A participação dos laboratórios no ensaio colaborativo foi fundamental para a obtenção dos valores designados para cada analito em estudo. O material de referência produzido poderá ser utilizado por laboratórios de nutrição animal para a avaliação da precisão de métodos e como controle de qualidade de rações.

Foi possível observar que o lote de ração para peixe pode ser considerado homogêneo para $\mathrm{Ca}, \mathrm{Cu}, \mathrm{Fe}, \mathrm{Mg}, \mathrm{Mn}$ e $\mathrm{Na}$, uma vez que não foi verificada diferença significativa no nível de confiança de $95 \%$. Para o K, P e Zn houve diferença significativa e, nesse enfoque, deve ser considerado o grau de heterogeneidade do material $\left(F_{\text {calculadoK }}>F_{\text {crítico }}=3,44>2,39\right.$; $\mathrm{F}_{\text {calculadoP }}>\mathrm{F}_{\text {crítico }}=2,81>2,39$ e $\left.\mathrm{F}_{\text {calculadoZn }}>\mathrm{F}_{\text {crítico }}=4,02>2,39\right)$.

A avaliação da estabilidade a curto prazo foi realizada pela análise de variância de fator único (ANOVA), sendo possível observar que $\mathrm{F}_{\text {crítico }}>\mathrm{F}_{\text {calculado }}$ para $\mathrm{Ca}, \mathrm{Cu}, \mathrm{Fe}, \mathrm{K}, \mathrm{Mn}, \mathrm{P}$ e $\mathrm{Zn}$, enquanto que para $\mathrm{Mg}$ e $\mathrm{Na} \mathrm{F}_{\text {crítico }}<\mathrm{F}_{\text {calculado }}$ o que não deve ser encarado como um limitante no uso do RM, tornando necessária a verificação periódica durante todo o período de uso do material. O RM de ração para peixe tem se mantido estável para todos os parâmetros avaliados. O RM tem sido utilizado em análises de rotina na Embrapa Pecuária Sudeste e foram realizadas novas análises para os macro e micronutrientes e foram obtidas concentrações dentro da faixa do valor de consenso fornecido no Documento de Analises (Apêndice B).

O tempo de prateleira foi estipulado levando-se em consideração os CRMs disponíveis no mercado. O CRM NRC BRAN-1 tem prazo de validade de 10 ano, de modo que se estipulou que o tempo de prateleira poderia ser de 5 anos para o RM de ração para peixe. É possível que o material seja estável por tempo maior que o definido. Dessa forma, este material está como produto a ser monitorado semestralmente. 


\section{Capítulo 3}

Produção de Material de Referência para Nutrientes e Contaminantes Inorgânicos em Tecido de Peixe - Tilápia 


\section{REVISÃO BIBLIOGRÁFICA}

O potencial do Brasil para a pesca e aquicultura fez com que o país alcançasse a $4^{\mathrm{a}}$ posição em produção de tilápias no mundo, atrás de China, Indonésia e Egito. Segundo a Associação Brasileira da Piscicultura (PEIXE BR, 2018), o Brasil produziu 357.639 toneladas de tilápia em 2017 contra 260 mil toneladas em 2014 e 198 mil toneladas em 2011. A piscicultura nacional foi responsável pela produção de 697 mil toneladas de peixes. Atualmente a tilápia é a espécie mais importante nos cultivos brasileiros, respondendo por mais de $50 \%$ do mercado e estando presente principalmente nos cultivos das regiões Sul e Sudeste. A segunda posição pertence às espécies nativas brasileiras.

A tilápia responde por mais de $90 \%$ de todo pescado cultivado no Paraná e em São Paulo. Segundo a Secretaria de Comércio Exterior, do Ministério da Indústria, Comércio Exterior e Serviços (MDIC), o Brasil exportou pouco menos de US\$ 150 milhões em pescado em 2017, proveniente de captura e cultivo (PEIXE BR, 2018).

A oferta e consumo de pescado no país têm crescido junto com a expansão dos cultivos e as importações. E o crescimento das exportações também deve ser considerado, uma vez que foi o crescimento das exportações para países da América do Norte que impulsionou o desenvolvimento de indústrias pesqueiras e a entrada de investidores no setor. Em 2003, mais de $60 \%$ do camarão produzido no Brasil seguia para exportação. As primeiras grandes instalações industriais para processamento de tilápia também tinham como alvo o mercado externo (KUBITZA, 2015).

A expansão do consumo e comercialização de pescados, não apenas a tilápia, tem promovido o crescimento do interesse em qualidade e segurança alimentar, além de aspectos nutricionais e gestão de resíduos (FAO, 2018). Um dos grandes desafios, além do atendimento à crescente demanda por alimentos e produtos, em quantidade e qualidade, diz respeito ao atendimento das exigências do comércio de exportação, a aspectos regulatórios, garantindo a qualidade dos produtos. Por exemplo, o Codex Code of Practice for Fish and Fishery Products (Codex Alimentarius Commission, 2016) é um guia para implementação de boas práticas e gestão de perigos em segurança alimentar. No Brasil, temos a Resolução RDC ANVISA n ${ }^{\circ} 42$, de 29/08/2013 e o Decreto ${ }^{\circ}$ 55871, de 1965 que ditam limites aceitáveis de alguns metais em peixe, tais como As (1 mg/kg), Cd (0,05 a 0,3 mg/kg), Cr (0,1 mg/kg), Hg (0,5 a $1 \mathrm{mg} / \mathrm{kg})$ e Pb $(0,3 \mathrm{mg} / \mathrm{kg})$. 
Produtores e indústrias de pescados no mundo estão trabalhando para a evolução em termos de diversidade e qualidade dos produtos, mas ainda há várias lacunas no setor. Riscos associados a específicos contaminantes, possivelmente presentes em pescados, estão bem documentados na literatura e em todas as etapas da produção pesqueira existe a necessidade de análises químicas, importantes para averiguar e assegurar a qualidade nutricional e detectar a presença desses contaminantes. A segurança dos alimentos que chegam à mesa do consumidor é resultado de vários processos de avaliação e o desenvolvimento do mercado de pesca e aquicultura no País depende de informações fornecidas pelos laboratórios. Nesse sentido deverão ser fornecidos pelos laboratórios envolvidos resultados analíticos confiáveis, com métodos validados. Para tanto, a utilização de materiais de referência certificados torna-se imprescindível.

\subsection{Material de Referência de Tecido de Peixe}

A importância do uso de RMs e CRMs é indiscutível, todavia quando se trata de RMs de pescado existem questões que surgem como entraves para a utilização. A produção de RMs no Brasil é pequena, além do longo tempo de preparação e os custos associados. Há a questão da ausência de materiais adequados às necessidades nacionais ou com características similares aos espécimes brasileiros. Vários produtores têm ampla experiência no preparo de RMs de matrizes marinhas (MOREIRA et al, 2009; MOREIRA, 2010), contudo quando se trata de peixes de água doce, a quantidade de RMs disponíveis no mercado é limitada. CRMs adquiridos de produtores estrangeiros podem custar entre 500 e 1000 dólares americanos, quando comprados diretamente do produtor. Todavia esse valor pode chegar a $\mathrm{R} \$ 10$ mil quando o CRM é adquirido no Brasil.

Conforme mencionado anteriormente, atualmente existem 8044 RMs cadastrados na base de dados COMAR, destes foram verificados 13 materiais produzidos a partir de peixes. $\mathrm{Na}$ Tabela 25 são apresentados esses materiais e mais dois que foram verificados como disponíveis no site do Instituto Nacional de Padrões e Tecnologia dos Estados Unidos da América, NIST. 
Tabela 25 - Materiais de referência de peixe identificados no banco de dados internacional de RMs COMAR e na base de CRMs disponíveis do NIST.

\begin{tabular}{|c|c|c|}
\hline Código & Nome & $\begin{array}{l}\text { Parâmetros com valores de referência } \\
\text { atribuídos }\end{array}$ \\
\hline BCR-627 & Tuna fish tissue & Arsenobetaina, DMAA e As total \\
\hline BCR-725 & Lyophilised Salmon Tissue & ácido oxolínico e flumequina \\
\hline DOLT-5 & $\begin{array}{l}\text { Dogfish Liver Certified } \\
\text { Reference Material for Trace } \\
\text { Metals and other Constituents }\end{array}$ & $\begin{array}{l}\text { As, } \mathrm{Cd}, \mathrm{Ca}, \mathrm{Co}, \mathrm{Cu}, \mathrm{Fe}, \mathrm{Pb}, \mathrm{Mg}, \mathrm{Hg}, \mathrm{Mo}, \mathrm{K}, \\
\mathrm{Se}, \mathrm{Ag}, \mathrm{Na}, \mathrm{Sr}, \mathrm{Sn}, \mathrm{V}, \mathrm{Zn} \text {, arsenobetaina, Al, } \\
\quad \mathrm{Ni}, \mathrm{Cr} \text {, metilmercúrio, Mn, Sb, P, Tl, U }\end{array}$ \\
\hline DORM-4 & $\begin{array}{l}\text { Fish protein certified reference } \\
\text { material for trace metals }\end{array}$ & $\begin{array}{c}\mathrm{As}, \mathrm{Cd}, \mathrm{Ca}, \mathrm{Cu}, \mathrm{Cr}, \mathrm{Fe}, \mathrm{Pb}, \mathrm{Mg}, \mathrm{Mn}, \mathrm{Hg}, \mathrm{Ni} \text {, } \\
\text { K, } \mathrm{Sn}, \mathrm{Se}, \mathrm{Ag}, \mathrm{Sr}, \mathrm{V}, \mathrm{Zn} \text {, arsenobetaína e } \\
\text { metilmercúrio Al, Na, Co, Li, Mo, P, U }\end{array}$ \\
\hline ERM-BB422 & Fish muscle & $\mathrm{As}, \mathrm{Cd}, \mathrm{Cu}, \mathrm{Fe}, \mathrm{Hg}, \mathrm{I}, \mathrm{Mn}, \mathrm{Se}$ e $\mathrm{Zn}$ \\
\hline ERM-CE100 & Fish Tissue & hexaclorobenzeno e hexaclorobutadieno \\
\hline ERM-CE464 & Tuna fish & Hg e metilmercúrio \\
\hline GBW 10041 & PCBs in tuna tissue. & PCBs \\
\hline IAEA-406 & $\begin{array}{c}\text { Fish Homogenate* Pesticides } \\
\text { and PCBs }\end{array}$ & pesticidas \\
\hline IAEA-414 & $\begin{array}{l}\text { Radionuclides in Mixed Fish } \\
\text { from the Irish Sea and North Sea }\end{array}$ & radionuclideos \\
\hline IRMM-427 & FISH TISSUE (PIKE-PERCH) & PFASs \\
\hline $\begin{array}{l}\text { NMIJ CRM } \\
7403-\mathrm{a}\end{array}$ & $\begin{array}{c}\text { Trace Elements, Arsenobetaine } \\
\text { and Methylmercury in Swordfish } \\
\text { Tissue }\end{array}$ & $\begin{array}{l}\text { Arsenobetaina, metilmercurio, } \mathrm{Mn}, \mathrm{Fe}, \mathrm{Cu} \text {, } \\
\mathrm{Zn}, \mathrm{As}, \mathrm{Se}, \mathrm{Sr}, \mathrm{Cd}, \mathrm{Hg}, \mathrm{Na}, \mathrm{Mg}, \mathrm{P}, \mathrm{K} \text { e Ca }\end{array}$ \\
\hline $\begin{array}{c}\text { NMIJ CRM } \\
7404-\mathrm{a} \\
\end{array}$ & $\begin{array}{c}\text { Organic Pollutants in Japanese } \\
\text { Seabass Tissue }\end{array}$ & $\mathrm{PCBs}$ \\
\hline $\begin{array}{l}\text { NIST SRM } \\
1946\end{array}$ & Lake Superior Fish Tissue & PCBs, pesticidas clorados e PBDEs \\
\hline $\begin{array}{l}\text { NIST SRM } \\
\quad 1947\end{array}$ & Lake Michigan Fish Tissue & $\begin{array}{l}\mathrm{As}, \mathrm{Cu}, \mathrm{Fe}, \mathrm{Hg}, \mathrm{Mn}, \mathrm{Rb}, \mathrm{Se}, \mathrm{Zn}, \mathrm{MeHg} \text {, } \\
\mathrm{PCB} \text {, POCs, PBDEs, sólidos, cinzas, } \\
\text { proteina, extrato etéreo, calorias, ácidos } \\
\text { graxos, PFAAs, etc }\end{array}$ \\
\hline
\end{tabular}

Considerando a produção nacional de RMs, existem alguns trabalhos na literatura que reportam a produção de RMs de peixes, contudo muitos desses materiais foram preparados como parte de teses de doutorado ou dissertações de mestrado, de modo que não estão disponíveis. Também não se tem conhecimento a respeito da quantidade produzida. A Tabela 26 apesenta um panorama dos RMs de peixe reportados como produzidos no Brasil. 
Tabela 26 - Panorama geral de materiais de referência de peixe produzidos no Brasil.

\begin{tabular}{cccc}
\hline RM & Parâmetros & Produtor & Referência \\
\hline $\begin{array}{c}\text { Dourada (Brachyplatystoma } \\
\text { flavicans) }\end{array}$ & $\mathrm{Hg}, \mathrm{MeHg}$ & IPEN & ULRICH, 2011 \\
\hline Corvina & $\mathrm{As}, \mathrm{Cd}, \mathrm{Fe}, \mathrm{Hg}, \mathrm{K}, \mathrm{Na}$ e $\mathrm{Zn}$ & IPEN & MAIHARA et al, 2011 \\
\hline Atum & $\mathrm{Hg}, \mathrm{MeHg}$ & UFABC & CHELEG ̃̃O, 2012 \\
\hline Tucunaré & $\mathrm{As}, \mathrm{Cd}, \mathrm{Hg}$ e Pb & IPEN & SANTANA, 2013 \\
\hline Atum (músculo) e Robalo (fígado) & As, Cd, Cu e espécies de As & UFABC & CARIONI, 2014 \\
\hline Filé de tilápia & Dioxinas, furanos e bifenilas & UFMG & \multirow{2}{*}{ NUNES, 2015 } \\
\hline
\end{tabular}

Ulrich desenvolveu um RM de peixe, Dourada (Brachyplatystoma flavicans), oriundo da região Norte do Brasil, para a determinação de mercúrio e metilmercúrio. O material passou por todas as etapas necessárias para a adequada produção de um RM, com base nos guias ISO GUIA 30 a 35 (ULRICH, 2011; ULRICH, SARKIS, 2013).

Maihara e colaboradores (2011) avaliaram o potencial e comprovaram a viabilidade de produção e certificação de uma RM brasileiro de peixe, em faixas de concentração compatíveis com pescados nacionais para $\mathrm{As}, \mathrm{Cd}, \mathrm{Fe}, \mathrm{Hg}, \mathrm{K}, \mathrm{Na}$ e $\mathrm{Zn}$ em corvina.

Chelegão produziu um RM de tecido de peixe (atum), para mercúrio e metilmercúrio, empregando espectrometria de absorção atômica com geração de vapor frio (CV AAS) e a espectrometria de absorção atômica com forno de grafite (GF AAS) nas avaliações do RM (CHELEGÃO, 2012; CHELEGÃO et al., 2016).

Santana desenvolveu um RM de tecido de peixe (tucunaré) in natura para a determinação de As, Cd, Pb e Hg. Foram preparados 164 sachês com $10 \mathrm{~g}$ cada. A caracterização e definição dos valores de propriedade foi realizada através de um ensaio de proficiência com a participação e 10 laboratórios (SANTANA, 2013).

Nunes produziu e avaliou um RM para dioxinas, furanos e bifenilas em filé de tilápia, incluindo óleo de peixe e nonano. O RM foi produzido por adição de padrão de 29 contaminantes na matriz, seguido de liofilização e homogeneização. (NUNES, 2015).

Carioni e colaboradores avaliaram parâmetros para o preparo de um material de referência de atum para a determinação de arsênio total e produziram um RM de músculo de atum e tecido de robalo para microanálise de $\mathrm{As}, \mathrm{Cd}$ e $\mathrm{Cu}$ e especiação de As. As determinações foram realizadas por espectrometria de absorção atômica com forno de grafite com amostragem em suspensão (SLS-GF AAS) e espectrometria de absorção atômica com geração de hidretos e 
amostragem de suspensão (SLS-HG AAS), além de INAA. Os principais parâmetros avaliados foram: a homogeneidade, a segregação do analito durante a produção e a composição do material (CARIONI et al, 2012; CARIONI, 2014).

\section{PROCEDIMENTO EXPERIMENTAL}

\subsection{Preparo do Material Candidato}

\subsubsection{Obtenção e Preparação das Amostras de Tecido de Peixe}

Cerca de $150 \mathrm{~kg}$ de filés de tilápia foram obtidos de dois fornecedores comerciais das regiões Nordeste e Sudeste do Brasil. As amostras congeladas foram enviadas para liofilização e moagem. O material foi liofilizado em um liofilizador comercial marca LioBras modelo LP 1040, na empresa LioFoods. O liofilizador conta com uma unidade condensadora construída em aço inoxidável AISI304, com acabamento sanitário espelhado. Sua capacidade é de até 40 $\mathrm{kg}$ de gelo, contendo 10 bandejas de 55 x $55 \mathrm{~cm}$, com $3 \mathrm{~m}^{2}$ de área total. A temperatura do condensador é de $-40^{\circ} \mathrm{C}$ e tem uma bomba de vácuo de duas etapas que alcança os $700 \mu$ bar.

Após a liofilização e moagem, foram obtidos $30 \mathrm{~kg}$ de material seco e moído, que foi homogeneizado. Parte desse material foi utilizado para a preparação do lote do candidato a material de referência de tecido de peixe, sendo envasado em 600 frascos de vidro âmbar, previamente descontaminados em banho de $\mathrm{HNO}_{3} 10 \%$ (v/v) durante $24 \mathrm{~h}$ e secos em capela de fluxo laminar. Em cada frasco foram adicionadas porções típicas de aproximadamente $20 \mathrm{~g}$ (Figura 48)

O lote de 600 frascos foi submetido à irradiação com radiação gama (10-25 kGy), visando garantir a estabilidade do material e o aumento do tempo de prateleira e preservação das características da amostra, no Centro de Tecnologia das Radiações - CTR/IPEN/CNEN SP. Em seguida, foram armazenados à temperatura de $-20^{\circ} \mathrm{C}$ para os estudos subsequentes. 
Figura 48 - Amostras envasadas em frasco de vidro âmbar com porções de aproximadamente $20 \mathrm{~g}$ cada.

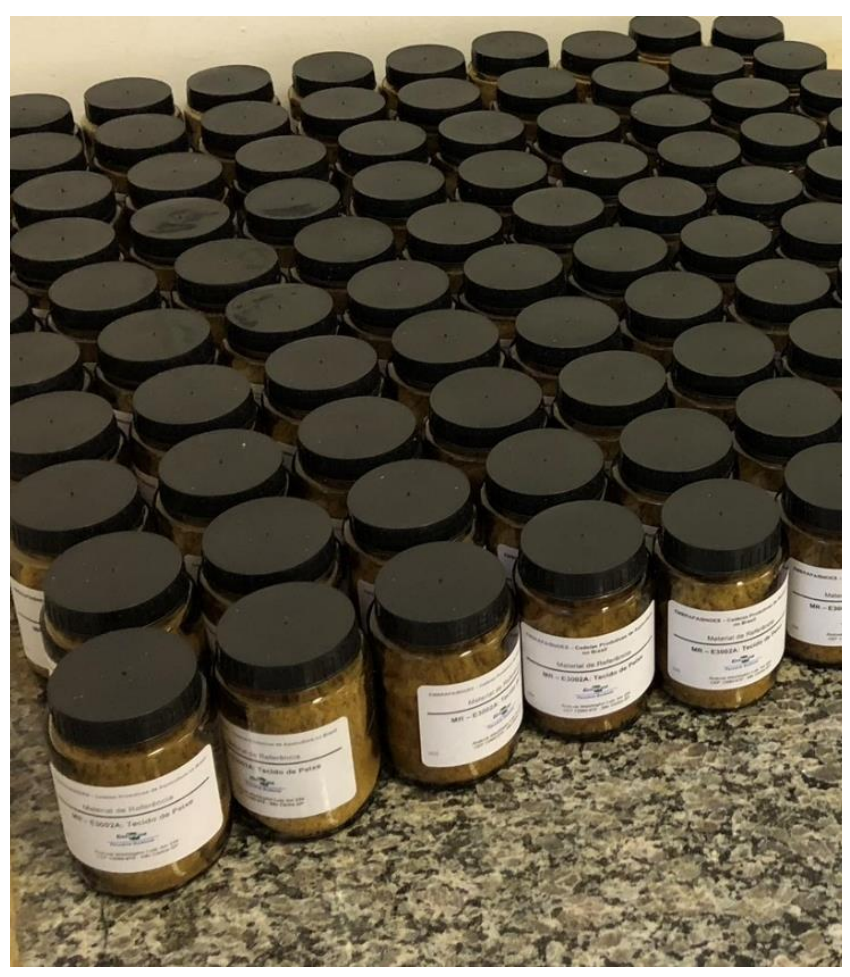

\subsection{Caracterização Física do Material Candidato}

\subsubsection{Distribuição de Tamanho de Partícula}

O material de tecido de peixe foi avaliado em classificador de tamanho de partículas para verificar a distribuição atingida, uma vez que esta é uma característica importante para a homogeneidade. Um dos frascos do RM de ração foi submetido ao ensaio de distribuição de tamanho de partículas, em triplicata, com dispersão úmida, em água. O procedimento foi realizado no Centro de Energia Nuclear na Agricultura, na Universidade de São Paulo (CENA, USP), Piracicaba-SP, utilizando o equipamento Laser Particle Sizer Analysette 22 MicroTec Plus (Fritsch, Alemanha). 


\subsubsection{Determinação da Umidade Residual}

Conforme Moreira (2010) menciona, materiais de referência biológicos são mais suscetíveis a serem higroscópicos, de modo que a umidade residual deve estar abaixo de 4\%, para garantir a restrição de atividade microbiológica. Ademais, o método deve ser claramente definido e facilmente realizável, para que os usuários possam expressar resultados em base seca comparáveis com os valores de propriedade do RM.

Para a realização do estudo de umidade residual, foram analisados, em seis replicatas, 6 (seis) frascos de RM candidato de tecido de peixe $(52,158,294,345,474,547)$, selecionados aleatoriamente. O método utilizado foi secagem em estufa até peso constante. Os cadinhos vazios foram secos em estufa, por $2 \mathrm{~h}$ a $105^{\circ} \mathrm{C}$, colocados em dessecador por $1 \mathrm{~h}$ e pesados em balança analítica (Shimadzu AUX-220, $\pm 0,0001 \mathrm{~g}$ ) até peso constante (massa registrada como $\left.m_{\text {cad }}\right)$. Em seguida, foi adicionado aproximadamente $1 \mathrm{~g}$ de amostra de cada frasco nos diferentes cadinhos e a massa novamente registrada $\left(m_{\text {amostra }}\right)$. Cada um dos seis frascos foi avaliado em 6 (seis) replicatas. Os cadinhos foram levados à estufa a $105^{\circ} \mathrm{C}$ por 24 h e, após este período foram colocados em dessecador por $1 \mathrm{~h}$, sendo, por fim, pesadas $\left(\mathrm{m}_{\mathrm{cad}}+\mathrm{MS}\right)$.

O cálculo da umidade residual foi realizado através da Equação 4, apresentada no Capítulo 2, item 2.2.2.

\subsection{Determinação dos Elementos por ICP OES}

Assim como no preparo do RM de ração para peixe, para o RM candidato de tecido de peixe foi utilizada a técnica analítica de espectrometria de emissão óptica com plasma indutivamente acoplado, ICP OES, para a determinação da concentração de macro e micronutrientes ( $\mathrm{Ca}, \mathrm{Fe}, \mathrm{K}, \mathrm{Mg}, \mathrm{Na}, \mathrm{P}$ e $\mathrm{Zn})$.

\subsubsection{Preparo de amostras}

Todos os reagentes utilizados neste trabalho foram de grau analítico. Todas as soluções e diluições foram preparadas com a utilização de água deionizada proveniente de um sistema de purificação Milli-Q® (Millipore, São Paulo, Brasil), com resistividade de 18,2 M $\Omega \mathrm{cm}$.

Toda vidraria e material utilizado no preparo de padrões e amostras, como ponteiras e 
tubos Falcon utilizados neste trabalho foram previamente descontaminados por imersão em $\mathrm{HNO}_{3} 10 \%$ (v/v) por, no mínimo, 24h, sendo posteriormente enxaguados com água deionizada e submetidos a secagem em capela de fluxo laminar.

Para a pesagem das amostras foi utilizada balança analítica modelo AUX220 (Shimadzu, Japão).

Soluções-padrão foram preparadas a partir de soluções estoque monoelementares com concentração de 1000 mg/L (Specsol, São Paulo, Brasil).

Para a digestão das amostras foi empregado $6 \mathrm{~mL}$ de $\mathrm{HNO}_{3} 50 \%$ e $2 \mathrm{~mL}$ de $\mathrm{H}_{2} \mathrm{O}_{2} 30 \%$ $(\mathrm{m} / \mathrm{v})$, utilizando o programa de aquecimento descrito na Tabela 4, do item 2.3.1 do Capítulo 2. $\mathrm{O} \mathrm{HNO}_{3}$ foi previamente destilado abaixo do ponto de ebulição em sistema de destilação de ácidos Distillacid BSB-939-IR (Berghof, Eningen, Alemanha).

As digestões das amostras, preparo dos brancos e as determinações dos analitos foram realizadas nas dependências da Embrapa Pecuária Sudeste.

\subsubsection{Quantificação de macro e micronutrientes}

$\mathrm{Ca}, \mathrm{Fe}, \mathrm{K}, \mathrm{Mg}, \mathrm{Na}, \mathrm{P}$ e Zn foram quantificados por espectrometria de emissão óptica com plasma indutivamente acoplado (ICP OES) utilizando um equipamento da marca Agilent, modelo 5110 (Figura 49), com a tecnologia de combinador espectral dicroico (DSC), visão axial e radial e o modo dupla visualização simultânea (SVDV), cujos parâmetros estão descritos na Tabela 27. 
Figura 49 - ICP OES Agilent 5110

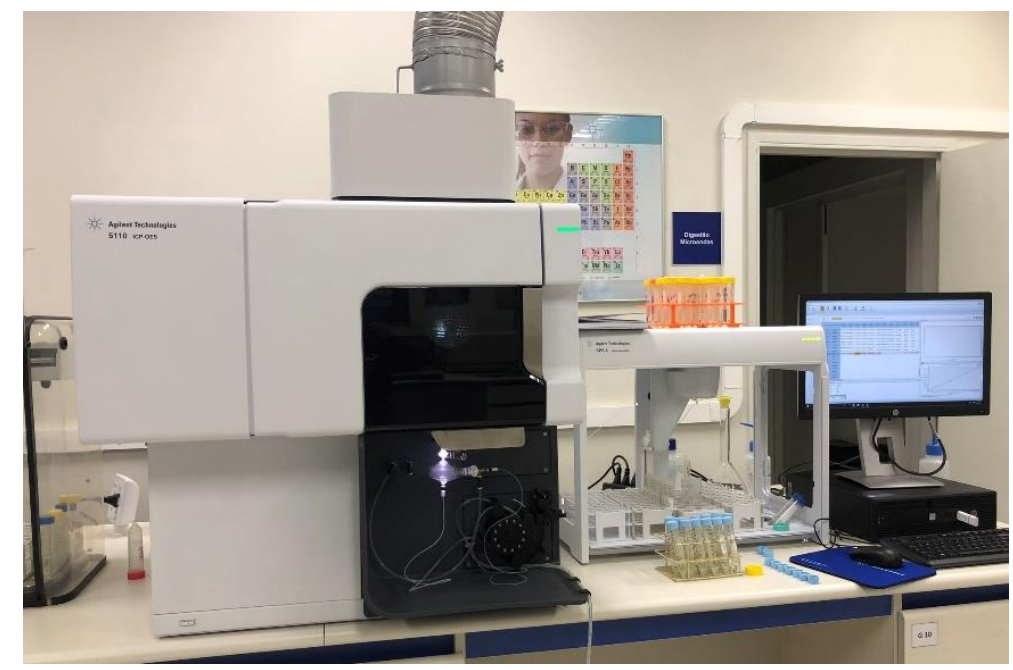

Tabela 27 - Parâmetros Operacionais para a determinação multielementar no ICP OES Agilent 5110.

\begin{tabular}{cc}
\hline Parâmetro & Características \\
\hline Potência de Radiofrequência $(\mathrm{kW})$ & 1,2 \\
Vazão de gás do plasma $\left(\mathrm{L} \mathrm{min}^{-1}\right)$ & 12 \\
Vazão do gás auxiliar $\left(\mathrm{L} \mathrm{min}^{-1}\right)$ & 1 \\
Vazão do nebulizador $\left(\mathrm{L} \mathrm{min}^{-1}\right)$ & 0,7 \\
Nebulizador & Concêntrico \\
Câmara de nebulização & Ciclônica \\
Modos de visualização & Axial, Radial e SVDV \\
Tempo de estabilização & 21 s \\
Replicatas & 3 \\
& Ca 422,673 (SVDV) \\
& Fe 238,204 (SVDV) \\
K 766,491 (Radial) \\
Mg 285,213 (Axial) \\
Na 589,592 (Radial) \\
P 263,618 (Axial) \\
Zn 213,857 (Radial) \\
\hline
\end{tabular}


As amostras digeridas foram analisadas, com calibração externa, mediante diluições adequadas para avaliação dos analitos alvo, os quais foram avaliados em mais de um comprimento de onda e nas três configurações possíveis (axial, radial e SVDV), com o intuito de se escolher o procedimento com maior sensibilidade, menores desvios-padrão relativos e com os melhores valores de recuperação dos CRMs analisados. Após a digestão, as amostras foram diluídas de 5 a 10 vezes com água deionizada.

Para a validação do método foram analisados, juntamente com as amostras os CRMs: NIST SRM 1566b - Oyster tissue (tecido de ostra) e DOLT-5 - Dogfish liver (Fígado de cação) e o RM IPEN 001 - Trace element in fish tissue (Elementos traços em tecido de peixe).

\subsection{Determinação dos Elementos por ICP-MS}

A técnica de Espectrometria de Massas com Plasma Acoplado Indutivamente (ICP-MS) foi empregada para a determinação de micronutrientes e contaminantes no candidato a RM de tecido de peixe.

ICP-MS é uma técnica amplamente empregada para a determinação de elementos em níveis traços em diversos tipos de matrizes e aplicações. Íons gerados no plasma indutivo são introduzidos no espectrômetro de massas, os quais são separados em função da razão massa/carga, através do transporte sob ação de campos elétricos e magnéticos que modificam as suas trajetórias. Esta técnica permite determinar quase todos os elementos na tabela periódica, com limites de detecção que são frequentemente várias ordens de magnitude menores que os obtidos com ICP OES ou outros métodos óticos (SKOOG et al., 2015).

A técnica apresenta alta sensibilidade, precisão, robustez, baixos limites de detecção e ampla faixa linear. No entanto, a determinação de alguns elementos é limitada pela ocorrência de interferências isobáricas causadas por moléculas poliatômicas ou íons divalentes, que podem ser contornadas por estratégias ou tecnologias instrumentais como o uso de células de reação e/ou colisão que antecedem o detector. 


\subsubsection{Quantificação de microelementos e contaminantes inorgânicos}

Os mesmos digeridos preparados para a determinação por ICP OES foram utilizados para as determinações de As, Ba, Co, Cr, Cu, Mn, Mo, Ni, Se, Sr, Ti e V por ICP-MS, empregando um equipamento da marca Agilent, modelo 7800 (Figura 50), que apresenta a tecnologia de célula de colisão com a $4^{\mathrm{a}}$ geração do sistema de reação octopolar $\left(\mathrm{ORS}^{4}\right)$ Agilent, otimizada para o modo de colisão com hélio $(\mathrm{He})$.

A diluição de amostras utilizada foi de 20 a 30 vezes com água deionizada. Os parâmetros operacionais estão descritos na Tabela 28. Assim como para as análises por ICP OES, para a validação do método foram analisados, juntamente com as amostras os CRMs: NIST SRM 1566b - Oyster tissue (tecido de ostra) e DOLT-5 - Dogfish liver (Fígado de cação) e o RM IPEN 001 - Trace element in fish tissue (Elementos traços em tecido de peixe).

Para as determinações nesta técnica, foi necessário fazer a otimização das melhores condições para a determinação dos isótopos ${ }^{75} \mathrm{As},{ }^{137} \mathrm{Ba},{ }^{59} \mathrm{Co},{ }^{53} \mathrm{Cr},{ }^{63} \mathrm{Cu},{ }^{55} \mathrm{Mn},{ }^{96} \mathrm{Mo},{ }^{60} \mathrm{Ni}$, ${ }^{78} \mathrm{Se},{ }^{88} \mathrm{Sr},{ }^{48} \mathrm{Ti}$ e ${ }^{51} \mathrm{~V}$.

As condições estudadas para o ICP-MS foram: modo no gas (sem célula de colisão) com e sem adição online de solução de $10 \mathrm{ppb}$ de padrões internos $\mathrm{de}^{74} \mathrm{Ge}^{+} \mathrm{e}^{103} \mathrm{Rh}^{+}$; com o uso da célula de colisão (4,5 $\mathrm{mL} \mathrm{min}^{-1}$ de He), utilizando ou não os padrões internos. Os padrões internos são comumente empregados para a correção de possíveis efeitos de transporte. 
Figura 50 - ICP-MS Agilent 7800 empregado na determinação multielementar no RM candidato de tecido de peixe

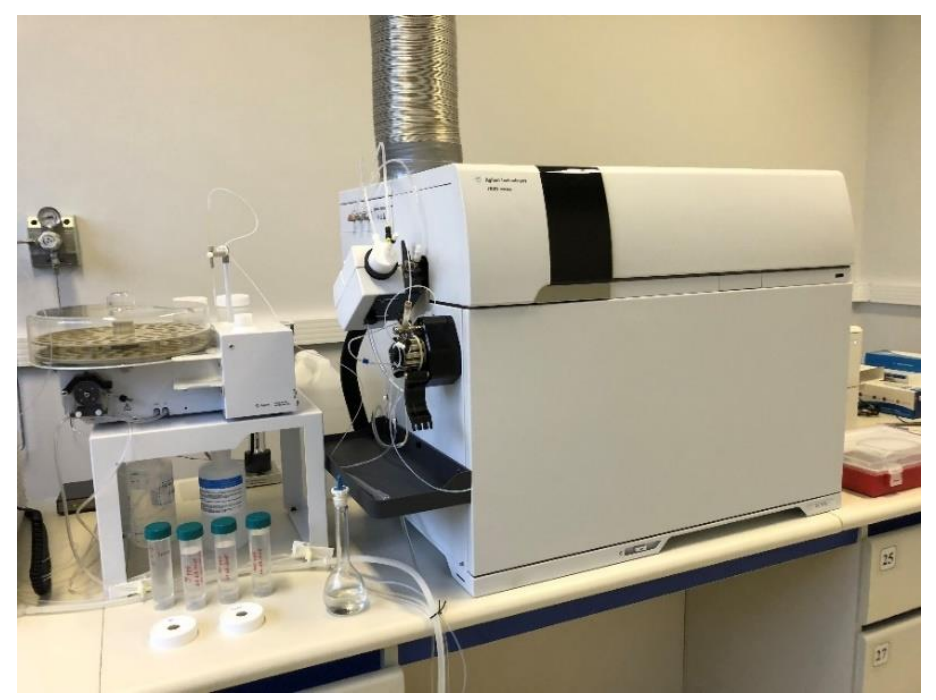

Tabela 28 - Parâmetros Operacionais para a determinação multielementar no ICP-MS Agilent 7800.

\begin{tabular}{cc}
\hline Parâmetro & Características \\
\hline Gerador de Radiofrequência $(\mathrm{MHz})$ & 27 \\
Potência de Radiofrequência $(\mathrm{W})$ & 1550 \\
Vazão de gás do plasma $\left(\mathrm{L} \mathrm{min}^{-1}\right)$ & 15 \\
Vazão do gás auxiliar $\left(\mathrm{L} \mathrm{min}^{-1}\right)$ & 0,60 \\
Vazão do gás de nebulização $\left(\mathrm{L} \mathrm{min}^{-1}\right)$ & 0,42 \\
Profundidade de amostragem $(\mathrm{mm})$ & 10 \\
Tempo de Integração $(\mathrm{s})$ & 3 \\
Número de elementos/padrões internos & $12 / 2$ \\
Modos de tuning da célula & $\mathrm{No}$ gas/He \\
Vazão de He na célula de colisão $\left(\mathrm{mL} \mathrm{min}{ }^{-1}\right)$ & 4,5 \\
Nebulizador & $\mathrm{MicroMist}(\mathrm{concêntrico})$ \\
Câmara de nebulização & $\mathrm{Scott} \mathrm{double} \mathrm{pass}$ \\
Remperatura da câmara de nebulização $\left({ }^{\circ} \mathrm{C}\right)$ & 2 \\
Isótopos monitorados & 3 \\
Padrões Internos & ${ }^{75} \mathrm{As},{ }^{137} \mathrm{Ba},{ }^{59} \mathrm{Co},{ }^{53} \mathrm{Cr},{ }^{63} \mathrm{Cu},{ }^{55} \mathrm{Mn}$, \\
& ${ }^{96} \mathrm{Mo},{ }^{60} \mathrm{Ni},{ }^{78} \mathrm{Se},{ }^{88} \mathrm{Sr},{ }^{48} \mathrm{Ti} \mathrm{e}{ }^{51} \mathrm{~V}$ \\
& ${ }^{74} \mathrm{Ge} \mathrm{e} \mathrm{e}{ }^{103} \mathrm{Rh}$ \\
\hline
\end{tabular}




\subsection{Estudo da Homogeneidade da Amostra de Tecido de Peixe Candidata a RM}

O estudo da homogeneidade é uma das etapas mais importantes na produção de um candidato a RM. A homogeneidade está relacionada ao tipo de material, a granulometria, os analitos avaliados e a precisão e exatidão da determinação (SANTOS et al, 2015). No processo de produção de um candidato a RM, o estudo de homogeneidade é empregado para a avaliação de variações decorrentes de qualquer heterogeneidade do material.

Assim como foi feito com o RM de ração para peixe, foi realizada uma avaliação inicial de homogeneidade entre frascos, através da coleta de espectros com o emprego de um espectrofotômetro de infravermelho próximo (NIRS) da marca BÜCHI modelo NIR-Flex N500. As análises foram realizadas em duplicata, sendo que os espectros NIR foram obtidos no modo de reflectância difusa, por meio do software Operator 1.2 (Buchi, Flawil, Suiça), na faixa que abrange a região espectral de 10.000 a $4.000 \mathrm{~cm}^{-1}$, com resolução de $4 \mathrm{~cm}^{-1}$ e 32 varreduras por amostra. Para a avaliação qualitativa da homogeneidade e interpretação dos dados, realizouse a análise de componentes principais (PCA) executada no software Pirouette ${ }^{\circledR}$ 4.0. A normalização dos espectros NIR foi utilizada como pré-tratamento dos dados. Foram utilizados 500 frascos do lote para esta primeira avaliação.

De acordo com Linsinger et al (2001), o estudo de homogeneidade compreende dois tipos de avaliação. Primeiramente, o estudo da homogeneidade dentro do frasco, a qual é responsável pela definição da massa mínima para a qual a incerteza calculada será válida. Em segundo lugar, tem-se o estudo dentre frascos, que avalia a variação frasco a frasco.

\subsubsection{Homogeneidade intra-frasco e Estimativa da Massa Mínima}

De acordo com o ABNT ISO Guia 35 (2012): "Ao se lidar com materiais de referência no estado sólido, inclusive suspensões e lodos, recomenda-se prever um estudo de homogeneidade dentro do frasco para determinar a massa mínima de amostra." Esta é a porção mínima de ensaio que, quando tirada corretamente, pode ser considerada representativa do RM dentro da incerteza certificada. Analisando um intervalo de diferentes massas da amostra, podese estimar a massa mínima do material.

O estudo de homogeneidade intra-frasco e a estimativa da massa mínima foram realizados utilizando o frasco $n^{\circ} 469$, selecionado aleatoriamente. Foram analisadas seis sub- 
amostras para as seguintes massas: 100, 200, 250, 300 e $400 \mathrm{mg}$ por ICP OES e ICP-MS, nas condições operacionais supracitadas.

Os diversos testes de estatística clássica (testes de normalidade de Shapiro-Wilk, de Levene para homogeneidade de variâncias, Kruskal - Wallis, etc.) foram realizados com o programa PAST 3.21

O teste Shapiro-Wilk, calcula uma variável estatística (W) que investiga se uma amostra aleatória provém de uma distribuição normal.

A variável $\mathrm{W}$ é calculada da seguinte forma:

$$
W=\frac{\left(\sum_{i=1}^{n} a_{i} x_{i}\right)^{2}}{\sum_{i=1}^{n}\left(x_{i}-\bar{x}\right)^{2}}
$$

Onde:

$x_{i:}$ os valores ordenados de amostras ( $x_{1}$ é o menor).

$a_{i:}$ constantes geradas a partir de meio, variâncias e covariâncias da ordem estatística de uma amostra de tamanho n e uma distribuição normal.

Sendo W uma característica em estudo, então formulam-se as hipóteses:

$\mathrm{H}_{0}:$ W tem distribuição Normal;

$\mathrm{H}_{1}$ : W não tem distribuição Normal.

A repetibilidade do método foi avaliada através do desvio padrão relativo, RSD e para avaliar se existem diferenças significativas entre os resultados obtidos nas diferentes massas utilizou-se a análise de variância com fator único (ANOVA) em um nível de significância de $5 \%(\alpha=0,05)$. Assim, foi determinada a massa mínima da alíquota a ser analisada, na qual a homogeneidade estaria assegurada.

\subsubsection{Homogeneidade entre frascos}

O estudo da homogeneidade é essencial para a garantia da manutenção das propriedades físico-químicas do material candidato, de modo que o número de frascos deve ser representativo do lote. De acordo com o ABNT ISO Guia 35 (2012), para a avaliação da homogeneidade, dentre frascos, devem ser selecionados de 10 a 30 frascos do lote preparado. As determinações devem ser executadas em condições de repetitividade: mesmo laboratório, mesmo analista, mesmo dia de análise. 
A homogeneidade entre frascos, do material de tecido de peixe candidato a RM, foi avaliada conforme os critérios estabelecidos pelo ABNT ISO Guia 35 (2012). Para a realização deste estudo, foram selecionados aleatoriamente 15 frascos do lote de 600 frascos preparado (6, $41,95,108,141,182,226,264,293,324,368,399,408,518$ e 596).

Seis sub-amostras de cada frasco, de aproximadamente $250 \mathrm{mg}$, foram submetidas à digestão seguindo procedimento mencionado anteriormente. Os parâmetros empregados para as determinações por ICP OES estão apresentados na Tabela 27 e por ICP-MS, na Tabela 28.

A avaliação estatística dos resultados de homogeneidade foi realizada por meio da análise de variância com fator único (ANOVA) em um nível de significância de $5 \%(\alpha=0,05)$.

\subsection{Estudo de Estabilidade da Amostra de Tecido de Peixe Candidata a RM}

Moreira (2010) menciona que RM biológicos tendem a sofrer degradação ou alteração na concentração dos analitos-alvo ao longo do tempo. Deste modo, o produtor do RM deve informar quais as condições ideais de armazenamento e transporte para a garantia da manutenção dos valores de propriedade estabelecidos para o material.

De acordo com os ABNT ISO Guias 30 (2016) e 35 (2012), existem dois estudos a serem considerados: a estabilidade a longo prazo e a curto prazo. $\mathrm{O}$ estudo de estabilidade a curto prazo é empregado para a verificação de alterações nas características de interesse do material sob condições de transporte e o estudo da estabilidade a longo prazo é empregado para avaliar o tempo de prateleira do material e as condições de armazenamento.

Com o objetivo de diminuir a variabilidade analítica foi empregado o planejamento isócrono, tanto para o estudo de estabilidade de curto prazo quando para o de longo prazo. O planejamento isócrono foi proposto inicialmente por Lamberty et al (1998) e, ao contrário do método clássico de estudo de estabilidade (empregado na produção do RM de ração), neste método é possível realizar todas as medidas sob condições de repetibilidade (LINSINGER et al, 2004). O termo "isócrono" reflete o fato de que todas as medições ocorrem no mesmo tempo (utilizando-se os mesmos equipamentos, analistas, condições de calibração, etc.) e não distribuídas ao longo do tempo do estudo, como foi o caso do planejamento clássico empregado na produção do RM de ração para peixe. Ademais, segundo o ABNT ISO Guia 35 (2012), uma vez que os dados do planejamento isócrono estão menos dispersos ao longo do tempo, há uma consequente otimização do estudo de estabilidade, logo a incerteza proveniente do estudo 
clássico tende a ser maior do que aquela obtida pelo isócrono. Desta maneira, a incerteza obtida pelo planejamento isócrono favorece a obtenção de um tempo de prateleira mais longo.

Os resultados médios, obtidos nas diversas temperaturas avaliadas, foram normalizados aos resultados obtidos dos frascos armazenadas na temperatura de referência, $-20^{\circ} \mathrm{C}$. Os resultados são expressos pela razão $R_{T}$, de acordo com a Equação 31 (LAMBERTY et al, 1998):

$$
R_{T}=\frac{X_{T}}{X_{-20^{\circ} \mathrm{C}}}
$$

Onde $X_{T}$ é a concentração média do elemento na temperatura T.

Assim também deve ser calculada a incerteza de medição combinada, $U_{T}$, que leva em consideração os coeficientes de variância resultantes das medições em cada uma das temperaturas, conforme Equação 32 (LAMBERTY et al, 1998):

$$
U_{T}=\sqrt{\left(C V_{T}^{2}+C V_{-20^{\circ} \mathrm{C}}^{2}\right)} \times \frac{R_{T}}{100}
$$

O material é considerado estável se RT \pm UT não for significativamente diferente de 1 .

\subsubsection{Estabilidade a Curto Prazo}

No planejamento isócrono, a determinação elementar é realizada apenas após todas as amostras terem sido submetidas às várias temperaturas e intervalos de tempo do estudo. Frascos do material candidato foram escolhidos aleatoriamente e armazenados em diferentes temperaturas $\left(-20^{\circ} \mathrm{C}, 4^{\circ} \mathrm{C}, 18^{\circ} \mathrm{C}\right.$ e $\left.37^{\circ} \mathrm{C}\right)$ por períodos de 20,40 e 60 dias, obtendo-se um total de 30 frascos ao final do estudo. Na Tabela 29 é apresentado o planejamento do estudo e as áreas sombreadas correspondem ao tempo de armazenamento dos frascos na referida temperatura.

Para a avaliação a $37 \pm 3^{\circ} \mathrm{C}$ e $100 \pm 4 \%$, a cada 20 dias, 3 frascos foram acondicionados dentro de um aparato em que a temperatura e a umidade foram controladas. $\mathrm{O}$ aparato correspondeu a um recipiente de vidro com tampa, dentro do qual foram adicionados cerca de 2L de água e frascos de vidro com água. Sobre os frascos abertos foi fixada uma superfície uniforme para suporte para os frascos a serem avaliados. A água, inserida no sistema, foi a responsável pela garantia de umidade relativa a $100 \pm 4 \%$. Os aparatos com os frascos foram colocados dentro de uma estufa com temperatura controlada, fixada em $37 \pm 3^{\circ} \mathrm{C}$ (Figura 51). 
Após o tempo de exposição, as massas características de As, $\mathrm{Ba}, \mathrm{Ca}, \mathrm{Co}, \mathrm{Cr}, \mathrm{Cu}, \mathrm{Fe}, \mathrm{K}$, $\mathrm{Mg}, \mathrm{Mn}, \mathrm{Mo}, \mathrm{Na}, \mathrm{Ni}, \mathrm{P}, \mathrm{Se}, \mathrm{Sr}, \mathrm{Ti}, \mathrm{V}$ e Zn foram determinadas por ICP OES e ICP-MS em seis replicatas para cada frasco. Para avaliar se o material poderia ser transportado sob condições normais, foi realizada uma comparação dos valores obtidos para as várias temperaturas com aqueles obtidos para os frascos controle, armazenados na temperatura de referência a $-20^{\circ} \mathrm{C}$.

Tabela 29 - Planejamento isócrono para estudo de estabilidade a curto prazo

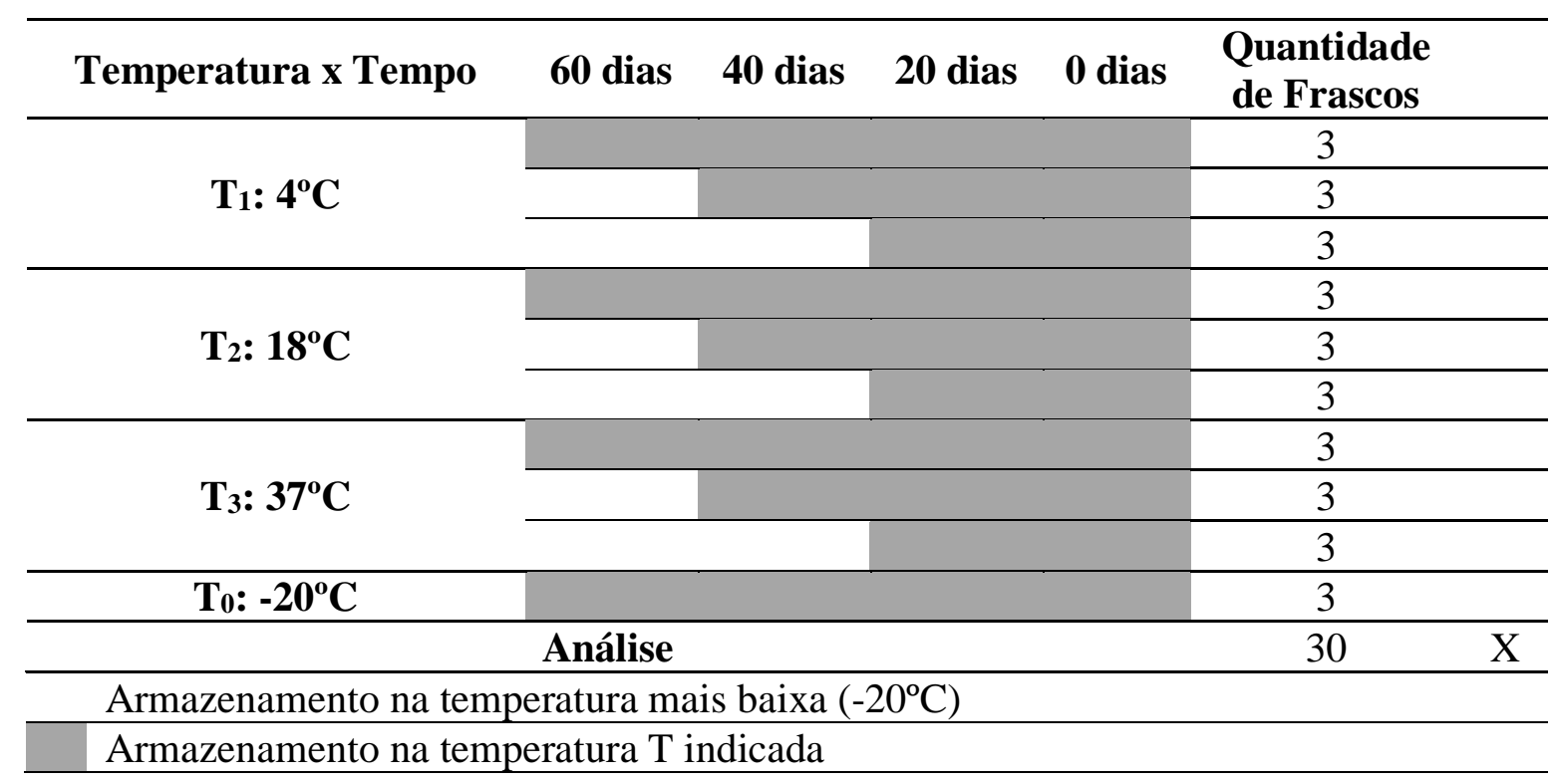

Figura 51 - Estudo isócrono de estabilidade a curto prazo, $37^{\circ} \mathrm{C}$ e $100 \%$ U.R.
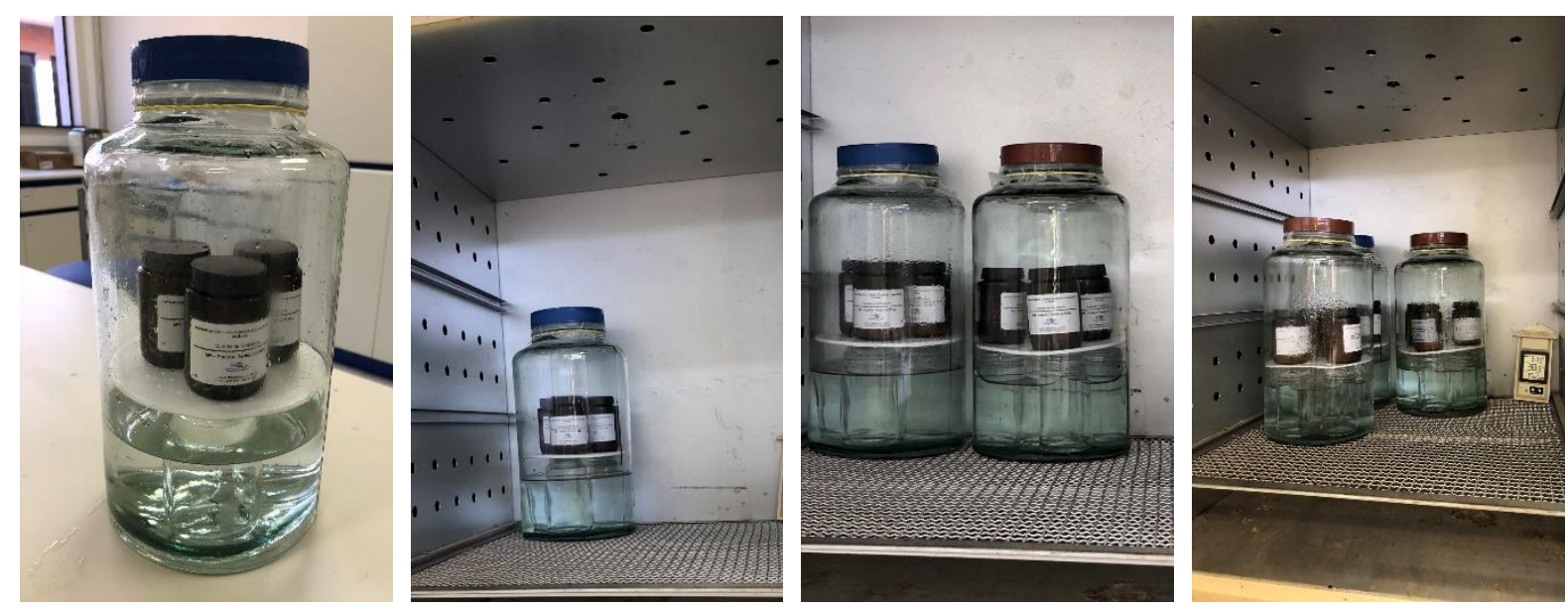


\subsubsection{Estabilidade a Longo Prazo}

Para o estudo de estabilidade a longo prazo, frascos do material candidato estão sendo selecionados aleatoriamente e armazenados em diferentes temperaturas $\left(-20^{\circ} \mathrm{C}, 4^{\circ} \mathrm{C}, 18^{\circ} \mathrm{C}\right)$ por períodos de tempo de 3, 6, 9 e 12 meses (Tabela 30). Este estudo será realizado entre junho de 2018 e junho de 2019.

Tabela 30 - Planejamento isócrono para estudo de estabilidade a longo prazo

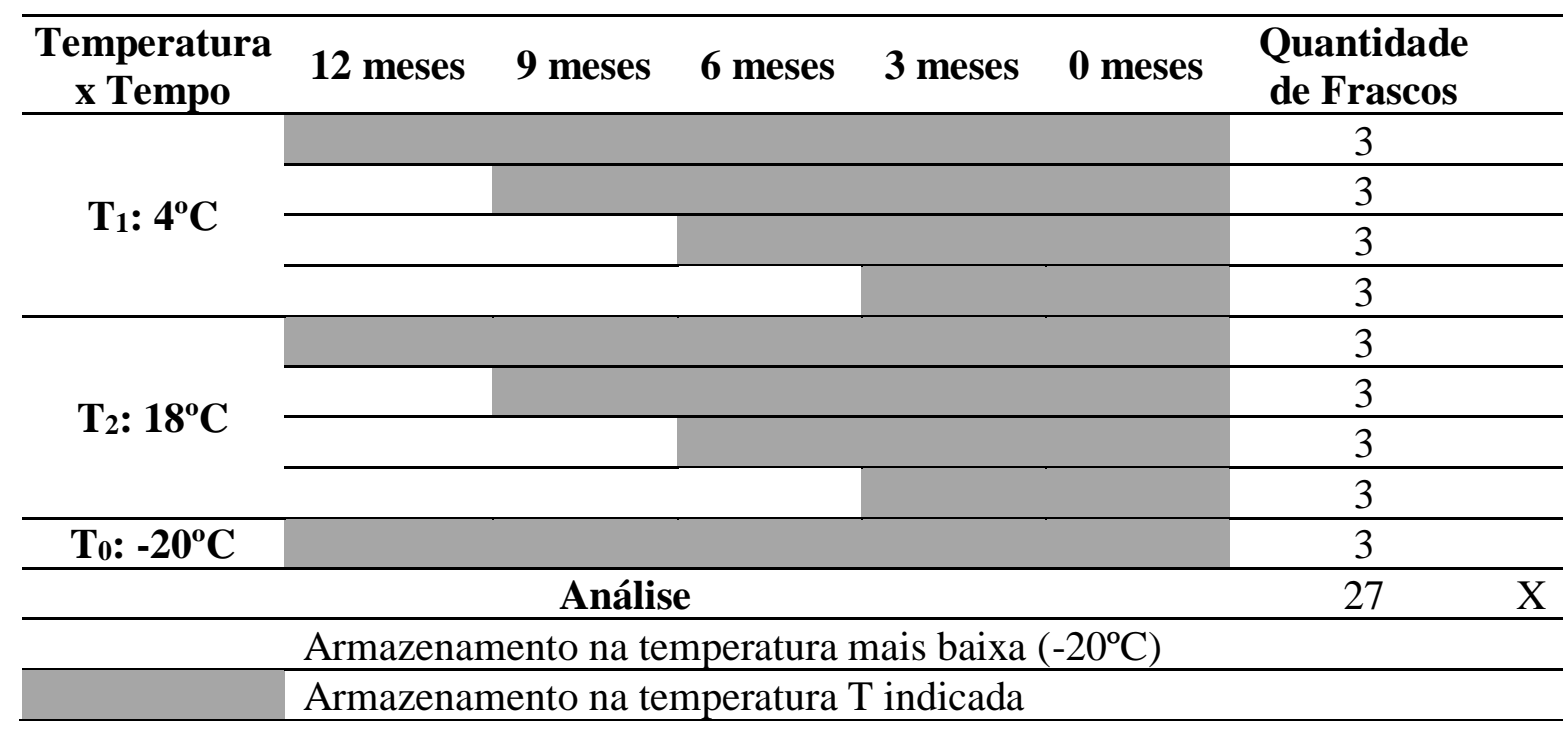

Assim como no estudo a curto prazo, após o tempo de exposição, as massas características de As, Ba, Ca, Co, Cr, Cu, Fe, K, Mg, Mn, Mo, Na, Ni, P, Se, Sr, Ti, V e Zn serão determinadas por ICP OES e/ou ICP-MS em seis replicatas para cada frasco e será realizada uma comparação dos valores obtidos para as várias temperaturas com aqueles obtidos para os frascos controle, armazenados na temperatura de referência a $-20^{\circ} \mathrm{C}$.

A avaliação da estabilidade a longo prazo do material será feita pela análise de resíduos da regressão em conjunto com a análise de variância com fator único (ANOVA) em um nível de significância de $5 \%(\alpha=0,05)$. Os cálculos das incertezas serão realizados conforme o ABNT ISO Guia 35. 


\subsection{Ensaio Colaborativo}

Conforme mencionado no item 2.7 do Capítulo 2, o ABNT ISO Guia 35 (2012) estabelece quatro abordagens tecnicamente válidas para caracterizar o material de referência. Tais abordagens incluem a realização de medições empregando-se: um método único, primário, definitivo em um único laboratório; por dois ou mais métodos de referência independentes em um laboratório; por uma rede de laboratórios que utilizam um ou mais métodos de exatidão demonstrável; uma abordagem de ensaio colaborativo que forneça apenas valores de propriedades avaliados para este método. Assim como foi realizado para o RM de ração para peixe, pretende-se empregar, para o RM candidato de tecido de peixe, o método específico, através do ensaio colaborativo, de forma a obter valores de propriedades avaliados através de diferentes técnicas analíticas.

Foram elaborados os documentos orientativos e as cartas convites, que estão sendo distribuídos aos possíveis participantes. Os elementos de interesse são $\mathrm{As}, \mathrm{Ba}, \mathrm{Ca}, \mathrm{Co}, \mathrm{Cr}, \mathrm{Cu}$, $\mathrm{Fe}, \mathrm{K}, \mathrm{Mg}, \mathrm{Mn}, \mathrm{Mo}, \mathrm{Na}, \mathrm{Ni}, \mathrm{P}, \mathrm{Se}, \mathrm{Sr}, \mathrm{Ti}, \mathrm{V}$ e Zn, contudo os participantes são convidados a avaliar também $\mathrm{Hg}$ e quaisquer outros elementos que sejam de interesse. Solicita-se que os participantes realizem seis determinações independentes dos elementos no frasco recebido, com emprego de métodos de escolha, disponíveis em seus laboratórios, enviando os resultados expressos em $\mathrm{mg} \mathrm{kg}^{-1}$, em base seca. Junto com os frascos do RM candidato estão sendo enviadas planilhas de cadastro e registro dos resultados e informações especificas das análises.

O tratamento dos resultados do ensaio colaborativo será realizado através de diversas ferramentas estatísticas como o teste de Grubbs para identificação de dados anômalos e exclusão de outliers significativos, o teste de Cochran para verificar a homogeneidade das variâncias e a análise de variância (ANOVA) de fator único. 


\section{RESULTADOS E DISCUSSÕES}

\subsection{Distribuição de Tamanho de Partícula}

Na Figura 52 é apresentado o perfil de distribuição granulométrica típica do material de tecido de peixe candidato a material de referência. Observa-se apenas um pico na curva, isto significa que a distribuição do tamanho de partícula do material tem uma distribuição homogênea. Este resultado é muito importante, pois distribuições granulométricas multimodais podem inviabilizar a homogeneidade do material candidato a RM. O estudo mostrou que $10 \%$ abaixo de $5 \mu \mathrm{m}, 50 \%$ abaixo de $168 \mu \mathrm{m}$ e $90 \%$ abaixo de $418 \mu \mathrm{m}$.

Figura 52 - Curva da distribuição granulométrica do material de tecido de peixe candidato a material de referência.

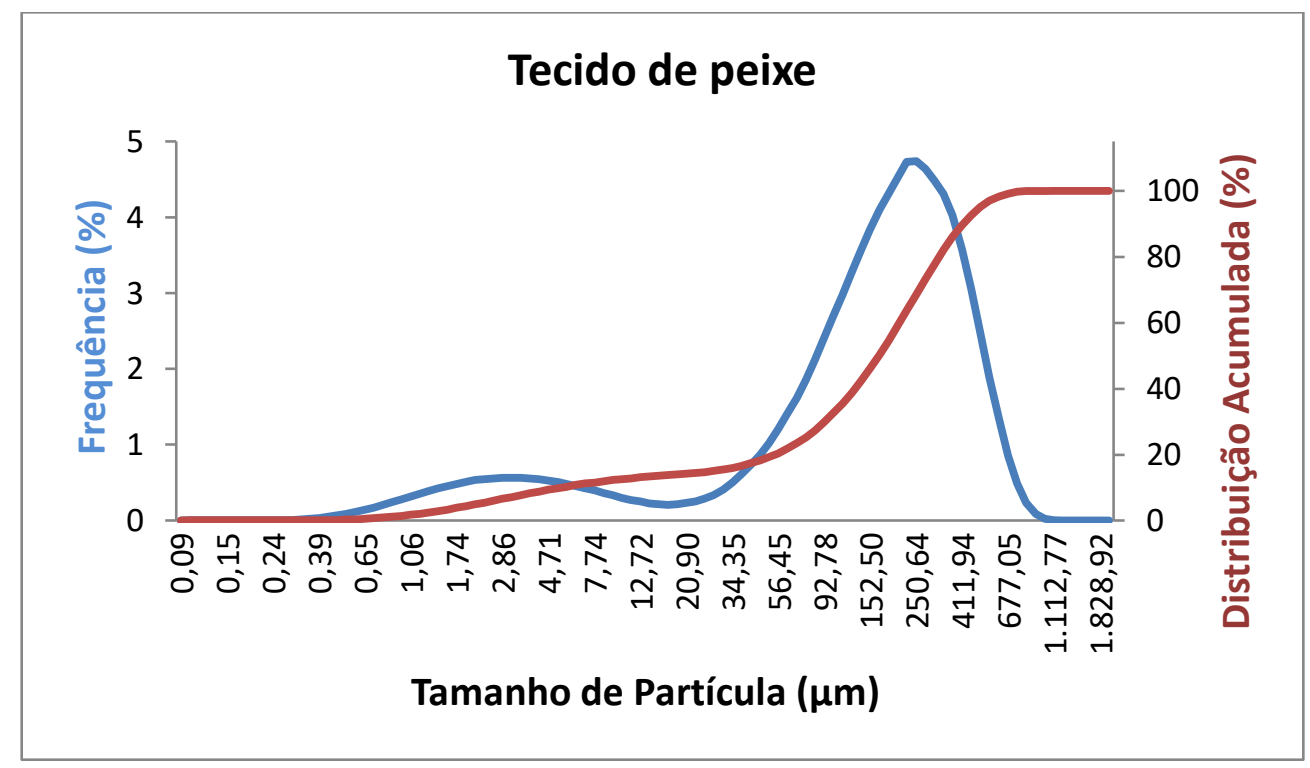

\subsection{Determinação da Umidade Residual}

Foram sorteados aleatoriamente 6 frascos $(52,158,294,345,474$ e 547) e foi conduzido o estudo de umidade residual conforme apresentado anteriormente. Foi observado um resultado médio de 3\% ( $\mathrm{n}=36)$. A Tabela 31 apresenta todos os dados obtidos neste estudo. 
Tabela 31 - Umidade residual do RM candidato de tecido de peixe.

\begin{tabular}{|c|c|c|c|c|c|}
\hline Amostra & $\mathbf{m}_{\text {cad }}$ & $\mathbf{m}_{\text {amostra }}$ & $\mathbf{m}_{\mathrm{cad}}+\mathrm{MS}$ & MS (\%) & $\begin{array}{c}\text { Umidade } \\
\text { residual (\%) }\end{array}$ \\
\hline F052-1 & 8,8463 & 1,0052 & 9,8204 & 96,9061 & 3,0939 \\
\hline F052-2 & 8,7344 & 1,0071 & 9,7101 & 96,8821 & 3,1179 \\
\hline F052-3 & 8,4087 & 1,0043 & 9,3823 & 96,9431 & 3,0569 \\
\hline F052-4 & 8,5549 & 1,0054 & 9,5301 & 96,9962 & 3,0038 \\
\hline F052-5 & 7,9014 & 1,0085 & 8,8796 & 96,9955 & 3,0045 \\
\hline F052-6 & 8,7329 & 1,0013 & 9,7057 & 97,1537 & 2,8463 \\
\hline F158-1 & 9,0473 & 1,0016 & 10,0204 & 97,1546 & 2,8454 \\
\hline F158-2 & 8,2605 & 1,0042 & 9,2326 & 96,8034 & 3,1966 \\
\hline F158-3 & 9,0615 & 1,0090 & 10,0389 & 96,8682 & 3,1318 \\
\hline F158-4 & 8,8377 & 1,0040 & 9,8112 & 96,9622 & 3,0378 \\
\hline F158-5 & 9,5540 & 1,0064 & 10,5301 & 96,9893 & 3,0107 \\
\hline F158-6 & 8,0239 & 1,0044 & 8,9993 & 97,1127 & 2,8873 \\
\hline F294-1 & 8,9464 & 1,0033 & 9,9200 & 97,0398 & 2,9602 \\
\hline F294-2 & 9,1669 & 1,0130 & 10,1485 & 96,9003 & 3,0997 \\
\hline F294-3 & 8,9252 & 1,0481 & 9,9399 & 96,8133 & 3,1867 \\
\hline F294-4 & 9,1486 & 1,0154 & 10,1321 & 96,8584 & 3,1416 \\
\hline F294-5 & 8,1969 & 1,0170 & 9,1797 & 96,6372 & 3,3628 \\
\hline F294-6 & 9,1874 & 1,0020 & 10,1596 & 97,0259 & 2,9741 \\
\hline F345-1 & 8,9594 & 1,0154 & 9,9504 & 97,5970 & 2,4030 \\
\hline F345-2 & 8,5231 & 1,0056 & 9,5047 & 97,6134 & 2,3866 \\
\hline F345-3 & 9,1275 & 1,0139 & 10,1122 & 97,1200 & 2,8800 \\
\hline F345-4 & 8,1440 & 1,0055 & 9,1210 & 97,1656 & 2,8344 \\
\hline F345-5 & 8,5858 & 1,0072 & 9,5632 & 97,0413 & 2,9587 \\
\hline F345-6 & 9,0235 & 1,0010 & 9,9969 & 97,2428 & 2,7572 \\
\hline F474-1 & 8,3744 & 1,0090 & 9,3555 & 97,2349 & 2,7651 \\
\hline F474-2 & 8,9967 & 1,0039 & 9,9725 & 97,2009 & 2,7991 \\
\hline F474-3 & 7,7979 & 1,0016 & 8,7748 & 97,5339 & 2,4661 \\
\hline F474-4 & 7,1212 & 1,0054 & 8,0971 & 97,0658 & 2,9342 \\
\hline F474-5 & 8,7866 & 1,0109 & 9,7697 & 97,2500 & 2,7500 \\
\hline F474-6 & 8,6411 & 1,0060 & 9,6184 & 97,1471 & 2,8529 \\
\hline F547-1 & 9,3735 & 1,0785 & 10,4184 & 96,8846 & 3,1154 \\
\hline F547-2 & 8,4313 & 1,0040 & 9,4037 & 96,8526 & 3,1474 \\
\hline F547-3 & 8,6931 & 1,0260 & 9,6836 & 96,5400 & 3,4600 \\
\hline F547-4 & 9,0217 & 1,0044 & 9,9916 & 96,5651 & 3,4349 \\
\hline F547-5 & 8,1703 & 1,0050 & 9,1396 & 96,4478 & 3,5522 \\
\hline F547-6 & 9,5978 & 1,0057 & 10,5683 & 96,5000 & 3,5000 \\
\hline
\end{tabular}


3.3 Caracterização de alguns parâmetros de validação das metodologias empregadas

\subsubsection{Limite de Detecção e Quantificação}

Para a estimativa dos Limites de Detecção (LOD) e Quantificação (LOQ) foram utilizadas as equações 13 a 16, apresentadas no Capítulo 2. Os limites de detecção e quantificação para as análises por ICP OES e ICP-MS, calculados, assim como a faixa linear estão apresentados nas Tabela 32 e 33.

Tabela 32 - Limites de detecção, quantificação, faixa linear, comprimento de onda e orientação da tocha na determinação dos elementos $\mathrm{Ca}, \mathrm{Fe}, \mathrm{K}, \mathrm{Mg}, \mathrm{Na}, \mathrm{P}$ e Zn, por ICP OES.

\begin{tabular}{cccccr}
\hline Elemento & Comprimento de onda $(\mathbf{n m})$ & $\begin{array}{c}\text { Faixa Linear }(\mathbf{m g} \\
\left.\mathbf{L}^{\mathbf{- 1}}\right)\end{array}$ & $\mathbf{L O D}\left(\mathbf{m g} \mathbf{L}^{-\mathbf{1}}\right)$ & $\mathbf{L O Q}\left(\mathbf{m g} \mathbf{L}^{\mathbf{- 1}}\right)$ & $\mathbf{R}^{\mathbf{2}}$ \\
\hline $\mathbf{C a}$ & $422,673^{\mathrm{c}}$ & $0,01-10$ & 0,043 & 0,144 & 0,9999 \\
\hline $\mathbf{F e}$ & $238,204^{\mathrm{c}}$ & $0,01-2$ & 0,0008 & 0,0028 & 0,9999 \\
\hline $\mathbf{K}$ & $766,491^{\mathrm{b}}$ & $1-100$ & 0,0347 & 0,1155 & 0,9999 \\
\hline $\mathbf{M g}$ & $285,213^{\mathrm{c}}$ & $0,01-20$ & 0,0042 & 0,0140 & 0,9994 \\
\hline $\mathbf{N a}$ & $589,592^{\mathrm{b}}$ & $0,1-100$ & 0,0045 & 0,0149 & 0,9999 \\
\hline $\mathbf{P}$ & $213,618^{\mathrm{a}}$ & $1-100$ & 0,0134 & 0,0446 & 0,9995 \\
\hline $\mathbf{Z n}$ & $213,857^{\mathrm{b}}$ & $0,01-2$ & 0,0015 & 0,0051 & 0,9994 \\
\hline
\end{tabular}

a - vista axial; $\mathrm{b}$ - vista radial e c - SVDV

Tabela 33 - Limites de detecção e quantificação, uso de padrões internos e de célula de colisão na determinação dos isótopos por ICP-MS.

\begin{tabular}{ccccc}
\hline Isótopo & Célula de Colisão & Padrão Interno & LOD $\left(\boldsymbol{\mu g} \mathbf{L}^{-\mathbf{1}}\right)$ & LOQ $\left(\boldsymbol{\mu g} \mathbf{L}^{-\mathbf{1}}\right)$ \\
\hline${ }^{75} \mathrm{As}$ & - & - & 0,011 & 0,035 \\
\hline${ }^{137} \mathrm{Ba}$ & - & - & 0,046 & 0,152 \\
\hline${ }^{59} \mathrm{Co}$ & - & - & 0,003 & 0,011 \\
\hline${ }^{53} \mathrm{Cr}$ & - & ${ }^{103} \mathrm{Rh}$ & 0,034 & 0,113 \\
\hline${ }^{63} \mathrm{Cu}$ & - & ${ }^{74} \mathrm{Ge}$ & 0,025 & 0,084 \\
\hline${ }^{55} \mathrm{Mn}$ & $\mathrm{He}$ & ${ }^{74} \mathrm{Ge}$ & 0,025 & 0,085 \\
\hline${ }^{96} \mathrm{Mo}$ & $\mathrm{He}$ & - & 0,012 & 0,040 \\
\hline${ }^{60} \mathrm{Ni}$ & $\mathrm{He}$ & - & 0,040 & 0,134 \\
\hline${ }^{78} \mathrm{Se}$ & $\mathrm{He}$ & - & 0,372 & 1,239 \\
\hline${ }^{88} \mathrm{Sr}$ & - & - & 0,079 & 0,263 \\
\hline${ }^{48} \mathrm{Ti}$ & $\mathrm{He}$ & ${ }^{74} \mathrm{Ge}$ & 0,074 & 0,246 \\
\hline${ }^{51} \mathrm{~V}$ & $\mathrm{He}$ & ${ }^{74} \mathrm{Ge}$ & 0,012 & 0,039 \\
\hline
\end{tabular}




\subsubsection{Análise de Materiais de Referência Certificados}

Para validação do método, foram utilizados dois CRMs: NIST 1566b - Oyster Tissue e DOLT-5 - Dogfish liver e o RM IPEN 001 - Trace element in fish tissue. Foram escolhidas três linhas de emissão em ICP OES para cada elemento, sendo definidas para os estudos subsequentes as linhas que apresentaram os menores valores de coeficiente de variação e os melhores valores de recuperação em relação aos RMs avaliados.

Na Tabela 34 são apresentadas as médias das frações de massa obtidas por ICP OES, que se apresentaram dentro do valor certificado para $\mathrm{Ca}, \mathrm{Fe}, \mathrm{K}, \mathrm{Mg}, \mathrm{Na}, \mathrm{P}$ e $\mathrm{Zn}$ garantindo assim uma boa precisão nos resultados. Foi realizado o teste $t$-student não pareado, de modo que os elementos avaliados não demonstraram diferença significativa entre os resultados obtidos e os valores certificados, em um nível de $95 \%$ de confiança.

Tabela 34 - Média dos teores obtidos para os CRMs DOLT-5, NIST 1566b e RM FT-IPEN ( $\mathrm{n}=6$ ), determinados por ICP OES (base úmida).

\begin{tabular}{|c|c|c|c|c|c|c|c|c|c|}
\hline \multirow[b]{2}{*}{ Elemento } & \multicolumn{3}{|c|}{ DOLT- 5} & \multicolumn{3}{|c|}{ NIST 1566b } & \multicolumn{3}{|c|}{ Fish Tissue - IPEN } \\
\hline & $\begin{array}{c}\text { Valor } \\
\text { certificado } \\
\left(\mathrm{mg} \mathrm{kg}^{-1}\right)\end{array}$ & $\begin{array}{l}\text { Determinado } \\
\left(\mathrm{mg} \mathrm{kg}^{-1}\right)\end{array}$ & $\begin{array}{l}\text { Rec. } \\
(\%)\end{array}$ & $\begin{array}{c}\text { Valor } \\
\text { certificado } \\
\left(\mathrm{mg} \mathrm{kg}^{-1}\right)\end{array}$ & $\begin{array}{l}\text { Determinado } \\
\left(\mathrm{mg} \mathrm{kg}^{-1}\right)\end{array}$ & $\begin{array}{l}\text { Rec. } \\
(\%)\end{array}$ & $\begin{array}{c}\text { Valor } \\
\text { certificado } \\
\left(\mathrm{mg} \mathrm{kg}^{-1}\right)\end{array}$ & $\begin{array}{l}\text { Determinado } \\
\left(\mathrm{mg} \mathrm{kg}^{-1}\right)\end{array}$ & $\begin{array}{l}\text { Rec. } \\
(\%)\end{array}$ \\
\hline $\mathbf{C a}$ & $550 \pm 80$ & $\begin{array}{c}620,93 \pm \\
27,46\end{array}$ & 112,9 & $838 \pm 20$ & $\begin{array}{c}834,32 \pm \\
18,70\end{array}$ & 99,6 & - & $\begin{array}{c}752,20 \pm \\
17,19\end{array}$ & - \\
\hline $\mathbf{F e}$ & $1070 \pm 80$ & $956,49 \pm 5,39$ & 89,4 & $205,8 \pm 6,8$ & $181,70 \pm 6,00$ & 88,3 & $\begin{array}{c}13,55 \pm \\
1,05\end{array}$ & $11,98 \pm 0,30$ & 88,4 \\
\hline $\mathbf{K}$ & $\begin{array}{c}14400 \pm \\
3000\end{array}$ & $13847 \pm 51$ & 96,2 & $6520 \pm 90$ & $5997 \pm 78$ & 92,0 & $\begin{array}{c}12555 \pm \\
490\end{array}$ & $12336 \pm 171$ & 98,3 \\
\hline Mg & $940 \pm 100$ & $827,17 \pm 3,89$ & 88,0 & $1085 \pm 23$ & $\begin{array}{c}928,15 \pm \\
19,44\end{array}$ & 85,5 & - & $1005 \pm 17$ & - \\
\hline $\mathbf{N a}$ & $\begin{array}{c}9900 \pm \\
1600\end{array}$ & $10472 \pm 158$ & 105,8 & $3297 \pm 53$ & $2993 \pm 46$ & 91,5 & $4775 \pm 145$ & $4729 \pm 64$ & 99,1 \\
\hline $\mathbf{P}$ & $11500 * *$ & $11105 \pm 190$ & 96,6 & - & $6970 \pm 114$ & - & - & $7078 \pm 90$ & - \\
\hline $\mathbf{Z n}$ & $105,3 \pm 5,4$ & $86,62 \pm 0,11$ & 82,3 & $1424 \pm 46$ & $1169 \pm 22$ & 82,1 & $\begin{array}{c}16,65 \pm \\
0,50\end{array}$ & $14,41 \pm 0,27$ & 86,5 \\
\hline
\end{tabular}

(média \pm desvio padrão) *valor de referência; ** valor informativo

Conforme mencionado no item 2.4.1 deste Capítulo, para as determinações por ICPMS, foi necessário fazer a otimização das melhores condições para a determinação dos isótopos ${ }^{75} \mathrm{As},{ }^{137} \mathrm{Ba},{ }^{59} \mathrm{Co},{ }^{53} \mathrm{Cr},{ }^{63} \mathrm{Cu},{ }^{55} \mathrm{Mn},{ }^{96} \mathrm{Mo},{ }^{60} \mathrm{Ni},{ }^{78} \mathrm{Se},{ }^{88} \mathrm{Sr},{ }^{48} \mathrm{Ti}$ e ${ }^{51} \mathrm{~V}$. As condições estudadas para o ICP-MS foram: modo no gas (sem célula de colisão) com e sem adição online de solução de $10 \mu \mathrm{g} \mathrm{kg}{ }^{-1}$ de padrões internos de ${ }^{74} \mathrm{Ge}^{+} \mathrm{e}^{103} \mathrm{Rh}^{+}$; com o uso da célula de colisão $(4,5 \mathrm{~mL}$ $\min ^{-1}$ de He), utilizando ou não os padrões internos. Os padrões internos são comumente 
empregados para a correção de possíveis efeitos de transporte. Na Tabela 35 são apresentados os valores obtidos em relação à recuperação dos analitos-alvo nos RMs avaliados. Os melhores valores de recuperação estão destacados em negrito e refletem as condições utilizadas para avaliação do RM candidato de tecido de peixe.

Tabela 35 - Recuperações (\%) obtidas para as diferentes condições de operação do ICP-MS (n=6).

\begin{tabular}{|c|c|c|c|c|c|c|c|}
\hline Isótopos & RMs & $\begin{array}{l}\text { Modo } \\
\text { no gas }\end{array}$ & $\begin{array}{l}\text { Modo no gas } \\
{ }^{74} \mathrm{Ge}\end{array}$ & $\begin{array}{l}\text { Modo no gas } \\
{ }^{103} \mathrm{Rh}\end{array}$ & $\begin{array}{c}\text { Modo He } \\
\left(4,5 \mathrm{~mL} \mathrm{~min}^{-1}\right)\end{array}$ & $\begin{array}{l}\text { Modo He } \\
{ }^{74} \mathrm{Ge}\end{array}$ & $\begin{array}{l}\text { Modo He } \\
{ }^{103} \mathrm{Rh}\end{array}$ \\
\hline \multirow{3}{*}{${ }^{75} \mathrm{As}$} & DOLT-5 & 88 & 85 & 84 & 87 & 87 & 85 \\
\hline & NIST 1566b & 96 & 90 & 94 & 93 & 95 & 90 \\
\hline & FT-IPEN & 89 & 86 & 88 & 83 & 84 & 85 \\
\hline \multirow{3}{*}{${ }^{137} \mathbf{B a}$} & DOLT-5 & - & - & - & - & - & - \\
\hline & NIST 1566b & 88 & 81 & 84 & 85 & 84 & 82 \\
\hline & FT-IPEN & - & - & - & - & - & - \\
\hline \multirow{3}{*}{${ }^{59} \mathrm{Co}$} & DOLT-5 & 98 & 86 & 94 & 81 & 84 & 81 \\
\hline & NIST 1566b & 94 & 88 & 94 & 89 & 96 & 88 \\
\hline & FT-IPEN & - & - & - & - & - & - \\
\hline \multirow{3}{*}{${ }^{53} \mathrm{Cr}$} & DOLT-5 & 83 & 81 & 89 & 86 & 85 & 85 \\
\hline & NIST 1566b & - & - & - & - & - & - \\
\hline & FT-IPEN & - & - & - & - & - & - \\
\hline \multirow{3}{*}{${ }^{63} \mathrm{Cu}$} & DOLT-5 & 93 & 99 & 88 & 94 & 97 & 92 \\
\hline & NIST 1566b & 94 & 101 & 93 & 95 & 101 & 92 \\
\hline & FT-IPEN & 110 & 108 & 123 & 114 & 125 & 122 \\
\hline \multirow{3}{*}{${ }^{55} \mathrm{Mn}$} & DOLT-5 & 94 & 88 & 87 & 92 & 102 & 90 \\
\hline & NIST 1566b & 95 & 88 & 92 & 91 & 106 & 89 \\
\hline & FT-IPEN & 35 & 26 & 30 & 71 & 72 & 72 \\
\hline \multirow{3}{*}{${ }^{96} \mathrm{Mo}$} & DOLT-5 & 91 & 88 & 86 & 95 & 91 & 89 \\
\hline & NIST 1566b & - & - & - & - & - & - \\
\hline & FT-IPEN & - & - & - & - & - & - \\
\hline \multirow{3}{*}{${ }^{60} \mathrm{Ni}$} & DOLT-5 & 80 & 76 & 75 & 94 & 82 & 85 \\
\hline & NIST 1566b & 84 & 82 & 84 & 92 & 88 & 90 \\
\hline & FT-IPEN & - & - & - & - & - & - \\
\hline \multirow{3}{*}{${ }^{78} \mathrm{Se}$} & DOLT-5 & $<\mathrm{LOD}$ & $<\mathrm{LOD}$ & $<\mathrm{LOD}$ & 108 & 64 & 81 \\
\hline & NIST 1566b & $<\mathrm{LOD}$ & $<\mathrm{LOD}$ & $<\mathrm{LOD}$ & 99 & 85 & 92 \\
\hline & FT-IPEN & $\angle \mathrm{LOD}$ & $<\mathrm{LOD}$ & $<\mathrm{LOD}$ & 94 & 77 & 100 \\
\hline \multirow{3}{*}{${ }^{88} \mathrm{Sr}$} & DOLT-5 & 90 & 84 & 83 & 84 & 85 & 82 \\
\hline & NIST 1566b & 92 & 86 & 89 & 88 & 92 & 85 \\
\hline & FT-IPEN & - & - & - & - & - & - \\
\hline \multirow{3}{*}{${ }^{48} \mathrm{Ti}$} & DOLT-5 & - & - & - & - & - & - \\
\hline & NIST 1566b & 114 & 110 & 110 & 87 & 97 & 88 \\
\hline & FT-IPEN & - & - & - & - & - & - \\
\hline \multirow{3}{*}{${ }^{51} \mathrm{~V}$} & DOLT-5 & 111 & 108 & 110 & 90 & 97 & 89 \\
\hline & NIST 1566b & 97 & 98 & 96 & 94 & 106 & 92 \\
\hline & FT-IPEN & - & - & - & - & - & - \\
\hline
\end{tabular}


Na Tabela 36 são apresentados os valores médios de concentração obtidos em relação à recuperação para As, $\mathrm{Ba}, \mathrm{Co}, \mathrm{Cr}, \mathrm{Cu}, \mathrm{Mn}, \mathrm{Mo}, \mathrm{Ni}, \mathrm{Se}, \mathrm{Sr}$, Ti e V. Foi realizado o $t$ de Student não pareado, de modo que os elementos avaliados não demonstraram diferença significativa entre os resultados obtidos e os valores certificados, em um nível de 95\% de confiança. Dessa forma, pode-se confirmar a exatidão do método de decomposição e de determinação por ICPMS.

Tabela 36 - Média dos teores obtidos para os CRMs DOLT-5, NIST 1566b e RM FT-IPEN (n=6), determinados por ICP-MS.

\begin{tabular}{|c|c|c|c|c|c|c|c|c|c|}
\hline \multirow[b]{2}{*}{ Elemento } & \multicolumn{3}{|c|}{ DOLT - 5} & \multicolumn{3}{|c|}{ NIST 1566b } & \multicolumn{3}{|c|}{ Fish Tissue - IPEN } \\
\hline & $\begin{array}{c}\begin{array}{c}\text { Valor } \\
\text { certificado } \\
\left(\mathrm{mg} \mathrm{kg}^{-1}\right)\end{array} \\
\end{array}$ & $\begin{array}{c}\text { Determinado } \\
\left(\mathrm{mg} \mathrm{kg}^{-1}\right)\end{array}$ & $\begin{array}{l}\text { Rec. } \\
(\%)\end{array}$ & $\begin{array}{c}\text { Valor } \\
\text { certificado } \\
\left(\mathrm{mg} \mathrm{kg}^{-1}\right) \\
\end{array}$ & $\begin{array}{c}\text { Determinado } \\
\left(\mathrm{mg} \mathrm{kg}^{-1}\right)\end{array}$ & $\begin{array}{l}\text { Rec. } \\
(\%)\end{array}$ & $\begin{array}{c}\text { Valor } \\
\text { certificado } \\
\left(\mathrm{mg} \mathrm{kg}^{-1}\right) \\
\end{array}$ & $\begin{array}{c}\text { Determinado } \\
\left(\mathrm{mg} \mathrm{kg}^{-1}\right)\end{array}$ & $\begin{array}{l}\text { Rec. } \\
(\%)\end{array}$ \\
\hline As & $34,6 \pm 2,4$ & $30,50 \pm 0,06$ & 88 & $7,65 \pm 0,65$ & $7,37 \pm 0,05$ & 96 & $5,9 \pm 0,27$ & $5,232 \pm 0,007$ & 89 \\
\hline $\mathrm{Ba}$ & - & - & - & $8,6 \pm 0,3^{*}$ & $7,54 \pm 0,15$ & 88 & - & - & - \\
\hline Co & $\begin{array}{c}0,267 \pm \\
0,026\end{array}$ & $0,262 \pm 0,008$ & 98 & $\begin{array}{c}0,371 \pm \\
0,009 \\
\end{array}$ & $0,347 \pm 0,008$ & 94 & - & - & - \\
\hline $\mathrm{Cr}$ & $\begin{array}{l}2,35 \pm \\
0,58^{*}\end{array}$ & $2,10 \pm 0,04$ & 89 & - & - & - & - & - & - \\
\hline $\mathrm{Cu}$ & $35,0 \pm 2,4$ & $34,6 \pm 0,96$ & 99 & $71,6 \pm 1,6$ & $72,35 \pm 1,76$ & 101 & $1,16 \pm 0,07$ & $1,25 \pm 0,41$ & 108 \\
\hline $\mathrm{Mn}$ & $\begin{array}{c}8,91 \pm \\
0,70^{*} \\
\end{array}$ & $9,10 \pm 0,56$ & 102 & $18,5 \pm 0,2$ & $19,63 \pm 1,08$ & 106 & $\begin{array}{l}0,37 \pm \\
0,0027 \\
\end{array}$ & $0,267 \pm 0,006$ & 72 \\
\hline Mo & $1,41 \pm 0,22$ & $1,34 \pm 0,22$ & 95 & - & - & - & - & - & - \\
\hline $\mathrm{Ni}$ & $\begin{array}{c}1,71 \pm \\
0,56^{*} \\
\end{array}$ & $1,61 \pm 0,28$ & 94 & $1,04 \pm 0,09$ & $0,95 \pm 0,01$ & 92 & - & - & - \\
\hline $\mathrm{Se}$ & $8,3 \pm 1,8$ & $8,99 \pm 1,22$ & 108 & $2,06 \pm 0,15$ & $2,03 \pm 0,41$ & 99 & $2,95 \pm 0,14$ & $2,77 \pm 0,50$ & 94 \\
\hline $\mathrm{Sr}$ & $3,73 \pm 0,26$ & $3,35 \pm 0,21$ & 90 & $6,8 \pm 0,2^{*}$ & $6,24 \pm 0,31$ & 92 & - & - & - \\
\hline $\mathrm{Ti}$ & - & - & - & $\begin{array}{c}12,24 \pm \\
0,39 * \\
\end{array}$ & $11,87 \pm 1,03$ & 97 & - & - & - \\
\hline V & $0,51 \pm 0,06$ & $0,49 \pm 0,02$ & 97 & $\begin{array}{c}0.577 \pm \\
0.023\end{array}$ & $0,612 \pm 0,033$ & 106 & - & - & - \\
\hline
\end{tabular}

*valor de referência

\subsection{Estudo de Homogeneidade}

\subsubsection{Avaliação Inicial}

Assim como foi feito para o RM de ração para peixe, para a avaliação e interpretação dos dados, foi utilizada análise multivariada de componentes principais (PCA) executada no Software Pirouette ${ }^{\circledR}$ 4.0, com 500 frascos do lote preparado. Antes de efetuar estas análises, os 
espectros de NIR foram normalizados, a primeira derivada foi aplicada e, então, os espectros foram centrados na média.

Baseado na avaliação da homogeneidade pela PCA foi possível determinar que com as com as duas primeiras componentes principais é possível descrever 97,9\% da variância explicada para a avaliação entre frascos. Tendo em vista que a PCA possibilita o agrupamento de amostras com composição química similar, avaliada pelos espectros NIR, o gráfico de scores para a avaliação entre frascos (Figura 53), sugere uma boa correlação para a maioria dos 500 frascos avaliados e suas repetições, num intervalo de $95 \%$ de confiança (intervalo delineado pela elipse no gráfico de scores). Contudo, com base nesta avaliação inicial, decidiu-se pela exclusão de 27 frascos do lote, uma vez que eles se caracterizam como outliers nessa avaliação. Os frascos removidos do lote foram: 2, 3, 4, 36, 40, 65, 70, 93, 125, 132, 154, 181, 191, 236, $244,260,275,281,300,306,360,442,501,572,577,595$ e 598.

Figura 53 - Gráfico de scores com as duas componentes principais da avaliação de homogeneidade entre frascos.

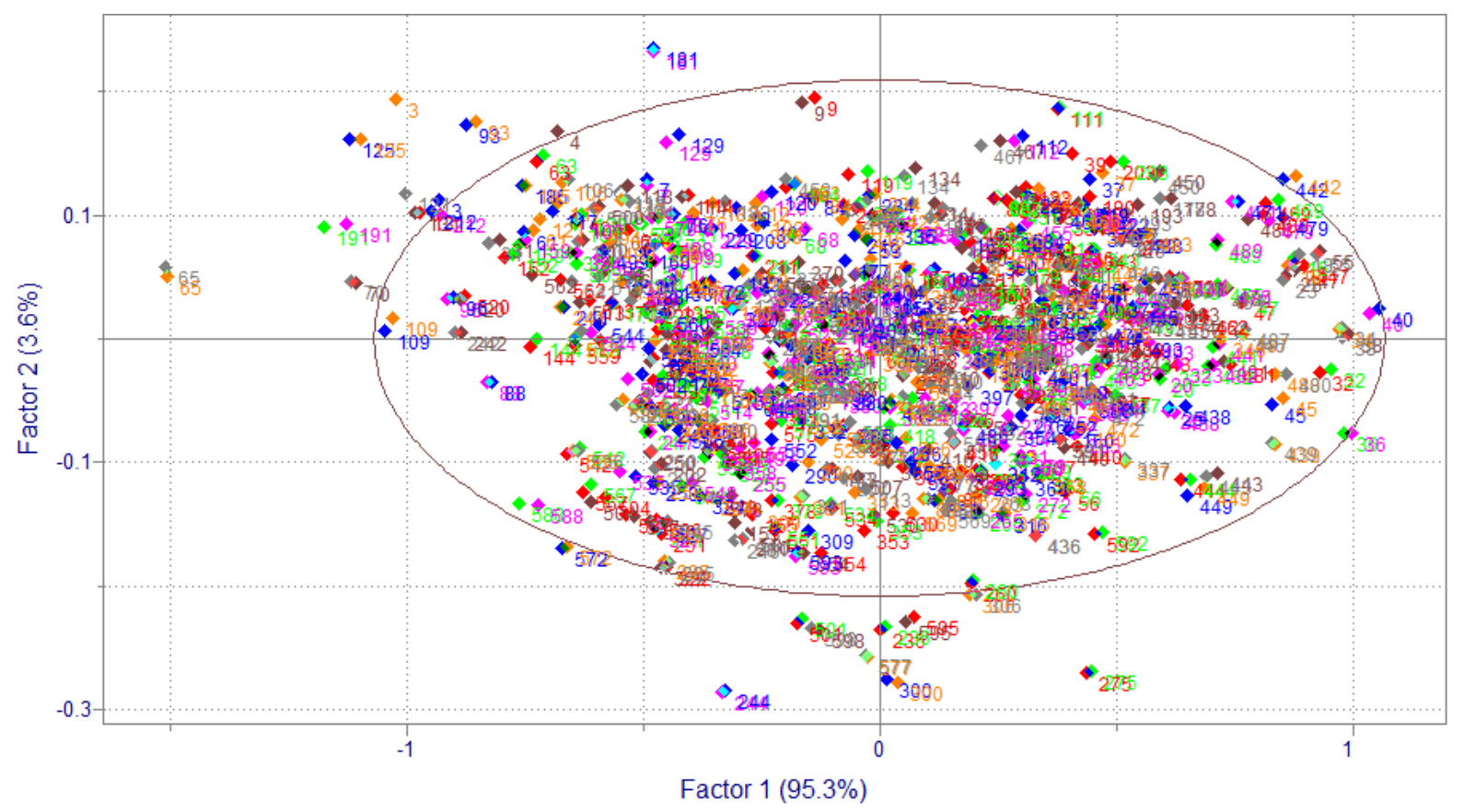

\subsubsection{Estudo de Homogeneidade Intra-frasco e Estimativa da massa mínima}

Este teste verifica se há diferença entre as porções amostradas dentro de um mesmo frasco. Este estudo foi realizado utilizando um frasco, $\mathrm{n}^{\circ} 469$, selecionado aleatoriamente, para verificar a existência de diferença entre as porções amostradas dentro de um mesmo frasco. 
Na Tabela 37 são apresentados os resultados das médias das concentrações obtidos por ICP OES e ICP-MS a partir de diferentes massas de amostra (100 mg, 200 mg, 250 mg, 300 mg e $400 \mathrm{mg}$ ), em seis sub-amostras.

Tabela 37 -Frações de massa de As, Ba, Ca, Co, Cr, Cu, Fe, K, Mg, Mn, Mo, Na, Ni, P, Se, Sr, Ti, V e $\mathrm{Zn}$, obtidas nas porções amostradas em digestão em micro-ondas com cavidade ( $\mathrm{n}=6)$.

\begin{tabular}{|c|c|c|c|c|c|c|c|c|c|c|}
\hline Elementos & $\begin{array}{l}100 \mathrm{mg} \\
(\mathrm{m} \pm \mathrm{SD})\end{array}$ & $\begin{array}{l}\text { RSD } \\
(\%)\end{array}$ & $\begin{array}{c}200 \mathrm{mg} \\
(\mathbf{m} \pm \text { SD })\end{array}$ & $\begin{array}{c}\text { RSD } \\
(\%)\end{array}$ & $\begin{array}{c}250 \mathrm{mg} \\
(\mathrm{m} \pm \mathrm{SD})\end{array}$ & $\begin{array}{c}\text { RSD } \\
(\%)\end{array}$ & $\begin{array}{c}300 \mathrm{mg} \\
(\mathbf{m} \pm \mathrm{SD})\end{array}$ & $\begin{array}{c}\text { RSD } \\
(\%)\end{array}$ & $\begin{array}{c}400 \mathrm{mg} \\
(\mathrm{m} \pm \mathrm{SD})\end{array}$ & $\begin{array}{c}\text { RSD } \\
(\%)\end{array}$ \\
\hline $\begin{array}{c}\text { As } \\
\left(\mu \mathbf{~ k g}^{-1}\right)\end{array}$ & $\begin{array}{c}45,35 \pm \\
7,00\end{array}$ & 15,42 & $\begin{array}{c}34,44 \pm \\
6,04\end{array}$ & 17,55 & $\begin{array}{c}34,72 \pm \\
2,96\end{array}$ & 8,52 & $\begin{array}{c}36,24 \pm \\
5,12\end{array}$ & 14,14 & $\begin{array}{c}36,00 \pm \\
3,67\end{array}$ & 10,20 \\
\hline $\begin{array}{c}\mathrm{Ba} \\
\left(\mu \mathrm{g} \mathrm{kg}^{-1}\right)\end{array}$ & $\begin{array}{c}286,86 \pm \\
49,67\end{array}$ & 17,32 & $\begin{array}{r}286,78 \\
\pm 71,99\end{array}$ & 25,10 & $\begin{array}{r}289,15 \\
\pm 11,74 \\
\end{array}$ & 4,06 & $\begin{array}{r}293,53 \\
\pm 48,35\end{array}$ & 16,47 & $\begin{array}{c}293,86 \pm \\
23,40\end{array}$ & 7,96 \\
\hline $\begin{array}{c}\mathrm{Ca} \\
\left(\mathrm{mg} \mathrm{kg}^{-1}\right)\end{array}$ & $\begin{array}{c}302,75 \pm \\
41,49\end{array}$ & 13,71 & $\begin{array}{r}315,26 \\
\pm 21,63 \\
\end{array}$ & 6,86 & $\begin{array}{l}333,52 \\
\pm 19,46 \\
\end{array}$ & 5,84 & $\begin{array}{c}440,54 \\
\pm 121,02 \\
\end{array}$ & 27,47 & $\begin{array}{c}443,31 \pm \\
111,10 \\
\end{array}$ & 25,06 \\
\hline $\begin{array}{c}\text { Co } \\
\left(\mu \mathbf{~ k g}^{-1}\right)\end{array}$ & $\begin{array}{c}27,16 \pm \\
2,79\end{array}$ & 10,29 & $\begin{array}{c}21,26 \pm \\
3,05\end{array}$ & 14,32 & $\begin{array}{c}19,89 \pm \\
1,60\end{array}$ & 8,03 & $\begin{array}{c}20,57 \pm \\
3,14\end{array}$ & 15,27 & $\begin{array}{c}20,10 \pm \\
6,21\end{array}$ & 30,89 \\
\hline $\begin{array}{c}\mathbf{C r} \\
\left(\mu \mathbf{~ k g}^{-1}\right)\end{array}$ & $\begin{array}{c}515,18 \pm \\
105,03\end{array}$ & 20,39 & $\begin{array}{c}671,70 \\
\pm 192,71 \\
\end{array}$ & 28,69 & $\begin{array}{c}713,36 \\
\pm 126,10 \\
\end{array}$ & 17,68 & $\begin{array}{c}694,63 \\
\pm 142,59 \\
\end{array}$ & 20,53 & & 18,17 \\
\hline$\underset{(\mu \mathrm{g} \mathrm{kg}}{\mathrm{Cu}})$ & $\begin{array}{c}893,65 \pm \\
146,18\end{array}$ & 16,36 & & 4,24 & & 3,67 & & 10,36 & & 6,17 \\
\hline $\begin{array}{c}\mathrm{Fe} \\
\left(\mathrm{mg} \mathrm{kg}^{-1}\right)\end{array}$ & $\begin{array}{c}11,79 \pm \\
1,45\end{array}$ & 12,30 & $\begin{array}{c}9,90 \pm \\
0,89\end{array}$ & 9,02 & $\begin{array}{c}10,04 \pm \\
0,26\end{array}$ & 2,58 & $\begin{array}{c}11,63 \pm \\
0,78\end{array}$ & 6,71 & $\begin{array}{c}10,66 \pm \\
0,59\end{array}$ & 5,51 \\
\hline $\begin{array}{c}\mathrm{K} \\
\left(\mathrm{mg} \mathrm{kg}^{-1}\right)\end{array}$ & $\begin{array}{c}8551 \pm \\
752\end{array}$ & 8,79 & $\begin{array}{c}8772 \pm \\
675 \\
\end{array}$ & 7,70 & $\begin{array}{c}9138 \pm \\
308 \\
\end{array}$ & 3,37 & $\begin{array}{c}9889 \pm \\
1145 \\
\end{array}$ & 11,58 & $\begin{array}{c}9591 \pm \\
1152 \\
\end{array}$ & 12,01 \\
\hline $\begin{array}{c}\mathrm{Mg} \\
\left(\mathrm{mg} \mathrm{kg}^{-1}\right)\end{array}$ & $\begin{array}{c}683,77 \pm \\
58,44 \\
\end{array}$ & 8,55 & $\begin{array}{r}719,30 \\
\pm 54,08\end{array}$ & 7,52 & $\begin{array}{r}743,32 \\
\pm 20,64 \\
\end{array}$ & 2,78 & $\begin{array}{c}842,37 \\
\pm 118,33\end{array}$ & 14,05 & $\begin{array}{c}837,57 \pm \\
147,30 \\
\end{array}$ & 17,59 \\
\hline $\begin{array}{c}M n \\
\left(\mu \mathrm{g} \mathrm{kg}^{-1}\right)\end{array}$ & $\begin{array}{c}304,30 \pm \\
84,95\end{array}$ & 27,92 & $\begin{array}{r}405,43 \\
\pm 74,99\end{array}$ & 18,50 & $\begin{array}{c}383,61 \\
\pm 25,19\end{array}$ & 6,57 & $\begin{array}{c}428,53 \\
\pm 57,08\end{array}$ & 13,32 & $\begin{array}{c}426,89 \pm \\
39,21\end{array}$ & 9,19 \\
\hline $\begin{array}{c}\text { Mo } \\
\left(\mu \mathrm{g} \mathrm{kg}^{-1}\right)\end{array}$ & $\begin{array}{c}98,33 \pm \\
19,65\end{array}$ & 19,99 & $\begin{array}{c}77,35 \pm \\
11,85\end{array}$ & 15,32 & $\begin{array}{c}83,37 \pm \\
10,54\end{array}$ & 12,64 & $\begin{array}{c}80,25 \pm \\
19,20\end{array}$ & 23,92 & $\begin{array}{c}76,26 \pm \\
11,40 \\
\end{array}$ & 14,95 \\
\hline $\begin{array}{c}\mathrm{Na} \\
\left(\mathrm{mg} \mathrm{kg}^{-1}\right)\end{array}$ & $\begin{array}{c}1148 \pm \\
78\end{array}$ & 6,79 & $\begin{array}{c}1004 \pm \\
92\end{array}$ & 9,13 & $\begin{array}{c}1027 \pm \\
40\end{array}$ & 3,86 & $\begin{array}{c}1173 \pm \\
199\end{array}$ & 16,98 & $1094 \pm 135$ & 12,35 \\
\hline $\begin{array}{c}\mathrm{Ni} \\
\left(\mu \mathrm{g} \mathrm{kg}^{-1}\right)\end{array}$ & $\begin{array}{c}385,96 \pm \\
143,02\end{array}$ & 37,05 & $\begin{array}{r}457,66 \\
\pm 88,31 \\
\end{array}$ & 19,30 & $\begin{array}{r}379,67 \\
\pm 24,92 \\
\end{array}$ & 6,56 & $\begin{array}{r}457,25 \\
\pm 83,03 \\
\end{array}$ & 18,16 & $\begin{array}{c}357,82 \pm \\
72,83\end{array}$ & 18,78 \\
\hline $\begin{array}{c}\mathbf{P} \\
\left(\mathrm{mg} \mathrm{kg}^{-1}\right)\end{array}$ & $\begin{array}{c}5755 \pm \\
323\end{array}$ & 5,61 & $\begin{array}{c}5329 \pm \\
332\end{array}$ & 6,23 & $\begin{array}{c}5523 \pm \\
211\end{array}$ & 3,82 & $\begin{array}{c}5939 \pm \\
789\end{array}$ & 13,29 & $5653 \pm 589$ & 10,42 \\
\hline $\begin{array}{c}\mathrm{Se} \\
\left(\mu \mathrm{kg}^{-1}\right)\end{array}$ & $\begin{array}{c}283,76 \\
\pm 155,91\end{array}$ & 54,94 & $\begin{array}{r}300,89 \\
\pm 98,70\end{array}$ & 32,80 & $\begin{array}{l}294,68 \\
\pm 70,84\end{array}$ & 24,04 & $\begin{array}{c}294,85 \\
\pm 158,44\end{array}$ & 53,74 & $\begin{array}{c}317,90 \pm \\
77,68\end{array}$ & 24,43 \\
\hline $\begin{array}{c}\mathrm{Sr} \\
\left(\mu \mathrm{g} \mathrm{kg}^{-1}\right)\end{array}$ & $\begin{array}{c}909,38 \\
\pm 478,22\end{array}$ & 52,59 & $\begin{array}{c}749,79 \\
\pm 124,22\end{array}$ & 16,57 & $\begin{array}{c}809,73 \\
\pm 110,11\end{array}$ & 13,60 & $\begin{array}{r}1072,87 \\
\pm 252,68\end{array}$ & 23,55 & $\begin{array}{l}1155,59 \\
\pm 460,01\end{array}$ & 39,81 \\
\hline $\begin{array}{c}\mathrm{Ti} \\
\left(\mu \mathrm{g} \mathrm{kg}^{-1}\right)\end{array}$ & $\begin{array}{c}870,01 \\
\pm 162,09\end{array}$ & 18,63 & $\begin{array}{c}801,20 \\
\pm 125,19\end{array}$ & 15,63 & $\begin{array}{r}812,59 \\
\pm 67,66\end{array}$ & 8,33 & $\begin{array}{c}811,24 \\
\pm 120,79\end{array}$ & 14,89 & $\begin{array}{c}813,19 \\
\pm 149,80\end{array}$ & 18,42 \\
\hline $\begin{array}{c}\mathrm{V} \\
\left(\mu \mathrm{kg}^{-1}\right)\end{array}$ & $\begin{array}{c}40,87 \pm \\
9,32\end{array}$ & 22,79 & $\begin{array}{c}38,97 \pm \\
3,52\end{array}$ & 9,02 & $\begin{array}{c}46,72 \pm \\
4,18\end{array}$ & 8,93 & $\begin{array}{c}49,12 \pm \\
10,78\end{array}$ & 21,94 & $\begin{array}{c}43,20 \pm \\
9,96\end{array}$ & 23,05 \\
\hline $\begin{array}{c}\mathrm{Zn} \\
\left(\mathrm{mg} \mathrm{kg}^{-1}\right)\end{array}$ & $\begin{array}{c}15,34 \pm \\
1,03\end{array}$ & 6,74 & $\begin{array}{c}14,66 \pm \\
0,93\end{array}$ & 6,37 & $\begin{array}{c}15,48 \pm \\
0,43\end{array}$ & 2,76 & $\begin{array}{c}17,49 \pm \\
0,62\end{array}$ & 3,52 & $15,99 \pm 1,81$ & 11,30 \\
\hline
\end{tabular}

O ABNT ISO Guia 35 (2012) menciona que a primeira etapa na avaliação dos dados consiste em verificar a existência de alguma tendência nos dados e sugere que uma aproximação linear é o modelo mais adequado. Na avaliação de tendência foi observado uma diferença das concentrações obtidas para a massa de 100mg (médias maiores que para as outras massas) para 
As, $\mathrm{Co}, \mathrm{Cu}, \mathrm{Fe}$ e Mo (vide Tabela 37). Foi observado aumento no valor da concentração com aumento da massa para $\mathrm{Ca}, \mathrm{Cr}, \mathrm{K}, \mathrm{Mg}, \mathrm{Mn}, \mathrm{Sr}, \mathrm{V}$ e Zn. Na Figura 54 é apresentada a investigação de tendência nos resultados em função da massa.

Figura 54 - Investigação de tendência no estudo de homogeneidade dentro do frasco. Resultados apresentados por ordem de massa, com ajuste de curva linear. (a) As, (b) Ba, (c) Ca, (d) Co, (e) Cr, (f) $\mathrm{Cu}$, (g) Fe, (h) K, (i) Mg, (j) Mn, (k) Mo, (l) Na, (m) Ni, (n) P, (o) Se, (p) Sr, (q) Ti, (r)V e (s) Zn.

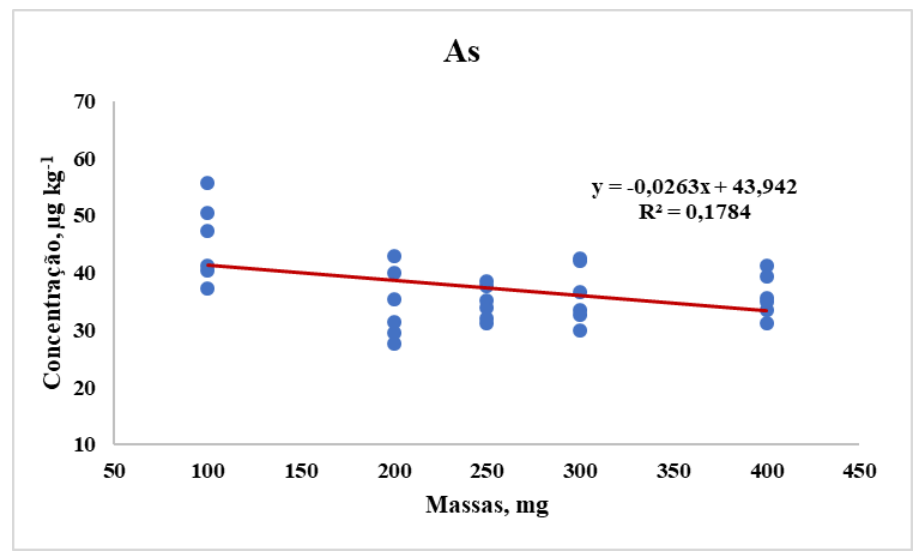

(a)

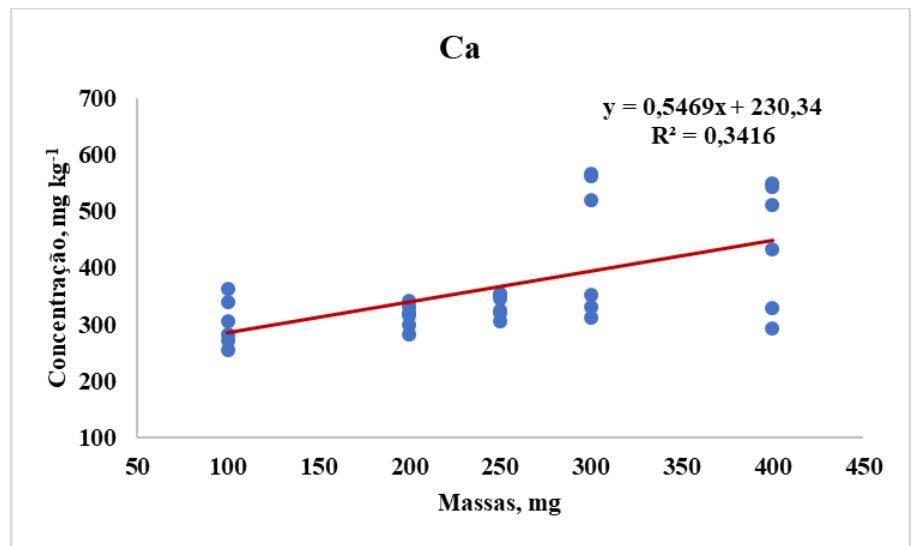

(c)

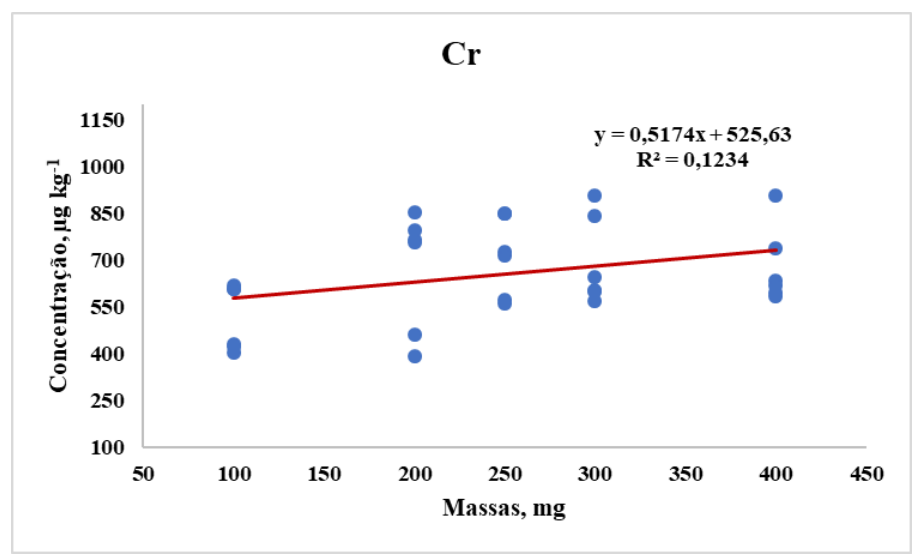

(e)

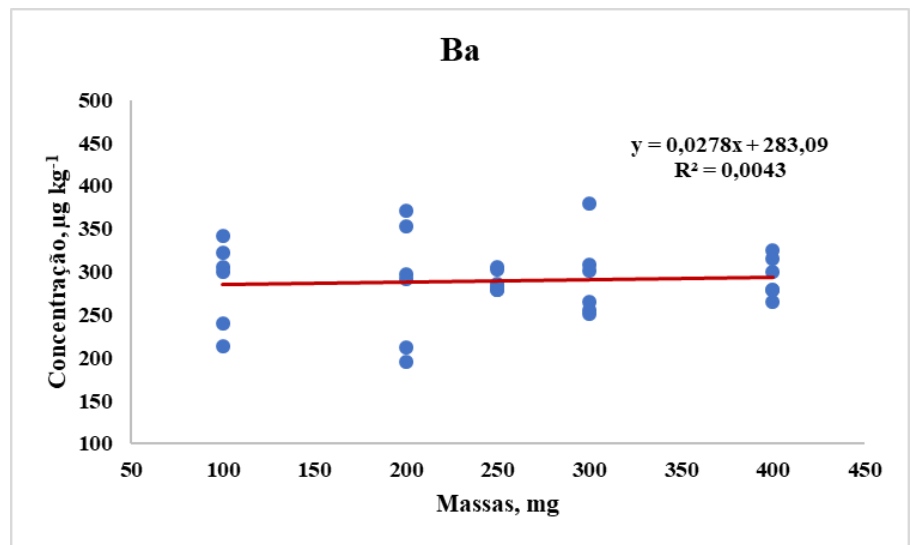

(b)

Co

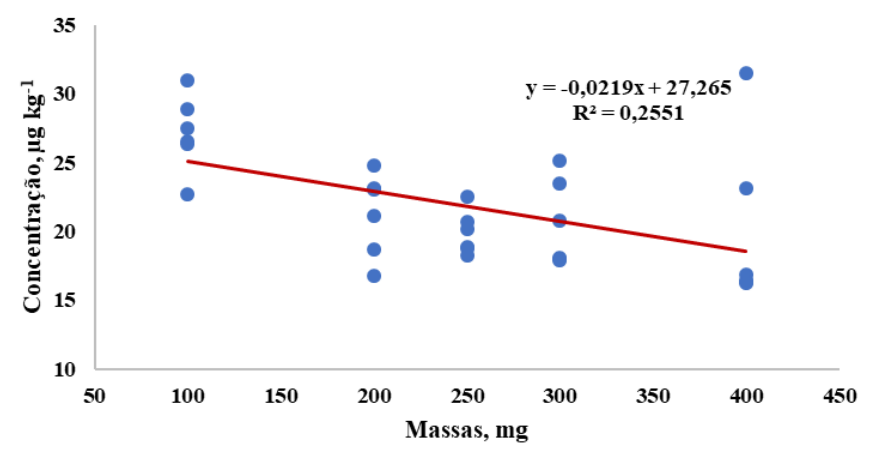

(d)

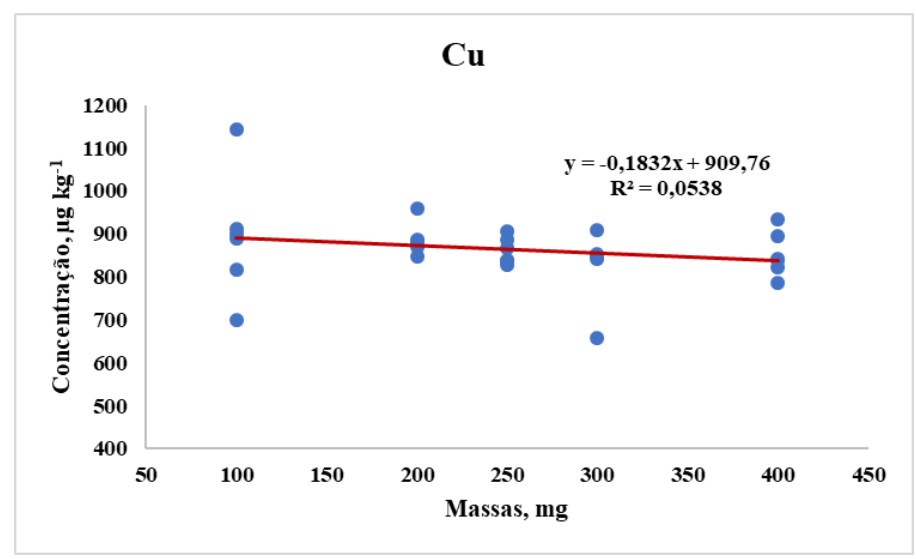

(f) 
Figura 54 - Investigação de tendência no estudo de homogeneidade dentro do frasco. Resultados apresentados por ordem de massa, com ajuste de curva linear. (a) As, (b) $\mathrm{Ba}$, (c) $\mathrm{Ca}$, (d) $\mathrm{Co}$, (e) $\mathrm{Cr}$, (f) $\mathrm{Cu}$, (g) Fe, (h) K, (i) Mg, (j) Mn, (k) Mo, (l) Na, (m) Ni, (n) P, (o) Se, (p) Sr, (q) Ti, (r)V e (s) Zn. Continuação.

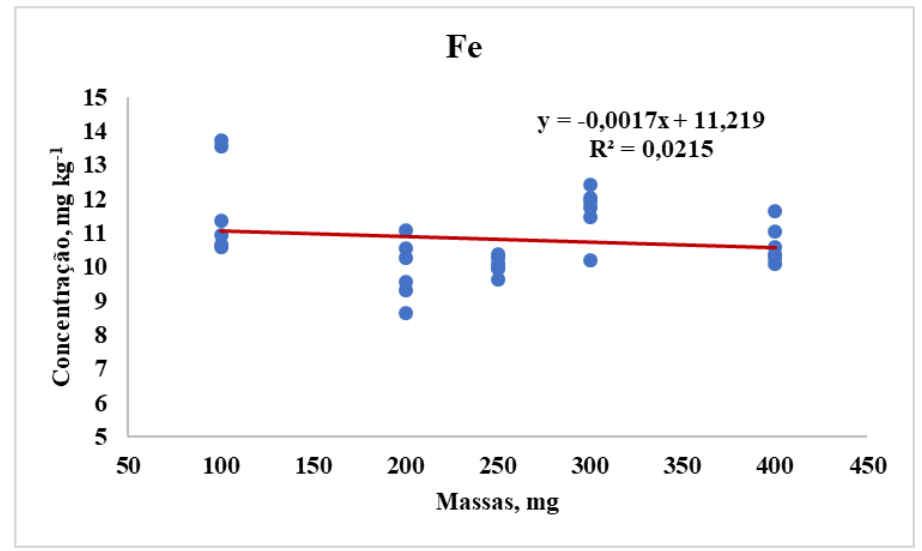

$(\mathrm{g})$

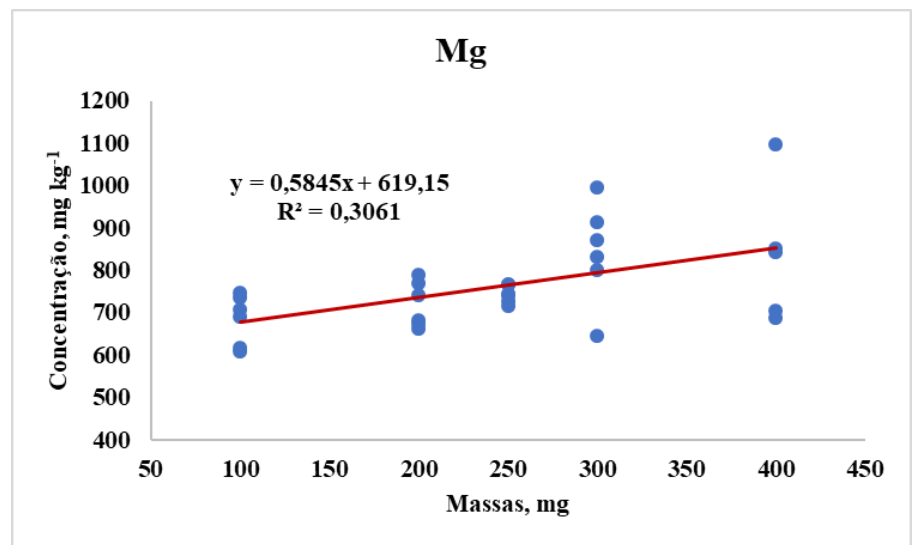

(i)

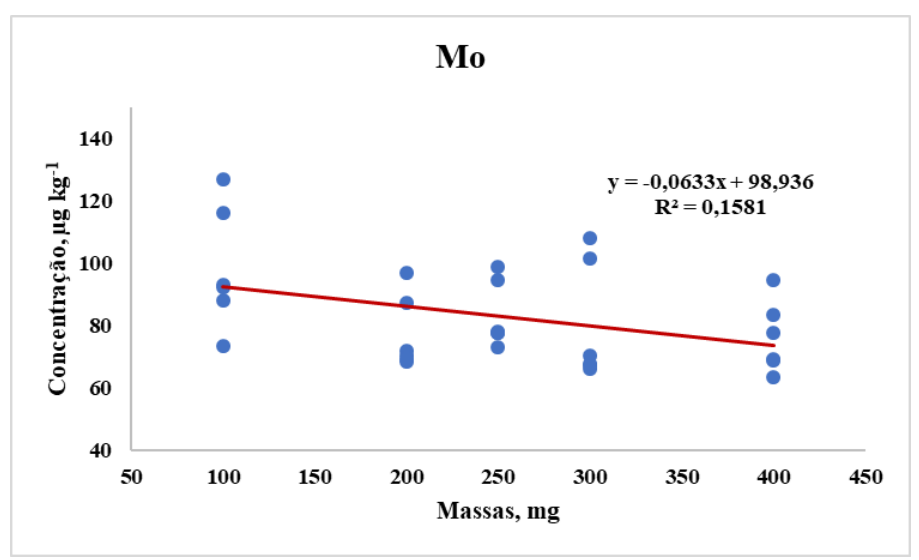

(k)

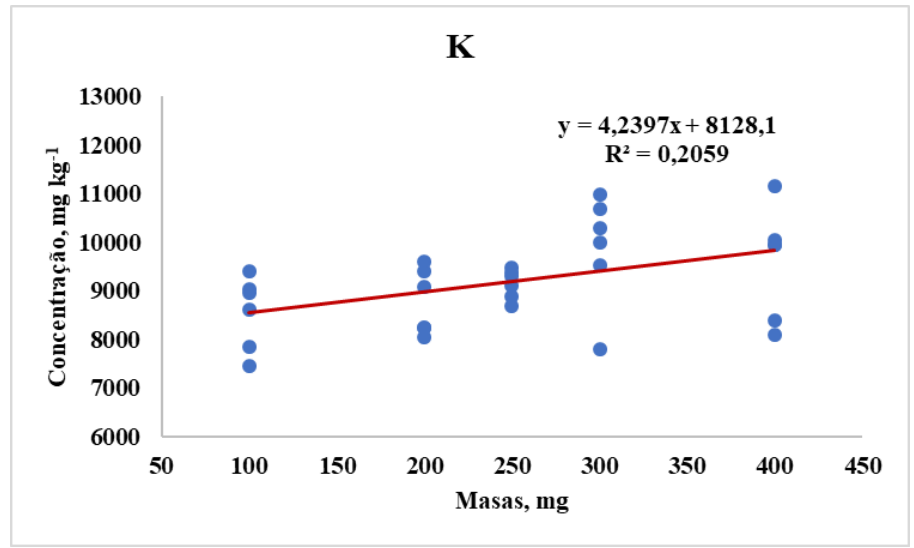

(h)

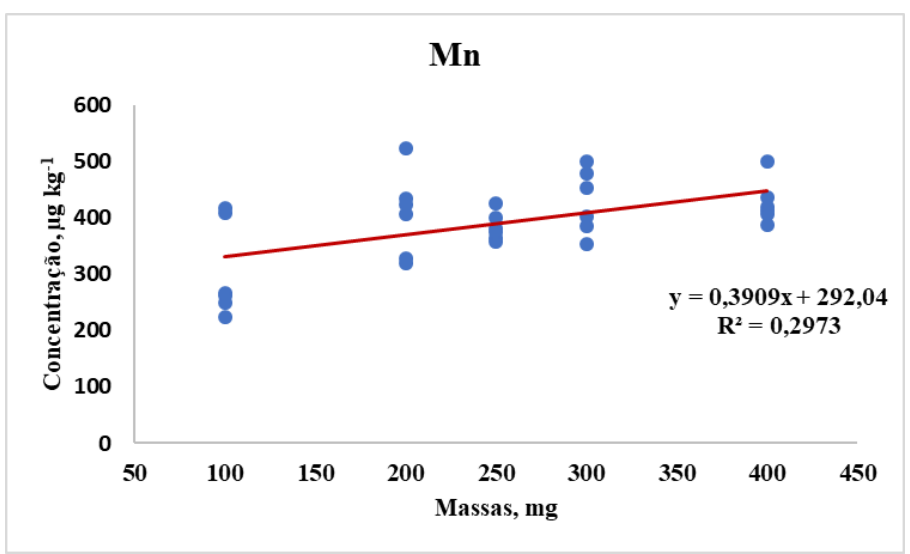

(j)

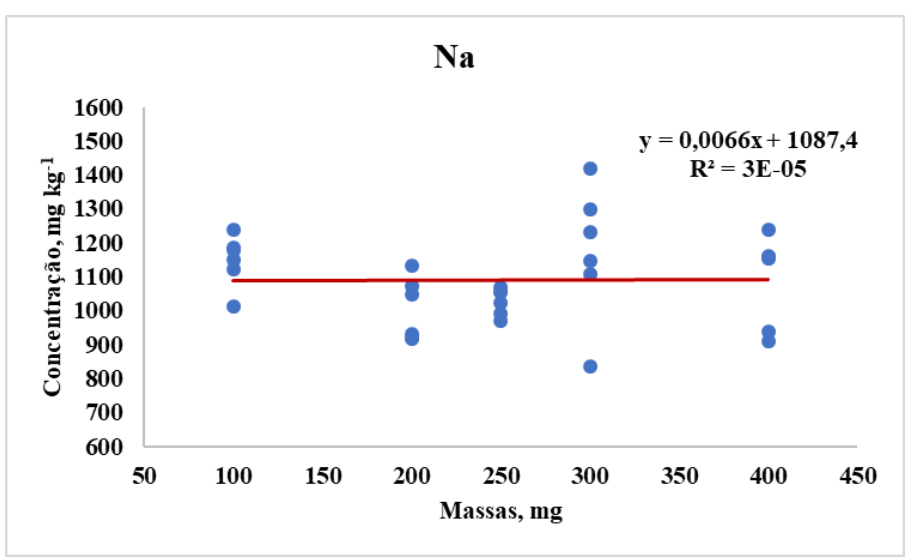

(1) 
Figura 54 - Investigação de tendência no estudo de homogeneidade dentro do frasco. Resultados apresentados por ordem de massa, com ajuste de curva linear. (a) As, (b) $\mathrm{Ba}$, (c) $\mathrm{Ca}$, (d) $\mathrm{Co}$, (e) $\mathrm{Cr}$, (f) $\mathrm{Cu}$, (g) Fe, (h) K, (i) Mg, (j) Mn, (k) Mo, (l) Na, (m) Ni, (n) P, (o) Se, (p) Sr, (q) Ti, (r)V e (s) Zn. Continuação.

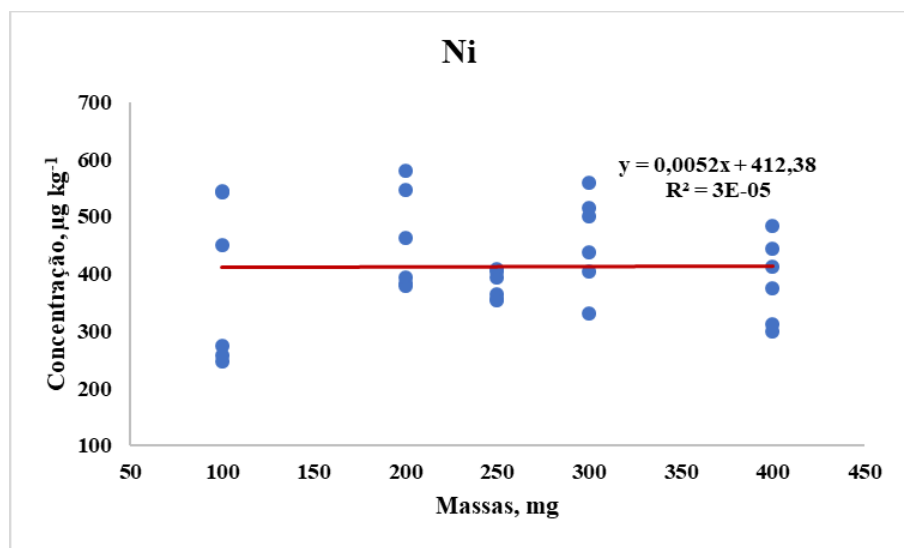

(m)

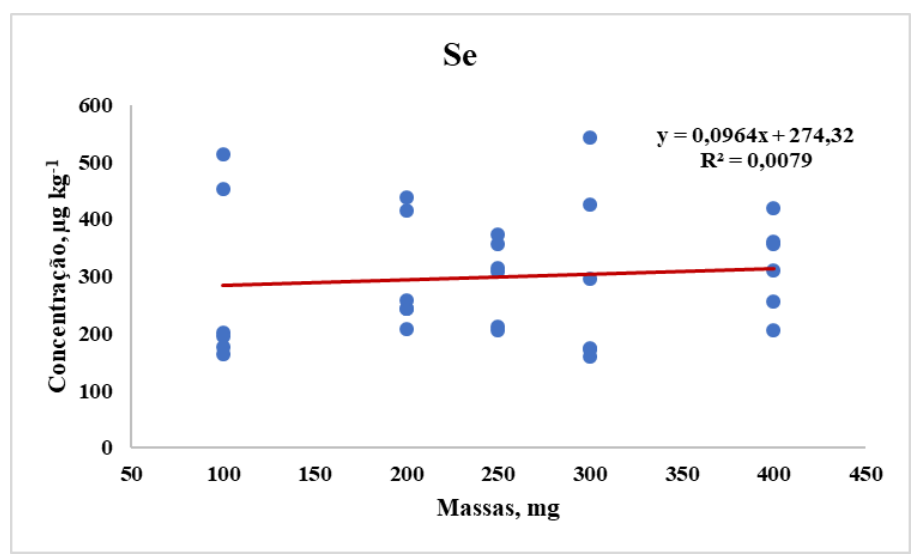

(o)

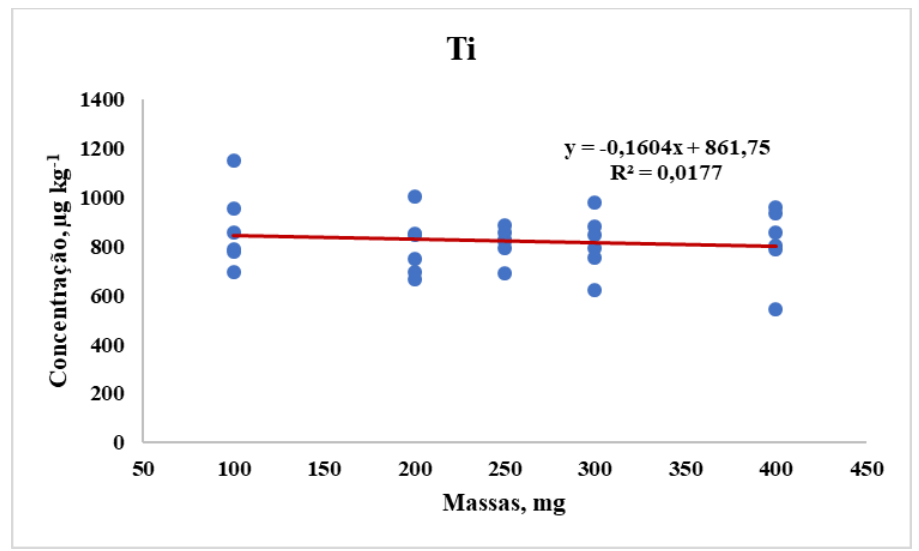

(q)

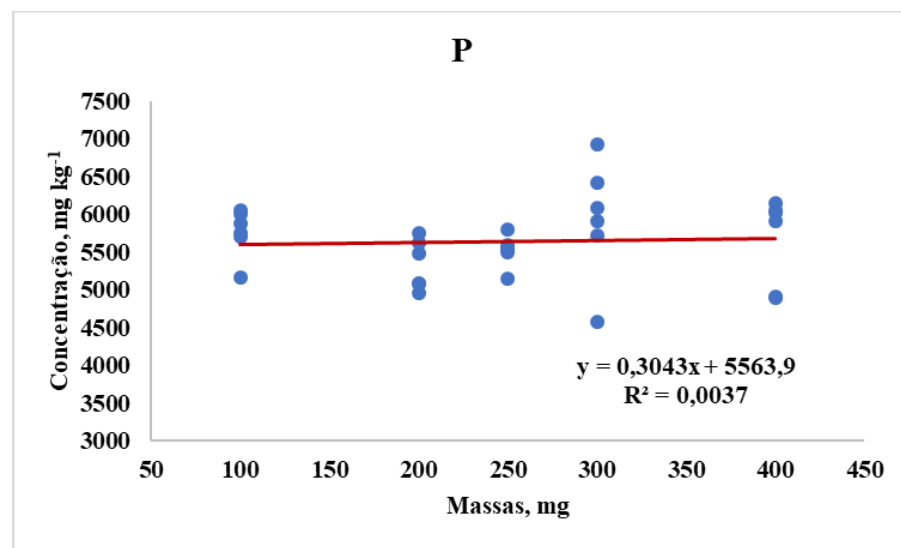

(n)

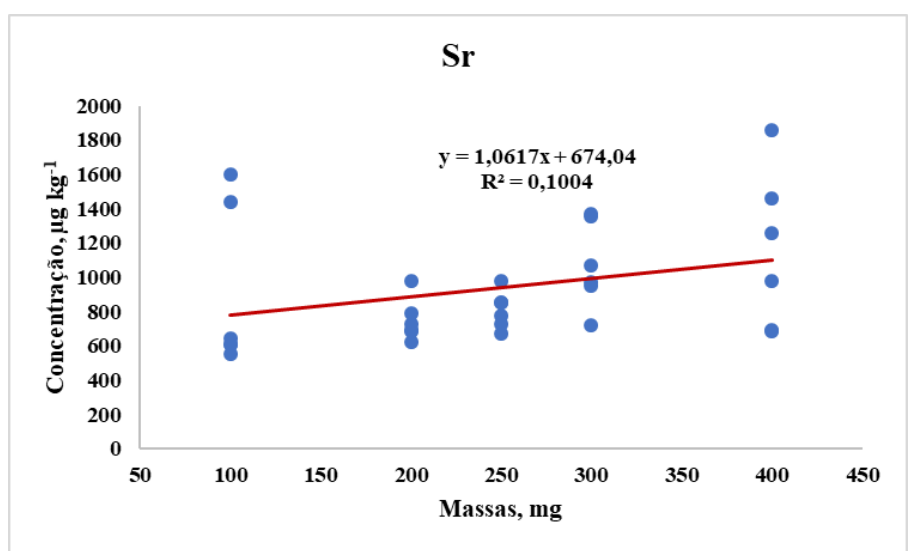

(p)

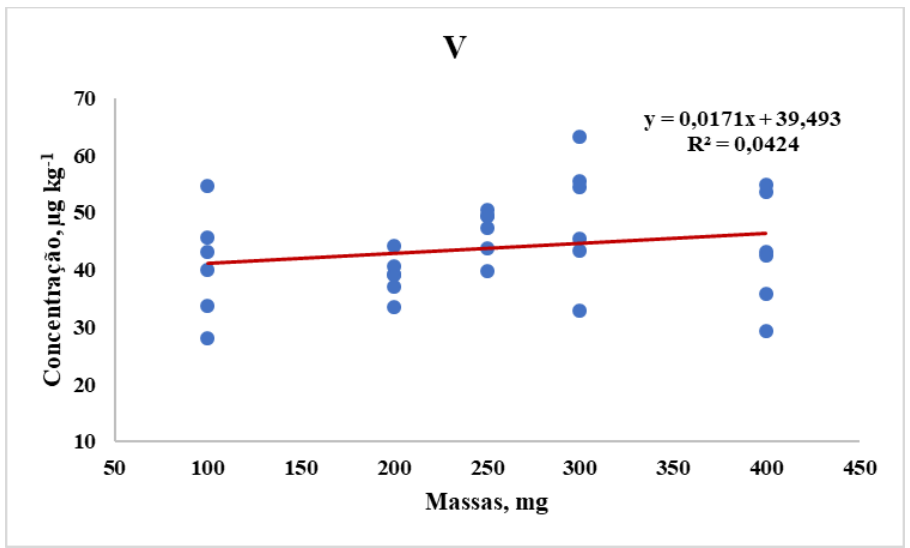

(r) 
Figura 54 - Investigação de tendência no estudo de homogeneidade dentro do frasco. Resultados apresentados por ordem de massa, com ajuste de curva linear. (a) As, (b) $\mathrm{Ba}$, (c) $\mathrm{Ca}$, (d) $\mathrm{Co}$, (e) $\mathrm{Cr}$, (f) $\mathrm{Cu}$, (g) Fe, (h) K, (i) Mg, (j) Mn, (k) Mo, (l) Na, (m) Ni, (n) P, (o) Se, (p) Sr, (q) Ti, (r)V e (s) Zn. Continuação.

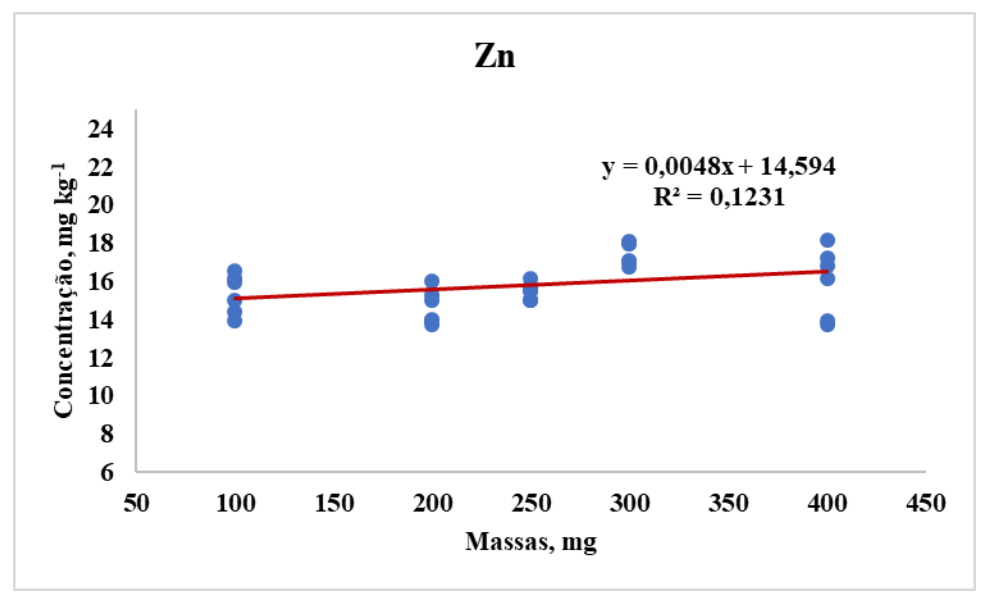

(s)

Para análise dos resultados, primeiramente foram aplicados os testes de Grubbs, para detectar a presença de dados anômalos, o teste de Shapiro-Wilks (Software Past 3.21), para verificar a distribuição normal dos resultados, apresentado para cada massa, juntamente com o gráfico de probabilidade normal no Apêndice C, e o teste de Levene (software Past 3.21) para verificar a homogeneidade das variâncias. Os resultados obtidos para cada elemento em um nível de confiança de $95 \%$ podem ser observados na Tabela 38. 
Tabela 38 - Resultados dos testes estatísticos realizados para avaliar os requisitos de ANOVA na avaliação da homogeneidade intra-frasco.

\begin{tabular}{|c|c|c|c|c|c|}
\hline \multirow{2}{*}{ Elemento } & \multirow{2}{*}{$\begin{array}{c}\text { Grubbs (n' de dados } \\
\text { anômalos) }\end{array}$} & \multicolumn{2}{|c|}{ Shapiro-Wilk } & \multirow{2}{*}{\begin{tabular}{|l|} 
Levene \\
Valor-p
\end{tabular}} & \multirow{2}{*}{$\mathbf{n}$} \\
\hline & & $\mathbf{W}$ & Valor-p & & \\
\hline As & - & 0,967 & 0,469 & 0,145 & 30 \\
\hline Ba & - & 0,973 & 0,610 & 0,092 & 30 \\
\hline $\mathbf{C a}$ & - & 0,963 & 0,374 & $6,12 \mathrm{E}-06$ & 30 \\
\hline Co & - & 0,910 & 0,015 & 0,705 & 30 \\
\hline $\mathrm{Cr}$ & - & 0,957 & 0,257 & 0,929 & 30 \\
\hline $\mathbf{C u}$ & - & 0,875 & 0,002 & 0,323 & 30 \\
\hline $\mathbf{F e}$ & - & 0,973 & 0,611 & 0,172 & 30 \\
\hline $\mathbf{K}$ & - & 0,963 & 0,362 & 0,513 & 30 \\
\hline Mg & - & 0,932 & 0,057 & 0,206 & 30 \\
\hline Mn & - & 0,953 & 0,205 & 0,371 & 30 \\
\hline Mo & - & 0,891 & 0,005 & 0,825 & 30 \\
\hline $\mathbf{N a}$ & - & 0,956 & 0,243 & 0,196 & 30 \\
\hline $\mathbf{N i}$ & - & 0,971 & 0,565 & 0,002 & 30 \\
\hline $\mathbf{P}$ & - & 0,944 & 0,113 & 0,305 & 30 \\
\hline Se & - & 0,915 & 0,020 & 0,587 & 30 \\
\hline $\mathbf{S r}$ & - & 0,945 & 0,121 & 0,160 & 30 \\
\hline $\mathbf{T i}$ & - & 0,994 & 1,000 & 0,612 & 30 \\
\hline $\mathbf{V}$ & - & 0,977 & 0,750 & 0,107 & 30 \\
\hline $\mathbf{Z n}$ & - & 0,978 & 0,781 & 0,033 & 30 \\
\hline
\end{tabular}

Tabela 39 - Resultados dos testes estatísticos realizados para avaliar os requisitos de ANOVA na avaliação da homogeneidade intra-frasco, desconsiderando os dados da massa de 100mg para Ca e Co e sem a massa de $300 \mathrm{mg}$ para $\mathrm{Zn}$.

\begin{tabular}{|c|c|c|c|c|c|}
\hline \multirow{2}{*}{ Elemento } & \multirow{2}{*}{$\begin{array}{c}\text { Grubbs (n' de dados } \\
\text { anômalos) }\end{array}$} & \multicolumn{2}{|c|}{ Shapiro-Wilk } & \multirow{2}{*}{\begin{tabular}{|l|} 
Levene \\
Valor-p
\end{tabular}} & \multirow{2}{*}{$\mathbf{n}$} \\
\hline & & $\mathbf{W}$ & Valor-p & & \\
\hline $\mathbf{C a}$ & - & 0,948 & 0,248 & $2,49 \mathrm{E}-05$ & 24 \\
\hline Co & - & 0,891 & 0,014 & 0,634 & 24 \\
\hline $\mathbf{Z n}$ & - & 0,982 & 0,933 & 0,0546 & 24 \\
\hline
\end{tabular}


Como pode ser observado na tabela os valores obtidos para o valor- $\mathrm{p}$, no teste de Shapiro-Wilk, resultaram maiores que 0,05 indicando a aceitação da hipótese $\mathrm{H}_{0}$ dos testes aplicados com 95\% de confiança, exceto para Co e para Ca, o teste de Levene obteve valor-p inferior a 0,05 . No teste de Shapiro-Wilks, $\mathrm{H}_{0}$ é que os resultados seguem uma distribuição normal, e no teste de Levene, $\mathrm{H}_{0}$ é que as variâncias dos dados são homogêneas.

Os conjuntos de dados, por massa, foram considerados normais, no nível de significância de 0,05, no teste de normalidade de Shapiro-Wilk, conforme apresentado no Apêndice C1. Conforme pode ser visto no Apêndice C2, a maioria dos dados provem de uma população normal, haja vista a não aleatoriedade da distribuição dos pontos na reta.

Foi realizada a análise de variância (ANOVA) de fator único dentro de um intervalo de confiança de 95\% $(\alpha=0,05)$ para avaliar se existem diferenças entre as quatro massas amostradas. Para avaliação comparou-se o valor de $\mathrm{F}_{\text {crítico }}$ em relação ao valor do $\mathrm{F}_{\text {calculado }}$ para cada elemento. Como foi verificada variação na concentração obtida em função da massa da sub-amostra utilizada para diversos elementos, o teste ANOVA foi repetido, após avaliação com teste Grubbs e remoção da massa de $100 \mathrm{mg}$ que apresentou maior variação nos testes para As, $\mathrm{Ca}, \mathrm{Co}, \mathrm{Fe}, \mathrm{Mg}$ e $\mathrm{Mn}$ e a massa de $300 \mathrm{mg}$ para $\mathrm{Zn}$, até que o conjunto de dados fosse aprovado no teste de igualdade de massas. A Tabela 40 apresenta os dados estatísticos da variância ANOVA e a Tabela 41 contempla os elementos em que foi realizada a exclusão de

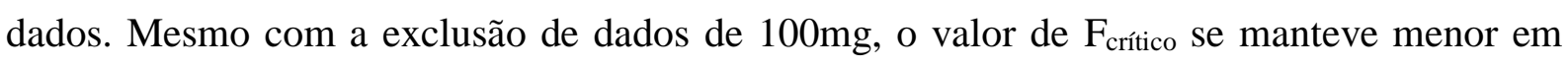
relação ao valor do $\mathrm{F}_{\text {calculado }}$ para $\mathrm{Ca}, \mathrm{Fe}, \mathrm{Zn}$.

Uma vez que não se pode definir a massa mínima pela avaliação de diferenças, foi definida a quantidade que resultou no menor desvio padrão relativo (RSD). Dessa forma, foi estabelecida a massa de $250 \mathrm{mg}$ para os estudos subsequentes, sendo obtidos os menores desvios para os elementos avaliados. 
Tabela 40 - Dados ANOVA fator único para a estimativa da massa mínima da amostra de tecido de peixe candidata a RM.

\begin{tabular}{|c|c|c|c|c|c|c|c|}
\hline Elemento & Fonte da variação & $S Q$ & $g l$ & $M Q$ & $F_{\text {calculado }}$ & valor-P & $\boldsymbol{F}_{\text {crútico }}$ \\
\hline \multirow{3}{*}{ As } & Entre frascos & 497,94 & 4 & 124,48 & 4,65 & 0,01 & 2,76 \\
\hline & Dentro dos frascos & 669,86 & 25 & 26,79 & & & \\
\hline & Total & 1167,79 & 29 & & & & \\
\hline \multirow{3}{*}{$\mathbf{B a}$} & Entre frascos & 290 & 4 & 72,49 & 0,03 & 1,00 & 2,76 \\
\hline & Dentro dos frascos & 53366 & 25 & 2134,63 & & & \\
\hline & Total & 53656 & 29 & & & & \\
\hline \multirow{3}{*}{$\mathbf{C a}$} & Entre frascos & 114941 & 4 & 28735,34 & 4,86 & 0,005 & 2,76 \\
\hline & Dentro dos frascos & 147782 & 25 & 5911,27 & & & \\
\hline & Total & 262723 & 29 & & & & \\
\hline \multirow{3}{*}{ Co } & Entre frascos & 222,48 & 4 & 55,62 & 4,09 & $1,10 \mathrm{E}-02$ & 2,76 \\
\hline & Dentro dos frascos & 340,23 & 25 & 13,61 & & & \\
\hline & Total & 562,71 & 29 & & & & \\
\hline \multirow{3}{*}{$\mathrm{Cr}$} & Entre frascos & 152573 & 4 & 38143 & 1,91 & 0,14 & 2,76 \\
\hline & Dentro dos frascos & 498357 & 25 & 19934 & & & \\
\hline & Total & 650930 & 29 & & & & \\
\hline \multirow{3}{*}{$\mathrm{Cu}$} & Entre frascos & 17936 & 4 & 4484 & 0,66 & 0,62 & 2,76 \\
\hline & Dentro dos frascos & 169362 & 25 & 6774 & & & \\
\hline & Total & 187298 & 29 & & & & \\
\hline \multirow{3}{*}{$\mathbf{F e}$} & Entre frascos & 18,48 & 4 & 4,62 & 5,89 & 0,002 & 2,76 \\
\hline & Dentro dos frascos & 19,62 & 25 & 0,78 & & & \\
\hline & Total & 38,10 & 29 & & & & \\
\hline \multirow{3}{*}{$\mathbf{K}$} & Entre frascos & 7417095 & 4 & 1854274 & 2,47 & 0,07 & 2,76 \\
\hline & Dentro dos frascos & 18776666 & 25 & 751067 & & & \\
\hline & Total & 26193761 & 29 & & & & \\
\hline \multirow{3}{*}{ Mg } & Entre frascos & 122451 & 4 & 30613 & 3,60 & 0,02 & 2,76 \\
\hline & Dentro dos frascos & 212320 & 25 & 8493 & & & \\
\hline & Total & 334771 & 29 & & & & \\
\hline \multirow{3}{*}{ Mn } & Entre frascos & 62808 & 4 & 15702 & 4,30 & 0,01 & 2,76 \\
\hline & Dentro dos frascos & 91348 & 25 & 3654 & & & \\
\hline & Total & 154156 & 29 & & & & \\
\hline \multirow{3}{*}{ Mo } & Entre frascos & 1919,86 & 4 & 479,97 & 2,11 & 0,11 & 2,76 \\
\hline & Dentro dos frascos & 5680,55 & 25 & 227,22 & & & \\
\hline & Total & 7600,41 & 29 & & & & \\
\hline \multirow{3}{*}{$\mathbf{N a}$} & Entre frascos & 130096 & 4 & 32524 & 2,20 & 0,10 & 2,76 \\
\hline & Dentro dos frascos & 369657 & 25 & 14786 & & & \\
\hline & Total & 499752 & 29 & & & & \\
\hline \multirow{3}{*}{$\mathbf{N i}$} & Entre frascos & 38559 & 4 & 9640 & 1,17 & 0,35 & 2,76 \\
\hline & Dentro dos frascos & 205356 & 25 & 8214 & & & \\
\hline & Total & 243915 & 29 & & & & \\
\hline
\end{tabular}


Tabela 40 - Dados ANOVA fator único para a estimativa da massa mínima da amostra de tecido de peixe candidata a RM. Continuação.

\begin{tabular}{|c|c|c|c|c|c|c|c|}
\hline Elemento & Fonte da variação & $S Q$ & $g l$ & $M Q$ & $F_{\text {calculado }}$ & valor-P & $\boldsymbol{F}_{\text {crítico }}$ \\
\hline \multirow{3}{*}{$\mathbf{P}$} & Entre frascos & 1279672 & 4 & 319918 & 1,30 & 0,30 & 2,76 \\
\hline & Dentro dos frascos & 6147062 & 25 & 245882 & & & \\
\hline & Total & 7426734 & 29 & & & & \\
\hline \multirow{3}{*}{$\mathrm{Se}$} & Entre frascos & 3764 & 4 & 941 & 0,07 & 0,99 & 2,76 \\
\hline & Dentro dos frascos & 351020 & 25 & 14041 & & & \\
\hline & Total & 354784 & 29 & & & & \\
\hline \multirow{3}{*}{$\mathrm{Sr}$} & Entre frascos & 709313 & 4 & 177328 & 1,67 & 0,19 & 2,76 \\
\hline & Dentro dos frascos & 2658478 & 25 & 106339 & & & \\
\hline & Total & 3367791 & 29 & & & & \\
\hline \multirow{3}{*}{$\mathbf{T i}$} & Entre frascos & 18111 & 4 & 4528 & 0,27 & 0,89 & 2,76 \\
\hline & Dentro dos frascos & 417772 & 25 & 16711 & & & \\
\hline & Total & 435883 & 29 & & & & \\
\hline \multirow{3}{*}{$\mathbf{V}$} & Entre frascos & 414,51 & 4 & 103,63 & 1,56 & 0,22 & 2,76 \\
\hline & Dentro dos frascos & 1659,41 & 25 & 66,38 & & & \\
\hline & Total & 2073,92 & 29 & & & & \\
\hline \multirow{3}{*}{$\mathbf{Z n}$} & Entre frascos & 27,00 & 4 & 6,75 & 5,85 & 0,002 & 2,76 \\
\hline & Dentro dos frascos & 28,85 & 25 & 1,15 & & & \\
\hline & Total & 55,85 & 29 & & & & \\
\hline
\end{tabular}

SQ: Soma Quadrática; g.l.: Grau de Liberdade; MQ: Média Quadrática; F crítico para $\alpha=0,05$

Tabela 41 - Dados da ANOVA fator único para a estimativa da massa mínima da amostra candidata a material de referência, após exclusão de dados.

\begin{tabular}{|c|c|c|c|c|c|c|c|}
\hline Elemento & Fonte da variação & $S Q$ & $g l$ & $M Q$ & $F_{\text {calculado }}$ & valor-P & $F_{\text {crútico }}$ \\
\hline \multirow{3}{*}{ As } & Entre frascos & 14,67 & 3 & 4,89 & 0,23 & 0,87 & 3,10 \\
\hline & Dentro dos frascos & 425,12 & 20 & 21,26 & & & \\
\hline & Total & 439,79 & 23 & & & & \\
\hline \multirow{3}{*}{$\mathbf{C a}$} & Entre frascos & 83910 & 3 & 27970 & 4,02 & 0,02 & 3,10 \\
\hline & Dentro dos frascos & 139173 & 20 & 6959 & & & \\
\hline & Total & 223083 & 23 & & & & \\
\hline \multirow{3}{*}{ Co } & Entre frascos & 6,70 & 3 & 2,23 & 0,15 & 0,93 & 3,10 \\
\hline & Dentro dos frascos & 301,19 & 20 & 15,06 & & & \\
\hline & Total & 307,90 & 23 & & & & \\
\hline \multirow{3}{*}{$\mathbf{F e}$} & Entre frascos & 11,19 & 3 & 3,73 & 8,20 & 0,001 & 3,10 \\
\hline & Dentro dos frascos & 9,09 & 20 & 0,45 & & & \\
\hline & Total & 20,28 & 23 & & & & \\
\hline \multirow{3}{*}{ Mg } & Entre frascos & 72639 & 3 & 24213 & 2,48 & 0,09 & 3,10 \\
\hline & Dentro dos frascos & 195246 & 20 & 9762 & & & \\
\hline & Total & 267885 & 23 & & & & \\
\hline
\end{tabular}


Tabela 41 - Dados da ANOVA fator único para a estimativa da massa mínima da amostra candidata a material de referência, após exclusão de dados. Continuação.

\begin{tabular}{cccccccc}
\hline Elemento & $\boldsymbol{F o n t e}$ da variação & $\boldsymbol{S Q}$ & $\boldsymbol{g} \boldsymbol{M}$ & $\boldsymbol{M Q}$ & $\boldsymbol{F}_{\text {calculado }}$ & valor- $\boldsymbol{P}$ & $\boldsymbol{F}_{\text {críico }}$ \\
\hline \multirow{4}{*}{ Mn } & Entre frascos & 8045 & 3 & 2681,56 & 0,97 & 0,43 & 3,10 \\
\cline { 2 - 9 } & Dentro dos frascos & 55267 & 20 & 2763,36 & & & \\
\cline { 2 - 8 } & Total & 63312 & 23 & & & & \\
\hline \multirow{3}{*}{ Zn } & Entre frascos & 5,41 & 3,00 & 1,80 & 1,34 & 0,29 & 3,10 \\
\cline { 2 - 8 } & Dentro dos frascos & 26,96 & 20,00 & 1,35 & & & \\
\cline { 2 - 8 } & Total & 32,37 & 23,00 & & & & \\
\hline
\end{tabular}

O teste de Levene detectou um desvio para $\mathrm{Ca}$, Ni e $\mathrm{Zn}$ e o teste de Shapiro-Wilks detectou um desvio da normalidade para $\mathrm{Co}, \mathrm{Cu}$, Mo e Se, motivo pelo qual será utilizado no estudo, além do teste de ANOVA tradicional, o teste de Kruskal-Wallis, que é um teste não paramétrico que também é utilizado para determinar se existem diferenças significativas entre as médias de grupos de dados, mas não assume a normalidade da distribuição. A Tabela 42 apresenta as estatísticas do teste de Kruskal-Wallis, onde podemos observar que o valor-p é maior que 0,05, assim como verificado na ANOVA sem os dados da massa de 100mg para Co e sem a de 300mg para $\mathrm{Zn}$ e com todos as massas para $\mathrm{Cu}$, Mo, Ni e Se. Todavia, na ANOVA para Ca o valor-p se manteve menor que 0,05 .

Tabela 42 - Estatísticas de ANOVA e teste de Kruskal-Wallis para os resultados obtidos.

\begin{tabular}{|c|c|c|c|}
\hline \multirow[t]{2}{*}{ Elemento } & \multicolumn{2}{|c|}{ ANOVA } & \multirow{2}{*}{$\begin{array}{c}\text { Kruskal-Wallis } \\
-\end{array}$} \\
\hline & $F_{\text {critico }}$ & 3,10 & \\
\hline \multirow[t]{3}{*}{$\mathbf{C a}$} & $F_{\text {calculado }}$ & 4,02 & - \\
\hline & Valor-p & 0,02 & 0,08 \\
\hline & $\boldsymbol{F}_{\text {critico }}$ & 3,10 & - \\
\hline \multirow[t]{3}{*}{ Co } & $F_{\text {calculado }}$ & 0,15 & - \\
\hline & Valor-p & 0,93 & 0,56 \\
\hline & $\boldsymbol{F}_{\text {critico }}$ & 2,76 & - \\
\hline \multirow[t]{2}{*}{$\mathrm{Cu}$} & $F_{\text {calculado }}$ & 0,66 & - \\
\hline & Valor-p & 0,62 & 0,56 \\
\hline
\end{tabular}


Tabela 42 - Estatísticas de ANOVA e teste de Kruskal-Wallis para os resultados obtidos. Continuação.

\begin{tabular}{|c|c|c|c|}
\hline \multirow[t]{2}{*}{ Elemento } & \multicolumn{2}{|c|}{ ANOVA } & \multirow{2}{*}{$\begin{array}{c}\text { Kruskal-Wallis } \\
-\end{array}$} \\
\hline & $F_{\text {critico }}$ & 2,76 & \\
\hline \multirow[t]{3}{*}{ Mo } & $F_{\text {calculado }}$ & 2,11 & - \\
\hline & Valor-p & 0,11 & 0,16 \\
\hline & $F_{\text {critico }}$ & 2,76 & - \\
\hline \multirow[t]{3}{*}{$\mathbf{N i}$} & $F_{\text {calculado }}$ & 1,17 & - \\
\hline & Valor-p & 0,35 & 0,35 \\
\hline & $F_{\text {critico }}$ & 2,76 & - \\
\hline \multirow[t]{3}{*}{ Se } & $\boldsymbol{F}_{\text {calculado }}$ & 0,07 & - \\
\hline & Valor-p & 0,99 & 0,81 \\
\hline & $F_{\text {critico }}$ & 3,10 & - \\
\hline \multirow[t]{2}{*}{$\mathbf{Z n}$} & $\boldsymbol{F}_{\text {calculado }}$ & 1,34 & - \\
\hline & Valor-p & 0,29 & 0,32 \\
\hline
\end{tabular}

\subsubsection{Estudo de Homogeneidade Entre Frascos}

Para este estudo, foram pesadas massas de $250 \mathrm{mg}$ de amostra, em seis replicatas, de cada um dos 15 frascos selecionados $(6,41,95,108,141,182,226,264,293,324,368,399$, 408, 518 e 596), em frascos de digestão, sendo adicionados $6 \mathrm{~mL}$ de $\mathrm{HNO}_{3} 50 \%$ e $2 \mathrm{~mL}$ de $\mathrm{H}_{2} \mathrm{O}_{2} 30 \%(\mathrm{~m} / \mathrm{v})$ e realizado o preparo conforme citado anteriormente e as determinações multielementares por ICP OES e ICP-MS.

Para avaliar se há ou não homogeneidade no lote de frascos preparados do material de tecido de peixe candidato a material referência, foi utilizado ANOVA fator único no nível de significância de 5\% $(\alpha=0,05)$, como ferramenta estatística. A ANOVA verifica se há diferenças significativas nas concentrações dos elementos ao longo dos frascos, por meio do teste F. Portanto quando o $\mathrm{F}_{\text {calculado }}$ for menor que o $\mathrm{F}_{\text {crítico, }}$, se aceita que há homogeneidade entre as amostras em um nível de confiança de $95 \%$.

A Figura 55 representam a homogeneidade entre frascos para cada parâmetro avaliado. Nelas são apresentadas as réplicas e os limites superiores e inferiores (linha vermelha) e central (linha preta). A elaboração dos gráficos de controle aplicada nesta seção, foi explicada no Capítulo 2. 
Figura 55 - Homogeneidade entre os frascos para os macro e micronutrientes e contaminantes. (a) As, (b) $\mathrm{Ba}$, (c) $\mathrm{Ca}$, (d) $\mathrm{Co}$, (e) Cr, (f) $\mathrm{Cu}$, (g) Fe, (h) K, (i) $\mathrm{Mg}$, (j) Mn, (k) Mo, (l) Na, (m) Ni, (n) P, (o) Se, (p) Sr, (q) Ti, (r)V e (s) Zn.

As

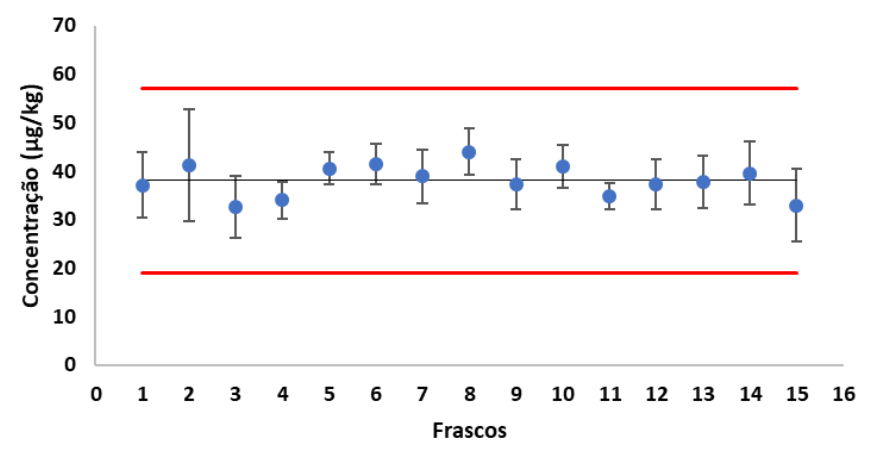

(a)

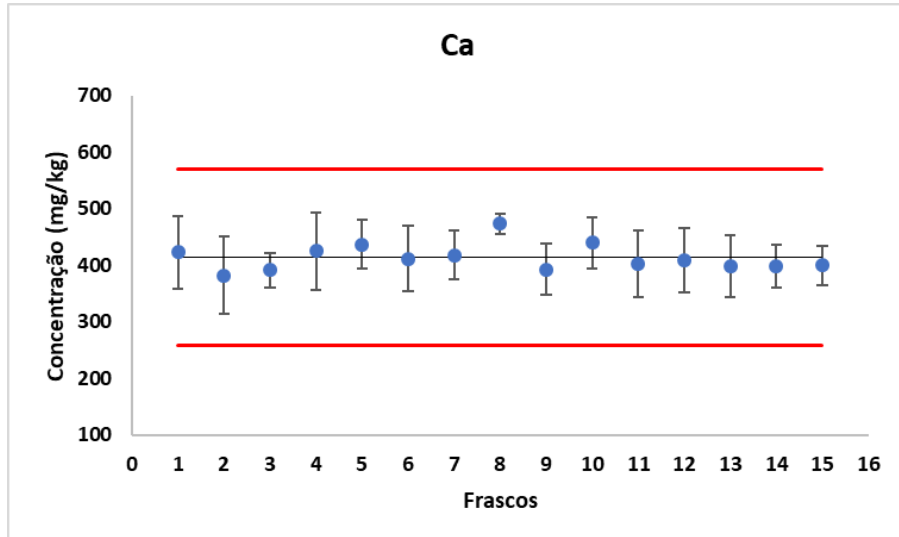

(c)

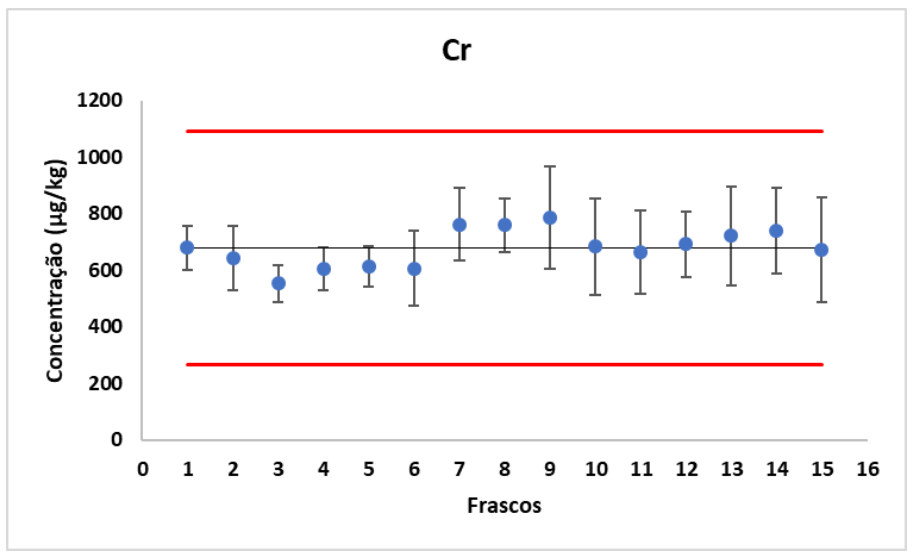

(e)
$\mathrm{Ba}$

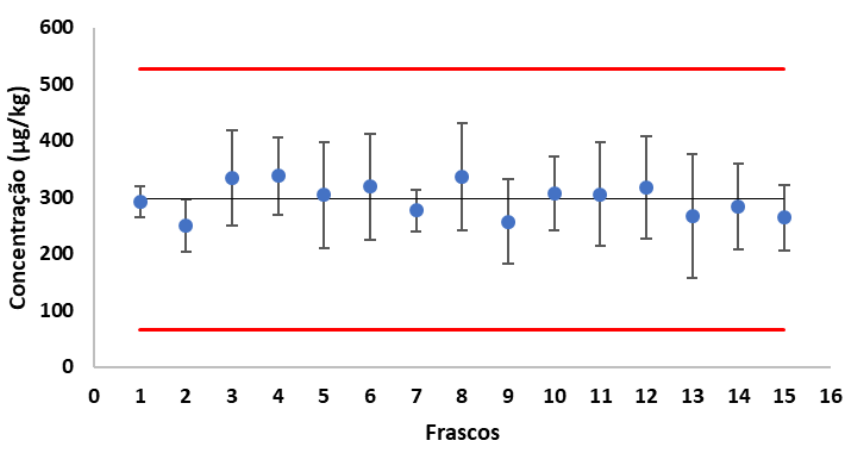

(b)

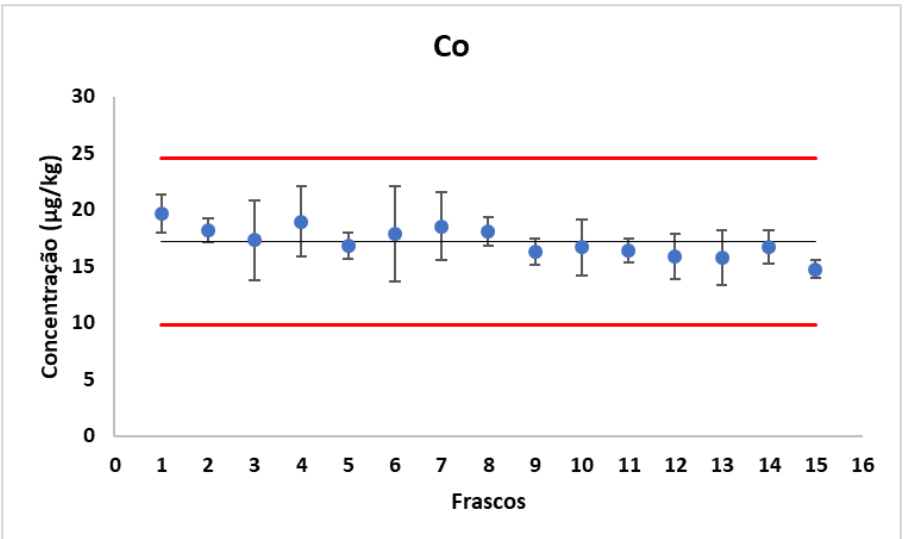

(d)

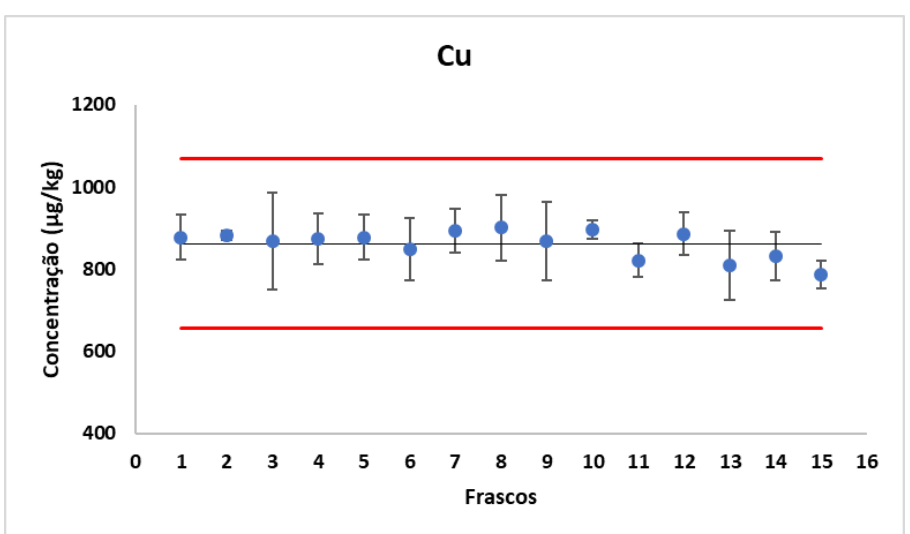

(f) 
Figura 55 - Homogeneidade entre os frascos para os macro e micronutrientes e contaminantes. (a) As, (b) $\mathrm{Ba}$, (c) $\mathrm{Ca}$, (d) $\mathrm{Co}$, (e) $\mathrm{Cr}$, (f) $\mathrm{Cu}$, (g) Fe, (h) K, (i) $\mathrm{Mg}$, (j) Mn, (k) Mo, (l) $\mathrm{Na}$, (m) Ni, (n) P, (o) Se, (p) Sr, (q) Ti, (r)V e (s) Zn. Continuação.

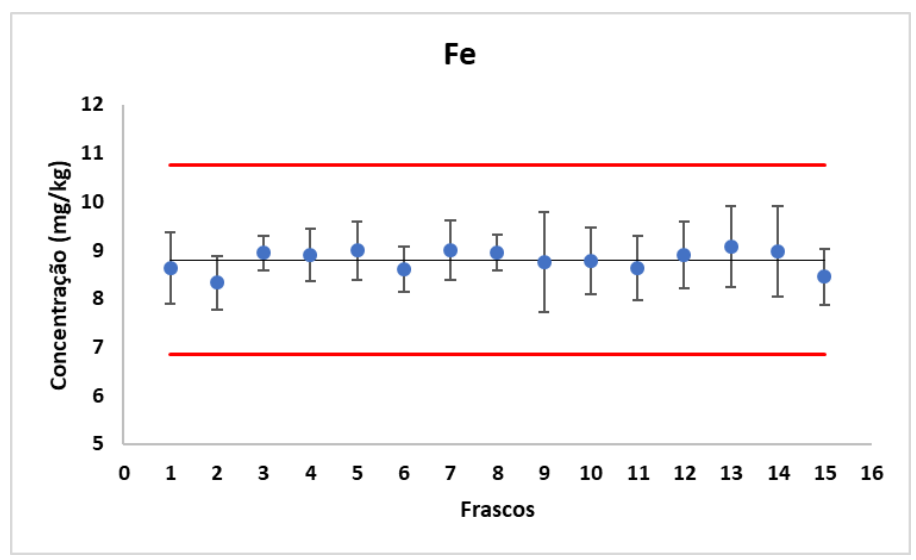

(g)

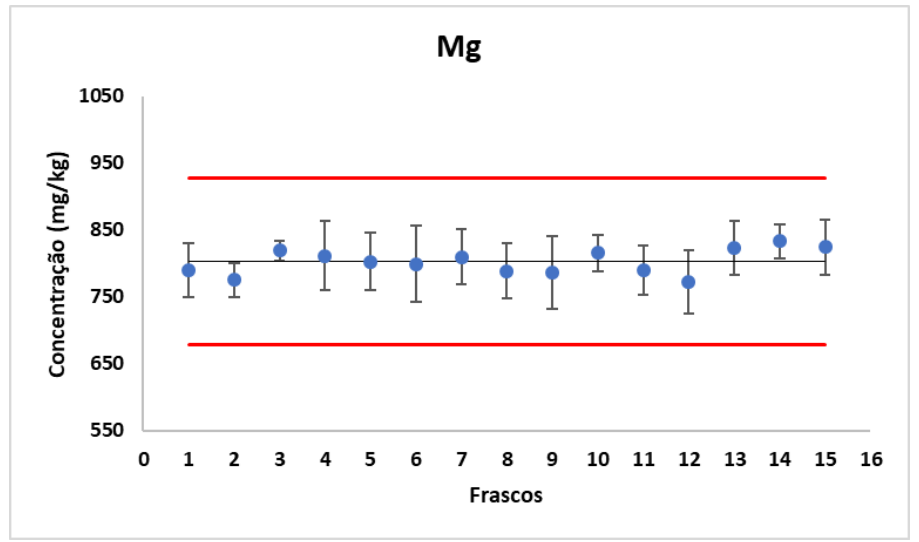

(i)

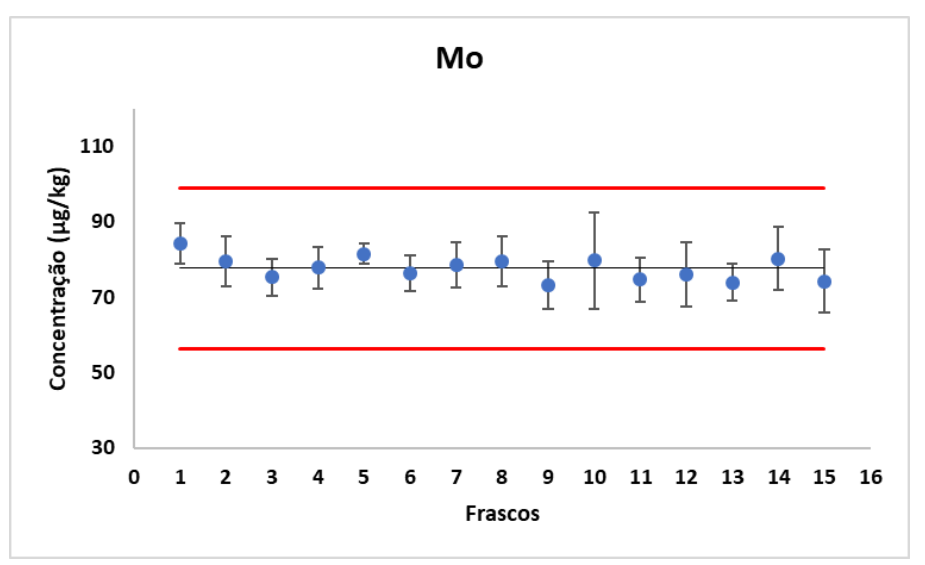

(k)

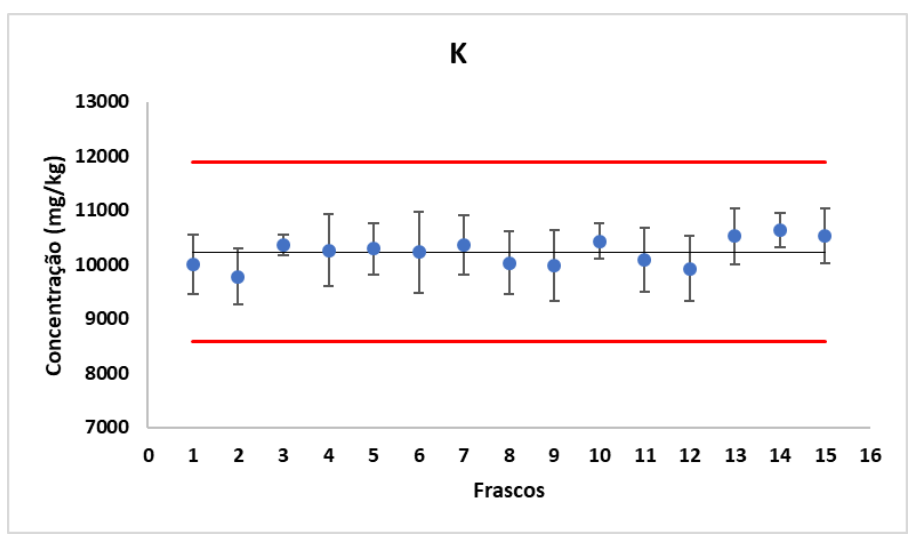

(h)

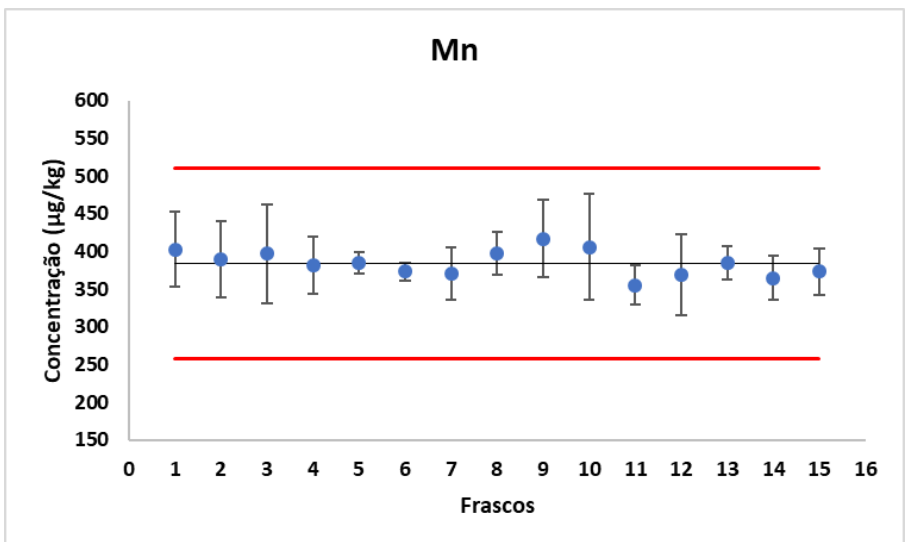

(j)

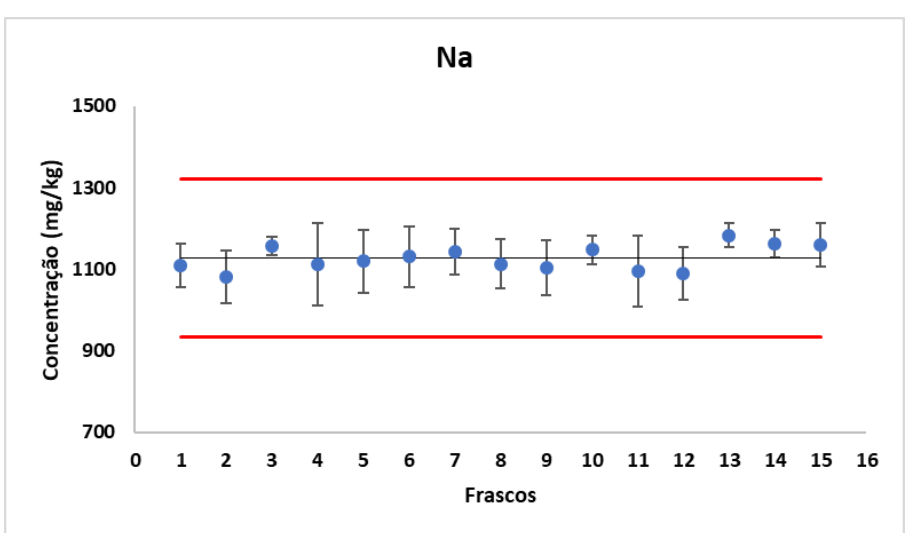

(1) 
Figura 55 - Homogeneidade entre os frascos para os macro e micronutrientes e contaminantes. (a) As, (b) $\mathrm{Ba}$, (c) $\mathrm{Ca}$, (d) $\mathrm{Co}$, (e) Cr, (f) $\mathrm{Cu}$, (g) Fe, (h) K, (i) $\mathrm{Mg}$, (j) Mn, (k) Mo, (l) Na, (m) Ni, (n) P, (o) Se, (p) Sr, (q) Ti, (r)V e (s) Zn. Continuação.

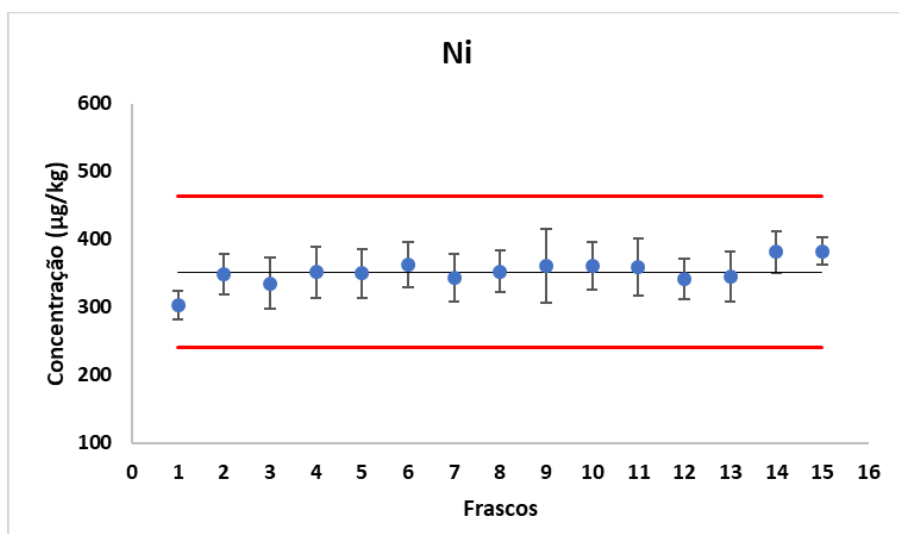

(m)

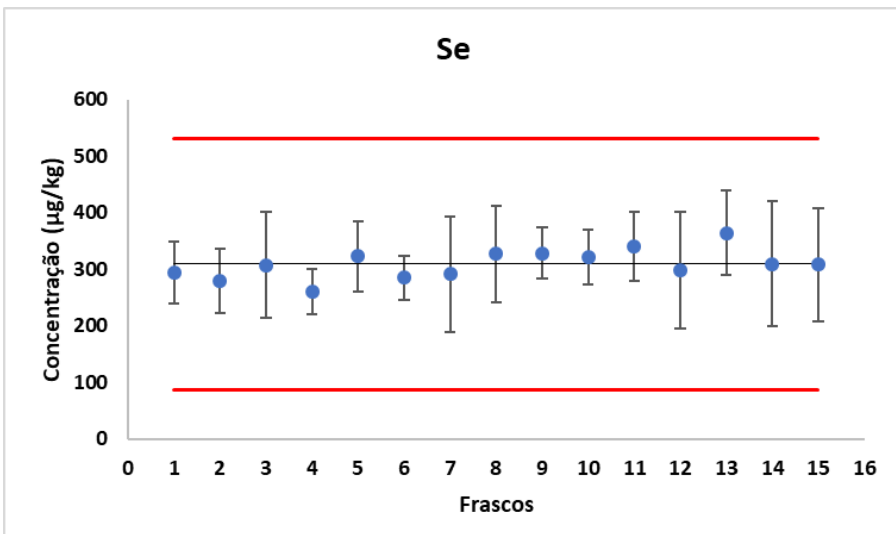

(o)

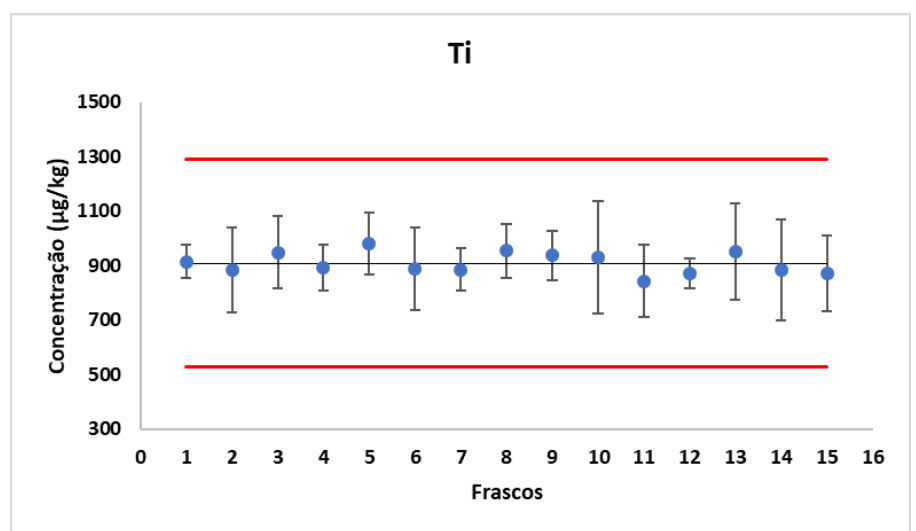

(q)

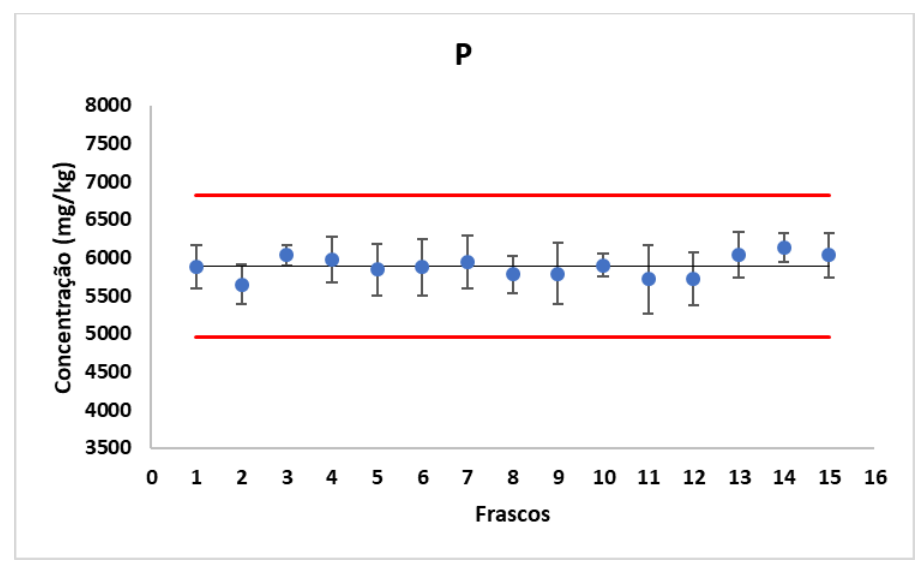

(n)

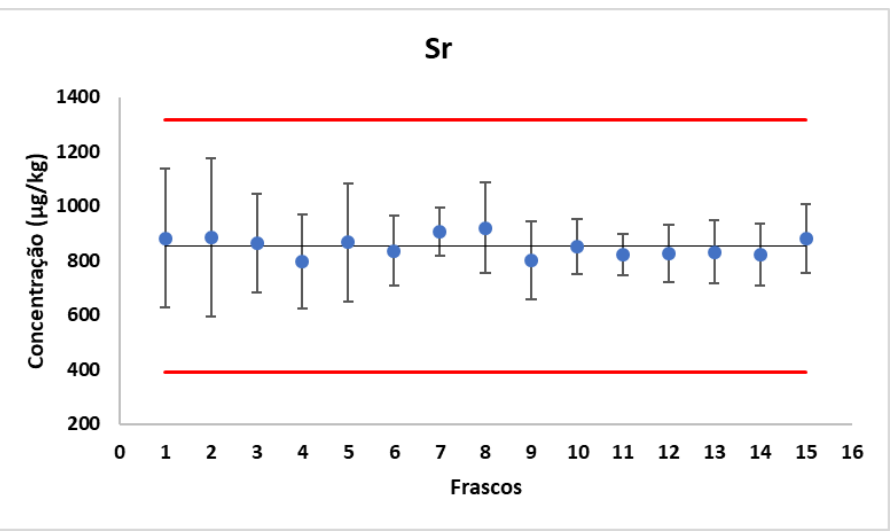

(p)

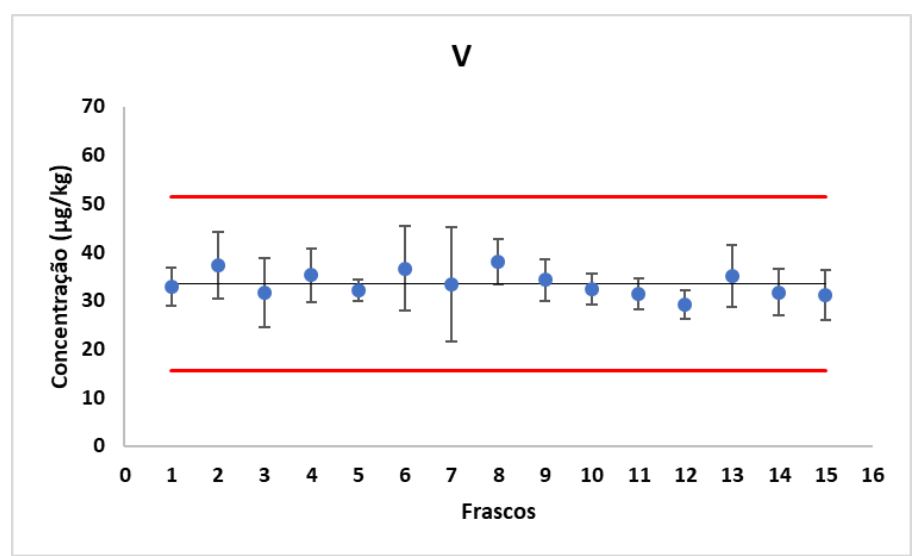

(r) 
Assim como na produção do RM de ração para peixe, os dados passaram por uma verificação quanto à sua normalidade. Primeiramente, realizou-se a avaliação da existência de valores extremos no conjunto de resultados, aplicando-se o teste de Grubbs para identificação de dados anômalos e a exclusão de outliers significativos.

Foi utilizado o valor crítico de $\mathrm{F}_{(\alpha=0,05)}=1,83$, o qual foi comparado ao $\mathrm{F}_{\text {calculado }}$ para cada elemento. A hipótese nula $\mathrm{H}_{0}$ assume que não há diferença significativa entre os valores das determinações, em um intervalo de confiança de 95\%. Enquanto que $\mathrm{H}_{1}$, a hipótese alternativa, assume que há diferença significativa, para o mesmo intervalo de confiança. Tendo

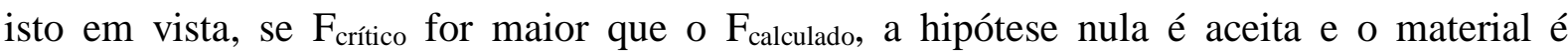

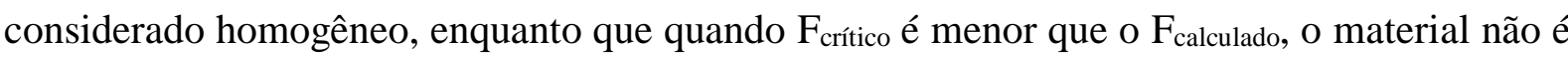
considerado homogêneo. As Tabelas 43 e 44 apresentam os dados da ANOVA fator único no nível de significância de $5 \%(\alpha=0,05)$ para os parâmetros avaliados.

Tabela 43 - Dados ANOVA fator único para a avaliação da homogeneidade entre frascos da ração candidata a RM para os dados obtidos por ICP OES.

\begin{tabular}{|c|c|c|c|c|c|c|c|}
\hline Elemento & Fonte da variação & $S Q$ & $g l$ & $M Q$ & $F_{\text {calculado }}$ & Valor-p & $\overline{F_{\text {crítico }}}$ \\
\hline \multirow{3}{*}{$\mathrm{Ca}$} & Entre frascos & 46421 & 14 & 3316 & 1,29 & 0,23 & 1,83 \\
\hline & Dentre frascos & 192586 & 75 & 2568 & & & \\
\hline & Total & 239007 & 89 & & & & \\
\hline \multirow{3}{*}{$\mathrm{Fe}$} & Entre frascos & 4,18 & 14 & 0,30 & 0,66 & 0,80 & 1,83 \\
\hline & Dentre frascos & 33,76 & 75 & 0,45 & & & \\
\hline & Total & 37,94 & 89 & & & & \\
\hline \multirow{3}{*}{ K } & Entre frascos & 5276400 & 14 & 376886 & 1,30 & 0,23 & 1,83 \\
\hline & Dentre frascos & 21674269 & 75 & 288990 & & & \\
\hline & Total & 26950670 & 89 & & & & \\
\hline \multirow{3}{*}{$\mathrm{Mg}$} & Entre frascos & 29203 & 14 & 2086 & 1,26 & 0,25 & 1,83 \\
\hline & Dentre frascos & 124036 & 75 & 1654 & & & \\
\hline & Total & 153239 & 89 & & & & \\
\hline \multirow{3}{*}{$\mathrm{Na}$} & Entre frascos & 77452 & 14 & 5532 & 1,43 & 0,16 & 1,83 \\
\hline & Dentre frascos & 290056 & 75 & 3867 & & & \\
\hline & Total & 367508 & 89 & & & & \\
\hline \multirow{3}{*}{$\mathrm{P}$} & Entre frascos & 1632514 & 14 & 116608 & 1,24 & 0,26 & 1,83 \\
\hline & Dentre frascos & 7028828 & 75 & 93718 & & & \\
\hline & Total & 8661342 & 89 & & & & \\
\hline \multirow{3}{*}{$\mathrm{Zn}$} & Entre frascos & 25,79 & 14 & 1,84 & 1,44 & 0,16 & 1,83 \\
\hline & Dentre frascos & 95,74 & 75 & 1,28 & & & \\
\hline & Total & 121,53 & 89 & & & & \\
\hline
\end{tabular}


Tabela 44 - Dados ANOVA fator único para a avaliação da homogeneidade entre frascos da ração candidata a RM para os dados obtidos por ICP-MS.

\begin{tabular}{|c|c|c|c|c|c|c|c|}
\hline Elemento & Fonte da variação & $S Q$ & $g l$ & $M Q$ & $F_{\text {calculado }}$ & Valor-p & $F_{\text {crítico }}$ \\
\hline \multirow{3}{*}{ As } & Entre frascos & 944,42 & 14 & 67,46 & 1,94 & 0,04 & 1,83 \\
\hline & Dentre frascos & 2611,29 & 75 & 34,82 & & & \\
\hline & Total & 3555,71 & 89 & & & & \\
\hline \multirow{3}{*}{$\mathrm{Ba}$} & Entre frascos & 73024 & 14 & 5215,98 & 0,87 & 0,60 & 1,83 \\
\hline & Dentre frascos & 450949 & 75 & 6012,65 & & & \\
\hline & Total & 523973 & 89 & & & & \\
\hline \multirow{3}{*}{ Co } & Entre frascos & 151,39 & 14 & 10,81 & 2,10 & 0,02 & 1,83 \\
\hline & Dentre frascos & 385,66 & 75 & 5,14 & & & \\
\hline & Total & 537,05 & 89 & & & & \\
\hline \multirow{3}{*}{$\mathrm{Cr}$} & Entre frascos & 378499 & 14 & 27036 & 1,54 & 0,12 & 1,83 \\
\hline & Dentre frascos & 1314654 & 75 & 17529 & & & \\
\hline & Total & 1693153 & 89 & & & & \\
\hline \multirow{3}{*}{$\mathrm{Cu}$} & Entre frascos & 99116 & 14 & 7080 & 1,64 & 0,09 & 1,83 \\
\hline & Dentre frascos & 323028 & 75 & 4307 & & & \\
\hline & Total & 422144 & 89 & & & & \\
\hline \multirow{3}{*}{$\mathrm{Mn}$} & Entre frascos & 24475 & 14 & 1748 & 0,98 & 0,48 & 1,83 \\
\hline & Dentre frascos & 133324 & 75 & 1778 & & & \\
\hline & Total & 157799 & 89 & & & & \\
\hline \multirow{3}{*}{ Mo } & Entre frascos & 853 & 14 & 61 & 1,27 & 0,25 & 1,83 \\
\hline & Dentre frascos & 3596 & 75 & 48 & & & \\
\hline & Total & 4449 & 89 & & & & \\
\hline \multirow{3}{*}{$\mathrm{Ni}$} & Entre frascos & 30320 & 14 & 2166 & 1,75 & 0,06 & 1,83 \\
\hline & Dentre frascos & 92940 & 75 & 1239 & & & \\
\hline & Total & 123260 & 89 & & & & \\
\hline \multirow{3}{*}{$\mathrm{Se}$} & Entre frascos & 57300 & 14 & 4093 & 0,71 & 0,76 & 1,83 \\
\hline & Dentre frascos & 432756 & 75 & 5770 & & & \\
\hline & Total & 490055 & 89 & & & & \\
\hline \multirow{3}{*}{$\mathrm{Sr}$} & Entre frascos & 116951 & 14 & 8354 & 0,31 & 0,99 & 1,83 \\
\hline & Dentre frascos & 2010339 & 75 & 26805 & & & \\
\hline & Total & 2127290 & 89 & & & & \\
\hline \multirow{3}{*}{$\mathrm{Ti}$} & Entre frascos & 126756 & 14 & 9054 & 0,52 & 0,91 & 1,83 \\
\hline & Dentre frascos & 1308800 & 75 & 17451 & & & \\
\hline & Total & 1435556 & 89 & & & & \\
\hline \multirow{3}{*}{$\mathrm{V}$} & Entre frascos & 540 & 14 & 39 & 1,10 & 0,37 & 1,83 \\
\hline & Dentre frascos & 2620 & 75 & 35 & & & \\
\hline & Total & 3160 & 89 & & & & \\
\hline
\end{tabular}


Ademais, foram calculados os valores das incertezas da homogeneidade $\left(\mathrm{u}_{\mathrm{bb}}\right)$ e o valorp, conforme ISO GUIA 35, usando as equações 1 e 2 citadas inicialmente.

Foi possível observar que o lote pode ser considerado homogêneo para praticamente todos os elementos, uma vez que não foi verificada diferença estatística significativa no nível de confiança de 5\% (Tabela 45 e 46). Para As e Co houve diferença significativa e, nesse enfoque, deve ser considerado o grau de heterogeneidade para esses parâmetros.

Tabela 45 - Resumo da avaliação estatística para o estudo de homogeneidade para os elementos determinados por ICP OES.

\begin{tabular}{|c|c|c|c|c|c|}
\hline Analito & $\mathbf{F}_{\text {crítico }}$ & $\mathbf{F}_{\text {calculado }}$ & Média (mg kg-1) & $\mathrm{U}_{\mathbf{b b}}\left(\mathrm{mg} \mathrm{kg}^{-1}\right)$ & Valor-p \\
\hline $\mathbf{C a}$ & 1,83 & 1,29 & 413,92 & 11,17 & 0,23 \\
\hline $\mathbf{F e}$ & 1,83 & 0,66 & 8,80 & 0,111 & 0,80 \\
\hline $\mathbf{K}$ & 1,83 & 1,30 & 10234,47 & 121,03 & 0,23 \\
\hline Mg & 1,83 & 1,26 & 802,93 & 8,49 & 0,25 \\
\hline $\mathrm{Na}$ & 1,83 & 1,43 & 1127,44 & 16,66 & 0,16 \\
\hline $\mathbf{P}$ & 1,83 & 1,24 & 5889,22 & 61,77 & 0,26 \\
\hline $\mathbf{Z n}$ & 1,83 & 1,44 & 16,11 & 0,307 & 0,16 \\
\hline
\end{tabular}

Tabela 46 - Resumo da avaliação estatística para o estudo de homogeneidade para os elementos determinados por ICP-MS

\begin{tabular}{|c|c|c|c|c|c|}
\hline Analito & $\mathbf{F}_{\text {crítico }}$ & $F_{\text {calculado }}$ & Média $\left(\mu \mathrm{g} \mathrm{kg}^{-1}\right)$ & $\mathrm{U}_{\mathrm{bb}}\left(\mu \mathrm{g} \mathrm{kg}^{-1}\right)$ & Valor-p \\
\hline${ }^{75} \mathrm{As}$ & 1,83 & 1,94 & 38,05 & 2,33 & 0,04 \\
\hline${ }^{137} \mathbf{B a}$ & 1,83 & 0,87 & 296,95 & 12,79 & 0,60 \\
\hline${ }^{59} \mathrm{Co}$ & 1,83 & 2,10 & 17,20 & 0,97 & 0,02 \\
\hline${ }^{53} \mathrm{Cr}\left({ }^{103} \mathrm{Rh}\right)$ & 1,83 & 1,54 & 679,25 & 39,81 & 0,12 \\
\hline${ }^{63} \mathrm{Cu}\left({ }^{74} \mathrm{Ge}\right)$ & 1,83 & 1,64 & 861,69 & 21,50 & 0,09 \\
\hline${ }^{55} \mathrm{Mn}\left(\mathrm{He} \mathrm{e}^{74} \mathrm{Ge}\right)$ & 1,83 & 0,98 & 384,83 & 6,96 & 0,48 \\
\hline${ }^{96} \mathrm{Mo}(\mathrm{He})$ & 1,83 & 1,27 & 77,69 & 1,47 & 0,25 \\
\hline${ }^{60} \mathrm{Ni}(\mathrm{He})$ & 1,83 & 1,75 & 352,17 & 12,43 & 0,06 \\
\hline${ }^{78} \mathrm{Se}(\mathrm{He})$ & 1,83 & 0,71 & 309,55 & 12,53 & 0,76 \\
\hline${ }^{88} \mathrm{Sr}$ & 1,83 & 0,31 & 853,54 & 27,01 & 0,99 \\
\hline${ }^{48} \mathrm{Ti}(\mathrm{He})$ & 1,83 & 0,52 & 909,86 & 21,79 & 0,91 \\
\hline${ }^{51} \mathbf{V}\left({ }^{74} \mathbf{G e}\right)$ & 2,83 & 1,10 & 33,53 & 0,78 & 0,37 \\
\hline
\end{tabular}




\subsection{Estudo de Estabilidade}

\subsubsection{Estabilidade a Curto Prazo}

Para o estudo de estabilidade a curto prazo do RM candidato de tecido de peixe, foi aplicado o planejamento isócrono (Lamberty et al., 1998). Todos os frascos do estudo foram armazenados inicialmente na temperatura referência de $-20^{\circ} \mathrm{C}$. De 20 em 20 dias, 3 frascos foram retirados da temperatura de $-20^{\circ} \mathrm{C}$ e colocados na temperatura selecionada, conforme supracitado. Três frascos $(28,327$ e 587), selecionados aleatoriamente, foram mantidos na temperatura de referência $-20^{\circ} \mathrm{C}$ durante os 60 dias do experimento. Os frascos, selecionados aleatoriamente que ficaram na temperatura de $4^{\circ} \mathrm{C}$ foram: 137, 351, 538 (permaneceram por 60 dias); 21, 364, 458 (permaneceram por 40 dias) e 17, 200, 510 (permaneceram por 20 dias). $\mathrm{Na}$ temperatura de $18^{\circ} \mathrm{C}: 256,342,417$ (permaneceram por 60 dias); 5, 396, 599 (permaneceram por 40 dias) e $265,336,558$ (permaneceram por 20 dias) e na temperatura de $37^{\circ} \mathrm{C}$ e umidade relativa de 100\%: 87, 184, 496 (permaneceram por 60 dias); 66, 194, 468 (permaneceram por 40 dias) e 83, 262, 356 (permaneceram por 20 dias).

São apresentadas nas Tabelas 47 e 48, as concentrações em base úmida, obtidas por ICP OES e ICP-MS, para o estudo de estabilidade a curto prazo.

Tabela 47 - Frações de massa dos elementos $\left(\mathrm{mg} \mathrm{kg}^{-1}\right)$ obtidas por ICP OES para o estudo de estabilidade a curto prazo (base úmida).

\begin{tabular}{|c|c|c|c|c|c|c|c|c|}
\hline $\mathbf{T}\left({ }^{\circ} \mathbf{C}\right)$ & $\begin{array}{c}\text { Tempo } \\
\text { (dias) }\end{array}$ & $\mathbf{C a}$ & $\mathrm{Fe}$ & $\mathbf{K}$ & Mg & $\mathbf{N a}$ & $\mathbf{P}$ & $\mathbf{Z n}$ \\
\hline-20 & 60 & $\begin{array}{c}446,94 \pm \\
36,05\end{array}$ & $\begin{array}{c}10,40 \pm \\
0,66\end{array}$ & $\begin{array}{c}10981 \pm \\
188\end{array}$ & $\begin{array}{c}855,50 \pm \\
15,14\end{array}$ & $\begin{array}{c}1185 \pm \\
19\end{array}$ & $5937 \pm 45$ & $\begin{array}{c}16,85 \pm \\
0,37\end{array}$ \\
\hline 4 & 60 & $\begin{array}{c}442,69 \pm \\
30,07\end{array}$ & $\begin{array}{c}10,09 \pm \\
0,57\end{array}$ & $\begin{array}{c}10674 \pm \\
265\end{array}$ & $\begin{array}{c}840,01 \pm \\
18,54\end{array}$ & $\begin{array}{c}1164 \pm \\
20\end{array}$ & $5814 \pm 71$ & $\begin{array}{c}16,52 \pm \\
0,30\end{array}$ \\
\hline 4 & 40 & $\begin{array}{c}443,33 \pm \\
35,22\end{array}$ & $\begin{array}{c}10,20 \pm \\
0,40\end{array}$ & $\begin{array}{c}10730 \pm \\
289\end{array}$ & $\begin{array}{c}856,17 \pm \\
19,08\end{array}$ & $\begin{array}{c}1182 \pm \\
23\end{array}$ & $5853 \pm 54$ & $\begin{array}{c}16,73 \pm \\
0,36\end{array}$ \\
\hline 4 & 20 & $\begin{array}{c}445,60 \pm \\
30,42\end{array}$ & $\begin{array}{c}10,01 \pm \\
0,52\end{array}$ & $\begin{array}{c}10826 \pm \\
289\end{array}$ & $\begin{array}{c}848,40 \pm \\
20,21\end{array}$ & $\begin{array}{c}1175 \pm \\
27\end{array}$ & $5866 \pm 45$ & $\begin{array}{c}16,60 \pm \\
0,34\end{array}$ \\
\hline 18 & 60 & $\begin{array}{c}440,11 \pm \\
35,13\end{array}$ & $\begin{array}{c}10,11 \pm \\
0,36\end{array}$ & $\begin{array}{c}10780 \pm \\
156\end{array}$ & $\begin{array}{c}864,42 \pm \\
12,23\end{array}$ & $\begin{array}{c}1178 \pm \\
16 \\
\end{array}$ & $6084 \pm 72$ & $\begin{array}{c}17,14 \pm \\
0,34\end{array}$ \\
\hline 18 & 40 & $\begin{array}{c}437,04 \pm \\
34,82\end{array}$ & $\begin{array}{c}10,08 \pm \\
0,45\end{array}$ & $\begin{array}{c}10758 \pm \\
157\end{array}$ & $\begin{array}{c}858,97 \pm \\
15,10\end{array}$ & $\begin{array}{c}1178 \pm \\
21\end{array}$ & $\begin{array}{c}6078 \pm \\
111\end{array}$ & $\begin{array}{c}16,94 \pm \\
0,31\end{array}$ \\
\hline 18 & 20 & $\begin{array}{c}438,55 \pm \\
32,62\end{array}$ & $\begin{array}{c}10,70 \pm \\
0,66\end{array}$ & $\begin{array}{c}10820 \pm \\
188\end{array}$ & $\begin{array}{c}861,48 \pm \\
14,69\end{array}$ & $\begin{array}{c}1181 \pm \\
16\end{array}$ & $6079 \pm 88$ & $\begin{array}{c}17,13 \pm \\
0,37\end{array}$ \\
\hline 37 & 60 & $\begin{array}{c}394,00 \pm \\
31,08\end{array}$ & $9,51 \pm 0,73$ & $\begin{array}{c}10134 \pm \\
311\end{array}$ & $\begin{array}{c}795,78 \pm \\
27,39 \\
\end{array}$ & $\begin{array}{c}1100 \pm \\
35\end{array}$ & $5604 \pm 77$ & $\begin{array}{c}15,87 \pm \\
0,59\end{array}$ \\
\hline 37 & 40 & $\begin{array}{c}445,23 \pm \\
38,13\end{array}$ & $9,96 \pm 0,51$ & $\begin{array}{c}10576 \pm \\
109\end{array}$ & $\begin{array}{c}837,92 \pm \\
14,73 \\
\end{array}$ & $\begin{array}{c}1149 \pm \\
10\end{array}$ & $\begin{array}{c}5855 \pm \\
112\end{array}$ & $\begin{array}{c}16,65 \pm \\
0,24\end{array}$ \\
\hline 37 & 20 & $\begin{array}{c}436,07 \pm \\
32,85\end{array}$ & $9,45 \pm 0,42$ & $\begin{array}{c}10616 \pm \\
312\end{array}$ & $\begin{array}{c}844,21 \pm \\
27,97\end{array}$ & $\begin{array}{c}1157 \pm \\
30\end{array}$ & $5871 \pm 50$ & $\begin{array}{c}16,53 \pm \\
0,28\end{array}$ \\
\hline
\end{tabular}


Tabela 48 - Frações de massa dos elementos $\left(\mu \mathrm{g} \mathrm{kg}^{-1}\right)$ obtidas por ICP-MS para o estudo de estabilidade a curto prazo (base úmida).

\begin{tabular}{|c|c|c|c|c|c|c|c|}
\hline $\begin{array}{c}\mathbf{T} \\
\left({ }^{\circ} \mathbf{C}\right)\end{array}$ & $\begin{array}{c}\text { Tempo } \\
\text { (dias) }\end{array}$ & As & Ba & Co & $\mathrm{Cr}$ & $\mathrm{Cu}$ & Mn \\
\hline-20 & 60 & $33,83 \pm 2,12$ & $249,46 \pm 14,66$ & $20,08 \pm 0,61$ & $708,80 \pm 24,47$ & $878,37 \pm 38,97$ & $398,83 \pm 12,33$ \\
\hline 4 & 60 & $31,38 \pm 3,17$ & $291,48 \pm 11,58$ & $19,88 \pm 1,20$ & $704,27 \pm 20,43$ & $872,02 \pm 53,87$ & $398,79 \pm 22,36$ \\
\hline 4 & 40 & $31,94 \pm 5,35$ & $291,25 \pm 15,54$ & $19,73 \pm 2,08$ & $705,43 \pm 30,32$ & $873,65 \pm 35,48$ & $397,92 \pm 20,61$ \\
\hline 4 & 20 & $31,66 \pm 6,57$ & $290,06 \pm 14,84$ & $20,06 \pm 2,30$ & $704,98 \pm 40,44$ & $876,12 \pm 25,92$ & $395,62 \pm 17,53$ \\
\hline 18 & 60 & $30,65 \pm 2,84$ & $289,37 \pm 13,46$ & $19,59 \pm 1,90$ & $706,50 \pm 46,96$ & $877,86 \pm 24,91$ & $392,46 \pm 42,47$ \\
\hline 18 & 40 & $29,79 \pm 2,19$ & $290,58 \pm 9,74$ & $19,41 \pm 1,07$ & $704,75 \pm 37,98$ & $878,09 \pm 32,00$ & $395,96 \pm 19,48$ \\
\hline 18 & 20 & $30,16 \pm 3,80$ & $290,81 \pm 15,41$ & $19,29 \pm 1,40$ & $702,97 \pm 51,02$ & $875,42 \pm 26,65$ & $394,57 \pm 18,27$ \\
\hline 37 & 60 & & & $18,31 \pm 1,00$ & & & \\
\hline 37 & 40 & $27,42 \pm 5,20$ & $277,06 \pm 11,79$ & $18,58 \pm 1,49$ & $691,06 \pm 45,60$ & $871,33 \pm 23,89$ & $384,87 \pm 24,03$ \\
\hline 37 & 20 & & & & $696,85 \pm 44,02$ & $878,06 \pm 28,68$ & $392,34 \pm 33,25$ \\
\hline $\begin{array}{c}\mathbf{T} \\
\left({ }^{\circ} \mathbf{C}\right) \\
\end{array}$ & $\begin{array}{c}\text { Tempo } \\
\text { (dias) }\end{array}$ & Mo & $\mathbf{N i}$ & Se & Sr & $\mathbf{T i}$ & $\mathbf{V}$ \\
\hline-20 & 60 & $83,15 \pm 7,00$ & $390,24 \pm 36,69$ & $301,45 \pm 78,17$ & $867,98 \pm 172,40$ & $857,21 \pm 64,21$ & $46,63 \pm 3,73$ \\
\hline 4 & 60 & $83,08 \pm 5,22$ & $388,18 \pm 18,96$ & $299,04 \pm 84,52$ & $86,20 \pm 118,30$ & $855,19 \pm 81,00$ & $44,18 \pm 3,99$ \\
\hline 4 & 40 & $82,19 \pm 3,86$ & $388,33 \pm 37,48$ & $294,29 \pm 60,19$ & $865,03 \pm 129,73$ & $853,93 \pm 84,50$ & $44,62 \pm 3,84$ \\
\hline 4 & 20 & $82,49 \pm 3,80$ & $389,95 \pm 47,75$ & $293,09 \pm 76,21$ & $865,90 \pm 171,89$ & $857,04 \pm 125,82$ & $44,67 \pm 2,65$ \\
\hline 18 & 60 & $82,40 \pm 4,62$ & $389,86 \pm 52,19$ & $294,01 \pm 61,86$ & $863,10 \pm 165,33$ & $856,61 \pm 90,76$ & $45,72 \pm 3,85$ \\
\hline 18 & 40 & $81,46 \pm 5,96$ & $387,42 \pm 28,36$ & $292,38 \pm 54,76$ & $864,12 \pm 168,67$ & $854,89 \pm 87,56$ & $45,87 \pm 3,01$ \\
\hline 18 & 20 & $82,30 \pm 5,37$ & $386,03 \pm 51,63$ & $300,86 \pm 60,10$ & $859,68 \pm 157,81$ & $856,11 \pm 129,23$ & $45,75 \pm 3,33$ \\
\hline 37 & 60 & $78,90 \pm 4,02$ & $355,99 \pm 53,96$ & $252,32 \pm 48,51$ & $789,85 \pm 212,23$ & $836,29 \pm 99,76$ & $42,43 \pm 2,80$ \\
\hline 37 & 40 & $79,50 \pm 4,84$ & $367,31 \pm 59,26$ & $262,41 \pm 35,80$ & $839,96 \pm 241,94$ & $850,27 \pm 78,89$ & $43,93 \pm 3,21$ \\
\hline 37 & 20 & $80,25 \pm 2,77$ & $378,56 \pm 37,26$ & $299,15 \pm 70,69$ & $853,74 \pm 145,23$ & $853,37 \pm 63,37$ & $45,75 \pm 2,84$ \\
\hline
\end{tabular}

Nas Figuras 56 e 57 são apresentados os gráficos da investigação e tendência para as três temperaturas avaliadas. A dispersão aleatória dos dados observada na investigação gráfica de possíveis tendências ao longo do tempo, nas temperaturas indicadas, leva à sugestão de alteração considerável para as concentrações para quase todos os elementos na temperatura de $37^{\circ} \mathrm{C}$ por 60 dias, com exceção de $\mathrm{Co}$, Fe e Ti. 
Figura 56 - Investigação de tendência no estudo de estabilidade a curto prazo para elementos obtidos por ICP OES, com resultados apresentados por ordem de tempo e ajuste de curva linear. (a) $\mathrm{Ca}$, (b) Fe, (c) K, (d) Mg, (e) Na, (f) P e (g) Zn.

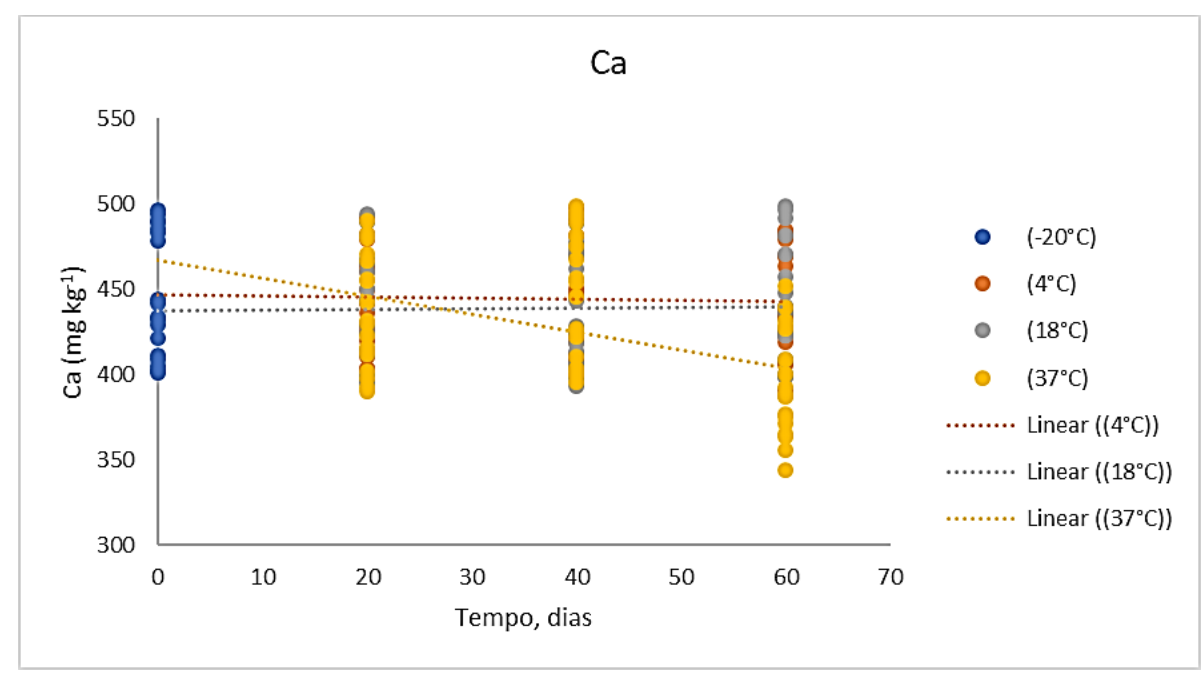

(a)

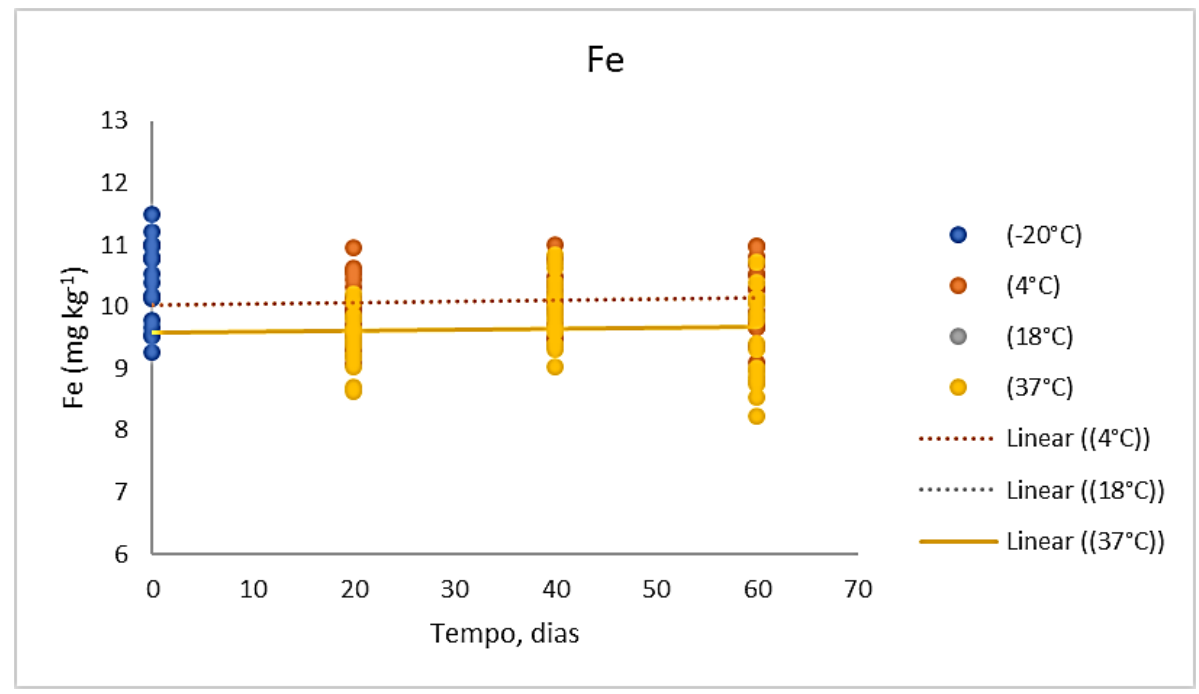

(b) 


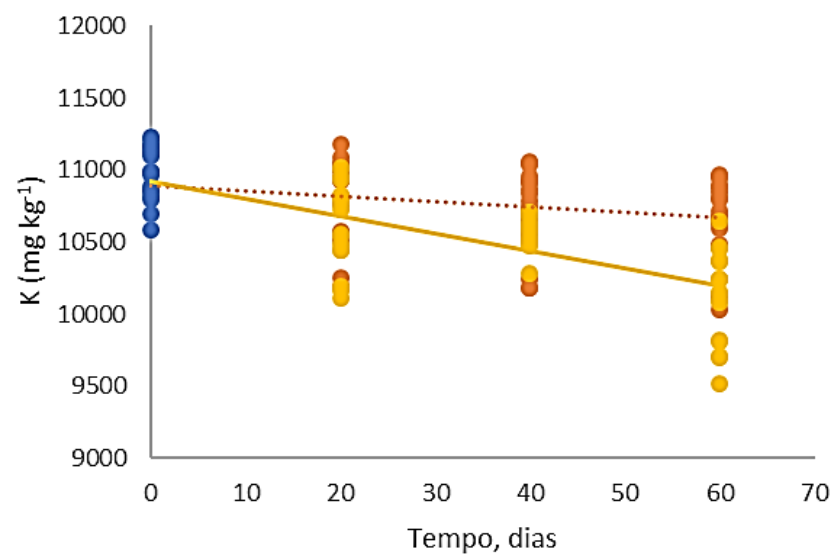

- $\left(-20^{\circ} \mathrm{C}\right)$

- $\left(4^{\circ} \mathrm{C}\right)$

- $\left(18^{\circ} \mathrm{C}\right)$

- $\left(37^{\circ} \mathrm{C}\right)$

......... Linear $\left(\left(4^{\circ} \mathrm{C}\right)\right)$ . Linear $\left(\left(18^{\circ} \mathrm{C}\right)\right)$ - Linear $\left(\left(37^{\circ} \mathrm{C}\right)\right)$

(c)

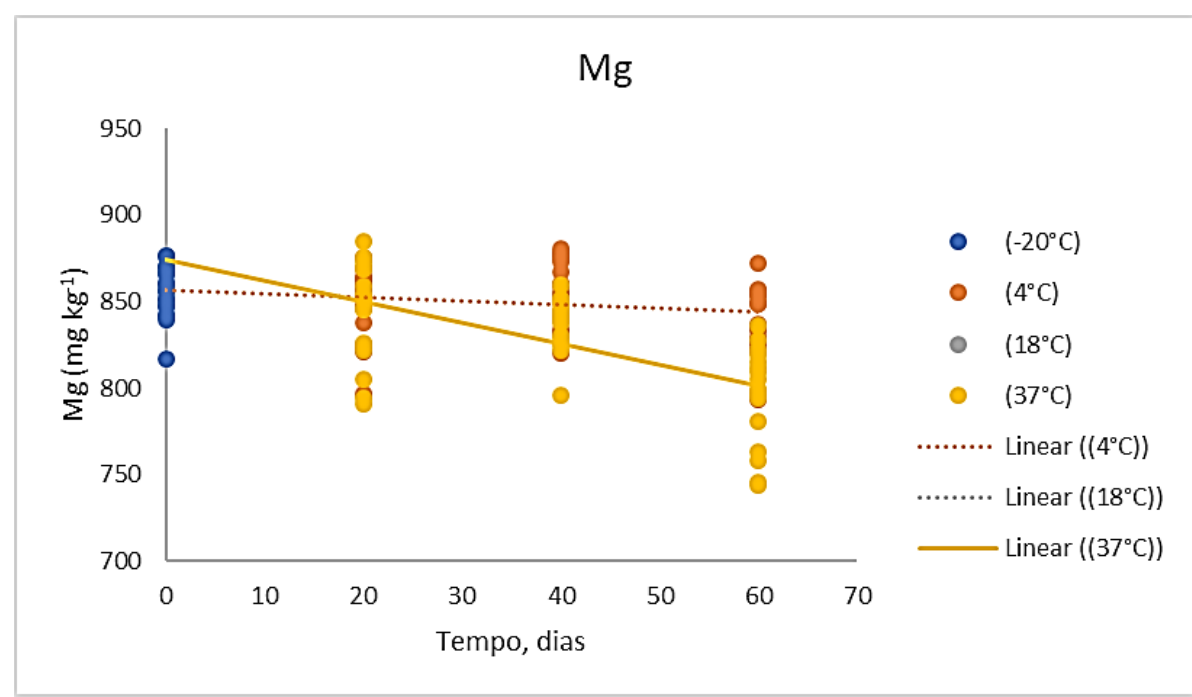

(d)

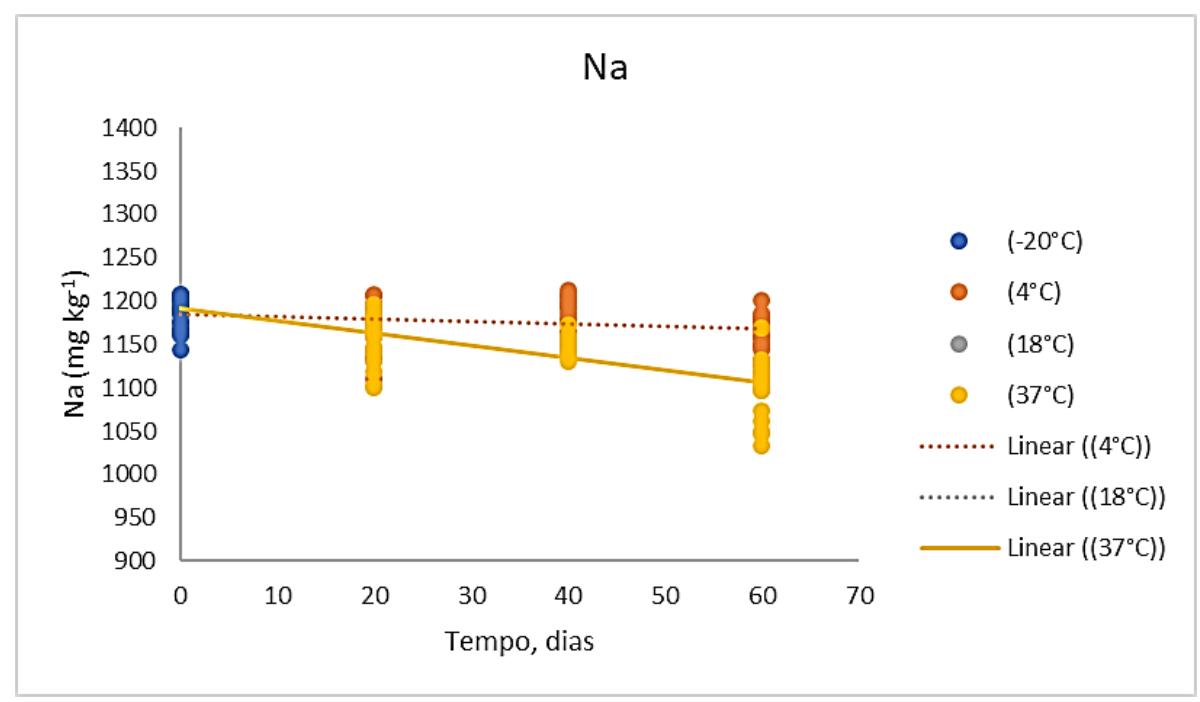

(e) 


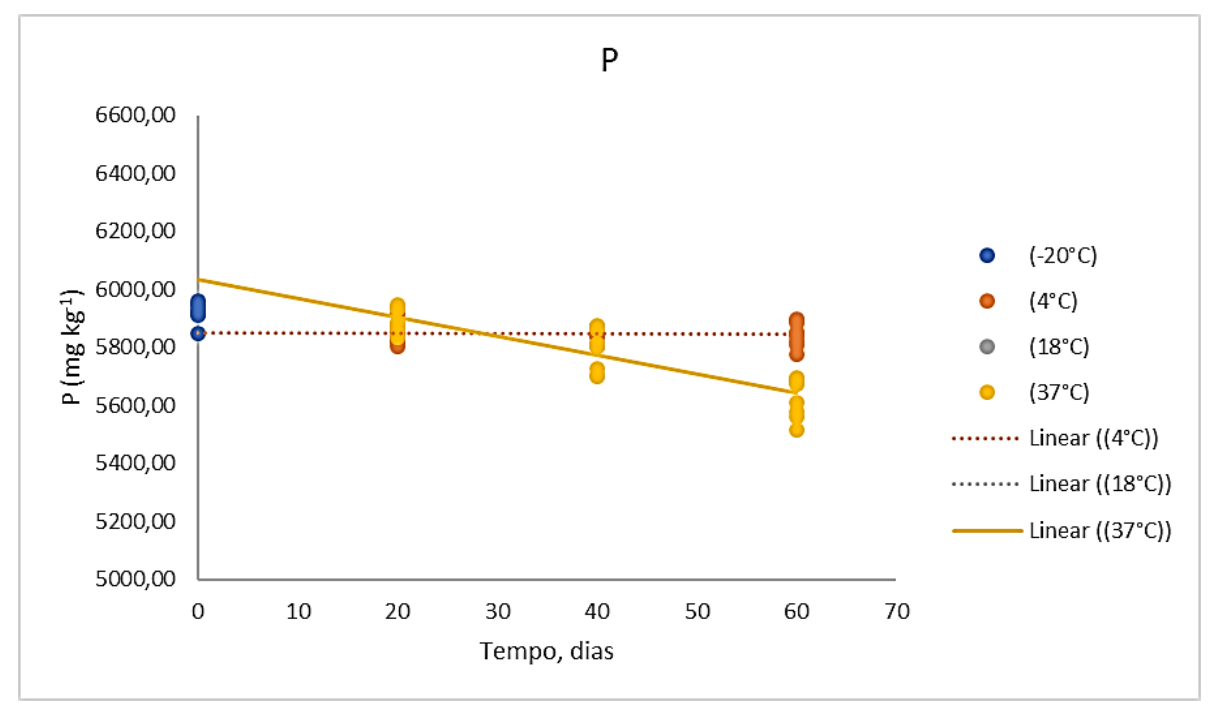

(f)

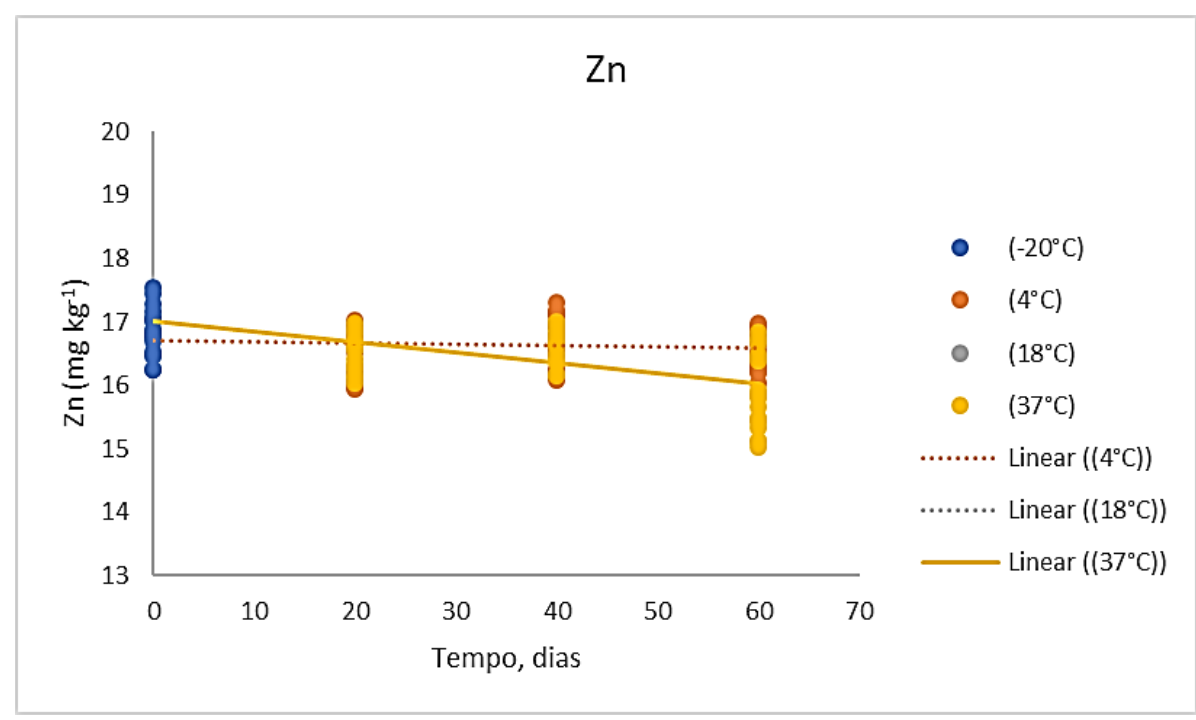

(g) 
Figura 57 - Investigação de tendência no estudo de estabilidade a curto prazo para elementos obtidos por ICP-MS, com resultados apresentados por ordem de tempo e ajuste de curva linear. (a) As, (b) Ba, (c) $\mathrm{Co}$, (d) Cr, (e) Cu, (f) Mn, (g) Mo, (h) Ni, (i) Se, (j) Sr, (k) Ti e (l)V.

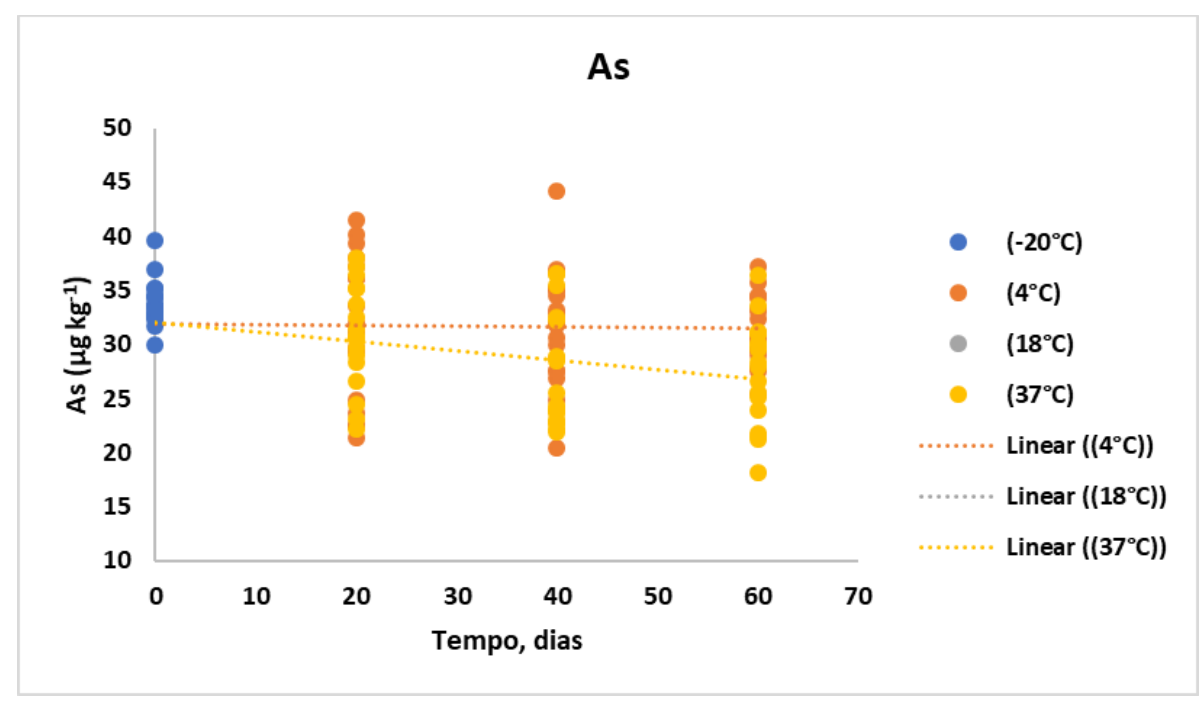

(a)

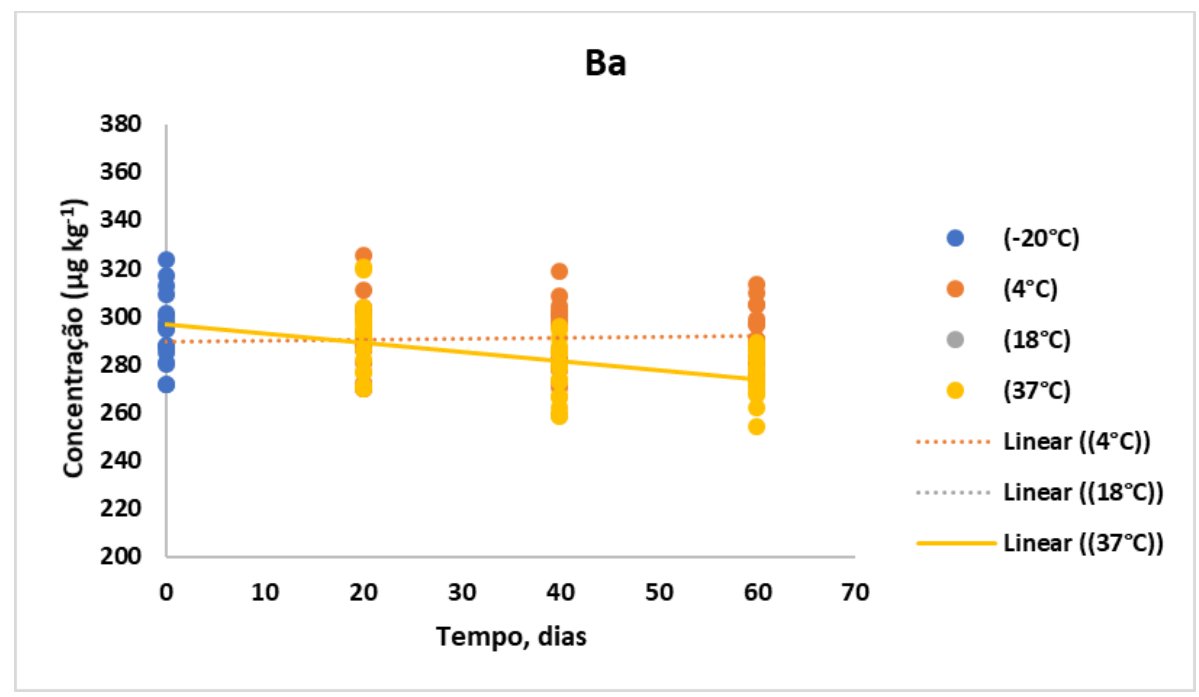

(b) 


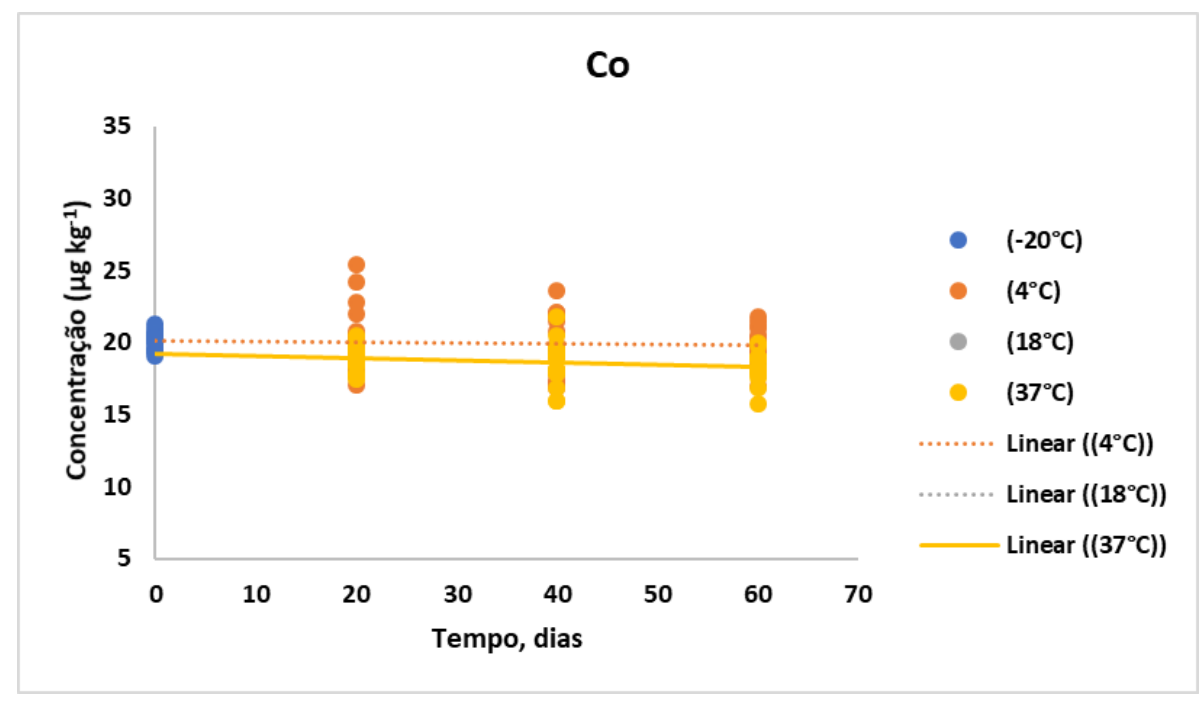

(c)

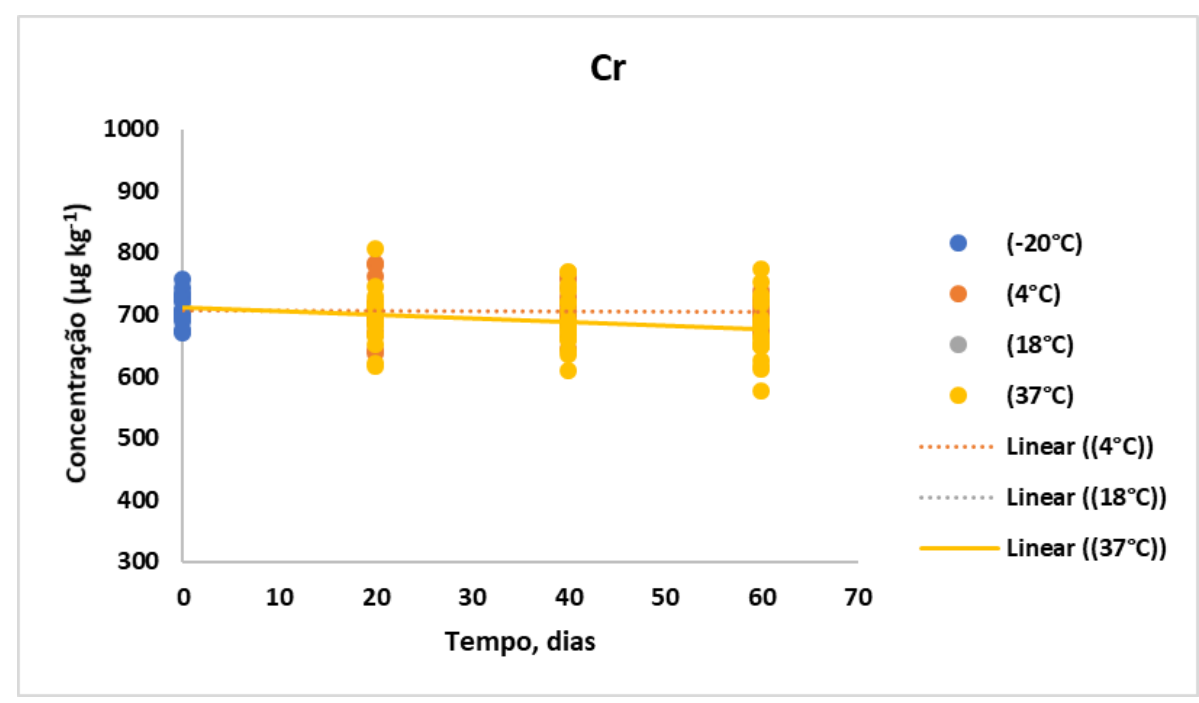

(d)

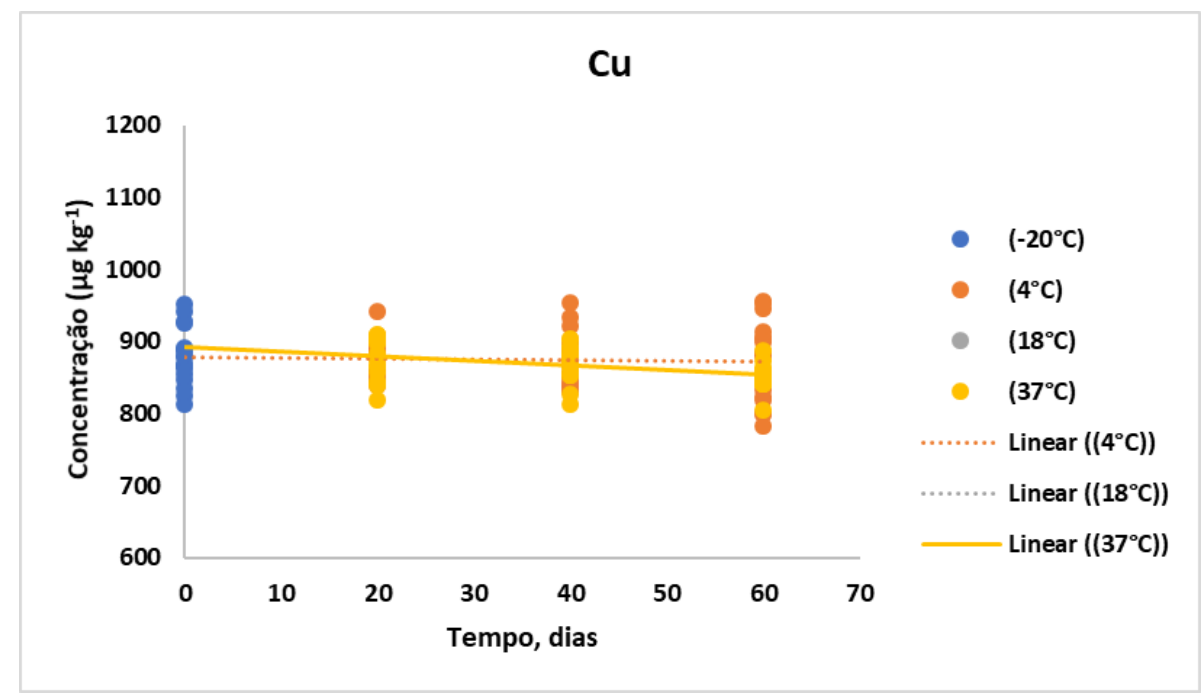

(e) 
Mn

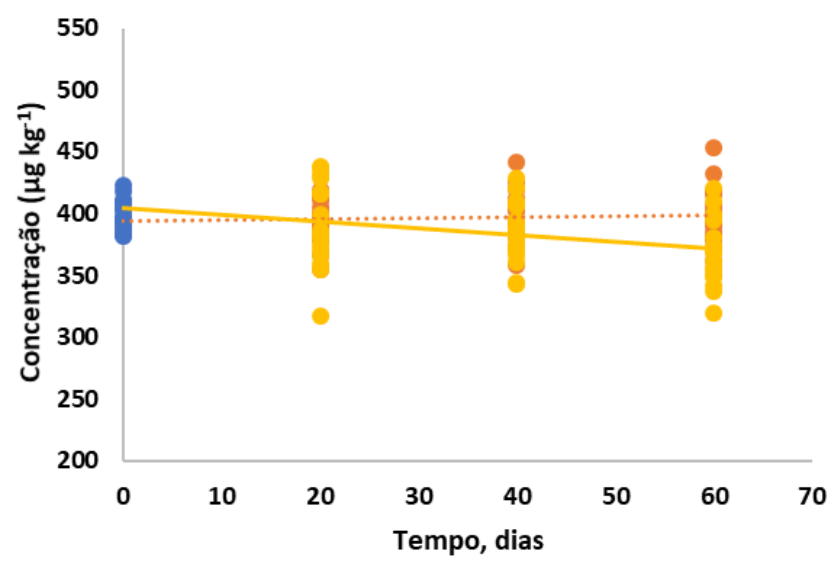

- $\left(-20^{\circ} \mathrm{C}\right)$

- $\left(4^{\circ} \mathrm{C}\right)$

- $\left(18^{\circ} \mathrm{C}\right)$

- $\left(37^{\circ} \mathrm{C}\right)$

Linear $\left(\left(4^{\circ} \mathrm{C}\right)\right)$

Linear $\left(\left(18^{\circ} \mathrm{C}\right)\right)$

- Linear $\left(\left(37^{\circ} \mathrm{C}\right)\right)$

(f)

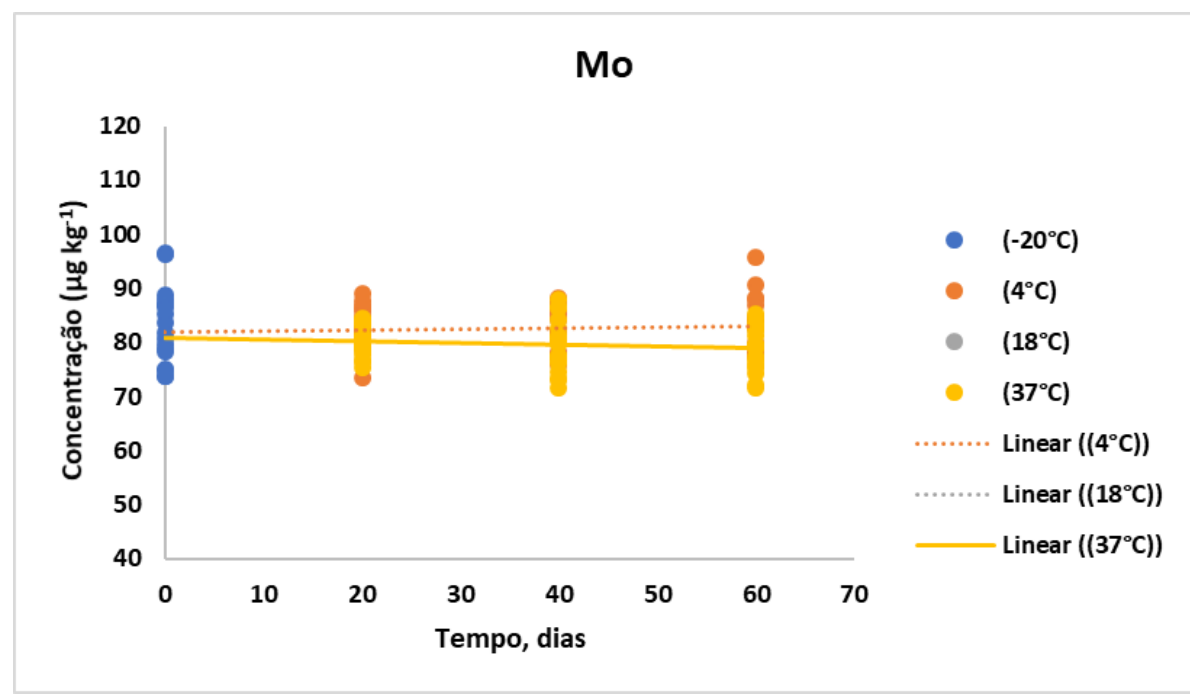

(g)

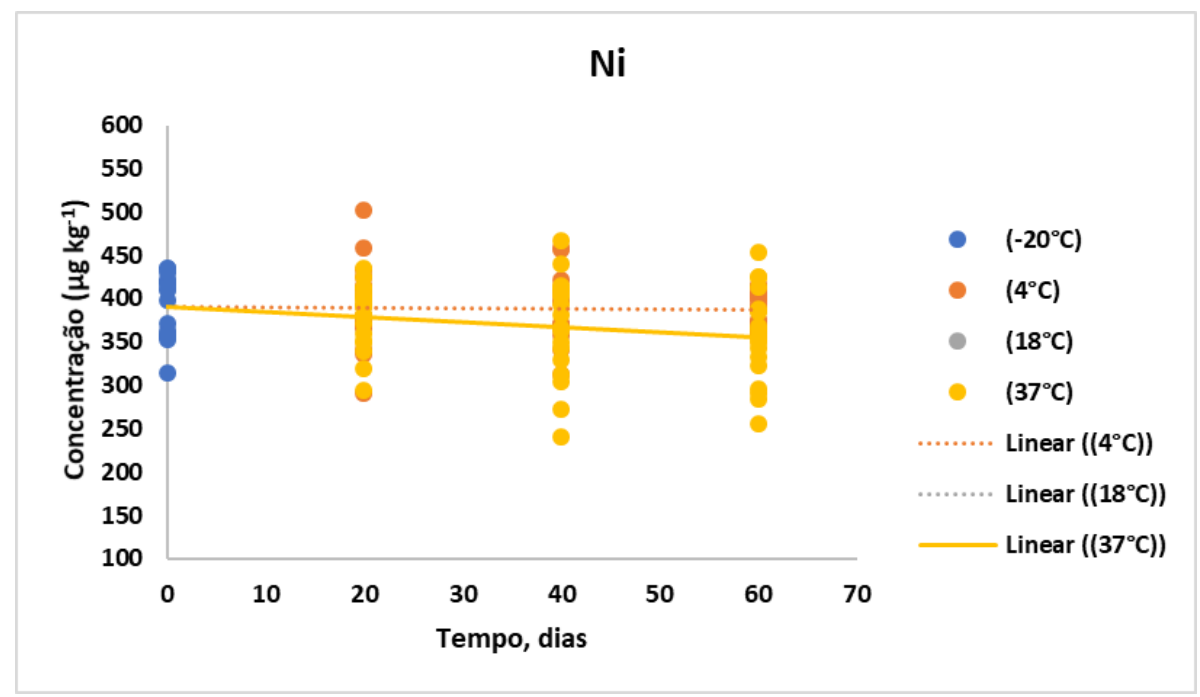

(h) 


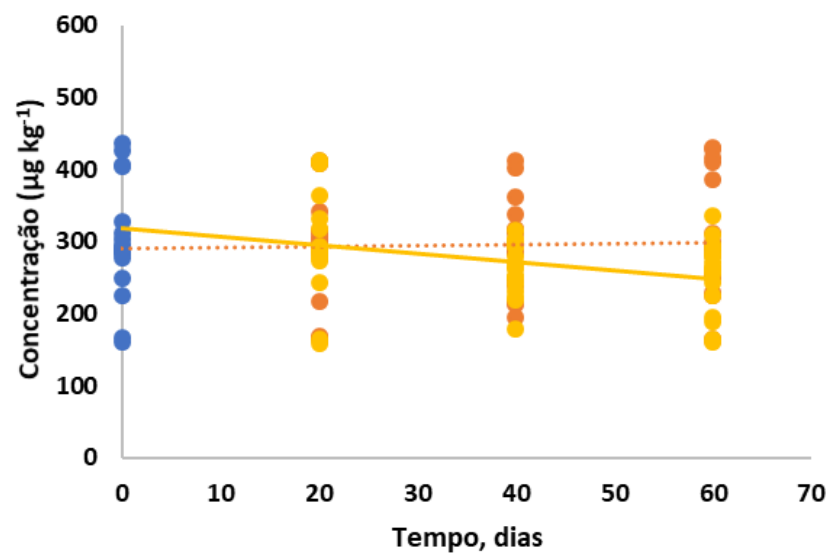

- $\left(-20^{\circ} \mathrm{C}\right)$

- $\left(4^{\circ} \mathrm{C}\right)$

- $\left(18^{\circ} \mathrm{C}\right)$

- $\left(37^{\circ} \mathrm{C}\right)$ Linear $\left(\left(4^{\circ} \mathrm{C}\right)\right)$ Linear $\left(\left(18^{\circ} \mathrm{C}\right)\right)$ - Linear $\left(\left(37^{\circ} \mathrm{C}\right)\right)$

(i)

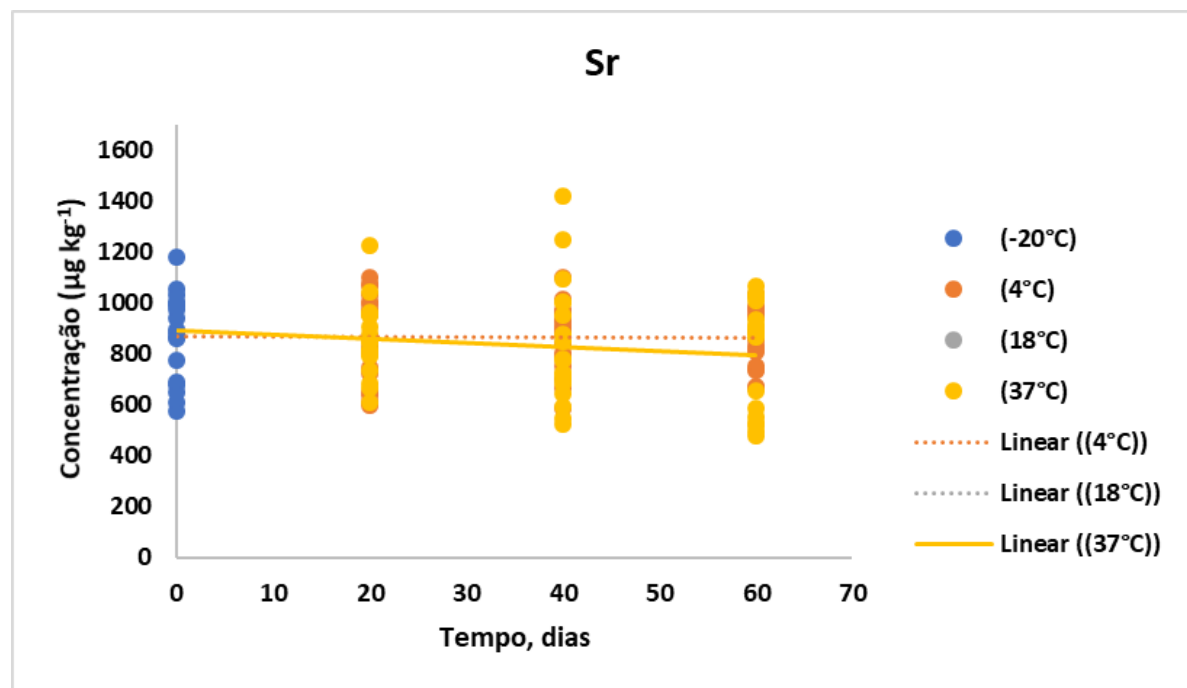

(j)

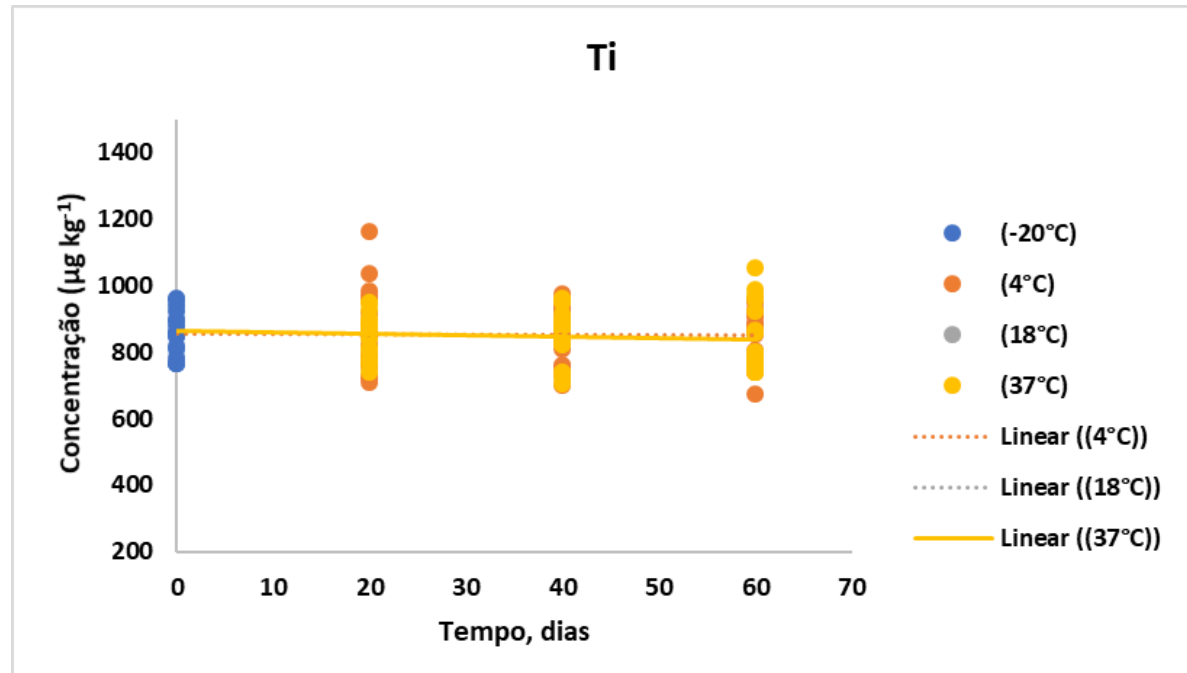

(k) 


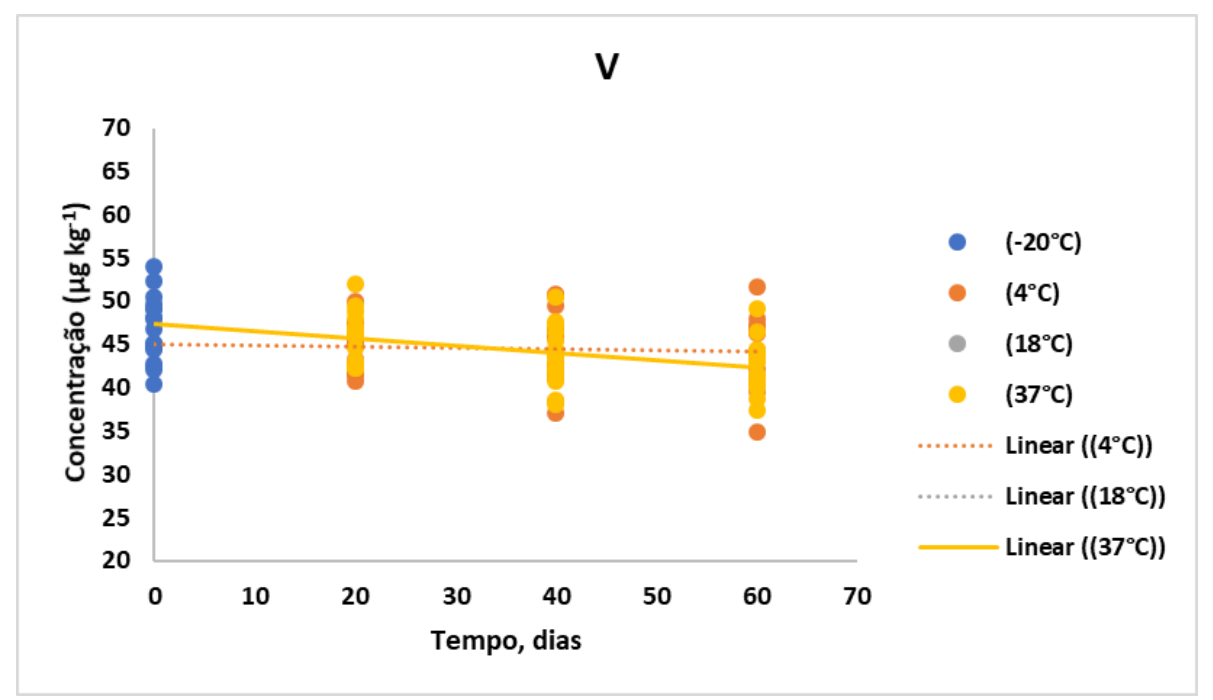

(1)

Para a complementação da avaliação de estabilidade a curto prazo, os resultados médios obtidos em cada temperatura normalizados aos resultados obtidos na temperatura de referência, $-20^{\circ} \mathrm{C}$, de acordo com a Equação 31 , obtendo-se a razão $R_{T}$. Para o caso de estabilidade a razão $R_{T}$ deve ser igual a 1 . A incerteza combinada foi calculada de acordo com a Equação 32. As Tabelas 49 e 50 apresentam $R_{T} \pm U_{T}$ para todos os tempos e temperaturas avaliados e a partir da avaliação dos resultados obtidos, pode-se afirmar que a maioria dos valores de $\mathrm{R}_{\mathrm{T}} \pm \mathrm{U}_{\mathrm{T}}$ não diferiu significativamente de 1 , de modo que o material pode ser considerado estável para as condições testadas, com ressalvas para a temperatura de $37^{\circ} \mathrm{C}$ por 60 dias, onde foram obtidas as menores concentrações médias, o que foi evidenciado nas Tabelas 49 e 50 e pode ser visto nas Figuras 58 e 59.

As Figuras 58 e 59 apresentam as razões $R_{T}$ para os elementos avaliados, as incertezas não foram representadas graficamente por motivos de clareza para a avaliação. Corroborando com os gráficos de avaliação de tendência, apresentados nas Figuras 56 e 57, pode-se verificar uma variação em quase todos os elementos no tratamento de $37^{\circ} \mathrm{C}$ por 60 dias, com exceção de o, $\mathrm{Cr}, \mathrm{Cu}, \mathrm{Fe}$, Mo e Ti. Contudo, se considerarmos os desvios padrão, todas as medidas, nas diferentes temperaturas, estão em concordância. A observação dos padrões dos gráficos leva à conclusão que as variações observadas sugerem um maior cuidado no transporte (refrigeração, por exemplo) sob temperaturas superiores a $35^{\circ} \mathrm{C}$ por mais que 30 dias, para que sejam conservadas as propriedades do RM candidato. 
Tabela 49 - Resultados normalizados do estudo de estabilidade a curto prazo obtidos por ICP OES.

\begin{tabular}{|c|c|c|c|c|}
\hline \multirow{2}{*}{ Elemento } & \multirow{2}{*}{$\mathbf{T}\left({ }^{\circ} \mathbf{C}\right)$} & \multicolumn{3}{|c|}{$\overline{\mathbf{R}_{\mathrm{T}} \pm \mathbf{U}_{\mathrm{T}}}$} \\
\hline & & 60 dias & 40 dias & 20 dias \\
\hline \multirow{3}{*}{$\mathbf{C a}$} & 4 & $0,990 \pm 0,104$ & $0,992 \pm 0,112$ & $0,997 \pm 0,105$ \\
\hline & 18 & $0,985 \pm 0,112$ & $0,978 \pm 0,111$ & $0,981 \pm 0,108$ \\
\hline & 37 & $0,882 \pm 0,099$ & $0,996 \pm 0,117$ & $0,976 \pm 0,108$ \\
\hline \multirow{3}{*}{$\mathbf{F e}$} & 4 & $0,970 \pm 0,082$ & $0,981 \pm 0,073$ & $0,963 \pm 0,079$ \\
\hline & 18 & $0,972 \pm 0,070$ & $0,969 \pm 0,075$ & $1,029 \pm 0,091$ \\
\hline & 37 & $0,914 \pm 0,091$ & $0,958 \pm 0,078$ & $0,909 \pm 0,070$ \\
\hline \multirow{3}{*}{$\mathbf{K}$} & 4 & $0,972 \pm 0,029$ & $0,977 \pm 0,031$ & $0,986 \pm 0,031$ \\
\hline & 18 & $0,982 \pm 0,022$ & $0,980 \pm 0,022$ & $0,985 \pm 0,024$ \\
\hline & 37 & $0,923 \pm 0,032$ & $0,963 \pm 0,019$ & $0,967 \pm 0,033$ \\
\hline \multirow{3}{*}{ Mg } & 4 & $0,982 \pm 0,028$ & $1,001 \pm 0,028$ & $0,992 \pm 0,029$ \\
\hline & 18 & $1,010 \pm 0,023$ & $1,004 \pm 0,025$ & $1,007 \pm 0,025$ \\
\hline & 37 & $0,930 \pm 0,036$ & $0,979 \pm 0,024$ & $0,987 \pm 0,037$ \\
\hline \multirow{3}{*}{$\mathbf{N a}$} & 4 & $0,982 \pm 0,023$ & $0,997 \pm 0,025$ & $0,991 \pm 0,028$ \\
\hline & 18 & $0,994 \pm 0,021$ & $0,994 \pm 0,024$ & $0,996 \pm 0,021$ \\
\hline & 37 & $0,928 \pm 0,033$ & $0,970 \pm 0,018$ & $0,976 \pm 0,030$ \\
\hline \multirow{3}{*}{$\mathbf{P}$} & 4 & $0,979 \pm 0,014$ & $0,986 \pm 0,012$ & $0,988 \pm 0,011$ \\
\hline & 18 & $1,025 \pm 0,014$ & $1,024 \pm 0,020$ & $1,024 \pm 0,017$ \\
\hline & 37 & $0,944 \pm 0,015$ & $0,986 \pm 0,020$ & $0,989 \pm 0,011$ \\
\hline \multirow{3}{*}{$\mathbf{Z n}$} & 4 & $0,981 \pm 0,028$ & $0,993 \pm 0,031$ & $0,986 \pm 0,030$ \\
\hline & 18 & $1,017 \pm 0,030$ & $1,006 \pm 0,029$ & $1,017 \pm 0,031$ \\
\hline & 37 & $0,942 \pm 0,041$ & $0,988 \pm 0,026$ & $0,981 \pm 0,027$ \\
\hline
\end{tabular}


Tabela 50 - Resultados normalizados do estudo de estabilidade a curto prazo obtidos por ICP-MS.

\begin{tabular}{|c|c|c|c|c|}
\hline \multirow{2}{*}{ Elemento } & \multirow{2}{*}{$\mathbf{T}\left({ }^{\circ} \mathbf{C}\right)$} & \multicolumn{3}{|c|}{$\mathbf{R}_{\mathrm{T}} \pm \mathbf{U}_{\mathrm{T}}$} \\
\hline & & 60 dias & 40 dias & 20 dias \\
\hline \multirow{3}{*}{ As } & 4 & $0,928 \pm 0,110$ & $0,944 \pm 0,169$ & $0,936 \pm 0,203$ \\
\hline & 18 & $0,906 \pm 0,101$ & $0,881 \pm 0,085$ & $0,891 \pm 0,125$ \\
\hline & 37 & $0,810 \pm 0,150$ & $0,810 \pm 0,162$ & $0,911 \pm 0,150$ \\
\hline \multirow{3}{*}{$\mathbf{B a}$} & 4 & $0,990 \pm 0,063$ & $0,989 \pm 0,072$ & $0,985 \pm 0,070$ \\
\hline & 18 & $0,983 \pm 0,067$ & $0,987 \pm 0,059$ & $0,988 \pm 0,072$ \\
\hline & 37 & $0,937 \pm 0,056$ & $0,943 \pm 0,062$ & $0,989 \pm 0,071$ \\
\hline \multirow{3}{*}{ Co } & 4 & $0,990 \pm 0,067$ & $0,983 \pm 0,108$ & $0,999 \pm 0,118$ \\
\hline & 18 & $0,975 \pm 0,099$ & $0,967 \pm 0,061$ & $0,961 \pm 0,076$ \\
\hline & 37 & $0,912 \pm 0,057$ & $0,925 \pm 0,079$ & $0,941 \pm 0,052$ \\
\hline \multirow{3}{*}{$\mathrm{Cr}$} & 4 & $0,994 \pm 0,045$ & $0,995 \pm 0,055$ & $0,995 \pm 0,067$ \\
\hline & 18 & $0,997 \pm 0,075$ & $0,994 \pm 0,064$ & $0,992 \pm 0,080$ \\
\hline & 37 & $0,950 \pm 0,080$ & $0,975 \pm 0,073$ & $0,983 \pm 0,071$ \\
\hline \multirow{3}{*}{$\mathbf{C u}$} & 4 & $0,993 \pm 0,076$ & $0,995 \pm 0,060$ & $0,997 \pm 0,053$ \\
\hline & 18 & $0,999 \pm 0,053$ & $1,000 \pm 0,057$ & $0,997 \pm 0,054$ \\
\hline & 37 & $0,970 \pm 0,047$ & $0,992 \pm 0,052$ & $1,000 \pm 0,055$ \\
\hline \multirow{3}{*}{ Mn } & 4 & $1,000 \pm 0,064$ & $0,998 \pm 0,060$ & $0,992 \pm 0,054$ \\
\hline & 18 & $0,984 \pm 0,111$ & $0,993 \pm 0,058$ & $0,989 \pm 0,055$ \\
\hline & 37 & $0,930 \pm 0,075$ & $0,965 \pm 0,067$ & $0,984 \pm 0,089$ \\
\hline \multirow{3}{*}{ Mo } & 4 & $0,999 \pm 0,105$ & $0,988 \pm 0,095$ & $0,992 \pm 0,095$ \\
\hline & 18 & $0,991 \pm 0,100$ & $0,980 \pm 0,109$ & $0,990 \pm 0,105$ \\
\hline & 37 & $0,949 \pm 0,093$ & $0,956 \pm 0,099$ & $0,965 \pm 0,088$ \\
\hline \multirow{3}{*}{$\mathbf{N i}$} & 4 & $0,995 \pm 0,105$ & $0,995 \pm 0,134$ & $0,999 \pm 0,154$ \\
\hline & 18 & $0,999 \pm 0,163$ & $0,993 \pm 0,118$ & $0,989 \pm 0,162$ \\
\hline & 37 & $0,912 \pm 0,163$ & $0,941 \pm 0,176$ & $0,970 \pm 0,132$ \\
\hline \multirow{3}{*}{$\mathrm{Se}$} & 4 & $0,992 \pm 0,380$ & $0,976 \pm 0,322$ & $0,972 \pm 0,357$ \\
\hline & 18 & $0,975 \pm 0,326$ & $0,970 \pm 0,310$ & $0,998 \pm 0,327$ \\
\hline & 37 & $0,837 \pm 0,270$ & $0,870 \pm 0,255$ & $0,992 \pm 0,348$ \\
\hline \multirow{3}{*}{$\mathbf{S r}$} & 4 & $0,994 \pm 0,240$ & $0,997 \pm 0,248$ & $0,998 \pm 0,280$ \\
\hline & 18 & $0,994 \pm 0,274$ & $0,996 \pm 0,277$ & $0,990 \pm 0,268$ \\
\hline & 37 & $0,910 \pm 0,304$ & $0,968 \pm 0,339$ & $0,984 \pm 0,257$ \\
\hline \multirow{3}{*}{$\mathbf{T i}$} & 4 & $0,998 \pm 0,120$ & $0,996 \pm 0,124$ & $1,000 \pm 0,165$ \\
\hline & 18 & $0,999 \pm 0,130$ & $0,997 \pm 0,127$ & $0,999 \pm 0,168$ \\
\hline & 37 & $0,976 \pm 0,137$ & $0,992 \pm 0,118$ & $0,996 \pm 0,105$ \\
\hline \multirow{3}{*}{$\mathbf{V}$} & 4 & $0,947 \pm 0,114$ & $0,957 \pm 0,112$ & $0,958 \pm 0,095$ \\
\hline & 18 & $0,980 \pm 0,114$ & $0,984 \pm 0,102$ & $0,981 \pm 0,106$ \\
\hline & 37 & $0,910 \pm 0,094$ & $0,942 \pm 0,102$ & $0,981 \pm 0,099$ \\
\hline
\end{tabular}


Figura 58 - Razões $\mathrm{R}_{\mathrm{T}}$ para o estudo de estabilidade a curto prazo por ICP OES. (a) $\mathrm{Ca}$, (b) $\mathrm{Fe}$, (c) $\mathrm{K}$, (d) $\mathrm{Mg}$, (e) Na, (f) P e (g) Zn.

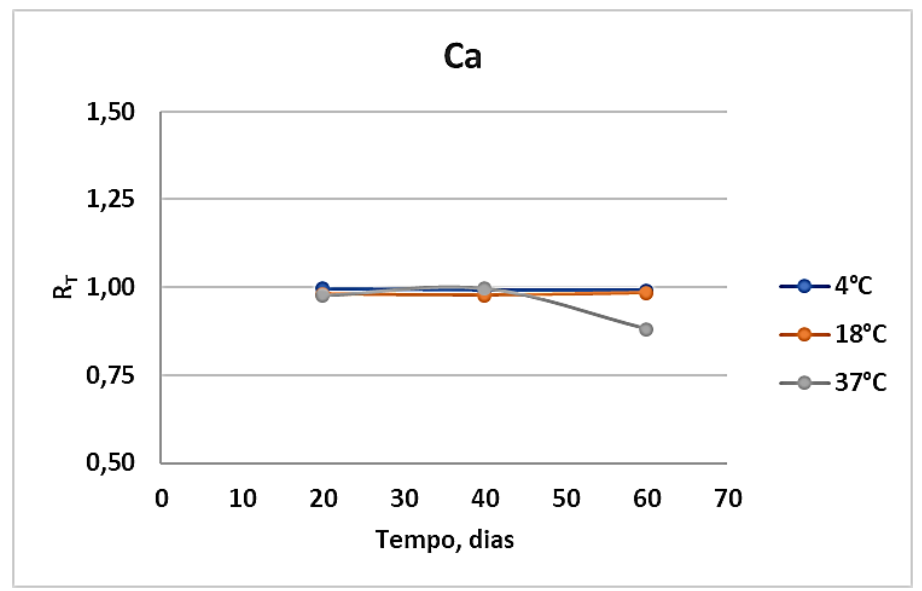

(a)

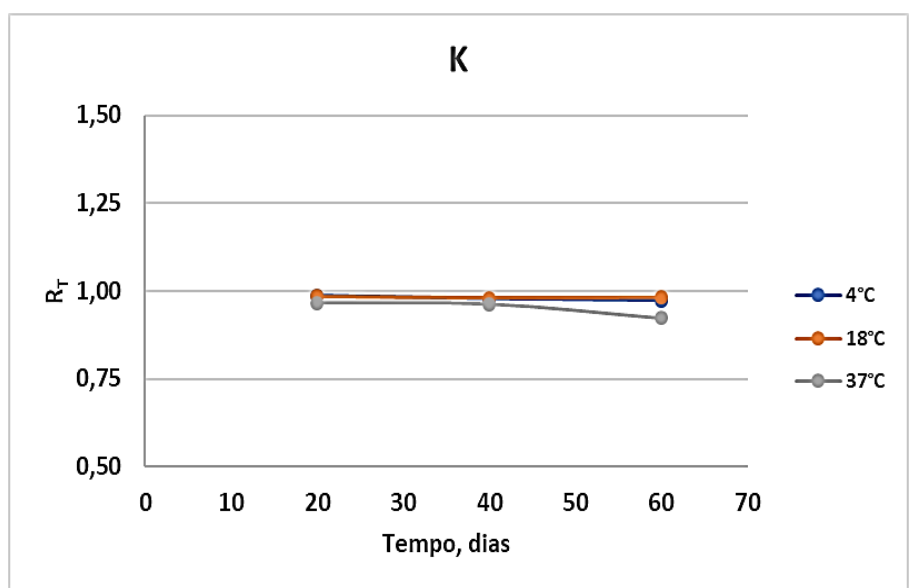

(c)

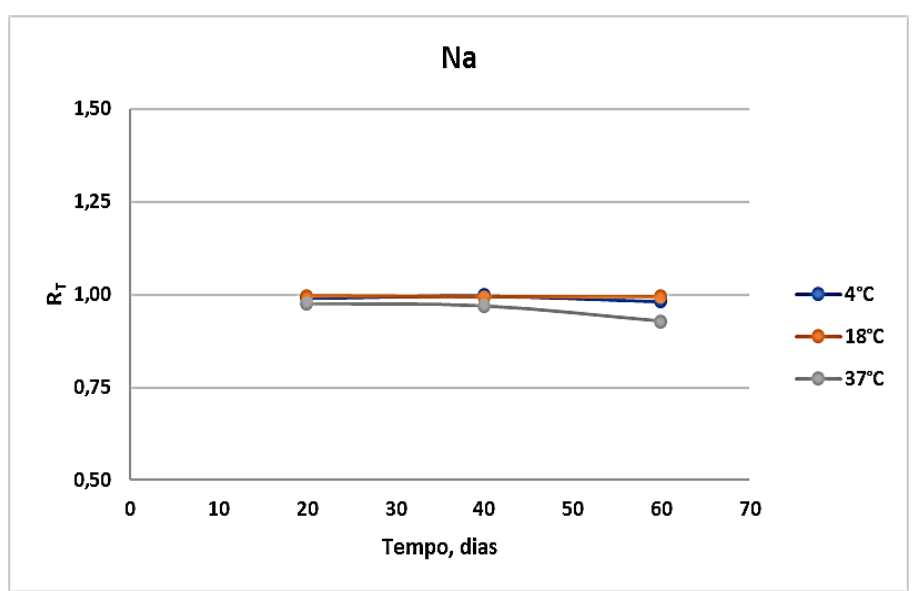

(e)

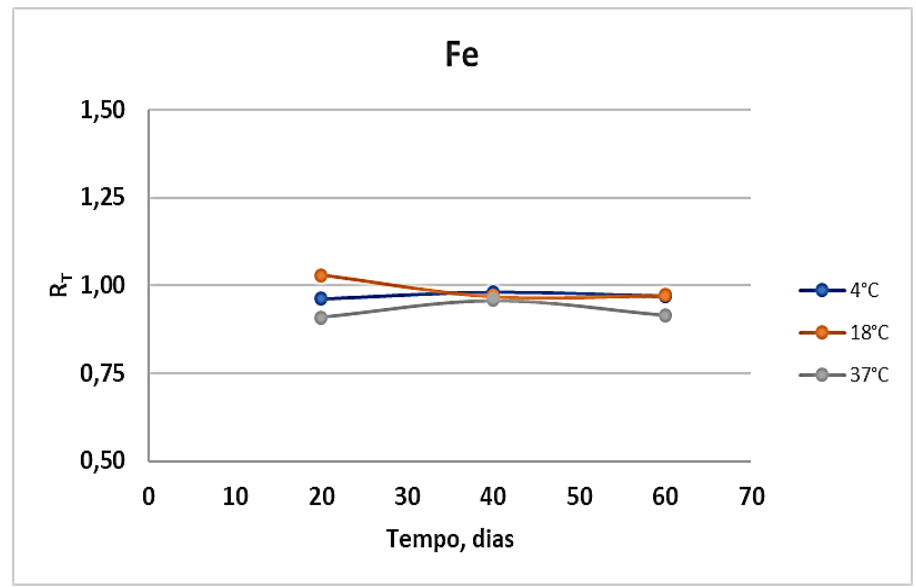

(b)

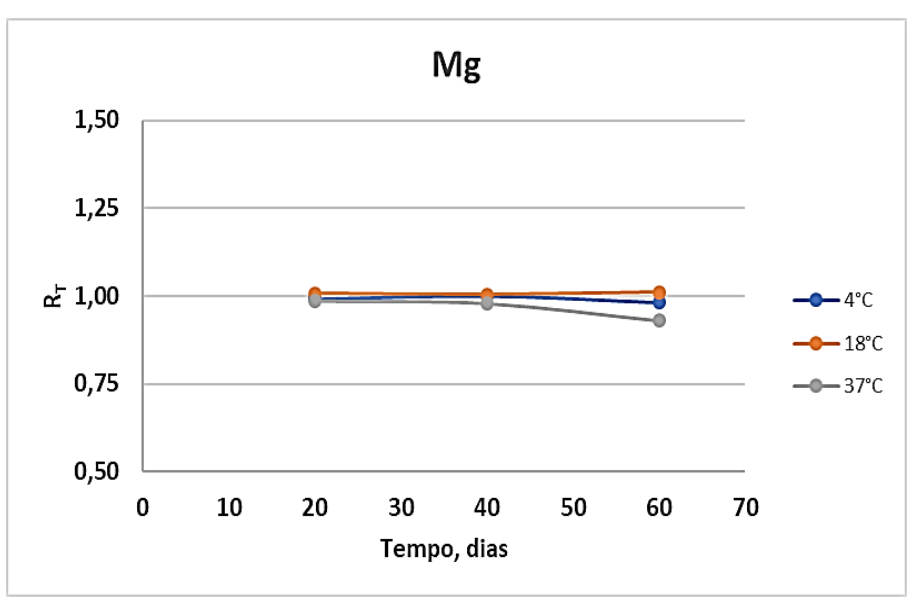

(d)

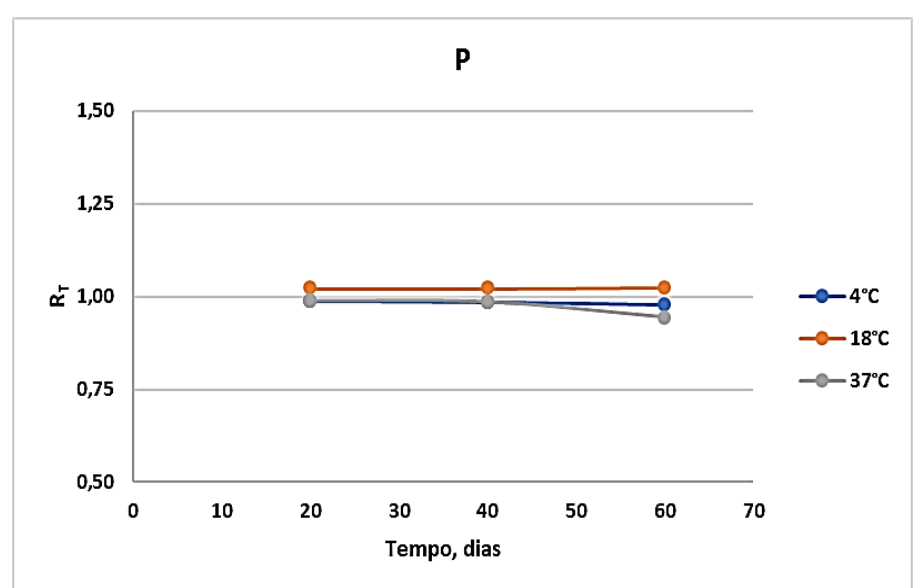

(f) 
Figura 58 - Razões $\mathrm{R}_{\mathrm{T}}$ para o estudo de estabilidade a curto prazo por ICP OES. (a) $\mathrm{Ca}$, (b) $\mathrm{Fe}$, (c) $\mathrm{K}$, (d) Mg, (e) Na, (f) P e (g) Zn. Continuação.

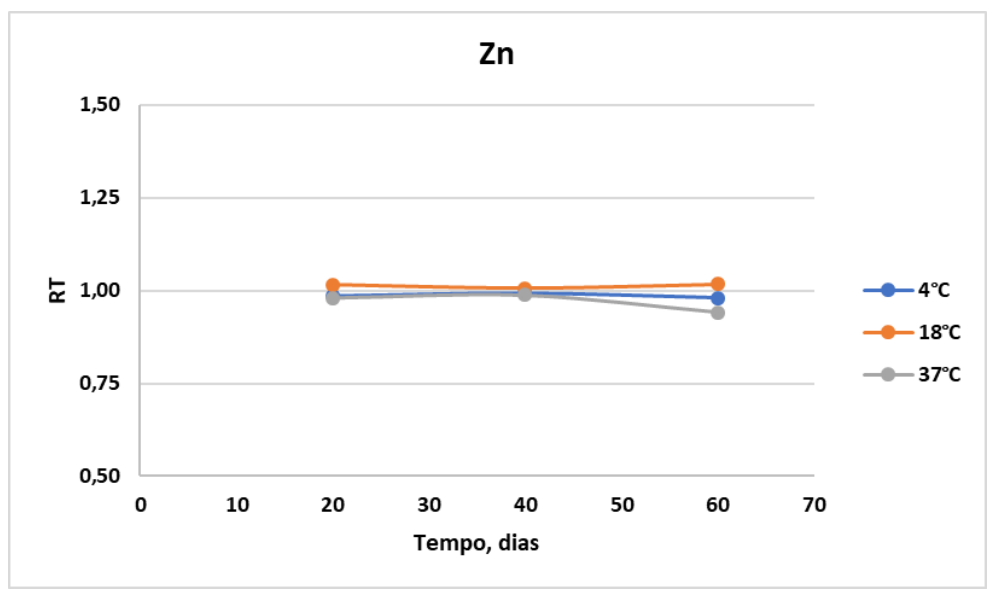

(g)

Figura 59 - Razões $\mathrm{R}_{\mathrm{T}}$ para o estudo de estabilidade a curto prazo por ICP-MS. (a) As, (b) Ba, (c) Co, (d) $\mathrm{Cr}$, (e) $\mathrm{Cu}$, (f) Mn, (g) Mo, (h) Ni, (i) Se, (j) Sr, (k) Ti e (l) V.

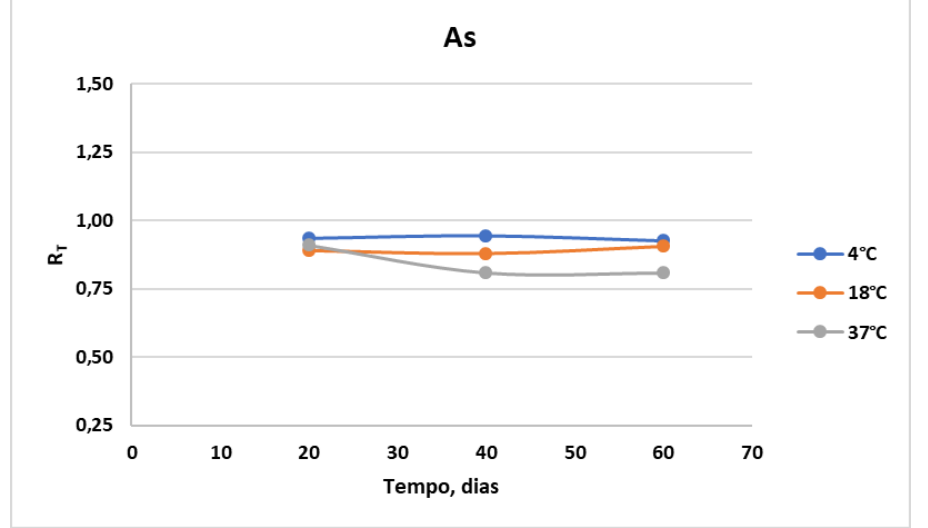

(a)

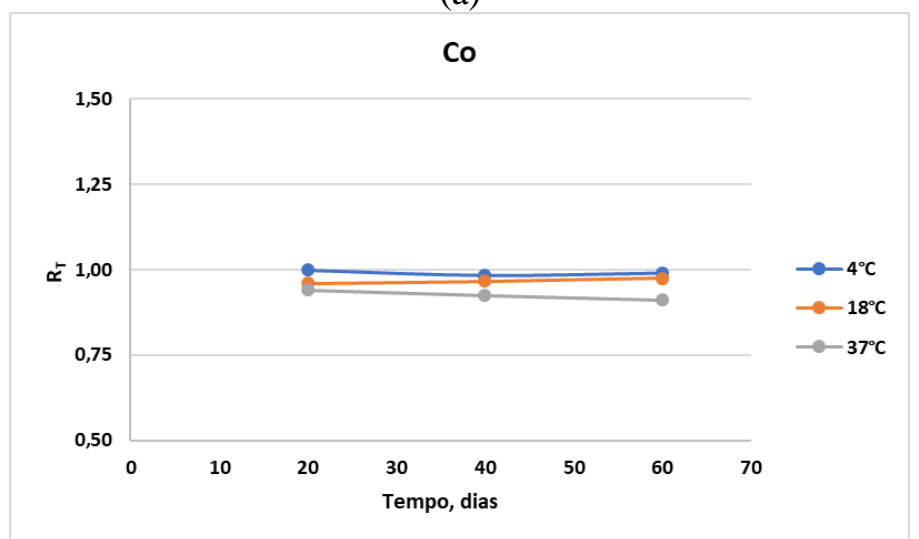

(c)

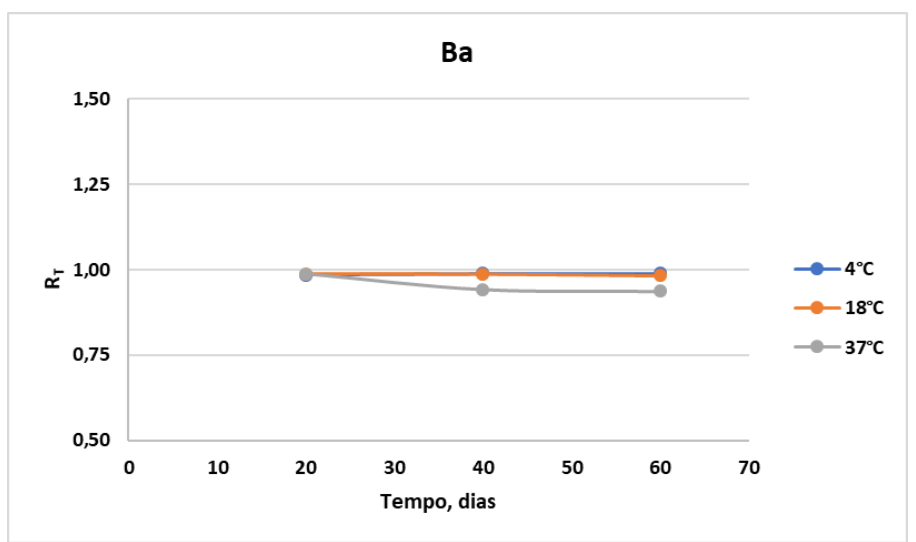

(b)

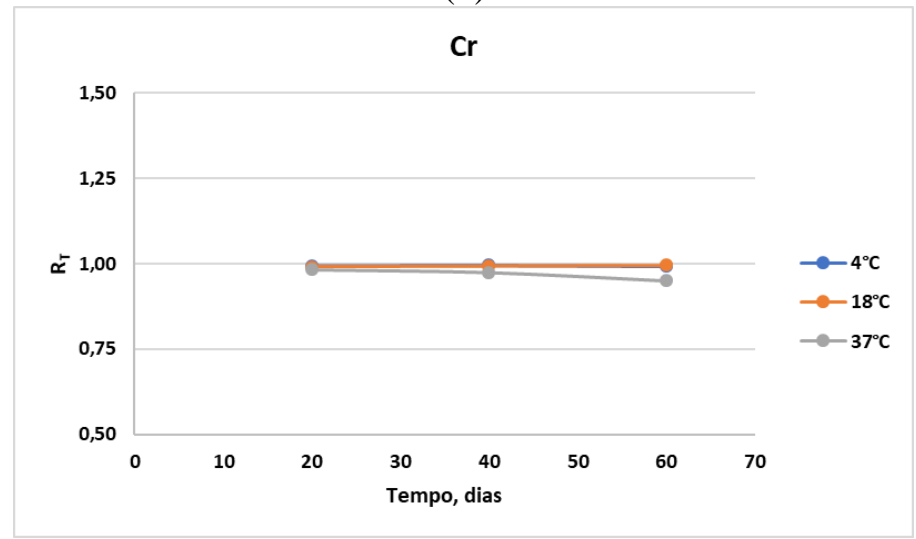

(d) 
Figura 59 - Razões $\mathrm{R}_{\mathrm{T}}$ para o estudo de estabilidade a curto prazo por ICP-MS. (a) As, (b) Ba, (c) Co, (d) Cr, (e) Cu, (f) Mn, (g) Mo, (h) Ni, (i) Se, (j) Sr, (k) Ti e (l) V. Continuação.

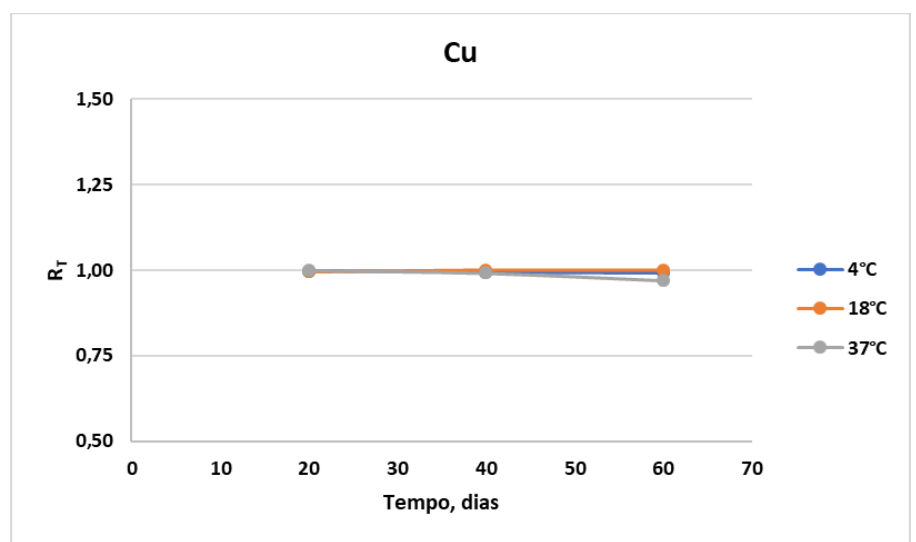

(e)

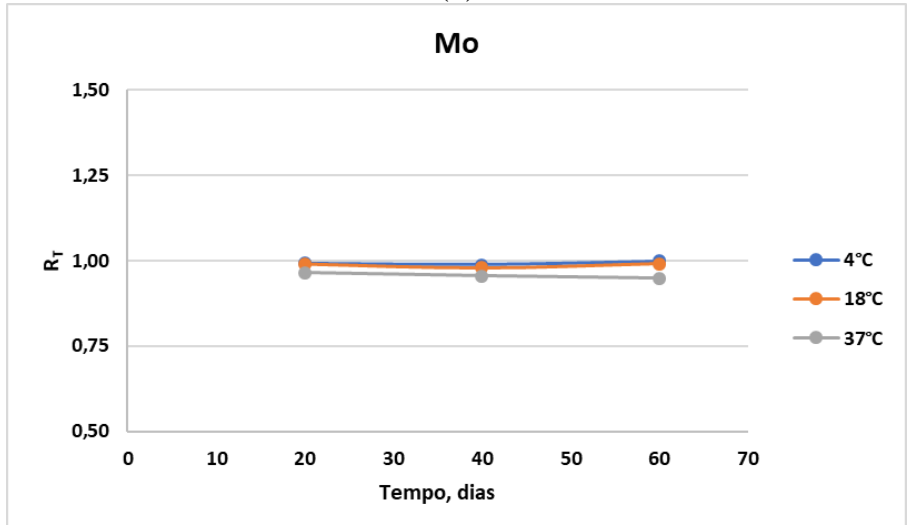

$(\mathrm{g})$

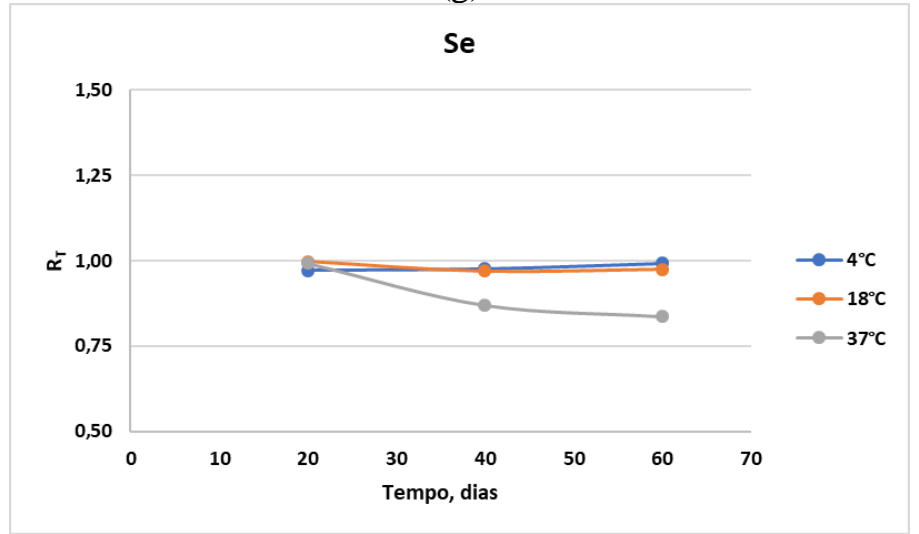

(i)

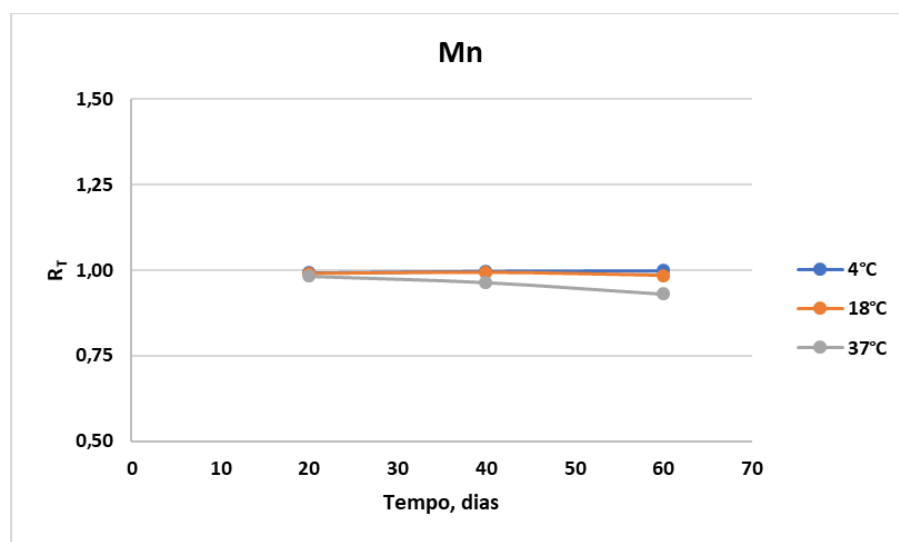

(f)

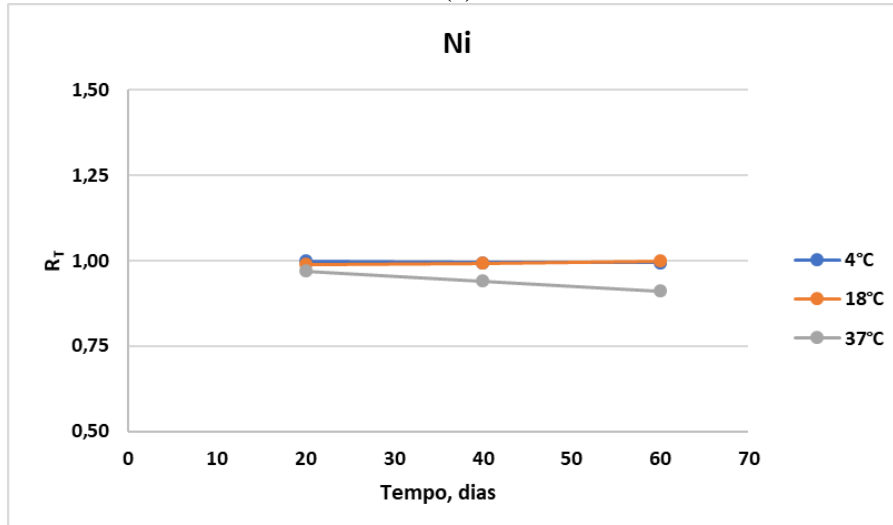

(h)

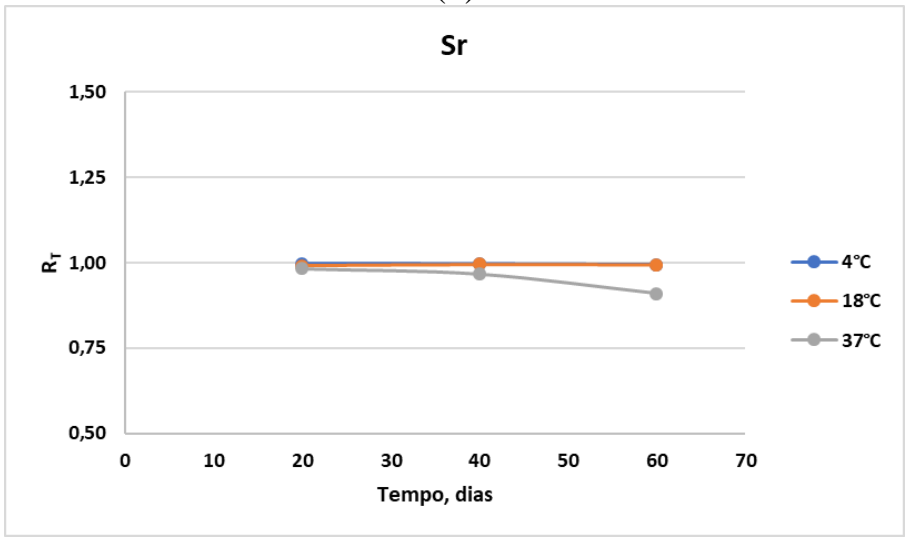

(j) 
Figura 59 - Razões $\mathrm{R}_{\mathrm{T}}$ para o estudo de estabilidade a curto prazo por ICP-MS. (a) As, (b) Ba, (c) Co, (d) Cr, (e) Cu, (f) Mn, (g) Mo, (h) Ni, (i) Se, (j) Sr, (k) Ti e (l) V. Continuação.

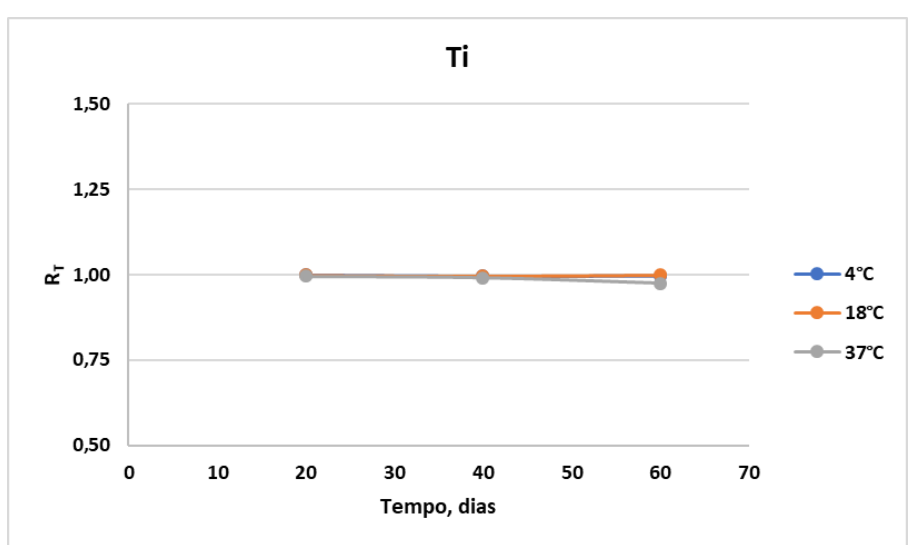

(k)

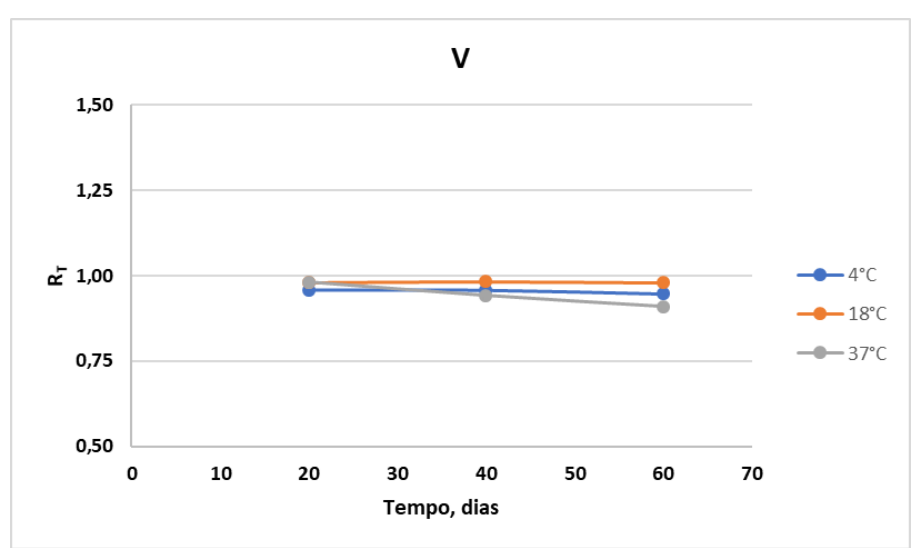

(1) 


\section{CONCLUSÕES E ETAPAS FUTURAS}

O RM candidato de tecido de peixe está em fase final de produção. O material foi recebido de fornecedores comerciais no começo de 2018 e foi liofilizado, moído, homogeneizado, envasado em 600 frascos de vidro âmbar que, posteriormente, foram submetidos à irradiação com radiação gama. Das etapas envolvidas no processo de produção de um material de referência já foram desenvolvidos os estudos de homogeneidade dentro e entre frascos e a estabilidade a curto prazo, seguindo um planejamento isócrono. A componente de incerteza da homogeneidade foi calculada e foi possível observar que o material é homogêneo para quase todos os elementos avaliados, uma vez que não foi observada diferença significativa no nível de confiança de 95\%, com exceção de As e Co, para os quais deverá ser avaliado o grau de heterogeneidade. A aplicação do estudo isócrono para avaliação de estabilidade a curto prazo possibilitou avaliar a manutenção das propriedades do material, em condições de transporte.

A avaliação da estabilidade a longo prazo está em andamento, com previsão de finalização em junho de 2019 e a partir dos dados obtidos será realizado o cálculo dessa componente de incerteza. Para $\mathrm{Cr}, \mathrm{Cu}, \mathrm{Mo}, \mathrm{Ni}, \mathrm{Se}, \mathrm{Sr}$ e Ti não foi evidenciada degradação em função de tempo e temperatura, uma vez que não houve diferença significativa entre as concentrações nos tratamentos, contudo para os demais elementos houve diferença significativa nas concentrações dos frascos armazenados por 60 dias a $37^{\circ} \mathrm{C}$ e $100 \%$ de umidade relativa. Desse modo deve se ter especial atenção à temperatura quando o material foi transportado por período superior a 30 dias.

O material será submetido à caracterização e estabelecimento de valores de consenso através de um ensaio colaborativo. Frascos do lote preparado já estão sendo enviados aos laboratórios que manifestaram interesse e outros laboratórios serão contatados para verificar a possibilidade de participação. 


\section{Conclusões Gerais}




\section{CONCLUSÕES GERAIS}

O trabalho de produção do RM de ração para peixe demonstrou a viabilidade de produção e caracterização de um material de referência, a partir de um produto nacional, através de um ensaio colaborativo, contando com a participação de diversos laboratórios, de instituições públicas e privadas. A elevada participação de laboratórios é um indicativo do interesse, do setor de nutrição animal, neste tipo de material.

O RM de ração produzido foi distribuído novamente aos laboratórios participantes do EPLNA para uso no controle interno de qualidade. Destaca-se a não disponibilidade de material de referência específico de ração para peixe, tanto nacional quanto estrangeiro, uma das razões consideradas para o desenvolvimento deste RM, além da forte demanda existente no setor de aquicultura por rações de qualidade e que atendam às necessidades nutricionais das espécies cultivadas no país.

O RM de tecido de peixe está em fase final de produção. Já foram realizados os estudos de homogeneidade e estabilidade a curto prazo. Quando o RM de tecido de peixe estiver com valores de propriedade atribuídos em conjunto com a incerteza associada, ele poderá ser utilizado pelos laboratórios para a avaliação da precisão de métodos e como controle de qualidade de pescados produzidos e capturados no país. 
Referências Bibliográficas Gerais 


\section{REFERÊNCIAS BIBLIOGRÁFICAS}

ANKOM Technology. Crude Fiber Method. Disponível em:

<https://www.ankom.com/analytical-methods-support/fiber-analyzer-a200>. Acesso em: 04 set. 2018.

ASSOCIAÇÃO BRASILEIRA DE NORMAS TÉCNICAS. NBR ISO/IEC 17025: requisitos gerais para a competência de laboratórios de ensaio e calibração. Rio de Janeiro, 2017. 32 p.

ASSOCIAÇÃO BRASILEIRA DE NORMAS TÉCNICAS. NBR ISO 17034: requisitos gerais para a competência de produtores de material de referência. Rio de Janeiro, 2017. 27 p.

ASSOCIAÇÃO BRASILEIRA DE NORMAS TÉCNICAS. ABNT ISO GUIA 30: materiais de referência - Termos e definições selecionados. Rio de Janeiro, 2016. 9 p.

ASSOCIAÇÃO BRASILEIRA DE NORMAS TÉCNICAS. ABNT ISO GUIA 31: materiais de referência - Conteúdo de certificados, rótulos e documentação associada. Rio de Janeiro, 2017. $11 \mathrm{p}$.

ASSOCIAÇÃO BRASILEIRA DE NORMAS TÉCNICAS. ABNT ISO GUIA 33: utilização de materiais de referência certificados. Rio de Janeiro, 2002. 28 p.

ASSOCIAÇÃO BRASILEIRA DE NORMAS TÉCNICAS. ABNT ISO GUIA 35: materiais de referência - Princípios gerais e estatísticos para certificação. Rio de Janeiro, 2012. 73 p.

BIANCHI, S. R.; PEIXOTO, A. M. J.; SOUZA, G. B.; TULLIO, R. R.; NOGUEIRA, A. R. A. Production and characterization of a bovine liver candidate reference material. Journal of Physics: Conference Series (online), v. 733, p. 012006, 2016.

BOSSU, C. M. Produção e caracterização de material de referência de forrageira para nutrientes e contaminantes orgânicos. 2013. 137 f. Tese (Doutorado em Ciências) Departamento de Química, Universidade Federal de São Carlos, São Carlos, 2013.

CARIONI, V. M. O. Produção de candidato a material de referência de tecido de peixe para determinação de As, Cd e Cu e espécies de As. 2014. 127 f. Tese (Doutorado em Ciência \& Tecnologia - Química) - Universidade Federal do ABC, Santo André, 2014.

CARIONI, V.M.O.; CHELEGÃO, R.; NAOZUKA, J.; NOMURA C.S. Feasibility study for the preparation of a tuna fish candidate reference material for total As determination.

Accreditation and Quality Assurance, v. 16, p. 453-458, 2011. 
CHELEGÃO, R. Produção de material de referência de peixe visando à determinação de Hg e MHg+. 2012. 103 f. Tese (Doutorado em Ciência \& Tecnologia - Química) Universidade Federal do ABC, Santo André, 2012.

CHELEGÃO, R.; CARIONI, V. M. O.; NAOZUKA, J.; NOMURA, C. S. Feasibility of using AAS for the characterization of a tuna fish candidate reference material for total hg and methyl-hg measurement. Journal of the Brazilian Chemical Society, v. 27, n. 4, p. 712-718, 2016.

COMAR Database. Certified reference materialss. Disponível em:

$<$ https://www.comar.bam.de/home/index.php>. Acesso em 05 de outubro de 2018.

ELLISON, S.L.R.; WILLIAMS, A. (Ed.). EURACHEM/CITAC Guide: Quantifying uncertainty in analytical measurement. 3. ed. Londres, 2012. 141 p.

ELPO, E. R. S.; FREITAS, R. J. S. Avaliação dos teores de cádmio, chumbo, cromo e níquel nos alimentos da cesta básica. Boletim do Centro de Pesquisa e Processamento de Alimentos, v. 13, n. 2, p. 71-84, 1995.

FOOD AND AGRICULTURAL ORGANIZATION OF THE UNITED NATIONS (FAO). Codex Alimentarius Commission. Code of practice for fish and fishery products. CAC/RCP 52-2003, updated 2016. Roma, 2016. Disponível em: <www.fao.org/fao-whocodexalimentarius/codex-texts/codes-of-practice>. Acesso em: 10 out. 2018.

FOOD AND AGRICULTURAL ORGANIZATION OF THE UNITED NATIONS (FAO). The state of world fisheries and aquaculture 2018. Roma, 2018. 227 p.

FREITAS, L.E.L.; RODRIGUES, A.P.O.; MORO, G.V.; LUNDSTEDT, L. Práticas para avaliação da qualidade física em rações para peixes. Palmas: Embrapa Pesca e Aquicultura, 2016. Disponível em: <https://ainfo.cnptia.embrapa.br/digital/bitstream/item/158772/1/CNPASA-2016-ct3.pdf>. Acesso em: 08 out. 2018.

HERZIG, R.; REHNERT, A.; KORHAMMER, S.; KUMPULAINEN, J.; SCHRAMEL, P.; MUNTAU, H.; LINSINGER, T.; QUEVAUVILLER, P. Certification of a new cabbage reference material for the quality control of trace-element determinations with some considerations on moisture. TrAC Trends in Analytical Chemistry, v. 21, n. 11, p. 746-761, 2002 . 
HOU, X; JONES, B. T. Inductively coupled plasma/optical emission spectroscopy. In: MEYERS, R.A. (Ed.). Encyclopedia of analytical chemistry: instrumentation and applications. Chichester: John Wiley and Sons, 2000. p. 9468-9485.

INSTITUTO NACIONAL DE METROLOGIA, QUALIDADE E TECNOLOGIA (INMETRO). Vocabulário internacional de metrologia: conceitos fundamentais e gerais e termos associados (VIM 2012). Duque de Caxias, 2012. 94 p.

INSTITUTO NACIONAL DE METROLOGIA, QUALIDADE E TECNOLOGIA (INMETRO). DOQ-CGCRE-016: orientação para a seleção e uso de materiais de referência. Duque de Caxias, 2010. 15 p.

INSTITUTO NACIONAL DE METROLOGIA, QUALIDADE E TECNOLOGIA (INMETRO). DOQ-CGCRE-033: orientações sobre análise crítica da documentação associada aos materiais de referência adquiridos. Duque de Caxias, 2018. 9 p.

INTERNATIONAL ORGANIZATION FOR STANDARDIZATION. ISO Guide 30: terms and definitions used in connection with reference materials. Geneva, 2015. 8 p.

INTERNATIONAL ORGANIZATION FOR STANDARDIZATION. ISO Guide 35: reference materials - Guidance for characterization and assessment of homogeneity and stability. Geneva, 2017. 114 p.

KUBITZA, F. Aquicultura no Brasil: principais espécies, áreas de cultivo, rações, fatores limitantes e desafios. Panorama da Aquiicultura, 2015. p. 10-23.

LAMBERTY, A.; SCHIMMEL, H.; PAUWELS, J. The study of the stability of reference materials by isochronous measurements. Fresenius' Journal of Analytical Chemistry, v. 360, p. 359-361, 1998.

LINSINGER, T. P. J.; PAUWELS, J.; VAN DER VEEN, A. H.; SCHIMMEL, H.; LAMBERTY, A. Homogeneity and stability of reference materials. Accreditation and Quality Assurance, v. 6, p. 20-25, 2001.

LINSINGER, T. P. J.; VAN DER VEEN, A. H.; GAWLIK, B. M.; LAMBERTY, A.; PAUWELS, J. Planning and combining of isochronous studies of CRMs. Accreditation and Quality Assurance, v. 9, p. 464-472, 2004. 
MAIHARA, V. A.; MOREIRA, E. G; CLAIN A. F.; FONSECA, A. G.; BRAGANÇA, M.J.C.S. Desenvolvimento de um material de referência de peixe para estudos nutricionais e ambientais. In: XII Encontro Nacional sobre Contaminantes Inorgânicos-ENCI, 2011, São Paulo. Anais do XII ENCI, 2011. p. 49-53.

MOREIRA E. G. Preparo e caracterização de um material de referência de mexilhão Perna perna. 2010. 283 f. Tese (Doutorado em Ciências) - Instituto de Pesquisas Energéticas e Nucleares, Universidade de São Paulo, São Paulo, 2010.

MOREIRA, E.G.; VASCONCELLOS, M. B. A.; CATHARINO, M. G. M.; MAIHARA, V. A.; SAIKI, M. Perna perna mussel reference material: short term stability assessment. Journal of Radioanalytical and Nuclear Chemistry, v. 282, p. 957-962, 2009.

NEVES, R.C.F.; MORAES, P.M.; SALEH, M.A.D.; LOUREIRO, V.R.; SILVA, F.A.; BARROS, M.M.; PADILHA, C.C.F.; JORGE, S.M.A.; PADILHA, P.M. FAAS determination of metal nutrients in fish feed after ultrasound extraction. Food Chemistry, v. 113 , p. 679-683, 2009.

NOGUEIRA, A. R. A.; SOUZA, G. B.; BOSSU, C. M.; BIANCHI, S. R.; VERHALEN, T. R.; SILVA, P. T.; PEIXOTO, A. A. J.; SILVA, C. S. Embrapa's experience in the production and development of agriculture reference materials. Journal of Physics: Conference Series (online), v. 733, p. 012005, 2016.

NOGUEIRA, A. R. A.; SOUZA, G. B. (Ed.). Manual de laboratório: solo, água, nutrição vegetal, nutrição animal e alimentos. São Carlos: Embrapa Pecuária Sudeste, 2005. 334 p.

NUNES, C. M. Produção e avaliação de material de referência para o escopo dioxinas, furanos e bifenilas policloradas em filé de pescado. 2015. 125 f. Dissertação (Mestrado em Ciência de Alimentos) - Universidade Federal de Minas Gerais, Belo Horizonte, 2015.

ORGANISATION FOR ECONOMIC CO-OPERATION AND DEVELOPMENT /FOOD AND AGRICULTURE ORGANIZATION OF THE UNITED NATIONS (OECD-FAO) Agricultural Outlook 2015-2024. Paris, 2015. Disponível em: <http://www.fao.org/3/ai4738e.pdf>. Acesso em: 30 set. 2018.

OLIVARES, I. R. B.; SOUZA, G. B.; NOGUEIRA, A. R. A.; TOLEDO, G. T. K.; MARCKI, D. C. Trends in developments of certified reference materials for chemical analysis - focus on food, water, soil, and sediment matrices. TrAC Trends in Analytical Chemistry, v. 100, p. 53-64, 2018. 
PAUWELS, J.; LAMBERTY, A. CRMs for the 21st century: new demands and challenge. Fresenius' Journal of Analytical Chemistry, n. 370, p. 11-114, 2001.

PEIXEBR - ASSOCIAÇÃO BRASILEIRA DA PISCICULTURA. Anuário PeixeBR da Piscicultura - 2018. São Paulo, 2018. 71p.

RODRIGUES, A. P. O.; FREITAS, L. E. L.; SANTOS, V. R. V.; MORO, G. V.; HONDA, R. T.; ARAUJO, P. L. D.; BICUDO, A. J.A. Qualidade de rações comerciais utilizadas na alimentação do pirarucu Arapaima gigas em cativeiro. Palmas: Embrapa Pesca e Aquicultura, 2017. Disponível em:

<https://www.infoteca.cnptia.embrapa.br/infoteca/bitstream/doc/1081636/1/CNPASA2017bp d23.pdf>. Acesso em: 08 out. 2018.

SALEH, M.A.D.; NEVES, R.C.F.; MORAES, P.M.; LIMA, P.M.; SANTOS, F.A.; SILVA, F.A.; PADILHA, P.M. Iron determination by FAAS in fish feed and feces after ultrasoundassisted extraction. Sensing and Instrumentation for Food Quality and Safety, v. 3, n. 2, p. 108-113, 2009.

SANTANA, L. V. Preparo, caracterização e uso de um material de referência para ensaios de proficiência para determinação de metais em tecido de peixe in natura. 2013. 207 f. Tese (Doutorado em Ciências) - Instituto de Pesquisas Energéticas e Nucleares, Universidade de São Paulo, São Paulo, 2013.

SANTOS, A. M. P.; SANTOS, L. O.; BRANDAO, G. C.; LEAO, D. J.; BERNEDO, A. V. B.; LOPES, R. T.; LEMOS, V. A. Homogeneity study of a corn flour laboratory reference material candidate for inorganic analysis. Food Chemistry, v. 178, p. 287-291, 2015.

SENESI, G.S.; BALDASSARRE, G.; SENESI, N.; RADINA, B. Trace element inputs into soils by anthropogenic activities and implications for human health, Chemosphere, v. 39, p. 343-377, 1999.

SILVA, C. S. Produção e avaliação de materiais de referência para nutrientes e contaminantes inorgânicos em amostras agronômicas. 2016. 198 f. Tese (Doutorado em Ciências) - Departamento de Química, Universidade Federal de São Carlos, São Carlos, 2016.

SILVA, P. H. T. Avaliação de parâmetros e produção de materiais de referência de mistura mineral para nutrientes e contaminantes inorgânicos. 2011. 148 f. Dissertação (Mestrado em Química) - Departamento de Química, Universidade Federal de São Carlos, São Carlos, 2011. 
SINDICATO NACIONAL DA INDÚSTRIA DE ALIMENTAÇÃO ANIMAL -

SINDIRAÇÕES. Boletim informativo do setor de alimentação animal - setembro/2018.

Disponível em: <https://sindiracoes.org.br/wp-

content/uploads/2018/09/boletim_informativo_do_setor_setembro_2018_vs_final_port_sindir acoes.pdf >. Acesso em: 08 out. 2018.

SKOOG, D. A.; WEST, D. M.; HOLLER, F. J.; CROUCH, S. R. Fundamentos de química analítica. 9. ed. São Paulo: Cengage Learning, 2015. 1088 p.

SOUZA, G. B. de. Estabelecimento de parâmetros operacionais, implementação de ensaio de proficiência e avaliação crítica de métodos analíticos empregados em nutrição animal. 2007. 143 f. Tese (Doutorado em Ciências) - Instituto de Química de São Carlos, Universidade de São Paulo, São Carlos, 2007.

SOUZA, G. B.; NOGUEIRA, A. R. A.; BATISTA, L. A. R. Avaliação e aplicação de métodos de análise para o fracionamento do nitrogênio em amostras de alimentos para animais. São Carlos: Embrapa Pecuária Sudeste, 2006. 26 p.

SOUZA, G.B.; NOGUEIRA, A.R.A.; DEL-SANTO, V. R.; PICCHI, C. M. C.;

GUIMARÃES, E. S.; BARIONI JUNIOR, W. Proficiency testing of animal nutrition laboratories. Accreditation and Quality Assurance, v. 14, p. 455-460, 2009.

THOMSEN, V.; ROBERTS, G.; BURGESS, K. The concept of background equivalent concentration in spectrochemistry. Spectroscopy Letters, v. 15, n. 1, p.33-36, 2000.

ULRICH, J. C. Preparação e caracterização de um material de referência de peixe. 2011. 129f. Tese (Doutorado em Ciências) - Instituto de Pesquisas Energéticas e Nucleares Universidade de São Paulo, São Paulo, 2011.

ULRICH, J. C.; SARKIS, J. E. S. Preparation and certification of a reference material for the total mercury and methylmercury mass fractions in fish. Accreditation and Quality Assurance, v. 18, p. 511-516, 2013.

VAN DER VEEN, A.M.H.; LINSINGER, T.P.J.; PAUWELS, J. Uncertainty calculations in the certification of reference materials, 2. Homogeneity study. Accreditation and Quality Assurance, v. 6, p. 26-30, 2001a.

VAN DER VEEN, A.M.H.; LINSINGER, T.P.J.; LAMBERTY, A.; PAUWELS, J. Uncertainty calculations in the certification of reference materials, 3. Stability study. Accreditation and Quality Assurance, v. 6, p. 257-263, $2001 \mathrm{~b}$. 
VAN DER VEEN A.M.H.; LINSINGER T.P.J.; SCHIMMEL H.; LAMBERTY A.;

PAUWELS J. Uncertainty calculations in the certification of reference materials 4.

Characterisation and certification. Accreditation and Quality Assurance, v. 6, p. 290-294, 2001c.

VERHALEN, T. R. Preparo e caracterização de material de referência de solo para nutrientes e contaminantes inorgânicos. 2014. 123 f. Dissertação (Mestrado em Química) Departamento de Química, Universidade Federal de São Carlos, São Carlos, 2014.

ZSCHUNKE, A. Reference materials in analytical chemistry: a guide for selection and use. Berlin: Springer, 2000. 218 p. 
Apêndice 
APÊNDICE A - Resultados Fornecidos pelos Laboratórios Participantes do Ensaio

Colaborativo para a Caracterização do candidato a RM de ração para peixe

Tabela A1 - Parâmetros Bromatológicos

\begin{tabular}{|c|c|c|c|c|c|c|c|c|c|c|c|c|c|c|c|c|c|c|}
\hline \multirow{2}{*}{ Lab } & \multicolumn{6}{|c|}{ MS (\%) } & \multicolumn{6}{|c|}{ PB (\%) } & \multicolumn{6}{|c|}{ FDA $(\%)$} \\
\hline & 1 & 2 & 3 & 4 & 5 & 6 & 1 & 2 & 3 & 4 & 5 & 6 & 1 & 2 & 3 & 4 & 5 & 6 \\
\hline 1 & 94,09 & 94,50 & 93,73 & & & & 30,67 & 31,38 & 31,46 & & & & & & & & & \\
\hline 2 & 94,42 & 94,55 & 94,47 & & & & 30,78 & 31,31 & 30,83 & & & & 10,20 & 10,11 & 10,58 & & & \\
\hline 3 & 94,73 & 94,93 & 94,55 & 94,48 & 94,67 & 95,88 & & & & & & & & & & & & \\
\hline 4 & 94,62 & 93,88 & 93,60 & 93,68 & 93,63 & 94,51 & 28,10 & 29,53 & 30,90 & 29,53 & 30,41 & 28,86 & 6,47 & 6,60 & 5,97 & 5,11 & 5,29 & 6,28 \\
\hline 5 & 94,42 & 94,30 & & & & & & & & & & & & & & & & \\
\hline 6 & 94,34 & 94,28 & 94,29 & & & & 31,09 & 31,00 & 31,21 & & & & 4,09 & 4,85 & 4,30 & & & \\
\hline 7 & 93,35 & 93,50 & 93,48 & 93,39 & 93,46 & 93,36 & 32,13 & 32,11 & 32,08 & 32,15 & 32,09 & 32,15 & 6,72 & 6,87 & 6,81 & 6,50 & 7,00 & 6,85 \\
\hline 8 & 94,26 & 95,03 & 94,98 & & & & 31,43 & 31,37 & 31,16 & & & & 7,49 & 7,29 & 7,37 & & & \\
\hline 9 & 94,16 & 94,16 & 94,16 & 94,16 & 94,16 & 94,16 & 31,68 & 31,61 & 31,73 & 31,68 & 31,61 & 31,73 & & & & & & \\
\hline 10 & 93,85 & 94,04 & 92,05 & 94,02 & 93,94 & 94,04 & 33,43 & 33,85 & 33,90 & 33,89 & 33,83 & 33,78 & & & & & & \\
\hline 11 & 94,70 & 94,10 & 94,00 & 93,90 & 94,50 & 93,90 & 32,00 & 31,90 & 32,10 & 31,30 & 31,10 & 31,30 & 3,50 & 3,50 & 3,40 & 3,60 & 3,50 & 3,60 \\
\hline 12 & 94,27 & 94,28 & 94,26 & & & & 30,04 & 30,12 & 30,16 & & & & 6,32 & 6,02 & 6,78 & & & \\
\hline 13 & 94,61 & 94,61 & 94,54 & & & & & & & & & & & & & & & \\
\hline 14 & 94,14 & 94,14 & 94,19 & 94,16 & 94,16 & 94,15 & 32,50 & 33,30 & 32,40 & 33,40 & 32,60 & 32,30 & 3,71 & 3,64 & 3,69 & 3,56 & 3,68 & 3,82 \\
\hline 15 & 94,41 & 94,48 & 94,00 & & & & & & & & & & & & & & & \\
\hline 16 & 94,36 & 94,39 & 94,25 & 94,28 & 94,29 & 94,33 & 28,99 & 28,97 & 28,94 & 28,98 & 28,88 & 28,84 & 4,21 & 4,18 & 5,99 & 4,51 & 5,48 & 4,62 \\
\hline 17 & 94,59 & 94,69 & 94,58 & 94,51 & 94,49 & 94,44 & 31,88 & 32,17 & 31,56 & 31,95 & 31,98 & 32,05 & 3,49 & 3,46 & 3,92 & 3,54 & 3,35 & 3,38 \\
\hline 18 & 94,15 & 94,04 & 94,10 & 94,07 & 94,13 & 94,10 & 31,77 & 31,77 & 32,41 & 31,50 & 31,54 & 31,88 & 5,40 & 7,41 & 6,38 & 5,61 & 5,43 & 6,51 \\
\hline 19 & & & & & & & 29,87 & 29,69 & 29,42 & 28,98 & 29,60 & 29,72 & 3,19 & 4,15 & 3,51 & 3,34 & 2,08 & 7,97 \\
\hline 20 & 94,24 & 94,27 & 94,16 & 94,34 & 94,31 & 94,35 & 30,70 & 30,76 & 30,71 & 31,05 & 30,60 & 29,86 & & & & & & \\
\hline 21 & 94,85 & 94,70 & 94,84 & 94,58 & 94,85 & 94,83 & 29,94 & 30,45 & 30,50 & 30,25 & 30,14 & 30,23 & 6,95 & 6,28 & 6,57 & 6,85 & 6,83 & 6,92 \\
\hline 22 & & & & & & & 28,33 & 28,76 & 28,85 & 28,79 & 28,67 & 28,81 & & & & & & \\
\hline 23 & 93,96 & 94,01 & 94,04 & 94,10 & 94,14 & 94,02 & 32,00 & 31,71 & 32,40 & 31,41 & 31,53 & 32,32 & & & & & & \\
\hline 24 & 94,29 & 94,26 & 94,28 & 93,71 & 93,66 & 93,56 & 31,66 & 31,60 & 31,81 & 31,82 & 31,55 & 31,85 & 1,33 & 1,42 & 1,52 & 1,58 & 1,52 & 1,60 \\
\hline 25 & 94,33 & 94,31 & 94,16 & 94,45 & 94,14 & 94,28 & & & & & & & & & & & & \\
\hline 26 & 93,83 & 93,87 & 93,90 & & & & & & & & & & 4,69 & 4,31 & 4,40 & 4,83 & & \\
\hline 27 & & & & & & & 31,00 & 31,09 & 31,31 & 31,12 & 31,34 & 31,00 & & & & & & \\
\hline 28 & 94,00 & 93,72 & 94,27 & 94,04 & 94,10 & 93,92 & 30,07 & 29,18 & 27,67 & 28,02 & 28,27 & 28,19 & 4,66 & 4,91 & 4,13 & 3,67 & 4,38 & 4,87 \\
\hline 29 & 94,41 & 94,58 & 94,65 & 94,32 & 94,35 & 94,31 & 31,08 & 31,02 & 31,16 & 31,70 & 31,84 & 31,85 & & & & & & \\
\hline 30 & & & & & & & 31,89 & 31,75 & 32,03 & 32,43 & 32,31 & 32,30 & 4,54 & 4,80 & 5,14 & 5,41 & 4,80 & 4,76 \\
\hline 31 & 95,23 & 95,56 & 95,87 & 96,10 & 96,26 & 95,00 & & & & & & & 4,00 & 5,52 & 4,91 & 4,15 & 4,21 & 4,50 \\
\hline 32 & & & & & & & 32,03 & 32,33 & 32,06 & 31,73 & 31,72 & 32,03 & & & & & & \\
\hline 33 & 93,50 & 93,30 & 94,10 & 94,10 & 93,80 & 93,10 & 29,95 & 30,55 & 29,76 & 30,18 & 30,28 & 30,93 & 3,64 & 3,32 & 3,61 & 3,51 & 3,41 & 3,44 \\
\hline 34 & 94,12 & 94,12 & 94,06 & 94,09 & 94,02 & 94,05 & 31,56 & 31,39 & 31,53 & 31,52 & 31,29 & 31,06 & & & & & & \\
\hline 35 & 94,04 & 94,07 & 94,08 & 94,35 & 94,34 & 94,26 & 18,72 & 18,92 & 18,85 & 18,28 & 18,52 & 17,97 & 4,40 & 4,22 & 4,65 & 4,21 & 3,96 & 4,23 \\
\hline 36 & 94,34 & 94,26 & 94,50 & 94,42 & 94,32 & 94,26 & 31,20 & 30,74 & 32,30 & 31,50 & 31,79 & 31,21 & 4,14 & 4,28 & 4,29 & 4,74 & 4,50 & 4,45 \\
\hline 37 & 94,11 & 93,58 & 93,12 & 93,48 & 93,28 & 93,37 & 28,79 & 28,63 & 28,66 & 28,69 & 28,82 & 28,63 & 7,26 & 4,08 & 4,21 & 3,89 & 3,73 & 3,78 \\
\hline 38 & 94,01 & 93,96 & 94,14 & 93,94 & 93,88 & 93,90 & 28,39 & 27,24 & 26,67 & 28,77 & 28,17 & 28,68 & & & & & & \\
\hline 39 & 94,82 & 94,77 & 94,79 & 94,05 & 94,02 & & 31,47 & 31,16 & 31,16 & 31,14 & 30,99 & & & & & & & \\
\hline 40 & 94,23 & 94,47 & 93,86 & 93,31 & 93,32 & 93,84 & 31,72 & 31,59 & 31,16 & 31,48 & 31,25 & 31,44 & & & & & & \\
\hline 41 & 95,02 & 94,99 & 94,85 & 95,03 & 94,58 & 94,70 & 30,94 & 31,30 & 31,31 & 30,98 & 31,60 & 31,67 & & & & & & \\
\hline 42 & 94,56 & 94,59 & 94,48 & 94,54 & 94,53 & 94,55 & 31,01 & 30,93 & 31,00 & 30,91 & 30,95 & 30,99 & 7,72 & 7,10 & 7,99 & 6,50 & 7,18 & 6,52 \\
\hline 43 & 93,17 & 93,11 & 92,92 & 93,08 & 93,12 & 93,08 & 29,90 & 29,53 & 29,37 & 28,87 & 28,65 & 29,26 & & & & & & \\
\hline 44 & 94,48 & 94,62 & 94,78 & 94,85 & 94,65 & 94,60 & 31,45 & 31,41 & 31,55 & 31,38 & 31,65 & 31,38 & 7,36 & 6,91 & 7,60 & 7,36 & 8,62 & 7,08 \\
\hline \multicolumn{19}{|l|}{45} \\
\hline 46 & 93,95 & 93,88 & 93,72 & 94,00 & 94,01 & 94,15 & 31,14 & 31,65 & 31,22 & 34,44 & 29,97 & 31,00 & 6,60 & 6,55 & 6,30 & 7,01 & 6,50 & 6,44 \\
\hline 47 & 96,00 & 95,44 & 95,07 & & & & 30,99 & 30,78 & 31,04 & & & & 3,41 & 3,29 & 3,31 & & & \\
\hline 48 & 94,90 & 95,14 & 95,00 & & & & 29,38 & 29,29 & 29,51 & & & & 4,40 & 4,44 & 4,45 & & & \\
\hline
\end{tabular}




\begin{tabular}{|c|c|c|c|c|c|c|c|c|c|c|c|c|c|c|c|c|c|c|}
\hline 49 & 94,49 & 94,48 & 94,50 & 94,49 & 94,48 & 94,52 & 34,35 & 32,22 & 33,29 & 34,25 & 33,48 & 34,08 & 6,57 & 6,75 & 6,38 & 6,21 & 6,57 & 6,38 \\
\hline 50 & 95,01 & 94,92 & 94,85 & & & & 31,29 & 30,71 & 30,57 & & & & 5,76 & 6,32 & 5,71 & & & \\
\hline 51 & 93,91 & 93,60 & 93,91 & 94,02 & 93,34 & 93,75 & 27,39 & 27,38 & 27,15 & 27,38 & 27,17 & 26,96 & & & & & & \\
\hline 52 & 94,18 & 94,32 & 94,93 & 94,48 & 94,20 & 94,90 & 29,36 & 29,26 & 30,18 & 29,96 & 29,46 & 29,35 & & & & & & \\
\hline 53 & 94,59 & 94,82 & 94,77 & 94,70 & 94,58 & 94,73 & 30,81 & 30,16 & 30,14 & 30,22 & 30,21 & 30,08 & 4,72 & 5,26 & 5,30 & 4,62 & 4,84 & 5,02 \\
\hline 54 & & & & & & & & & & & & & 3,45 & 3,81 & 3,53 & & & \\
\hline 55 & 94,73 & 95,11 & 94,98 & 94,48 & 94,47 & 94,26 & & & & & & & & & & & & \\
\hline 56 & 94,90 & 95,03 & 94,98 & 95,00 & 94,96 & 94,99 & 27,44 & 27,82 & 27,52 & 27,90 & 27,82 & 27,80 & 3,73 & 3,47 & 3,35 & 3,28 & 3,21 & 3,77 \\
\hline
\end{tabular}

\begin{tabular}{|c|c|c|c|c|c|c|c|c|c|c|c|c|c|c|c|c|c|c|}
\hline \multirow{2}{*}{ Lab } & \multicolumn{6}{|c|}{ FDN (\%) } & \multicolumn{6}{|c|}{ FB (\%) } & \multicolumn{6}{|c|}{ Cinzas (\%) } \\
\hline & 1 & 2 & 3 & 4 & 5 & 6 & 1 & 2 & 3 & 4 & 5 & 6 & 1 & 2 & 3 & 4 & 5 & 6 \\
\hline 1 & & & & & & & & & & & & & 10,21 & 10,15 & 10,91 & & & \\
\hline 2 & 25,07 & 25,31 & 26,03 & & & & 3,78 & 4,28 & 3,96 & & & & 10,50 & 10,42 & 10,61 & & & \\
\hline 3 & & & & & & & 4,36 & 4,02 & 4,26 & 4,47 & 4,22 & 4,19 & 9,62 & 9,69 & 10,46 & 10,25 & 10,11 & 9,66 \\
\hline 4 & & & & & & & & & & & & & 9,76 & 9,75 & 9,55 & 9,53 & 9,77 & 9,72 \\
\hline \multicolumn{19}{|l|}{5} \\
\hline 6 & 16,73 & 16,48 & 15,82 & & & & & & & & & & 10,30 & 10,25 & 10,23 & & & \\
\hline 7 & 15,74 & 15,76 & 15,90 & 15,81 & 15,85 & 15,39 & 2,52 & 2,51 & 2,54 & 2,39 & 2,53 & 2,41 & 10,23 & 10,23 & 10,24 & 10,23 & 10,27 & 10,23 \\
\hline 8 & 19,99 & 19,10 & 20,83 & & & & 3,74 & 3,49 & 3,07 & & & & 10,04 & 10,07 & 10,24 & & & \\
\hline 9 & & & & & & & 2,61 & 2,62 & 2,30 & 2,61 & 2,62 & 2,30 & 10,24 & 10,39 & 10,17 & 10,24 & 10,39 & 10,17 \\
\hline \multicolumn{19}{|l|}{10} \\
\hline 11 & 14,50 & 13,00 & 13,00 & 13,40 & 13,80 & 12,80 & 2,70 & 2,90 & 2,90 & 2,80 & 2,70 & 2,90 & 10,00 & 9,30 & 9,80 & 9,60 & 9,50 & 9,90 \\
\hline 12 & 19,11 & 20,81 & 21,53 & & & & & & & & & & 10,77 & 10,42 & 10,65 & & & \\
\hline 13 & & & & & & & 2,06 & 2,57 & 2,74 & & & & 10,32 & 10,25 & 10,04 & & & \\
\hline 14 & 28,22 & 28,52 & 29,86 & 28,80 & 29,04 & 28,74 & & & & & & & 9,89 & 9,43 & 9,61 & 9,79 & 9,89 & 9,93 \\
\hline 15 & 15,30 & 13,75 & 15,97 & & & & 2,19 & 2,46 & 2,28 & & & & 10,87 & 10,87 & 10,84 & & & \\
\hline 16 & & & & & & & & & & & & & 10,00 & 10,42 & 10,27 & 10,12 & 10,37 & 10,23 \\
\hline 17 & 17,87 & 17,66 & 19,80 & 20,91 & 19,48 & 18,69 & 1,85 & 2,19 & 1,95 & 2,23 & 2,28 & 1,78 & 10,04 & 10,20 & 9,94 & 10,35 & 10,28 & 10,33 \\
\hline 18 & 15,06 & 18,42 & 18,28 & 15,96 & 16,42 & 17,29 & 3,54 & 3,37 & 3,48 & 3,28 & 2,91 & 3,33 & 10,10 & 10,27 & 10,28 & 10,07 & 10,20 & 10,17 \\
\hline 19 & & & & & & & & & & & & & 9,66 & 9,40 & 9,66 & 9,42 & 9,55 & 9,48 \\
\hline 20 & & & & & & & 2,25 & 2,25 & 2,27 & 2,28 & 2,34 & 2,24 & 12,46 & 11,03 & 11,13 & 10,17 & 11,48 & 11,73 \\
\hline 21 & 11,83 & 12,28 & 12,25 & 12,03 & 12,24 & 12,11 & 1,61 & 1,88 & 1,44 & 1,70 & 1,63 & 1,65 & 10,29 & 10,23 & 10,16 & 10,09 & 10,24 & 10,30 \\
\hline 22 & & & & & & & 2,10 & 2,72 & 2,45 & 2,20 & 2,21 & 2,18 & 9,60 & 9,66 & 9,59 & 9,60 & 9,53 & 9,60 \\
\hline 23 & & & & & & & 1,89 & 1,76 & 1,88 & 1,86 & 1,76 & 1,89 & 10,30 & 10,22 & 10,24 & 10,37 & 10,44 & 10,45 \\
\hline 24 & 11,44 & 12,18 & 10,84 & 12,29 & 11,76 & 11,89 & 2,09 & 2,31 & 2,30 & 2,11 & 1,64 & 1,54 & 10,44 & 10,46 & 10,45 & 10,42 & 10,61 & 10,36 \\
\hline \multicolumn{19}{|l|}{25} \\
\hline 26 & 20,30 & 20,06 & 19,11 & 20,10 & & & 1,17 & 1,13 & 1,23 & 1,24 & & & 9,54 & 9,61 & 9,47 & & & \\
\hline 27 & & & & & & & 2,95 & 2,63 & 2,27 & 2,58 & 2,42 & 2,95 & 10,64 & 10,64 & 10,48 & 10,27 & 10,38 & 10,54 \\
\hline 28 & 17,22 & 19,77 & 17,75 & 15,91 & 16,19 & 18,53 & 1,80 & 1,18 & 2,23 & 1,87 & 1,70 & 1,60 & 10,23 & 10,15 & 9,52 & 9,83 & 9,62 & 9,70 \\
\hline 29 & & & & & & & 2,43 & 2,59 & 2,04 & 2,33 & 2,51 & 2,24 & 10,35 & 10,16 & 9,94 & 10,01 & 9,90 & 10,19 \\
\hline 30 & 13,59 & 12,64 & 13,02 & 12,60 & 13,87 & 13,11 & 2,43 & 2,38 & 2,90 & 2,66 & 2,35 & 2,54 & 10,25 & 10,39 & 10,76 & 10,39 & 10,15 & 10,51 \\
\hline 31 & 9,42 & 8,79 & 9,37 & 8,21 & 8,49 & 7,46 & & & & & & & 9,97 & 10,23 & 9,85 & 10,06 & 9,50 & 10,03 \\
\hline 32 & & & & & & & & & & & & & 9,98 & 10,01 & 10,00 & 9,95 & 9,98 & 10,06 \\
\hline 33 & 18,18 & 16,08 & 17,22 & 18,60 & 19,08 & 17,40 & 2,57 & 2,79 & 2,23 & 2,66 & 2,67 & 2,58 & 10,27 & 10,29 & 10,31 & 10,31 & 10,34 & 10,20 \\
\hline 34 & & & & & & & 1,75 & 1,78 & 1,89 & 1,46 & 1,90 & 1,96 & 10,31 & 10,33 & 10,48 & 10,57 & 10,37 & 10,19 \\
\hline 35 & & & & & & & & & & & & & 10,19 & 10,50 & 10,28 & 10,34 & 10,32 & 10,29 \\
\hline 36 & 12,97 & 13,00 & 12,61 & 13,44 & 13,17 & 12,98 & & & & & & & 10,73 & 11,09 & 10,90 & 11,02 & 10,75 & 10,88 \\
\hline 37 & 15,90 & 18,60 & 13,78 & 16,38 & 13,80 & 17,09 & 1,84 & 1,50 & 1,65 & 1,60 & 1,75 & 1,70 & 9,69 & 9,63 & 9,32 & 9,57 & 9,27 & 9,23 \\
\hline \multicolumn{19}{|l|}{38} \\
\hline 39 & & & & & & & 3,29 & 3,09 & 3,20 & 3,21 & 3,24 & & 10,48 & 10,47 & 10,36 & 10,32 & 10,28 & 5,39 \\
\hline 40 & & & & & & & & & & & & & 10,34 & 10,30 & 10,29 & 9,99 & 10,11 & 10,17 \\
\hline 41 & & & & & & & 2,03 & 1,87 & 2,10 & 2,06 & 1,99 & 1,83 & 10,27 & 10,12 & 10,40 & 10,23 & 10,20 & 10,12 \\
\hline 42 & 21,31 & 19,51 & 19,42 & 20,05 & 20,08 & 20,41 & 1,89 & 1,82 & 2,02 & 1,91 & 1,93 & 1,88 & 9,53 & 9,88 & 9,40 & 9,75 & 9,64 & 9,77 \\
\hline 43 & & & & & & & & & & & & & 9,72 & 10,05 & 10,13 & 10,17 & 9,96 & 10,12 \\
\hline
\end{tabular}




\begin{tabular}{|c|c|c|c|c|c|c|c|c|c|c|c|c|c|c|c|c|c|c|}
\hline 44 & 33,91 & 33,82 & 34,06 & 33,84 & 33,33 & 33,83 & 3,99 & 3,23 & 3,66 & 3,62 & 3,38 & 3,91 & 10,19 & 10,12 & 10,13 & 10,13 & 10,17 & 10,14 \\
\hline 45 & & & & & & & 2,73 & 3,18 & 3,34 & & & & 10,41 & 10,23 & 10,47 & & & \\
\hline 46 & & & & & & & 1,98 & 1,99 & 1,90 & 2,04 & 2,00 & 2,10 & 10,50 & 11,21 & 10,30 & 10,01 & 10,42 & 10,77 \\
\hline 47 & 13,34 & 13,29 & 13,59 & & & & 1,33 & 1,38 & 1,34 & & & & 10,03 & 9,61 & 10,24 & & & \\
\hline 48 & 15,05 & 15,75 & 16,10 & & & & 1,92 & 1,80 & 1,77 & & & & 10,76 & 10,31 & 10,51 & & & \\
\hline 49 & & & & & & & 2,28 & 2,41 & 2,34 & 2,21 & 2,34 & 2,48 & 10,33 & 10,25 & 10,59 & 10,34 & 10,85 & 10,59 \\
\hline 50 & 12,89 & 13,80 & 12,20 & & & & 4,73 & 4,32 & 4,60 & & & & 10,32 & 10,14 & 10,14 & & & \\
\hline \multicolumn{19}{|l|}{51} \\
\hline \multicolumn{19}{|l|}{52} \\
\hline 53 & 25,00 & 25,09 & 25,36 & 24,32 & 25,86 & 25,98 & 2,79 & 2,94 & 3,07 & 2,83 & 2,96 & 3,04 & 10,36 & 10,27 & 10,36 & 10,17 & 10,22 & 10,33 \\
\hline 54 & & & & & & & 3,90 & 4,18 & 4,03 & & & & 9,69 & 9,73 & 9,88 & & & \\
\hline 55 & & & & & & & & & & & & & 10,06 & 10,15 & 10,18 & & & \\
\hline 56 & 18,24 & 18,00 & 17,54 & 17,77 & 18,39 & 17,64 & 2,55 & 2,54 & 2,50 & 2,53 & 2,51 & 2,52 & 9,86 & 9,67 & 9,75 & 9,74 & 9,72 & 9,79 \\
\hline
\end{tabular}

\begin{tabular}{|c|c|c|c|c|c|c|c|c|c|c|c|c|c|c|c|c|c|c|}
\hline \multirow{2}{*}{ Lab } & \multicolumn{6}{|c|}{$\operatorname{EE}(\%)$} & \multicolumn{6}{|c|}{ Lignina (\%) } & \multicolumn{6}{|c|}{$\operatorname{NNP}(\%)$} \\
\hline & 1 & 2 & 3 & 4 & 5 & 6 & 1 & 2 & 3 & 4 & 5 & 6 & 1 & 2 & 3 & 4 & 5 & 6 \\
\hline 1 & 3,67 & 3,98 & 4,01 & & & & & & & & & & & & & & & \\
\hline 2 & 3,70 & 3,72 & 3,96 & & & & & & & & & & & & & & & \\
\hline \multicolumn{19}{|l|}{3} \\
\hline \multicolumn{19}{|l|}{4} \\
\hline \multicolumn{19}{|l|}{5} \\
\hline 6 & 3,73 & 3,69 & 3,65 & & & & 1,42 & 1,97 & 2,18 & & & & & & & & & \\
\hline 7 & & & & & & & 3,03 & 2,85 & 3,28 & 3,20 & 3,15 & 3,20 & & & & & & \\
\hline 8 & 3,00 & 3,22 & 3,23 & & & & & & & & & & & & & & & \\
\hline \multicolumn{19}{|l|}{9} \\
\hline \multicolumn{19}{|l|}{10} \\
\hline 11 & & & & & & & 0,77 & 0,85 & 0,82 & 0,78 & 0,79 & 0,83 & & & & & & \\
\hline 12 & 3,42 & 3,22 & 3,33 & & & & 2,76 & 2,38 & 3,10 & & & & & & & & & \\
\hline 13 & 1,48 & 1,20 & 1,43 & & & & & & & & & & & & & & & \\
\hline 14 & 2,62 & 2,88 & 3,22 & 3,11 & 2,83 & 2,74 & & & & & & & & & & & & \\
\hline 15 & 3,73 & 3,74 & 4,13 & & & & 1,90 & 1,10 & 1,41 & & & & & & & & & \\
\hline 16 & 3,78 & 3,72 & 3,87 & 3,57 & 3,40 & 3,48 & & & & & & & & & & & & \\
\hline 17 & 7,68 & 7,58 & 7,74 & 7,66 & 7,58 & 7,63 & 0,55 & 0,54 & 0,55 & 0,71 & 0,72 & 0,72 & & & & & & \\
\hline 18 & 3,32 & 3,59 & 3,46 & 3,45 & 3,43 & 3,50 & & & & & & & & & & & & \\
\hline 19 & 7,43 & 7,71 & 7,66 & 7,91 & 7,27 & 7,49 & & & & & & & & & & & & \\
\hline 20 & 6,05 & 5,96 & 5,70 & 5,95 & 5,85 & 6,10 & & & & & & & 0,12 & 0,12 & 0,12 & 0,13 & 0,12 & 0,13 \\
\hline \multicolumn{19}{|l|}{21} \\
\hline 22 & 7,35 & 7,43 & 7,36 & 7,41 & 7,43 & 7,37 & & & & & & & & & & & & \\
\hline 23 & 3,70 & 3,73 & 3,72 & 3,58 & 3,56 & 3,57 & & & & & & & & & & & & \\
\hline 24 & 3,49 & 3,34 & 3,37 & 3,72 & 3,80 & 4,00 & & & & & & & & & & & & \\
\hline 25 & 3,67 & 3,27 & 3,54 & 3,85 & 3,58 & 3,42 & & & & & & & & & & & & \\
\hline 26 & 3,38 & 3,21 & 3,30 & & & & 1,13 & 1,29 & 1,05 & 1,18 & & & & & & & & \\
\hline \multicolumn{19}{|l|}{27} \\
\hline 28 & 3,18 & 3,29 & 3,00 & 3,23 & 2,99 & 2,62 & & & & & & & & & & & & \\
\hline \multicolumn{19}{|l|}{29} \\
\hline \multicolumn{19}{|l|}{30} \\
\hline \multicolumn{19}{|l|}{31} \\
\hline 32 & 7,03 & 6,66 & 6,84 & 7,18 & 6,93 & 6,34 & & & & & & & & & & & & \\
\hline 33 & 3,74 & 3,97 & 3,83 & 3,83 & 3,84 & 3,76 & & & & & & & & & & & & \\
\hline 34 & 7,24 & 7,03 & 7,29 & 7,31 & 7,38 & 7,84 & & & & & & & & & & & & \\
\hline 35 & 7,29 & 7,31 & 7,12 & 7,01 & 7,21 & 7,18 & & & & & & & & & & & & \\
\hline \multicolumn{19}{|l|}{36} \\
\hline 37 & 6,87 & 7,23 & 10,35 & 7,07 & 7,07 & 7,20 & & & & & & & & & & & & \\
\hline 38 & & & & & & & & & & & & & & & & & & \\
\hline
\end{tabular}




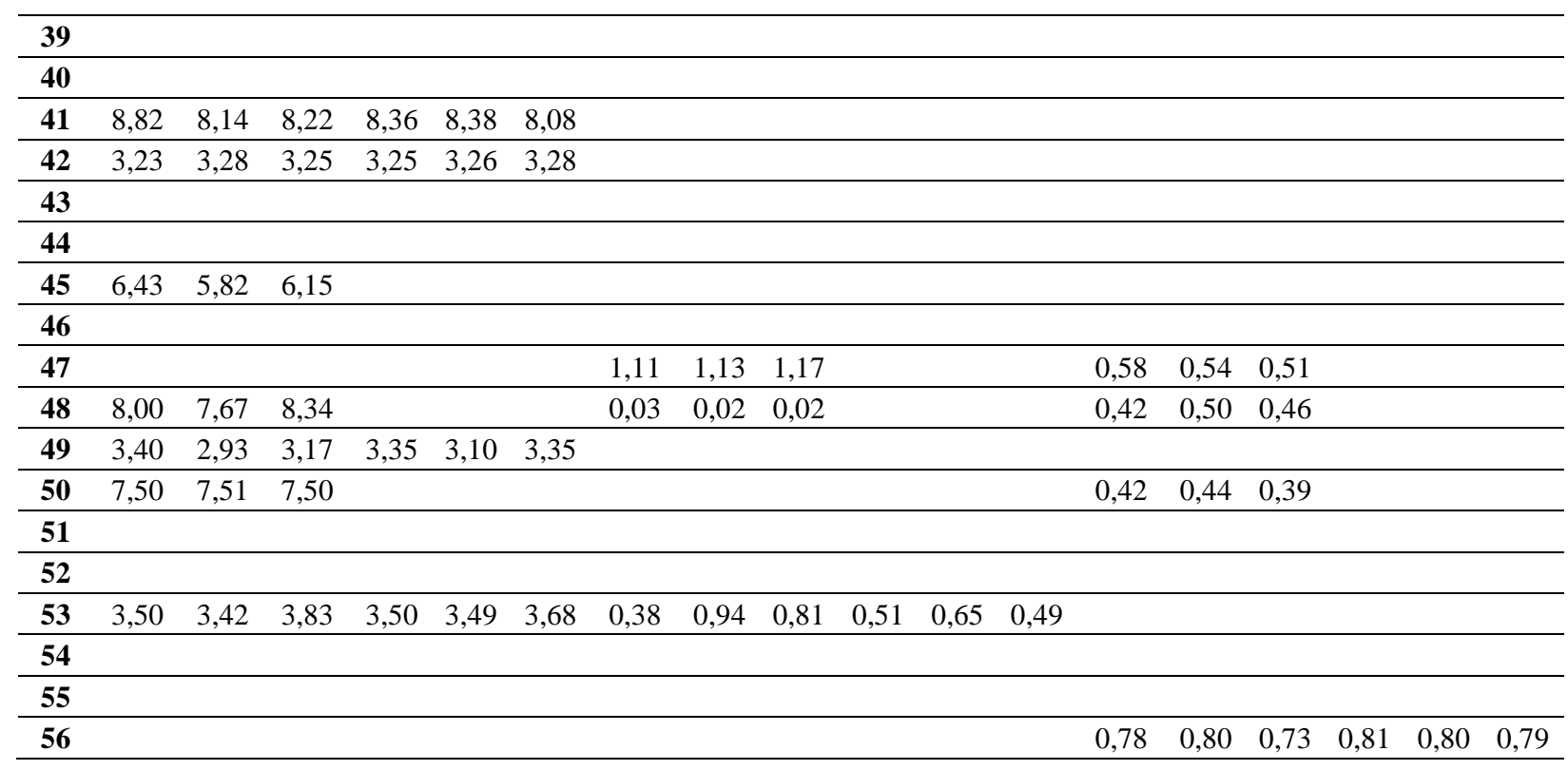


Tabela A2 - Macro e Micronutrientes

\begin{tabular}{|c|c|c|c|c|c|c|c|c|c|c|c|c|c|c|c|c|c|c|}
\hline \multirow{2}{*}{ Lab } & \multicolumn{6}{|c|}{$\mathrm{Ca}(\mathrm{g} / \mathrm{kg})$} & \multicolumn{6}{|c|}{$\operatorname{Mg}(\mathrm{g} / \mathrm{kg})$} & \multicolumn{6}{|c|}{$P(\mathrm{~g} / \mathrm{kg})$} \\
\hline & 1 & 2 & 3 & 4 & 5 & 6 & 1 & 2 & 3 & 4 & 5 & 6 & 1 & 2 & 3 & 4 & 5 & 6 \\
\hline \multicolumn{19}{|l|}{1} \\
\hline 2 & 28,10 & 30,50 & 29,93 & & & & 1,60 & 1,60 & 1,50 & & & & 17,30 & 16,00 & 17,15 & & & \\
\hline 3 & & & & & & & 2,75 & 2,85 & 2,64 & 2,79 & 2,59 & 2,72 & 14,76 & 12,18 & 14,28 & 12,70 & 14,53 & 12,44 \\
\hline 4 & 32,56 & 32,32 & 30,85 & 31,04 & 30,61 & 33,43 & 1,83 & 1,62 & 1,62 & 1,58 & 1,61 & 1,87 & 11,11 & 10,45 & 10,78 & 10,69 & 11,07 & 10,43 \\
\hline 5 & 25,21 & 26,74 & 28,91 & 26,31 & 25,67 & 27,75 & & & & & & & & & & & & \\
\hline 6 & & & & & & & 1,27 & 1,30 & 1,17 & & & & 13,73 & 13,64 & 12,05 & & & \\
\hline 7 & 22,30 & 22,10 & 22,10 & 22,20 & 22,10 & 22,10 & 1,70 & 1,70 & 1,70 & 1,70 & 1,70 & 1,70 & 15,50 & 15,50 & 15,60 & 15,60 & 15,60 & 15,60 \\
\hline 8 & 29,66 & 31,35 & 28,40 & & & & 1,78 & 1,60 & 1,70 & & & & 16,05 & 16,26 & 15,31 & & & \\
\hline 9 & & & & & & & 1,22 & 1,45 & 1,24 & 1,25 & 1,27 & 1,24 & & & & & & \\
\hline 10 & 33,33 & 33,09 & 33,26 & 32,66 & 33,42 & 32,96 & 1,98 & 1,99 & 1,98 & 1,93 & 1,98 & 1,95 & 16,57 & 16,34 & 16,35 & 16,06 & 16,27 & 16,21 \\
\hline \multicolumn{19}{|l|}{11} \\
\hline \multicolumn{19}{|l|}{12} \\
\hline 13 & 31,49 & 32,04 & 31,85 & 31,85 & 32,73 & 33,09 & 1,58 & 1,59 & 1,55 & 1,54 & 1,54 & 1,55 & 15,68 & 16,47 & 15,99 & 16,46 & 16,89 & 17,29 \\
\hline \multicolumn{19}{|l|}{14} \\
\hline 15 & 29,39 & 28,14 & 25,30 & & & & & & & & & & & & & & & \\
\hline 16 & 24,48 & 22,54 & 23,31 & 23,67 & 22,29 & 23,77 & 0,66 & 0,63 & 0,64 & 0,65 & 0,62 & 0,65 & 21,99 & 20,70 & 21,33 & 19,95 & 18,84 & 18,92 \\
\hline \multicolumn{19}{|l|}{17} \\
\hline 18 & 28,68 & 29,46 & 28,71 & 27,08 & 26,87 & 28,31 & & & & & & & 14,73 & 15,47 & 15,25 & 11,79 & 15,32 & 15,68 \\
\hline 19 & 28,55 & 26,46 & 28,28 & 29,31 & 29,04 & 29,18 & 1,54 & 1,44 & 1,51 & 1,57 & 1,53 & 1,55 & 16,11 & 14,69 & 15,82 & 16,26 & 16,44 & 16,35 \\
\hline 20 & 26,95 & 27,71 & 28,38 & 27,89 & 28,22 & 28,86 & 1,53 & 1,46 & 1,43 & 1,42 & 1,38 & 1,42 & 14,92 & 14,72 & 14,96 & 15,02 & 15,43 & 15,37 \\
\hline 21 & 25,75 & 26,50 & 26,20 & 26,50 & 26,80 & 26,75 & 1,79 & 1,80 & 1,79 & 1,79 & 1,84 & 1,80 & 17,85 & 17,91 & 17,95 & 17,45 & 18,10 & 17,65 \\
\hline 22 & 29,78 & 29,44 & 29,76 & 30,09 & 29,85 & 29,54 & 1,47 & 1,63 & 1,47 & 1,52 & 1,57 & 1,61 & 15,84 & 15,59 & 15,67 & 15,51 & 15,42 & 15,66 \\
\hline 23 & 28,19 & 30,58 & 29,37 & 28,61 & 29,39 & 25,02 & & & & & & & & & & & & \\
\hline \multicolumn{19}{|l|}{24} \\
\hline \multicolumn{19}{|l|}{25} \\
\hline \multicolumn{19}{|l|}{26} \\
\hline \multicolumn{19}{|l|}{27} \\
\hline 28 & 28,23 & 28,23 & 29,28 & 29,49 & 30,89 & 29,14 & & & & & & & 13,22 & 12,71 & 12,81 & 13,48 & 13,66 & 13,84 \\
\hline 29 & 29,75 & 25,45 & 31,25 & 27,15 & 33,35 & 30,20 & 1,28 & 1,20 & 1,40 & 1,25 & 1,30 & 1,35 & 14,20 & 14,20 & 14,16 & 13,84 & 14,44 & 14,50 \\
\hline 30 & 29,76 & 30,77 & 27,79 & 30,22 & 28,93 & 29,58 & & & & & & & 16,74 & 16,71 & 15,21 & 16,01 & 16,96 & 17,18 \\
\hline 31 & 21,50 & 28,90 & 30,00 & 24,50 & 26,20 & 26,20 & 1,90 & 1,80 & 1,80 & 1,70 & 1,70 & 1,90 & 16,70 & 17,00 & 16,50 & 16,70 & 14,40 & 16,70 \\
\hline 32 & & & & & & & & & & & & & 17,40 & 17,40 & 16,90 & 17,10 & 17,40 & 17,40 \\
\hline 33 & 27,89 & 27,75 & 28,63 & 26,85 & 27,57 & 28,24 & 1,36 & 1,31 & 1,37 & 1,37 & 1,36 & 1,31 & 15,65 & 15,44 & 15,49 & 15,70 & 15,42 & 15,32 \\
\hline 34 & 25,03 & 24,65 & 25,72 & 30,29 & 28,57 & 29,22 & & & & & & & 18,18 & 17,47 & 18,38 & 15,94 & 15,67 & 16,00 \\
\hline 35 & 39,64 & 38,08 & 34,75 & 35,88 & 36,54 & 38,22 & 2,33 & 2,05 & 1,84 & 2,15 & 2,22 & 2,00 & 19,76 & 19,16 & 17,71 & 18,99 & 19,12 & 18,19 \\
\hline \multicolumn{19}{|l|}{36} \\
\hline \multicolumn{19}{|l|}{37} \\
\hline 38 & & & & & & & & & & & & & & & & & & \\
\hline 39 & & & & & & & & & & & & & 15,30 & 14,20 & 13,10 & 13,50 & 13,20 & 13,00 \\
\hline 40 & 28,54 & 27,80 & 27,94 & 28,96 & 28,43 & 28,23 & 1,44 & 1,44 & 1,46 & 1,51 & 1,51 & 1,49 & 16,18 & 15,81 & 15,99 & 15,80 & 15,52 & 15,78 \\
\hline 41 & & & & & & & & & & & & & & & & & & \\
\hline 42 & & & & & & & 1,53 & 1,82 & 1,61 & 1,65 & 1,55 & 1,60 & 15,43 & 20,52 & 16,28 & 18,22 & 20,35 & 15,87 \\
\hline 43 & & & & & & & & & & & & & & & & & & \\
\hline 44 & 31,44 & 31,01 & 32,61 & 32,82 & 30,16 & 29,09 & 1,71 & 1,71 & 1,71 & 1,71 & 1,71 & 1,71 & 20,46 & 21,21 & 21,10 & 22,27 & 19,82 & 19,18 \\
\hline 45 & 31,05 & 31,06 & 29,73 & 30,73 & 29,71 & 29,99 & & & & & & & 16,63 & 20,63 & 16,34 & 16,84 & 16,39 & 17,32 \\
\hline 46 & 29,50 & 30,30 & 28,50 & 29,40 & 29,55 & 29,90 & & & & & & & 17,80 & 17,60 & 17,10 & 17,50 & 17,70 & 17,60 \\
\hline 47 & & & & & & & & & & & & & & & & & & \\
\hline 48 & & & & & & & & & & & & & & & & & & \\
\hline
\end{tabular}




\begin{tabular}{|c|c|c|c|c|c|c|c|c|c|c|c|c|c|c|c|c|c|c|}
\hline 49 & 31,61 & 30,76 & 32,77 & & & & & & & & & & & & & & & \\
\hline 50 & 24,20 & 25,15 & 25,15 & 27,05 & 25,39 & 26,50 & 1,44 & 1,37 & 1,50 & 1,59 & 1,47 & 1,50 & & & & & & \\
\hline 51 & & & & & & & 1,54 & 1,51 & 1,72 & 1,48 & 1,47 & 1,50 & 16,42 & 16,28 & 16,50 & 16,65 & 16,22 & 16,13 \\
\hline 52 & 23,22 & 23,39 & 23,44 & & & & 1,74 & 1,68 & 1,71 & & & & 15,77 & 16,17 & 15,86 & & & \\
\hline \multicolumn{19}{|l|}{53} \\
\hline 54 & 19,10 & 18,10 & 18,30 & 18,00 & 19,36 & 19,15 & & & & & & & 16,40 & 15,60 & 15,40 & 16,51 & 16,29 & 16,40 \\
\hline \multicolumn{19}{|l|}{55} \\
\hline 56 & 34,50 & 32,30 & 33,00 & & & & & & & & & & 16,00 & 16,50 & 15,90 & & & \\
\hline \multicolumn{19}{|l|}{57} \\
\hline \multicolumn{19}{|l|}{58} \\
\hline \multicolumn{19}{|l|}{59} \\
\hline 60 & 22,62 & 25,21 & 23,40 & & & & 1,45 & 1,49 & 1,43 & & & & 17,27 & 17,82 & 17,31 & & & \\
\hline 61 & 31,82 & 32,15 & 33,25 & & & & 1,47 & 1,46 & 1,53 & & & & & & & & & \\
\hline 62 & 32,90 & 31,90 & 31,80 & 32,40 & 33,00 & 32,30 & 0,50 & 0,60 & 0,60 & 0,50 & 0,50 & 0,60 & & & & & & \\
\hline 63 & 29,82 & 30,44 & 29,82 & 29,74 & & & & & & & & & & & & & & \\
\hline
\end{tabular}

\begin{tabular}{|c|c|c|c|c|c|c|c|c|c|c|c|c|c|c|c|c|c|c|}
\hline \multirow{2}{*}{ Lab } & \multicolumn{6}{|c|}{ K (g/kg) } & \multicolumn{6}{|c|}{$\mathrm{Na}(\mathrm{g} / \mathrm{kg})$} & \multicolumn{6}{|c|}{$\mathrm{Cu}$ (mg/kg) } \\
\hline & 1 & 2 & 3 & 4 & 5 & 6 & 1 & 2 & 3 & 4 & 5 & 6 & 1 & 2 & 3 & 4 & 5 & 6 \\
\hline \multicolumn{19}{|l|}{1} \\
\hline 2 & 6,50 & 6,10 & 6,40 & & & & 2,20 & 2,10 & 2,20 & & & & & & & & & \\
\hline 3 & 5,10 & 5,45 & 5,41 & 4,86 & 5,45 & 5,34 & 2,92 & 2,86 & 2,91 & 2,69 & 2,95 & 2,93 & 8,62 & 7,76 & 7,33 & 8,23 & 8,20 & \\
\hline 4 & 6,17 & 5,69 & 5,69 & 5,69 & 5,69 & 6,18 & 2,00 & 1,41 & 2,25 & 2,25 & 2,25 & 2,00 & & & & & & \\
\hline 5 & 6,55 & 5,71 & 6,95 & 5,94 & 6,24 & 7,41 & 1,98 & 1,80 & 2,69 & 2,01 & 2,75 & 2,07 & & & & & & \\
\hline 7 & 5,90 & 5,80 & 5,90 & 5,70 & 5,90 & 5,90 & & & & & & & 10,40 & 10,44 & 10,20 & 10,25 & 10,35 & 10,32 \\
\hline 8 & 6,35 & 6,15 & 6,53 & & & & 2,43 & 2,48 & 2,37 & & & & & & & & & \\
\hline 9 & 5,29 & 4,81 & 5,15 & 4,59 & 4,94 & 5,31 & 1,81 & 1,92 & 1,98 & 1,59 & 2,02 & 2,06 & 9,71 & 9,56 & 7,17 & 9,14 & 9,56 & 9,34 \\
\hline 10 & 6,67 & 6,58 & 6,55 & 6,73 & 6,74 & 6,57 & & & & & & & 11,76 & 11,78 & 12,39 & 11,71 & 11,84 & 11,72 \\
\hline \multicolumn{19}{|l|}{11} \\
\hline 16 & 5,33 & 5,01 & 5,12 & 5,46 & 5,06 & 5,28 & & & & & & & 6,24 & 6,55 & 6,41 & 7,79 & 8,05 & 7,84 \\
\hline \multicolumn{19}{|l|}{17} \\
\hline 18 & 5,71 & 5,76 & 5,87 & 5,93 & 5,93 & 5,35 & 2,37 & 2,28 & 2,32 & 2,18 & 2,19 & 2,16 & 9,51 & 10,56 & 9,52 & 11,64 & 10,05 & 11,12 \\
\hline 19 & 5,32 & 5,38 & 5,52 & 5,52 & 5,36 & 5,44 & 1,98 & 1,84 & 1,97 & 1,87 & 1,93 & 1,90 & 9,24 & 9,68 & 9,85 & 10,45 & 10,31 & 10,38 \\
\hline 20 & & & & & & & 1,98 & 1,97 & 1,97 & 1,98 & 1,98 & 1,97 & 11,20 & 10,00 & 10,90 & 10,10 & 9,90 & 10,60 \\
\hline 21 & 5,42 & 5,34 & 5,51 & 5,45 & 5,22 & 5,15 & 1,56 & 1,55 & 1,58 & 1,54 & 1,56 & 1,56 & 12,01 & 13,10 & 12,50 & 12,25 & 12,00 & 12,60 \\
\hline 22 & 5,88 & 6,09 & 5,69 & 6,09 & 5,71 & 5,86 & 2,39 & 2,31 & 2,41 & 2,21 & 2,31 & 2,22 & 10,52 & 10,50 & 10,50 & 10,85 & 10,88 & 10,50 \\
\hline \multicolumn{19}{|l|}{23} \\
\hline \multicolumn{19}{|l|}{24} \\
\hline \multicolumn{19}{|l|}{32} \\
\hline 33 & & & & & & & 2,20 & 2,12 & 2,20 & 2,06 & 2,02 & 2,20 & 10,95 & 10,75 & 10,70 & 10,35 & 10,75 & 10,85 \\
\hline
\end{tabular}




\begin{tabular}{|c|c|c|c|c|c|c|c|c|c|c|c|c|c|c|c|c|c|c|}
\hline 34 & 6,31 & 6,32 & 6,48 & 6,48 & 6,50 & 6,34 & 2,25 & 2,14 & 2,13 & 2,76 & 2,56 & 2,58 & & & & & & \\
\hline 35 & & & & & & & & & & & & & 12,57 & 11,32 & 10,85 & 11,19 & 11,53 & 11,00 \\
\hline \multicolumn{19}{|l|}{36} \\
\hline \multicolumn{19}{|l|}{37} \\
\hline \multicolumn{19}{|l|}{38} \\
\hline \multicolumn{19}{|l|}{39} \\
\hline 40 & 6,50 & 6,50 & 6,50 & 7,00 & 7,00 & 7,00 & 2,06 & 2,01 & 2,06 & 2,01 & 2,06 & 2,01 & 11,86 & 11,99 & 12,11 & 12,44 & 12,26 & 12,16 \\
\hline \multicolumn{19}{|c|}{ 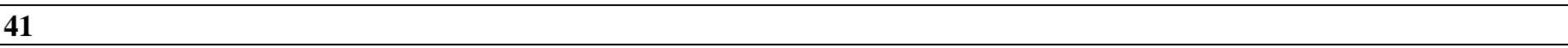 } \\
\hline 42 & 5,79 & 7,62 & 6,11 & 5,80 & 6,45 & 7,13 & 2,07 & 2,93 & 2,94 & 2,19 & 2,21 & 2,10 & 9,19 & 11,72 & 9,70 & 9,87 & 9,15 & 9,83 \\
\hline 43 & 6,61 & 6,72 & 6,77 & 6,34 & 6,18 & 6,48 & 2,57 & 2,62 & 2,62 & 2,08 & 2,01 & 2,32 & 11,64 & 11,64 & 10,59 & 11,40 & 11,40 & 11,35 \\
\hline 44 & 5,44 & 5,22 & 5,33 & 5,01 & 5,12 & 6,18 & 2,56 & 2,24 & 2,13 & 2,24 & 2,34 & 2,34 & 10,58 & 10,94 & 10,37 & 10,57 & 11,09 & 11,36 \\
\hline \multicolumn{19}{|c|}{ (3) } \\
\hline \multicolumn{19}{|l|}{46} \\
\hline \multicolumn{19}{|l|}{47} \\
\hline \multicolumn{19}{|l|}{48} \\
\hline 49 & & & & & & & 2,19 & 2,12 & 2,23 & & & & & & & & & \\
\hline 50 & 7,10 & 6,94 & 6,43 & 7,02 & 6,87 & 6,66 & 2,73 & 2,70 & 2,76 & 2,73 & 3,10 & 2,84 & & & & & & \\
\hline 51 & & & & & & & & & & & & & 12,79 & 12,60 & 12,85 & 12,45 & 12,90 & 12,62 \\
\hline 52 & 6,07 & 6,05 & 6,23 & & & & 1,77 & 1,81 & 1,78 & & & & 6,81 & 7,93 & 7,68 & & & \\
\hline \multicolumn{19}{|c|}{53} \\
\hline 54 & & & & & & & 1,95 & 1,90 & 1,93 & 1,88 & 1,92 & 1,90 & & & & & & \\
\hline \multicolumn{19}{|l|}{55} \\
\hline \multicolumn{19}{|l|}{56} \\
\hline \multicolumn{19}{|l|}{57} \\
\hline \multicolumn{19}{|l|}{58} \\
\hline \multicolumn{19}{|l|}{59} \\
\hline 60 & & & & & & & 1,80 & 1,95 & 1,89 & & & & 8,60 & 8,63 & 8,06 & & & \\
\hline 61 & & & & & & & 3,23 & 3,22 & 3,58 & & & & & & & & & \\
\hline 62 & 6,40 & 6,60 & 6,10 & 6,60 & 6,50 & 6,50 & 2,10 & 2,30 & 1,90 & 2,00 & 2,20 & 2,00 & & & & & & \\
\hline 63 & 6,03 & 6,07 & 6,23 & 6,23 & & & 2,18 & 2,16 & 2,17 & 2,17 & & & & & & & & \\
\hline
\end{tabular}




\begin{tabular}{|c|c|c|c|c|c|c|c|c|c|c|c|c|c|c|c|c|c|c|}
\hline \multirow{2}{*}{ Lab } & \multicolumn{6}{|c|}{$\mathrm{Fe}(\mathrm{mg} / \mathbf{k g})$} & \multicolumn{6}{|c|}{ Zn (mg/kg) } & \multicolumn{6}{|c|}{ Mn (mg/kg) } \\
\hline & 1 & 2 & 3 & 4 & 5 & 6 & 1 & 2 & 3 & 4 & 5 & 6 & 1 & 2 & 3 & 4 & 5 & 6 \\
\hline \multicolumn{19}{|l|}{1} \\
\hline 2 & 221,06 & 223,22 & 225,96 & & & & 122,07 & 120,59 & 121,55 & & & & 20,58 & 17,37 & 15,94 & 19,35 & & \\
\hline 3 & 244,40 & 253,84 & 263,43 & 230,58 & 253,39 & 251,92 & 133,41 & 134,78 & 136,71 & 126,19 & 139,95 & 139,09 & 15,30 & 16,74 & 16,57 & 14,80 & 16,64 & 16,84 \\
\hline 4 & 179,72 & 185,20 & 182,46 & 247,89 & 253,10 & 244,87 & 133,19 & 130,14 & 131,67 & 127,16 & 127,34 & 136,93 & & & & & & \\
\hline 5 & 214,32 & 231,71 & 294,02 & 238,83 & 287,61 & 240,41 & 147,63 & 128,81 & 139,72 & 98,97 & 140,22 & 111,53 & 18,79 & 19,40 & 16,53 & 17,07 & 19,07 & 18,32 \\
\hline 6 & 257,06 & 245,01 & 238,64 & & & & & & & & & & 12,19 & 11,14 & 11,67 & & & \\
\hline 7 & 246,38 & 252,33 & 251,39 & 242,20 & 250,43 & 253,26 & 124,26 & 124,32 & 125,68 & 125,30 & 124,98 & 125,86 & 19,43 & 19,39 & 20,00 & 20,04 & 20,04 & 20,00 \\
\hline 8 & & & & & & & 122,45 & 126,68 & 135,12 & & & & & & & & & \\
\hline 9 & 203,80 & 202,46 & 223,82 & 212,19 & 197,76 & 237,30 & 118,08 & 118,15 & 118,20 & 117,98 & 106,15 & 124,69 & 18,59 & 21,10 & 16,80 & 15,20 & 18,49 & 16,16 \\
\hline 10 & 258,85 & 299,46 & 282,51 & 255,74 & 264,57 & 286,55 & 132,18 & 129,54 & 127,39 & 131,44 & 129,11 & 126,62 & 25,49 & 30,89 & 20,82 & 19,17 & 19,70 & 18,93 \\
\hline \multicolumn{19}{|l|}{11} \\
\hline \multicolumn{19}{|l|}{12} \\
\hline 13 & 235,38 & 239,20 & 231,27 & 271,10 & 240,10 & 241,98 & 137,21 & 135,43 & 132,48 & 135,97 & 135,68 & 136,84 & 28,84 & 19,04 & 17,77 & 23,10 & 19,17 & 19,93 \\
\hline \multicolumn{19}{|l|}{14} \\
\hline 15 & 121,78 & 122,78 & 151,72 & & & & & & & & & & & & & & & \\
\hline 16 & 229,58 & 220,27 & 216,28 & 228,66 & 223,86 & 234,10 & & & & & & & & & & & & \\
\hline \multicolumn{19}{|l|}{17} \\
\hline 18 & 270,48 & 265,04 & 267,47 & 262,30 & 276,12 & 253,54 & 142,64 & 139,92 & 143,78 & 148,07 & 150,76 & 140,80 & 18,49 & 19,01 & 17,97 & 17,98 & 21,16 & 18,53 \\
\hline 19 & 212,90 & 212,41 & 233,16 & 227,42 & 221,25 & 224,34 & 125,28 & 116,92 & 126,30 & 125,82 & 125,50 & 125,66 & 18,34 & 16,97 & 18,26 & 18,77 & 16,58 & 17,67 \\
\hline 20 & 179,00 & 195,00 & 180,00 & 173,00 & 172,00 & 179,00 & 120,00 & 121,00 & 129,00 & 128,00 & 125,00 & 133,00 & 17,00 & 17,00 & 18,00 & 19,00 & 17,00 & 17,00 \\
\hline 21 & 210,00 & 214,15 & 212,80 & 220,00 & 210,50 & 215,20 & 137,50 & 136,00 & 136,40 & 140,10 & 135,50 & 137,50 & 31,70 & 31,40 & 31,00 & 32,00 & 31,30 & 31,50 \\
\hline 22 & 259,30 & 263,51 & 243,54 & 260,23 & 261,69 & 258,21 & 132,28 & 132,84 & 132,43 & 134,90 & 133,30 & 132,28 & 25,26 & 24,15 & 25,20 & 25,73 & 24,29 & 25,37 \\
\hline \multicolumn{19}{|l|}{23} \\
\hline \multicolumn{19}{|l|}{24} \\
\hline \multicolumn{19}{|l|}{25} \\
\hline \multicolumn{19}{|l|}{26} \\
\hline \multicolumn{19}{|l|}{27} \\
\hline 28 & & & & & & & & & & & & & & & & & & \\
\hline 29 & 234,00 & 238,00 & 226,00 & 237,00 & 204,00 & 227,00 & 117,00 & 118,00 & 117,00 & 122,00 & 115,00 & 113,00 & 17,00 & 16,00 & 17,00 & 21,00 & 20,00 & 18,00 \\
\hline 30 & & & & & & & & & & & & & & & & & & \\
\hline 31 & 288,88 & 238,54 & 264,60 & 267,68 & 276,86 & 330,98 & 128,68 & 132,44 & 134,54 & 116,96 & 119,18 & 127,50 & 18,68 & 15,24 & 14,16 & 17,26 & 18,18 & 15,96 \\
\hline 32 & & & & & & & & & & & & & & & & & & \\
\hline 33 & & & & & & & 123,37 & 125,87 & 122,99 & 122,81 & 124,12 & 125,60 & 19,00 & 18,95 & 19,10 & 18,90 & 18,95 & 18,65 \\
\hline 34 & 262,03 & 245,44 & 247,61 & 238,04 & 265,46 & 316,86 & & & & & & & 15,29 & 16,40 & 17,53 & 21,57 & 21,86 & 24,60 \\
\hline 35 & 191,71 & 207,57 & 189,81 & 188,21 & 174,65 & 199,99 & & & & & & & 25,92 & 21,89 & 21,91 & 22,46 & 23,74 & 22,64 \\
\hline 36 & & & & & & & & & & & & & & & & & & \\
\hline 37 & & & & & & & & & & & & & & & & & & \\
\hline 38 & & & & & & & & & & & & & & & & & & \\
\hline 39 & & & & & & & & & & & & & & & & & & \\
\hline 40 & 248,02 & 257,53 & 251,74 & 250,93 & 272,23 & 272,59 & 134,38 & 137,51 & 136,31 & 142,30 & 142,04 & 141,16 & 18,79 & 16,34 & 18,67 & 18,06 & 17,86 & 18,25 \\
\hline 41 & & & & & & & & & & & & & & & & & & \\
\hline 42 & 148,40 & 224,72 & 156,59 & 149,90 & 158,54 & 157,15 & 100,34 & 127,01 & 105,87 & 102,67 & 108,45 & 100,12 & 17,54 & 18,37 & 18,51 & 18,28 & 17,31 & 17,23 \\
\hline 43 & 239,89 & 241,00 & 255,82 & 212,14 & 201,47 & 226,19 & 110,77 & 110,80 & 107,62 & 101,30 & 99,94 & 105,17 & 19,40 & 19,41 & 20,47 & 13,26 & 14,31 & 16,77 \\
\hline 44 & 261,30 & 237,32 & 243,50 & 240,20 & 242,97 & 261,83 & 123,51 & 129,16 & 137,15 & 125,11 & 132,78 & 129,90 & 20,86 & 18,31 & 19,38 & 19,01 & 19,99 & 19,94 \\
\hline 45 & & & & & & & & & & & & & & & & & & \\
\hline 46 & & & & & & & & & & & & & & & & & & \\
\hline 47 & & & & & & & & & & & & & & & & & & \\
\hline 48 & & & & & & & & & & & & & & & & & & \\
\hline 49 & 259,01 & 249,68 & 240,66 & & & & & & & & & & & & & & & \\
\hline 50 & 220,00 & 245,00 & 234,00 & 246,00 & 236,25 & 228,30 & 116,00 & 120,00 & 116,00 & 117,33 & 118,00 & 119,02 & 19,00 & 24,00 & 17,00 & 19,00 & 19,75 & 22,40 \\
\hline
\end{tabular}




\begin{tabular}{|c|c|c|c|c|c|c|c|c|c|c|c|c|c|c|c|c|c|c|}
\hline 51 & & & & & & & 132,78 & 130,22 & 128,55 & 129,48 & 140,12 & 128,21 & 22,28 & 21,94 & 22,54 & 22,44 & 22,09 & 23,10 \\
\hline 52 & 221,49 & 227,75 & 226,83 & & & & & & & & & & 20,27 & 20,54 & 20,14 & & & \\
\hline \multicolumn{19}{|l|}{53} \\
\hline \multicolumn{19}{|l|}{55} \\
\hline \multicolumn{19}{|l|}{56} \\
\hline \multicolumn{19}{|l|}{57} \\
\hline \multicolumn{19}{|l|}{59} \\
\hline 60 & 234,06 & 246,94 & 254,14 & & & & 119,61 & 126,41 & 121,95 & & & & 17,68 & 17,46 & 17,88 & & & \\
\hline 61 & 235,23 & 235,65 & 224,91 & & & & & & & & & & & & & & & \\
\hline 62 & 250,00 & 222,00 & 200,00 & 240,00 & 227,00 & 226,00 & 189,00 & 193,00 & 172,00 & 190,00 & 194,00 & 198,00 & & & & & & \\
\hline 63 & 259,09 & 299,33 & 247,41 & 278,15 & & & 134,13 & 133,07 & 134,12 & 133,07 & & & & & & & & \\
\hline
\end{tabular}


APÊNDICE B - Documento de Análises do RM de Ração para Peixe

\title{
Documento de Análises
}

MATERIAL DE REFERÊNCIA

\author{
Ração para Peixe \\ Código: RM - E1002A
}

Data de emissão: Janeiro de 2017

Tabela 1. Valores de referência para a fração massa (na base seca) atribuídos aos macro e micronutrientes determinados no material de referência de ração para peixe $(\mathrm{RM}-18)$ e incerteza expandida $\left(U_{\mathrm{RM}}\right)^{*}$ em porcentagem

\begin{tabular}{|c|c|c|}
\hline Elementos & Média $\pm U_{\mathrm{RM}}$ & $U_{\mathrm{RM}}(\%)$ \\
\hline $\mathrm{Ca}\left(\mathrm{g} \mathrm{kg}^{-1}\right)$ & $28,65 \pm 1,96$ & 6,84 \\
\hline $\mathrm{Cu}\left(\mathrm{mg} \mathrm{kg}^{-1}\right)$ & $10,51 \pm 0,89$ & 8,48 \\
\hline $\mathrm{Fe}\left(\mathrm{mg} \mathrm{kg}^{-1}\right)$ & $231,97 \pm 20,94$ & 9,03 \\
\hline $\mathrm{K}\left(\mathrm{g} \mathrm{kg}^{-1}\right)$ & $5,86 \pm 0,33$ & 5,64 \\
\hline $\operatorname{Mg}\left(\mathrm{g} \mathrm{kg}^{-1}\right)$ & $1,55 \pm 0,16$ & 10,30 \\
\hline $\operatorname{Mn}\left(\mathrm{mg} \mathrm{kg}^{-1}\right)$ & $19,46 \pm 2,33$ & 11,96 \\
\hline $\mathrm{Na}\left(\mathrm{g} \mathrm{kg}^{-1}\right)$ & $2,16 \pm 0,22$ & 10,27 \\
\hline$P\left(\mathbf{g ~ k g}^{-1}\right)$ & $16,06 \pm 0,98$ & 6,13 \\
\hline $\mathrm{Zn}\left(\mathrm{mg} \mathrm{kg}^{-1}\right)$ & $129,56 \pm 6,93$ & 5,35 \\
\hline
\end{tabular}

*Intervalo a 95\% de confiança.

Tabela 2. Valores de referência para a fração massa (na base seca) atribuídos aos parâmetros bromatológicos determinados no material de referência de ração para peixe $(\mathrm{RM}-18)$ e incerteza expandida $\left(U_{\mathrm{RM}}\right)^{*}$ em porcentagem

\begin{tabular}{ccc}
\hline & Média (\%) \pm URM & URM (\%) \\
\hline Matéria Seca (MS) & $94,29 \pm 1,07$ & 1,14 \\
Proteína Bruta (PB) & $30,46 \pm 0,85$ & 2,81 \\
Fibra em Detergente Ácido (FDA) & $5,01 \pm 3,16$ & 63,02 \\
Fibra em Detergente Neutro (FDN) & $17,61 \pm 2,51$ & 14,23 \\
Fibra Bruta (FB) & $2,49 \pm 0,87$ & 34,79 \\
Cinzas & $10,17 \pm 0,37$ & 3,64 \\
Extrato Etéreo (EE) & $4,97 \pm 0,93$ & 18,63 \\
Lignina & $1,34 \pm 0,56$ & 42,24 \\
Nitrogênio Não Protéico (NNP) & $0,45 \pm 0,30$ & 67,78 \\
\hline
\end{tabular}




\section{Ensaio colaborativo}

Os resultados foram obtidos através do ensaio de proficiência com a participação efetiva de empresas da iniciativa privada, instituições de pesquisa estatais e de ensino superior.

\section{Obtenção do material}

Para o preparo do material candidato a material de referência de ração para peixe, foi utilizada ração obtida a partir de fornecedor comercial, com constituição típica às utilizadas pelos produtores, que possui $32 \%$ de proteína bruta.

\section{Uso pretendido}

Esta amostra destina-se ao uso como um material de referência para a medição de macro e micronutrientes e parâmetros bromatológicos em amostras de ração. $\mathrm{O}$ material também pode ser utilizado em controle de qualidade para a avaliação de um trabalho analítico, para a validação de métodos de análise e de controle de qualidade dentro do laboratório.

\section{Preparação do material}

Após secagem, em estufa com circulação forçada de ar, a $60^{\circ} \mathrm{C}$ por 48 horas, a ração para peixe foi moída em moinho ultracentrífugo, modelo ZM $200 \AA$ (Retsch, Alemanha), com peneira de $0,75 \mathrm{~mm}$ e empregando-se velocidade de $6000 \mathrm{rpm}$ visando diminuição do tamanho de partícula. Foram preparados aproximadamente 30 $\mathrm{kg}$ do material seco. Após a moagem as amostras foram homogeneizadas e envasadas em 300 frascos de vidro âmbar, previamente desmineralizados, onde foram separadas porções típicas de aproximadamente $85 \mathrm{~g}$. Visando assegurar a estabilidade a longo prazo e esterilização do material, foi realizada a irradiação com raios gama (5 a $10 \mathrm{kGy}$ ) no Instituto de Pesquisas Energéticas e Nucleares (IPEN). Todas as etapas de preparo seguiram as normas ISO Guide $30^{5}$, ABNT NBR ISO Guia $31,33,34$ e $35^{1-4}$.

\section{Instruções para uso}

A massa mínima recomendada para a análise é de $250 \mathrm{mg}$. Deve-se realizar uma homogeneização manual prévia do frasco antes da análise e deve-se tomar as devidas precauções para evitar a contaminação do material restante no frasco.

Procedimentos de digestão em micro-ondas com cavidade (sistema fechado) são indicados para determinação dos macro e micronutrientes, utilizando ácido nítrico diluído e peróxido de hidrogênio. Procedimento de digestão em bloco digestor (sistema aberto) utilizando ácido nitrico e ácido perclórico também pode ser empregado.

\section{Homogeneidade}

$\mathrm{Na}$ produção de um candidato a RM, o estudo de homogeneidade deve ser conduzido para avaliar a variabilidade analítica e entre frascos e obter a incerteza referente à heterogeneidade do material. $O$ estudo da homogeneidade dentro do frasco (1 frasco) e entre os frascos (10 frascos) foi realizado através de determinações por ICP OES para $\mathrm{Ca}, \mathrm{Cu}, \mathrm{Fe}, \mathrm{K}, \mathrm{Mg}, \mathrm{Mn}, \mathrm{Na}, \mathrm{P}$ e Zn e para através da realização dos ensaios bromatológicos. Foi realizada a análise de variância ANOVA de fator único, sendo possível observar que o lote de ração para peixe pode ser considerado homogêneo para $\mathrm{Ca}, \mathrm{Cu}, \mathrm{Fe}, \mathrm{Mg}, \mathrm{Mn}$ e $\mathrm{Na}$, uma vez que não foi verificada diferença significativa no nível de confiança de $95 \%$. Para o $\mathrm{K}, \mathrm{P}$ e $\mathrm{Zn}$ houve diferença 
significativa e, nesse enfoque, deve ser considerado o grau de heterogeneidade para esses elementos.

\section{Estabilidade}

Foram avaliados dois tipos de testes de estabilidade a serem considerados em materiais de referência: a estabilidade a curto prazo e a estabilidade a longo prazo. Para o estudo da estabilidade a curto prazo, 3 frascos do material foram colocados à temperatura de $38^{\circ} \mathrm{C}$ e umidade relativa próxima a $100 \%$ por 4 (quatro) semanas, simulando condições de transporte. Após este período foi realizada a quantificação em triplicata dos parâmetros de interesse. Para o estudo da estabilidade a longo prazo foram selecionados aleatoriamente 10 frascos do lote preparado que foram armazenados à temperatura ambiente (cerca de $25 \stackrel{\circ}{\circ}$ ), a fim de acompanhar a estabilidade do material sob condições de armazenamento. A cada 3 meses foi efetuada uma quantificação dos parâmetros em estudo, em triplicata, até completar 1 (um) ano. Após esse período as medidas serão realizadas semestralmente. Foram feitas as determinações por ICP OES para $\mathrm{Ca}, \mathrm{Cu}, \mathrm{Fe}, \mathrm{K}, \mathrm{Mg}, \mathrm{Mn}, \mathrm{Na}, \mathrm{P}$ e Zn e foram realizados os ensaios bromatológicos. A avaliação da estabilidade a curto prazo foi obtida por meio de regressão linear simples e da estabilidade a longo prazo do material foi feita pela análise de resíduos da regressão em conjunto com a ANOVA.

\section{Tamanho de partículas}

Foi realizado ensaio de distribuição de tamanho de partículas (Analysette 22 MicroTec Plus, da Fritsch, Alemanha) no Centro de Energia Nuclear na Agricultura, na Universidade de São Paulo (CENA, USP), Piracicaba-SP. O estudo mostrou que $90 \%$ das partículas apresentavam granulometria inferior a $400 \mu \mathrm{m}$ de acordo com 0 gráfico abaixo.

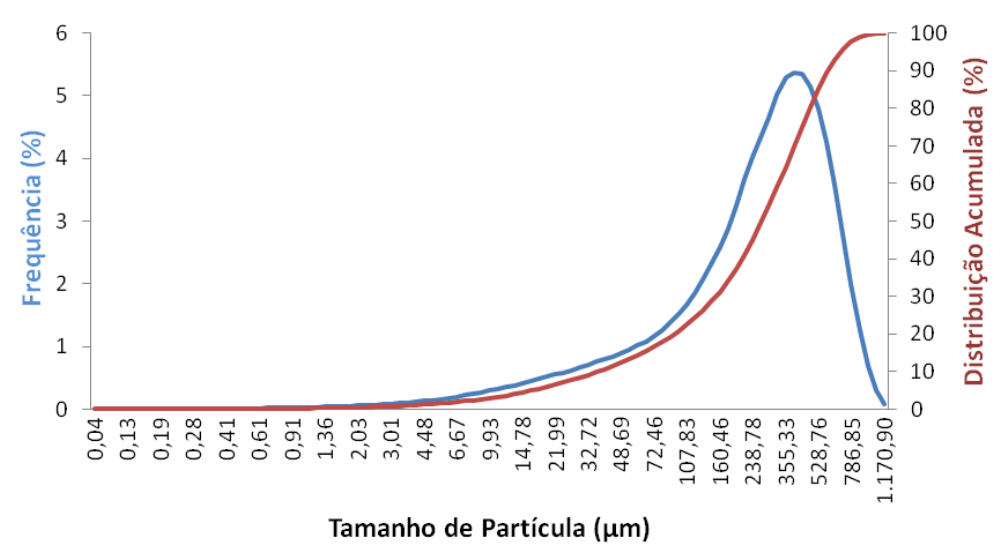

\section{Incertezas}

A abordagem das incertezas em medições químicas, conforme preconizada pelos assuntos de metrologia indicada na norma ISO Guia $35^{4}$, que dispõe sobre os procedimentos para a certificação de materiais de referência, pressupõe a declaração de suas incertezas de todas as etapas de sua preparação. Assim, é exigido do produtor de material de referência agregar a incerteza dos valores certificados. Dessa forma, a estimativa da incerteza expandida associada aos valores de concentração $\left(U_{\mathrm{RM}}\right)$ é obtida pela combinação das contribuições referentes à incerteza padrão da caracterização ( $\left.u_{\mathrm{char}}\right)$, da homogeneidade $\left(u_{\mathrm{bb}}\right)$ e da estabilidade a longo prazo $\left(u_{\mathrm{lts}}\right)$, conforme equação abaixo: 


$$
U_{\mathrm{RM}}=k \sqrt{u_{c h a r}^{2}+u_{b b}^{2}+u_{l t s}^{2}}
$$

Adotou-se para o fator de abrangência $k$ igual a 2, o intervalo de confiança é de $95 \%$. Para os cálculos das incertezas da homogeneidade, da estabilidade e da caracterização foi também seguida a norma ISO Guia $35^{6}$.

\section{Armazenamento}

O material deve ser mantido fechado no frasco original e armazenado no escuro em temperatura de aproximadamente $25^{\circ} \mathrm{C}$. Os frascos também podem ser armazenado em dessecador.

\section{Determinação do peso seco}

Todos os valores estão expressos na base seca. Portanto, o peso seco tem de ser determinado no momento da análise, utilizando-se sub-amostras separadas de pelo menos $1 \mathrm{~g}$ até peso constante em estufa a temperatura de $105^{\circ} \mathrm{C}$ em alíquota que não será utilizada para determinação dos elementos de interesse.

\section{Prazo de validade}

Estipulou-se que o tempo de prateleira poderia ser em torno de 5 anos para o candidato a material de referência de ração para peixe. É possível que o material seja estável por tempo maior que o definido. Dessa forma, este material ficará como produto a ser monitorado semestralmente. Qualquer alteração será informada.

Tabela 3. Métodos analíticos utilizados pelos laboratórios participantes do ensaio colaborativo para determinação dos valores de referência da concentração dos macro e micronutrientes.

\begin{tabular}{cccc}
\hline Elemento & Código da técnica & Elemento & Código da técnica \\
\hline \multirow{2}{*}{ Cálcio $(\mathrm{Ca})$} & FAAS & Manganês $(\mathrm{Mn})$ & FAAS \\
& ICP OES & & ICP OES \\
INAA & FAAS & Sódio $(\mathrm{Na})$ & FP \\
& ICP OES & & ICP OES \\
& FAAS & & INAA \\
Ferro $(\mathrm{Fe})$ & ICP OES & Fósforo $(\mathrm{P})$ & COLOR \\
& INAA & & ICP OES \\
Potássio $(\mathrm{K})$ & FP & Zinco $(\mathrm{Zn})$ & FAAS \\
& ICP OES & & INA OES \\
Magnésio $(\mathrm{Mg})$ & INAA & & \\
& FAAS & & \\
\hline
\end{tabular}

Técnicas:

FAAS Espectrometria de Absorção Atômica com Chama

FP Fotometria de Chama

COLOR Espectrofotometria de Absorção Molecular UV-VIS

ICP OES Espectrometria de Emissão Ôptica com Plasma Acoplado Indutivamente

INAA Analise por ativação Neutrônica Instrumental 
Tabela 4. Alguns dos Laboratórios Participantes do Ensaio Colaborativo.

\begin{tabular}{|c|}
\hline Ad'oro S/A \\
\hline Arasolo Análises Ltda \\
\hline BRNova Sistemas Nutricionais S/A \\
\hline CAMDA (Cooperativa Agrícola Mista de Adamantina) \\
\hline Cargill $\circledast$ Animal Nutrition \\
\hline Centro de Energia Nuclear na Agricultura - CENA \\
\hline Centralmyx Ind. Com. e Rep. LTDA \\
\hline Coop.Regional de Cafeicultores em Guaxupé Ltda \\
\hline Embrapa Acre \\
\hline Embrapa Agroindustria de Alimentos \\
\hline Embrapa Agropecuária Oeste -CPAO \\
\hline Embrapa Cerrados \\
\hline Embrapa Pecuária Sul \\
\hline Embrapa Soja \\
\hline EMPARN - Empresa de Pesquisa Agropecuária do Rio Grande do Norte S/A \\
\hline Faculdade de Engenharia de Ilha Solteira/UNESP \\
\hline FATEC Industria de Nutrição e Saúde Animal \\
\hline Fazu - Faculdades Associadas de Uberaba \\
\hline Fundação ABC \\
\hline Fundación CETABOL \\
\hline IAPAR/Londrina \\
\hline Instituto de Pesquisas Energéticas e Nucleares \\
\hline Instituto de Zootecnia \\
\hline Invivo Nutrição e Saúde Animal Ltda \\
\hline JBS Aves Brasil Ltda. \\
\hline Laboratório Exata \\
\hline Laboratório Plante Certo Ltda \\
\hline Matsuda Minas Com. e Ind. Ltda. \\
\hline Mig-PLUS Agroindustrial Ltda \\
\hline Ministério da Agricultura Pecuária e Abastecimento - MAPA - LANAGRO-SP \\
\hline Núcleo De Análises Físico-Químicas \\
\hline Nutrifarma - Nutrição e Saúde Animal AS \\
\hline Nutrivil Ind. Comércio de Rações Ltda \\
\hline Ribersolo Laboratorio de Analises Agricolas Ltda. \\
\hline Selecta Pet Care Ind. E Comércio Ltda \\
\hline Souza Neto \& Souza Ltda /Agroanálise \\
\hline Vaccinar Industria e Comércio Ltda \\
\hline Yessinergy do Brasil Agroindustrial Ltda \\
\hline
\end{tabular}




\section{Referências}

'ASSOCIAÇÃO BRASILEIRA DE NORMAS TÉCNICAS. ABNT ISO GUIA 31. Materiais de referência - Conteúdo de certificados e rótulos. ABNT, 2004. 2ASSOCIAÇÃO BRASILEIRA DE NORMAS TÉCNICAS. ABNT ISO GUIA 33. Utilização de materiais de referência certificados. ABNT, 2002.

${ }^{3}$ ASSOCIAÇÃO BRASILEIRA DE NORMAS TÉCNICAS. ABNT ISO GUIA 34: Requisitos gerais para a competência de produtores de material de referência, ABNT, 2012.

${ }^{4}$ ASSOCIAÇÃO BRASILEIRA DE NORMAS TÉCNICAS. ABNT ISO GUIA 35: Materiais de referência - Princípios gerais e estatísticos para certificação, ABNT, 2012.

IINTERNATIONAL ORGANIZATION FOR STANDARDIZATION, ISO Guide 30: Terms and definitions used in connection with reference materials, ISO, 1992. 
APÊNDICE C - Teste de Shapiro-Wilk para normalidade a 95\% de confiança.

Tabela C1 - Resultados do teste de homogeneidade dentro do frasco, para o RM candidato de tecido de peixe, obtidos por ICP OES e ICP-MS.

\begin{tabular}{|c|c|c|c|c|c|}
\hline Elemento & Massa, mg & $W$ & Valor de $p$ & Decisão no nível 0,05 & $\mathbf{n}$ \\
\hline \multirow{5}{*}{ As } & 100 & 0,974 & 0,849 & normal & 6 \\
\hline & 200 & 0,936 & 0,747 & normal & 6 \\
\hline & 250 & 0,937 & 0,753 & normal & 6 \\
\hline & 300 & 0,907 & 0,487 & normal & 6 \\
\hline & 400 & 0,959 & 0,933 & normal & 6 \\
\hline \multirow{5}{*}{$\mathbf{B a}$} & 100 & 0,911 & 0,522 & normal & 6 \\
\hline & 200 & 0,917 & 0,573 & normal & 6 \\
\hline & 250 & 0,844 & 0,162 & normal & 6 \\
\hline & 300 & 0,863 & 0,227 & normal & 6 \\
\hline & 400 & 0,938 & 0,763 & normal & 6 \\
\hline \multirow{5}{*}{$\mathbf{C a}$} & 100 & 0,949 & 0,858 & normal & 6 \\
\hline & 200 & 0,978 & 0,996 & normal & 6 \\
\hline & 250 & 0,900 & 0,438 & normal & 6 \\
\hline & 300 & 0,805 & 0,081 & normal & 6 \\
\hline & 400 & 0,872 & 0,269 & normal & 6 \\
\hline \multirow{5}{*}{ Co } & 100 & 0,970 & 0,980 & normal & 6 \\
\hline & 200 & 0,941 & 0,795 & normal & 6 \\
\hline & 250 & 0,922 & 0,615 & normal & 6 \\
\hline & 300 & 0,835 & 0,137 & normal & 6 \\
\hline & 400 & 0,720 & 0,020 & não normal & 6 \\
\hline \multirow{5}{*}{$\mathrm{Cr}$} & 100 & 0,753 & 0,033 & não normal & 6 \\
\hline & 200 & 0,820 & 0,105 & normal & 6 \\
\hline & 250 & 0,872 & 0,267 & normal & 6 \\
\hline & 300 & 0,818 & 0,101 & normal & 6 \\
\hline & 400 & 0,805 & 0,080 & normal & 6 \\
\hline \multirow{5}{*}{$\mathbf{C u}$} & 100 & 0,922 & 0,621 & normal & 6 \\
\hline & 200 & 0,831 & 0,128 & normal & 6 \\
\hline & 250 & 0,902 & 0,450 & normal & 6 \\
\hline & 300 & 0,734 & 0,024 & não normal & 6 \\
\hline & 400 & 0,949 & 0,860 & normal & 6 \\
\hline \multirow{5}{*}{$\mathrm{Fe}$} & 100 & 0,786 & 0,576 & normal & 6 \\
\hline & 200 & 0,976 & 0,993 & normal & 6 \\
\hline & 250 & 0,960 & 0,938 & normal & 6 \\
\hline & 300 & 0,863 & 0,227 & normal & 6 \\
\hline & 400 & 0,898 & 0,421 & normal & 6 \\
\hline
\end{tabular}


Tabela C1 - Resultados do teste de homogeneidade dentro do frasco, para o RM candidato de tecido de peixe, obtidos por ICP OES e ICP-MS.. Continuação

\begin{tabular}{|c|c|c|c|c|c|}
\hline Elemento & Massa, mg & $W$ & Valor de $p$ & Decisão no nível 0,05 & $\mathbf{n}$ \\
\hline \multirow{5}{*}{$\mathbf{K}$} & 100 & 0,927 & 0,662 & normal & 6 \\
\hline & 200 & 0,861 & 0,218 & normal & 6 \\
\hline & 250 & 0,931 & 0,701 & normal & 6 \\
\hline & 300 & 0,885 & 0,336 & normal & 6 \\
\hline & 400 & 0,895 & 0,403 & normal & 6 \\
\hline \multirow{5}{*}{ Mg } & 100 & 0,886 & 0,342 & normal & 6 \\
\hline & 200 & 0,883 & 0,323 & normal & 6 \\
\hline & 250 & 0,930 & 0,691 & normal & 6 \\
\hline & 300 & 0,967 & 0,971 & normal & 6 \\
\hline & 400 & 0,861 & 0,218 & normal & 6 \\
\hline \multirow{5}{*}{ Mn } & 100 & 0,784 & 0,056 & normal & 6 \\
\hline & 200 & 0,927 & 0,067 & normal & 6 \\
\hline & 250 & 0,937 & 0,755 & normal & 6 \\
\hline & 300 & 0,951 & 0,877 & normal & 6 \\
\hline & 400 & 0,855 & 0,197 & normal & 6 \\
\hline \multirow{5}{*}{ Mo } & 100 & 0,932 & 0,707 & normal & 6 \\
\hline & 200 & 0,779 & 0,051 & normal & 6 \\
\hline & 250 & 0,809 & 0,087 & normal & 6 \\
\hline & 300 & 0,732 & 0,023 & não normal & 6 \\
\hline & 400 & 0,939 & 0,774 & normal & 6 \\
\hline \multirow{5}{*}{$\mathbf{N a}$} & 100 & 0,926 & 0,658 & normal & 6 \\
\hline & 200 & 0,853 & 0,190 & normal & 6 \\
\hline & 250 & 0,896 & 0,405 & normal & 6 \\
\hline & 300 & 0,957 & 0,923 & normal & 6 \\
\hline & 400 & 0,821 & 0,107 & normal & 6 \\
\hline \multirow{5}{*}{$\mathbf{N i}$} & 100 & 0,803 & 0,078 & normal & 6 \\
\hline & 200 & 0,850 & 0,181 & normal & 6 \\
\hline & 250 & 0,844 & 0,161 & normal & 6 \\
\hline & 300 & 0,968 & 0,974 & normal & 6 \\
\hline & 400 & 0,947 & 0,842 & normal & 6 \\
\hline \multirow{5}{*}{$\mathbf{P}$} & 100 & 0,854 & 0,195 & normal & 6 \\
\hline & 200 & 0,887 & 0,347 & normal & 6 \\
\hline & 250 & 0,880 & 0,310 & normal & 6 \\
\hline & 300 & 0,948 & 0,851 & normal & 6 \\
\hline & 400 & 0,743 & 0,028 & não normal & 6 \\
\hline
\end{tabular}


Tabela C1 - Resultados do teste de homogeneidade dentro do frasco, obtidos por ICP OES e ICP-MS. Continuação

\begin{tabular}{|c|c|c|c|c|c|}
\hline Elemento & Massa, mg & $W$ & Valor de $p$ & Decisão no nível 0,05 & $\mathbf{n}$ \\
\hline \multirow{5}{*}{ Se } & 100 & 0,755 & 0,034 & não normal & 6 \\
\hline & 200 & 0,801 & 0,075 & normal & 6 \\
\hline & 250 & 0,873 & 0,275 & normal & 6 \\
\hline & 300 & 0,850 & 0,181 & normal & 6 \\
\hline & 400 & 0,970 & 0,980 & normal & 6 \\
\hline \multirow{5}{*}{$\mathbf{S r}$} & 100 & 0,724 & 0,020 & não normal & 6 \\
\hline & 200 & 0,866 & 0,240 & normal & 6 \\
\hline & 250 & 0,971 & 0,983 & normal & 6 \\
\hline & 300 & 0,921 & 0,604 & normal & 6 \\
\hline & 400 & 0,928 & 0,672 & normal & 6 \\
\hline \multirow{5}{*}{$\mathbf{T i}$} & 100 & 0,923 & 0,624 & normal & 6 \\
\hline & 200 & 0,933 & 0,716 & normal & 6 \\
\hline & 250 & 0,913 & 0,536 & normal & 6 \\
\hline & 300 & 0,989 & 1,000 & normal & 6 \\
\hline & 400 & 0,878 & 0,296 & normal & 6 \\
\hline \multirow{5}{*}{$\mathbf{V}$} & 100 & 0,988 & 1,000 & normal & 6 \\
\hline & 200 & 0,976 & 0,994 & normal & 6 \\
\hline & 250 & 0,865 & 0,238 & normal & 6 \\
\hline & 300 & 0,972 & 0,986 & normal & 6 \\
\hline & 400 & 0,935 & 0,738 & normal & 6 \\
\hline \multirow{5}{*}{$\mathbf{Z n}$} & 100 & 0,924 & 0,639 & normal & 6 \\
\hline & 200 & 0,891 & 0,374 & normal & 6 \\
\hline & 250 & 0,940 & 0,789 & normal & 6 \\
\hline & 300 & 0,837 & 0,142 & normal & 6 \\
\hline & 400 & 0,904 & 0,466 & normal & 6 \\
\hline
\end{tabular}


Apêndice C2 - Gráficos da Probabilidade Normal obtidos para os resultados do estudo de homogeneidade dentro do frasco para o RM de tecido de peixe.

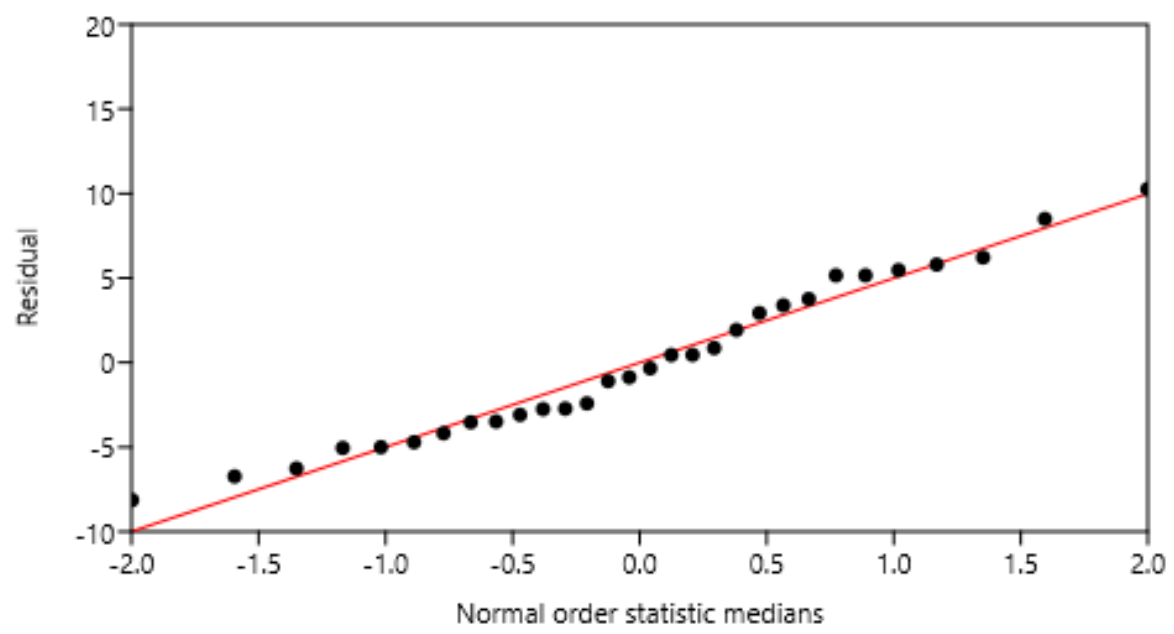

As

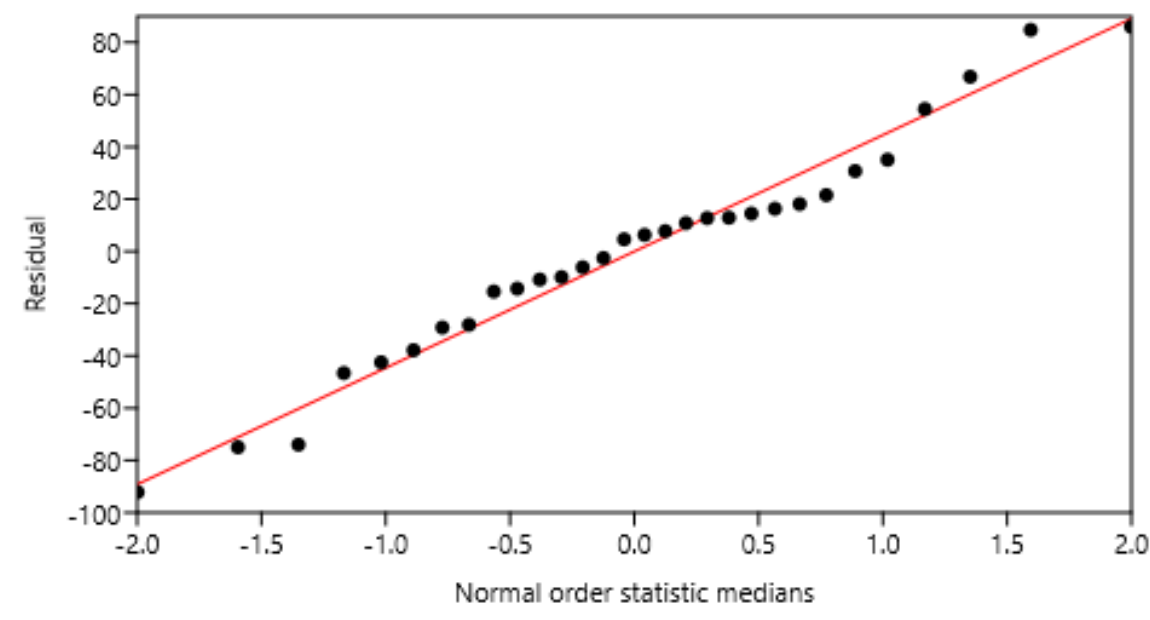

$\mathrm{Ba}$

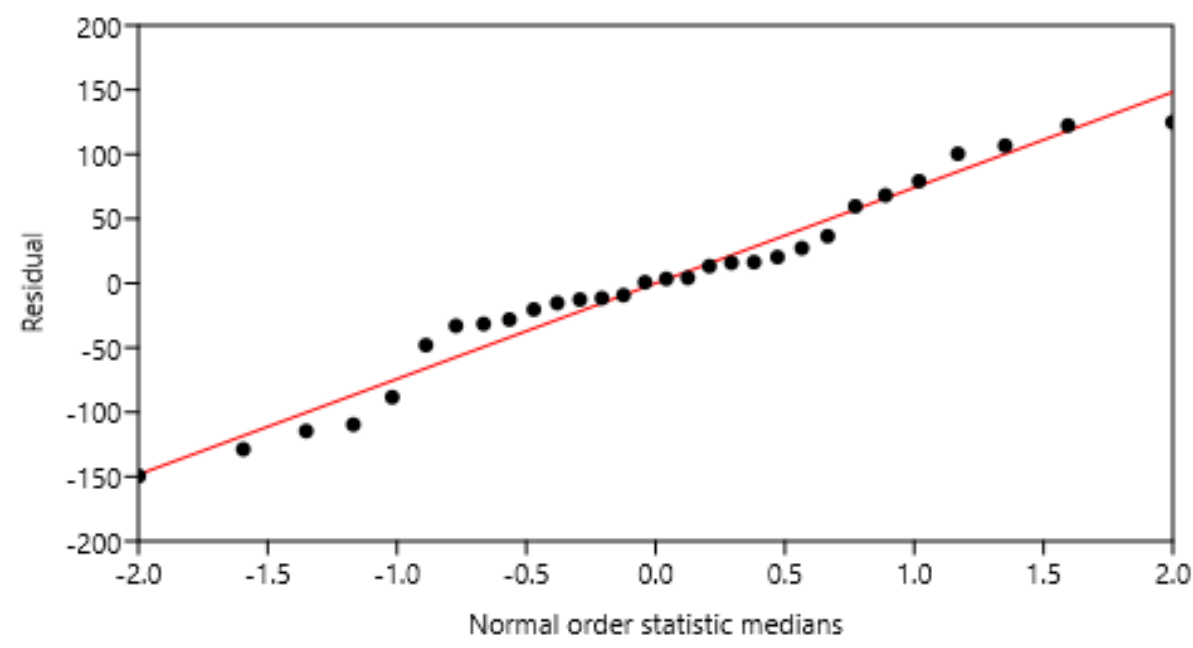


$\mathrm{Ca}$

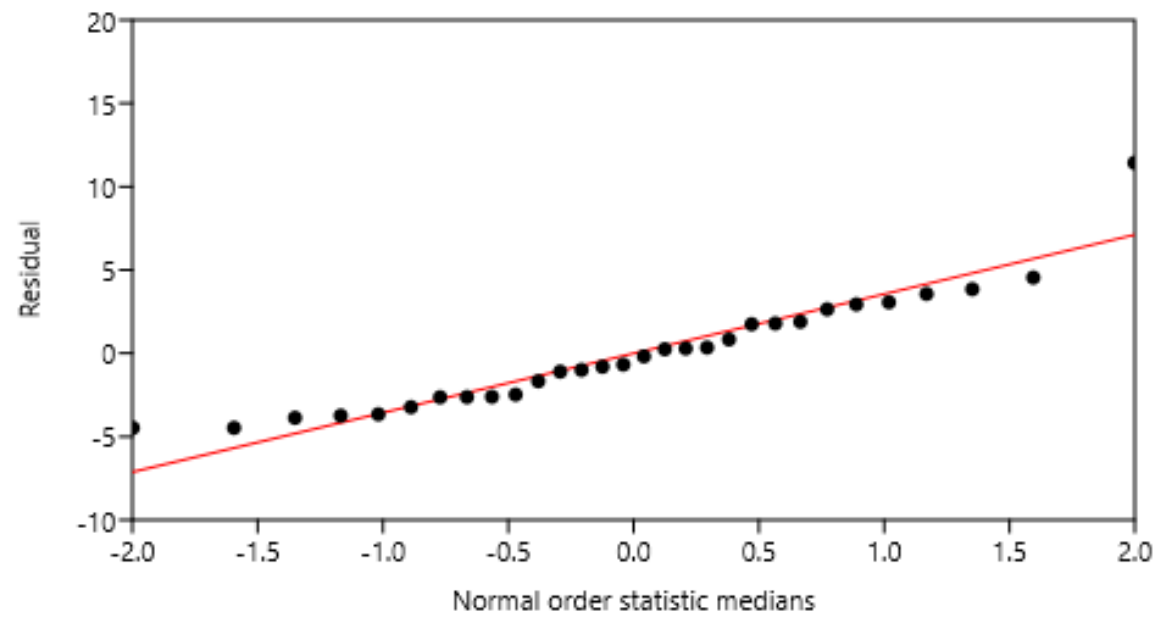

Co

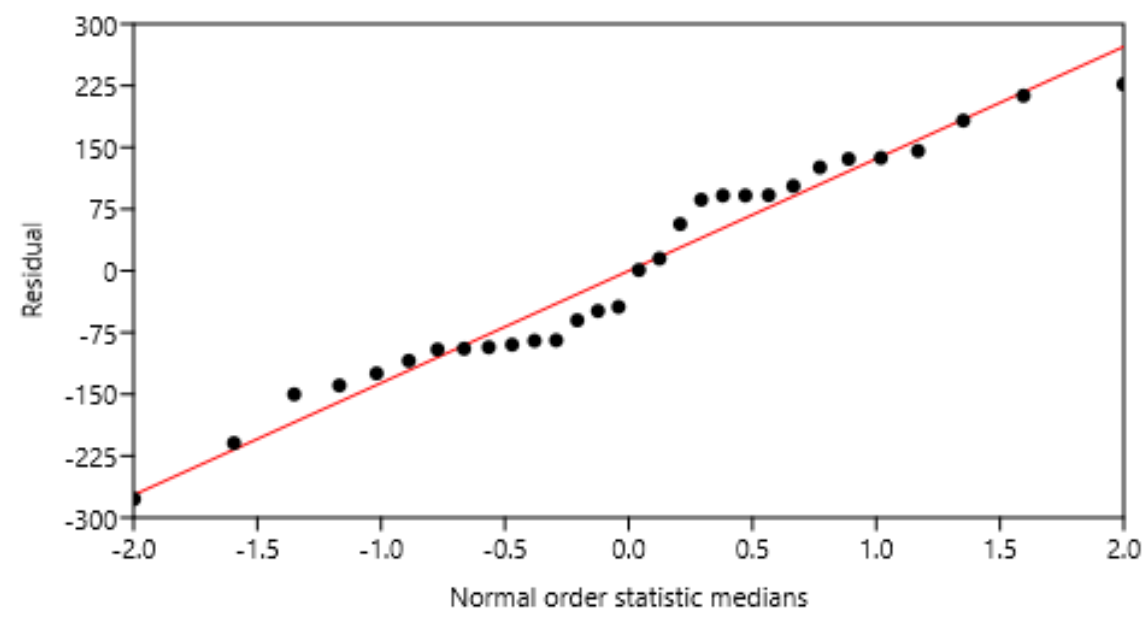

$\mathrm{Cr}$

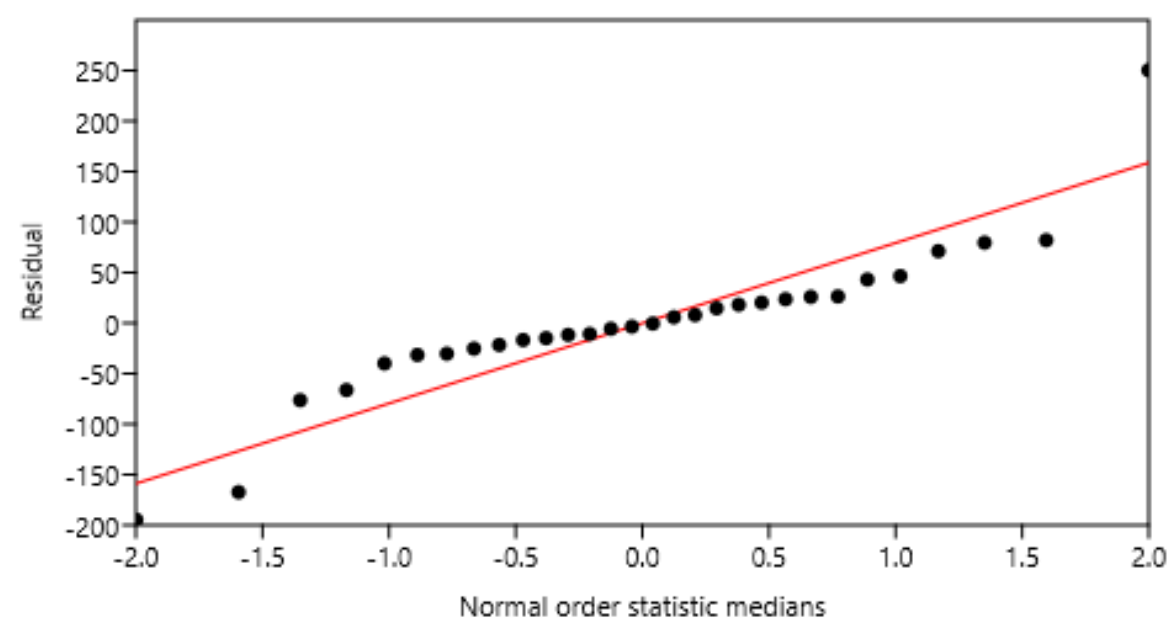

$\mathrm{Cu}$ 


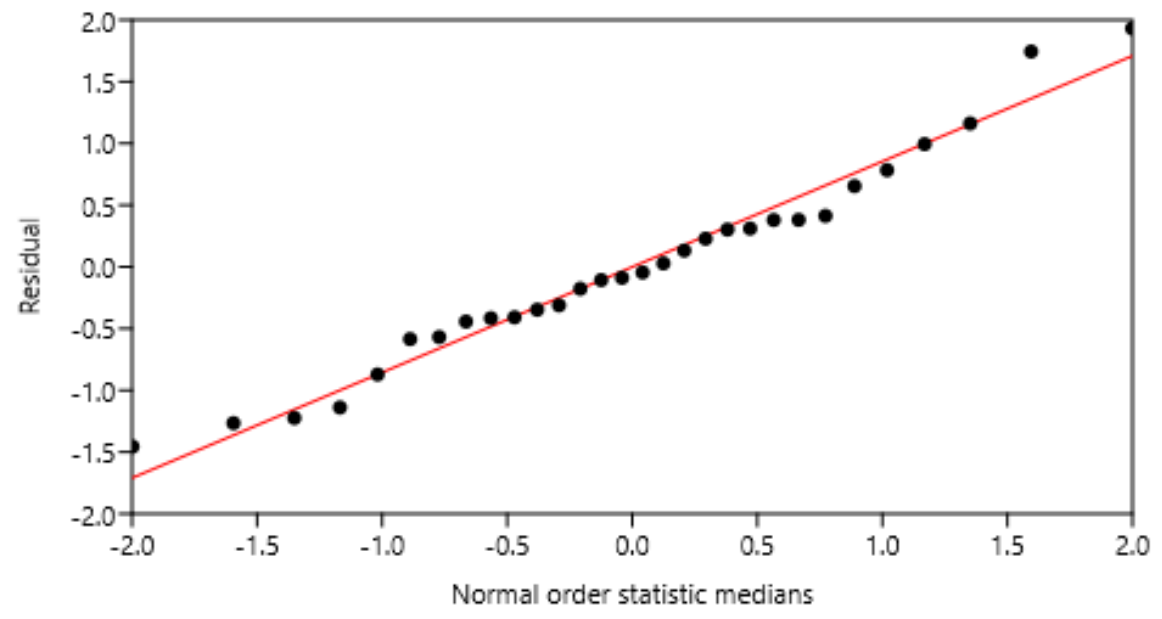

$\mathrm{Fe}$

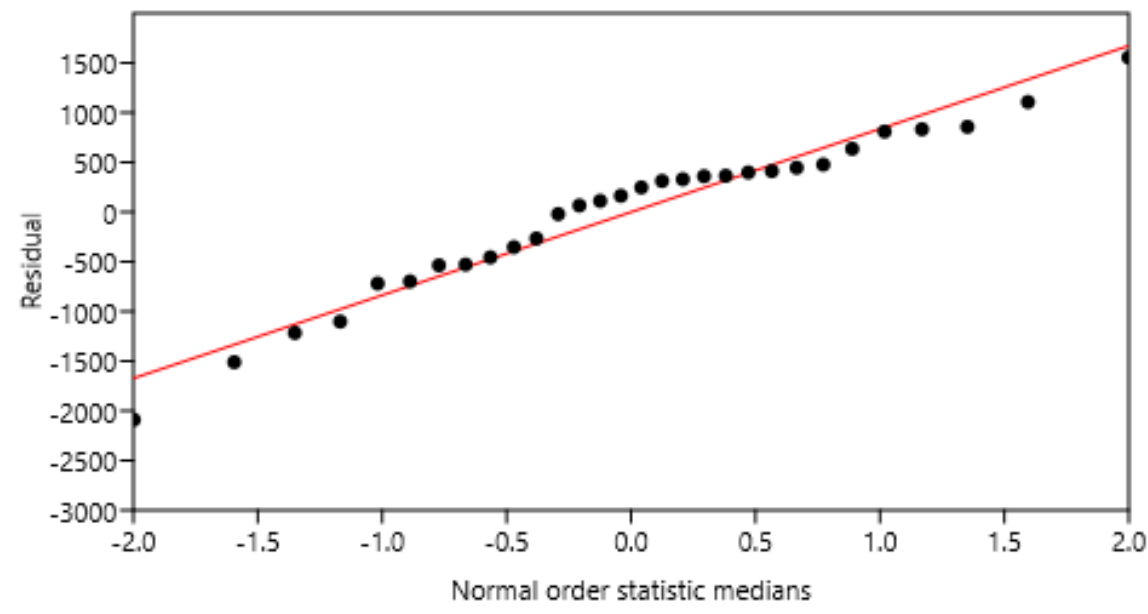

K

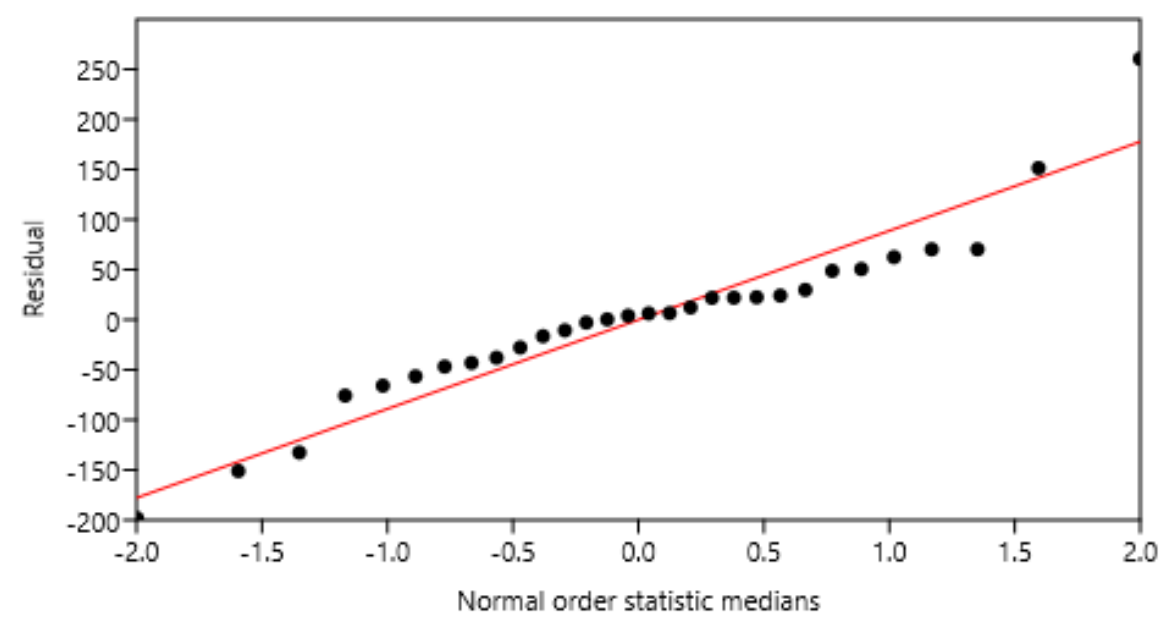

$\mathrm{Mg}$ 


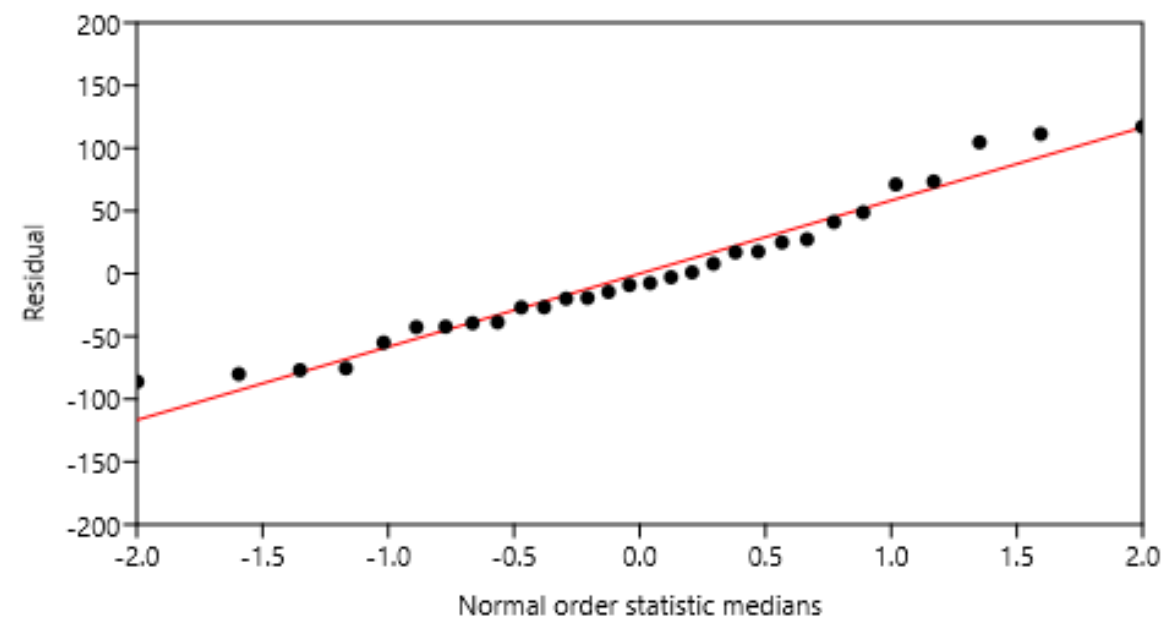

Mn

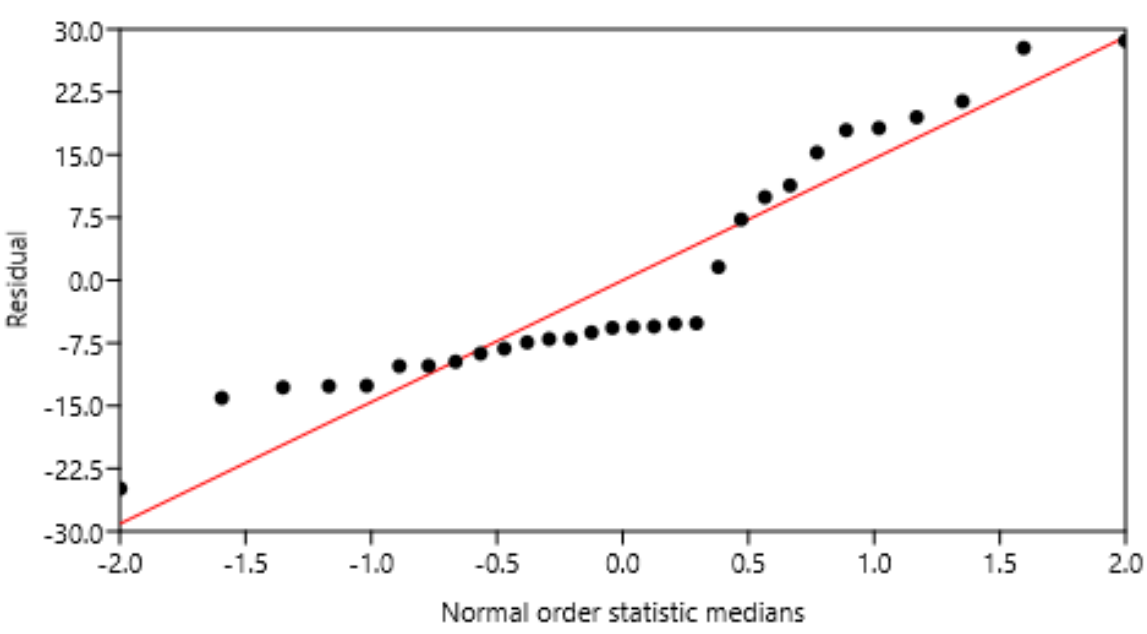

Mo

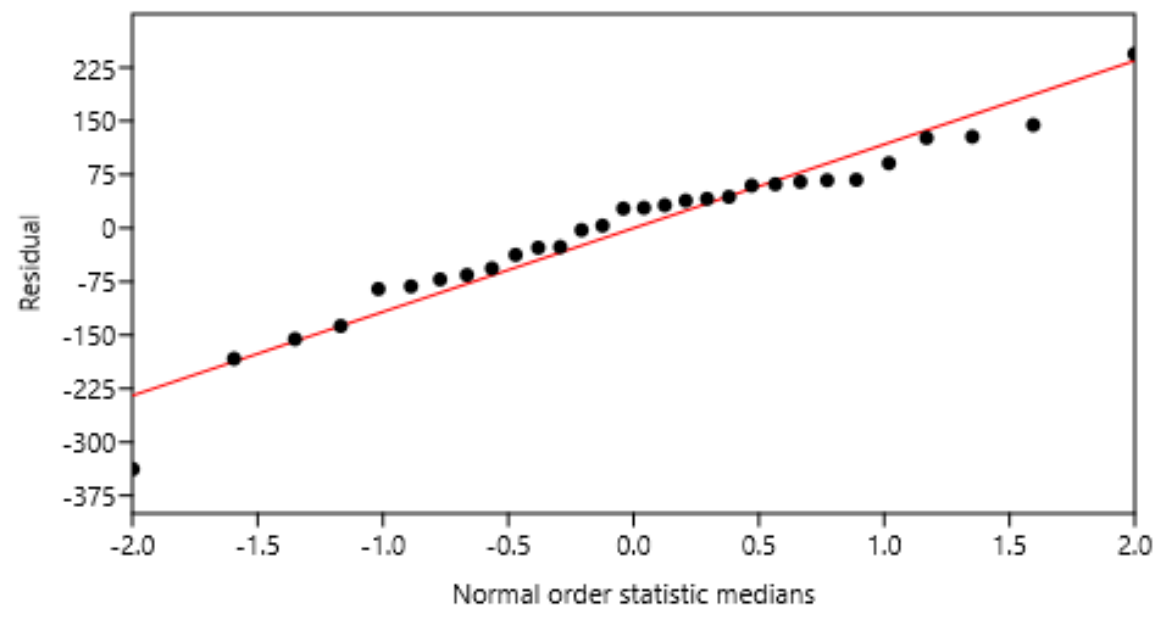

$\mathrm{Na}$ 


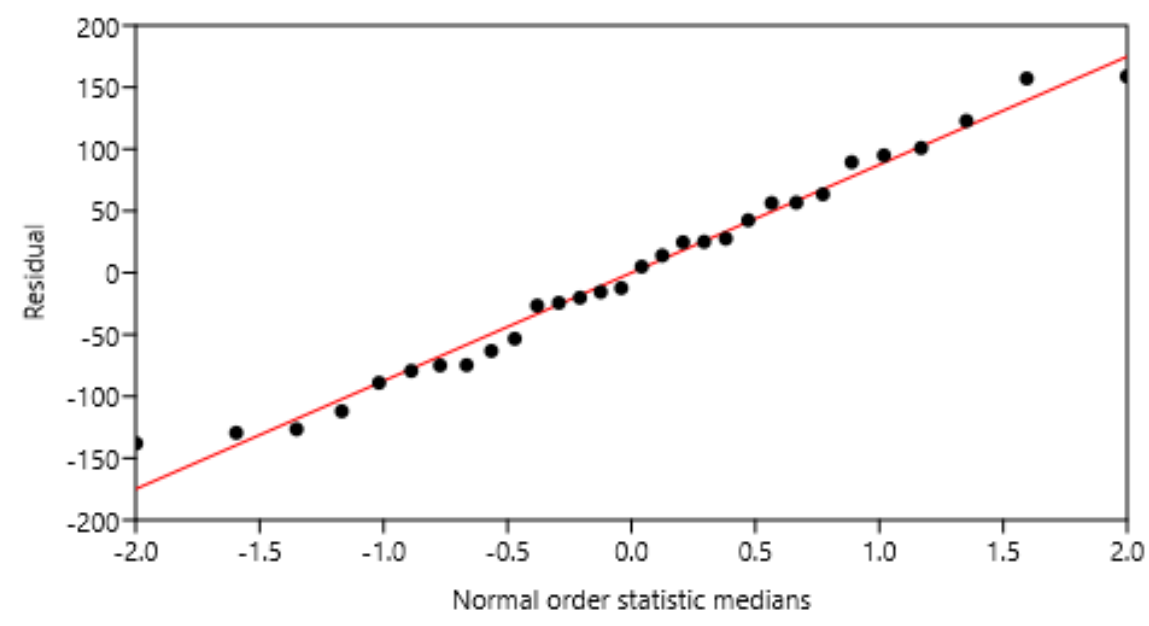

$\mathrm{Ni}$

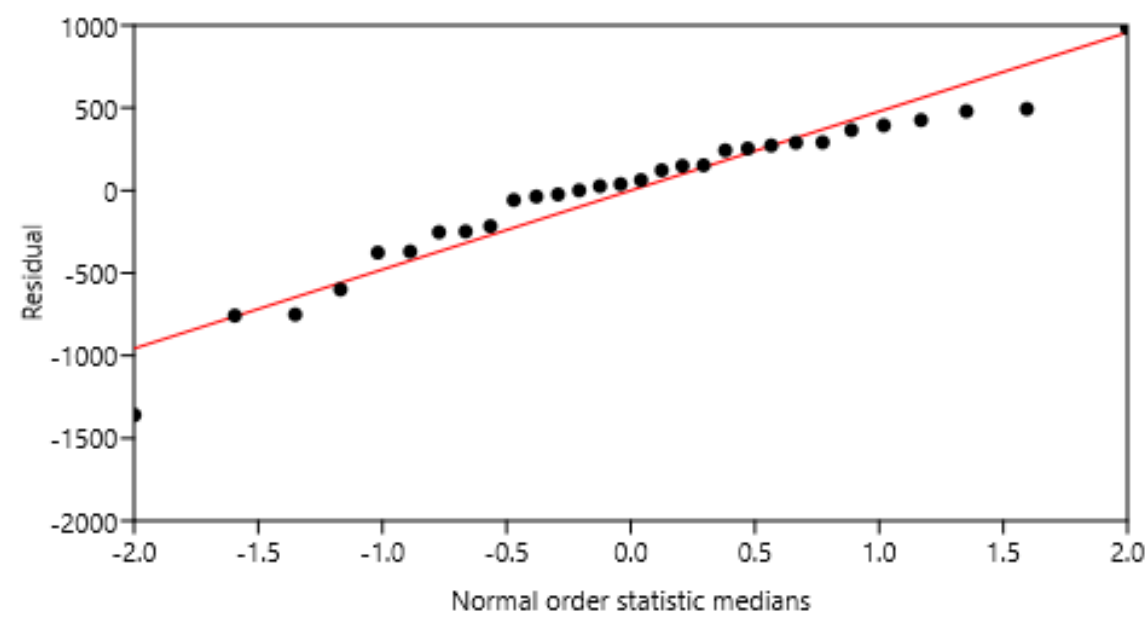

P

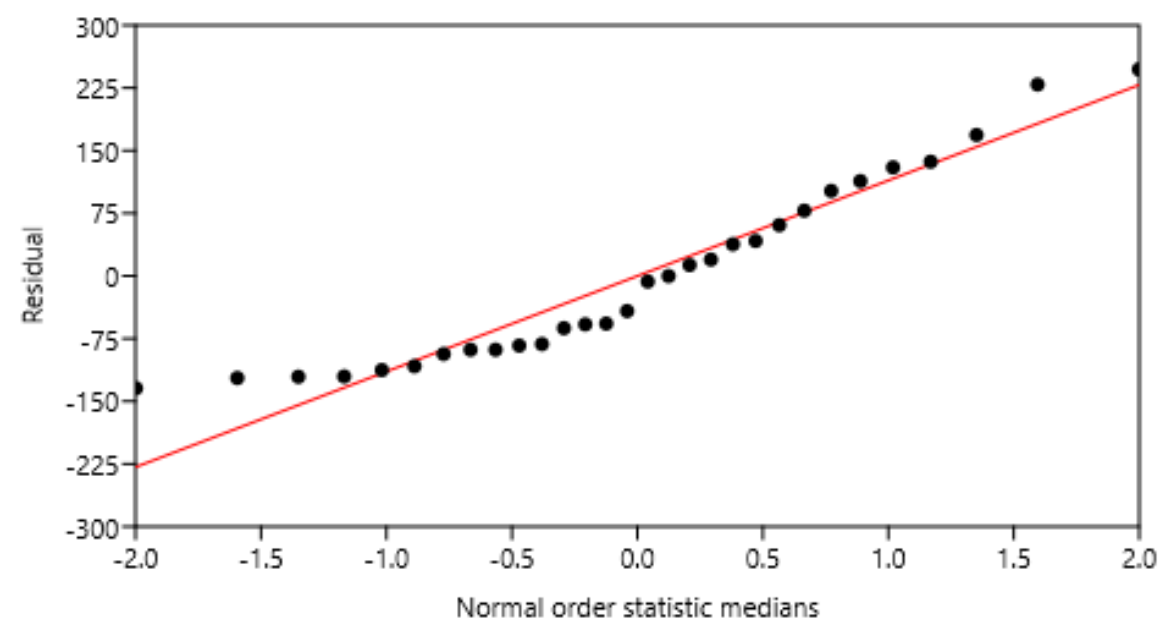

Se 


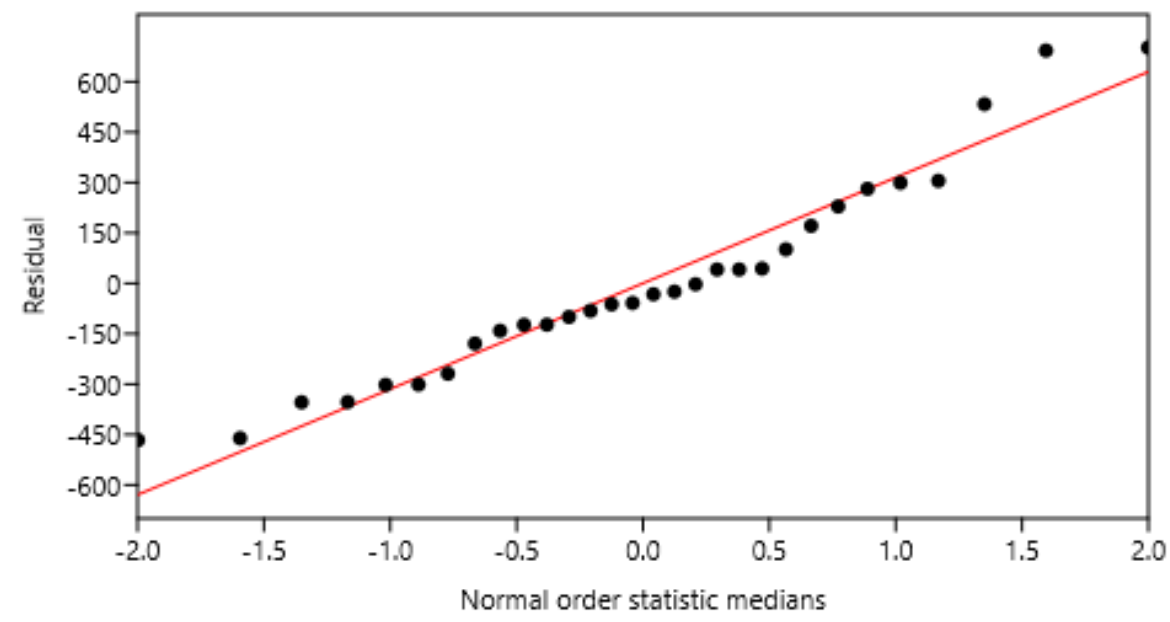

$\mathrm{Sr}$

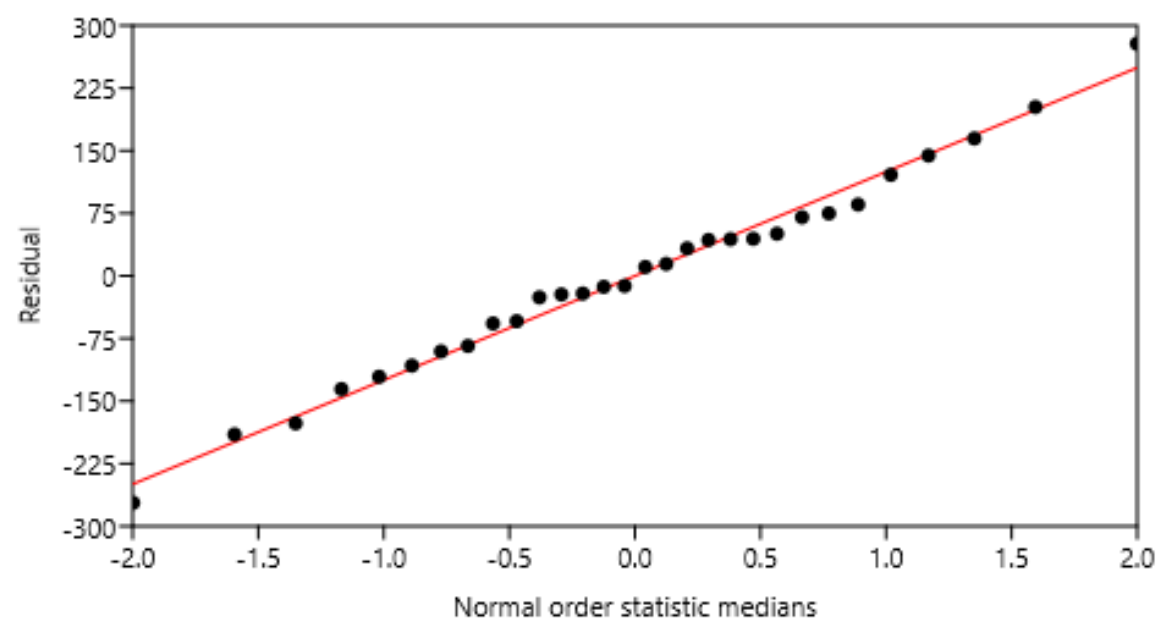

$\mathrm{Ti}$

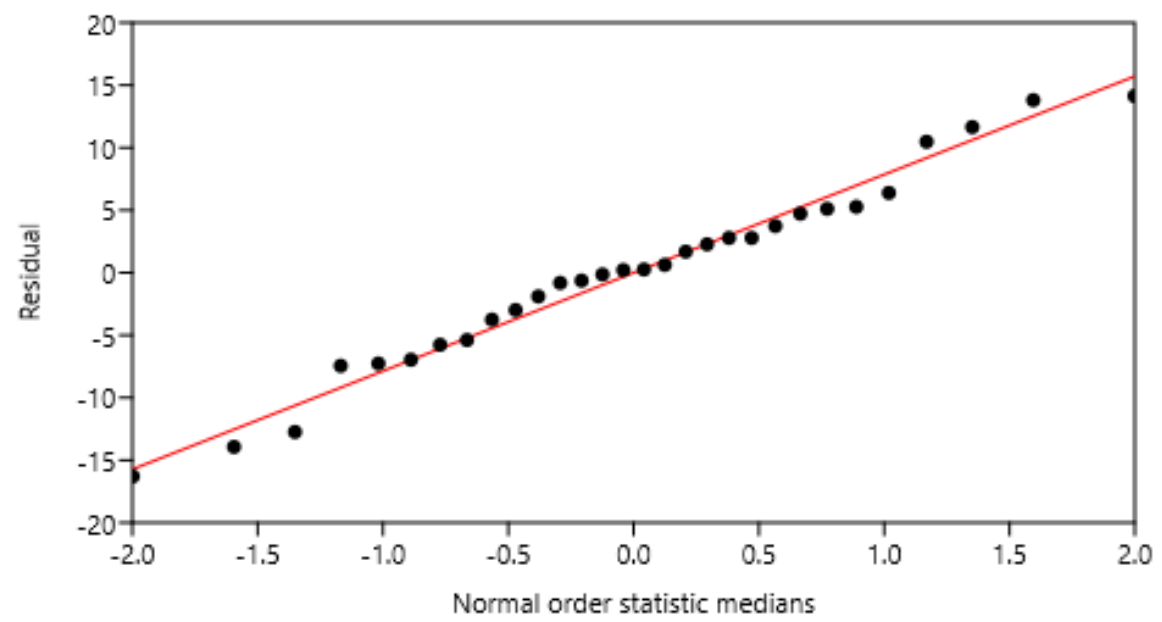

V 


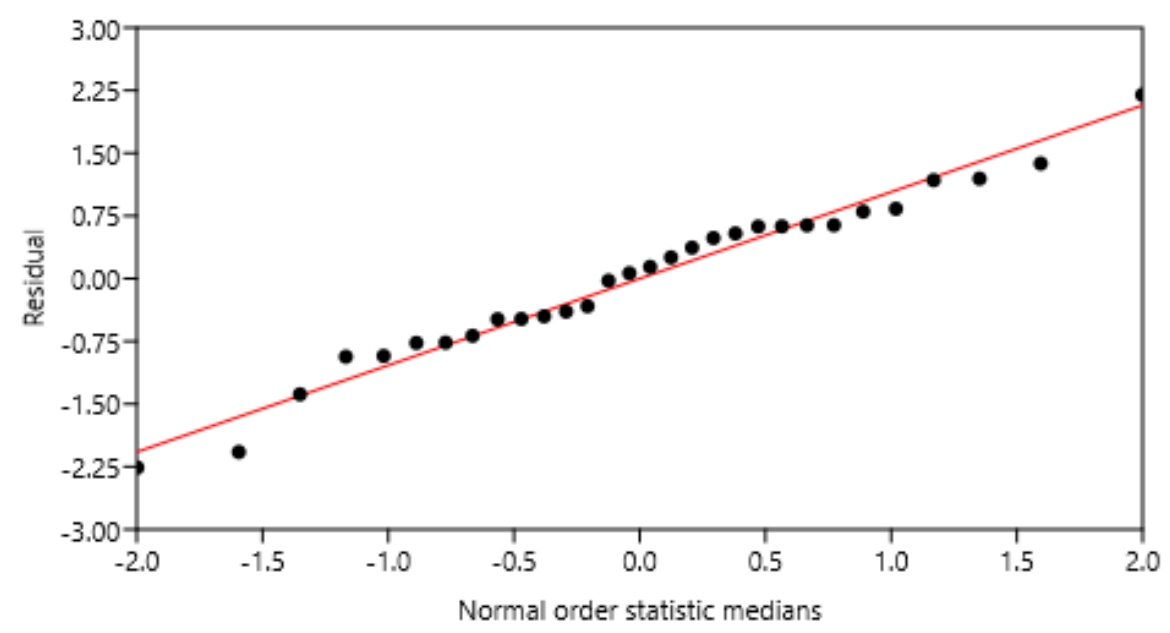

Zn 